PROCEEDINGS

\title{
AEROSPACE NUCLEAR SAFETY
}

OCTOBER $1-4,1963$

\author{
Edited and Published \\ by \\ Sandia Corporation
}

\author{
AMERICAN NUCLEAR SOCIETY - TRINITY SECTION \\ NATIONAL TOPICAL MEETING \\ Albuquerque, New Mexico
}




\section{DISCLAIMER}

This report was prepared as an account of work sponsored by an agency of the United States Government. Neither the United States Government nor any agency Thereof, nor any of their employees, makes any warranty, express or implied, or assumes any legal liability or responsibility for the accuracy, completeness, or usefulness of any information, apparatus, product, or process disclosed, or represents that its use would not infringe privately owned rights. Reference herein to any specific commercial product, process, or service by trade name, trademark, manufacturer, or otherwise does not necessarily constitute or imply its endorsement, recommendation, or favoring by the United States Government or any agency thereof. The views and opinions of authors expressed herein do not necessarily state or reflect those of the United States Government or any agency thereof. 


\section{DISCLAIMER}

Portions of this document may be illegible in electronic image products. Images are produced from the best available original document. 
General Committee

Genera1 Chairman

Alternate General Chairman and Director of Publicity

Associate General Chairman and Technical Program

Director

Registration Director

Pub1ications Director

Social Director

Special Arrangements Director

Finance Director

Ladies Program Director

Assistant Technical
Program Director

Assistant Registration Director

Assistant Special Arrangements Director

Consultant

Consultant

Proceedings TypistCompositor

Secretary to the Staff

Staff Stenographers
Lt. Col. Herman W. Baker,

Air Force Systems Command, Washington, D.C.

Mr. Andrew J. Smith, III,

Air Force Weapons Laboratory, Kirtland AFB, New Mexico

Dr. Hugh C. Paxton, Los Alamos

Scientific Laboratory (U. Cal.), Los Alamos, New Mexico

Lt. Co1. Claude A. DeLorenzo, Air Force Directorate of Nuclear Safety, Kirtland AFB, New Mexico

Dr. D. Maxwe11 Ellett, Sandia Corporation, Sandia Base, New Mexico

Dr. D. Wayne Sherwood, Albuquerque Operations office, AEC, Sandia Base, New Mexico

Dr. Glenn A. Whan, University of New Mexico, Albuquerque, New Mexico

Mr. Paul D. O'Brien, Sandia Corporation

Mrs. M. E. Sorte, Air Force Weapons Laboratory

Dr. William R. Stratton, Los Alamos Scientific Laboratory

Capt. Donald B. Hente, Air Force Directorate of Nuclear Safety

Capt. William B. Anders, Air Force Weapons Laboratory

Dr. R. E. Schreiber, Los Alamos Scientific Laboratory

Dr. Harold M. Busey, Scientific Advisor to Gov. of New Mexico

Mrs. Julia M. Polito

Sandia Corporation

Miss Betty Kish, Air Force Weapons Laboratory

Mrs. Gloria E. Anderson, Mrs. Alberta E. Osborne, Air Force Weapons Laboratory 
$\mathrm{SC}-\mathrm{DC}-3553$

TID-4500 (24th Edition)

UC-36, AEROSPACE SAFETY

PROCEEDINGS

\title{
AEROSPACE NUCLEAR SAFETy
}

October 1-4, 1963

\author{
TRINITY SECTION - AMERICAN NUCLEAR SOCIETY \\ NATIONAL TOPICAL MEETING \\ Albuquerque, New Mexico
}

\author{
Prepared by \\ Technical Information Department, Sandia Corporation \\ R. E. Dunlap, Editor \\ Published January 1964
}

\footnotetext{
Printed in USA. Price $\$ 4.50$. Available from the office of Technical Services, Department of Commerce, Washington 25, D.C.
} 


\section{SPONSOR \\ Trinity Section \\ American Nuclear Society}

\section{CO-SPONSORS}

Air Force Special Weapons Center

Air Force Weapons Laboratory

Albuquerque Operations Office, USAEC
Directorate of Nuclear Safety, USAF

Los Alamos Scientific Laboratory

Sandia Corporation

University of New Mexico 
TABLE OF CONTENTS

BANQUET ADDRESS

AEROSPACE NUCLEAR SAFETY--LESSONS FROM CIVILIAN AND MILITARY REACTOR EXPERIENCE

James T. Ramey, Commissioner, United States Atomic Energy

Commission . . . . . . . . . . . . . . . . . . .

LUNCHEOIN ADDRESS

SAFETY IN SCIENCE

N. E. Bradbury, Director, Los Alamos Scientific Laboratory . .

SESSION I

\section{SAFETY PROGRAMS AND PHILOSOPHY}

1. Techtopia or Techmania

F. C. Di Luzio, Staff Director, Senate Committee on

Aeronautical and Space Sciences . . . . . . . . . . . . .

2. The NASA Aerospace Nuclear Safety Philosophy

H. B. Finger, Manager, Space Nuclear Propulsion Office, AEC-NASA; Director, Office of Nuclear Systems, NASA . . . . . .

3. AEC Aerospace Safety Programs and Philosophy

F. K. Pittman, Director, Division of Reactor Development, United States Atomic Energy Comission . . . . . . . . . .

4. USAF Aerospace Nuclear Safety Program and Philosophy

Co1. C. B. Stewart, Director, Directorate of Nuclear Safety Deputy the Inspector Genera1, USAF . . . . . . . . . . .

\section{SESSION II}

NUCLEAR SAFETY ASPECTS OF SNAP DESIGN

1. Design and Safety Aspects of Hydride Fuel SNAP Reactors

D. J. Cockeram and R. L. Detterman, Atomics International . . .

2. SNAP Reactor Transient Tests

I. I. Moss, Atomics Internationa1

T. R. Wilson, Phillips Petroleum Company . . . . . . . . . .

3. Aerospace Nuclear Safety Ground Test Program

J. L. Colp, Sandia Corporation . . . . . . . . . . . . . . . . •

4. Safety of Isotopic SNAP Generators

W. Hagis and D. G. Harvey, Martin Company . . . . . . . . . . . .

5. Nuclear Safety of Advanced Nuclear Space Power Plants; Nonboiling Lithium-Cooled Reactor

D. L. Cochran, J. P. Lehman, and G. H. Anno, Aerojet-General Nucleonics . . . . . . . . . . . . . . . . . . . 
TABLE OF CONTENTS (cont)

$\underline{\text { Page }}$

\section{SESSIOV III}

NUCLEAR SAFETY ASPECTS OF PROPULSION REACTOR DESIGN

1. Safety of RIFT Vehicle Launch and Flight Operations

Major R. C. Hock, USAF, Launch Operations Center . . . . . . . . 131

2. A Brief Description of the Rover-Type Reactor--Its Inherent Safety Problems and Test Programs

L. D. P. King, Los Alamos Scientific Laboratory . . . . . . . . . 145

3. Rover Reactor Transient Analyses

W. R. Stratton and C. G. Chezem, Los Alamos Scientific Laboratory . . . . . . . . . . . . . . . . 155

4. Flight Operational Safety Systems for NERVA

R. I. Unger, Aerojet-General Corporation . . . . . . . . . . . . . . 167

5. Nuclear Ramjet Missile Flight Safety

W. J. Hesse and J. E. Standefer, Ling-Temco-Vought, Inc. . . . . . 181

SESSION IV

\section{ENVIRONMENTAL FACTORS}

1. Marine Sciences Related to Aerospace Uses of Nuclear Power Arnold B. Joseph, Environmental Sciences Branch, USAEC . . . . • . 195

2. Meteorological Studies as Related to Aerospace Nuclear Safety Isaac Van der Hoven, U. S. Weather Bureau . . . . . . . . . . . 209

3. Fallout Prediction Techniques

J. Z. Holland and A. W. Klement, Jr., Division of Biology and Medicine, U. S. Atomic Energy Commission . . . . . . . . . . 219

4. Environmental Safety Aspects of Rocket Flight Operations

M. I. Goldman and C. R. McCullough, Nuclear Utility Services, Inc. . 231

5. The Space Environment and Its Implications for Spacecraft Design J. B. Rittenhouse and F. J. Clauss, Lockheed Missiles and Space Company . . . . . . . . . . . . . . . . . . . . . 241

6. Supplementary Paper: Off-Site Radiological Monitoring Procedures for Missile Test Ranges

M. W. Carter, R. D. Coleman, and D. J. Ne1son, Jr., Division of Radiological Health, U. S. Public Health Service. . . . . . • . 255

\section{SESSION V}

RE-ENTRY AND POSTMISSION DISPOSAL

1. Combustion and Disintegration of Zirconium Hydride-Uranium Fue1 Rods F. E. Littman and A. E. Levy-Pasca1, Astropower, Inc. . . . . . . . 261 
2. Aerospace Nuclear Safety Re-Entry Flight Test Program

A. J. Clark, Jr., Sandia Corporation . . . . . . . . . . . . .

3. Re-Entry Burnup Enhancement of Hydrided Zirconium Uranium A11oy Fue1

E. L. Foster, Jr., Battelle Memorial Institute . . . . . . . .

4. Re-Entry of Fueled Graphite Particles

J. M. Bridges and H. G. Hargrove, Westinghouse Astronuclear Laboratory . . . . . . . . . . . . . . . . . . . . .

5. Source Term Program--An Integrated Treatment of Re-Entry Problems H. I. Kraig and J. M. Bridges, Westinghouse Astronuclear Laboratory . . . . . . . . . . . . . . . . . . . .

6. Special Topic: The Air Force Niclear Weapon Safety Program Col. C. B. Stewart, Director, Directorate of Nuclear Safety, USAF 


\section{BLANK}


BANQUET ADDRESS 


\section{BLANK}




\author{
AEROSPACE NUCLFAR SAFETY--LESSONS FROM \\ CIVILIAN AND MILITARY REACTOR EXPERIENCE \\ James T. Ramey, Commissioner \\ United States Atomic Energy Commission
}

It is always a pleasure and a challenge to speak under the auspices of the American Nuclear Society. And it is especially so to discuss the subject of aerospace nuclear safety.

At the outset, I might say that I am not entirely a newcomer in this field. As a matter of fact, I can remember when the nuclear aerospace program was known as the nuclear space program. I can even recall investigating in 1956 why somebody right here in Albuquerque "leaked" the existence of the Rover nuclear rocket project, which up to that time had been classified. I well recall fighting along with Senator Anderson and Congressmen Holifield, Price, Morris, and their associates in the never-ending battle of the budget, when the Rover project was on an "on-again, off-again" basis. Sometimes more recently, I have begun to feel the same way and say, "Isn't this where I came in?"

My interest in nuclear safety goes back somewhat further--to the days at Argonne in the late $40^{\prime} \mathrm{s}$ when we tried to figure out the basis of Fermi's informal rule of a half-mile radius around reactors and the decision leading to the establishment of the Idaho test site.

Shortly after I joined the staff of the Joint Committee on Atomic Energy in 1956, we encountered an interesting reactor safety problem involving a Midwestern atomic power plant. As a result of the AEC's actions in this case, Joint Committee Chairman Anderson requested me to head up a staff study in 1957 of' AEC's regulatory and safety procedures which led to some legislative changes. In 1960 and 1961 , the staff did a follow-up study which resulted in some relaxation of those legislative requirements. During this same period, as a result of various AEC proposals, the Joint Committee staff also looked at the responsibilities and procedures related to the safety of military reactors.

This then leads me to the subject of my discussion with you this evening--to see what we have learned from our safety experience with civilian and military reactors and how we can apply this experience to our nuclear aerospace systems. Some of this will obviously be "what not to do," but I hope that we may also develop some positive guidelines.

As you know, the AEC has the job not only of advancing the development of atomic energy but also of making sure that such development will not create conditions harmful to the health and safety of the public. To discharge this latter responsibility, we have developed comprehensive procedures for the thorough safety review of civilian and military reactors. It might be helpful to summarize these procedures and point out some of their significant characteristics.

I recognize that most of you at this meeting are on the operational side of our aerospace nuclear effort. Discussion of our formal safety procedures for licensed civilian reactors may seem to be somewhat far afield for such a developmental effort. However, since the protection of the general public is involved in each case, I believe that aerospace safety can learn much from our procedures for licensed reactors as we 11 as from those procedures for the more developmenta1 reactors operated by the AEC and DOD. 
In this connection, there are three questions which I hope you will keep in mind throughout my remarks:

1. How formal should we become in our procedures for aerospace nuclear safety?

2. How much independent safety review should we provide?

3. How is the public to be informed, and how is it to participate in the safety review process?

Procedures for Civilian and Military Reactors

First, then, let us look at the procedures for licensed reactors. Interested private groups are required to file an application with the AEC prior to initiation of construction. This application, which includes a hazards summary report that sets out the technical details of the proposed project, is reviewed by the AEC's hazards staff and, in appropriate cases, by the independent Advisory Committee on Reactor Safeguards (ACRS). On the basis of this review, a construction permit can be issued after a mandatory public hearing in the case of power and test reactors and after notice providing opportunity for public hearing in all other cases.

The public hearings are generally conducted before a Safety and Licensing Board made up of three members, two of whom are technically qualified and one of whom is experienced in administrative proceedings. The decision of the board is subject to review by the Commission upon its own initiative or upon petition by a party to the proceedings.

Essentially the same type of review process occurs before an operating 1icense can be issued--the applicant submits a final hazards summary report which is reviewed by the hazards staff and the ACRS. A public hearing may then be held, although it is not required unless requested by the applicant or an intervenor.

Commission-owned power reactors located at non-AEC sites and operated as part of conventiona1 utility systems are not licensed. However, procedures which are "parallel" to those of the licensed reactors are used in the issuance of authorizations for construction and operation of such reactors.

Managers of the various AEC field offices have direct responsibility for the safe operation of those reactors which are owned by and operated for the AEC at government sites. Nuclear safety reviews are conducted by field office staff, cognizant program division staff, and the hazards staff. In appropriate cases, the ACRS is requested to review and comment on the safety of these reactors.

Field station military reactors, like the SM-1 reactor at Fort Belvoir, Virginia, have been acquired by the Army and Air Force under authority of Section 91(b) of the Atomic Energy Act. Internal nuclear safety reviews are conducted within the Army by staff of the Corps of Engineers and within the Air Force by staff of the Inspector General. Within the AEC, safety reviews are conducted by our hazards staff and, in appropriate cases, by the ACRS.

The military reactors for our nuclear submarines have also been acquired under Section 91(b) of the Act. The major safety reviews and controls of the safety aspects of these reactors are accomplished by a joint AEC-Navy staff under the able direction of Admiral Rickover. Supplementing the detailed review by the joint staff of each reactor, further evaluations are made by the AEC's hazards staff and, in appropriate cases, by the ACRS. These evaluations cover the design of each class of reactor, and the scope and adequacy of the reviews and controls being exercised by the joint staff. 


\section{Characteristics of AEC Procedures}

The AEC safety review procedures as developed for civilian and military reactors have several characteristics which are pertinent to our discussion here tonight:

1. The procedures place great emphasis on the responsibility of the operator--whether a private organization or a government group-for the safety of the reactor.

2. A system of independent safety reviews by qualified technical groups is provided. In the case of licensed power and test reactors, safety reviews are made by three groups, namely the hazards siaff, the ACRS, and the three-man Safety and Licensing Board. However, the Commission, or its designee, the Director of Regulation, retains final authority under the law.

3. Safety reports are required to be made public in the case of licensed reactors. Public hearings are required or permitted in such cases.

Special Considerations of Aerospace Systems

Now that you have a better idea of the way in which we go about assuring the safety of civilian and military reactors, let me proceed with aerospace nuclear safety. First, I want to cite some special considerations which have considerable bearing on the safe use of nuclear systems in space:

1. The nuclear system is operating in an entirely new environment.

2. The entire space vehicle, including its nuclear system, is highly developmental in nature.

3. The nuclear system is only one component of a larger and more complicated space vehicle which has its own safety problems.

4. A whole host of new safety problems, including such things as re-entry burnup, must be evaluated.

5. A substantial potential hazard exists with isotopic systems as well as reactor systems.

6. Many groups in and out of government are responsible for various aspects of each aerospace mission using a nuclear system.

7. Any flight of a nuclear system has associated with it many international ramifications.

With these considerations in mind, then, what are the lessons from our civilian and military reactor experience, and how can we apply them to the aerospace nuclear program?

Review Process Evolution

The first lesson is that we can expect and, in fact, should press for changes in the safety review process as experience is gained in the use of the nuclear system and the review process itself. 
The prime example of such evolution is what we have seen with the procedures for licensing of civilian power and test reactors. Under the 1954 Atomic Energy Act, the AEC was not required to hold public hearings, and the role of the ACRS was not specified. In 1957, the Act was amended to provide for mandatory public hearings and a statutory ACRS. Then, last year, the Act again was amended to give the AEC authority to establish atomic safety and licensing boards (in lieu of single hearing examiners) to limit the mandatory public hearings to the construction permit stage, and to permit greater informality in the conduct of the hearings.

And this evolution is not finished yet by any means!

As most of you know, no formal process has been established for the safety review of aerospace nuclear systems. I'Il have more to say about this later. However, whatever approach is initially selected, I am sure that as time goes along, we shall see many ways of improving the review process just as we have with the civilian and military reactors. There certainly are some inportant new considerations which call for an evolutionary type of approach to the safety review process for aerospace nuclear systems.

\section{Technical Staff}

A lesson of extreme importance is that there is a strong requirement for a highly competent and independent technical reviewing staff within the government.

Fulfilling this requirement is, of course, no substitute for a competent, safety-minded design and operating staff, which after all has the fundamental responsibility for establishing the safety of the nuclear system. As I indicated earlier, a11 of our safety review processes place great emphasis on the operator. It should be readily apparent that the independent reviewing staff is in no position to duplicate the work of the operator or to explore exhaustively every last aspect of design and operation having a bearing on safety. The reviewing staff must necessarily devote its attention to probing sensitive points and evaluating the technical competence of the operator's staff.

Fortunately, the AEC has been able to develop and maintain a very good reactor safety staff over the years. The safety groups at our field offices and headquarters are made up of highly trained individuals with a substantial amount of experience. This point was verified in a recent survey which indicated that staff assigned to the safety review of $\mathrm{AEC}$-owned reactors have an average of over six years of reactor experience.

The ACRS is a well-established group composed of eminent scientists and engineers who are specialists in various disciplines important to nuclear safety. In general, individual members have served with the Committee for long terms and thus have acquired a very high degree of skill and experience in the safety field.

Although our 1icensing boards have only recently been formed, the Commission exercised great care in selecting individual board members and is confident that these men wil1 make a substantial contribution to the safety review process.

Personally, I am convinced that our excellent safety record in the reactor field can be attributed in a large measure to the efforts, at all levels, of this safety organization.

Another important lesson in the staffing area is that close and informal contact between the independent reviewing staff and the other staff of the agency and the operator should be encouraged. Such contact is essential since nuclear technology is rapidly advancing and constantly posing new problems for safety analysis and evaluation. 
With respect to the aerospace nuclear program, there is a similar requirement for a highly competent technical reviewing staff which has ready access to the developing aerospace technology. In fact, the requirement seems to be even more severe in view of the special safety considerations typical of aerospace systems. I can assure you that the Commission fully intends to meet this requirement.

\author{
Safety Standards
}

A lesson which has proved somewhat difficult to apply to our civilian and military reactor programs is the need to establish over-all standards for the safe design and operation of our nuclear systems.

In all technical fields of activity, man has tended to develop general criteria and standards to assist him in making proper safety judgments. In determining the reasonableness of such standards, it is always necessary to carefully assess the degree of hazard associated with the activity and weigh this hazard against the benefits to be gained from the activity. In other words, all safety standards must be delicately balanced on a scale of low acceptable risks versus resulting benefits. If this is not done and "absolute safety" is what is required, then the activity must cease.

The development of safety standards in the relatively new field of reactors has been difficult, since no two systems have been alike, and thus standards which might be applicable in one situation cannot be applied across the board. Nevertheless, the need to adopt standards has been recognized and some initial steps taken. For example, the AEC has established some basic criteria for siting of power and test reactors, and the American Nuclear Society is considering establishment of safety standards on such things as the design of reactor control systems and methods of containment leak testing.

Establishing safety standards in the aerospace nuclear program obviously is going to be as difficult as it has been in the reactor program. At least initially, al1 such nuclear systems will be "one of a kind," and their missions will be quite varied. This difficulty, however, should not discourage us from trying to establish some basic standards for the use of nuclear systems in space. For example, we should be thinking right now about standards dealing with matters such as acceptable radiation levels for manned missions and limits on disposal of radioactive waste.

Safety Research Program

An important lesson which we wisely have been applying to the aerospace nuclear prograin is the recognition of the need for experimental evidence to verify theoretical predictions regarding the safety of nuclear systems.

The AEC recognized this lesson early in its reactor development programs. For instance, the well known SPERT tests date back to 1954, and these in turn go back to the early BORAX experiments. Initially, the safety research programs involved mostly work on reactor excursions, meta1-water reactions, and fission product release. More recently, the AEC has realized that large-scale engineering tests, such as a proposed loss-of-coolant experiment leading to meltdown of an experimental reactor will provide valuable information which should place the safety of reactors on an even firmer technical footing.

In the aerospace nuclear program, the AEC has sponsored a very extensive research program. Since Dr. Pittman and others have discussed it in some detail, I wil1 not comment on it except to say that the information developed wil1 undoubtedly add considerable confidence in our safety analyses of nuclear aerospace missions. 
Thare is, however, one noteworthy aspect of the aerospace safety research program: the designation of Sandia as the nuclear safety contractor for the AEC. Sandia is working with the various project contractors to establish meaningful safety test programs and will assist the AEC in actual aerospace safety testing and flight programs. This concept, which has a number of advantages, is a lesson learned from our extensive weapons safety program.

Technical Information Exchange

An important lesson which is probably very evident to each of you here is that there is definite need to encourage exchange of technical information by means of publications such as the AEC's "Nuclear Safety" magazine and, of course, by meetings such as this one you have been attending.

In the carly days of the atomic energy program, there was quite rigid separation and classification of the various programs. Gradually through the years, the information channels have been opened. Recently, in the safety field, the AEC established an information center at Oak Ridge to encourage such exchange.

The AEC went even one step further in this area when it initiated its access permit program in which classified nuclear information is made available to individuals with a legitimate interest. Classified information developed on the aerospace nuclear systems is being made available under this program.

This exchange of information and cross fertilization of technical ideas is as important in acrospace nuclear safety as in other areas of nuclear technology. Indeed, it is probably much more important in view of the wide variety of scientific disciplines involved and the large numbex of government and contractor groups associated with the aerospace effort.

Public Information and Education

In the area of education, we have learned the value of providing the public with easily understood information regarding the safety of nuclear systems.

The AEC has had to learn its lessons the hard way with respect to public information on civilian reactors. Back in 1956, the Commission failed to heed the advice of its Safeguards Committee in the Midwestern case previously referred to, and indeed refused to make the safety report public until questions were asked by the Joint Committee on Atomic Energy and certain labor organizations. As a result, various legislative changes were made to require that the safety reports be made public and to establish the ACRS as a statutory committee.

Since that time, the AEC has made laudable efforts to educate the public on reactor safety and has made many improvements in its system of making safety information available to the public. But, despite these rather extensive efforts on the part of the AEC and other interested organizations, there is still much misunderstanding on the potential hazards of reactors and the methods used to protect the public.

The aerospace nuclear program currently is faced with a somewhat analogous problem in the apparent reluctance on the part of using groups and others to incorporate nuclear systems into space vehicles because of a concern for safety. I am also certain that the general public will display a similar concern when nuclear systems are ready for extensive use in space. In fact, it has been said that the ultimate utilization of aerospace nuclear systems may well depend on the impact of safety considerations. 
Although we still have much to learn, I can assure you that the AEC will do its best, in a forthright and honest way, to improve public understanding of the safety of nuclear systems.

\author{
Interagency Cooperation
}

\begin{abstract}
"Interagency cooperation" - - I am sure you have heard these words more than once at this meeting.

People have been saying that the aerospace nuclear program will require a very high degree of interagency cooperation and coordination in safety and other areas. By just looking at the number of different groups represented at this mecting, I am inclined to agree with this proposition.

The AEC actually has had considerable experience in cooperating with other agencies in the nuclear safety field. We have a continuing responsibility for the safety of nuclear reactors and weapons acquired by the DoD under Section 91(b) of the Atomic Energy Act. As a long-time advocate of improving these particular safety review processes, I can think of several important lessons in interagency cooperation:
\end{abstract}

1. There should be a formal understanding and procedures which clearly define the safety review process.

2. There should be a clear-cut definition of respective arency responsibility (especially from a legal standpoint).

3. There should be a mechanism for periodically checking up on the review system to make certain safety responsibility is being discharged adequately.

These are certainly three lessons which we can apply to the aerospace nuclear program.

\author{
Aerospace Review Process and Organization
}

These lessons from our experience with civilian and military reactors lead me to the question which I am sure is in everybody's mind at this meeting: "What type of safety review process and organization is required for the aerospace nuclear program?"

The Joint Committee staff was faced with a similar question in 1961 when it was considering what changes should be made in the AEC regulatory process to improve the procedures for licensing power reactors. We felt at that time that, preliminary to a consideration of alternative new organizations, the main objectives of the safety review process should be stated. This same statement of objectives might be helpful in answering the nuclear aerospace question.

The primary objective of the review process should be, of course, to protect the health and safety of the public and operating personnel. As I indicated previously, in attaining this objective there must be appreciation of the fact there will be some minor degree of risk which is judged acceptable in view of the benefits to be gained.

A second objective should be to gain the confidence of the public. This can be done by placing the decisions involving safety in the hands of highly qualified men who are not under pressure to compromise safety in order to achieve developmental goals. The safety review process also should include means whereby 
interested members of the public can obtain full information on the hazards consistent with security requirements.

A third objective should be to organize the review process so as to attract and retain competent personnel who are highly qualified in nuclear safety analysis and technology.

A final objective of the safety review process should be administrative efficiency. The review process should not impose burdensome requirements which do not make corresponding contributions toward the achievement of safety or the enhancement of public confidence.

With these objectives in mind, then, what is required for the aerospace nuclear program?

One approach that has been suggested is the establishment of an Interagency Review Panel composed of high-level experts from the agencies principally involved in the application of nuclear systems to space. Associated with this Panel would be an interagency working group composed of the safety staffs of the various agencies. For each aerospace nuclear mission, the working group, in cooperation with the contractors, would prepare a comprehensive safety analysis for presentation to the Pane1. After review of this analysis, the Panel would transmit its specific advice and recommendations concurrently to the agency heads who would then make the final safety decision.

The pros and cons of the Interagency Panel approach have been discussed in some detail within the AEC. Favoring this approach is the argument that an Interagency Panel could provide a mechanism for providing a coordinated safety review for all of the agencies involved. This coordinated review could minimize review duplication and possibly expedite the decision-making process required for the use of nuclear systems. Arguments against this approach are that an Interagency panel might not have a sufficient sense of responsibility to individual agencies and that there might not be sufficient fixing of safety responsibility.

My own view, for whatever it may be worth, is that we need both an interagency working group and an independent review group or groups of a competence and stature comparable to the AEC's hazards staff and the ACRS. Whether an Interagency Pane1 can fulfill completely this role of independent review is not clear to me. In any event, I believe that for some time to come there should be some role for the AEC's hazards staff and the ACRS in the development of standards and the review of the more important aerospace nuclear cases.

In conclusion, I want to re-affirm the basic AEC policy that all activities under its cognizance will be conducted in a manner which assures that operating personnel and the general public are well protected against all hazards.

I firmly believe this can and will be done without representing an obstacle to the beneficial use of nuclear systems in our national aerospace program. 
LUNCHEON ADDRESS 


\section{BLANK}




\section{SAFETY IN SCIENCE \\ N. E. Bradbury, Director \\ Los Alamos Scientific Laboratory}

I will try to present a point of view which, in part, has been presented by a number of speakers this morning. Perhaps I will take it a little farther. The basic point I want to make first is that science--by which I mean both science and technology--has historically generated new hazards and, equally historically, invented new safeties for mankind. It has produced a safer way of life, a lesser dependence on natural environment, and a lesser dependence on man's physical frailities.

Let's take a couple of examples: suppose the automobile had been subjected to a safety review. We know it is incredibly dangerous; it goes on wheels, it goes fast, and it kills people. And yet, if we had therefore said, "No," we would have stuck by the horse. The number of deaths per capita from people falling off horses, being kicked by horses, being stepped on by horses, being run away with by horses then would have enormously outstripped all the deaths that would have ever occurred as a consequence of the automobile. In other words, here was a new hazard, something new and something different--it would present problems but it replaced an older hazard and made life in general much safer than it would have been had not this new technological development appeared.

Take the airplane: obviously a most unsafe vehicle. It falls down, it can't stay up, and it kills people. Indeed it does, but more people were lost in the sinking of the Titanic than have ever been lost in flying across the Atlantic. The loss rate per passenger mile of the sailing vessel was enormously higher than that of vessels driven by steam. Certainly steamboats exploded. Iron ships fell apart, and some sank, but still travel was never safer. Wherever science has made an advance it has developed a new hazard, but in general the new hazards have been less overall than the hazards made obsolete by the new development.

Another example: when houses had to be heated by fireplaces, they often burned down. The technology of fuels, gas and electricity, made buildings enormously safer, yet electricity is dangerous and gas explodes.

Take another example: in the field of medicine, $\mathrm{X}$-rays were at first terribly dangerous. Even now we are frightened to death of radiation. Yes, indeed, people were hurt, killed, maimed in the early explorations of X-rays, but a new and safer way of life from this new technology came about.

Or anesthetics: one of the original investigators of anesthesia, William Ha1stead, looked into cocaine as a means for reducing the shock incident to surgical operations. He made himself an addict, inadvertently, in his studies. He cured himself only with the greatest of effort. You can't let a man do that: it's unsafe. Yet who would say that about the development of anesthetics over the years? As a consequence, this has been one of the greatest boons to mankind. Ether was one of the earliest anesthetics. Yet, it is terribly unsafe. It explodes, and even kills people in being used. Nevertheless, it is a boon to mankind and has saved far more lives than it ever took. Technology brings new hazards but ordinarily it brings more safety if one lets the technology progress.

The next point I'd like to make about safety in science is that man is, by nature, an adventurous creature. He loves adventure, he loves to be challenged, 
and he loves to meet that challenge. Experimental science is an adventurous science. In spite of Mr. Finger's remarks this morning about the safety of astronauts, I doubt if anybody really regards astronautics as a safe occupation. Yet there seems to be no lack of people willing to try it. Man makes his progress this way: by trying things out, by finding things, by not always following the safe route. I don't mean by this only physical safety, i.e., not getting hurt. I am sure a11 of you have heard of the Fermi definition of a good experiment: an experiment that has a 50-percent chance of failing. A man should be penalized, not congratulated, for doing the experiment that is bound to work.

Man is an adventurous animal. If we are concerned only for his physical safety, we take away the challenge of new aspirations. We take away much of the challenge, perhaps a11, of experimental physical science. This leaves one in a very awkward position. How about somebody like Benjamin Franklin and the experiment with the key, the string, the kite, and the lightning storm? Goodness, what an unsafe experiment! I am not sure I'd defend it either. And yet, how about $\mathrm{X}$-rays? How about the Curies in nuclear physics? But in the early days of science, one didn't worry so much about safety; one worried about finding out about nature. Was the experiment exciting? Would it tell you something? What were the gains?

This doesn't, of course, mean that the experimenter should have free license to kill himself or anybody else. Common sense is required in these matters. The gain must be weighed against the chances. Life itself is a series of chances, one after another. In each case we have to weigh the probable gain against the probable hazard. Where the gains are great, one may take, with justification, great chances. If the gains are small, inversely, one should only take a small chance. Again, if something is worth doing, it is obviously worth doing we11; and if it is not worth doing, it is not worth doing unsafely.

We have always been occupied with this basic question: "How can one maximize the knowledge that one is getting and still get it safely?" I know of no firm rule.

I worry that we sometimes lose sight of our objectives in the concern that the path toward that objective be "safe." I say that things are never safe. A number of people have made the point already this morning that there has to be a calculated risk, but how does one calculate it? One can't. One has to make some sort of an intuitive judgment that the objectives that one is striving for are worth taking the chance. The objectives vary with time. I am convinced that with today's rules for safety of operations, today's procedures, regulations, reports, studies, etc., we wouldn't have gotten past the first study report in the development of the first atomic bomb. "It has fall-out, it is dangerous, and we can't tolerate that. You haven't done all the experiments. It may not work, and it would be a terrible black eye if you tried it and it doesn't work. You must do some more calculations and some more experiments. You must prove that it is going to work before you try it." We'd still be getting the study committees to look at the first atomic bomb if we had operated in that day the way we tend to operate now. Of course this is not said in any critical sense, because atomic weapons clearly had a role in history and a role in the art at that time. It is not a role played at the moment by any phase of nuclear energy. We don't have to have it in the same sense that we had to have the atomic weapon. The gains in nuclear energy, compared to chemical explosives, are less by the many powers of 10 today than they were when one developed the first atomic weapon. Nevertheless, I suspect very strongly that when the day comes that people really want and really need nuclear power, for example--when fuels get scarce and power is really needed--then the safety committees and the study groups and the hazard reporters will be elbowed aside. We would say, I think, "We know it has some hazards, but our need is real, and the hazards are problematical."

So it ends up as a weighing of gains, and of risks, but let us always look where we are trying to go. Let us look at what the gains are. Let us recognize that science and technology have traditionally brought new hazards and brought new safeties. 
It is always tempting in this subject to discuss things in cliches and there are more in this field than you can shake a stick at. "Better be safe than sorry." "Nothing ventured, nothing gained." The point that I would like to leave with you is this: It is all very well to say, "Better be safe than sorry," but, if we are too careful, we may be safe and sorry. 


\section{BLANK}


SESSION I

\section{SAFETY PROGRAMS AND PHILOSOPHY}

\section{Chairman}

K. F. Hertford, Manager

Albuquerque Operations Office

Session Coordinator

Lt. Col. H. W. Baker

Air Force Systems Command, Washington D. C. 


\section{BLANK}


TECHTOPIA OR TECHMANIA

\author{
F. C. Di Luzio, Staff Director \\ Senate Committee on Aeronautical and Space Sciences
}

The subjects I will discuss are all related to the promise and problems of atomic energy in space and research and development in general. I know of your interests, and I hope I can make a small contribution to your understanding of the problems from the legislative point of view.

The activities of this group in aerospace safety has made and will continue to make a major contribution to the use of nuclear energy in space. For reasons I will cover later, safety of space nuclear power and propulsion units has a meaning which far transcends the technical implications. It involves national and international considerations in the political, psychopolitical, and economic fields.

Some time ago the Administration was faced with making a far-reaching policy decision on whether to permit the use of nuclear power in satellites. Technically, the decision was important for the future of the space program, the reason being that small nuclear power units offered a solution to the critical problem of providing a sustained, reliable source of electricity for operating satellites, radios, and instruments during long periods in orbit.

The problems, however, which concerned the Administration were not so much technological as diplomatic, political, and psychological. On the one hand, the engineers and scientists of the AEC were ready to put a nuclear power source known as SNAP-3 into a satelite. On the other, the State and Defense Departments were concerned about possible adverse world opinion if the United States were to put radioactive material in space and if by a slim chance the material landed on foreign soil in returning to the earth. Many engineers and scientists were also seriously concerned about a possible adverse decision after the expenditure of approximately $\$ 60$ million to develop atomic electrical sources for satellites. The question that could have been asked then--a question that is still pertinent--is why we would develop small nuclear power sources in the absence of a positive decision that they would be used. The point is that the technological worth of the program is merely one factor to be considered in the decision-making pattern for large-scale scientific and technological projects.

To further make the point, during the recent debate on the Ravenswood Reactor in New York, proposed by Consolidated Edison, it was difficult, if not almost impossible, to find an expert who could make a disinterested judgment of the AEC findings on the application. To get an opinion on Ravenswood, the New York City Health Department may literally have to go outside the country. Nevertheless, the issue is so complex that many nonscientists have thrown up their hands and cried, "Leave it to the scientist to decide." Dr. Sidney Sokolar, it is reported, does not agree. Dr. Sokolar, a biophysicist at Columbia University and a member of the Scientist Committee for Radiation Information, told the New York City Council, "Science cannot tell you whether a nuclear reactor should be built in New York. That, in fact, is why scientists disagree about it. What science can do is to provide a picture of the advantages and of the disadvantages." From there on, the issue is simply this: "Are the benefits from each reactor worth the unknown but small risk of a serious accident?" That question is a social and political one that public administrators should decide.

One can say that the same curse existed and still to some extent exists in the Plowshare Program. In 1957 I proposed that an effort be made to start 
separating Plowshare experiments from the atomic weapon program for the reason that, unless one did intellectually separate these programs, the curse of weapons would hamper the progress of Plowshare. I believe historic event's have justified this prediction.

There is a ray of sunshine, however. Recently, a satellite powered by a SNAP-9A radioisotope-fueled generator was successfully launched. The Martin Company device, which is only 20 inches in diameter and 10 inches high, will provide 25 watts of direct current for some 5 years. This important event is another step toward full acceptance of this method to provide power in space.

I have for a number of years been involved in research and development program formulation, administration, and budget defense. During the past 6 months, I have also been exposed to the legislative process of program authorization and legislative overseeing of space-related research and development programs. Having seen both sides of the coin, I can now make some constructive comments on the general problems surrounding research and development programs in the Washington environment.

Since you are all familiar with the process of determining research and development program objectives, establishing program phases, setting target dates, and, most importantly, estimating national resources required, I wil1 not describe it again. I will, however, refer to this process during my discussion of the legislative processes of authorization, justification, and funding of government research and development programs.

Quite recent1y, NASA and DOD testified before the Senate Committee on Aeronautical and Space Sciences during authorization hearings. They presented their 1964 space program, which included research and development for both nuclear propulsion and nuclear power units. Since $I$ had been exposed to both programs during my 16 years with the Atonic Energy Commission, it was a revelation to me to see the other side under a different set of responsibilities and after a 30 -month break in continuity of information. It had been some $2-1 / 2$ years since I had last been exposed to the status of these programs.

I think it might be well at this point to refer to a program with which we are all familiar--the late lamented Manned Aircraft Nuclear Propulsion Program. One could talk for hours about the reasons why this program failed to reach a flyable aircraft, but I believe it has been succinctly stated by the Comptroller General of the United States in a Report to the Congress of the United States, February, 1963, which stated,

"The ANP program was a technically complex and difficult research and development program carried out in competition with other programs for national defense. As a result, the importance attached to the ANP program varied greatly throughout its history and frequent changes in emphasis and direction of the program occurred. Because the ANP was carried out over a period of 15 years and involved expenditures in excess of a billion dollars, our review was generally limited, of necessity, to selected administrative phases of the program.

"Although the ANP program has been terminated, we have found deficiencies in administration and have certain observations which we are reporting for the information of the congress and for consideration by executive agencies so that appropriate steps can be taken to minimize the possibility of similar situations arising in future research and development programs."

This quotation, in general, states the scope of the GAO's audit of the ANP program. The report further stated: 
"The ANP program was characterized by frequent changes in emphasis and objectives, varying from research and development programs to an accelerated program to develop a weapon system for the Air Force.

"The ANP program was carried out in competition with other programs for national defense. As a result, the importance attached to the ANP program varied greatly throughout its history. Although it was outside our scope to look into the reasonableness or justification for the frequent changes in program objectives, we do not believe that a research and development effort of the complexity and magnitude of the ANP program can reach its goal in an effective and efficient manner unless a certain degree of stability in objectives is accorded to the program."

The ANP program may have another lesson to teach us, and one that even now is not well appreciated. The General Accounting office also commented about multiple organization management of a complex program, and the pitfalls of diluted responsibilities and authority. We all know of programs suffering from this same malady.

My only reason in referring to the ANP program is because it illustrates some of the points I will make later on in my talk.

At some point in the sequence of events in large research and development programs arises the first critical area which calls for tremendous scientific judgment and sound and responsible administrative judgment. A decision must be made on the emphasis to be placed on the program. Underselling a program by not developing its defense properly could well mean total denial of support or death by financial malnutrition. Overselling a system or program by overestimating what is known about the state of the art, by underestimating the difficulties to be encountered or the dollars required, or by being overly optimistic about the date on which the system wil1 be available for use is perhaps worse. If the program has been oversold, the effects have a much more traumatic effect. It might wel1 mean that another worthwhile project has been denied support, and the support given to the doubtful project, if permitted to continue, will benefit no one. In the area of national defense this could be disastrous if millions of dollars have already been spent on carriers, missiles, aircraft, or satellites and in the training of men and the development of logistic systems.

The oversold program faces another problem: its supporters in the decisionmaking and budgeting channels become disenchanted. When a program recovers and has much to offer, such supporters are not easily won back. A word of caution is that one must be extremely careful not to oversell a program that requires a substantial portion of the nation's resources. The problem of turning a program off is almost as difficult as getting one started. Senator Anderson has stated many times that one must spend at least $\$ 1$ billion on a program before it is worth turning off. It may be that the acceptable price for "hope" stops at the \$1 billion mark--or that one does not know the advantages or disadvantages of a system until he has spent $\$ 1$ billion to find out.

Another problem which you as technical people must face up to is that major scientific programs have in many cases been oversold to the extent they fail to meet target dates by many months or by years. Lack of usable hardware on schedule has given the skeptics facts with which to criticize and slow down the appropriation of money for programs. It is a great disservice to promise more than one can deliver. Every program looks either attractive or unattractive depending upon many elements, an important one being the target date on which an operational system can be delivered for a given expenditure of national resources. An anticipated long delay in delivering an operable system within the promised timetable is many times justified on the grounds that to continue it as defined would produce an obsolete system and, therefore, it should be reoriented into a more sophisticated program at greater cost and much more time. The common fact here is that less is known about how to build the proposed new system than was known about the original program at its beginning. A good example of the effects of time upon a program is the ANP experience, to which I referred previously. 
The problems of research and engineering programs in obtaining adequate support are not different for many other programs in our national effort, and there is no success like success. The people who must pass upon the funding requirements for large research and development programs and who must defend the expenditure of funds for these programs need repeated bolstering of their faith in the program by successful demonstrations of progress. If any long period of time goes by with no apparent activity or no physical evidence of success, there is a tendency to become more and more reluctant to appropriate large sums of money for the specific program. The competition for support is very keen.

Everyone here is involved in a technical sense with atomic energy, I am sure. You are all familiar with the favorable characteristics of nuclear propulsion units with high specific impulse and low total weight and the advantages of nuclear power in space. What must puzzle you is that if all of the highly favorable technical characteristics of nuclear propulsion and power systems in space are obtainable, why is it that nuclear systems have not moved into direct application more rapidly. This problem is one which is much broader than its technical implications. It must be remembered that the peaceful uses of atomic energy, and more specifically nuclear rocket engines and nuclear power sources, are offshoots of the military weapons development. During the early years of the Atomic Energy program, a11 of the effort was directed to the design, test, and manufacture of military weapons systems. Very little planned effort went into the peaceful uses of atomic energy. However, even as early as 1944, Stanislaw Ulam and F. de Hoffman speculated about the fact that nuclear energy opened new vistas by offering a weightless source of energy. One must also remember that our weapons stockpile had as its primary mission to act as a deterrent to war. For weapon systems to act effectively as a deterrent force, their effects in terms of shock, thermal, and radiation effects had to be made understandable and credible. In order to do this we had to advertise the terrifying military characteristics of atomic energy including the genetic effects of radiation upon present and future generations. In doing this job well, we may have also terrified ourselves into an unconscious resistance to the use of nuclear energy except under certain narrow and predictable conditions. This terror has, for example, delayed the use of nuclear power sources in satellites such as Transit and stil1 raises questions about the use of nuclear power sources in other satellites.

Nuclear propulsion systems come into their own only in terms of interplanetary travel and a high frequency of space missions. At the present time, however, there is no clear, definable national program for interplanetary travel. Thus, without a definable mission, support for nuclear propulsion systems will remain rather thin.

In addition to the psychopolitical hesitancy in using nuclear energy, there are many other considerations. The situation is further aggravated by the delays and setbacks experienced in early prototypes of both nuclear propulsion and power units. The basic differences of the various ideas for nuclear propulsion make a comparison of performance very, very difficult. On the basis of available data, the time for definite association of particular systems with a specific application has not yet arrived, and for no type of nuclear propulsion system do we have an availability date nor limiting characteristics. Project Rover is, however, close to such a status. Performance estimates as a function of time are available by the dozens but remain on a parametric basis.

Many unkind words have been said about the legislative process in Washington, and I have been as guilty as anyone. I now rise to its defense and admit that it was partly because of my own ignorance and partly because of a narrow interest in what I was trying to promote that I became disenchanted with washington. It was quite a revelation to me to find that the question should not be why it is so difficult to get things accepted in Washington when they are technically so worthwhile, but how anything ever gets done at a11.

In the course of analyzing current and prospective R\&D programs by comparing various approaches, I commonly hear in industry briefings on technical programs those who have competing systems to sell predict the failure of the systems with which the agency is working. They question the cost estimate, promised dates, design, credibility of technological performance, anything that will make their 
proposal and paper design sound better than the one that is under development. The desire to sell frequently results in a proposal which has every possible virtue. What the promoters of the new schemes try to se11 is a development proposal with all its new problems rather than an acceptable design.

The complexity of major research and development programs is such that it is virtually impossible for persons in legislative channels to be fully familiar with its scientific contents. The best evidence that this has been and is still a serious problem is the effort now being made in the Congress somehow to get better information and advice on complex technical and scientific programs which involve both public policy and dollars. The pending bills in Congress are in my opinion not realistic. I do not believe that the mere addition of a handful of scientists to advise the Congress would solve the problem. In fact, it may create a false sense of security in their legislative judgments on large scientific programs, a situation which is perhaps a greater danger to technology than the lack of detailed knowledge.

The one factor in all this that was of concern to me was the lack of interest on the part of the very people who will either benefit or suffer the consequences of an ill-advised solution to the problem. It would seem to me that they, the scientists and engineers, should be looking at the problem and hopefully offer alternatives to the proposals contained in the Congressional bills, but I have not seen any concerted effort on their part to do so. Of course, individual members of the various disciplines have voiced opinions, but they are in the minority. It will take a massive interest on the part of scientists and engineers to make their comments effective.

Dr. Charles Franke1, professor of philosophy at Columbia University has questioned whether government by an elite corps of experts is desirable: "The view that expertise is a prerequisite for holding competent opinions on public affairs is one that does not disqualify only some of us. It disqualifies all of us. No one today can be an expert in all the fields that he should really be an expert in, in order to make public decisions. What is called for in making public decisions, accordingly, is not omniscience or omnipotent knowledge but something closer to wisdom, and common sense, and an understanding of when and where and for what reasons to rely on the advice of experts."

During the recent limited-test-ban hearings, many of the nation's leading scientists were asked to testify. Many days of hearings were held by both the Senate Foreign Relations Committee and the Subcomnittee on Military Preparedness. I do not believe that the final decision on the part of each individual Senator was made any easier by the complex testimony and the opposite positions taken by knowledgeable scientists. All the capable advice in the world will not replace the individual judgment of each Senator. The responsibility for making the decision has always been his, and will continue to be solely his. In this complex age and in a democratic country, there are no easy decision-making patterns.

Another disturbing thing, too, about the test-ban hearing was the fact that scientists were asked to comment on system reliability. With due deference to scientists, they are not the best source of advice on system reliability, or, for that matter, safety. The engineers who designed, tested, and produced the systems, should have been called upon to testify on that subject, but no one bothered to do it. Senator Anderson in a floor speech during the senate debate put reliability of weapons into its proper perspective. Before his speech, however, no one had attempted to point out on the Senate floor that the responsibility for the design of systems was assigned by law to the AEC and basically to the Albuquerque Operations office, headed by my long-time friend General Hertford. The laboratories, who of course did the actual work, were Los Alamos Scientific Laboratory and Livermore Radiation Laboratory in the field of nuclear design, Sandia Corporation in the field of ordnance engineering, including safety and reliability, and the manufacturing complex of the AEC, which includes Bendix, ACF, Monsanto, and others.

During the test-ban hearings, one of the questions asked was the effect of the limited-test-ban treaty upon the use of nuclear devices in space. I have 
discussed this with knowledgeable people and have found that the only nuclear program which runs the risk of being denied is the Orion Program because it in fact constitutes nuclear explosions in space and is therefore within the meaning of the language of the limited-test-ban treaty. There is some hope that Plowshare Programs which may involve the possibility of venting in the atmosphere can be done with proper prior agreements.

Now let us return to the application of nuclear energy in space, its promise, and its problems.

Dr. Edward C. Welsh, Executive Secretary, of the National Aeronautics and Space Council in testimony before the JCAE during the September 1962 hearings on Space Nuclear Power Applications stated that, "When the basic decisions were being made during 1961 to put vigor and substance into our space program, the Space Council made a strong and effective recommendation to the President to request additional funds for nuclear engine development, as well as for development of liquid and solid fuel engines.

"Also when there was much uncertainty as to whether a SNAP power unit should be flown in the Transit Navigational Satellite the Space Council coordinated an affirmative decision which resulted in the June 29,1961 flight.... Th2 net result was an important first for the United States. Even more important was the fact that such a decision avoided the serious pitfall of letting fear of international reaction determine the course of our operational research. In my judgment, it is better to risk failure, after taking reasonable precautions, than to avoid action."

Dr. Welsh further stated that, "The use of nuclear energy is essential to a we11-planned and forward-looking space program. There is no practical substitute for the application of nuclear power for exploration of the planets, for longduration space maneuvers, and for other extensive space flights. It is reasonable to consider in such space applications the employment of a nuclear stage for travel to the moon and particularly for so called 'shuttle-flights' to and from the moon. However, I stress particularly its value for even longer duration and continuous alert space trave1."

He further stated, "That the use of advanced nuclear engines holds real promise for substantial improvements in the economics of space travel is a proposition which merits additional consideration. In my judgment, we have no proper alternative but to explore space at a continuing and accelerated pace, even though it will be an expensive endeavor. However, it would be indeed foolish not to develop and use the propulsion system which would carry the greatest weights the greatest distances at the lowest cost per mile-ton ratio. The potentiality of nuclear propulsion in such an objective is substantial.

"Similar conclusions as to importance appropriately apply to the development and use of auxiliary nuclear power supplies. Particularly when several tens of kilowatts are needed, requirements for such power units should outrun their availability. In this connection it is also worth considering the merits of having such auxiliary power supplies since they are not sensitive to the radiation which may be encountered in outer space.

"In al1 space activities, major consideration needs be given to the factor of safety to the payload, particularly if such be human passengers. Likewise, major consideration needs be given to the safety factor as it may affect others, including the contamination and other damage to areas and people. This calls for reasonable safety measures, not absolute safety objectives, as the latter would discourage any and al1 space exploration if carried to the extreme." I am in complete agreement with Dr. Welch's position.

The role of nuclear energy in our nation's future is assured. Of this fact I am confident for many reasons. In spite of the fears of radiation dangers to man which plague atomic energy, one must rely on the fact that the years to come will be very little influenced by anyone here today. New generations are always unimpressed by the problems, fears, and, for that matter, achievements of the old 
generation. This is understandable because the new generation will not have been subjected to the traumatic experience of mankind in the first military atomic explosion. To it, atomic energy could well be a fact of 1 ife and but one other form of energy to be used by man for his purposes. Ironically, this always means for the benefit of man or for his destruction.

To new generations, atomic energy will only mean an obvious engineering exercise, and further, no one, except possibly a philosopher, will have guilt feelings over mankind having unleashed atomic horror on the world. Throughout history, revolutionary developments of science and technology have always been accepted by succeeding generations quietly and efficiently with no understanding of the neuroses of the previous generations.

A quotation from Max Planck is appropriate: "An important scientific innovation rarely makes its way by gradually winning over and converting its opponents; what does happen is that its opponents die out--and the growing generation is familiarized with the idea from the beginning."

Historically, it has been the experience that predictions concerning science and technology generally fail in two respects:

1. possible short-range accomplishments are always overexaggerated, and

2. Inng-range achievements have always been underexaggerated.

There is evidence that much of this has happened to nuclear energy in space or, for that matter, on earth. It is sometimes possible to make reasonably accurate predictions by successfully constraining the problem until it becomes manageable with such qualifying items as:

1. assuming the national motivation remains the same,

2. assuming roughly the current budgetary expenditures, and

3. assuming no technological breakthroughs.

The length of time over which a technological extrapolation is accurate is obviously directly proportional to the number of qualifications imposed. All false and pessimistic predictions of the future of atomic energy in space can be excused by claiming that a technological breakthrough occurred, but, obviously, no one can predict technological breakthroughs "although many a budget has been defended on just such unpredictable technological breakthroughs."

Now, let's talk a little more about predictions and evaluations of science and technology. In 1953, in a "mid-century appraisa1" in the IAS Aero Engineering Review of December, a prognosis of the future of aeronautics was made by top aircraft and missile experts. Following is a quotation:

"There was only cautious hope for supersonic operational flight. Missiles were projected primarily as winged atmospheric vehicles-there was no projection of massive ICBM threats nor predictions that missile systems would commence to take over many of the roles of aircraft. There was no reference to a common space age. If the space age could be completely missed from 4 years away, it would seem reasonable to at least speculate on the role of nuclear energy in space with a little imagination."

In spite of the dangers inherent in predictions, I will make the following: In a hundred years I expect to see completely reusable nuclear-powered vehicles which will be capable of carrying more than half their gross weight in payload at speeds up to 300,000 feet per second (DeIta V), and ranging in capacity from 50 tons of payload up to 10,000 tons. Fusion power may be used. We can expect passenger and freight-carrying space ships running on regular schedules to operations in space. 
Victor Hugo once stated, "No army can withstand the strength of an idea whose time has come." During the next century nuclear propulsion and power sources will come into their own, since space and nuclear energy were made for each other.

My remarks may have incorrectly implied that I am unhappy about the reluctance of our society to accept nuclear energy along with its real and imagined hazards. They may also have implied that I am unhappy about the fact that the safety considerations seem to have been overemphasized and may have had an adverse impact upon the use of atomic energy in competition with conventional forms. If they have left this implication, it is not intended. One must remember that the other side of the coin is that many inventions did in fact result in unpredicted adverse effects upon the society. Let me mention a few. The development of the internal combustion gasoline engine used in cars has become a major source of air pollution. Not only has it caused eye-smarting, coughing, and other detriments to health, but we are suffering millions of dollars loss in crops and plants, and in deterioration of buildings and houses. The effect of the use of pesticides and insecticides needs no lengthy description. Rachel Carson has done this for us. Synthetic detergents built up by Madison Avenue as the wife's closest friend have now become a major source of water pollution. It is fouling up our recreation, is causing our drinking water to be off color, is increasing the cost of sewage treatment, and is causing highway accidents. Numerous drugs and medicines have been introduced without adequate safeguards and in some instances have had very severe consequences. We are beginning to reap a harvest from research and development which in part is not so green. In fact, these advances and technological innovations are giving birth to new problems which did not previously exist. The point to be made is that scientists have not always looked ahead after giving birth to their new products and thought about the possible problems we were likely to encounter along with the good. There has been much recent criticism of scientists on this account. I think that any reservation one might have put on scientific improvements should be judged by a full analysis of the possible effects of the innovation measured against the need for the innovation. Perfect safety is never achievable and as a goal it should not be allowed to interfere with bringing new and better forms of energy to man. Science, however, should not carelessiy do things to man's environment. The cliche, "Stop the world, I want to get off" is not yet possible.

With atomic energy we may have a different case. It is probably the first scientific advance or technical invention that has permitted us to see the potential harm and hazards to mankind before its widespread exploitation in the peaceful arena. Hence we may have been able to prepare accordingly for any possible eventuality. We have time to educate the public. We have been able to furnish protective measures and safety criteria in connection with the use of atomic energy construction, manufacturing, the use of isotopes, disposal of waste, and so forth. Al1 of these things were possible in atomic energy because of its initial long-term orientation as a weapon.

Gentlemen, science and technology can create either Techtopia, heaven on earth--or Techmania, he1l on earth. Which shall it be? It's up to us collectively to decide.

I believe that the following personal motto expresses the role of all decision makers more effectively than I can: "God grant me the serenity to accept the things I cannot change, the courage to change the things I can, and the wisdom to know the difference." 


\author{
THE NASA AEROSPACE NUCLEAR SAFETY PHILOSOPHY \\ $\underbrace{2} \ldots$ \\ H. B. Finger, Manager \\ Space Nuclear Propulsion Office, AEC-NASA \\ Director, Office of Nuclear Systems, NASA
}

I seldom have the opportunity to philosophize. I talk about the programs that we are running, principally the nuclear rocket program. My talk today, however, will not cover the nuclear rocket program at all. I have been asked to talk about NASA's philosophy of safety; since I don't really know what that is, I'11 give you my own philosophy. Certainly for my programs it represents the project philosophy. Where I can, I'Il include NASA examples.

The philosophy of nuclear safety in aerospace systems is, to me, just like the philosophy used in the development of any space system in which human life may be involved, whether it be human life in the vehicle itself or the effects that may be felt on the ground. The main point must be that the system will be as reliable as possible; its operation must be assured. We would like 100 percent reliability.

I think the main effort must be in ensuring that the system will work as designed. In addition, we believe that even when we do everything possible to make it work as we intend, we assume that something will go wrong and design appropriate countermeasures. I think we can develop a system that really is reliable, one with a negligible probability of abort and damage. I will later indicate some examples to show that such systems do exist in the space program, as established by the record of space flights.

I also believe we can develop reliable countermeasures. My real worry, however, is that countermeasures may make the basic system unreliable and may make it almost impossible to operate the system satisfactorily. This is where the judgment that Mr. Diluzio talked about enters. I have seen many countermeasure gadgets that we could add to nuclear rockets and nuclear electric power systems which would, I am afraid, make it impossible for the basic system to operate successfully. At some point, tradeoffs must be made to optimize overall safety. I believe it has to come at the beginning of the development program and be integrated throughout the program.

Everything I have talked about so far--development of the system and development of the countermeasures--is, to my way of thinking, a project responsibility. It is up to the people who are developing the system to handle these responsibilities. Only the project people can make the design decisions and tradeoffs to ensure overall safety and reliability. Over and above this, we get what is usually referred to as an independent review. As Mr. DiLuzio pointed out, it is frequently difficult to get such a review, but we try. This independent review hardly ever does, or should, dig into the development program of the system to determine whether the system will operate successfully. What it looks at are the countermeasures, which, of course, we hope are never used. Thus, it looks at only a sma11 part of the overall problem. My concern is that a review may be so independent that its only purpose is to say, "No, there is something you haven't looked at, and until you look at it we won't let you fly." I think the project has a responsibility to be as objective as it can, to point out every trouble, to force itself to be aware of the problems it may run into, and to explain these and discuss them with anybody who wants to know about them so that it may objectively make a responsible decision on the safe operation of the system. I am frankly concerned, however, that both the countermeasures and a too-independent review may reduce the likelihood of successful operation and application of nuclear systems in space. 
I'd like now to discuss how we go about getting a system to operate successfully. We have, I think, several examples of the kind of reliability we want. Though few in number and statistically a poor sample, the four successful flights by the Marshall Space Flight Center of the Saturn I first stage indicate that a reliable system can be developed. To do so, it requires a thorough enough understanding of the system so that if anything troublesome shows up in the development program, it can be located and corrected. Then again, we try to put enough margin into the system to make the operation reliable.

We have had 19 consecutive successful Thor-Delta flights out of a total of 20 tries. It is clear once again that it is possible to develop successful systems.

The Mercury program is probably the best example of all. There were no mission failures. Human life was involved. The main emphasis was on ensuring that each flight would be successful, whether it was manned, unmanned, or flew a monkey. In addition, countermeasures were always available so that in the event anything happened the astronaut would get out safely. Happily, the abort countermeasures never had to be used--and that really is our goal, it seems to me in nuclear aerospace systems.

Another example appears in the successful space flights of the Goddard Space Flight Center, which has had 30 successful flights out of 31 attempts. Thus, it is clear that methods exist for obtaining reliability.

The problem with nuclear systems, however, is that these systems will fly with hardware which has never been tested before--a rather unique situation. In almost every other case, ground tests are made of the hardware flown. In general, the philosophy is to test the hardware to be flown. This philosophy cannot be followed with nuclear systems and, hence, it will have to be ensured that, throughout the development program, each unit is exactly like the next and any damage appearing in one is understood well enough to avoid similar damage in later units.

The burden, then, is on the process of developing such reliability, and I'11 spend most of my time talking about this area of work.

In order to achieve high reliability, we must have a good design, the test equipment and hardware must be built as designed, and a thorough development test program must be conducted including extensive testing under simulated space flight environmental conditions. First, we obviously must start with a good design. The entire system must be designed with as much margin as we can build into it and with redundancy for critical or uncertain operations and components. The problem is that we don't necessarily know how the system will operate under a11 conditions. Therefore, we don't really know where the margin must be added and how much is required to ensure reliability, especially when we are in an early part of the program and are developing a new technology.

Secondly, and I think this is where we get into many of our problems, we must be sure that the hardware is built as designed. I know all of you who are responsible for building systems or hardware are shocked at what frequently happens in procurement and fabrication. Although we monitor and direct vendors and contractors and succeed in catching some errors and deviations, some get through because we lack sufficient manpower and because we are not necessarily, in all areas, better than the many competent industrial people participating on our programs. Many examples can be cited. For instance, a raw material delivered to us is certified to have a certain heat treatment; when checked for certain properties after fabrication, we find that it isn't the material we were supposed to have had to do the job. Obviously, the vendor of the raw material must have his quality control techniques reviewed. Such problems take us back to the supplier of the raw material--all the way through every one of the vendors, fabricators, and inspectors and through every step along the way if we are to ensure that the hardware delivered is, in fact, as designed.

There is frequently a feeling that quality assurance need not start in an early research and development phase of a program. I don't agree. I think the 
fault in this concept is that as we establish a design, every result must be able to be correlated with certain reasoning and certain things which happen in the system. There may be anomalies in the results from different systems, and we must be able to track back to ascertain that the piece of hardware we started with is everywhere the same. In addition, it must be recognized that every bit of data must contribute to the setting of specifications, to establishing quality control procedures, and to proving out the design, especially when comparatively few systems are to be built. I think it is a real problem. It requires that we start quality assurance efforts very early in research and development.

In addition, we must not fail to recognize that our quality assurance techniques themselves require research. There are many areas of inspection and quality control that are not yet established. We don't always know how to measure the inclusions in a weld. We don't always know how to ensure the physical properties which we want over the full range of conditions required. Where there are thick sections, X-rays may not always be satisfactory; means must then be found both for inspecting such sections and tracing them through the fabrication process in order to ensure that we have in fact, even with prototypes, a way of building hardware as designed. Al1 this work, it seems to me, must start in the research and development phase of the program.

It is, in addition, necessary that a comprehensive analysis and development test program on all system components and subsystems be conducted in a program leading to full system tests so that all the phenomena encountered are thoroughly understood. This development work must include full system tests on the ground under simulated space flight conditions. Some feel that it is too difficult to test nuclear systems under simulated space conditions and that because of the cost this step should be skipped. Thus the system goes from component and system tests under nonsimulated conditions directly to flight. I don't believe, however, that the full system simulated environmental tests can be skipped. Such tests are made on every other system; why not on nuclear systems? Nuclear systems are not simple; they are not easier to develop than other systems; they involve as much or more test work. There must be a clear, comprehensive test program that includes every step able to provide assurance that the end item will operate as intended.

I don't believe there are any short cuts in these developments. We cannot plan on any luck. We must build success into the system during development, and we must build it in by including every facility, every piece of test equipment, and every test that will help to ensure successful operations. The development time will not be longer with such a program; the time will be shorter in terms of delivering the thing we want. Nor will the cost be any greater with such a program. Rather, it will lead to success that would not be assured by any short-cut approach.

In the hearings before the House Appropriations Committee just a few weeks ago, a rather interesting question was asked by Congressman Thomas, Chairman of the Independent offices Subcommittee, with which NASA works. This question was asked of Dr. Robert Gilruth, Director of the Manned Spacecraft Center: "To what do you attribute your main success, Doctor? I think the outstanding thing in my 1ifetime has been the Mercury program that you gentlemen put on so successfully. You did not lose even a monkey, much less a human being." Dr. Gilruth replied, "I think it is the great care on the part of the government personnel and skill on the contractors', which, in this case, were McDonne11 Aircraft for the spacecraft and General Dynamics for the booster--the great care, checkout, and testing and retesting, going as far as we possibly could in assuring it would work when we tried it. Even when you do all this you cannot always guarantee success." Later in the discussion, Mr. James E. Webb, the NASA Administrator, added, "You see, one of the things that is so essential in these matters is never to proceed, when something shows up that you do not understand, until you rea11y understand it and know what the cause of any particular phenomenon or difficulty is. I think Dr. Gilruth, perhaps more than any other person, has been the driving force to make absolutely sure that nothing unknown will be permitted, that you must really identify the cause of some occurrence before you proceed to the next step." 
This, I think, is the NASA philosophy, It does lead to successful systems as indicated by the Mercury program and the several others I mentioned. Hopefully, the same philosophy will be used in nuclear programs. Even though it may appear to delay the programs at first, it will actually give successful completion in the shortest possible time, and, I am convinced, at the least cost.

Incidentally, in the Mercury program and later in these House Appropriation Subcommittee hearings, Dr. Gilruth made the point that in order to ensure the required booster reliability, the Atlas boosters delivered for the Mercury program were different from military boosters. The parts were carefully tracked through fabrication and assembly; more severe requirements were put on the parts than on those for military use, and the cost of the system went up by about 30 percent, I believe he said. But the point is that the program ran successfully, and every mission was a successful one. Let me give you an example of the requirement to explain every detected flaw. On Cooper's flight, there was an inverter and 0.05-g signal problem. Months after the flight, tests were still being run to figure out what went wrong in the electrical system, even though it was known that no Mercury flights were to follow. Detailed explanations must be available for everything that happens in a test or a flight. I believe this applies as well to ground testing. I agree also with Dr. Gilruth that no matter how hard you try, there may still be difficulties that you won't find. You do your full system tests on the ground and your flight tests as part of the development program to find these troubles. When you fly an operational system, you should have worked all of those bugs out.

I will only mention a few other areas which, I think from a systems approach, must be developed at an early time. These include all aspects of ground checkout at the launch site. A means must be developed to check the vehicle out and ensure that every system is working properly. The range safety system must also be checked out to be sure that the sensors and the transmitted data it will have to read will, indeed, give the kind of information that is needed. This is a very large and important overall system development problem.

A11 these things I have talked about are project responsibilities. No independent safety committee looks deeply into this part of the program. The project establishes the way it wants to work and the way the system is to be developed. The success of the program depends upon the serious attitude of the people who are responsible for the development of the system. Beyond this, however, because we can't always be assured that every piece will work as intended on a flight, we apply countermeasures. In nuclear systems, the particular hardware will not have been tested before. We, therefore, try to postulate anything that can happen anywhere along the operating cycle--in the shipping of the reactor to the Cape, the assembly of the reactor with the rest of the system, its installation on the vehicle, the initial boost phase, along the trajectory, and after operation. Everything must be considered. We then postulate every possible accident that could occur, and we try to devise a countermeasure for each one. Hopefully it is a passive countermeasure, but we can't always do that. Sometimes we need active countermeasures. We must then go off on a new development program to develop the countermeasures, following the same philosophy as on the basic system itself.

As I have said, I am concerned that some of the things we talk about as active countermeasures in these nuclear systems will have some effect on our ability to successfully operate the basic system. We haven't yet reached the point of making a11 the necessary tradeoffs, but they will have to be made. Some judgments must be made, and some risks must be accepted as long as we can show that the probability of an incident is sma11.

Now, this is the one area, to my mind, that needs some safety review. It should not be a project review, but it should not be a review whose entire purpose is to say, "No, don "t fly." It has to be a review that is constructive. It must look at the problems associated with the entire system and at its reliability, especially its countermeasure reliability. It will not follow the same ground rules as the ACRS review of ground reactor systems. I believe the ACRS has established an enviable record in ensuring the safety of ground systems, but we are talking now about a different kind of environmental situation where different technologies are required. 
How does one obtain a single review when there are so many different groups involved? NASA is responsible for the mission, the AEC and NASA for developing the systems, and the Air Force for the range and the launch area (if launch is from the old Cape C.inaveral area; NASA is responsible if it is from the new Merritt Island launch area). A coordinated review is, therefore, extremely important. Each agency has some review function, but, if we went through all of them one by one, we might never fly. There must be some pulling together of all these groups to review the safety of the system. From a technical point of view, several agencies were involved in the review of SNAP-9A system safety and potential hazards. The Division of Reactor Development and the Division of Licensing and Regulation in the AEC drew on experts from the different agencies in their particular fields of competence. Sandia was deeply involved in this program of testing as well as Corne 11 Aeronautical Laboratories and various other groups. I think it was a very constructive exercise. But the fact is, even after going through al1 this review, we couldn't have at the launch site a whole committee trying to make decisions. One man will have to be delegated to speak for the project and make the very final judgments within a broad framework of specifications that the review committee presents. One man must have the authority to make the decision, and he will have to be responsible. He will have to be a very competent man with a real understanding of the responsibility that he will take on.

In summary, I would like to say that I believe that nuclear systems can be developed to be reliable. In some ways, they are simpler than the systems we are working with now--simpler than the chemical combustion rocket systems, the solar cel1 systems, etc. I believe we can apply countermeasures, but these will have to be applied with judgment to ensure maximum reliability and overall safety. I believe also we will need some kind of an integrated interagency safety review. This is the basis upon which we will establish a nuclear space capability for the country that will permit us to explore in areas that we would not otherwise be able to approach. 


\section{BLANK}




\author{
AEC AEROSPACE SAFETY PROGRAMS AND PHILOSOPHY \\ F. K. Pittman, Director \\ Division of Reactor Development \\ United States Atomic Energy Commission
}

\begin{abstract}
Recently, an operational satellite carrying the radioisotopic SNAP-9A as its power source was launched from Vandenberg Air Force Base. This launch, among other things, ended two long years of aerospace nuclear safety research, development, test, analysis, and evaluation. It also demonstrated how a large number of organizations and many scientific and technical disciplines can collectively and effecttively get a job done. Although we had no doubts that SNAP-9A could be used in this aerospace mission with a high degree of safety, we recognized that we had barely crossed the threshold of the broad subject of aerospace nuclear safety. Space systems are so varied and our experience with nuclear units in space so limited that it seems quite clear that only the surface of aerospace nuclear safety technology has been scratched. A lot of work in aerospace safety analysis, research, development, and testing is ahead of us before we can ensure the safe use of nuclear devices in a large number of applications.
\end{abstract}

\title{
History
}

Although the course of aerospace nuclear safety has obviously been short, there is nevertheless some history that might we 11 be related briefly. In 1959, the SNAP Hazards Committee and ANP Life Sciences Working Group within the AEC recognized the need for some aerospace nuclear safety criteria on which to base safety analyses and judgments for the use of aerospace nuclear devices. Based on their recommendations and on those of the DOD, NASA, and President's Science Advisor that such criteria be established by the AEC, the Aerospace Nuclear Safety Board was formed within the AEC.

This Board was set up to analyze and predict the possible effect of nuclear space devices upon the health and safety of the public, to recommend standards of safe practice for the employment of nuclear-powered space devices, and to recommend policy and procedures to be followed in regulating the use of nuclear energy for devices in space vehicles and satellites.

It was readily apparent to the Board that nuclear safety questions would arise as a result of missile launch-pad failures, preorbital failure of the space vehicles, release to the atmosphere or into space of radioactivity, and random return to earth of intact or partially intact devices as a result of failure to burn up on re-entry, or deviations from programmed missile trajectories. In order to ensure safety, the Board felt that it would be realistic to expect compromises of performance, economy, and operational flexibility in the early flights, but it felt that such compromises would be reduced as a result of the accumulation of experience and the advancement of space technology.

About the same time, two other groups, the SNAP Safety Committee and the Joint Committee on Hazards of Nuclear Space'Systems, took a hard look at the programs. The SNAP Safety Committee reached the conclusion that the most desirable means for disposal of the radioactive material would be (1) to ensure that the heat source would remain in orbit throughout the effective lifetime of the isotopic fuel 
or fission products (after the reactor were shut down), (2) inject the device into a solar orbit from its initial terrestrial orbit, or (3) to return it from a terrestrial orbit to a specific location on the earth's surface.

However, because the missile art at that time was not sufficiently advanced to ensure that these procedures would work with adequate dependability, this group believed that the planned return of the intact isotope-containing package (or reactor with a fission-product inventory) was inadvisable except under specific circumstances.

A11 of the early groups, as we11 as the more recent, agree that, for the proposed space missions (assuming adequate reliability and performance of the nuclear device itself), the achievement of the normal operational orbit would not result in a hazard to people and that the only hazards would be the result of an aborted mission or missile malfunction. This leads to the conclusion that basic to the design and use of a safe nuclear device safely in space is knowledge of (1) the missile abort or malfunction environment to which the nuclear device may be subjected, and (2) the effect of these environments on the nuclear device.

In 1960 , there was a reasonable understanding of what the radiobiological hazards of the various radioisotopes would be if people were exposed to them on the surface of the earth. Dependent on the form, ground concentrations, and location of the isotopes, the potential hazards could be related to a generally accepted framework of radiation protection. This gave us a fair handle on the end point of the safety problem, but the most important pieces of the total problem were essentially unknown--the abort environments and the effect of such environments on the nuclear device.

Thus, our early endeavors to formulate aerospace nuclear safety philosophy were directed for the most part toward the nuclear considerations, with our attention focused on radiobiological factors which constituted the end point of the safety problem. In the next few years, however, from 1960 to 1962 , we became so engrossed in defining the unknowns of our problem--the missile abort environments and their effects--that we, to some extent, neglected the area in which we had made a good beginning, the analysis of the potential radiation exposure. We are now achieving a much more balanced approach to our problem.

It has now become apparent that the best approach to the analysis and evaluation of aerospace nuclear system safety is through coordinated effort across the board first to define and analyze the missile abort environments, second, to identify the probability that such environments can result in the release of radioactivity from the nuclear device to the biosphere, and, third, to analyze the extent of the hazards associated with this release. The coordination of physicists, aerodynamicists, aeronautical engineers, metallurgists, electronic engineers, meteorologists, oceanographers, biomedics, etc., has shown us that we can reduce or eliminate effort on some problems because there is little or no safety problem involved and has allowed us to make a preliminary scoping of the areas where true safety problems seemed to exist. By initiating such a coordinated safety analysis effort at an early stage, we have made possible a continuous evaluation of the safety aspects of the several aerospace nuclear programs during their development period. This has been particularly useful in pointing out where the safety efforts should be concentrated.

We are now beginning to learn that an understanding of al1 aspects of a program is necessary and that it takes the coordinated effort of experts in all the aerospace and nuclear safety disciplines for adequate safety assurance. The analysis of SNAP-9A has given us some insight into how much input can be expected for any one specific discipline and how the efforts of all groups must be overlapped and coordinated to eliminate the voids.

It is axiomatic that as we move ahead in the aerospace nuclear era further progress and improvement in our safety analysis capability must be made. 
Technical Philosophy

The issue of safety is paramount. But when we say this, we should and must recognize the concept of acceptable risk commensurate with the advantages and benefits to be achieved. The trivial solution, "Zero use equals zero risk," can be dispensed with right now.

The aerospace use of nuclear systems presents an interesting and indeed exciting challenge because of the variety and complexity of the vehicle systems that they are to be used in and the missions that these systems are to accomplish. It is fairly certain even now that the safety problems are not represented by a single question with a single solution. There are likely to be a variety of acceptably safe solutions to a multitude of problems. The aerospace nuclear safety programs must be flexible enough to solve each of the safety problems in such a way that the safety approach to a specific system is compatible with the physical constraints of the system.

An extensive safety analysis and evaluation and test program on the SNAP-9A device that assisted us in obtaining approval to fly has been accomplished. Many lessons were learned in the safety iterations for this program, and many more 1ikely will become apparent. One of the things that we have known for a long time was that the safety of a system could be "paper-studied" at length without developing an irrefutable, data-supported safety evaluation. Our SNAP-9A evaluation served to reaffirm and strengthen this truism. At some point in the safety iterations, "paper-studies" must be supplemented with experimental data. For maximum safety assurance of systems requiring program approval at the highest levels of government, experimental evidence on which to base the safety of a system is imperative.

SNAP-9A has emphasized that safety involves the nuclear device and its associated components--the whole system and its mission. However, it has also taught us that the significant, controlling problems on the safety, or degree of safety, of the proposed use in aerospace require an understanding of missile malfunctions or aborts, the probabilities of such occurrences, the environments associated with the malfunction or aborts, and their effect on the nuclear device. The environments are not only severe but extremely difficult to analyze and understand.

Although the conclusions on the safety of SNAP-9A were based in part on the judgment of the best technical competence in the nation, the desirability of further supporting experimental and test data was also evident. The need for developing fundamental data on each of the missile abort environments cannot be overemphasized. These data must be obtained at an early date because of the control the environments have on the design of the device and on the safety philosophy to be followed on the mission.

I have mentioned flexibility of design and safety systems. Up to now, the major safety philosophy used in the design of aerospace nuclear systems has been complete containment of radioactivity during a11 phases of early launch aborts and complete burn-up on re-entry at or near orbital velocities. However, we have put only three devices up in orbit under this general philosophy and there are many, many more to come--of all sizes, shapes and types.

With the appearance of larger, more complex, nuclear systems in the relatively near future, it may well be that the current philosophy of design may not be the best. Therefore, we are looking for other ways of ensuring safety as wel1 as providing maximum flexibility for aerospace use. Envisioned are such schemes as:

1. controlled re-entry,

2. selection of a fuel form that would permit high-altitude burn-up or intact re-entry without the release of the radioactivity to the biosphere,

3. in-orbit recovery by another satellite for return to earth or ejection into a solar orbit, and 
4. positive destruct devices on re-entry to ensure disassembly and burn-up on re-entry at extremely high altitudes.

As previously stated, we are not approaching the aerospace nuclear safety program on a single-problem, single-solution basis. Each program or system could for a long time present a different problem that requires a different approach.

Protection of the public from real hazards is not the only underlying motive for a flexible safety approach to the use of aerospace nuclear devices. We must also consider the impact of public opinion, both here and abroad. Even though we could show that the use of nuclear devices in aerospace will not result in significant levels of radioactivity to which people may be exposed, and even though these conclusions may be reached on very conservative bases, we would be something less than realistic if we did not recognize and anticipate the potential problems associated with public and political reaction in this area. Public acceptance from both a political and psychological viewpoint will ease the way to the widespread safe use of nuclear power in space. It is important that this aspect of the business be given adequate consideration and attention since, to be pragmatic, it is conceivable that the factors involved may in some cases be governing.

\section{Safety Program}

In order to support our flexible aerospace nuclear safety philosophy and to ensure the safe use of these devices in space, an extensive aerospace nuclear safety test program is necessary. The recommendations of the Aerospace Nuclear Safety Board and the recognition that an across-the-board aerospace nuclear safety program was required resulted about 2 years ago in several organizational changes within my staff. A Nuclear Safety group was established under the direction of J. A. Lieberman with across-the-board responsibility for nuclear safety R\&D, analysis, evaluation, and testing.

Within this office, the Engineering and Test Branch conducts prototype-scale tests on the safety of the $R \& D$ reactor systems, and a specific group has been formed to handle aerospace nuclear safety test programs.

Sandia Corporation here in Albuquerque was chosen as the primary AEC contractor for the aerospace nuclear safety test program. Because of background experience and available facilities, tests involving reactor excursions were assigned to the Phillips Petroleum Company at NRTS.

Many technical advantages accrue from focusing the responsibility for aerospace nuclear safety testing in a single AEC organization and in a single contractor, particularly one with the field-test experience of Sandia. In addition, because such groups are not involved in the development of specific nuclear systems, they can present to the public a degree of objectivity and independence which is readily accepted. This requires in those responsible for development of the systems* excellent working relations between the safety test groups and the project development contractors, and such relations, I am glad to say, have developed.

\section{Engineering and Test Program}

The Aerospace Safety Test program being conducted by the Division of Reactor Development may be divided into five principal areas:

1. basic or general research and development in areas significant to aerospace safety,

\footnotetext{
* May I hasten to point out that in the final analysis actual safety, as opposed to analysis thereof, depends upon the developers and designers of the system and not on those who test and evaluate systems.
} 
2. flight testing of generalized prototype and research systems in a true space environment,

3. ground testing of prototype systems in missile launch abort environments and flight testing in space,

4. reactor excursion tests, and

5. independent assessment of the system's nuclear safety.

The objective of this program is to acquire basic data; from this we can extend our knowledge of areas significant to aerospace nuclear safety. Examples of areas to be investigated are as follows:

1. orbital re-entry burnup of aerospace nuclear fuels,

2. high-altitude dispersion of particles,

3. oxidation and dispersion of hazardous materials under conditions simulating launch abort fires,

4. test verification of analytical aerodynamic equations, and

5. space investigation of physical properties of materials.

A series of scientific passenger pod flights has been completed in which various test items, containing flare material, were attached to ATLAS missiles and released at predetermined altitudes and trajectories. These tests, conducted by the Martin Company under AEC contract, were designed to verify analytical equations developed to predict the re-entry phenomena.

A comprehensive investigation of the physical properties of nuclear aerospace fuels and materials, particularly at elevated temperatures in the space environment, has been initiated. Knowledge of these properties is essential for an understanding of the behavior of these materials in space and for the development of effective aerodynamic codes for the analysis of space phenomena.

Flight testing will continue to play an important role in our testing program. No ground facilities are available today in which all the parameters of re-entry can be simulated simultaneously; therefore, we must continue to use space itself as a laboratory. These tests will be conducted with vehicles purchased by the AEC for that purpose. During Fiscal Year 1963, our first re-entry flight test on the SNAP-10A reactor system was conducted. The results of this pioneer effort are described in another paper.*

During 1964, we anticipate another re-entry flight test to get re-entry data on second-generation isotope generators as well as reactors. The data will enhance the level of confidence in our ability to predict the sequence of aerodynamic events during re-entry. In addition, "piggy-back" experiments are contemplated, where feasible, in cooperation with DOD and NASA on ATLAS, TITAN, and space vehicles such as Apollo to acquire data on specific aspects of the aerodynamic heating of reactors and radioisotopic components on re-entry. Low-level, high-velocity flights may also be used to ablate fuel material so that the resulting particulate cloud can be sampled by high-altitude aircraft.

In the ground test area, the AEC has already completed a series of terrestrial environmental tests on the SNAP-10A core vessel at Holloman Air Force Base in conjunction with the Air Force and Atomics International. In these tests, the reactor

Fee Paper V-2, "Aerospace Nuclear Safety Re-Entry F1ight Test Program," A. J. Clark, Jr., pp 279-294. 
core vesse1 was subjected to various missile launch-abort envixonments to test its reaction to chemical, fire, explosion, and mechanical hazards. A second phase of these tests on the SNAP-10A reactor is scheduled this coming year.

In isotopic SNAP systems, a comprehensive series of ground tests has already been conducted on the SNAP-9A capsule. The terminal velocity and freefall stability of these capsules were obtained in drop tests conducted at the Sandia Tonopah Test Range.

Flight-qualified capsules were then impacted on granite (the most stringent target material) at velocities and temperatures approximating terminal conditions resulting from booster vehicle abort. In addition, the Sandia Radiant Heat Facility has been used to test these capsules under simulated launch-fire conditions.

As previously stated, excursion testing of nuclear aerospace reactors under the engineering and test program will be done by the Phillips Petroleum Company at NRTS, Idaho. One of the most serious accidents postulated for space reactor systems, both SNAP and nuclear propulsion devices, is a nuclear excursion induced by an accidental immersion of the reactor in water or by an inadvertent rotation of the controls to a critical position. Either of these conditions could conceivably occur under launch-abort conditions. Accordingly, safety testing of space reactors and nuclear propulsion systems will include a series of transient tests, including excursions to the destructive range, to determine the maximum energy release to be expected should such an accident occur. These tests will also determine the ultimate shutdown mechanism of these reactors and will provide information on the quantity and distribution of fission products and radioactive materials as we 11 as the energy release. The initial excursion test designated as SNAPTRAN-3 wi11 mode 1 a major accident resulting from launch-pad or flight accidents which immerse the nuclear reactor in water. Subsequent tests will investigate the transient behavior of the reactor by varying amounts of reactivity insertion that might result from events which cause rotation of the control elements to a position beyond critical or which result in the inadvertent addition of other reflector materials. Supplementary experiments will explore the transport rates of hydrogen from zirconium hydride fuel elements at high temperatures, since this represents the expected inherent shutdown mechanism for SNAP reactor systems using hydride type fuel.

Another area which will be investigated is the disposal of radioisotopes and fission products from nuclear aerospace devices at the end of a useful space mission or after a missile abort.

\section{Administrative Philosophy}

In this relatively new field of nuclear engineering for space application, the AEC has found itself deeply enmeshed with the many branches of the DOD and NASA, not only in the development of the space satellite systems but also in the integration of the system into a space vehicle and booster and into launch operations, range operations and safety, and space tracking. Each group has distinct responsibilities that include safety and that, of necessity, overlap the responsibilities of other groups and agencies. Although the AEC has an overall responsibility for the nuclear safety of the aerospace nuclear systems, this responsibility, in effect, must be shared with the other agencies and their expert knowledge must be relied on to ensure safe use of the system. Examples of this sharing are launch operations, where the AEC depends on the Air Force to ensure safety under a11 launch conditions, and the preorbital boost flight, where Navy or Air Force Range Operations is expected to ensure flight within a safe trajectory envelope.

A11 of the agencies in discharging their safety responsibilities must seek advice of the experts in the other agencies because the assurance of safe use of an aerospace nuclear system requires the coordination of the technical competence of all the agencies involved. To make efficient use of this expertise, to avoid duplication of effort, and to ensure a technically sound depiction of the system safety, coordination is required early in the system development. 
Within each of the aerospace nuclear programs, interagency agreements have been written and working groups established to solve interface problems in the system development and to start the analysis of the system safety. SNAP-9A showed us that these were not enough to present a technically sound basis for the assurance of safe use in space. When we looked at the safety pieces put together some 6 or 8 months ago by the various working groups in the several agencies, it was found that gaps existed in the overall safety program and that some portions of the picture were somewhat deficient.

In a meeting with the nuclear safety groups within the Navy, Air Force, AEC, and NASA, it was decided what had to be done and who would do it. We jointly embarked on an extensive safety analysis and evaluation and test effort to present a complete and technically competent safety analysis upon which could be based approval by the highest levels of government of the proposed aerospace use of SNAP-9A. I would like to stress that this effort was done on an informal basis but was initiated and carried to a successful conclusion because of a mutual understanding of each other's safety responsibilities and technical competence by everyone concerned.

Not every safety problem was completely resolved. However, the picture was reasonably clear as to the extent of the small risk involved and why even a small risk remained. In certain areas, analysis and personal judgment were not enough to ensure beyond a shadow of a doubt that no hazards would result. Even with the advice of the technically expert group assembled, further experimentation would be necessary to answer completely some of the questions raised. This, of course, is to be expected in any complex aerospace program. SNAP-9A can be used in space with a high degree of nuclear safety. However, in some minds a small risk will exist until the judgment of the experts can be substantiated by experimental data.

If a formal mechanism had existed to draw the agencies together at the outset of the SNAP-9A development and space system integration, it is quite possible that many of the partially resolved problems could have been looked at in a joint agency experimental program. Hopefully, the aerospace agencies can establish a joint agency panel or group that can formally bring the expertise of all the agencies to bear on a program at a very early phase of development. Problem areas will be recognized early, a meaningful safety test program can be conducted on a noncrash basis, and, if necessary, time would still remain for modifying the system design to ensure a high degree of safety. Final approval of a program would be administratively less complex. Although the individual responsibilities of the agencies can never be delegated or abrogated, the duplication and voids inherent in a system of overlapping responsibilities can be minimized. The discharge of responsibility will be more efficient.

\section{Conclusion}

In conclusion, I would like to reiterate four points:

1. The fundamental parameters of missile abort environments must be experimentally established to form a technically sound basis for aerospace nuclear safety philosophies and device design.

2. Aerospace nuclear systems require a flexible safety approach--it is not a case of a single problem with a single solution.

3. As aerospace systems become more complex and more agencies are involved in their integration, we will have to work on an interagency basis from the very beginning of each program. Formal means of accomplishing the interchange of this expertise will enhance the overall safety of the systems.

4. Every effort will continue to be made to minimize the safety barrier to the use of aerospace nuclear systems. It is my firm conviction that safety need not represent an insurmountable obstacle to the widespread and important applications of nuclear devices in aerospace systems. 


\section{BLANK}


USAF AEROSPACE NUCLEAR SAFETY PROGRAM AND PHILOSOPHY

Co1. C. B. Stewart, Director

Directorate of Nuclear Safety

Deputy the Inspector General, USAF

Today, national policy requires our military forces to be at all times in a state of advanced readiness throughout the world. And the use of nuclear energy for propulsion and auxiliary power is rapidly becoming more than a scientific theory. Both of these facts mean that a major effort is required to ensure that the safety of operating personnel and the general public is adequate. This morning I would like to describe for you the Air Force approach to this problem.

But before we get into a discussion of safety, let us use a time-honored method and define it. According to webster, safety is freedom from danger or hazard. There is, therefore, no absolute safety inasmuch as there is no operation conducted by man which is inherently free from all danger or hazard. A determination of whether a specific operation is safe, or rather safe enough, is therefore greatly dependent on the need for the operation. It is really a determination of whether the risk is warranted by the operational requirement.

I am reminded of a test pilot at Edwards Air Force Base in California who tested many types of new and untried aircraft at supersonic speeds. He cracked up once and twice he had to bail out of a flaming aircraft. However, on Sundays, his wife couldn't get him out of the house for a drive or to visit friends. He said it wasn't safe to be on the highways on Sunday. He was weighing "risk versus requirement."

Safety cannot be the determining factor in the conduct of military operations although it is one of the prime considerations. The operational requirements play a major part in determining the acceptability of the risk. In keeping with this philosophy, the statement of the goal of the entire Air Force nuclear safety program reads: "Maximum safety consistent with operational requirements."

This is a direct quote from the present Department of Defense directive which established nuclear safety study and review procedures for the three services. In a sense, it reversed the goal stated a number of years ago by the Department of Defense and the Atomic Energy Commission. The words used then were: "To determine an optimum balance between required nuclear safety and the desired operational readiness."

I believe that the change of wording is significant. The present wording signifies that we feel we can meet the required operational posture "safely"; in other words we feel we can make the risk acceptable when the requirement is valid. The maintenance of the required operational posture is, of course, the primary goal of the Department of Defense.

The Air Force in its overall nuclear safety program has two fundamental objectives:

First, maintaining our record of no accidental or unauthorized detonation of a nuclear weapon and maintaining our record of no major accidents involving reactors and advanced systems. 
Second, improving the professionalism of our nuclear operation in order to reduce the number of incidents involving nuclear systems to as close to zero as possible.

The fundamental thesis of the Air Force's nuclear safety program is that no accident is truly inevitable. Theoretically, a11 accidents can be prevented. However, we must be practical. The extremes to which one goes in order to prevent an accident are directly proportional to the consequences of such an accident. Since the consequences of an accidental nuclear detonation are extraordinary, I can assure you that the measures taken in our nuclear weapons safety program to prevent such an accident are also extraordinary.

A number of essential elements are required if any safety program is to function effectively. I would like to describe the Air Force program by discussing four of these elements.

First, there must be organization for safety. A successful safety program does not result from random motion; it is not something that just grows like Topsy, nor does it occur by accident. It must be planned, organized, and adequately manned. A good, sound organizational structure is the prime requisite for an aggressive, efficient, and effective program. The Air Staff has long recognized this, and flight safety and ground safety programs were organized over 20 years ago. In more recent years, the growing importance of nuclear and missile safety and other considerations pointed toward the need for consolidation of all safety areas under one agency. On 2 Apri1, 1959, General LeMay as Vice Chief of Staff signed a directive that created a central office for safety. This directive consolidated the four basic safety areas of ground, flight, missile, and nuclear under what is now the Deputy The Inspector General, Brigadier General Harrison. General Harrison is directly responsible to the Inspector Genera1, Lt. Genera1 John D. Ryan. Ground, flight and missile safety activities operate from Norton Air Force Base in California. Nuclear safety, for obvious reasons, sets up shop at Kirtland Air Force Base, here in Albuquerque. As Director of Nuclear Safety, I report to General Harrison.

Thus, the focal point for all safety in the Air Force is the Deputy The Inspector General. The focal point for nuclear safety is the Directorate of Nuclear Safety, or DNS as we call it.

As you can we11 imagine, the nuclear weapons program has absorbed the attention of most of DNS personne1 since the inception of our formal program over 4 years ago. The Air Force is operating today, all over the world, a considerable number of different nuclear weapon systems. On Thursday, * I will describe to those of you who are interested various details of our nuclear weapons safety program.

A sma11, but extremely important, division of DNS is concerned with that part of the Air Force nuclear safety program related to the development and operation of nuclear reactors such as the one now being operated by the Air Defense Command at Sundance and to advanced aerospace systems using nuclear energy for power or propulsion. This division is entitled the Reactors and Advanced Systems Division. Its chief is Lt. Co1. C. A. Delorenzo, the Chairman of the Registration Committee for this topical meeting. Lt. Col. DeLorenzo's program is organized and patterned along the lines of the nuclear weapons program. I would like to point out, before I launch into my discussion of the reactor and advanced system program, several significant points about its relationship to the weapons program. In the first place, the scope of reactors and advanced systems within the Air Force at present is far less than that of the weapons program. However, we foresee that this program will grow and are preparing for expansion. Secondly, after the nuclear weapon system becomes operational, it is clear that the Air Force has the sole responsibility for its safe operation during peacetime. This responsibility also holds for

*See Paper V-6, "The Air Force Nuclear Weapon System Safety Program," Col. C. B. Stewart, pp 361-366. 
a nuclear reactor system such as the Sundance reactor. However, the Air Force does not have the sole responsibility for many of the advanced aerospace systems such as SNAP plus SPUR. The Air Force may have only a part of a program such as the successful launch of a nuclear-powered satellite into space. The Atomic Energy Commission, NASA, the Navy, and others often have joint interests in the project and joint responsibilities. One of the goals of our Air Force program in this area is to ensure clear definition of the responsibilities. As I will discuss later, safety cannot be separated from command and supervision, and it is essential in any safety program that who is responsible for what be clearly defined.

In our program we have two groups, the Nuclear Weapon System Safety Group, which is responsible for nuclear weapon studies, and the Nuclear Reactor System Safety Group, which is responsible for nuclear devices other than weapons. In a sense, these groups are similar in function to the Atomic Energy Commission's Advisory Committee for Reactor Safeguards, the ACRS, with which most of you are familiar. These groups are composed of individuals highly qualified in the design and operation of the system under review. Their members are experts drawn from Air Staff offices, the major air commands, other military services, and other government agencies such as the Atomic Energy Commission and the Public Health Service. These safety groups review the design, technical safety analysis, operational plans, special studies, and other information on the nuclear weapon system or nuclear reactor system. Based on such reviews, recommendations are made in such areas as safety of location, design, or plan of operation of the system. These recommendations are forwarded to the Air Staff for approval and after approval are directive on Air Force action agencies. The DNS provides the chairman and supervises the action of both safety groups.

The second element of a successful safety program is, as I mentioned earlier, clearly fixed and unambiguously delineated responsibility for safety at all levels of command. Safety, as we practice it in the Air Force, is a specific responsibility of command and an integral part of management. It is a command responsibility which can never be entirely delegated. Nevertheless, it is also axiomatic that a group independent of the design, developing, and operating agencies should review and evaluate the safety aspects of any operation to ensure adherence with approved safety principles and procedures and to recomend means to enhance safety. It is for this reason that the Air Force has established its safety program under The Inspector Genera1.

A word of caution here: the existence of these safety agencies does not in any way remove or reduce the direct responsibility for the safety of any operation from the commander of that operation. Too often the operator develops the attitude that safety is the responsibility of safety organizations; when for expediency's sake he can avoid procedures established to ensure safety, he might tend to do so. On the other hand, this attitude can also be fostered by safety people themselves who try to impose overly rigid and limiting safety rules, some of which tend to usurp unnecessarily the commander's authority to make operational decisions.

I repeat: prime responsibility for safety is a function of command and supervision, who must be clearly aware of their responsibilities for safety. Safety agencies provide the tools to assist the commander and the supervisor in the execution of a safe operation.

The third element of a successful safety program is the continuity of the program. Safety programs, particularly in this age of complex man-machine ccmbinations, must begin early in the planning phase and continue until the operation is complete or the system is phased out of the inventory. Thus, the USAF nuclear safety program contains a number of time-phased milestones which I will now briefly describe.

If the nuclear operation is to be conducted at a specific site, a site evaluation study must be accomplished. This study is intended to evaluate the suitability of the site for nuclear operation by determining how environmental and other factors inherent in the location affect safety of the operation. It is a1so intended to ensure that adequate environmental data is available or will be obtained to realistically appraise the hazards associated with the proposed operation. 
For example, as we move into the use of aerospace nuclear devices, we know that the Atlantic Missile Range will be one of the operational sites. The Air Force has completed a site evaluation study of the AMR which was reviewed by the Nuclear Reactor System Safety Group in December 1962. Factors which were very carefully examined included the topography, geology, hydrology, meteorology, oceanography, population density, and land usage. In genera1, none of these factors was found to be detrimental to nuclear operations. In fact, some were favorable in that they tended to minimize any radiation exposure to personnel either directly or through the food and water chain in the event of a nuclear accident. A number of recommendations were made to attain a better understanding of the environment at the Atlantic Missile Range in order to achieve greater operational flexibility and to establish more effective and efficient techniques and procedures to reduce even further any radiation risk. These recommendations have been implemented.

The second milestone in the Air Force program is the initial safety study. This study, as the name implies, is the first comprehensive examination of the safety of design and operation of the particular nuclear system under consideration. It is conducted early in the development phase as soon as there is sufficient data to make an evaluation meaningful. This study's chief purpose is to provide guidance for design changes or for any further research and development required to enable the system to meet appropriate safety standards.

Shortly before operation of the system, a preoperational safety study is conducted. By this time, design is presumably fixed and emphasis during this study is placed on operational procedures. If it is necessary in the interest of safety, last minute changes in design may be made even if the operation must be delayed, but norma1ly the preoperational safety study is to ensure the adequacy of operational procedures.

Fina11y, if the nuclear operation is of a continuous nature and not a onetime launch, periodic safety surveys are conducted to examine the adequacy and suitability of safety features and procedures under operational conditions. These surveys also serve to ensure compliance or adherence to existing safety rules, radiological health standards, and approved operational procedures. In addition, the DNS provides staff assistance to the operating commands and conducts special safety studies as required.

The fourth and most important element in a successful safety program is the human being himself. Human error can usually be traced to lack of training, lack of safety consciousness, or lack of physical or mental capability to do the job properly. These factors can be minimized by appropriate measures.

In the nuclear weapon systems safety area we expend a significant effort in our human reliability and education and training programs. Another feature of the personnel ingredient in our weapons program is the application of the two-man concept. These factors will be discussed in more detail on Thursday.

We cannot be satisfied that initial screening, selection, and training is sufficient for personnel engaged in nuclear operations. Design and procedures change. Incidents which have an accident potential and methods to avoid such incidents must be brought to the attention of all personnel. We use every form of communication to get this information to the man in the field. This includes motion pictures, magazines and other publications, formal training courses, correspondence courses, posters, decals, and so on. To establish interest and esprit de corps, slogan contests and suggestion programs are conducted and honors and commendations for outstanding service are awarded. In addition, a safety congress is held annually to discuss problems, disseminate new information, and offer recommendations for a better, more effective safety program. Participants in this congress come from Air Force bases throughout the world. The last one was held just a month ago at Sandia Base here in Albuquerque.

Our whole effort is to educate and motivate the individual to adopt the positive attitude that safety is of paramount importance and that he personally is going to see that it is attained. 
Safety programs, conducted continuously and aggressively, have a big payoff. Maximum safety consistent with operational requirements does not restrict operational capability but, in a broader sense, enhances it. We are aware that any nuclear accident with either weapons or other nuclear devices will not only cause widespread damage, pain, and suffering but also public reaction leading to serious limitations of our military deterrent capability or restrictions on the use of nuclear energy for power or propulsion. Our goal is a zero accident rate.

The Air Force is proud of its outstanding nuclear safety record. We feel that this record is not an accident but the result of an aggressive and we 11organized accident-prevention program, carried out through the competent and diligent efforts of a large number of officers and airmen throughout the Air Force. You may be assured that whatever human effort is required to maintain this record will be expended. 


\section{BLANK}


SESSION II

NUCLEAR SAFETY ASPECTS OF SNAP DESIGN

Chairman

Richard L. Kirk, SNAP Program Director Division of Reactor Development, USAEC

Session Coordinator

Harold M. Busey

Los Alamos Scientific Laboratory 


\section{BLANK}




\section{DESIGN AND SAFETY ASPECTS OF HYDRIDE FUEI, SNAP REACTORS*}

D. J. Cockeram

R. L. Detterman

Atomics Internationa1

SNAP reactors present safety problems different from those associated with central-station power reactors. The special problems arise because SNAP reactors (1) undergo special preoperational procedures including ground transportation and installation in a space vehicle, (2) operate in a fixed orbit rather than at a fixed site, and (3) use a low operating power which reduces fission product buildup by a factor of as much as 10,000. Designs which optimize SNAP reactors for space use combine minimum weight with maximum operational reliability; at the same time, they reduce the probability of nuclear accidents and include provisions to minimize the consequences of any accidents that might occur. These optimized designs, together with the controlled procedures and safety practices customary in space booster launch operations, provide for safe operational usage of the SNAP systems.

The discussion which follows describes the process of optimizing the reactor design. It also covers (1) the inherent features determining the physical characteristics of the system, and (2) safeguards incorporated into the final reactor design.

Space power systems must incorporate safeguards to protect the reactor throughout the factory-to-eventual-disposal sequence. These safeguards must both (1) prevent reactor excursions caused by inadvertent reactivity insertions, and (2) prevent exposure to fission products generated during power operation. During the entire handling and launch sequence before orbit is established, only those safeguards which prevent accidental reactor excursions are required since the reactor core does not contain radioactive by-products until operation in space begins. The following discussion considers first those safeguards provided to prevent inadvertent criticality. Measures to control disposal of the fission products are discussed subsequently.

\section{Optimizing the Reactor Design}

Moderating ratio is an important consideration in the safety and design of possible space reactor systems. Figure 1 shows the effect of moderating ratio on the critical mass with a spherical reactor system. This curve compares the critical mass of a bare reactor with that of a water-reflected reactor as a function of the moderating ratio. At the extremely small moderating ratios typical of an al1-metal uranium system, the critical mass is approximately 48 kilograms for an unreflected system and 23 kilograms for a water-reflected system. The critical mass rapidly decreases to a minimum of about 1.5 kilograms for a bare sphere, for which the moderating ratio is approximately 500. The extent to which safety would be affected by the selection of an undermoderated system for space use can be seen by comparing the critical masses for the water-reflected and bare systems. The difference between these two curves shows how much excess reactivity could be added to these reactors by water immersion.

\footnotetext{
* This work performed under AEC contract AT(11-1)-GEN-8. Presented by Mr. Detterman.
} 


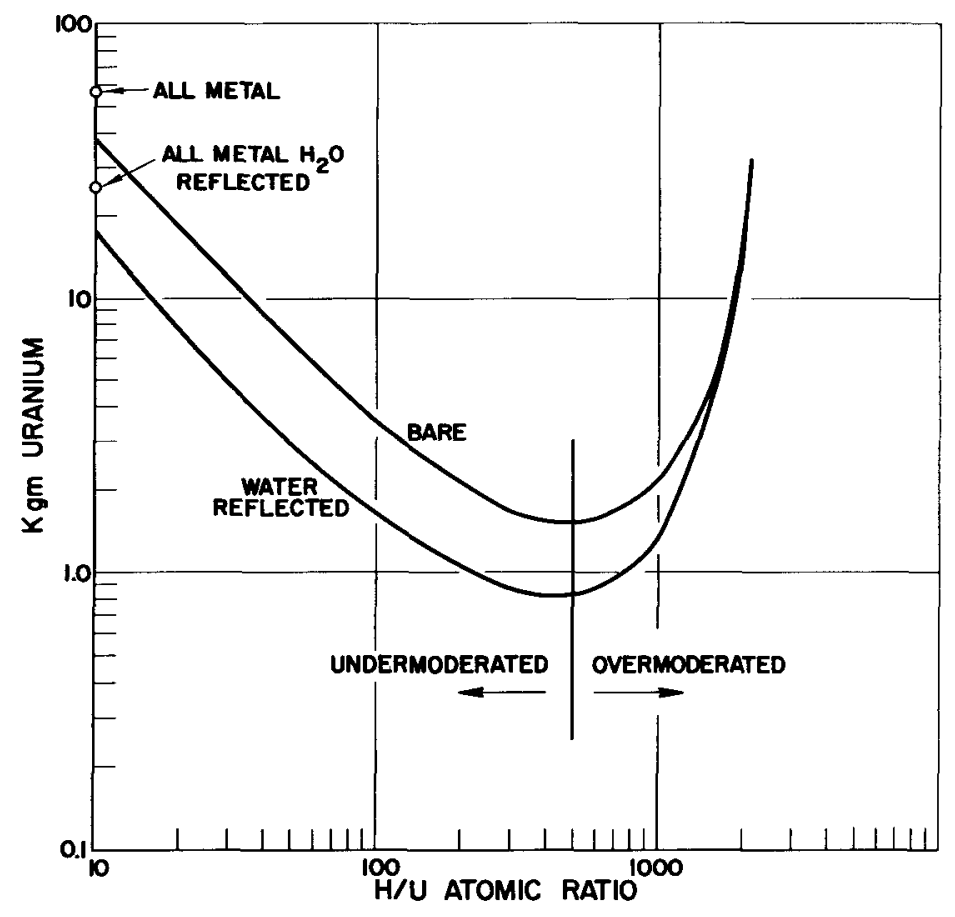

Figure 1. Critical mass spherical reactor systems

One goal of the design program was to obtain a high-temperature reactor of minimum weight. Figure 2 shows the weight of a bare spherical zirconium hydride reactor system as a function of the moderating ratio. This study showed that the weight penalties for $\mathrm{H} / \mathrm{U}$ ratios greater than 100 are excessive and indicated that a moderating ratio below 100 should be selected. (The increase in weight for high moderating ratios is a direct result of the increased reactor size inherent in these systems.) On the other hand, moderating ratios less than 10 give reactor systems with short prompt-neutron lifetimes and smal1 temperature coefficients. These are capable of producing very high energy releases in accidental excursions, and they require complex control systems for startup in space. The selection of a design point on the basis of $\mathrm{H} / \mathrm{U}$ ratio is, therefore, limited to ratios between 10 and 100 .

The effect on the reactor of extraneous external environments such as water can be minimized by including an appropriate reflector to add reactivity to the system, minimize the system weight, and, at the same time, limit the effects of extraneous media. Optimization of a reactor of this type is illustrated in Figure 3, a three-dimensional plot showing weight as a function of core height and core radius for a uranium zirconium-hydride system with an $\mathrm{H} / \mathrm{U}$ ratio of 47 . This $\mathrm{H} / \mathrm{U}$ ratio was dictated by material considerations and by regard for minimum weight and falls between the moderation ratio limits established at 10 and 100 . This three-dimensional plot demonstrates that there is a definite minimum weight relative to core height and radius and also to the thickness of the beryllium reflector. The final design point was selected as close as possible to this minimum. 


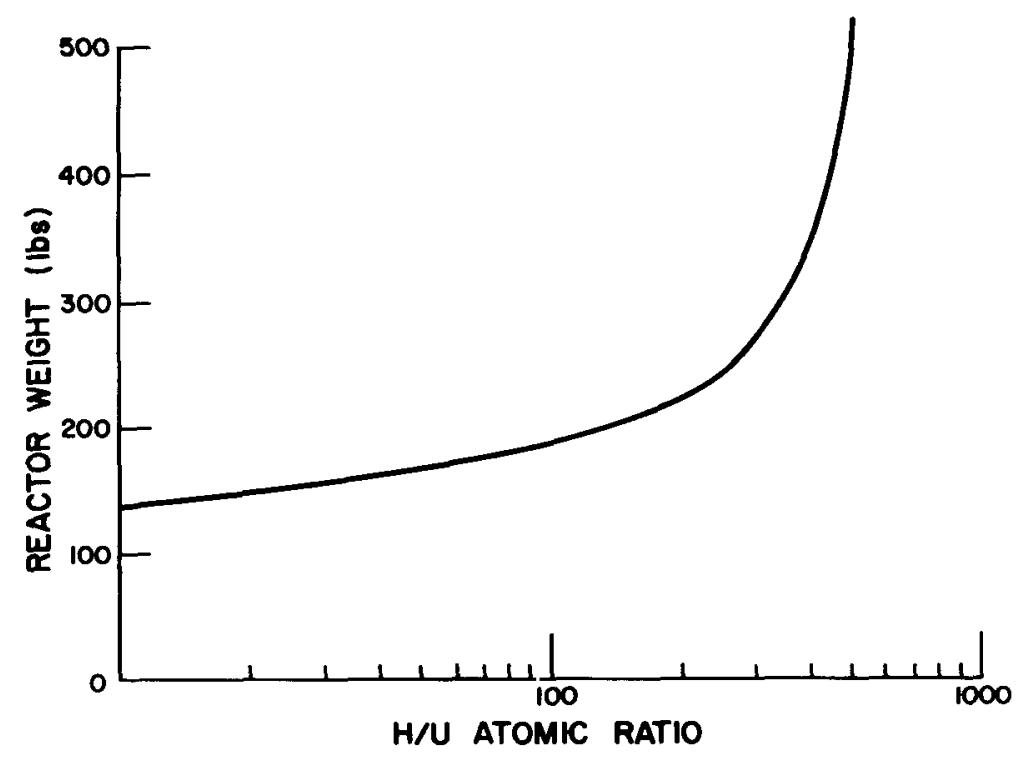

Figure 2. Weight of bare spherical reactor as a
function of moderator-to-uranium atom
ratio

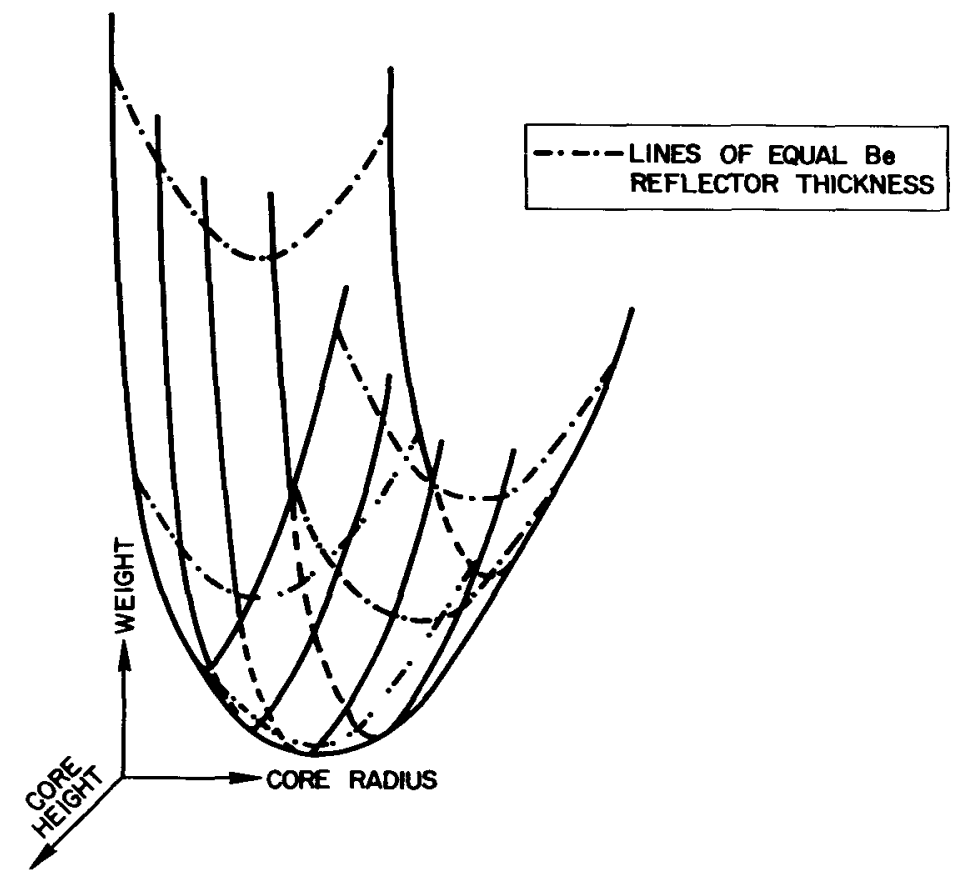

Figure 3. Typical SNAP reactor weight optimization curve 
The selection of uranium zirconium-hydride for this reactor inherently limits the magnitude of any nuclear excursions which might result from accidental insertions of reactivity. Figure 4 shows the calculated maximum energy release from a uranium zirconium-hydride reactor as a function of reactivity input. The initial slope of this curve is a function of the heat capacity and temperature coefficient of the reactor. If this initial slope were extrapolated to high-reactivity inputs of approximately 10 dollars, the energy release would be approximately 300 megawattseconds. However, the binding effect of hydrogen in the zirconium lattice places definite limits on the maximum energy release from these reactors: at temperatures in the neighborhood of $1600^{\circ} \mathrm{F}$, hydrogen evolves rapidly and so provides a mechanism for shutting down the reactor. In addition, the small size of the reactor provides for intense energy densities which rapidly disassemble the reactor system. The energy density in a SNAP reactor is approximately seven times that in a SPERT reactor, if the total energy in the transient is the same. Thus the disassembly of the SNAP reactor will be more violent than that of the SPERT, although the energy generations with the SNAP are much less than those experienced in similar transients with the SPERT. The maximum amount of energy which can be generated, and therefore the fission products available to produce a nuclear hazard, is further limited by the physical disassembly of the reactor which follows the violent evolution of hydrogen. The pressure generated within the SNAP reactor during excursions of greater than 3 dollars has been estimated to be approximately 500,000 psi; however, the mechanical energy associated with such a postulated release is still minute as compared to the propellant energy of the space booster. In other words, such an excursion, if it could occur, would lead to irrevocable reactor shutdown, but it would have no significant effect on the potential energy release from a vehicle abort.

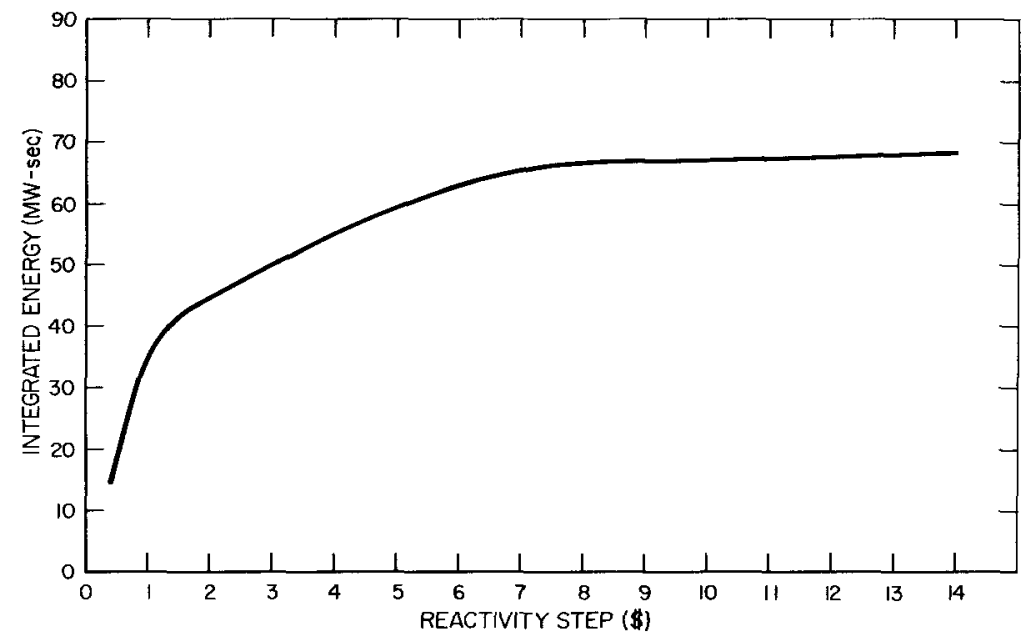

Figure 4. Integrated energy versus reactivity step (excluding reactor disassembly)

The reactor design based on $\mathrm{U}-\mathrm{ZrH}_{\mathrm{X}}$ technology has, therefore, a low possible energy release due to nuclear excursions. Incorporated in this design are many additional safety features which provide nuclear safeguards. The reactors currently being developed which use this technology include the SNAP-10A, -2 , and -8 systems. The SNAP-10A system (Figure 5 ) is typical, consisting essentially of a reactor used as the heat source, a thermoelectric converter used as the electrical generator, and a thermal radiator used as the heat rejection device. Heat produced in the reactor is transferred to the converter by a liquid-metal coolant which is circulated by a DC conduction pump. The converter and radiator, an integral unit, consists of an array of thermoelectric modules and thermal radiating surfaces 
mounted on a series of tubes through which the liquid metal is pumped. Electricity is generated in the converter as a result of the flow of heat through the thermoelectric material. The temperature difference across the converter is maintained on the hot side by the circulating liquid metal and on the cold side by the aluminum radiating surface which rejects the waste heat to outer space.

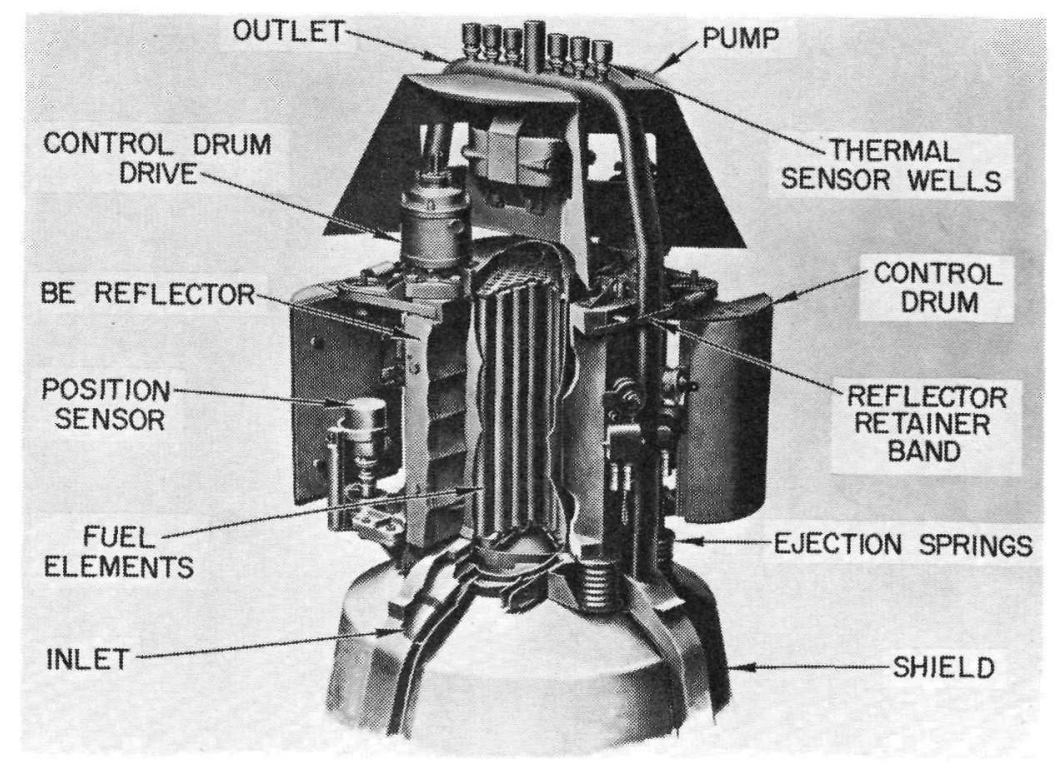

Figure 5. SNAP-10A reactor

The SNAP-10A core consists of 37 moderator fuel elements of uranium zirconiumhydride packed within a stainless-steel reactor vesse 18.9 inches in diameter and 16.12 inches long. The elements are cylindrical in shape, 1.25 inches in diameter and 12.25 inches long. The high hydrogen density of the uranium zirconium-hydride fuel results in a small lightweight reactor with the relative control simplicity characteristic of the thermal neutron spectrum system. Each of the fuel elements is clad in Hastelloy-N tubing, which has a ceramic hydrogen barrier applied to its inner surface to limit hydrogen loss rate to a satisfactorily low leve1. A samarium oxide burnable poison compensates for stable fission-product buildup and hydrogen loss, thereby maintaining long-term reactivity stability. The fuel elements are arranged in a triangular array on 1.26-inch centers forming a core which is hexagonal in cross section. The elements are positioned in the vesse1 between grid plates. The lower grid plate is permanently fixed in the core vessel, but the top grid plate is spring-loaded against the top head of the vessel to permit thermal expansion of the core in the axial direction. All coolant flow through the core is through the interstices formed between adjacent elements or between elements and the core vessel wa11. Coolant passes through the grid plates by means of coolant holes $3 / 8$ inch in diameter which are drilled to line up with the core coolant passages. Coolant plenum chambers located above and below the core assembly in the vesse1 provide mixing space for the coolant and produce the proper flow distribution through the core.

\section{Safeguards Incorporated in Fina1 Reactor Design}

Various design features have been incorporated to meet the safety requirements for this reactor. First is the shipping sleeve, which will prevent criticality during the initial shipping and handling phases from Atomics International to Vandenberg AFB. 
The reactor will be shipped to the launch site with its reflector removed and replaced by this shipping sleeve (Figure 6), which is designed to ensure that the SNAP-10A reactor remains in a subcritical condition during shipment. Since the greatest potential criticality hazard is accidental immersion of the reactor in a hydrogenous fluid such as water, the sleeve is designed to provide sufficient reactivity protection even if the reactor should be totally externally reflected and internally flooded with such fluids. The sleeve is also designed to withstand a 15-foot fall onto solid rock or a concrete surface without being significantly distorted or breaking loose from the reactor.

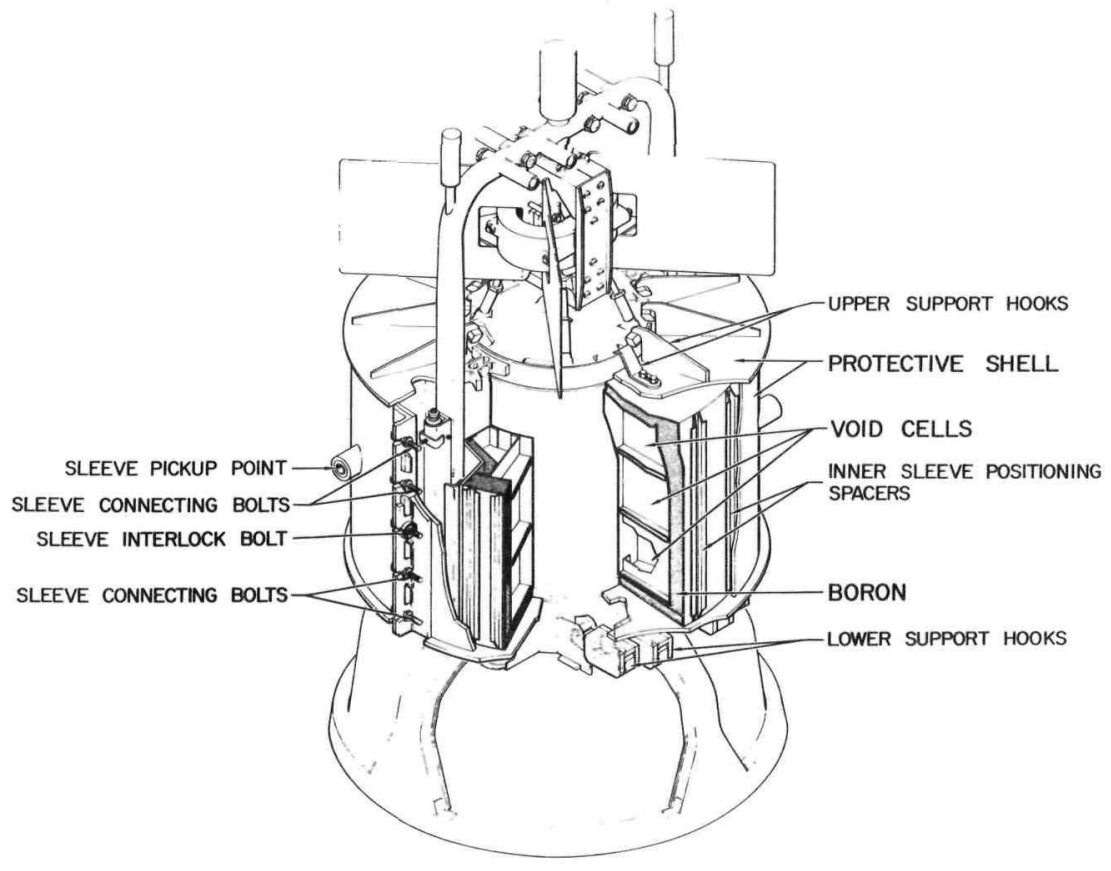

Figure 6. SNAP-10A reactor shipping sleeve

The annular structure of the sleeve consists of a 3.75-inch layer of void ce11s surrounded by a 1-inch layer of natural boron powder, which is followed by a 1/4-inch plate of energy-absorbing material and a $1 / 4$-inch plate of 304 stainless steel. The void cell section is divided into 144 watertight compartments by 0.01 -inch sheets of 304 stainless stee1. The stee1 occupies about 2.75 percent of the volume. Each compartment is isolated from all other compartments so that the puncture of one cell does not violate the integrity of the others.

Boron powder occupies the volume between the outside of the void cells and the 1/4-inch plate of energy-absorbing materia1. The powder is packed to approximately 20 percent of theoretical density and provides a thermal-neutron poison for neutrons which are slowed down outside the sleeve.

The energy-absorbing material consists of several $1 / 4$-inch stainless-steel spacers equally spaced around the steel container holding the boron powder. The spacers allow the external steel plate to deform plastically and absorb energy themselves by crushing. 
The 1/4-inch stainless-steel plate offers protection from puncture of the boron and void cel1 layers. The plate extends over both ends of the sleeve and anchors to the core vessel grid plates to supply structural integrity in that area. Impact loads originating on the cylindrical portion of the sleeve are transmitted to the end plates and, from there, directly to the reactor core vesse1. The thin gauge stock in the void and boron poison regions are not load-bearing members. The boron powder extends over the ends of the sleeve in a 1/4-inch layer.

The sleeve consists of two halves, each of which replaces one-half of the beryllium reflector. The halves are joined together with a total of 10 bolts (five on each side). One bolt on each side functions as an interlock, since a special tool is required for removal. Support hooks on the bottom and top of the sleeve secure it to the reactor and prevent sliding up and down.

Following shipment and reassembly of the reactor and reflector, criticality protection is provided by one or more of the following:

1. void filler blocks,

2. keyed drum locking arms, or

3. drum locking pins.

During the phases of final assembly and until final arming of the reactor, criticality protection is maintained by void filler blocks (Figure 7 ) surrounding the reflector. These filler blocks partially occupy the four control drum voids in the reflector and thereby positively prevent the drums from moving inward. They will also keep the reactor subcritical if it is completely submerged in water or another neutron reflecting media.

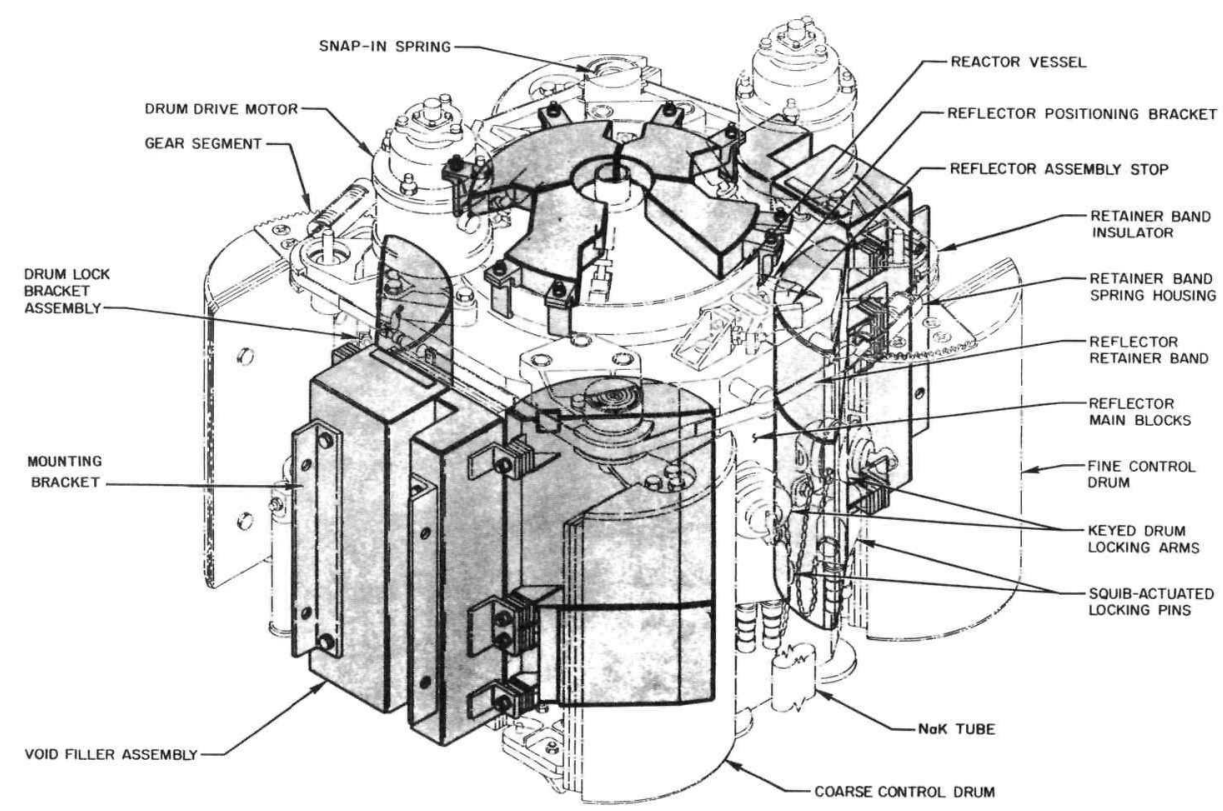

Figure 7 . SNAP-10A void filler assemblies 
The void filler assembly consists of (1) four half-cylinder blocks partially occupying the voids left in the beryllium reflector by the outward rotated control drums, (2) two rectangular blocks, each of which joins two' of the half-cylinder blocks together, and (3) a plate fitted to the end of the core vessel. The enclosing structural material is 0.06 -inch stainless stee1. The outer $1 / 2$ inch of the half-cylinders is packed with natural boron powder to 20 percent of theoretical density. The remainder of the volume is void (air). The rectangular sections have the void volume on the outside surface and a similar boron layer on the inside (next to the reflector) surface.

The void filler blocks are removed before the nose cone is installed. A1though the primary design objective of the void filler assembly is to provide nuclear protection against potential sources of reactivity additions in the environment, the placement of the half-cylinder blocks in the drum voids also ensures against accidental drum rotation.

Keyed drum-locking arms are provided for each control drum. These devices are active whenever the void filler assemblies are in place, and they provide backup for that safeguard. They also remain active after installation of the nose cone and up to the time of fueling the launch vehicle. The complete assembly, consisting of an arm assembly which rigidly holds the drum to the main reflector, may be removed by a special key; a mechanical interlock prevents removal of the keyed lockout unless the drum-locking pins are engaged. These keyed devices are removed in the countdown procedure as one of the last steps before the launch vehicle is fueled.

The final protection against drum rotation is the drum-1ocking pin. This device is squib activated and remains as a criticality protection device until the reactor arming command is received in orbit. Like the keyed drum-locking arms, it rigidly pins the drum to the main reflector block.

In addition to the protection offered by these special devices, reactor shutdown may be effected by ejection of the control and reflector assembly. Ejection is accomplished by means of compression springs located at the bottom of the reflector halves. When the reflector retainer band is released, the two springs pivot the reflector halves outward around their support hinges.

These three independent modes of reactor shutdown using reflector ejection are capable of reducing reactivity by more than 20 dollars. Together they provide a versatile safeguard technique.

Three distinctly different signals are used to initiate the first mode of reflector ejection. Al1 three signals activate an electrical device which releases the reflector retainer band. This electrical signal can be provided by (1) ground command, through an umbilical, before liftoff, (2) telemetry, or (3) a failuresensing device (low converter output voltage). The failure-sensing device, which provides for both failure and end-of-life shutdown, starts a 1-minute timer which resets if the malfunction signal is removed. If the signal persists, a 1-hour delay timer is started. This in turn triggers the electrically actuated band release device, which consists of two concentric cylinders brazed together with a lowtemperature melting alloy. These cylinders house a small electrical heater which is activated by the ejection signal. When the heater raises the temperature of the braze to its melting point (approximately $1250^{\circ} \mathrm{F}$ ), the two cylinders are pulled apart by springs (thus severing the band). Since the 1/2-inch overlap of the two cylinders is less than the available stroke of the two springs in the band, the springs ensure complete separation of the device.

A mechanical device provides the second mode used to sever the reflector retaining band and provides an additional end-of-1ife shutdown system. This device is activated by a drop in temperature of the NaK in the outlet line adjacent to the reactor. The temperature-actuated band release device works on the principle of the differential thermal expansion of two materials. In this design, a steel rod is used inside a molybdenum tube. While the temperature is increasing, the steel rod, which has a much higher coefficient of thermal expansion than the molybdenum, is allowed to grow freely inside of the tube. With decreasing temperature, the rod 
is gripped and placed in tension as it tries to decrease in length relative to the tube. With a temperature drop of $350^{\circ} \mathrm{F}$, the tension becomes great enough to break a bolt holding the retainer band together. A temperature drop of greater than $500^{\circ} \mathrm{F}$ at the location of the device can occur in one of two ways: (1) if the NaK flow stops, or (2) if the system is punctured and a11 NaK is lost. If one of these failures does not occur, the reactor outlet temperature will degrade enough to cause actuation of the device in 10 to 20 years.

The retainer band is also designed to release upon re-entry heating. This third mode of reflector ejection will be used only if reflector ejection has not already occurred. At about 300,000 feet, the brazed joint in the electrically actuated band release device will melt, thereby releasing the reflectors. If for some reason this does not occur, the entire band will melt at about 285,000 feet, resulting in reflector ejection and subsequent exposure of the reactor fuel and vesse1 to re-entry heating.

These safety features of SNAP-U- $\mathrm{ZrH}_{\mathrm{X}}$ reactors provide protection from the two possible nuclear hazards: accidental excursions, and exposure to fission products generated during operation. Possible accidental excursions are limited in magnitude by the inherent nuclear and physical characteristics of the reactor. Additionally, various safeguards are incorporated into the reactor design to prevent the accidental insertion of reactivity.

Since the orbital location of the power unit is fixed by natural laws and is ideally remote from any population, no hazard is possible from any malfunction or from fission products generated during operation as long as this location is maintained. At the end of the useful life of the power unit, designed-in shutdown of the reactor will permit the reduction of the fission product inventory through radioactive decay during the remainder of its orbital lifetime. This shutdown is automatically accomplished by ejection of the reflectors when either the output voltage of the power conversion system falls below a prescribed voltage or the reactor outlet coolant temperature decreases by $350^{\circ} \mathrm{F}$. Reflector ejection can also be initiated by telemetry as long as ground contact is maintained.

When re-entry of the satellite occurs, atmospheric heating and ablation forces are expected to result in disassembly of the reactor vesse1 structure, causing individual fuel elements to be dispersed before impact occurs. Under the design conditions of reactor operation and under orbital lifetime conditions, the post-reentry radiological hazards are negligible. 


\section{BLANK}




\author{
SNAP REACTOR TRANSIENT TESTS* \\ L. I. Moss \\ Atomics Internationa1 \\ T. R. Wilson \\ Philips Petroleum Company
}

Introduction

Since achievement of a high degree of safety for all nuclear systems has always been and continues to be a national goal, an extensive analytical and experimental program has been initiated by the Atomic Energy Commission to assess the safety of aerospace nuclear systems. A portion of this program is directed toward determining the consequences of nuclear accidents and providing physics and engineering information of importance to understanding the kinetic behavior, assessing the nuclear safety, and improving the design of these systems with respect to safety. Tests to provide this information will initially be performed on SNAP-2 and SNAP-10A type reactors, which are sma11, uranium zirconium-hydride-fueled, beryllium-reflected assemblies. The test program has been designated SNAPTRAN, or SNAP Reactor Transient Tests.

Conceivably an aborted flight could cause a reactor assembly to be impacted into the ocean within the controlled downrange firing cone. If this occurred without substantial damage to the reactor from the abort or if it was before attaining an altitude which would provide substantial re-entry heating, a rapid insertion of reactivity could result. The SNAPTRAN experiments will include a simulation of such accident conditions as we11 as experiments which, although not involving such a simulation, will provide physics and engineering information basic to a prediction of other possible transients.

The SNAPTRAN program will use several reactor test machines. The first pair, SNAPTRAN-10A/2-1 and -2 , wil1 have bery11ium-reflected SNAP-10A/2 core vesse1s. The -2 machine will permit further experiments with the beryllium-reflected assembly following a destructive test of the first machine. SNAPTRAN-10A/2-3 wil1 consist of a flight reactor core vesse1, less the beryllium reflectors, immersed in water. In the destructive test of this machine, rapid assembly of the water reflector will provide for a large reactivity input before self-destruction. SNAPTRAN-10A/2-4 will also be a water-reflected assembly but for the different purpose of evaluating the conditions under which SNAP reactors could possibly achieve steady-state operation in water.

The SNAPTRAN experiments are a joint effort of Atomics International and Phillips Petroleum Company, with Atomics International furnishing the reactor systems and Phillips Petroleum Company carrying out testing at the NRTS.

The first tests to be conducted in the series will be with the SNAPTRAN-10A/2-3 reactor. It is this series of experiments which are briefly described in this paper.

\footnotetext{
Work performed under AEC Contract AT(11-1)-GEN-8 Presented by the authors
} 
SNAPTRAN-10A/2-3 Test Program

\section{Objectives}

The SNAPTRAN-10A/2-3 experiments are best described as scoping tests and are intended to provide information for assessing the potential hazards of a waterimmersion accident. Information on the transient behavior of the water-reflected reactor and the reactor disassembly processes will also be obtained. Specific technical objectives are:

1. to measure the nuclear and mechanical energy release during a power excursion approaching the maximum credible by water immersion,

2. to measure the fission-product release and the dispersion of fission products from this excursion, and

3. to provide physics and engineering data which will assist in understanding the kinetic behavior of water-reflected SNAP reactors.

\section{Test Program}

The experiments are to include measurement of the effectively reduced promptneutron lifetime ( $\left.\boldsymbol{\ell} * / \beta_{\text {eff }}\right)$ at delayed critical, calibration of nuclear instruments at low power, several long-period-transient tests, and a destructive power excursion initiated by rapid withdrawal of the Binal control sleeve which surrounds the reactor. This destructive experiment will simulate to the extent possible the physical behavior and reactivity assembly rate which can conceivably be obtained by impact of an undamaged SNAP-10A/2 reactor with water. With respect to the physical behavior, tests performed at Holloman Air Force Base, to be discussed in the next paper, indicated that the beryllium reflector surrounding the reactor vessel on an undamaged flight reactor will separate from the reactor upon impact with water at the expected velocities while the reactor core will probably remain intact. The bare reactor vesse1 containing the fuel will therefore be used to conduct the SNAPTRAN-10A/2-3 experiment.

The reactivity assembly rate in such an accident is dependent upon the reactor impact velocity and the entry attitude. Impact velocities of about 550 feet per second may result in reactivity assembly rates approaching $2 \times 10^{3}$ dollars per second. With this assembly rate, the entire available excess reactivity will be inserted before the occurrence of negative reactivity feedback. The SNAPTRAN-3 experiment has been designed to satisfy this criterion.

For any reactor, the superprompt-critical reactivity which can be added before feedback effects is a function of the reactivity insertion rate. This is illustrated in a qualitative fashion in Figure 8 , which shows the effective delayed neutron fraction ( $\left.\beta_{\text {eff }}\right)$ divided by the effective prompt-neutron lifetime $(\boldsymbol{l} *)$ on the abscissa as a function of assembly rate in dollars per second on the ordinate. The lines show the assembly rate required to produce 1-, 2-, and 5-dollar superprompt criticality. For the SNAP reactor, the value of $\beta_{\text {eff }} / \ell *$ is approximately $500 \mathrm{sec}^{-1}$. The graph indicates that a minimum assembly rate of about 150 dollars per second is needed. The degree to which the minimum assembly rate is exceeded in the experiment determines the margin of available time during which the asymptotic period can be measured.

The experimental techniques to be employed are best described by a brief description of the equipment. 


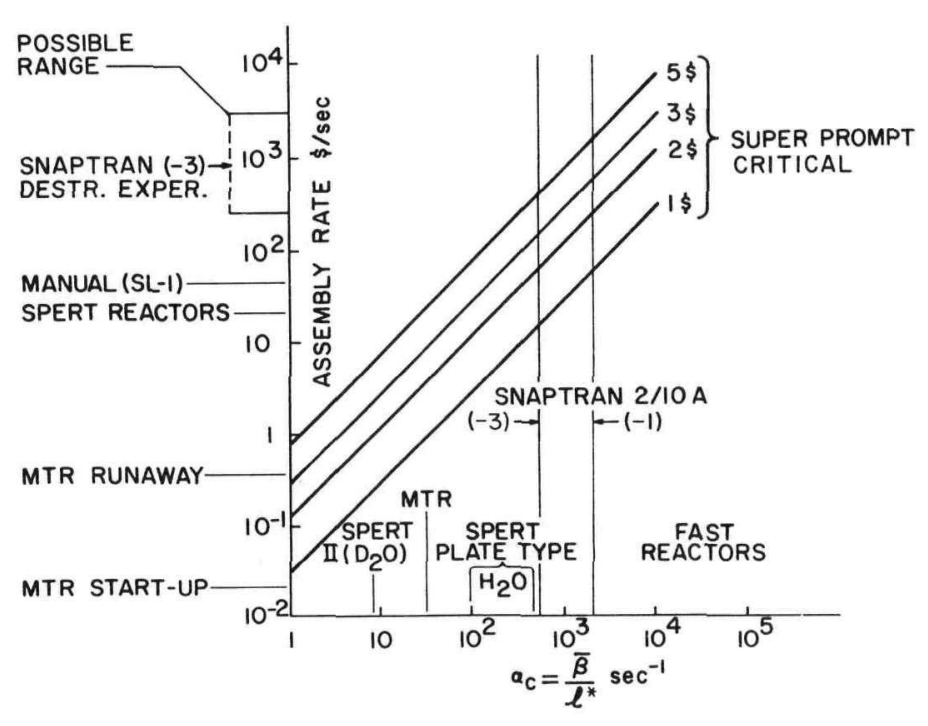

Figure 8. Required assembly rates for superprompt criticality

Description of Experimental Equipment

The SNAP-10A/2 reactor core, shown in Figure 9 , is a cylinder 9 inches in diameter and 13 inches long. The fuel rods are fabricated of an alloy of 10 weightpercent uranium (fully enriched) and 90 weight-percent zirconium, hydrided to an $\mathrm{H} / \mathrm{Zr}$ ratio of 1.8 . The rods are clad with Hastelloy $-\mathrm{N}$. The core is composed of 37 fue 1 rods arranged in a close-packed triangular lattice and contains $4.75 \mathrm{~kg}$ of U-235 and 464 gm-moles of hydrogen. These rods are enclosed in a stainless-stee 1 vesse 1 having a wall thickness of 0.032 inch. The space between the hexagonal fue1rod array and the cylindrical vessel is occupied by beryllium filler pieces. Nak fills the core vessel.

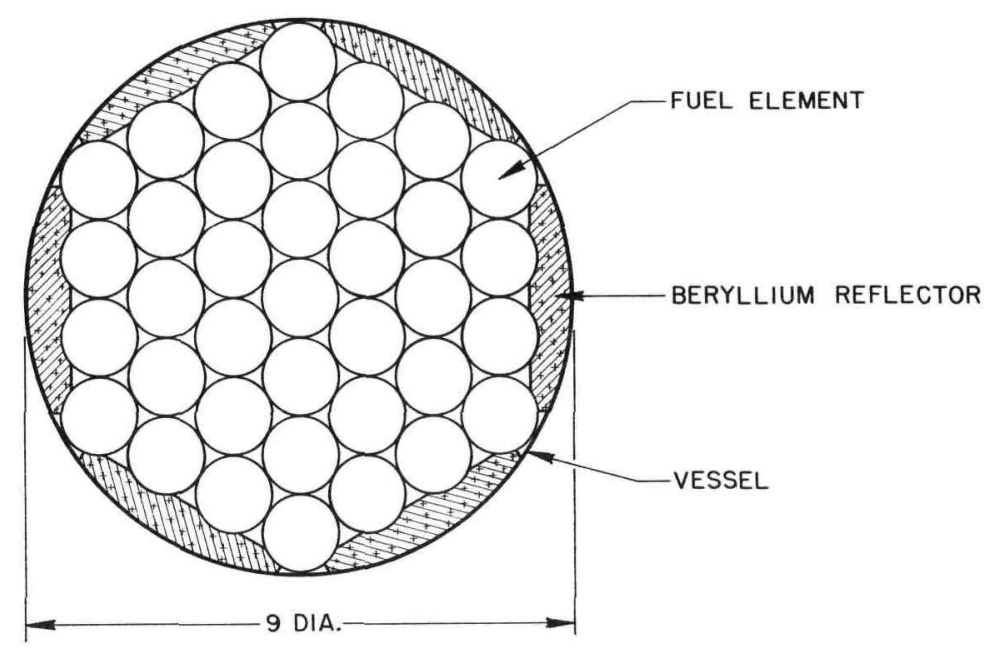

Figure 9 . SNAPTRAN-2/10A core cross section 
In the SNAPTRAN-3 test, the bare reactor vessel will be mounted on a pedesta1 inside a large concrete tank filled with water as shown in Figure 10. The size and construction of the tank are such that water loss from the anticipated excursion will be insufficient to cause reactor shutdown. Thus the final shutdown will be controlled by the inherent characteristics of the reactor. It is also large enough that pressure measurements in the vicinity of the core should be the same as for infinite medium conditions. Since the bulk of the water will be retained, metal-water reactions after the nuclear transient can be observed if they should occur.

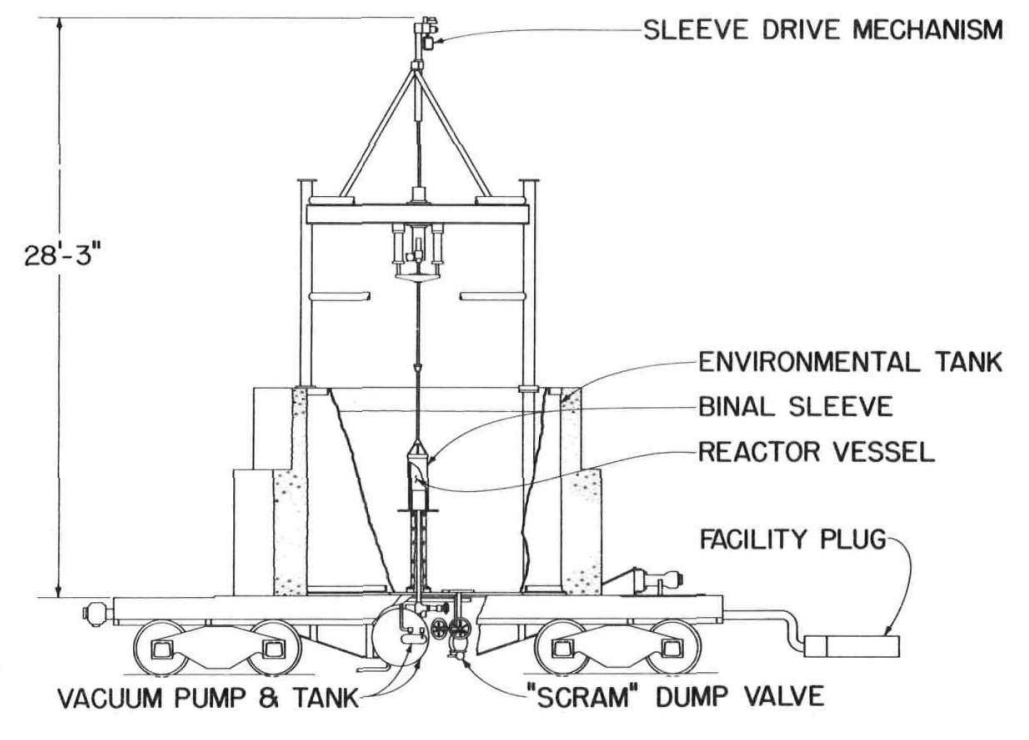

Figure 10. SNAPTRAN-10A/2-3

The reactor is controlled by a cylindrical poison sleeve, fabricated of 0.25-inch thick Binal which surrounds the reactor. Experiments performed by Atomics International have demonstrated that this sleeve will maintain the reactor subcritical by several dollars. Two sleeve drive mechanisms are provided, one a conventional motor drive and magnetic clutch for slow sleeve removal and scram, and the second a pyrotechnic actuator for removing the effective portion of the sleeve in a few milliseconds. Low-power physics measurements can be carried out safely using the slow speed drive; the destructive excursion can be conducted using the pyrotechnic actuator with assurance that essentially a11 the excess reactivity available in the system will be introduced in a sufficiently short time. Not shown in Figure 10 is a sma11 plexiglass calorimeter tank, which can be installed around the reactor, and a multitude of experimental instrumentation to be installed in and around the concrete tank. The calorimeter tank and associated electric heaters, agitators, and precise instrumentation for temperature measurement will be used to calibrate ionchamber current as a function of reactor power by direct comparison with a measured electric-power heat input.

The entire system is mounted on a railroad flatcar, as shown in Figure 11, to facilitate cleanup and transport of the remains of the reactor to the hot shop for examination following the destructive test. 


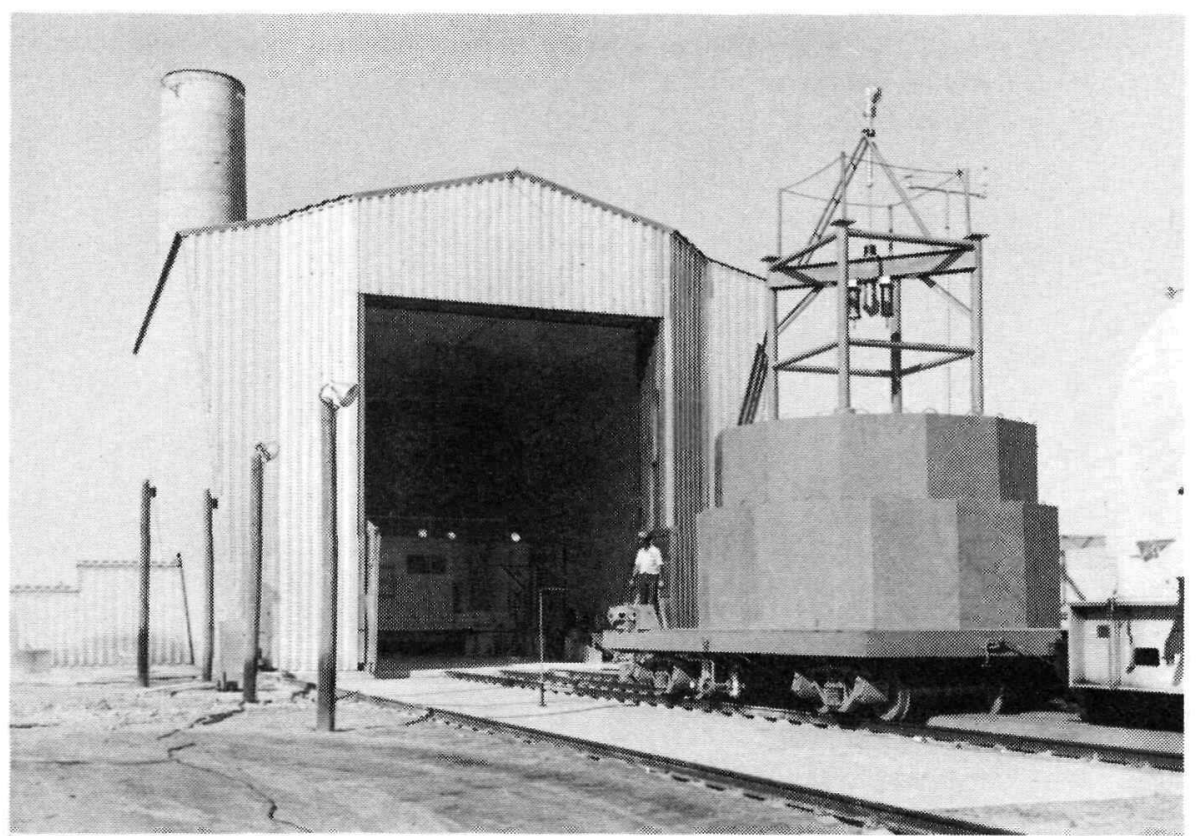

Figure 11. System mounted on flatcar

Experimenta1 Measurements

In order to attain the objectives previously specified for the test, a large number of experimental measurements must be made to provide data on the power-burst behavior, energy release, physical behavior, and the fission-product release and dispersion. It is outside the scope of this paper to give a detailed description of a11 the measurements to be attempted, equipment to be used, and considerations which have gone into selection of the number, type, range, priority, accuracy, etc., of the various transducers. However, it appears appropriate to briefly summarize the kinds of data to be obtained.

Data on the power-burst behavior of the reactor, that is, the flux distribution, power, and period, will be obtained from nuclear detectors located at several positions in the core, in the environmental tank, and under the flatcar. Several miniature flux chambers and special fast-response fuel temperature probes will be located within the reactor vesse1. External to the reactor vessel at various positions in and under the concrete tank are additional ion chambers. These include two ion chambers located in a neutron flight tube for obtaining fast-neutron flux measurements. Two gamma scintillation detectors are also in this location. The power burst will be covered from the region of power calibration ( $\left.10^{10} \mathrm{nv}\right)$ to one decade above the expected peak power $\left(10^{19} \mathrm{nv}\right)$.

Data on the mechanical energy release and physical behavior of the reactor will be provided by measuring strain, pressure, heat deposition, and particle displacement and velocity in air and in water. Measurement of the acceleration and displacement of the flatcar is also expected to aid in determining the total energy appearing as mechanical energy.

Disassembly of the reactor inititated by the rapid deposition of nuclear heat is expected to occur. Data on the sequence of events during disassembly will also be determined by strain, pressure, and time-of-arrival measurements. To obtain this data, a number of strain gages will be installed directly on fuel rods located at 
various radial and axial positions in the core. Additional strain gages will be installed at locations on the reactor vesse1, concrete tank, and the flatcar. Active pressure transducers will be located radially and axially throughout the water in the concrete tank together with a number of passive transducers for determining peak pressures.

Additionally, a number of passive devices for obtaining information about the neutron spectrum and the integrated neutron and gamma flux will be located at various positions in the vicinity of the reactor. Extensive photographic coverage of the test will also be provided.

During and following the power excursion, measurements will be made to determine the radiological consequences of the experiment. A grid network, as shown in Figure 12, has been surveyed and instrumented for this purpose. The test will be conducted under strict meteorological control so that released fission products will pass over this grid. The grid consists of concentric arcs with radii of a minimum of 25 meters and a maximum of 2514 meters. Information will be obtained on both the dispersion of radioactive particulate matter and the direct radiation dose from residual fission products. The various types of detection equipment on the grid include air samplers for obtaining airborne activities and beryllium concentrations, fission-gas detectors for obtaining the noble-gas activities, fallout plates for determination of fission-product deposition, film badges, chemical and nuclear accident dosimeters for obtaining total doses, and remote area monitors (ion chambers) for dose-rate determinations. Much of the information will be telemetered from field stations to a central data-gathering station.

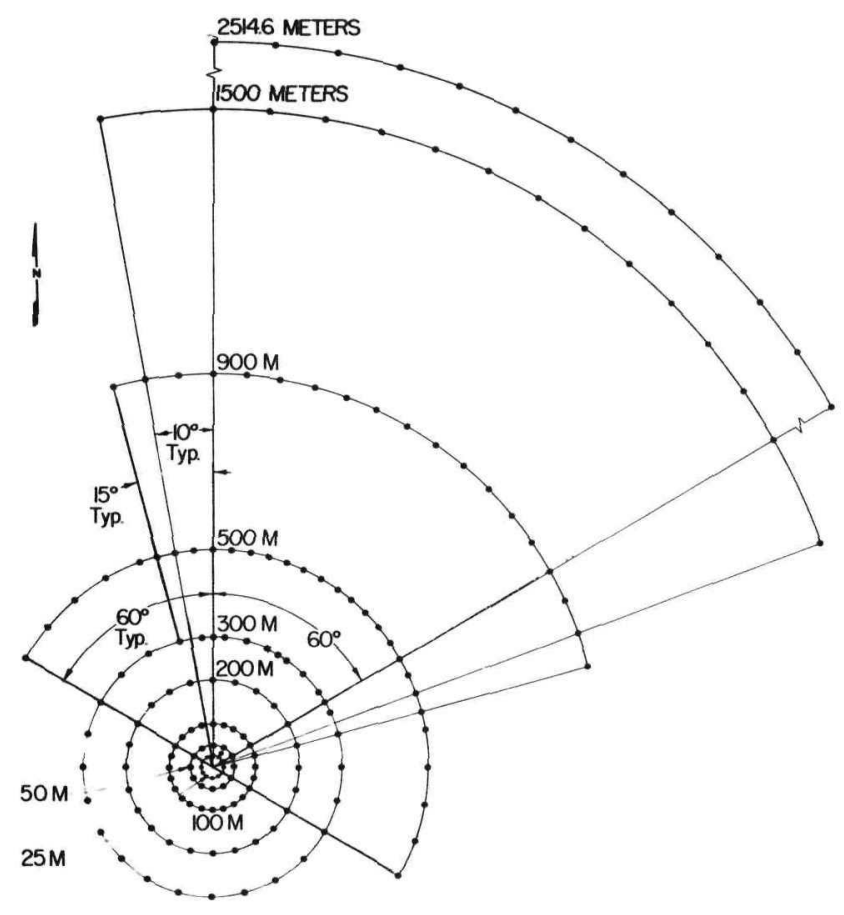

Figure 12. IET monitoring grid

Mobile tracking and monitoring of the radioactive plume on the larger radii arcs will be performed by radiological surveillance vehicles. As soon as permissible exposure conditions exist, the vehicles will also be used in the operation to recover the various filters, instruments, and samplers. 
Characteristics of Superprompt-Critical Transients in SNAP Reactors

Some Qualitative Considerations

When the Binal sleeve is ejected from the vicinity of the core vessel, the SNAPTRAN-3 reactor will be in a superprompt-critical state. Before reactivity feedback effects, the reactor power will reach an asymptotic period and an asymptotic spatial distribution of the neutron flux which may be calculated by means of the $1 / \mathrm{v}$ poison addition method.' Eventually the energy deposited in the fue 1 will begin to produce an appreciable temperature rise. In turn, this will cause thermal expansion of the fuel as well as a shift in the energy spectrum of neutrons that are in equilibrium with the fuel. Each of these contributes to a fuel temperature coefficient of reactivity that is negative and approximately constant with temperature. ${ }^{2}$

The transient behavior of a reactor with these characteristics is usually we 11 described with the Fuchs-Nordheim model3,4,5,6 in which delayed neutron, heat transfer, and space and neutron-energy-dependent effects are neglected. With these assumptions, the neutron kinetics equation can be readily solved. A heat capacity that varies linearly with temperature, as is appropriate for the uranium zirconium-hydride SNAP fue $1^{7,8,9}$ can be included.

For transients in which all of the negative reactivity feedback is provided by the constant fuel temperature coefficient, the above model provides a satisfactory description of the entire transient. It is expected, however, that this condition will not be met for the case of large reactivity inputs. There is an additional negative reactivity contribution which is expected to become dominant at a time during the transient when high temperatures $\left(\sim 1500^{\circ} \mathrm{C}\right)$ are reached by a portion of the fuel. The fuel will disintegrate as the internal gas pressure in the microscopic voids of the structure exceeds the limits for integrity of the fuel, which is about $2.0 \times 10^{4} \mathrm{psia}$. An extreme upper limit on fuel temperature would be given by the condition that the internal pressure (energy density) be equal to the strength of the lattice bonds. Above this pressure, which has been estimated at $6.5 \times 10^{5}$ psia (44 kilobars), ${ }^{10}$ lattice disintegration, as distinct from the above crystal disintegration, would occur.

Crystal or lattice disintegration in itself will have only a small reactivity effect. It will, however, produce pressures in the core which will eventually cause expansion of the fuel, giving a large negative reactivity effect. The time behavior of this expansion will be discussed in this paper, and the neutron kinetics equation solved for a simple, representative case. It will be seen that core expansion results in a significantly more rapid decrease in reactor power, and thus a lower nuclear energy release, than would otherwise be so.

\section{Description of a Typical Transient Before Core Expansion}

The asymptotic period $(\tau)$ for a reactivity input of $\$ 3.5\left(\delta \mathrm{k}_{\mathrm{p}}=0.02\right)$ has been calculated ${ }^{12}$ to be $5 \times 10^{-4}$ second, using the $1 / \mathrm{v}$ poison addition method. The effective prompt-neutron lifetime $\left(\boldsymbol{\ell} *=\tau \cdot \delta \mathrm{k}_{\mathrm{p}}\right)$ is therefore $10^{-5}$ second. When reactivity feedback effects occur, the value of $\ell *$ will change somewhat with time because of space and energy considerations; however, in the following calculation $\ell *$ will be assumed constant in the interest of simplicity. This assumption is not expected to introduce a large error.

The equations to be solved are as follows:

$$
\begin{gathered}
\mathrm{C}=\mathrm{C}_{\mathrm{o}}+\gamma \mathrm{T} \\
\frac{\mathrm{dP}}{\mathrm{dt}}=\frac{\delta \mathrm{k}_{\mathrm{p}}-a \mathrm{~T}}{\ell *} \mathrm{P} \\
\mathrm{C} \frac{\mathrm{dT}}{\mathrm{dt}}=\mathrm{P}
\end{gathered}
$$


where

$$
\begin{aligned}
\mathrm{C} & =\text { heat capacity, varying linearly with temperature as in Eq. (1) } \\
\mathrm{T} & =\text { average fuel temperature } \\
\mathrm{P} & =\text { reactor power } \\
\mathrm{t} & =\text { time } \\
\delta \mathrm{k}_{\mathrm{p}} & =\text { superprompt-critical multiplication } \\
\boldsymbol{a} & =\text { fuel temperature coefficient of reactivity } \\
\boldsymbol{\ell *} & =\text { effective prompt-neutron lifetime }
\end{aligned}
$$

Division of Eq. (2) by (3) and integration gives

$$
\mathrm{P}=\mathrm{P}_{\mathrm{o}}+\frac{1}{\ell *}\left[\mathrm{C}_{\mathrm{o}} \delta \mathrm{k}_{\mathrm{p}} \mathrm{T}+\frac{1}{2}\left(\gamma \delta \mathrm{k}_{\mathrm{p}}-\boldsymbol{a C}_{\mathrm{o}}\right) \mathrm{T}^{2}-\frac{1}{3}\left(\alpha \gamma \mathrm{T}^{3}\right)\right]
$$

Substitution of Eq. (4) in (3) gives

$$
\int_{0}^{\mathrm{T}} \frac{\mathrm{C}_{0}+\mathrm{T}}{\mathrm{P}_{\mathrm{o}}+\frac{1}{\ell *}\left[\mathrm{C}_{0} \sigma \mathrm{k}_{\mathrm{p}} \mathrm{T}+\frac{1}{2}\left(\gamma \delta \mathrm{k}_{\mathrm{p}}-a \mathrm{C}_{\mathrm{o}}\right) \mathrm{T}^{2}-\frac{1}{3} \alpha \gamma \mathrm{T}^{3}\right]} \mathrm{dT}=\mathrm{t}
$$

which can be split into partial fractions and integrated to give $t(\mathrm{~T})$. Both the power and the time for each temperature can therefore be found from Eqs. (4) and (5), respectively.

The energy release can be calculated from Eqs. (1) and (3):

$$
E=\int_{0}^{t} P d t=\int_{0}^{T} C d T=\int_{0}^{T}\left(C_{0}+\gamma T\right) d T=C_{0} T+\frac{1}{2} \gamma T^{2}
$$

\section{Description of a Typical Transient During Core Expansion}

As the temperature of the fuel increases, the internal pressure will rapidly increase. At a pressure of about $2.0 \times 10^{4} \mathrm{psia}$, failure can occur along the grain boundaries of this polycrystalline material as hydrogen diffuses into microscopic voids. At an estimated pressure of $6.5 \times 10^{5}$ psi, actual lattice disintegration can occur. From a logarithmic extrapolation of dissociation pressure data (which is available only for lower temperatures) as a function of reciprocal temperature, it is seen that this range of pressures corresponds to a temperature range of $1000^{\circ}$ to $1500^{\circ} \mathrm{C}$.

The peak power and thus the peak temperature occur in the center of the reactor. The ratio of peak to average flux during the transient will be about 1.3 radia11y, 1.4 axially, and 1.8 overal1. Fue1 disintegration is therefore expected to occur first in the center of the reactor. Consideration must then be given to the possibility that core expansion is initiated at that time by the high pressure in the core center.

On the basis of measurements ${ }^{13,14}$ of the propagation and attenuation of highpressure waves in the fuel materia1, it is not expected that propagation of a stable shock wave or a plastic wave to the edge of the core will occur. The threshold pressure for stable shock formation in the fuel material is estimated at greater than $100 \mathrm{~kb}\left(1.5 \times 10^{6} \mathrm{psia}\right)$; a pressure this high in the center of the core is 
unlikely to occur, at least not before most of the fuel in other locations would have already disintegrated.

Measurements have shown a rapid attenuation of the plastic wave with distance. It was found that a 26-kb plastic wave will attenuate to less than $3 \mathrm{~kb}$ and be transformed to an elastic (accoustic) wave in a distance of 1 inch. The elastic wave (propagated at 5200 meters per second will not cause extensive spalling at the fuel edge, since the energy in this wave is sma11 compared with that in either a stable shock or a plastic wave.

Having ruled out the possibility of significant core expansion from either a stable shock or a plastic wave, the effect of the high pressures in the core center acting to accelerate the bulk of the fuel outside the region of disintegration should be considered. This calculation has been performed for a simple spherical model of the reactor as shown in Figure 13. The derivation of the equations is given in Appendix A. The result, plotted in Figure 14 for a typical transient using the parameter values listed in Table $I$, is that this mode of expansion provides a significant reactivity feedback that acts to terminate the transient, with a lower nuclearenergy release ( $46 \mathrm{mw}-\mathrm{sec})$ than would be so otherwise.

The calculation also provides an estimate of the fraction of the fue 1 that is disintegrated at the time the transient is essentially terminated. For the above example, this fraction is 0.2 .

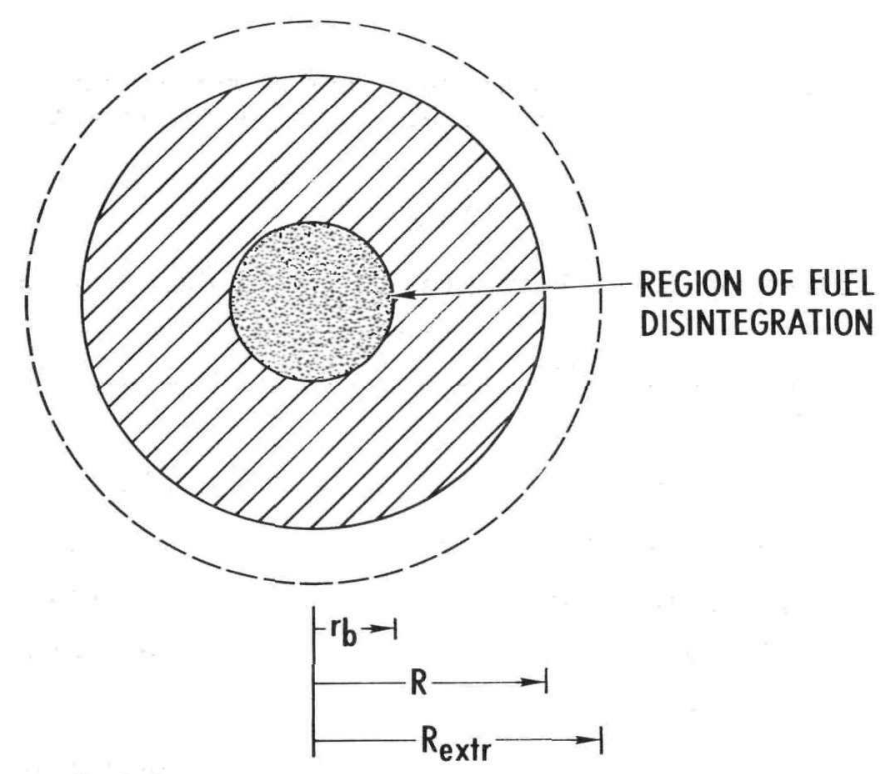

Figure 13. Core expansion mode1 


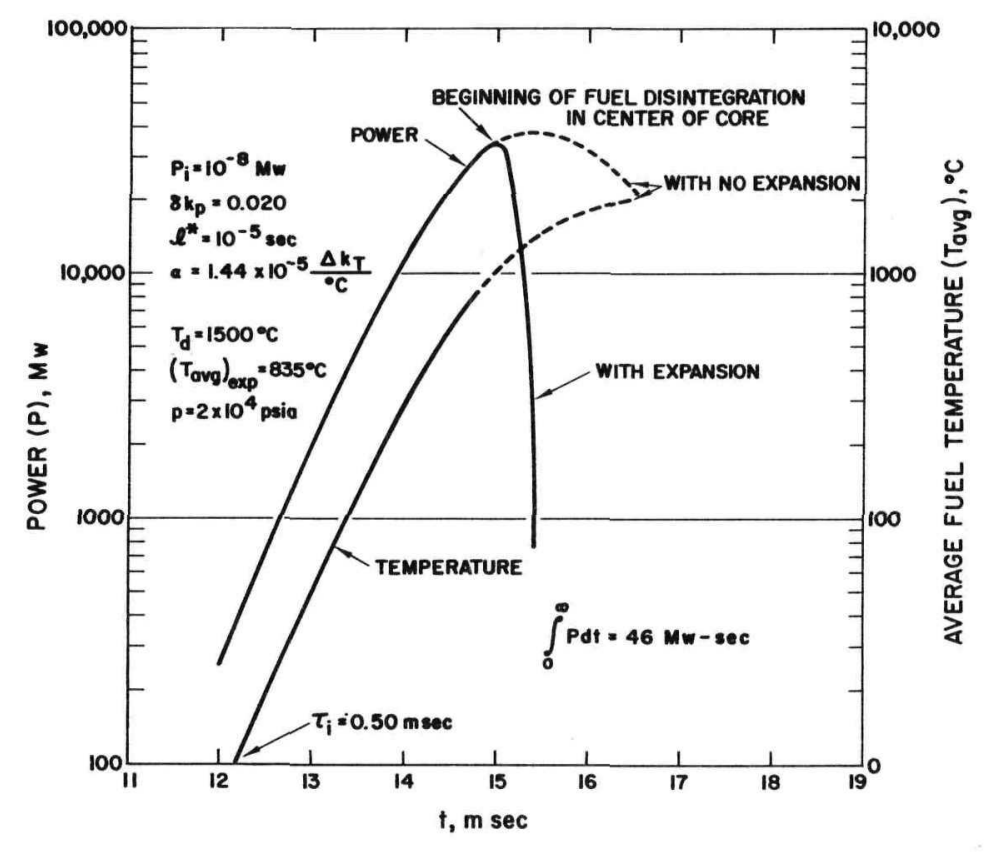

Figure 14. Temperature and power versus time after start of transient

TABLE I

Values of Input Parameters Used in Calculation

\begin{tabular}{|c|c|c|}
\hline Parameter & Value & Source \\
\hline$\delta \mathrm{k}_{\mathrm{p}}$ & 0.02 & -- \\
\hline$c_{0}$ & $0.01945 \mathrm{mw}-\mathrm{sec} /{ }^{\circ} \mathrm{C}$ & NAA-SR-7736 \\
\hline$\gamma$ & $1.828 \times 10^{-5} \mathrm{mw}-\mathrm{sec} /{ }^{\circ} \mathrm{C}^{2}$ & NAA-SR-7736 \\
\hline$a$ & $1.44 \times 10^{-5} /{ }^{\circ} \mathrm{C}$ & NAA-SR-7140 \\
\hline$\ell *$ & $10^{-5} \mathrm{sec}$ & See text \\
\hline$P_{0}$ & $10^{-8} \mathrm{mw}$ & -- \\
\hline $\mathrm{R}_{\mathrm{o}}$ & $13.5 \mathrm{~cm}$ & Radius of equivalent sphere \\
\hline $\mathrm{R}_{\text {extr }}$ & $16.0 \mathrm{~cm}$ & $\mathrm{R}_{\mathrm{i}}+$ extrapolation distance \\
\hline $\mathrm{T}_{\mathrm{d}}$ & $1500^{\circ} \mathrm{C}$ & See text \\
\hline $\mathrm{p}$ & $1.38 \times 10^{9}$ dyne $/ \mathrm{cm}^{2}$ & See text \\
\hline m & $6.0 \times 10^{4} \mathrm{gm}$ & -- \\
\hline $\mathrm{c}_{1}$ & $8.1 \times 10^{5}{ }^{\circ} \mathrm{C} / \mathrm{sec}$ & $\begin{array}{l}\text { Calculated from } P \text { and } \\
\mathrm{C}_{\mathrm{o}}+\gamma \mathrm{T}\end{array}$ \\
\hline $\mathrm{B}_{\mathrm{o}}{ }^{2} \tau_{\mathrm{o}}$ & 0.56 & $\begin{array}{l}\text { From 1-group, Fermi age } \\
\text { approximation }\end{array}$ \\
\hline
\end{tabular}


Present Status and Schedule for SNAPTRAN-3

At the present time, the test equipment has been fabricated, assembled and moved to the IET Facility for checkout. Fuel loading is expected to begin the second week of October and, weather permitting, the destructive test should be completed in late November.

References

1. A. F. Henry, Computation of Parameters Appearing in the Reactor Kinetics Equations, WA $\mathrm{PD}-142,1955$.

2. J. Miller, R. L. Brehm, and W. J. Roberts, Temperature Coefficients and Spectra in the Hydride Moderated SNAP Reactors, NAA-SR-7140, 1962.

3. G. Goertze1, Reactor Handbook, Physics, Vo1. 1, Chap. 1.6, AECD-3645, 1955.

4. R. Scalettar, Space and Energy Dependent Corrections to the Fuchs-Nordheim Mode 1, GA-3400 (1963).

5. K. Fuchs, Efficiency for Very Slow Assembly, LA-596 (1946).

6. G. E. Hansen, Burst Characteristics Associated with the Slow Assembly of Fissionable Materials, LA-1441 (1952).

7. R. Scalettar, "The Fuchs-Nordheim Model with Variable Heat Capacity," letter to the editor, Nuclear Science and Engineering 16:4, pp. 459-460, 1963.

8. R. Scalettar, The Fuchs-Nordheim Mode1 with Variable Heat Capacity, GA-3416, Appendix (1963).

9. R. E. Taylor, Pulse Heating of Modified Zirconium-Uranium Hydrides, NAA-SR-7736 (1963).

10. J. M. Waage, editor, Safety Analysis Report - SNAPTRAN-2/10A-1 Safety Tests, IDO-16825 (1963) (Confidentia1).

11. B. W. Colston, personal communication (September 1963).

12. G. G. Libowitz, The Zirconium-Hydrogen System at High-Hydrogen Contents, NAA-SR-5015 (1960).

13. L. L. Udy, Shock Propagation Through Zirconium Uranium Hydride - Fina1 Report, Intermountain Research and Engineering Company (1963).

14. R. B. Clay, Formation and Behavior of Shock Waves in Solids, Ph. D. thesis, University of Utah (1960). 
Equations of Motion*

$$
\text { Acceleration }=\frac{\text { force }}{\text { mass }}
$$

$$
\frac{\mathrm{d}^{2} \mathrm{R}}{\mathrm{dt}}=\frac{4 \pi \mathrm{p}}{\mathrm{m}} \mathrm{r}_{\mathrm{b}}^{2}
$$

Assuming that $P(t) \simeq P_{i}$

$$
T(r, t)=\left(T_{d}+C_{1} t\right) \cos \left(\frac{\pi r}{2 R_{\text {extr }}}\right)
$$

when

$$
T(r, t)=T_{d} \text {, }
$$

then $r=r_{b}$, and

$$
r_{b}=\frac{2 R_{\text {extr }}}{\pi} \cos ^{-1}\left[\frac{1}{1+\frac{\mathrm{C}_{1}}{T_{d}} t}\right] \simeq \frac{2 R_{\text {extr }}}{\pi} \cos ^{-1}\left[1-\frac{C_{1}}{T_{d}} t\right]
$$

Solving these equations with the following boundary conditions,

and with the substitution

$$
\left.\begin{array}{l}
R(0)=R_{0} \\
\left(\frac{d R}{d t}\right)_{t=0}=0
\end{array}\right\}
$$

$$
x=\cos ^{-1}\left[1-\frac{C_{1}}{T_{d}} t\right]
$$

gives as the result

$$
\begin{gathered}
R-R_{0}=\frac{16 p R_{\text {extr }}^{2}}{\pi m}\left(\frac{T_{d}}{C_{1}}\right)^{2}\left[\frac{x^{2}}{4}-\frac{3}{2} x \sin x \cos x-\frac{7}{4} \cos ^{2} x\right. \\
\left.+\frac{x^{2}}{2} \cos ^{2} x+2 \cos x-\frac{1}{4}\right]
\end{gathered}
$$

*See page 78 for definitions of symbols. 
Neglecting terms of order $\mathrm{x}^{3}$ and higher, Eq. (13) becomes

$$
R-R_{O}=\frac{16 \mathrm{p} \mathrm{R} \operatorname{extr}^{2}}{\mathrm{~m} \pi}\left(\frac{\mathrm{T}_{\mathrm{d}}}{\mathrm{C}_{1}}\right)^{2}\left[\frac{\mathrm{x}^{6}}{24}\right]
$$

Neglecting terms of order $x^{6}$ and higher, Eq. (12) becomes

$$
\mathrm{x}^{2}=2\left(\frac{\mathrm{C}_{1}}{\mathrm{~T}_{\mathrm{d}}}\right) \mathrm{t}\left[1+\frac{1}{6} \frac{\mathrm{C}_{1}}{\mathrm{~T}_{\mathrm{d}}} \mathrm{t}\right]
$$

With Eq. (14) and (15) and with $1 / 6\left(\mathrm{C}_{1} / \mathrm{T}_{\mathrm{d}}\right) \mathrm{t} \ll 1$,

the final result is

$$
R-R_{0}=\frac{16}{3} \frac{p}{\pi m} R_{\operatorname{extr}}{ }^{2} \frac{C_{1}}{T_{d}} t^{3}\left[1+\frac{1}{2} \frac{C_{1}}{T_{d}} t\right]
$$

Influence of Core Expansion on Reactivity

$$
\begin{gathered}
\mathrm{k}=\frac{\mathrm{k}_{\infty}}{1+\mathrm{L}^{2} \mathrm{~B}^{2}} \mathrm{e}^{-\mathrm{B}^{2} \tau} \\
\tau=\tau_{\mathrm{o}}\left(\frac{\mathrm{R}}{\mathrm{R}_{\mathrm{o}}}\right)^{6} \\
\mathrm{~B}^{2}=\left(\frac{\pi}{\mathrm{R}+\mathrm{R}_{\text {extr }}-\mathrm{R}_{\mathrm{o}}}\right)^{2}
\end{gathered}
$$

With $L^{2} \ll \tau$ and neglecting terms of higher than first order in $R$ and $\Delta R$,

$$
\Delta \mathrm{k}=-2 \mathrm{~B}_{\mathrm{O}}^{2} \tau_{\mathrm{o}}\left(\frac{3}{\mathrm{R}_{\mathrm{o}}}-\frac{1}{\mathrm{R}_{\text {extr }}}\right)\left(\mathrm{R}-\mathrm{R}_{\mathrm{o}}\right)
$$

Neutron Kinetics Equation During Core Expansion

If it is assumed that reactivity feedback terms due to temperature changes are negligible during core expansion, the neutron kinetics equation becomes

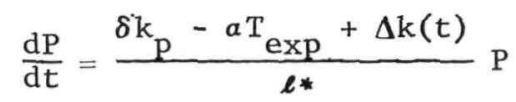

$$
\begin{aligned}
& \frac{\mathrm{P}_{2}}{\mathrm{P}_{1}}=\exp \left\{\frac{\delta \mathrm{k}_{\mathrm{p}}-a \mathrm{~T}_{\exp }}{\ell *} \mathrm{t}+\frac{1}{\ell *} \int_{0}^{\mathrm{t}} \Delta \mathrm{k}(\mathrm{t}) \mathrm{dt}\right\}
\end{aligned}
$$


with Eqs. (16) and (20) in (22),

$$
\begin{aligned}
& \frac{\mathrm{P}_{2}}{\mathrm{P}_{1}}=\exp \left\{\frac{\delta \mathrm{k}_{\mathrm{p}}-\alpha \mathrm{T}_{\exp }}{\ell^{*}} \mathrm{t}-\frac{2}{\ell^{*}}\left[\mathrm{~B}_{\mathrm{o}}^{2} T_{\mathrm{o}}\left(\frac{3}{\mathrm{R}_{\mathrm{o}}}-\frac{1}{\mathrm{R}_{\text {extr }}}\right) \frac{16}{3} \frac{\mathrm{p}}{\pi \mathrm{m}} \mathrm{R}_{\operatorname{extr}}{ }^{2} \frac{\mathrm{C}_{1}}{\mathrm{~T}_{\mathrm{d}}}\right]\right. \\
& {\left.\left[\frac{\mathrm{t}^{4}}{4}+\frac{\mathrm{C}_{1}}{\mathrm{~T}_{\mathrm{d}}} \frac{\mathrm{t}^{5}}{10}\right]\right\} }
\end{aligned}
$$

Symbols

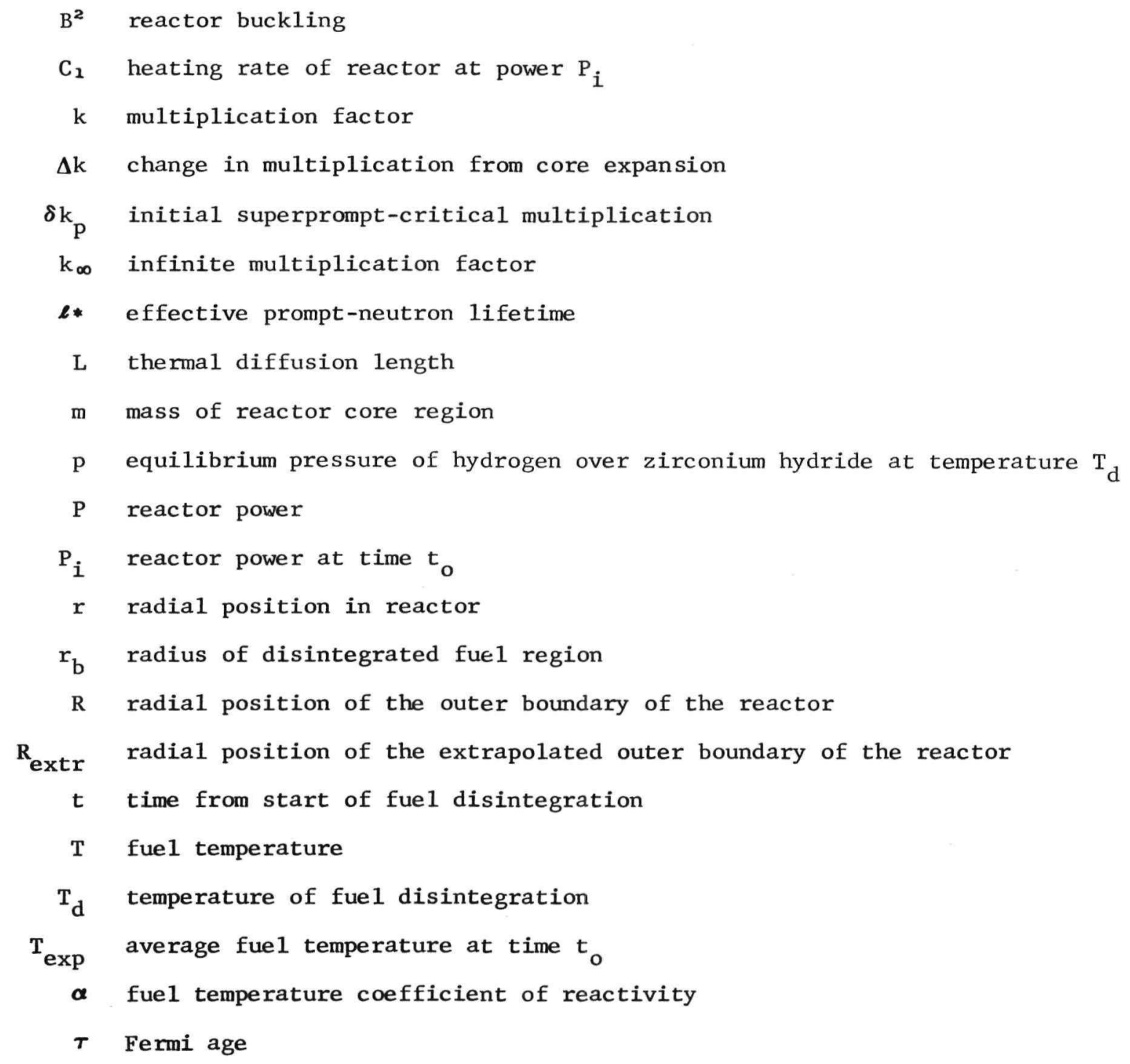

Subscript (o) refers to value at time of start of fuel disintegration 


\section{AEROSPACE NUCLEAR SAFETY GROUND TEST PROGRAM}

J. L. Colp

Sandia Corporation

The increasingly complex satellites and spacecraft developed by the U. S. in recent years have created demands for larger amounts of auxiliary electrical power than can be economically supplied by batteries, solar cells, or other means.

Longer-lived orbital vehicles, especially the manned versions now being developed, have further increased these demands for power.

Since nuclear power sources are the obvious solution to these requirements, development work was begun several years ago under contracts from the AEC and the DOD. This work is now resulting in operative nuclear power systems for these new applications. Designated Systems for Nuclear Auxiliary Power (SNAP), these power sources can be divided into two general categories: those using radioisotopes to generate heat, and those using operating nuclear reactors. Each of these nuclear power systems presents radiation hazards whenever it or its debris is within the earth's atmosphere. Considerable effort has been expended in determining the extent of this hazard.

In the latter half of 1961, Sandia Corporation was requested by the AEC Division of Reactor Development to serve as technical contractor in examining the safety of aerospace nuclear power sources and in performing the related basic research and development work. At the present time, these four distinct work areas have been delineated by AEC/DRD:

1. a Basic Aerospace Safety Research and Development Program,

2. an Aerospace Safety Ground Test Program,

3. an Aerospace Safety Flight Test Program, and

4. an Independent Assessment of the Safety of a11 Aerospace Nuclear Power Sources.

This paper will describe only the Aerospace Safety Ground Test Program; a paper by Mr. A. J. Clark, Jr. to be presented in Session V of this meeting will describe the Aerospace Safety Flight Test Program.

Sandia Corporation, under a prime contract with the Atomic Energy Commission, operates two laboratories and a test range, a11 of which are engaged in research and development work on the ordnance phases of nuclear weapons.

Sandia has been engaged in weapon work for the AEC for a number of years. During this time, capabilities have been developed at Sandia that are directly applicable and highly valuable to work in the Aerospace Nuclear Safety Program. Some of these are:

1. A research organization whose scientific fields of interest include physical electronics, plasma physics, high-temperature physics, solid-state physics, radiation effects, theoretical mechanics, molecular and crystal structure studies, high-rate chemical kinetics, and nuclear-burst phenomena. 
2. An environmental testing organization equipped with complete facilities to perform drop-tower, radiant-heat, vibration, shock, chemical-interaction, acoustical, and rocket-sled impact tests, as well as many others.

3. A materials and processes organization that develops new materials, keeps abreast of research and development in its fields, evaluates commercially available materials, and operates its own analytical and material properties laboratories.

4. A field testing organization that performs and supports Sandia test programs at its own ranges and at other locations around the world.

The Aerospace Nuclear Safety Organization at Sandia Corporation is under the Director of Aerospace Programs, Mr. Don B. Shuster, reporting to the Vice President of Development, Mr. G. A. Fowler. The Department Manager in direct charge is Mr. V. E. Blake, Jr. The Aerospace Nuclear Safety Department, 7410, is divided into three divisions as follows:

1. Division 7411, under H. E. Hansen, which is to perform the Basic Aerospace Safety Research and Development Program.

2. Division 7412, under A. J. Clark, Jr., which has full responsibility for the Aerospace Safety Ground Test Program and partial responsibility for the Aerospace Safety Test Program. In the latter program, this division is responsible for the mechanical and thermal design of flight-test hardware as well as for its fabrication and environmental and development testing and its compatibility with nuclear test articles, launch vehicles, etc. Nuclear and thermal studies and analyses are also included in the work of this division.

3. Division 7413, under A. E. Bentz, which is responsible for the design, development, testing, and operation of the telemetry systems used in the flight tests, and for all range instrumentation, both electronic and optical. This division is the contact with the ranges used for flights, and it makes all arrangements with the launch agencies.

In addition to the work done on the Aerospace Nuclear Safety Program in Department 7410, many other groups within Sandia Corporation make sizeable contributions.

Ground Test Program Description

The Aerospace Safety Ground Test Program at Sandia is broadly defined as an effort to assess the effects of mechanical actions, thermal and chemical interactions, and nuclear reactions upon the safety of nuclear power sources intended for aerospace application. This program is responsible for assessing all the possible effects of conceivable accidents between factory shipment and terrestrial reentry.

The work underway in this program is shown in Table I; it will be briefly described under the titles shown in the same table. 
TABLE I

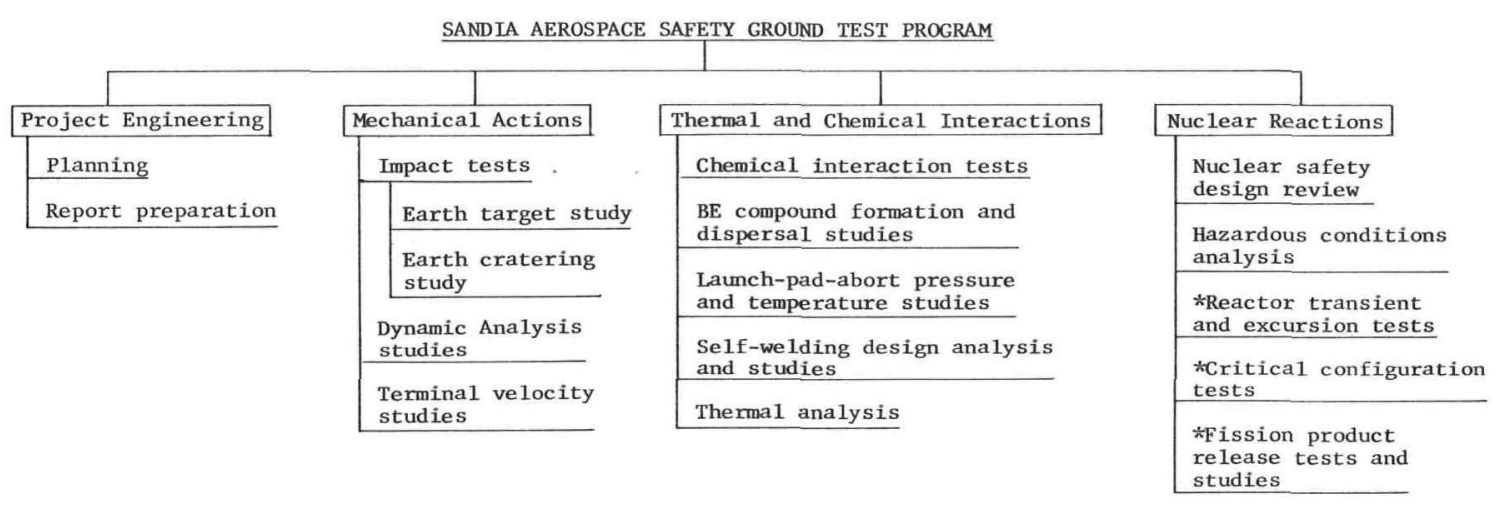

*Indicates experimental work performed by others, but planning, execution, and evaluation are monitored by Sandia.

\section{Project Engineering}

This task includes planning the work to be performed in the overall program. It includes liaison work with the various governmental agencies concerned with aerospace nuclear safety, especially in those fields which are not specifically concerned with an existing or already programmed nuclear power source. Also included in this task is the preparation of reports, budgets, and other administrative details necessary to the success of the overa11 program.

\section{Mechanical Actions}

Present efforts under mechanical actions can be divided into three general areas. As experience is gained in this field and additional programs are instituted, it may be necessary to add additional studies in this category.

Impact Tests -- The first task in this category is planning, performing, analyzing, and reporting impact tests on complete power units and their individual component parts. These impact tests are intended to simulate the conditions of every conceivable accident which might involve the unit being tested. Nonradioactive or inert simulations of radioactive materials are impact-tested by different types of test equipment (such as rocket-sled tracks, recoilless rifles, centrifuges, and drop towers).

Associated with this task is a generalized study to develop a method of specifying the design of an impact target fabricated from soil to simulate the earth's surface. This study consists of: (1) analytical work to set up a mathematical model of the mechanisms that occur in soil upon impact; and (2) experimental work to determine empirically the relationships that result from impact.

A study will be begun to determine the extent to which craters are formed by impacting bodies and the extent to which such craters will contain projectiles. The objective of this study is to define crater formation and crater retention of projectiles in the form of reactor core vesse1s. It will investigate impacts at various velocities into a variety of soil types and conditions.

Dynamic Analysis Studies -- The second task includes dynamic analysis studies to predict the effects of mechanical actions on nuclear power units and their individual components. Improved computer codes permit analysis of the effects of dynamic loading on such items, and dynamic analysis studies are performed by specially trained personnel using the latest available types of computers. These studies are 
performed as soon as design information is available in order to provide information for planning a series of impact tests on the design.

Terminal Velocity Studies -- The third task under this effort is the performance of terminal velocity studies, both by calculation and by experimentation. These studies are performed for entire nuclear power units as we11 as for certain of their components. The velocity determined is that which could result from accidental conditions imposed upon the power unit at various periods during its factory shipment to re-entry sequence.

Therma1 and Chemical Interactions

At the present time this area encompasses five separate tasks. Further tasks will be added as conditions warrant.

Chemical Interaction Tests -- The first task under this effort is to perform tests to experimentally determine the interactions that may occur between the various chemicals associated with certain designs of nuclear power units. These tests are nonnuclear. (Any nuclear items in the design are simulated by inert or nonnuclear substitutes.)

Beryllium Compound Formation and Dispersal Studies -- The second task in this effort is to study the formation and dispersal of beryllium compounds, particularly the toxicity hazards associated with these processes. Sandia Corporation is using the services of other laboratories under contract for experimental work in this area, but work is also being performed in Sandia Laboratory facilities so that work done by outside contractors in this specialized field may be clearly and completely evaluated.

Launch-Pad-Abort Pressure and Temperature Studies -- The third task involves launch-pad-abort pressure and temperature studies, both analytical and experimental. The services of other laboratories under contract to Sandia Corporation wil1 be used in this task, but design and development work on specialized instruments to obtain the necessary pressures and temperatures is being done by Sandia Corporation. The work of calibrating, fabricating, and installing such devices is also included under the scope of this task.

Self-Welding Design Analysis and Studies -- This task involves design analysis in vacuum self-welding, and studies of specific materials used in the designs of existing nuclear power units. It supplements similar work being done in the Sandia Aerospace Research and Development Program but is limited to specific applications.

Thermal Analysis -- This task consists of thermal analyses of specific nuclear power units and their components. The work consists primarily of analytical studies, but experimental determinations are performed as needed.

\section{Nuclear Reactions}

This effort presently consists of five individual tasks. Additiona1 tasks wil1 be added as may be warranted.

Nuclear Power Unit Safety Design Reviews -- These reviews are conducted on the design of specific nuclear power units during all stages of design from their conception to their final configuration. This task is performed in cooperation with the design group of the organization in charge of design and fabrication of the nuclear power unit. The object of this task is to acquaint Sandia Corporation with new designs and to provide the designer-fabricator with specialized information which may be incorporated in the design at an early stage to ensure adequate nuclear safety. 
Hazardous Conditions Analysis -- This task involves close study of the entire life cycle (from factory shipment to terrestrial re-entry) of each nuclear power unit with the object of identifying potentially hazardous conditions. These conditions are then set forth in chart form so that they can be considered at an early stage of the system design. On the basis of the information gained in the nuclear power unit safety design review (described immediately above), a probability figure for the occurrence of each individual hazardous condition is assigned. It becomes apparent from this hazardous condition analysis where special emphasis on safety devices and/or designs should be placed.

Reactor Transient and Excursion Tests -- In this task the experimenta1 test work is performed by others but the planning, execution, and evaluation of the work are monitored by Sandia Corporation. The objective of this task is to thoroughly acquaint Sandia Corporation with the design and experimental performance of safety devices included in the nuclear design of the power unit.

Critical Configuration Testing -- Again, the experimental work associated with this task is performed by others but the planning, execution, and evaluation of the results are monitored by Sandia Corporation.

Fission Product Release Tests -- As in the case of the two tasks immediately above, the experimental work in fission-product release testing is performed by others but the planning, execution, and evaluation of results are monitored by Sandia Corporation.

\author{
Current Reactor Safety Ground Test Program
}

The safety assessment of any nuclear power supply that is to be used in an aerospace application must be as complete and factual as it is possible to make it. All possible effort must be exerted to ensure the safety of the general public regardless of the location and condition of the aerospace unit.

The safety ground test task is to provide factual engineering information (to the extent that it can be obtained from ground-based tests) with which to assess the safety of the nuclear aerospace power unit during its entire lifetime, including shipment from the factory, launch, flight, terrestrial re-entry, and impact on the earth. Many environments seen during the lifespan of the unit can now be duplicated or simulated in existing ground-based laboratories and test facilities. However, some of the environments which the unit will face cannot at present be duplicated or simulated in ground-based facilities. For that reason, suborbital and orbital flight tests are also being planned and performed.

A fully comprehensive safety ground test program must be based on a thorough analysis of all of the hazardous conditions to which a nuclear power unit can be subjected during its lifespan. A11 the possible consequences to safety of a failure during any of the hazardous conditions postulated must be fully assessed. A complete engineering analysis of those aspects of the reactor design that are of concern to the safety of the system will be necessary to ensure that all possible consequences have been accurately foreseen. To complete such an analysis, a thorough understanding of all of the system design data is required.

Also required is a complex analysis of the consequences of all possible hazardous conditions. Such an analysis consists of outlining possible series of consequences and assigning a probability to each. On the basis of the most probable series, a comprehensive ground test program for a specific design can be formulated.

The current safety ground test program for reactor-type power units can be broadly divided into two parts. One, a genera1 studies program, includes efforts 
whose results can be applied to the safety assessment of many types of nuclear power units. The other is a program of testing to evaluate the safety of specific nuclear power unit designs and actual hardware. Each of these programs is described below.

\section{Genera1 Studies}

Launch-Pad-Abort Environment Study -- One of the more severe environments to which a SNAP power supply can be subjected is explosion and fire from the accidental abort of a rocket vehicle on its launch pad. The overpressures and temperatures of this environment are known to be extreme, but quantitative values have not been established by measurements within the firebal1 itself. phases:

The general study embarked upon under this program includes the following

1. A survey of a11 reported analytical studies and experiments on massive fireba11s, with the object of better understanding their hydrodynamics and related effects.

2. Planning and designing (in cooperation with other governmental agencies) instrumentation to be installed on certain existing missile launch pads to measure the pressures and temperatures within any fireballs that may result from future launch aborts. In this effort, Sandia Corporation will make use of experience in instrumentation gathered from years of participation in weapon testing activities.

3. Development work to extend the range of a previously designed Sandia passive thermal sensor device to a lower level so as to make it capable of close-in recording of the temperatures of missile-abort fireba11s on any launch pad.

4. Design and development of a passive pressure sensor to be used in conjunction with the thermal sensor described above.

5. Cooperation with other governmental agencies in scheduled future studies and experiments on missile-abort fireballs.

The objective of this effort is to obtain a reliable, quantitative definition of the environment which would result from a launch-pad abort of the rocket vehicle for a SNAP power supply. With the aid of this definition, laboratory and field tests simulating the environment can then be performed on actual SNAP hardware to determine the extent of the hazard that might result.

Bery11ium Compound Formation and Dispersal Study -- Many present and proposed SNAP reactor power supplies (as well as other nuclear propulsion reactors) use quantities of beryllium in their design. The high temperatures and pressures from launch-pad aborts to which these units might accidentally be subjected could cause the formation and dispersal of highly toxic compounds of beryllium. The fundamental mechanisms causing the formation and dispersal of beryliium compounds are not we 11 understood. This study is intended to increase knowledge of these mechanisms and to quantitatively define the amount, type, and particle size of beryllium compounds released under various conditions of pressure, temperature, and atmosphere. It will be conducted by means of a subcontract from Sandia to a qualified laboratory as wel1 as by laboratory investigations at Sandia.

Earth Target Simulation Study -- There is reason to believe that the targets commonly used for earth impact tests do not sufficiently simulate a condition of the surface of the earth; consequently, the effect on a projectile of impacting into such a target does not duplicate the effect that would be gotten from an actual earth impact. This study has been undertaken to determine whether or not the 
present earth impact tests do simulate impact into the surface of the earth and, if they do not, to develop a method of specifying the design of an earth target that will simulate the earth's surface.

Since the earth's surface is neither homogeneous nor isotropic, no statement about what will happen to a given item when it impacts the surface of the earth can be made unless some definite point of impact is specified. In the space of a very few feet, the properties of the soil can vary considerably both horizontally and vertically. This study will set up certain boundary conditions for a limited number of surface soil types. Earth impact tests can then be run on a limited number of simulated earth targets that will encompass the range of surface soil conditions upon which a falling test item might impact.

The study will consist of (1) analytical work to set up a mathematical mode1 of the mechanisms that occur upon impact, and (2) experimental work to empirically determine the relationships that result from impact. The experimental work will consist of laboratory model work, field model tests, and full-scale field tests.

Earth Cratering Studies -- An environment which might be critical for certain SNAP reactor designs would be water accumulated in a crater caused by and containing a nondispersed core following accidental impact into soil. The extent to which craters are formed and the extent to which a crater will retain a projectile is not quantitatively known for projectiles in the configuration of reactor core vesse1s impacting at various velocities into a variety of soil types and conditions.

The objectives of this effort are:

1. To analyze the mechanisms of crater formation from projectiles impacting at various attitudes and velocities.

2. To perform a series of impact cratering tests to gather empirical data on the formation of craters and their retention of the impacting projectile under various impact attitudes and velocities. The test series will be of a generalized nature. Test items simulating the size, weight, and configuration of the core vessels of presently conceived SNAP reactor type power supplies will be used. The impacting velocities and attitudes selected for this series will include those that could reasonably be expected from presently conceived SNAP reactor designs. The soil types tested in the cratering studies will be as nearly like those used in the earth target simulation study as is reasonable.

Terminal Velocity and Attitude Study -- Knowledge of the terminal velocity and aerodynamic attitude achieved by a free-falling SNAP power supply or its components is essential for a test series on the effects of impact. The terminal velocity and attitude of a free-falling configuration must be determined experimenta1ly as well as calculated aerodynamically.

The objective of this effort is to perform a series of tests to experimenta1ly determine the terminal velocity and aerodynamic attitude of various test items simulating the configurations of SNAP reactor power supplies and core vesse1s. The test items used will resemble in size, weight, and aerodynamic characteristics (1) presently conceived complete SNAP reactor power supplies, less shield, and (2) presently conceived SNAP core vessels.

Core-Vesse1 Impact Survival Study -- The effects of impacts at various velocities with a variety of target materials upon the structure of a reactor core vesse 1 must be known in order that its safety under all possible conditions may be estimated. The objective of this effort is (1) to calculate structural integrity, and (2) to experimenta1ly determine the effects of impacting at various attitudes and velocities against a variety of targets on the structure of test items simulating generalized SNAP reactor core vessels. The test items used will resemble a range of generalized examples of presently conceived SNAP reactor core vessels in size, weight, shape, and structural strength. 
The experimental portion of this effort will include several series of tests to determine the following: (1) the effect of impact attitude versus velocity, and (2) the effect of target materials versus velocity. The impact velocities and attitudes to be examined will be selected from the results of the Terminal Velocity and Attitude Study.

The target materials used will be concrete, water, and earth simulations selected from the Earth Target Simulation Study.

SNAP-10A Specific Studies

The Phase I Mechanical and Thermochemical Test Series on the SNAP-10A was conducted at Holloman Air Force Base, New Mexico, by Atomics International and the Air Force Special Weapons Center as one of the projects in the SNAP Aerospace Safety Program. The principal objective of these tests was to obtain data and information to analyze in evaluating the potential hazards before, during, and after the flight of a SNAP-10A reactor.

Phase II of the SNAP-10A Safety Ground Test Program was performed by Sandia Corporation. The plan for Part A of Phase II called for several impact tests, a series of fire tests, a chemical interaction test, and an explosion test; however, it was decided to postpone the explosion test until the overpressure environment of a launch-pad abort is more clearly defined.

Part B of the Phase II program consisted of a complete analysis of hazardous conditions and their possible consequences, dynamic analyses of impact configurations, impact tests to verify calculations, and laboratory tests to determine the mechanism responsible for the formation and dispersal of beryllium compound. The latter series of laboratory tests has been removed from Part $B$ and is being continued as part of the General Studies Program described earlier. Presently planned tests on the SNAP-10A reactor include the following:

1. Terminal Velocity and Attitude Study

The objectives of the terminal velocity and attitude test series are :

a. To experimentally determine the terminal velocity achieved by three specific configurations of the SNAP-10A system during free fall through the atmosphere.

b. To experimenta1ly determine the aerodynamic attitude of three specific configurations of the SNAP-10A system at terminal velocity during free fall through the atmosphere.

2. Impact Survival Study

a. Termina1 Velocity Impact Series

The objectives of the terminal velocity impact test series are:

(1) To experimentally determine the structural integrity of two specific configurations of the reactor system at sea-level terminal velocity under various impact attitude angles and temperatures when these configurations are impacted against a simulated earth target.

(2) To experimentally determine the fuel-rod dispersion characteristics under the same conditions as in (1) above.

(3) To experimentally determine the structural integrity of the reactor system under the same conditions as in (1) above, except that the system is impacted against an infinite water target. 
(4) To experimentally determine the fuel-rod dispersion characteristics under the same conditions as (3) above.

b. Reflector Separation Velocity Impact Series

The objective of this drop test series is to determine the minimum impact velocity at which the reactor reflector will separate from the reactor assembly.

\section{Explosion Survival Studies}

a. Launch-Pad-Abort Overpressures Series

A series of tests will be conducted to determine the structural damage sustained by specific configurations of the SNAP-10A reactor system at the launch-pad overpressure. The earlier explosion test which was run as part of the SNAP-10A Phase I series is believed to have provided insufficient data for fully assessing safety under this environment. Further explosion tests will be performed when the definition of launch-pad-abort overpressures is completed. (The work being performed on this definition is described earlier in this report.)

Current Isotopic Power Supply Safety Ground Test Program units.

This program is divided into two parts, as is the program for reactor power

\section{General Studies}

Fue1 Capsule Impact Testing Program -- This program will statistically determine the effects of impact loading on the structural integrity of fuel capsules like those of the SNAP-9A series when fuel configurations, fuel materials, operating temperatures, capsule designs, and impact attitudes are changed for various targets. Test item materials have been carefully selected to simulate at ambient temperature the properties of the actual materials at their operating temperatures. The test items are specially designed for low-cost fabrication so that enough testing may be done to permit statistical analysis of the results.

Concurrent with the impact testing program, a dynamic analysis study of the performance of the fue1-capsule test items will be pursued. The impact testing program will be modified according to the results obtained from the dynamic analysis study.

This program was begun when library research revealed practically no information in the field of applied mechanics on the effects of impact loading on closed hollow vesse1s. With an expected duration of 2 years, this program will provide the basic applied mechanics information prerequisite to safe practice in the design and selection of materials for isotope fuel capsules. (The need for this information became apparent during the SNAP-9A fuel capsule tests described later in this report.)

This impact testing series will test items similar to SNAP-9A fuel capsules; however, both its results and the accompanying dynamic analysis should be broad enough to apply in the design and testing of fuel capsules for subsequent isotopic SNAP units. 
SNAP-9A Specific Studies

A test plan for required SNAP-9A ground tests prepared by Sandia Corporation has already been carried out. The objectives of the SNAP-9A ground test plan were:

1. To verify aerodynamic calculations by experimentally determining the terminal velocity and associated attitude of: (a) the SNAP-9A generator, with and without radiator fins; and (b) the SNAP-9A fuel capsules both (1) with the CG located where it would be when the fuel is in the as-installed configuration, and (2) with the CG located where it would be when the fuel has melted and run into one end of the fuel rod.

2. To analyze the structural and dynamic effects on the SNAP-9A fue1 capsule and generator of impact loading under the determined terminal velocity conditions and under the most adverse conditions of impact attitude and loading.

3. To perform on the fuel capsule and generator the impact tests required to verify structural and dynamic effects analyses.

The following tests on SNAP-9A hardware have been completed and the results applied in the independent safety assessment of this system which has already been forwarded to the AEC/DRD.

Drop Tests -- The test units listed in the table below were dropped from aircraft at altitudes of 10,000 and 15,000 feet above the Tonopah Test Range and were tracked by cinematic theodolites. All units tumbled randomly and evidenced reasonable agreement with theoretical data.

TABLE II

SNAP-9A Generator and Capsule Drop Tests

\begin{tabular}{|c|c|c|}
\hline Test unit & No. & $\begin{array}{l}\text { Maximum velocity (ft/sec } \\
\text { corrected to sea leve } 1 \text { ) }\end{array}$ \\
\hline Simulated generator with fins & 2 & 118 \\
\hline Simulated generator without fins & 2 & 230 \\
\hline Ful1-scale simulated fuel capsule & 22 & 253 \\
\hline Scaled-up simulated fuel capsule & 12 & 301 \\
\hline
\end{tabular}

\section{Structura1 and Dynamic Effect Analyses}

Analyses of structural and dynamic effects on the SNAP-9A generator and fue 1 capsules were started in December 1962. Work to date has provided test conditions for a series of impact tests.

Impact Tests -- Eleven simulated SNAP-9A fue1 capsules were impacted against granite and angle-iron targets in an effort to determine whether the fuel capsule would contain the radionuclide fuel under the most severe of the predicted impact conditions. Granite and angle-iron targets were propelled into the suspended fuel capsules by a $155-\mathrm{mm}$ recoilless rifle for five of the tests and by a rocket-powered sled for the remaining six tests. A11 capsules were stabilized at a nominal $1150^{\circ} \mathrm{F}$ before impact.

The results of this test series indicated that the flight-quality capsules did not rupture when impacted end-on or side-on against a flat granite target or 
when impacted side-on against an angle-iron target at velocities appreciably greater than the predicted impact velocity. However, when impacted at a 45-degree angle against a flat granite target, the capsule ruptured at a velocity of 276 feet per second, which is near the predicted impact velocity. 


\section{BLANK}




\author{
W. Hagis \\ D. G. Harvey \\ Martin Company
}

In establishing a safety philosophy and design criteria for isotopic auxiliary power units in space, the degree of containment of the radioisotope fue 1 and its radiations was the primary concern. The factors to be considered are as follows:

1. the type and fuel inventory of the isotope selected,

2. the method of placing the isotopic power system into orbit and the replacement rate, if any,

3. the mission, altitude, and orbital inclination of the satellite, and

4. the period in which the systems are expected to be used and the technological advances to be achieved by this time.

The use of nuclear-fueled systems in space must be justified by weighing the risk against the benefits to be derived. This has been the underlying philosophy on many successful programs in the past.

The hazards posed by the use of isotopic power systems are ultimately the result either of the release of the isotopic material into the atmosphere or biosphere or the return of the fuel container intact with a large part of its original inventory. The fate of the fuel container in the event of catastrophic failure on the missile launch pad must also be considered as part of the safety study and must be included in the overall safety philosophy established.

Isotopic systems so far developed, SNAP-1A, -3, -9A and Transit 4A and 4B, were required to disassemble and burn up in the stratosphere and to disperse the fuel as particulate matter in worldwide fallout. The SNAP-11 generator, which is currently under design, is required to contain the fuel inventory under al1 credible operational and accidental modes and, in addition, to survive re-entry following orbital departure or high-altitude abort of the launch vehicle.

The safety philosophy of future systems must await their development and definition of their expected use. It is inconceivable that large inventories of fue 1 would be allowed to burn up in the atmosphere following either postmission re-entry or re-entry as a result of a late abort during the ascent of the carrier vehicle. Large systems, i.e., those employing several million curies of isotopic matter, will then require

1. controlled re-entry of the orbiting package to a predetermined location on the earth's surface at a predetermined time, or

2. guidance and propulsion systems to propel the orbiting system to higher-level orbits, either earth- or solar-oriented, or

\footnotetext{
*Presented by Mr. Hagis
} 
3. the presence of a man able to return the fuel inventory with him or before his departure from the space ship.

In addition, systems destined to be used for extraterrestrial exploration must also be designed not to release the fuel either by atmospheric burnup or by high-velocity impact. Re-entry into a foreign atmosphere or impact on earth upon return must be survived. As an additional safety requirement for these systems, very high velocity impact on a foreign body must result in containment of the radioisotopic fuel within its encapsulating body or within the immediate vicinity of the crater formed by impact.

\section{Description of Isotopic SNAP Generators}

In this paper, the SNAP-3 generator, shown in Figure 15 and the Transit 4A generator, Figure 16, are used to illustrate the internal configuration of isotopic systems and to describe the method of fuel containment. They are typical of systems designed for the 1962 to 1965 period. The generator used for the Transit mission is a modified SNAP-3 device, differing mainly in the type and amount of radioisotope fuel used and in the size and construction of the fuel capsule.

SNAP-3 produces power from the heat evolved in the radioactive decay of about 0.489 gram of Po-210 fuel. The activity of 2200 curies provides 69 watts of thermal power, which, at a conversion efficiency of about 5 percent, results in a 3.5-watt electrical output.

In SNAP-3, the fuel is divided equa11y between two capsules. Both capsules are made of Type 304 stainless steel with a wall thickness of 0.030 inch. Each is closed by a plug welded in place.

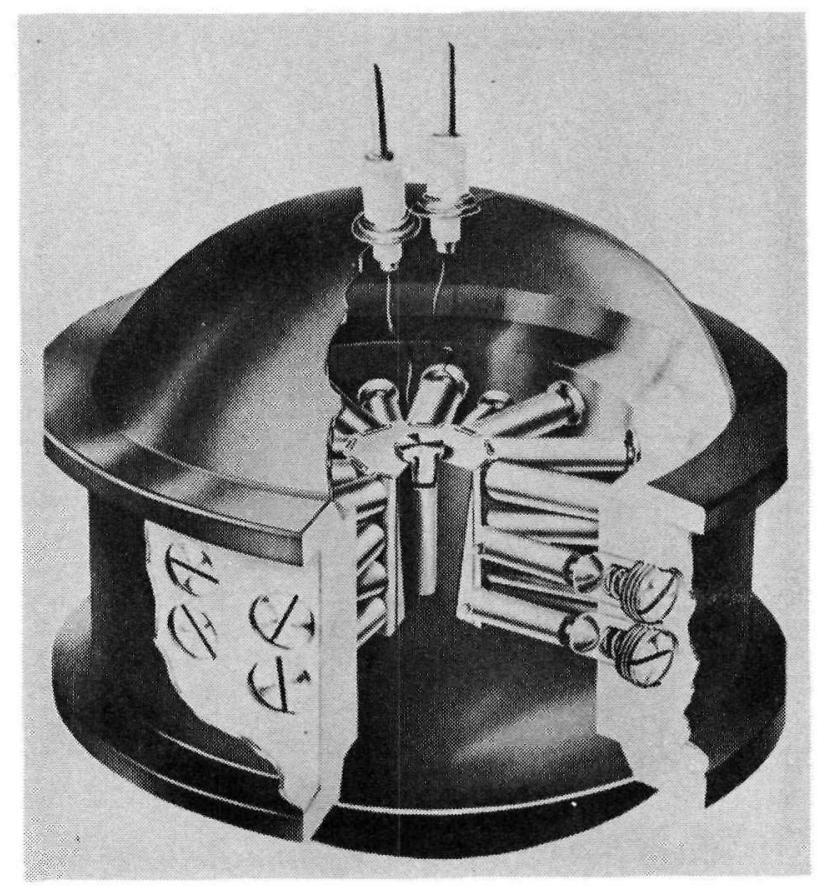

Figure 15. SNAP-3 thermoelectric generator 


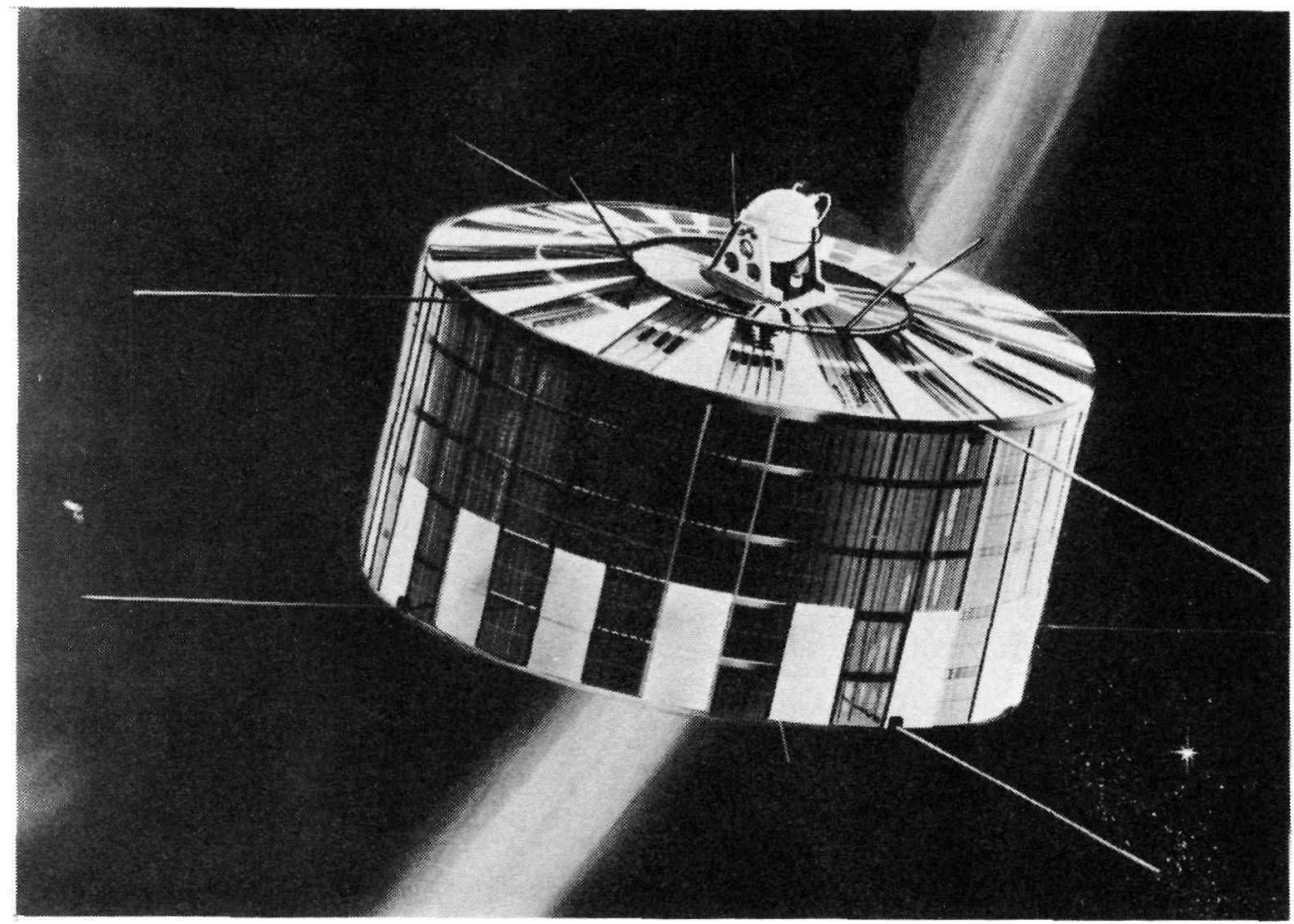

Figure 16. Transit $4 \mathrm{~A}$

The two fuel capsules are placed in a stainless steel canister with a wal1 thickness of 0.034 inch. The canister is then closed by welding. A heavy vesse1 made of the cobalt-base alloy, Haynes 25, contains the primary capsules and canister. Haynes-25 provides the mechanical strength and corrosion resistance necessary to ensure containment of the fue 1 under any condition encountered during manufacture, transportation, or installation of the generator.

The outer surface of the Haynes-25 vessel has a temperature of about $1100^{\circ} \mathrm{F}$ $\left(593^{\circ} \mathrm{C}\right)$. The interior temperature is slightly higher and well above the melting point of polonium. The hot junctions of the 27 pairs of lead telluride thermoelectric elements are placed against the Haynes-25 vesse1. The cold junctions are held in contact shoes which extend to the surface of the generator. The massive Haynes-25 vesse 1 and the assembly of thermoelectric elements are he1d in place by rigid heat-insulating material; the voids are filled with powdered insulation.

The generator is encased in a nearly spherical she11 of copper. This she11 is composed of segments soldered together so that on burnup during re-entry or after an abort the seams will open and allow the insulation and thermoelectric elements to fall away and expose the core.

\section{Nuclear Safety Study}

A complete safety evaluation of a nuclear system must include both a comprehensive analytical effort and a we11-coordinated test program. The studies and tests performed for the SNAP-3 and SNAP-9A systems are typical of those efforts required to assess the degree of safety that a system may have and to determine its acceptability for operational use. 


\section{Analytica1 Studies}

The safety evaluation of aerospace nuclear systems can conveniently be handled as three phases: prelaunch, launch, and operational. In each phase, the analyses cover the operation and fate of the radioisotopic fuel container both for satisfactory performance and for credible aborts. Early in the design stage of a new system, safety plays an important role in influencing the design so that the ultimate mission will not be unduly compromised.

Some of the more important factors to be considered in analytical studies are (1) internal pressure buildup within the fuel container, (for alpha-emitting fuels), (2) fuel compatibility with encapsulating material, and (3) ability of the fuel to be readily dispersed in the atmosphere, if desired, or to survive re-entry. These factors, though, are at times less critical than the hazards associated with malfunctions of the launch vehicle, transportation accidents, and release of the radioactive fuel into the atmosphere or water.

Prelaunch Abort -- The prelaunch period covers the time before the arrival of the nuclear unit at the launch pad until just after missile liftoff. The potential problems are transportation and handling accidents and missile aborts. Studies in the past have al1 indicated that forces imposed on SNAP systems by the latter far exceed those of other postulated malfunctions and, certainly, all forces of normal operations.

Launch-pad fires produced by liquid-fueled IRBM boosters produce fireba11s with maximum diameters of approximately 275 feet and maximum sustained temperatures of approximately $3000^{\circ} \mathrm{F}$. The fireball conditions resulting from relatively small solid-propellant boosters are of the same order of magnitude. A later section describes an experimental test with solid propellants. This test, in addition to other programs, shows that the materials used in operational generator systems are unaffected by the thermal environment. Indeed, scaled operational configurations constructed of aluminum alloy did not experience significant damage in tests to obtain an indication of the relative effects of fire.

Liquid fireballs produce heating fluxes on the order of 5 to $15 \mathrm{Btu} / \mathrm{sq} \mathrm{ft}-\mathrm{sec}$. It is not credible that the fire would be sustained for periods greater than a few minutes. The heat input to a system and thus the temperature rise and damage would therefore be smal1.

Shock overpressures caused by detonation of the launch vehicle can produce a significant force that must be considered in the safety design and analysis of nuclear systems. Although theoretical methods have been developed to calculate the magnitude of the overpressure, test programs are normally required to experimentally verify the initial design. Such a program is summarized in the next section. The magnitudes of the overpressures are functions primarily of weight of propellant, means of detonation, and location of system from centerline of the blast. Large liquid-fueled boosters produce pressures in the neighborhood of approximately $1500 \mathrm{psi}$. Analysis shows that the outer she11 of the generator system will normally be deformed and sometimes destroyed, but the inner hardware containing the fuel is unbreached.

Launch Aborts -- Aborts occurring between 1iftoff and orbital injection are other sources of potential failure for SNAP systems designed for space use. Here, the effects of sea-water corrosion, high-velocity impact with the earth's surface, and aerodynamic heating must be studied.

High-velocity impact of the SNAP system on the surface of the earth will result in the event of missile failure at relatively low altitudes. A conservative analysis is performed in which the payload package is assumed to be removed from the missile and the fuel capsule freed from its restraints. The capsule is assumed to fall unrestricted and reach its aerodynamic terminal velocity. This value is the theoretical maximum velocity that it can reach (approximately 300 feet per second for SNAP components). The most force to which the fuel capsule might be subjected is an impact on a material which would not be deformed, thus imparting all 
loads to the projectile. For this system, the capsule could be designed to resist the force elastically or be permitted to take a permanent set. Since the system in which the fuel will be used has a primary design objective of minimum weight, it is desirable to design the fuel capsule to be as light as possible without affecting safety. The capsule was therefore designed to deform plastically under maximum impact forces. In treating problems involving such forces, it is desirable to determine the distribution of impact pressure and to establish the manner in which the forces acting on the impacting bodies are distributed.

Analytical methods have shown that a capsule impacting at velocities of approximately $300 \mathrm{fps}$ can survive impact and not be breached. A program is described below which experimentally verifies these analytical conclusions.

Re-Entry -- When the orbiting payload package has departed orbit or an abort occurs late in the ascent portion of the trajectory, re-entry into the earth's atmosphere will result. The fate of the generator, fuel capsule, and fuel material, when exposed to re-entry aerodynamic heating, is of paramount importance, since some aborts will occur during the thrust period, and the payload and particularly the radioisotope fuel capsule will be only partially destroyed by aerodynamic forces and heating.

The location of impact, or of burnup, for those re-entries resulting from abort is required for re-entry analysis. The altitude of burnup during orbital or abort re-entry is also important for determining proper dispersion of the fuel. Those systems designed to survive re-entry and to impact without release of the radioisotope fuel require just as extensive an analysis as in the former case.

The method used to determine the time variation of stagnation-point heating rate and the distribution of these heating rates is described in Reference 1 . The laminar heating rate at the stagnation point on a hemispherical nose for flow in thermochemical equilibrium was computed empirically on the basis of results from a continuing experimental test program.

In addition, investigations are made to determine the mode of re-entry of the orbiting payload system as a function of altitude and initial conditions. Unfortunately, little experimental data are available on aerodynamic coefficients of irregular bodies under random entry conditions.

It is convenient to plot the ground trace of the ascent trajectory on a map and to include the maximum possible lateral deviations from the nominal trace. On this plot can be superimposed the splash points of postulated aborts and the condition of the generator at the time of impact. The loci of those points indicating the maximum lateral position of the "partial burnup zone" can be illustrated. Similarly, the locations of the impact zone for intact generators and the zone where no impact would result because of burnup can be shown. References 2 and 3 contain such maps. A comprehensive summary of the fate of a high-altitude, highvelocity abort can be likewise illustrated.

\section{Test Programs}

Test programs can be divided into two categories; ground tests and flight tests. The formulation of a test program can correspond to the various phases of the mission of the power source. Credible accidents and normal operational events are investigated and studied as previously described, and, if warranted, test programs are conducted to verify conclusions or to expose potential problem areas.

An abort of the launch vehicle before or just after liftoff will expose the generator to several distinct but interrelated environments that may have a detrimental effect on the radioisotopic-fuel containment mechanism. Among them are shock overpressures and fire on the pad caused by detonation of the missile propellant tanks. The shock overpressures expected from exploding liquid-fueled vehicles were studied, and methods were obtained to calculate these forces. A test program was performed in which the expected equivalent yield of a missile was experienced by the isotopic hardware. 
Shock Overpressure Test -- The impulsive force resulting from shock-pressure waves originating with the ignition of liquid oxygen and RP-1 has been determined analytically by methods derived from TNT tests. Initial analyses showed that shock loads from these fuels will produce forces equivalent to 77-percent TNT. Later studies by Space Technology Laboratory developed empirical relations for the prediction of shock overpressures from LOX/RP-1 at distances from the point of origin.

SNAP generators were tested under simulated vehicle-abort conditions at Aberdeen Proving Ground. In these tests, fuel cores and generators were subjected to a shock overpressure of $1020 \mathrm{psi}$ at an appropriately scaled distance from a 1650-pound TNT charge. The capsule material varied from super alloys to graded aluminum. Even the lowest grade aluminum core maintained its mechanical integrity. Figure 17 shows the test setup.

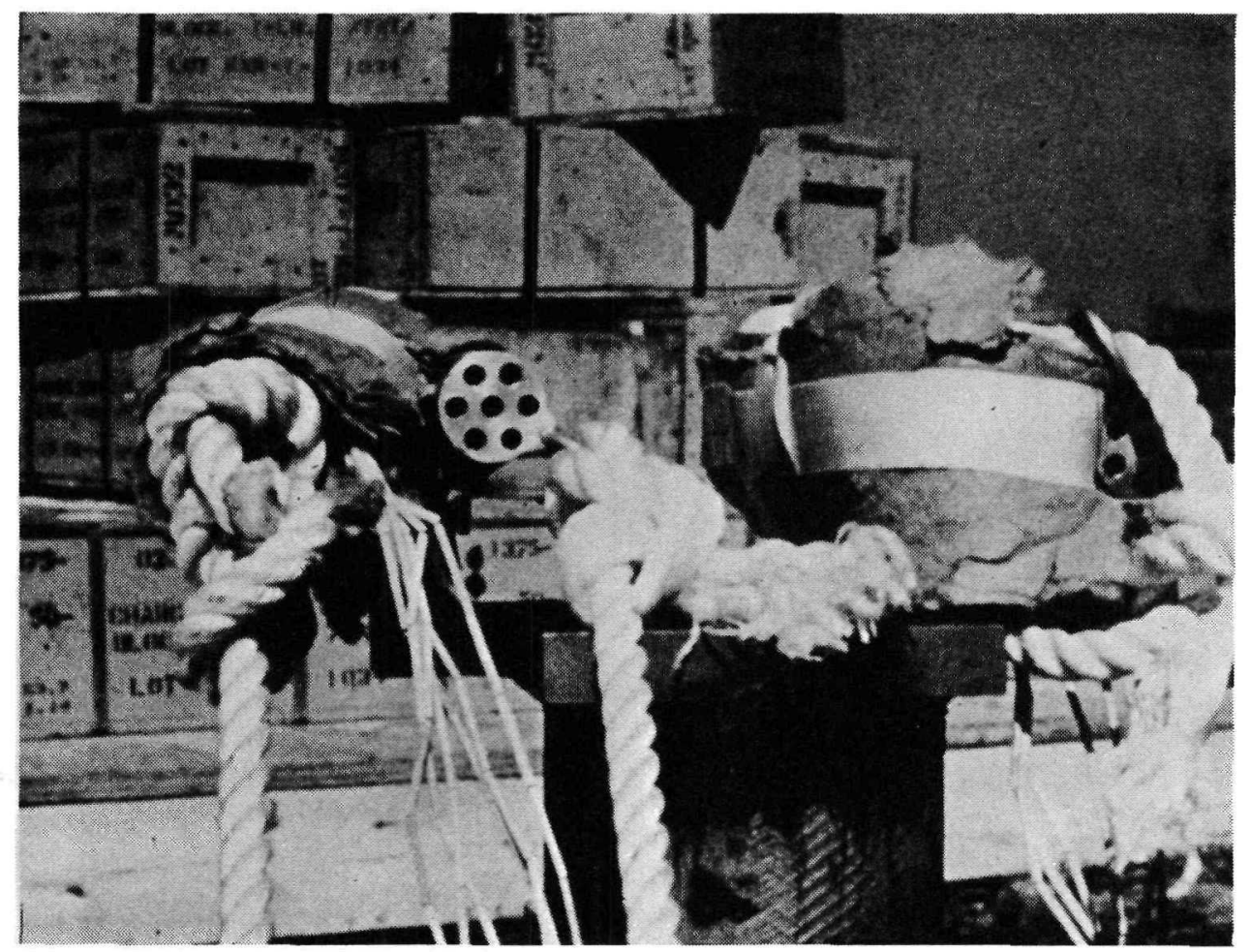

Figure 17. Shock overpressure test

Launch-Pad Fires -- Several tests were conducted to show the effect of a launch-pad fire, in the event of an early abort, on the fuel capsules and generator. Figure 18 shows a test simulating a solid-propellant-fueled missile burning in an erect position. Various types of simulated fuel capsules were exposed to the conflagration in order to show parametrically the integrity of the units in a thermal environment and to determine heat fluxes generated by such an environment.

The information available on full-scale, solid-propellant missile fires at the time of this test was extremely limited. Therefore, the best prediction of a pad thermal environment could only have been made by basing the analysis on a theoretical mode1 consistent with available data. The theoretical model used in the analysis assumed the following:

1. The products of combustion mix perfectly. 
2. The fireball formed during combustion is spherical in shape throughout the time of interest.

3. The size of the fireball and the maximum temperature within the environment is dependent on the expansion of the gases formed during combustion and a heat balance between the environment and the surroundings.

4. The structural materials exposed to the environment have infinite thermal conductivity, i.e., the temperature is uniform throughout the structure.

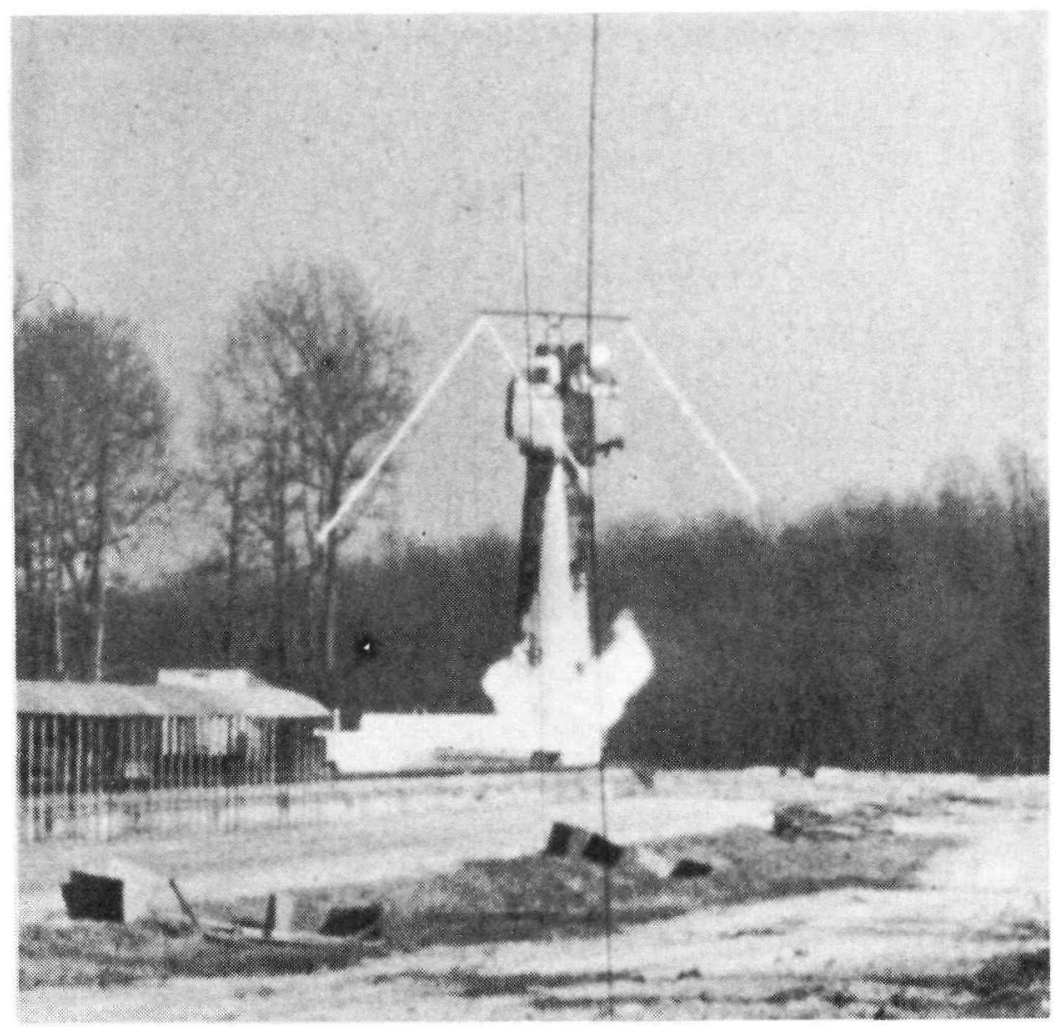

Figure 18. Thermal environment test

A total of 45 specimens simulating various capsule designs and generator systems was used. Each test specimen contained an electrical heater which maintained a heat flux from the specimen to simulate operating conditions. Each specimen also contained a chrome1-alumel thermocouple to record the centerline temperature.

A B-29 aircraft fuselage tail section served as the external container for the test specimens. It was used primarily as a heat sink and a container for the propellants. The tail section was severed immediately forward of the tail gunner's compartment bulkhead to leave an opening sufficiently large to permit the passage of the specimen support structure. The resulting structure was a large, conical fuselage section approximately 45 feet long, 9 feet in diameter at the base, and 43 inches in diameter at the top. It contained approximately 4000 pounds of aluminum and 1000 pounds of other materials. Four vertical rows of holes at 90 degrees to each other were cut in the outer skin of the body to vent the structure and prevent excessive pressure buildup during the test. The holes also provided access to 
the structure to facilitate loading of the propellants and photography of the test. The reworked fuselage was erected with its longitudinal axis vertical and secured in this position by four cables fastened to four steel blocks.

The propellants were 210 pounds of Type MI and 9770 pounds of Type M6. These were contained in burlap bags, each weighing approximately 55 pounds. The prope1lant was ignited by two igniters, each containing 780 grams of black powder and an electric squib. To augment and sustain burning of the propellant and structure, propane gas was released in the test structure for a 30-minute period.

The propellants were ignited without incident and burned to form a massive firebal1 whose shape varied constantly. In the early stages, it took the shape of a sphere. It then moved along the ground and formed a flat cylinder. The maximum fireba11 volume resulted when it reached its maximum horizontal expansion, just before it began to move vertically. The fire continued throughout the test structure for approximately 278 seconds after ignition.

The radiomatic pyrometers showed that the peak temperature of the fireba11, measured at the center of the test assembly, was $2800^{\circ} \mathrm{F}$. The peak temperature measured at the top of the assembly was $2900^{\circ} \mathrm{F}$. (The pyrometer data has been corrected for radiation heat losses, with a value of 0.95 used for the flame emissivity.)

A11 45 specimens subjected to the environment survived the test with damage limited to the fins of the simulated SNAP generators. These were badly warped and partially consumed. Al1 simulated fuel capsules were intact and still capable of containing radioactive fuel.

A study using data from the test specimens was conducted to investigate the thermal flux and temperature of the generated environment.

The thermal flux of the environment surrounding the test specimens varies from 1.35 to $6.80 \mathrm{Btu} / \mathrm{sq} \mathrm{ft}-\mathrm{sec}$ for the duration of the fireba11. An average of the thermal flux for the total number of test specimens was $3.0 \mathrm{Btu} / \mathrm{sq} \mathrm{ft}-\mathrm{sec}$.

The values determined from an analysis of the simulated generators are $5.72 \mathrm{Btu} / \mathrm{sq} \mathrm{ft}-\mathrm{sec}$ during the fireball and $1.95 \mathrm{Btu} / \mathrm{sq} \mathrm{ft}-\mathrm{sec}$ during the period after the firebal1. The maximum temperature of the outer she 11 was $752^{\circ} \mathrm{F}$.

High-Velocity Impact Tests -- Termina1-velocity impact tests were conducted for al of the isotopic SNAP development programs. The tests run for the SNAP-3 and SNAP-9A programs illustrate the test procedure and test results.

Parameters for the test program were established by considering the operation of the launch system. It was determined that the maximum force on the fuel capsule would occur from an abort before orbital injection and with impact at terminal velocity on a rigid material such as granite. These conditions provided the test criteria for the program, and test capsules were impacted against a granite block at a velocity equal to or greater than the terminal velocity of the operating system.

Flight orientations of the generator and fuel capsules considered in this study include tumbling and angles of attack parallel to and perpendicular to the axis of revolution. The maximum velocity of a tumbling fuel capsule was calculated to be approximately $300 \mathrm{fps}$ if impacted 10,000 feet above sea leve1. The peak terminal velocity of the generator was calculated to be approximately 325 fps at a 10,000-foot altitude if oriented para1le1 to the 1ongitudinal generator axis. Therefore, it was concluded that the fuel capsule should be tested for impact resistance at a velocity of $325 \mathrm{fps}$.

The tests showed that the capsule walls and closure plates were indeed capable of withstanding the impact force. The closure welds, however, required some development before a final design could be proved. Modifications made to the capsule during the test program corrected the condition, and five tests of the final configuration were successful. Internal pressure tests on the successful impact capsules showed that the structural integrity of the final configuration was not impaired by the impact. 
Flight Test Program -- An experimental flight test program was conducted as part of the safety analyses of SNAP generators designed for space use. In this program, a series of test specimens simulating components of isotopic generators were placed in ballistic trajectories by ATLAS vehicles. The primary purpose was to verify and improve the methods and techniques used to predict the aerothermodynamic effects on re-entering SNAP devices. An indication of the amount of aerodynamic heating as a function of body shape, size, and mode of entry was sought. Test specimens were designed to yield data on the trajectory, aerodynamic heating, heat distribution, and heat transfer of known bodies.

The test procedure and methods of calculating aerodynamic heating and heat transfer for this program are described in Reference 1. The IBM 7090 digital programs used were so constructed that one digital code complemented the other, i.e., at any time during the re-entry period, the complete thermal history of the body was known. The experiments were also designed to verify this technique, along with the equations and their modifications.

The test specimens, Figure 19, consisted of lead bodies containing alkali metals used as flaring materials to identify the body during re-entry burnup and a larger titanium cylinder containing telemetry equipment. The lead bodies were in four groups, each with a specific wall thickness; the flaring materials were sodium, lithium, rubidium, or cesium (see Table I below). The cylinder, which was designed to survive re-entry, was instrumented so as to monitor the exterior and interior wall temperatures. By judicious placement of transducer sensors, aerodynamic heating rates and mode of entry (tumbling, spinning, and/or stabilized) could be determined.

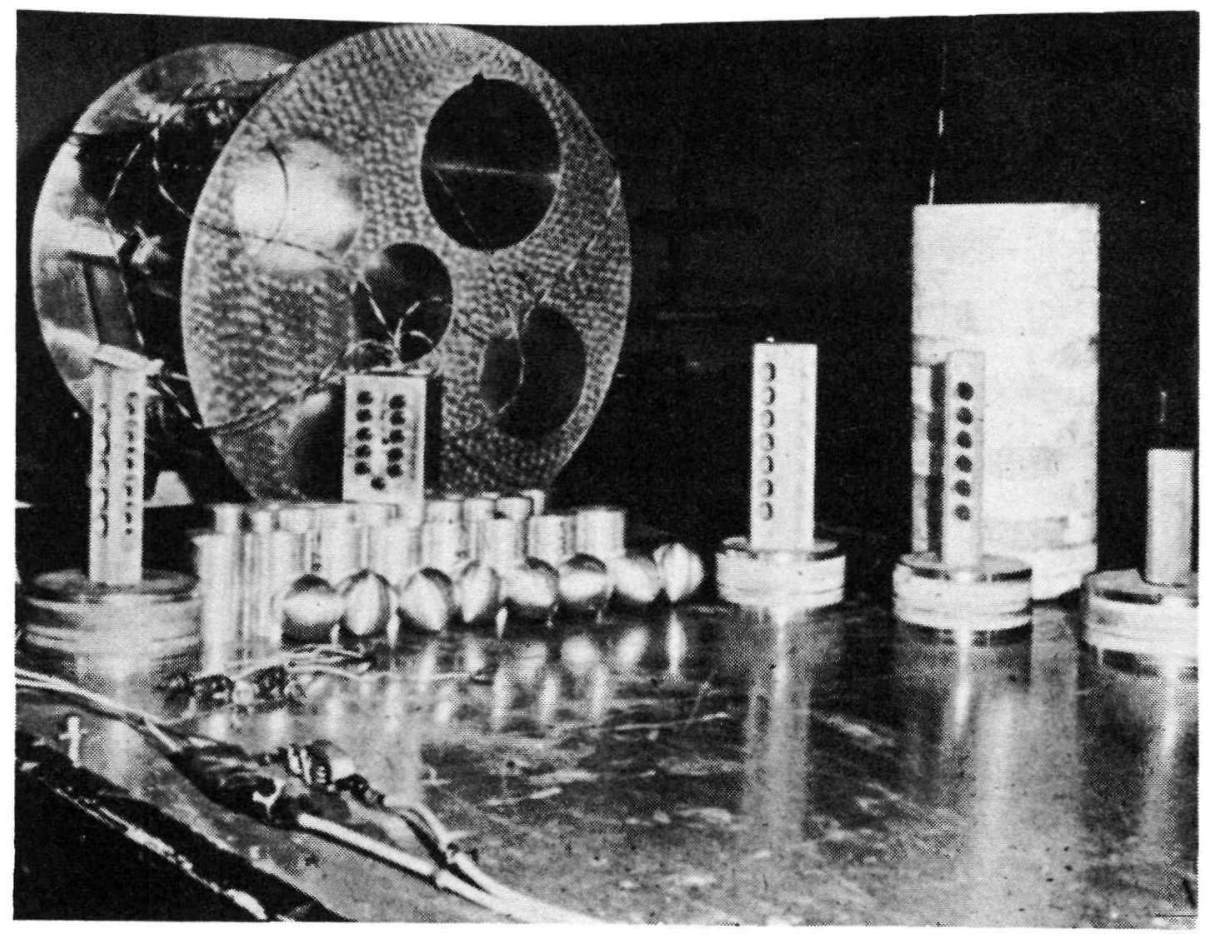

Figure 19. Test specimens and eject mechanism 
Optical, telemetry, and radar equipment located at several stations downrange about the re-entry area were used to acquire and identify the bodies, the altitude of burnup, the trajectory, and the temperature history of the telemetry capsule.

The optical data sought was obtained with almost complete success. Al1 of the test specimens were photographed, and the sodium- and lithium-loaded bodies were positively identified. Rubidium and cesium were identified with less certainty, and their correlation to specific lead bodies is considered only tentative. However, this tentative correlation is corroborated by predicted results. Figure 20 shows the re-entry. The test specimens are the streaks in the lower right corner.

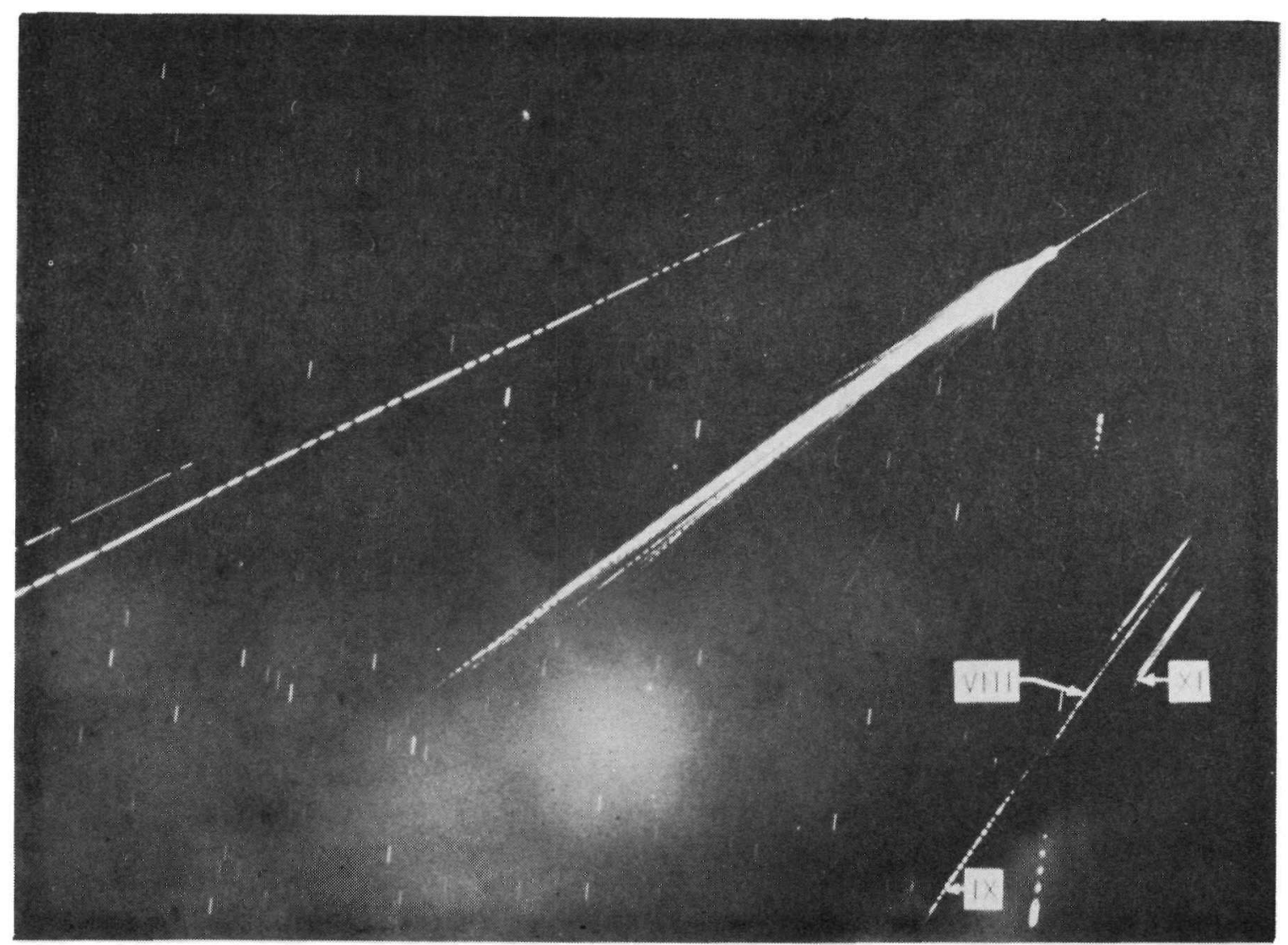

Figure 20. SNAP flight test program - re-entry

No useful telemetry information was obtained. As a result, the mode of entry of the bodies could not be obtained, although some surmises have been made on the basis of the optical data alone.

Before the flight test, a study was performed to predict the altitude of destruction of each lead body as a function of the mode of re-entry. Modes of reentry investigated were as follows:

1. tumbling and spinning,

2. stable, major axis normal to air stream,

3. stable, major axis at 45 degree to air stream, and

4. stable, major axis paralle1 to air stream. 
The best estimate was that the bodies would assume the re-entry mode of the SPP, i.e., with some tumbling in the pitch or yaw plane. The measured altitudes of destruction of the lead bodies best correlates with those predicted for re-entry with little or no tumbling and major axis normal to the air stream (Mode 2). The following table compares the predicted altitudes of destruction of each group of specimens for Mode 2 re-entry with those measured:

TABLE I

Comparison of Predicted and Measured Altitudes

\begin{tabular}{|c|c|c|c|}
\hline \multirow{2}{*}{$\begin{array}{l}\text { Group } \\
\text { No. }\end{array}$} & \multirow{2}{*}{$\begin{array}{c}\text { Specimen } \\
\text { Description }\end{array}$} & \multicolumn{2}{|c|}{ Altitude of Destruction (ft) } \\
\hline & & Predicted & Measured \\
\hline 1 & $\begin{array}{l}\text { Cylinder, wall thickness } \\
\text { of } 0.25 \text { inch, sodium flare }\end{array}$ & 183,000 & $\begin{array}{l}194,000 \text { to } \\
204,000\end{array}$ \\
\hline 2 & $\begin{array}{l}\text { Cylinder, wall thickness } \\
\text { of } 0.375 \text { inch, lithium flare }\end{array}$ & 192,000 & $\begin{array}{l}181,000 \text { to } \\
190,000\end{array}$ \\
\hline 3 & $\begin{array}{l}\text { Cylinder, wall thickness } \\
\text { of } 0.500 \text { inch, rubidium flare }\end{array}$ & 179,000 & $\begin{array}{l}175,000 \text { to } \\
191,000\end{array}$ \\
\hline 4 & $\begin{array}{l}\text { Cylinder, wall thickness } \\
\text { of } 0.625 \text { inch, cesium flare }\end{array}$ & 165,000 & $\begin{array}{l}163,000 \text { to } \\
175,000\end{array}$ \\
\hline
\end{tabular}

Figure 21 shows the predicted altitude of initiation of surface melting of the lead test specimen and of the point of release of the flare material. The heat transfer and ablation analysis assumed uniform ablation of the body wall and, as such, a complete melting of the lead material before exposure of the flare material.

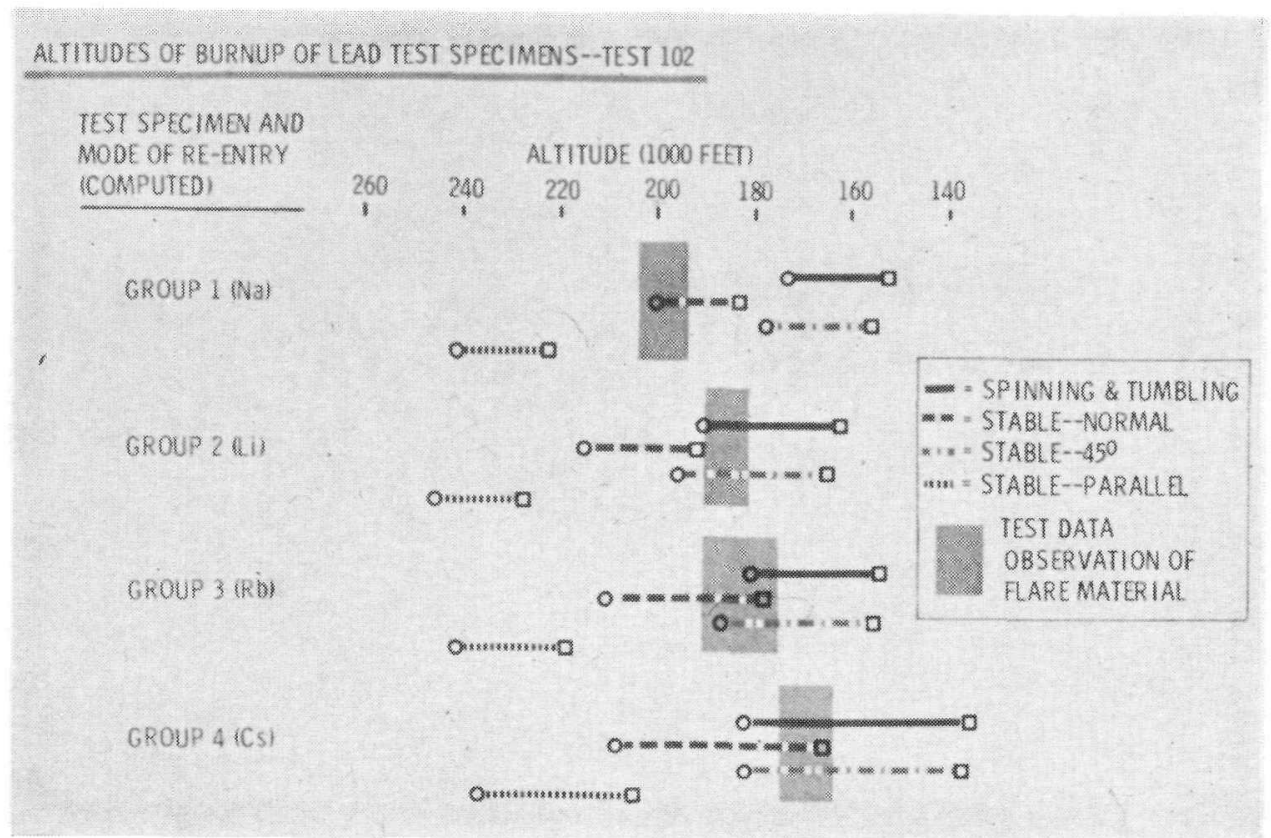

Figure 21. Comparative results 
Also shown in Figure 21 are the optica1ly measured a1titudes of flare ignition. It can be seen that the photographed altitudes of destruction correspond very nearly to the assumed modes of re-entry of a stable body. The analytical procedure used to calculate the point of flare release was as follows:

1. The cylindrical test specimen was assumed to enter relatively stable, with longitudinal axis normal to the air flow.

2. The semi-empirical equations used to compute aerodynamic heating on hemispherical bodies were modified to accommodate the right circular cylinder.

3. The aerodynamic heating was calculated by using the surfaceaveraged technique previously described.

The lack of telemetry data from the instrumented capsule leaves a void in the overall analysis. It can only be concluded that the cylindrical lead test specimens entered in a relatively stable mode and that the longitudinal axes were normal to the air flow. A11 specimens except for the sodium-filled bodies were predicted to be destroyed at altitudes bracketed by those measured. The sodium bodies were predicted to be destroyed at an altitude slightly lower than those measured. But it should be noted that, for these trajectories, the altitude change in 1 second is approximately 8000 feet. Aerodynamic heating for a period of 1 second at the altitude at which the sodium was destroyed is only 2.5 percent of the total integrated heating.

\section{References}

1. W. Hagis, SNAP Programs - Upper Atmosphere Experimenta1 Re-Entry Study Fina1 Summary Report, Martin Company, MND-P-2953, April 1963.

2. W. Hagis, T. J. Dobry, and G. P. Dix, "Nuclear Safety Analysis of SNAP-3 for Space Missions," ARS Journa1, December 1961.

3. T. J. Dobry, SNAP-9A Radioisotope-Fueled Generator - Fina1 Safety Analysis, Martin Company, MND-P-2775-2, March 1963, SRD. 


\title{
NUCLEAR SAFETY OF ADVANCED NUCLEAR SPACE POWER PLANTS NONBOILING LITHIUM-COOLED REACTOR*
}

\author{
D. L. Cochran** \\ J. P. Lehman \\ G. H. Anno \\ Aerojet-General Nucleonics
}

Reactor Description

An advanced space power plant is defined as one requiring a compact, highdensity, high-temperature reactor. These requirements apply particularly to plants with power levels greater than a few hundred kilowatts where (1) a smal1 reactor diameter is necessary for minimum shield weight and (2) high reactor operating temperatures are necessary to achieve a radiator small enough to be practicable. The metallurgical limitations on achievable fuel burnup fraction necessitate a relatively large fuel inventory. For example, production of $300 \mathrm{kw}(\mathrm{e})$ for 10,000 hours with a paak fuel burnup of 5 percent requires a fissile inventory of about $30 \mathrm{kilo-}$ grams for a peak-to-average power ratio of 1.5. These requirements (sma11 size, high temperature, and large fue1 inventory) are best met by a fast-neutron reactor using fully enriched ceramic fuel and refractory metal cladding and structure. Consideration of the method of reactor cooling and possible choice of coolants indicates the use of a nonboiling, lithium-cooled reactor. The selection of a reactor for advanced space power systems is analyzed in detail in Reference 1.

The reactor considered in the analysis presented in this paper is shown in Figure 22. The fuel inventory is approximately $100 \mathrm{~kg}$ of fully enriched uranium carbide pins. The reactor is cooled by nonboiling lithium and operates at a nominal temperature of about $2000^{\circ} \mathrm{F}$. The pressure vessel and other structural components in contact with the lithium are also made of $\mathrm{Cb}-1 \mathrm{Zr}$. This reactor would be suitable as a heat source for an alkali-metal, Rankine cycle, power-conversion system or possibly for an out-of-pile direct conversion system as described in Reference 2 .

The thermal expansion coefficient of UC is greater than Cb-1Zr. Therefore, the fuel pins and core would be designed to accommodate the differential thermal expansion and to achieve a core assembly that had a "solid-body" thermal expansion characteristic. Such a mechanically tight core would eliminate inward bowing of fuel elements which could otherwise cause a positive increase in reactivity. Moreover, a strong negative temperature coefficient of reactivity can be obtained with a core having a mechanically tight, or solid-body, expansion characteristic.

\footnotetext{
*Part of the analysis presented in this paper was performed under Contracts AF 29(601)-5131 and AF 29(601)-5978 sponsored by the Air Force Special Weapons Center, Air Force Systems Command, United States Air Force.

**Presented by Dr. Cochran, now with M. B. Associates.
} 
The core is surrounded by a coolant shroud and is supported by the lower perforated grid plate which is in turn fastened to the pressure vessel. A tungsten reflector gamma-ray shield is placed adjacent to the grid in the lower plenum. The sides and upper end of the pressure vessel are surrounded by a clad beryllium oxide reflector. Reactor control is achieved by adjusting neutron leakage to space through the use of movable "venetian blind" segments of the BeO reflector. The movable reflector segments (control rods) are positioned by shafts connected to control-drive motors placed on the far side of the shield.

An example of a typical vehicle using this reactor is shown in Figure 23. The main condensing radiator is a cylinder; a conical auxiliary cooling radiator is attached to the forward end of the main radiator. The reactor is located at the apex of the vehicle in front of the shadow shield. The power-conversion equipment is located along the centerline of the vehicle with the auxiliary radiator. The payload is stowed within the main radiator for launch but is moved away from the power plant by an extendable boom for operation in space. The overal1 vehicle diameter (with stowed payload) is about 10 feet, and the length is about 40 feet.

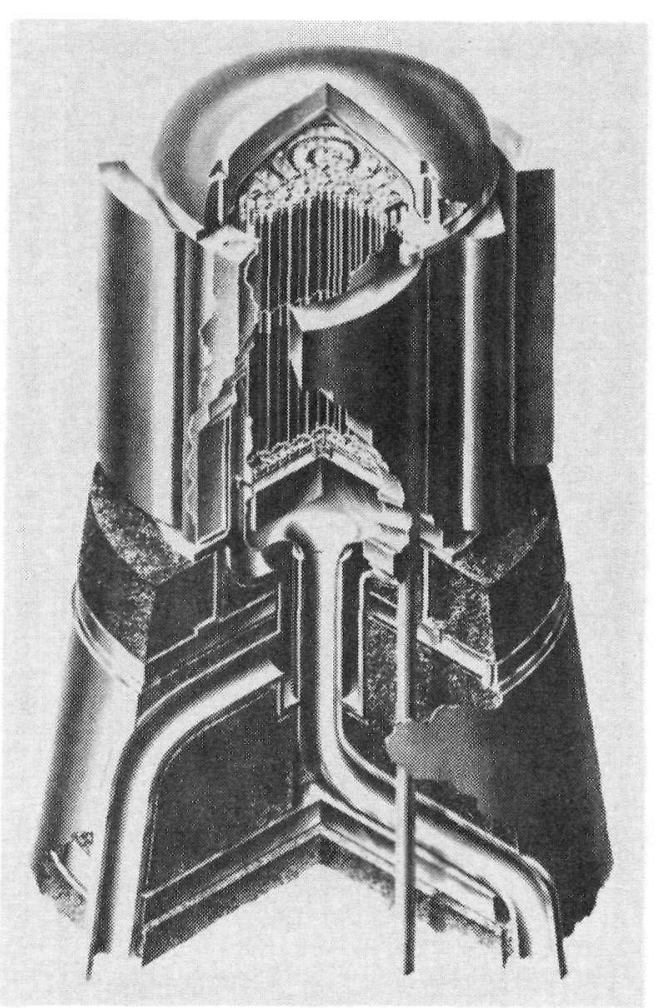

Figure 22. Cutaway of $300 \mathrm{kw}(\mathrm{e})$ reactor

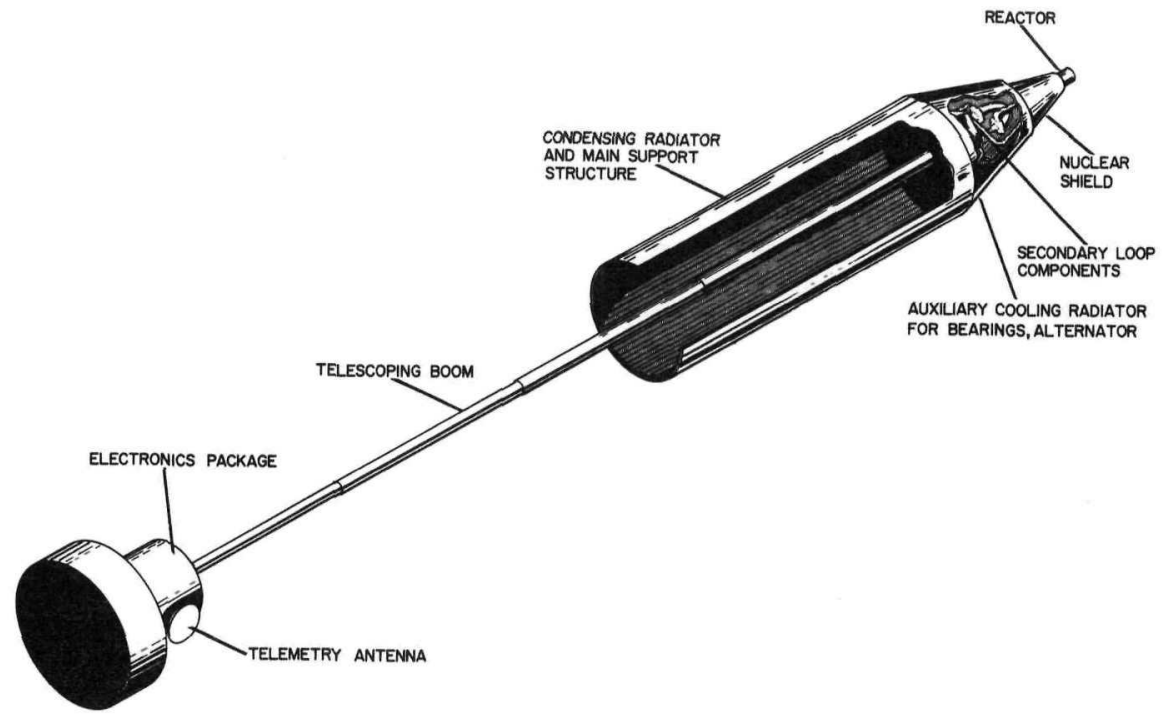

Figure 23. Typical vehicle concept 
Operational Sequence and Possible Accidents

The first step in analyzing possible operational accidents is to postulate a realistic operational sequence. We will assume that the power plant is fully developed and operational and that several or many launchings will take place. Thus, reactor storage, assembly, and checkout facilities are assumed to exist at the launch site.

The assumed operational sequence and corresponding procedures, reactor status, environmental conditions, and possible accidents are summarized below. These accidents are evaluated to establish their relative importance and only major or maximum credible accidents are analyzed in detail.

Transport to Launch Site

A11 components will have been fabricated, inspected, and approved, and a11 major assembly work will have been completed by the power-plant manufacturer. The power-conversion loop could probably be completely assembled and leak checked, although it may be desirable to defer loading the alkali-metal working fluid to prelaunch assembly. The reactor core presents the biggest problem, and it is assumed that the core will only be partially assembled so that no circumstance can cause criticality. This procedure necessitates a launch-site capability for final core assembly and criticality checks. The partially assembled core will be placed in the coolant shroud and surrounded with boral sheet to prevent criticality in the event of accidental water immersion. Note that the manufacturer will probably have made a zero-power, dry-core criticality checkout but no significant fission product radioactivity will be present in the fuel.

Receipt, Inspection, and Storage

Receipt, inspection, and storage will be a standard type of operation, and a11 hazards can be eliminated by proper design of facilities and use of proper procedures.

Assembly and Checkout

The boral sheet will be removed from the core and final core assembly completed. A nuclear excursion would now be possible by, for example, inadvertent closing of the reflectors or over-reflection by hydrogenous materials. Supercriticality during liquid-metal filling could also cause an incident. It is possible to have a positive, negative, or neutral void coefficient of reactivity by proper selection of the Li-6 to Li-7 ratio; however, the possibility of filling with the wrong composition still exists. All the potential accidents in this sequence can be prevented by use of proper procedures, equipment, and facilities. The need for discipline and we11-planned procedure is obvious.

It is assumed that the liquid metals (reactor coolant and power-conversion working fluids) have been loaded before transportation to the launch pad. The entire operation will become more complicated from this point on by the need to keep these metals in the molten state. Liquid metal filling could be postponed until after mating of the power-plant/payload-vehicle with the booster. However, final seal welding and inspection at the launch pad would then be required, and a method of maintaining the working fluids in the molten state would still be required.

\section{Transportation to Launch Pad}

No delicate assembly or adjustment operations are required during transportation to the launch pad, and the reactor will be secured with appropriate safety fixtures. A11 accidents can therefore be prevented by the use of proper transport and handiing equipment. 
Mating Reactor System with Booster

Mating of the reactor system with the booster will be a potentially hazardous step since the power-plant/payload-vehicle must be elevated and mated to the booster. The launch-pad area should be cleared of all unnecessary personnel.

\section{Fina1 Combined Prelaunch Checkout}

The nonflight safety devices will be removed during final combined prelaunch checkout. However, since al1 assembly work will have been completed, the 1ikelihood of a nuclear incident is not necessarily greater than before. An uncontrolled reflector insertion can be postulated, but the probability of its occurrence is extremely remote since great effort will be devoted in the design of the power plant and operating procedures to the avoidance of just such an occurrence; any incident which might be suspect will have been sought out before final checkout. If the mission is canceled, the sequence described thus far would be reversed and the potential hazards or accidents will remain similar to those described.

Launch Liftoff, Pitchover, and Stage Separation

Launch liftoff, pitchover, and stage separation are obviously critical sequences and mission abort can result in possible nuclear incidents. These accidents are discussed in more detail below under "Excursion Yields."

Orbita1 Startup, Mission Operation, and Disposa1

Startup would not be initiated unless it was determined that a satisfactory orbit had been achieved. Since an unmanned mission is being considered, no direct significant radiological consequences will result if an excursion occurs during startup or operation.

The only radiological concern is the possibility of atmospheric or ground contamination resulting from re-entry. A potential re-entry radiation problem exists since it appears that the reactor will not completely burn up during re-entry. This is discussed in greater detail below under "Re-Entry Considerations."

Excursion Yields

\section{Physica1 Properties of Materia1s}

During fast reactor excursions, sufficient energy may be generated to me1t and vaporize the reactor materials. The absolute yield of the excursion is directly related to the energy required to melt and vaporize the core components. Energy requirements are based on the specific heats of reactor materials as a function of temperature and the heats of fusion and vaporization of these materials. A recent search to determine these basic material properties from the literature indicated that such data for temperatures above $900^{\circ} \mathrm{K}$ is very sparse for ceramic fuels such as uranium monocarbide and uranium dioxide and for other materials of interest such as columbium, lithium, and beryllium oxide. It is therefore necessary to use theoretical estimates of physical properties for excursion calculations, and hence the calculational results are no more accurate than these estimates.

Typical thermal properties of reactor materials are given in Table I, and the approximate amounts of these materials used in a fast-spectrum space power reactor are given in Table II. Data from these tables were used to calculate the approximate energies required to melt and vaporize reactor components. The calculated energies are presented in Table III. 
TABLE I

Therma1 Properties of Reactor Materia1s

\begin{tabular}{|c|c|c|c|c|c|}
\hline \multirow[b]{2}{*}{ Property } & \multicolumn{5}{|c|}{ Material } \\
\hline & $\begin{array}{c}\text { (Ref. }{ }^{3)} \\
\mathrm{UO}_{2}\end{array}$ & $\begin{array}{c}(\operatorname{Ref.} 4) \\
\mathrm{UC}\end{array}$ & $\begin{array}{c}(\operatorname{Ref} .5) \\
\mathrm{Cb}\end{array}$ & $\begin{array}{c}(\operatorname{Ref} .6,7) \\
\mathrm{Li}\end{array}$ & $\begin{array}{c}\left(\begin{array}{l}\operatorname{Ref} .6) \\
\text { Beo }\end{array}\right. \\
\end{array}$ \\
\hline Me1ting Point $\left({ }^{\circ} \mathrm{K}\right)$ & 3030 & 2740 & 2700 & 454 & 2820 \\
\hline Boiling Point $\left({ }^{\circ} \mathrm{K}\right)$ & $4500 *$ & $4000 *$ & $5200 *$ & 1600 & $4100 *$ \\
\hline $\begin{array}{l}\text { Heat of Fusion } \\
\text { (cal } / \mathrm{gm})\end{array}$ & 65 & $45 *$ & $70 *$ & 103 & $550 *$ \\
\hline $\begin{array}{l}\text { Heat of Vaporization } \\
\quad(\mathrm{cal} / \mathrm{gm}) \\
\text { Specific Heat } \\
(\text { cal/gm } \mathrm{K})\end{array}$ & $550 *$ & $600 *$ & $1800 *$ & 5060 & $5700 *$ \\
\hline $\begin{array}{l}\text { Solid Phase } \\
\text { Liquid Phase }\end{array}$ & $\begin{array}{c}0.063-0.09 * \\
0.080 \%\end{array}$ & $\begin{array}{c}0.035-0.057 * \\
0.065 *\end{array}$ & $\begin{array}{c}0.064-0.089 * \\
0.086 *\end{array}$ & $\begin{array}{l}0.84-0.94 \\
1.0-0.97 * \\
0.71-0.78 *\end{array}$ & $\begin{array}{c}0.25-0.54 \\
0.64 *\end{array}$ \\
\hline Vapor Phase & $0.075 *$ & $0.054 *$ & $0.096 \%$ & $0.71-0.78 *$ & $0.37 *$ \\
\hline
\end{tabular}

TABLE II

Approximate Amounts* of Materials in Typical Advanced Space Power Reactor

\begin{tabular}{|c|c|c|c|c|}
\hline Region & $\underline{\mathrm{UC}}$ or $\mathrm{UO}_{2}$ & $\underline{\mathrm{Cb}}$ & $\underline{\mathrm{Li}}$ & $\mathrm{BeO}$ \\
\hline Fue1 & 100 & -- & -- & --- \\
\hline Core & 100 & 10 & 1 & -- \\
\hline Reactor & 100 & 50 & 10 & 100 \\
\hline${ }^{*}$ In kilo & & & \multicolumn{2}{|c|}{ Me1t and Vaporize } \\
\hline
\end{tabular}

TABLE III

Approximate Energies* Required to Me1t and Vaporize Reactor Components

\begin{tabular}{|lrc|}
\hline Component & Me1t & Me1t and Vaporize \\
\cline { 2 - 3 } Fue 1 & 60 & 400 \\
Core & 80 & 500 \\
Reactor & 800 & 4500 \\
\hline * In megawatt-seconds & \\
\hline
\end{tabular}

A11 materials in the reactor may not me1t and vaporize during an excursion. Since the energy is generated in the fue 1 and it is possible that the fue 1 will melt and perhaps vaporize before significant amounts of heat are transferred to other materials, the data presented in Table III should be used advisedly, depending on the excursion under investigation. 


\section{Kinetic Equations}

Yie1d calculations for excursions generated by a constant ramp reactivity input depend on evaluation of the following integral:

$$
\mathrm{Q}(\mathrm{t})=\mathrm{P}_{\mathrm{o}} \int_{0}^{\mathrm{t}} \exp \left(\mu \mathrm{t}^{2} / 2\right) \mathrm{dt} \text {, watt-seconds, }
$$

where

$\mathrm{P}_{\mathrm{O}}=$ power at prompt critical $(=0)$, watts

$$
\boldsymbol{\mu}=\frac{1}{\boldsymbol{\ell} * \mathrm{p}} \frac{\mathrm{dk} \mathrm{p}}{\mathrm{dt}}=\frac{\mathrm{d} \boldsymbol{\alpha}}{\mathrm{dt}}
$$

where

$$
\begin{aligned}
\boldsymbol{\alpha}_{\mathrm{p}} & =\text { inverse prompt period }=\Delta \mathrm{k}_{\mathrm{p}} /{ }_{\mathrm{p}}^{\boldsymbol{\ell}} \mathrm{p} \\
\Delta \mathrm{k}_{\mathrm{p}} & =\text { excess reactivity above prompt critical } \\
\boldsymbol{\ell}_{\mathrm{*}} \mathrm{p} & =\text { prompt neutron lifetime. }
\end{aligned}
$$

There is no known solution of Eq. (1) in closed form. Jahnke and Emde ${ }^{8}$ tabulate values of the integral for small values of the argument, but it was found that the region of interest lies beyond the Jahnke and Emde values. Argonne Nationa1 Laboratory presents the following approximate solution to Eq. (1) in the EBR-II hazards report.

$$
Q(t)=P_{0} \frac{\exp \left(\mu t^{2} / 2\right)}{\mu t}\left[1+\frac{1}{\mu t 2}+\cdots \cdots \cdot\right]
$$

Fortunately, Eq. (3) becomes a valid approximation of the integral at approximately the same value of $t$ which corresponds to the maximum argument 1 isted in the Jahnke and Emde table.

\section{Neutronic Parameters}

Space power reactors have a potential for very large reactivity insertion rates because of the high velocities associated with missile aborts either on or above the launch pad. Rates on the order of 1000 dollars per second are possible from water immersion or earth impact following a fall of about 100 feet to the pad or its environs. These rates are approximately a factor of 10 higher for a downrange impact at terminal velocity.

The inverse reactor period is directly proportional to reactivity addition and inversely proportional to the reactor system neutron lifetime. Reactivity addition is approximately the same for water immersion or earth impact. However, the system neutron lifetime is increased by about a factor of 10 and the inverse prompt period is decreased by about the same factor when the reactor is immersed in a hydrogenous medium such as water or certain rocket propellants. Thus, for a given reactivity increase, the resultant excursion will be much less rapid upon immersion in hydrogenous material than for the basic reactor in the same reactivity state. 
Yield Calculation Method

The method for nuclear yield calculations roughly follows that given by Brittan, et a1., in the ZPR-III hazards report. ${ }^{10} \mathrm{Calculations}$ were made of the energy generation for two different assumptions: (1) for very fast excursions, no significant core movement occurs before fuel melting and vaporization, and the nuclear shutoff mechanism is assumed to be an essentially constant-volume pressure buildup after fuel vaporization, followed by rapid adiabatic expansion to relieve the pressure; and (2) negative reactivity feedback occurs before meltdown and vaporization because of axial movement of the fuel elements. The second assumption is based on calculations which show that some fuel element movement takes place even for very fast excursions, but primarily in the axial direction. Fuel vaporization may still be the ultimate shutdown mechanism if the negative feedback is not sufficient to overcome external reactivity insertion.

\section{Nuclear Yie1d}

The nuclear yield from an excursion will vary depending upon the reactivity insertion rate, the system neutron lifetime, and the negative feedback assumption. (For a given accident, negative feedback reduces yield by about a factor of 3 .) Space power reactor excursions possible during launch operations can be grouped into three general categories: (1) reactor control malfunctions in which reactivity is added slowly and which could result in partial melting of the core, (2) booster aborts on the launch pad which cause the reactor to fall from the top of the booster to the pad, resulting in rapid reactivity insertion and perhaps in partial vaporization of the fuel, and (3) booster aborts above the pad or downrange causing the reactor to fall with terminal velocity, resulting in very rapid reactivity insertion and perhaps in total core vaporization. Each of the general excursion categories can be characterized by the approximate energy release and by the fission product release fractions given in Table IV.

TABLE IV

Genera1 Excursion Categories

\begin{tabular}{|c|c|c|c|c|c|}
\hline \multirow[b]{2}{*}{ Category } & \multirow{2}{*}{$\begin{array}{l}\text { Approximate Energy } \\
\text { Release (mw-sec) }\end{array}$} & \multirow[b]{2}{*}{ Core State } & \multicolumn{3}{|c|}{$\begin{array}{l}\text { Assumed Fission } \\
\text { Product Release Percentages }\end{array}$} \\
\hline & & & Volatile & Particulate & Tota1 \\
\hline A & 50 & $\begin{array}{l}\text { Partially } \\
\text { melted }\end{array}$ & 50 & 1 & 11 \\
\hline B & 100 & $\begin{array}{l}\text { Partially } \\
\text { vaporized }\end{array}$ & 100 & 50 & 60 \\
\hline $\mathrm{C}$ & 1000 & Vaporized & 100 & 100 & 100 \\
\hline
\end{tabular}

In this analysis, the volatile fission products are assumed to be composed of bromine, iodine, xenon, and krypton. Their collective fraction of the total activity actually varies between about 13 to 28 percent, depending on the time after an excursion. For this analysis, 20 percent was assumed as the volatile fraction.

\section{Chemical Yield}

Many chemical reactions are possible between the reactor components and $\mathrm{O}_{\mathbf{z}}$, $\mathrm{N}_{\mathrm{a}}$, and $\mathrm{H}_{\mathbf{a}} \mathrm{O}$ if the components are ejected into the atmosphere by a nuclear excursion. It was found that the sum of the heat released from all the chemical reactions can be of the same order as, or even exceed, the nuclear yield. Hence, chemical reactions following a nuclear excursion must be considered when analyzing the effects of such excursions. 
Operation of a nuclear space power system includes the responsibility of protecting human beings from potentially hazardous amounts of ionizing radiation. To satisfy this responsibility, the hazards must first be identified; secondly, a clear definition of the potential hazards must be maintained throughout the program; and finally, constant attention must be given to methods of ensuring that operation of the system will not constitute a general health hazard and will not result in exposure of operations personnel to radioactivity beyond the maximum safe degree in the event of an accident or malfunction.

After identification, clear definition of the potential radiological hazards depends upon (1) suitable determination of radiation exposures and (2) comparison of the exposures with applicable radiation standards. This allows the relationship of the potential hazards versus distance, one of the most important aspects of operational safety planning, to be determined.

\section{Radiation Protection Standards}

Application of the proper Radiation Protection Guides (RPG's) depends upon (1) the circumstances (accidental or norma1); (2) the population (radiation workers or members of the general population); and (3) the nature of the exposure (external or interna1). Protection during launch of the type of system considered here consists of the designation and use of criteria which will provide a reasonable margin of safety to individuals involved in the operations and to the general population in the event of a nuclear accident. Assuming that a11 possible safety countermeasures, both in the system and in operations, have been taken to prevent inadvertent criticality, nuclear accidents because of system malfunction should be extremely rare, and, for planning purposes, they may be considered as emergency situations.

Formal RPG's designated specifically for application in emergency situations have not been issued by the Federal Government to date, although the National Committee on Radiation Protection (NCRP) ${ }^{11}, 12$ and the AEC ${ }^{13}$ both discuss emergency radiation levels which provide some guidance. This paper, however, indicates exclusion distances around the system at the launch site based on the emergency criteria indicated under "Emergency" below.

Even though the occurrence of nuclear accidents in the vicinity of the launch site may be recognized as an emergency situation, it seems reasonable to plan operations under the requirement that the general public will not acquire exposures in excess of those allowed by the Federal Radiation Council (FRC) ${ }^{\mathbf{1 4}},{ }^{15}$ for peacetime operations. Therefore, a second set of exclusion radii is indicated in this paper based on the computed consequences of the assumed accidents in conjunction with the RPG criteria given under "General Population," below.

Emergency -- A number of types of exposures have been calculated for the postulated accidents. In order to lend some perspective to operational planning, it is necessary to designate safety criteria which may be used in developing exclusion radii about an accident point. At this time, some of these criteria can be stated in accordance with the fairly good agreement among the agencies closely concerned with these matters; other criteria may not even exist on a formal basis. The analysis of hazards in this paper has used the emergency guide levels of radiation exposure given in Table $\mathrm{V}$. 
TABLE V

Emergency Dose Levels ("One Shot" Exposure)

\begin{tabular}{|lc|}
\hline \multicolumn{1}{|c|}{ Type of Exposure } & Dose, rem \\
Total whole body & 25 \\
Thyroid & 300 \\
Skin beta-ray & 500 \\
Gastrointestinal tract & 25 \\
Lung & $50 \%$ \\
Bone & 45 \\
\hline * Reference 16 & \\
\hline
\end{tabular}

Genera1 Population -- The FRC's RPG 14,15 criteria for the general population during peacetime operations are listed in Table VI below; these were used in evaluating the potential hazards to the general public.

TABLE VI

FRC Radiation Protection Guides for Population Groups During Normal Peacetime Operations

\begin{tabular}{|lcccc|}
\hline Type of Exposure & Exposure Period & & \multicolumn{2}{c|}{ RPG Dose Limit (rem) } \\
\cline { 2 - 4 } & 1 year & & $\frac{\text { Andividual }}{0.17}$ \\
Whole body & 30 years & - & 5.0 \\
Gonads & 1 year & 1.5 & 0.5 \\
Thyroid & 1 year & 0.5 & 0.17 \\
Bone marrow & 1 year & 1.5 & 0.5 \\
Bone & & & 0.5 \\
\hline
\end{tabular}

In addition to the RPG for the general population given in Table VI, the FRC ${ }^{15}$ gives additional guides in terms of daily uptake levels of certain radioisotopes which can be related to contamination of open water supplies, grazing lands, or crop vegetation.

\section{$\underline{\text { Radiation Exposures }}$}

The environmental consequences from the accident categories given in Table IV above (indicated by $\mathrm{A}, \mathrm{B}$, and $\mathrm{C}$ ) are determined by calculating the following:

Total whole body dose (prompt neutron and gamma-ray plus cloud gamma-ray)

Skin beta-ray dose

Thyroid gland dose

Lung dose

Gastrointestina1 tract dose

Bone dose

Fallout gamma-ray dose (8-hour residence time after fallout)

Fa11out I-131 contamination

Prompt Neutron and Gamma-Ray Dose -- The prompt neutron dose is based on a reactor neutron leakage spectrum determined from TDC computations. ${ }^{17} \mathrm{~A} 1 / \mathrm{r}^{2} \mathrm{rela-}$ tionship and exponential attenuation in air were used to estimate the fast neutron 
dose as a function of distance from the reactor. A value of about 210 meters ${ }^{18}$ was assumed for the fast neutron mean free path in air.

Prompt gamma-ray dose is based on computations using six gamma-ray energy group core leakage and exponential attenuation and dose buildup in air. $\mathrm{A} 1 / \mathrm{r}^{2}$ geometric relationship was also assumed in estimating the gamma-ray dose.

Fission Product Exposure -- Exposures that result from fission-product release to the environment are determined in this paper by performing cloud dispersion calculations which assume a point release at ground level with depletion from fallout based on Chamberlain's method ${ }^{19}$ of adapting Sutton's equations ${ }^{20}$ to dry fallout deposition. A value of $0.01 \mathrm{~m} / \mathrm{sec}$ was assumed for the deposition velocity, $\mathrm{V}_{\mathrm{g}}$.

Lapse, neutra1, and inversion meteorological conditions are used to estimate the atmospheric dispersion hazards based on Sutton's methods. These three conditions correspond to those given by Hilsmeier and Gifford ${ }^{2}$ as moderately unstable (B), neutral (D), and moderately stable (F).

External Cloud Dose -- Estimates of cloud gamma radiation are based on determinations made with the aid of the graphical methods presented in Reference 22 . This assumes an average gamma-ray decay energy of $0.7 \mathrm{mev}$ from mixed fission products. The cloud doses reflect the source release fractions given in Table IV.

The beta irradiation dose delivered primarily to the skin layers from cloud passage is calculated by assuming that an individual is immersed in a cloud of radioactive material of concentration $\mathrm{X}$. Integrating the concentration over an effective limit of the cloud volume about a detector (determined by the maximum beta-ray range in air) and the time of cloud passage yields the beta-ray dose, i.e.,

$$
D_{\beta}(r)=\int_{t} \int_{V} x(r, t) J\left(r^{\prime}\right) d V\left(r^{\prime}\right) d t, \text { rem }
$$

where

$$
\begin{aligned}
\mathrm{X}(\mathrm{r}, \mathrm{t})= & \text { cloud concentration, curies } / \mathrm{m}^{3} \\
\mathrm{~J}\left(\mathrm{r}^{\prime}\right)= & \text { point source dose rate function for air including geometric } \\
& \text { and material radiation attenuation given by Hine and } \\
& \text { Brownel1 } 11^{23} \text { (rad/sec-curie) } \\
\mathrm{V}= & \text { cloud volume of integration, } \mathrm{m}^{3} .
\end{aligned}
$$

Assuming a maximum effective beta-ray decay energy of 1.0 mev for mixed fission products yields the following relationship:

$$
\mathrm{D}_{\beta}(\mathrm{x})=0.307 \mathrm{~T}(\mathrm{x}) \mathrm{Q}_{\beta}(\mathrm{x}) \text {, rem }
$$

where

$$
\begin{aligned}
\mathrm{x}= & \text { distance downwind } \mathrm{m} \\
\mathrm{T}(\mathrm{x})= & \text { total integrated exposure obtained for RISC code }{ }^{24} \\
& \text { calculations, c-sec } / \mathrm{m}^{3} \\
\mathrm{Q}_{\beta}(\mathrm{x})= & \text { beta-ray cloud activity, }{ }^{25} \text { curies. }
\end{aligned}
$$

Internal Exposures -- The doses to several body organs and tissues from the inhalation of released radioactive material were computed with the RISC code for an assumed breathing rate of $3.4 \times 10^{-4}$ cubic meters per second. In this code, the exposure to a given body organ or tissue from more than one type of radionuclide, which is dependent upon the intake concentration and activity, is computed by multiplying three matrices together to obtain a dose matrix, as follows: 
where
[D] = dose matrix (distance $\mathrm{x}$ organ)
$[\mathrm{T}]=$ tota1 integrated exposure matrix (distance $\mathrm{x}$ exposure)
$[I]=$ isotope source term matrix (distance $\mathrm{x}$ isotope)
$[\mathrm{F}]=$ isotope conversion matrix (isotope $\mathrm{x}$ organ)

The internal exposures calculated for the thyroid, lungs, gastrointestinal tract, and bone represent the doses which would be accumulated over the first year period after body intake, based on the computational methods of Morgan, et a1. 26,27, 28 The internal exposures are based on the potential release of 38 fission-product radioisotopes, individually summarized in Table VII, for the three accident categories described in Table IV.

TABLE VII

Fission Product Release

Initial

$\underline{\text { Radioisotope }}$

La -143

$\mathrm{Ce}-143$

Pr-143

$\mathrm{Ce}-144$

$\mathrm{Ba}-141$

La-141

$\mathrm{Ce}-141$

Ba-140

La-140

Cs -137

I -135

$\mathrm{Te}-134$

I-134

$\mathrm{I}-133$

$\mathrm{Te}-132$

I-132

$\mathrm{Te}-131$

I-13I

$\mathrm{Te}-129$

Te-129*

Ru-106

$\mathrm{Ph}-105$

Mo-99

Zr-95

$\mathrm{Y}-93$

$\mathrm{Rb}-92$

Sr -92

$\mathrm{Rb}-91$

Sr-91

$\mathrm{Y}-91$

Sr -90

$\mathrm{Y}-90$

$\mathrm{Kr}-89$

$\mathrm{Rb}-89$

Sr-89

$\mathrm{Np}-239$

$\mathrm{Y}-92$
Inventory, curies

per mw-sec

$2.92 \times 10^{1}$

$1.47 \times 10^{-2}$

$1.48 \times 10^{-6}$

$1.35 \times 10^{-3}$

$2.27 \times 10^{1}$

$1.7 \times 10^{-1}$

$8.46 \times 10^{-1}$

$3.27 \times 10^{-2}$

$1.21 \times 10^{-2}$

$3.7 \times 10^{-5}$

1.52

$1.57 \times 10^{1}$

1.50

$5.07 \times 10^{-2}$

$8.64 \times 10^{-3}$

$1.41 \times 10^{-1}$

$1.13 \times 10^{1}$

$2.52 \times 10^{-4}$

$2.63 \times 10^{-1}$

$1.43 \times 10^{-3}$

$7.22 \times 10^{-5}$

$4.06 \times 10^{-2}$

$1.47 \times 10^{-1}$

$6.24 \times 10^{-3}$

1.03

$3.36 \times 10^{2}$

$8.11 \times 10^{-1}$

$3.99 \times 10^{2}$

$6.34 \times 10^{-2}$

$\sim 0$

$3.82 \times 10^{-5}$

$\sim 0$

$1.15 \times 10^{2}$

6.49

$8.04 \times 10^{-6}$ $\sim 0$

$4.51 \times 10^{-2}$

\begin{tabular}{|c|c|c|}
\hline \multicolumn{3}{|c|}{ Fraction Released } \\
\hline $50 \mathrm{mw}-\mathrm{sec}$ & $100 \mathrm{mw}-\mathrm{sec}$ & $1000 \mathrm{mw}-\mathrm{sec}$ \\
\hline 0.01 & 0.05 & 1.0 \\
\hline 0.01 & 0.05 & 1.0 \\
\hline 0.01 & 0.05 & 1.0 \\
\hline 0.01 & 0.05 & 1.0 \\
\hline 0.01 & 0.05 & 1.0 \\
\hline 0.01 & 0.05 & 1.0 \\
\hline 0.01 & 0.05 & 1.0 \\
\hline 0.01 & 0.05 & 1.0 \\
\hline 0.01 & 0.05 & 1.0 \\
\hline 0.1 & 0.80 & 1.0 \\
\hline 0.5 & 1.0 & 1.0 \\
\hline 0.5 & 1.0 & 1.0 \\
\hline 0.5 & 1.0 & 1.0 \\
\hline 0.5 & 1.0 & 1.0 \\
\hline 0.5 & 1.0 & 1.0 \\
\hline 0.5 & 1.0 & 1.0 \\
\hline 0.5 & 1.0 & 1.0 \\
\hline 0.5 & 1.0 & 1.0 \\
\hline 0.5 & 1.0 & 1.0 \\
\hline 0.5 & 1.0 & 1.0 \\
\hline 0.02 & 0.6 & 1.0 \\
\hline 0.01 & 0.50 & 1.0 \\
\hline 0.01 & 0.50 & 1.0 \\
\hline 0.01 & 0.50 & 1.0 \\
\hline 0.01 & 0.50 & 1.0 \\
\hline 0.01 & 0.50 & 1.0 \\
\hline 0.01 & 0.50 & 1.0 \\
\hline 0.01 & 0.05 & 1.0 \\
\hline 0.01 & 0.05 & 1.0 \\
\hline 0.01 & 0.05 & 1.0 \\
\hline 0.01 & 0.05 & 1.0 \\
\hline 0.01 & 0.05 & 1.0 \\
\hline 0.5 & 1.0 & 1.0 \\
\hline 0.01 & 0.5 & 1.0 \\
\hline 0.01 & 0.5 & 1.0 \\
\hline 0.01 & 0.5 & 1.0 \\
\hline 0.01 & 0.5 & 1.0 \\
\hline
\end{tabular}


Fallout -- Using the RISC code, computations of fallout were performed in order to estimate the gamma radiation exposure from ground contamination of mixed fission products and also the I-131 levels.

Contamination Dosage -- The fallout is estimated based on Chamberlain's methods ${ }^{29}$ by the following relationship for ground releases:

$$
F_{\gamma}(x, t)=Q_{\gamma}(t) T(x) V_{g} \exp -\left(\frac{4 v_{g} x^{n / 2}}{n \bar{u} \sqrt{\pi} C_{z}}\right), \text { curie } / m^{2}
$$

where

$$
\begin{aligned}
\mathrm{Q}_{\gamma}(\mathrm{t}) & =\text { gamma-ray activity contained in the cloud, curies } \\
\mathrm{T}(\mathrm{x}) & =\text { total integrated exposure, } \mathrm{sec} / \mathrm{m}^{3} \\
\mathrm{~V}_{\mathrm{g}} & =\text { deposition velocity, } \mathrm{m} / \mathrm{sec}
\end{aligned}
$$

Assuming a gamma-ray dose-rate value of $10 \mathrm{r} / \mathrm{hr}^{12}$ at 3 feet above a ground surface contaminated with 1 curie $/ \mathrm{m}^{2}$ of mixed fission products, the initial fallout dose rate at a downwind distance $x$ from the release is given as:

$$
R(x, t)=10 F(x, t), r / h r
$$

The dose at $x$ that would be accumulated (at the 3-foot reference) 8 hours following the initial deposition is given by

$$
D(x)=\int_{\underline{\underline{x}}}^{8 \mathrm{hr}} R(x, t) d t, r
$$

Radioiodine -- The I-131 fallout contamination of the ground surface as a function of distance downwind from the radioactive fission product release was obtained from RISC code computations using essentially the same relationship as that for the gamma radiation in Eq. 7, except that the source activity was that of I-131 as a function of time after the accident.

\section{Summary}

The distances beyond which the exposure guide levels for the genera1 population and emergency situations are not exceeded for the three accident categories given in Table IV and three meteorological conditions are summarized in Table VIII.

Evaluation of the hazards for the worst accident case (1000 mw-sec excursion, inversion weather) indicates environmental dose levels to be below the general population exposure guides at distances beyond about 3 miles downwind from the accident. This is based on exposure to the thyroid. For this same accident, indications are that emergency exposures would not be encountered by unprotected individuals located beyond about 2100 feet directly downwind. This is based on the whole-body, cloud gamma-ray exposure and prompt neutron and gamma-ray dose from the reactor. 
TABLE VIII

Exposure Distances from Reactor, Meters

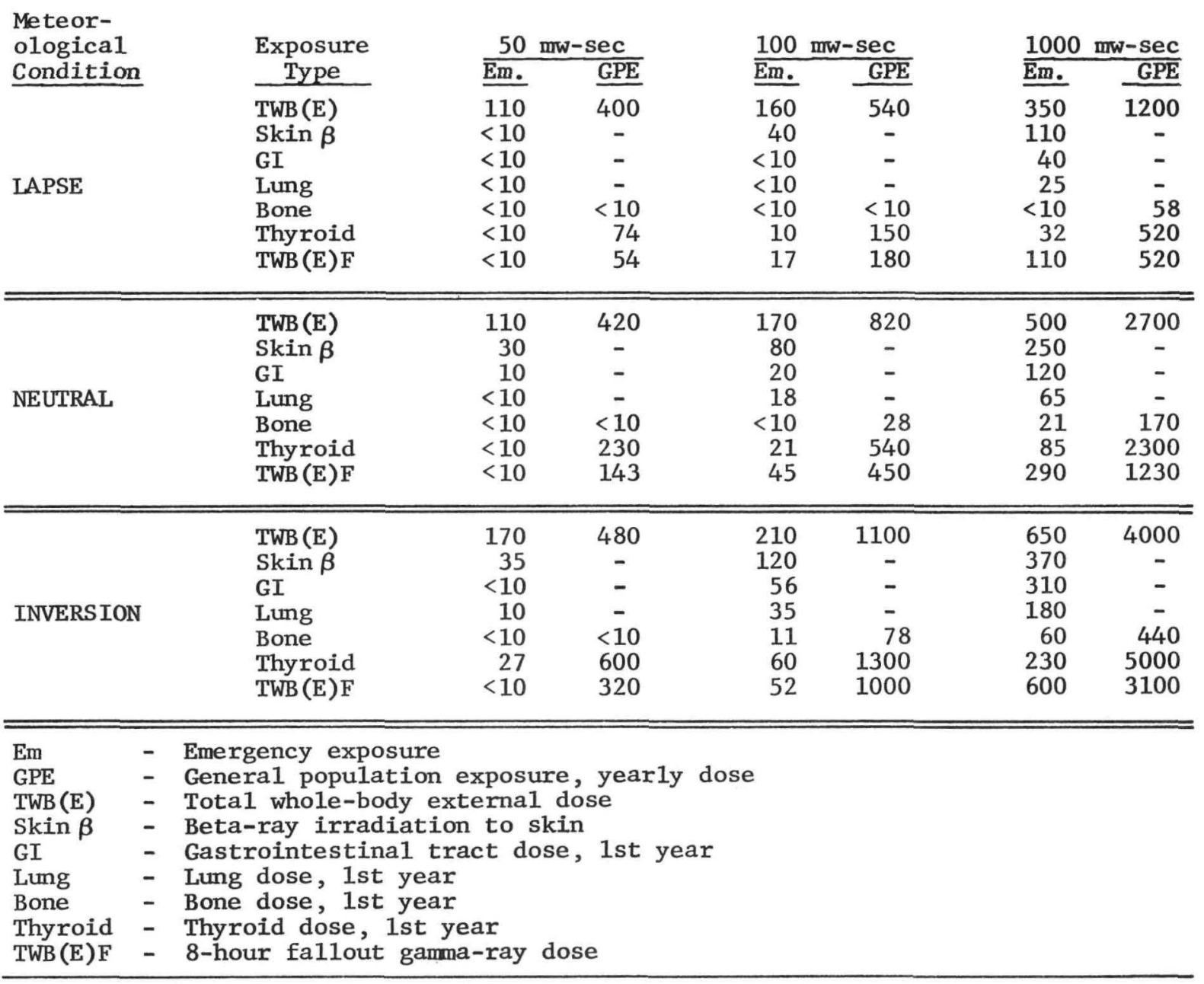

The occurrence of a $1000 \mathrm{mw}-\mathrm{sec}$ excursion in the vicinity of the launch site is extremely improbable in comparison to the possible chance occurrence of excursions yielding much smaller energy releases. This is because of the large impact velocity (about 700 feet per second) required to initiate such large energy releases; the associated impact point would ordinarily be downrange sufficiently far that local hazards are not created.

As indicated above in the section on excursion yields, impact velocities of about 100 feet per second could initiate nuclear accidents at the launch stand for this system yielding about $100 \mathrm{mw}-\mathrm{sec}$. For such an accident assumed to occur under stable meteorological conditions, exposures to the thyroid beyond about 4300 feet downwind would be less than the genera1 public RPG; emergency whole-body exposures would not be encountered by unprotected individuals beyond a distance of about 700 feet downwind from the accident.

The least severe class of nuclear accidents, associated with control system failures, which yield about $50 \mathrm{mw}-\mathrm{sec}$, would not produce emergency whole-body exposures beyond about 400 feet, and the general population RPG for the thyroid would not be exceeded beyond about 2000 feet. 
It is difficult to assess the significance of the computed iodine (I-131) fallout levels, since many assumptions and inferences must be made. Environmental conditions such as the ground surface texture and humidity and the exact chemical and physical form of the iodine determine the deposition velocity; these effects are not included in this analysis.

Moreover, in relating the fallout contamination to body intake quantities which can be compared to the FRC uptake guides for the general population, a transfer relationship must be assumed which may vary quite widely. Therefore no sound assessment of the potential I-131 contamination hazards based on this analysis can be made. On the basis of certain assumptions, however, this analysis does suggest that radioiodine contamination of grazing lands may require surveillance to distances in excess of those given in Table VIII; this assumes a deposition velocity of $0.01 \mathrm{~m} / \mathrm{sec}$, a milk transfer relationship of $0.091 \mu \mathrm{c} / 1$ iter of milk per $\mu \mathrm{c} / \mathrm{m}^{2}$ of grazing land contamination, ${ }^{29}$ and infant consumption of 1 liter of milk per day.

\section{Re-Entry Considerations}

Typically, earth satellite lifetimes at various altitudes range from days at 110 miles and months at 150 miles to tens of years at 600 miles and centuries at 1000 miles. Thus, the user of near-earth nuclear powered satellites or space vehicles must consider the potential radiological hazard which is present when the satellite or vehicle eventually re-enters the earth's atmosphere. The two main aspects of this problem are the reactivity level at the time of re-entry and the burnup characteristics of the reactor. A potential hazard does exist with the present advanced power plant under consideration because substantial quantities of about eight very long lived and biologically significant radioactive isotopes are produced during operation, and it does not appear that the reactor fuel elements will burn up during re-entry. Methods to eliminate this potential hazard or nullify its effects are required.

\section{Radioactivity Levels}

The concentration of a given radioactive species at any time $t$ is given approximately by the expression,

$$
\mathrm{n}_{i}(t)=\frac{\mathrm{T}_{i \frac{1}{2}} \boldsymbol{\Phi} \Sigma_{i}}{0.693}\left[1-\mathrm{e} \exp \left(-0.693 \frac{t}{\mathrm{~T}_{i \frac{1}{2}}}\right)\right]
$$

where

$$
\begin{aligned}
\mathrm{n}_{i} & =\text { number density of species }(i) \\
\boldsymbol{\phi} & =\text { average neutron flux } \\
\Sigma_{i} & =\text { flux averaged cross section for production of } \\
\mathrm{T}_{i \frac{1}{2}} & =\text { species half-1ife. }
\end{aligned}
$$

Species with half-lives that are short compared to the time of operation (for example $I-131$ with $T_{\frac{1}{2}}=8.08$ days) will reach equilibrium early in the power plant life ( $10^{4}$ hours). ${ }^{4}$ However, long-lived species such as $\mathrm{Sr}-90\left(\mathrm{~T}_{\frac{1}{2}}=27.7\right.$ years) continue to increase in concentration almost linearly throughout the lifetime of the power plant. Thus, the length of the power plant operating time has an important effect on the potential re-entry radiological hazard.

It is beyond the scope of this paper to consider many possible cases. However, the problem can be clearly defined by considering normal shutdown after 
10 hours of operation, i.e., a normal mission. The decay of 37 biologically significant isotopes in terms of curies/mw-sec of operation is shown in Table IX for decay times ranging from 0.1 to $10^{4}$ hours. The distribution of isotopes corresponds to about $10^{4}$ hours of operation. About one-half of these isotopes decay to insignificant levels in 300 to 500 hours. After 100 hours, I-134 and I-135 are no longer significant compared to I-131, I-132, and I-133. After 1000 hours, only I-131 has an. appreciable activity. The thyroid contributors (i.e., the iodine isotopes) are comparatively insignificant after about 10,000 hours decay.

After 10,000 hours of decay, only the following 8 of the 37 isotopes show significant activity (greater than 1 microcurie/mw-sec): Ru-106, Ce-144, Cs-137, $\mathrm{Zr}-95, \mathrm{Sr}-89, \mathrm{Sr}-90, \mathrm{Y}-90$ and $\mathrm{Y}-91$. Consequent1y, the 8 isotopes above have activities greater than 100 curies after 10,000 hours of decay. Important bone seekers among the above isotopes are Sr-89, Sr-90, Y-90, Y-91, and Ce-144. The most important dose contributor to muscle is $\mathrm{Cs}-137$, but it is also a contributor to lungs and the gastrointestinal tract. Other contributors to the lungs and gastrointestinal tract are Ru-106, Zr-95, Sr-89, Sr-90, Y-90, and Y-91.

\section{$\underline{\text { Re-Entry Burnup }}$}

For purposes of the present study, it has been assumed that the reactor is intact but is parted from the entire power plant and that the re-entry parameters are as follows:

$$
\begin{aligned}
& \text { Re-entry angle }=0.50^{\circ} \\
& \text { Re-entry speed }=24,500 \mathrm{fps} \\
& \text { Re-entry altitude }=400,000 \mathrm{ft} \\
& \text { Ballistic coefficient }(B)=\frac{\mathrm{W}}{\mathrm{C}_{\mathrm{D}}^{\mathrm{A}}} \approx \frac{450}{(1.0)(1.7)}=265 \mathrm{lb} / \mathrm{ft}^{2} .
\end{aligned}
$$

For $B=265$, maximum deceleration will occur at around 200,000 feet. The kinetic energy at entry is about

$$
\mathrm{KE}=\frac{\mathrm{V}^{2}}{2 \mathrm{~g}_{\mathrm{c}} \mathrm{J}}=\frac{\left(2.45 \times 10^{4}\right)^{2}}{2 \times 32.2 \times 778}-10^{4} \mathrm{Btu} / 1 \mathrm{~b}
$$

or

$$
\mathrm{KE}_{\text {tota1 }}=450 \times 10^{4}=4.5 \times 10^{6} \mathrm{Btu}
$$

Less than 10 percent of this energy will go to heating the reactor; however, assuming the total 10 percent, the maximum heating load would be

$$
Q_{\max } \approx 4.5 \times 10^{5} \mathrm{Btu} \text {. }
$$

About $10^{3} \mathrm{Btu} / 1 \mathrm{~b}$ are required to heat bery 11 ium oxide from $2000^{\circ} \mathrm{F}$ to its melting temperature $\left(4716^{\circ} \mathrm{F}\right)$ and another $10^{3} \mathrm{Btu} / 1 \mathrm{~b}$ are required to melt it. Thus, for the nominal 100-kilogram reflector surrounding the reactor,

$$
\begin{aligned}
& \mathrm{Q}_{\text {heating }} \approx(2.2)(100) \times 2 \times 10^{3}=4.4 \times 10^{5} \mathrm{Btu} . \\
& \quad \& \text { melt } \mathrm{BeO}
\end{aligned}
$$

Thus, even if radiation cooling is ignored and a pessimistic heating load is assumed, the reflector will absorb the entire heating energy put into the reactor. It is apparent that the reactor will re-enter nearly intact if the Beo reflector is not jettisoned. This conclusion is further substantiated by the re-entry heating rate data given by Roupe and Miller ${ }^{30}$ shown in Figure 24. The total integrated energy for a cross section of 1.7 square feet is about $7 \times 10^{4}$ Btu--about $1 / 6$ the 10 -percent value indicated above. 
Fission Product Decay After 10,000 Hour Operation, Curies/mw-sec

\begin{tabular}{|c|c|c|c|c|c|c|c|c|c|c|c|}
\hline & Column & 1 & 2 & 3 & 4 & 5 & 6 & 7 & 8 & 9 & 10 \\
\hline & & \multicolumn{10}{|c|}{ DECAY TIME, HOURS } \\
\hline & & 0.1 & 0.2 & 0.3 & 0.5 & 1 & 5 & 10 & 15 & 20 & 25 \\
\hline 1 & LA- 143 & $9.842 \mathrm{E}-04$ & $7.907 \mathrm{E}-04$ & $6.353 E-04$ & $4.101 \mathrm{E}-04$ & $1.373 E-04$ & $2.164 \mathrm{E}-08$ & $3.822 \mathrm{E}-13$ & $6.751 \mathrm{E}-18$ & $1.193 \mathrm{E}-22$ & $2.106 E-27$ \\
\hline 2 & $\mathrm{CE}-143$ & $2.451 \mathrm{E}-03$ & $2.448 \mathrm{E}-03$ & $2.445 \mathrm{E}-03$ & $2.437 \mathrm{E}-03$ & $2.414 \mathrm{E}-03$ & $2.221 \mathrm{E}-03$ & $2.000 \mathrm{E}-03$ & $1.801 \mathrm{E}-03$ & $1.621 \mathrm{E}-03$ & $1.460 \mathrm{E}-03$ \\
\hline 3 & PR- 143 & $2.456 \mathrm{E}-03$ & $2.456 \mathrm{E}-03$ & $2.456 \mathrm{E}-03$ & $2.456 \mathrm{E}-03$ & $2.456 \mathrm{E}-03$ & $2.455 \mathrm{E}-03$ & $2.451 \mathrm{E}-03$ & $2.445 E-03$ & $2.437 E-03$ & $2.428 \mathrm{E}-03$ \\
\hline 4 & $\mathrm{CE}-144$ & $8.195 \mathrm{E}-04$ & $8.195 \mathrm{E}-04$ & $8.195 \mathrm{E}-04$ & $8.195 \mathrm{E}-04$ & $8.195 \mathrm{E}-04$ & $8.191 \mathrm{E}-04$ & $8.187 \mathrm{E}-04$ & $8.183 \mathrm{E}-04$ & $8.179 \mathrm{E}-04$ & $8.174 \mathrm{E}-04$ \\
\hline 5 & $\mathrm{BA}-141$ & $9.552 \mathrm{E}-04$ & $7.581 \mathrm{E}-04$ & $6.016 \mathrm{E}-04$ & $3.790 \mathrm{E}-04$ & $1.193 \mathrm{E}-04$ & $1.153 \mathrm{E}-08$ & $1.104 \mathrm{E}-13$ & $1.058 \mathrm{E}-18$ & $1.013 \mathrm{E}-23$ & $9.703 E-29$ \\
\hline 6 & LA- 141 & $2.404 \mathrm{E}-03$ & $2.376 \mathrm{E}-03$ & $2.345 \mathrm{E}-03$ & $2.279 \mathrm{E}-03$ & $2.100 \mathrm{E}-03$ & $1.018 \mathrm{E}-03$ & $4.095 \mathrm{E}-04$ & $1.647 \mathrm{E}-04$ & $6.625 \mathrm{E}-05$ & $2.664 E-05$ \\
\hline 7 & $\mathrm{CE}-141$ & $3.701 \mathrm{E}-03$ & $3.701 \mathrm{E}-03$ & $3.701 \mathrm{E}-03$ & $3.701 \mathrm{E}-03$ & $3.700 \mathrm{E}-03$ & $3.693 \mathrm{E}-03$ & $3.680 \mathrm{E}-03$ & $3.665 \mathrm{E}-03$ & $3.650 \mathrm{E}-03$ & $3.634 \mathrm{E}-03$ \\
\hline 8 & $B A=140$ & $1.333 \mathrm{E}-03$ & $1.333 E-03$ & $1.332 \mathrm{E}-03$ & $1.332 \mathrm{E}-03$ & $1.330 \mathrm{E}-03$ & $1.318 \mathrm{E}-03$ & $1.304 \mathrm{E}-03$ & $1.289 \mathrm{E}-03$ & $1.274 \mathrm{E}-03$ & $1.260 \mathrm{E}-03$ \\
\hline 9 & LA -140 & $2.664 \mathrm{E}-03$ & $2.661 \mathrm{E}-03$ & $2.659 \mathrm{E}-03$ & $2.654 \mathrm{E}-03$ & $2.643 \mathrm{E}-03$ & $2.555 \mathrm{E}-03$ & $2.452 \mathrm{E}-03$ & $2.357 \mathrm{E}-03$ & $2.268 \mathrm{E}-03$ & $2.185 \mathrm{E}-03$ \\
\hline 10 & $C S=137$ & 3. $375 \mathrm{~B}-05$ & $3.375 E-05$ & $3.375 E-05$ & 3. $375 \mathrm{E}-05$ & 3. $375 E-05$ & 3. $375 E-05$ & 3. $375 E-05$ & $3.375 E-05$ & 3. $375 E-05$ & $3.375 E-05$ \\
\hline 11 & $I-135$ & $1.249 \mathrm{E}-03$ & $1.231 \mathrm{E}-03$ & $1.212 \mathrm{E}-03$ & $1.176 \mathrm{E}-03$ & $1.091 \mathrm{E}-03$ & $5.986 \mathrm{E}-04$ & $2.826 \mathrm{E}-04$ & $1.334 \mathrm{E}-04$ & $6.298 \mathrm{E}-05$ & $2.973 \mathrm{E}-05$ \\
\hline 12 & $\mathrm{TE}-134$ & $1.202 \mathrm{E}-03$ & $1.094 \mathrm{E}-03$ & $9.949 \mathrm{E}-04$ & $8.233 \mathrm{E}-04$ & $5.128 \mathrm{E}-04$ & 1. $162 \mathrm{E}-05$ & $1.022 \mathrm{E}-07$ & $8.980 \mathrm{E}-10$ & $7.895 \mathrm{E}-12$ & $6.940 \mathrm{E}-14$ \\
\hline 13 & $I-134$ & $1.491 E-03$ & $1.488 \mathrm{E}-03$ & $1.483 \mathrm{E}-03$ & $1.471 \mathrm{E}-03$ & $1.430 \mathrm{E}-03$ & $9.848 \mathrm{E}-04$ & $5.873 \mathrm{E}-04$ & $3.497 \mathrm{E}-04$ & $2.082 \mathrm{E}-04$ & $1.240 \mathrm{E}-04$ \\
\hline 14 & $I-133$ & 1. $392 \mathrm{E}-03$ & $1.388 \mathrm{E}-03$ & $1.383 \mathrm{E}-03$ & $1.373 \mathrm{E}-03$ & $1.350 \mathrm{E}-03$ & $1.179 \mathrm{E}-03$ & $9.945 \mathrm{E}-04$ & $8.391 \mathrm{E}-04$ & $7.080 \mathrm{E}-04$ & $5.973 \mathrm{E}-04$ \\
\hline 15 & $\mathrm{TE}-132$ & $1.009 \mathrm{E}-03$ & $1.008 \mathrm{E}-03$ & $1.008 \mathrm{E}-03$ & $1.006 \mathrm{E}-03$ & $1.001 \mathrm{E}-03$ & $9.658 \mathrm{E}-04$ & $9.233 \mathrm{E}-04$ & $8.827 \mathrm{E}-04$ & $8.438 \mathrm{E}-04$ & $8.067 \mathrm{E}-04$ \\
\hline 16 & $I-132$ & $1.929 \mathrm{E}-03$ & $1.903 \mathrm{E}-03$ & $1.877 \mathrm{E}-03$ & $1.828 \mathrm{E}-03$ & $1.718 \mathrm{E}-03$ & $1.212 \mathrm{E}-03$ & $1.004 \mathrm{E}-03$ & $9.231 \mathrm{E}-04$ & $8.738 \mathrm{E}-04$ & $8.333 E-04$ \\
\hline 17 & $\mathrm{TE}-131$ & $5.278 \mathrm{E}-04$ & $4.469 \mathrm{E}-04$ & $3.784 \mathrm{E}-04$ & $2.713 \mathrm{E}-04$ & 1. $181 \mathrm{E}-04$ & $1.524 \mathrm{E}-07$ & $3.728 \mathrm{E}-11$ & $9.118 \mathrm{E}-15$ & $2.230 \mathrm{E}-18$ & $5.454 \mathrm{E}-22$ \\
\hline 18 & $I-131$ & $1.247 \mathrm{E}-03$ & $1.246 \mathrm{E}-03$ & $1.246 \mathrm{E}-03$ & $1.245 \mathrm{E}-03$ & $1.244 \mathrm{E}-03$ & $1.226 \mathrm{E}-03$ & $1.205 \mathrm{E}-03$ & $1.184 \mathrm{E}-03$ & $1.163 \mathrm{E}-03$ & $1.142 \mathrm{E}-03$ \\
\hline 19 & $\mathrm{TE}-129$ & $3.860 \mathrm{E}-05$ & $3.650 \mathrm{E}-05$ & $3.450 \mathrm{E}-05$ & $3.084 \mathrm{E}-05$ & $2.329 \mathrm{E}-05$ & $2.463 \mathrm{E}-06$ & $1.486 \mathrm{E}-07$ & $8.964 \mathrm{E}-09$ & $5.408 \mathrm{E}-10$ & $3.262 \mathrm{E}-11$ \\
\hline 20 & $\mathrm{TE} * 129$ & $4.088 \mathrm{E}-05$ & $4.088 \mathrm{E}-05$ & $4.088 \mathrm{E}-05$ & $4.087 \mathrm{E}-05$ & $4.085 E-05$ & $4.071 \mathrm{E}-05$ & $4.053 \mathrm{E}-05$ & $4.035 E-05$ & $4.018 \mathrm{E}-05$ & $4.000 \mathrm{E}-05$ \\
\hline 21 & RU-106 & $4.607 \mathrm{E}-05$ & $4.607 \mathrm{E}-05$ & $4.607 \mathrm{E}-05$ & $4.607 \mathrm{E}-05$ & $4.607 \mathrm{E}-05$ & $4.605 \mathrm{E}-05$ & $4.603 E-05$ & $4.602 E-05$ & $4.600 \mathrm{E}-05$ & $4.598 \mathrm{E}-05$ \\
\hline 22 & RH- 105 & $1.931 \mathrm{E}-04$ & $1.927 \mathrm{E}-04$ & $1.923 \mathrm{E}-04$ & $1.916 \mathrm{E}-04$ & $1.897 \mathrm{E}-04$ & $1.757 \mathrm{E}-04$ & $1.595 \mathrm{E}-04$ & $1.449 \mathrm{E}-04$ & $1.316 \mathrm{E}-04$ & $1.195 \mathrm{E}-04$ \\
\hline 23 & MO-99 & $1.310 \mathrm{E}-03$ & $1.308 \mathrm{E}-03$ & $1.307 \mathrm{E}-03$ & $1.304 \mathrm{E}-03$ & $1.298 \mathrm{E}-03$ & $1.245 \mathrm{E}-03$ & $1.182 \mathrm{E}-03$ & $1.123 \mathrm{E}-03$ & $1.066 \mathrm{E}-03$ & $1.013 \mathrm{E}-03$ \\
\hline 24 & $2 R-95$ & $1.344 \mathrm{E}-03$ & $1.343 \mathrm{E}-03$ & $1.343 E-03$ & $1.343 \mathrm{E}-03$ & $1.343 \mathrm{E}-03$ & $1.341 \mathrm{E}-03$ & $1.337 \mathrm{E}-03$ & $1.334 \mathrm{E}-03$ & $1.331 \mathrm{E}-03$ & $1.328 \mathrm{E}-03$ \\
\hline 25 & $Y-93$ & $1.302 \mathrm{E}-03$ & $1.293 E-03$ & $1.285 \mathrm{E}-03$ & $1.267 \mathrm{E}-03$ & $1.225 \mathrm{E}-03$ & $9.329 \mathrm{E}-04$ & $6.639 \mathrm{E}-04$ & $4.725 \mathrm{E}-04$ & 3. $362 E-04$ & $2.393 \mathrm{E}-04$ \\
\hline 26 & $\mathrm{RB}-92$ & $3.264 E-24$ & 0 & 0 & 0 & 0 . & 0 . & 0. & 0. & 0. & 0. \\
\hline 27 & SR-92 & $2.073 \mathrm{E}-03$ & $2.020 \mathrm{E}-03$ & $1.968 \mathrm{E}-03$ & $1.867 \mathrm{E}-03$ & $1.638 \mathrm{E}-03$ & $5.750 \mathrm{E}-04$ & $1.554 \mathrm{E}-04$ & $4.198 \mathrm{E}-05$ & $1.134 \mathrm{E}-05$ & $3.065 \mathrm{E}-06$ \\
\hline 28 & $\mathrm{RB}-91$ & $9.664 \mathrm{E}-05$ & $8.003 E-06$ & $6.627 \mathrm{E}-07$ & $4.545 \mathrm{E}-09$ & $1.770 \mathrm{E}-14$ & 0 . & 0. & 0. & 0. & 0. \\
\hline 29 & SR-91 & $2.402 \mathrm{E}-03$ & $2.385 E-03$ & $2.368 \mathrm{E}-03$ & $2.334 \mathrm{E}-03$ & $2.253 \mathrm{E}-03$ & $1.694 \mathrm{E}-03$ & $1.186 \mathrm{E}-03$ & $8.304 E-04$ & $5.814 E-04$ & $4.071 \mathrm{E}-04$ \\
\hline 30 & $Y-91$ & $3.560 \mathrm{E}-03$ & $3.560 \mathrm{E}-03$ & $3.560 \mathrm{E}-03$ & $3.560 \mathrm{E}-03$ & $3.560 \mathrm{E}-03$ & $3.556 \mathrm{E}-03$ & $3.551 \mathrm{E}-03$ & $3.545 \mathrm{E}-03$ & $3.538 \mathrm{E}-03$ & $3.530 \mathrm{E}-03$ \\
\hline 31 & $S R-90$ & $3.556 \mathrm{E}-05$ & $3.556 \mathrm{E}-05$ & $3.556 \mathrm{E}-05$ & $3.556 \mathrm{E}-05$ & $3.556 \mathrm{E}-05$ & $3.556 \mathrm{E}-05$ & $3.556 \mathrm{E}-05$ & $3.556 \mathrm{E}-05$ & $3.556 \mathrm{E}-05$ & $3.556 \mathrm{E}-05$ \\
\hline 32 & $Y-90$ & $1.012 \mathrm{E}-04$ & $1.012 \mathrm{E}-04$ & $1.012 \mathrm{E}-04$ & $1.012 \mathrm{E}-04$ & $1.012 \mathrm{E}-04$ & $1.012 \mathrm{E}-04$ & $1.012 \mathrm{E}-04$ & $1.012 \mathrm{E}-04$ & $1.012 \mathrm{E}-04$ & $1.012 \mathrm{E}-04$ \\
\hline 33 & $\mathrm{KR}-89$ & $2.689 \mathrm{E}-04$ & $7.333 \mathrm{E}-05$ & $1.999 \mathrm{E}-05$ & $1.486 \mathrm{E}-06$ & $2.239 \mathrm{E}-09$ & $5.938 \mathrm{E}-32$ & & & & \\
\hline 34 & $\mathrm{RB}-89$ & $1.040 \mathrm{E}-03$ & $8.238 \mathrm{E}-04$ & $6.340 \mathrm{E}-04$ & $3.669 \mathrm{E}-04$ & $9.186 \mathrm{E}-05$ & $1.405 \mathrm{E}-09$ & $1.344 \mathrm{E}-15$ & $1.285 \mathrm{E}-21$ & $1.229 \mathrm{E}-27$ & $1.176 \mathrm{E}-33$ \\
\hline 35 & $S R-89$ & $2.228 \mathrm{E}-03$ & $2.228 \mathrm{E}-03$ & $2.228 \mathrm{E}-03$ & $2.228 \mathrm{E}-03$ & $2.227 \mathrm{E}-03$ & $2.222 \mathrm{E}-03$ & $2.216 \mathrm{E}-03$ & $2.210 \mathrm{E}-03$ & $2.203 \mathrm{E}-03$ & $2.197 \mathrm{E}-03$ \\
\hline 36 & NP -239 & $9.748 \mathrm{E}-04$ & $9.734 \mathrm{E}-04$ & $9.721 \mathrm{E}-04$ & $9.693 \mathrm{E}-04$ & $9.626 \mathrm{E}-04$ & $9.101 \mathrm{E}-04$ & $8.486 \mathrm{E}-04$ & $7.912 \mathrm{E}-04$ & $7.377 \mathrm{E}-04$ & $6.878 \mathrm{E}-04$ \\
\hline 37 & Y-92 & $2.186 \mathrm{E}-03$ & $2.184 E-03$ & $2.181 \mathrm{E}-03$ & $2.173 \mathrm{E}-03$ & $2.137 \mathrm{E}-03$ & $1.508 \mathrm{E}-03$ & $7.577 \mathrm{E}-04$ & 3. $384 \mathrm{E}-04$ & $1.425 \mathrm{E}-04$ & $5.798 \mathrm{E}-05$ \\
\hline
\end{tabular}


TABLE IX (Cont)

Fission Product Decay After 10,000 Hour Operation, Curies/mw-sec

\begin{tabular}{lllllllllll}
\hline Column & 11 & 12 & 13 & 14 & 15 & 16 & 17 & 18 & 19 & 20 \\
\hline & 50 & 75 & 100 & 200 & 300 & 500 & 750 & 1000 & 5000 & 10,000 \\
\hline
\end{tabular}

LA-143
$\mathrm{CE}-143$
$\mathrm{PR}-143$
$\mathrm{CE}-144$
$\mathrm{BA}-141$
$\mathrm{~L} A-141$
$\mathrm{CE}-141$
$\mathrm{BA}-140$
$\mathrm{~L} A-140$
$\mathrm{CS}-137$
$\mathrm{I}-135$
$\mathrm{TE}-134$
$\mathrm{I}-134$
$\mathrm{I}-133$
$\mathrm{TE}-132$
$\mathrm{I}-132$
$\mathrm{TE}-131$
$\mathrm{I}=131$
$\mathrm{TE}-129$
$\mathrm{TE} * 129$
$\mathrm{RU}-106$
$\mathrm{RH}-105$
$\mathrm{M} \mathrm{-}-99$
$\mathrm{ZR}-95$
$\mathrm{Y}-93$
$\mathrm{RB}-92$
$\mathrm{SR}-92$
$\mathrm{RB}-91$
$\mathrm{SR}-91$
$\mathrm{Y}-91$
$\mathrm{SR}-90$
$\mathrm{Y}-90$
$\mathrm{KR}-89$
$\mathrm{RB}-89$
$\mathrm{SR}-89$
$\mathrm{NP}-239$
$\mathrm{Y}-92$

0 .

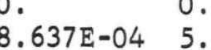

(2.

$\begin{array}{lll}8.637 \mathrm{E}-04 & 5.111 \mathrm{E}-04 & 3.024 \mathrm{E}-04 \\ 2.362 \mathrm{E}-03 & 2.275 \mathrm{E}-03 & 2.179 \mathrm{E}-03 \\ 8.153 \mathrm{E}-04 & 8.132 \mathrm{E}-04 & 8.111 \mathrm{E}-04\end{array}$

(..

$\begin{array}{llllll}3.556 \mathrm{E}-03 & 3.480 \mathrm{E}-03 & 3.406 \mathrm{E}-03 & 3.124 \mathrm{E}-03 & 2.866 \mathrm{E}-03 & 2\end{array}$

$\begin{array}{lllll}1.191 \mathrm{E}-03 & 1.126 \mathrm{E}-03 & 1.064 \mathrm{E}-03 & 8.495 \mathrm{E}-04 & 6.781 \mathrm{E}-04 \\ 1.848 \mathrm{E}-03 & 1.606 \mathrm{E}-03 & 1.426 \mathrm{E}-03 & 1.013 \mathrm{E}-03 & 7.865 \mathrm{E}-04\end{array}$

3.375E-05 $3.375 \mathrm{E}-05-3.375 \mathrm{E}-05$

$6.971 \mathrm{E}-07 \quad 1.635 \mathrm{E}-08 \quad 3.833 \mathrm{E}-10$

$3.645 \mathrm{E}-24 \quad 1.914 \mathrm{E}-34 \quad 0$.

$9.284 \mathrm{E}-06 \quad 6.951 \mathrm{E}-07 \quad 5.204 \mathrm{E}-08$

$2.554 \mathrm{E}-04 \quad 1,092 \mathrm{E}-04 \quad 4.670 \mathrm{E}-05$

$6.442 \mathrm{E}-04 \quad 5.144 \mathrm{E}-04 \quad 4.107 \mathrm{E}-04$

$6.649 \mathrm{E}-04$

. $309 \mathrm{E}-04$

$4.239 \mathrm{E}-04$

$1.045 \mathrm{E}-03 \quad 9.5$

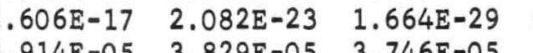

$4.589 \mathrm{E}-05 \quad 4.580 \mathrm{E}-05 \quad 4.571 \mathrm{E}-05$

$7.384 \mathrm{E}-05$
$7.562 \mathrm{E}-05 \quad 2.819 \mathrm{E}-05$

$7.822 \mathrm{E}-04$

$6.041 \mathrm{E}-04 \quad 4.666 \mathrm{E}-04$

4.367E-05

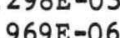

$1.284 \mathrm{E}-03$

$4.414 \mathrm{E}-09$

0

0

0.

$9.155 \mathrm{E}-15$

$3.489 \mathrm{E}-03$

$3.556 \mathrm{E}-05$

$3.446 \mathrm{E}-03 \quad 3.404 \mathrm{E}-03$

$3.404 \mathrm{E}-03$
$3.555 \mathrm{E}-05$

$1.012 \mathrm{E}-04$

$2.166 \mathrm{E}-03 \quad 2.135 \mathrm{E}-03$
0.

0 .

0.0

. 0.

$4.846 \mathrm{E}-04 \quad 3.415 \mathrm{E}-04 \quad 2.406 \mathrm{E}-04$

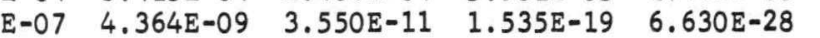

$3.501 \mathrm{E}-23$

$1.724 \mathrm{E}-04 \quad 7.008 \mathrm{E}-05$
0.

0.

$3.374 \mathrm{E}-05 \quad 3.373 \mathrm{E}-05$

0.0.

0.

$\begin{array}{lll}0.53 \mathrm{E}-08 & 3.597 \mathrm{E}-10 \quad 1.893 \mathrm{E}-12 & 0\end{array}$

. 78 E $-04 \quad 5.628 \mathrm{E}-04$

0.0 .0048

$.411 \mathrm{E}-03 \quad 1.94$

0.

4. $972 \mathrm{E}-042.460 \mathrm{E}-04$

$3.3718-052.829 \mathrm{E}-04$

$3.199 \mathrm{E}-36$ -

$1.158 \mathrm{E}-16$

$.561 \mathrm{E}-06 \quad 5.218 \mathrm{E}-08 \quad 5.830 \mathrm{E}-11 \quad 1.191 \mathrm{E}-14$

$\begin{array}{llll}.670 \mathrm{E}-04 & 6.789 \mathrm{E}-05 & 1.122 \mathrm{E}-05 & 1.183 \mathrm{E}-06\end{array}$

$1.158 \mathrm{E}-05$

$.138 \mathrm{E}-04 \quad 4.304 \mathrm{E}-04$

$2.116 \mathrm{E}-04$

$1.221 \mathrm{E}-06$

8.7

0 .

$3.432 \mathrm{E}-05 \quad 3.145 \mathrm{E}-0.05$

$4.108 \mathrm{E}-06$

$1.660 \mathrm{E}-04 \mathrm{5} 5.98 \mathrm{E}-07$

$2.640 \mathrm{E}-05$

$1.271 \mathrm{E}-08$

$7.483 \mathrm{E}-06$

. $1228=05$

3. $324 \mathrm{E}-04$

$7.394 \mathrm{E}-04$

0.

$.565 \mathrm{E}-03 \quad 4.939 \mathrm{E}-05$

$1.400 \mathrm{E}-04 \quad 1.703 \mathrm{E}-08$

$1.611 \mathrm{E}-04 \quad 1.959 \mathrm{E}-08$

$3.367 \mathrm{E}-05 \quad 3.331 \mathrm{E}-05$

$0 . \quad 0$.

0.

$2.433 \mathrm{E}-18 \quad 0$.

$1.247 \mathrm{E}-07 \quad 2.892 \mathrm{E}-23$

$1.287 \mathrm{E}-07 \quad 2.985 \mathrm{E}-23$

0.

$0.587 \mathrm{E}-05 \quad 2.44$

.446E-11

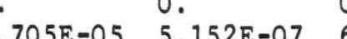

$342 \mathrm{E}-05 \quad 4.257 \mathrm{E}-05 \quad 3.102 \mathrm{E}-05$

$\begin{array}{llll}6.653 \mathrm{E}-07 & 4.271 \mathrm{E}-08 & 4.808 \mathrm{E}-26 \\ 3 & 9.536 \mathrm{E}-04 & 8.506 \mathrm{E}-04 & 1.366 \mathrm{E}-04\end{array}$

$1.613 \mathrm{E}-09 \quad 1.790 \mathrm{E}-12 \quad 2.202 \mathrm{E}-18$

0

$0.0940-260$.

0 .

0.

0 .

$8.506 \mathrm{E}-04 \quad 1.366 \mathrm{E}-04$

. $027 \mathrm{E}-26$ 3.700E-33 0

$0.12498-12$ 8.0428-19 0.46

$\begin{array}{lll}0.042 \mathrm{E}-19 & 1.466 \mathrm{E}-26\end{array}$

0.

0.

0.

0.

0.

0.

$2.674 \mathrm{E}-34$

$2.177 \mathrm{E}-03 \quad 2.984 \mathrm{E}-04 \quad 2.4$

$\begin{array}{lllllll}3.553 \mathrm{E}-05 & 3.551 \mathrm{E}-05 & 3.549 \mathrm{E}-05 & 3.546 \mathrm{E}-05 & 3.506 \mathrm{E}-05 & 3.457 \mathrm{E}-05\end{array}$

$1.012 \mathrm{E}-04$

$1.011 \mathrm{E}-04 \quad 1.010 \mathrm{E}-04$

0

0 .

0 .

$0.0745-030$.

$\begin{array}{llll}.988 \mathrm{E}-03 & 1.877 \mathrm{E}-03 & 1.674 \mathrm{E}-03 & 1.451 \mathrm{E}-03\end{array}$

0 .

0.2

$9.982 \mathrm{E}-05$

$0.982 \mathrm{E}-05$

$.931 \mathrm{E}-05 \quad 1.462 \mathrm{E}-05 \quad 8.884 \mathrm{E}-07$

0 .

0 .

$8.085 \mathrm{E}-10$

$1.274 E-04$

.

$7.281 \mathrm{E}-06$

$3.804 \mathrm{E}-34$

$950 \mathrm{E}-12$

$27 \mathrm{E}-04$

$6.569 \mathrm{E}-07$

$176 \mathrm{E}-13$

(1)

0.

0.

.

$.793 \mathrm{E}-19$

$492 E-09$

.089E-05

. $389 \mathrm{E}-05$

0 .

0 . 
If the BeO is jettisoned early (above 300,000 feet), the vesse1 can be exposed to the free steam and heated directly. There are two mechanisms, aside from explosive methods, which could conceivably destroy the $\mathrm{Cb}-1 \mathrm{Zr}$ vesse 1 and expose the core as the surface temperature rises. The first is a self-ignition phenomenon which has been observed at $2680^{\circ} \mathrm{F},{ }^{31}$ and the second is melting and subsequent ablation which occurs at $4380^{\circ} \mathrm{F}$.

The lower temperature ignition is attributed to the melting of $\mathrm{Cb}_{2} \mathrm{O}_{5}$ accompanied by increased oxygen diffusion to the parent metal. An exothermic reaction then takes place according to the relation,

$$
2 \mathrm{Cb}+\frac{5}{2} \mathrm{O}_{\mathbf{a}}=\mathrm{Cb}_{2} \mathrm{O}_{5}(-225 \mathrm{Kcal} / \mathrm{mole} \mathrm{Cb}) .
$$

If this heat of reaction is not dissipated by radiation or conduction, the process is regenerative and ignition results. It has been found that a mass-flow rate of at least $2000 \mathrm{lb} / \mathrm{hr}-\mathrm{ft}^{2}$ is necessary to initiate this reaction. Considering the range of velocities and the air density above 200,000 feet, it appears that this threshold cannot be reached. However, during the descent into more dense atmosphere, the columbium surface will begin to oxidize and its emissivity ( $\epsilon$ ) wil1 increase due to this effect. So instead of $\epsilon=0.4$ for $\mathrm{Cb}$, it will more probably be $\boldsymbol{\epsilon}=0.7$ for the oxidized surface.

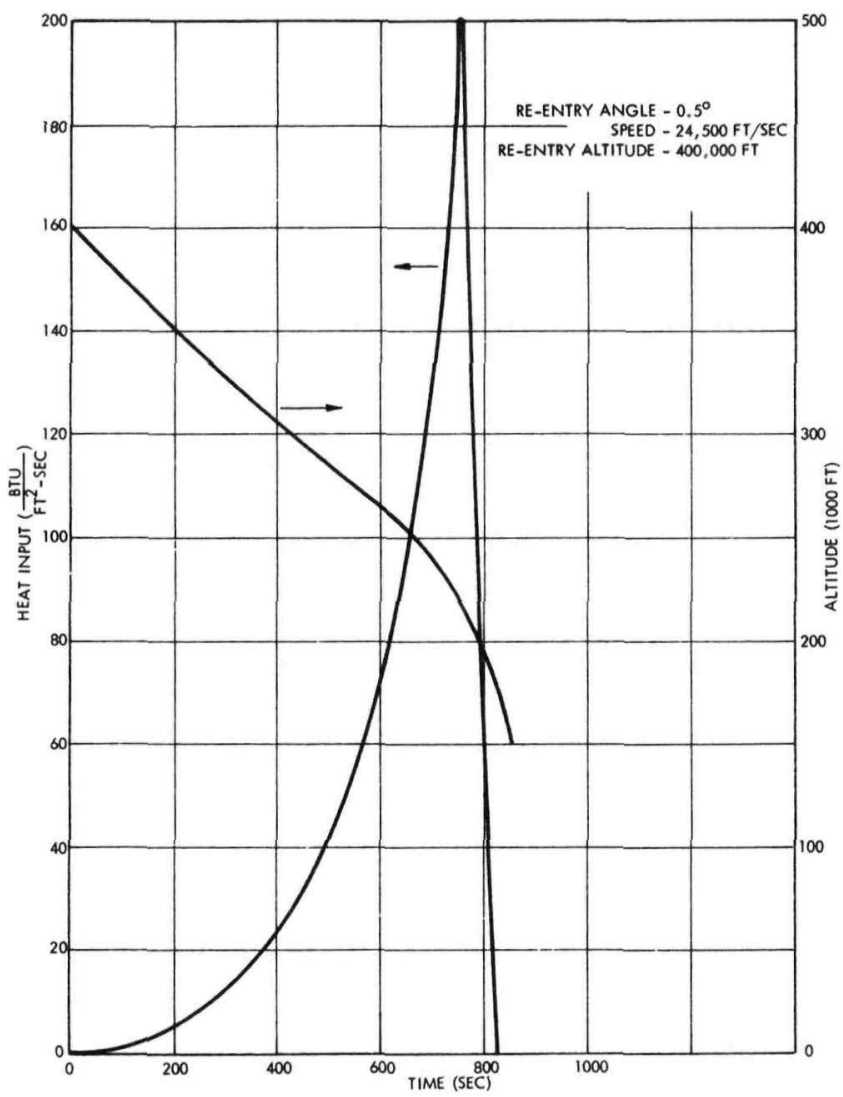

Figure 24 .

Re-entry heating on the reactor forward section (trimmed flight) 
The re-radiated energy for pure $\mathrm{Cb}(\epsilon=0.4)$ at its melting point is

$$
\frac{\mathrm{q}}{\mathrm{A}}=\frac{(0.17)(0.4)}{3600}\left(\frac{4840}{100}\right)^{4}=104 \mathrm{Btu} / \mathrm{sec}-\mathrm{ft}^{2} \text {. }
$$

According to the data of Roupe and Miller (Figure 24), the vesse1 surface will not reach its melting point until is has descended to 250,000 feet. Because of the probable higher emissivity, the ablation process would not start until about 225,000 feet. It is doubtful that even the majority of the vessel would be destroyed by this means. Therefore, to expose the core, not only must the BeO be jettisoned, but the vessel must be destroyed by external means.

Even if the core can be exposed by some method, and the assumption is made that it separates into single pins or 7-pin clusters, it is doubtful that these basic units will burn up, again because of re-radiated energy. Both single pins and clusters were analyzed, using an analog computer and the heating input given in Reference 32 as modified to account for the "smearing" effect of tumbling and geometry. Typical results are given in Figure 25 where it is shown that only for a single pin ejected at 300,000 feet with $\epsilon=0.25$ (which is lower than that for oxidized $\mathrm{Cb}$--the clad material during re-entry, or a ceramic fuel such as UC or $\mathrm{UO}_{2}$ ) does the temperature just reach the melting temperature. Therefore, it appears that neither re-entry heating nor oxidation can be relied upon to destroy the vesse1 or the core, even though partial disassembly has been accomplished by use of a shaped charge.

The tungsten reflector-shield located in the lower plenum (Figure 22) cannot be expected to melt and ablate away because of its high emissivity and melting temperature $\left(\epsilon=0.39\right.$ at 5000 to $\left.6000^{\circ} \mathrm{F}\right) .^{33}$ Therefore, the most probable occurrence will be a quick rise to "equilibrium temperature"--that governed by re-radiated thermal energy. During this period, air becomes more oxygen-rich and the bulk temperature will still be high enough to allow some oxidation to occur. However, the high-temperature portion of the trajectory $\left(2000\right.$ to $\left.6000^{\circ} \mathrm{F}\right)$ occurs in rarified air. Since tungsten is almost inert below $700^{\circ} \mathrm{C}\left(1292^{\circ} \mathrm{F}\right)^{34}$ at sea level, destruction by catastrophic oxidation should not occur in rarified air because of the lack of sufficient oxygen.

From the above results, it is apparent that the refractory and ceramic materials which allow an advanced reactor to operate at a very high temperature also make it difficult to destroy by aerodynamic heating upon re-entry. Alternate methods of reactor destruction or disposal are not fail-safe and cannot be fully depended upon. In other words, total reactor destruction and dispersal before or during re-entry cannot be assumed. However, this conclusion must be regarded as preliminary, because the high-temperature properties of the potential reactor materials are not well known and the re-entry heating rate information used in this analysis was only approximate.

Hazards Countermeasures

Certain nuclear accident hazards associated with launch operations or intact re-entry could be circumvented or reduced by employing hazards countermeasures as discussed below.

\section{Launch Operations}

Reflector Lockouts -- Neutron leakage contro1 in advanced space power reactors is generally accomplished by rotating or sliding reflectors which create a potentially critical situation as soon as they are assembled on the reactor. Because of the fast neutron spectrum of the reactor, external neutron poisons are relatively ineffective; therefore, it is mandatory to physically prevent the control reflectors from moving inward from the scram position during the prelaunch phase and until planned startup in space begins. It appears that the most practical 
way to achieve this is by spring-loaded wedges or chocks which are held in by the aerodynamic-fairing/heat-shield and separated from the reactor upon release of the fairing. This method is selected in preference to electrical means, because the lockouts operate as stored-energy devices, provide the necessary protection for the period of interest, and leave the reactor cleanly.

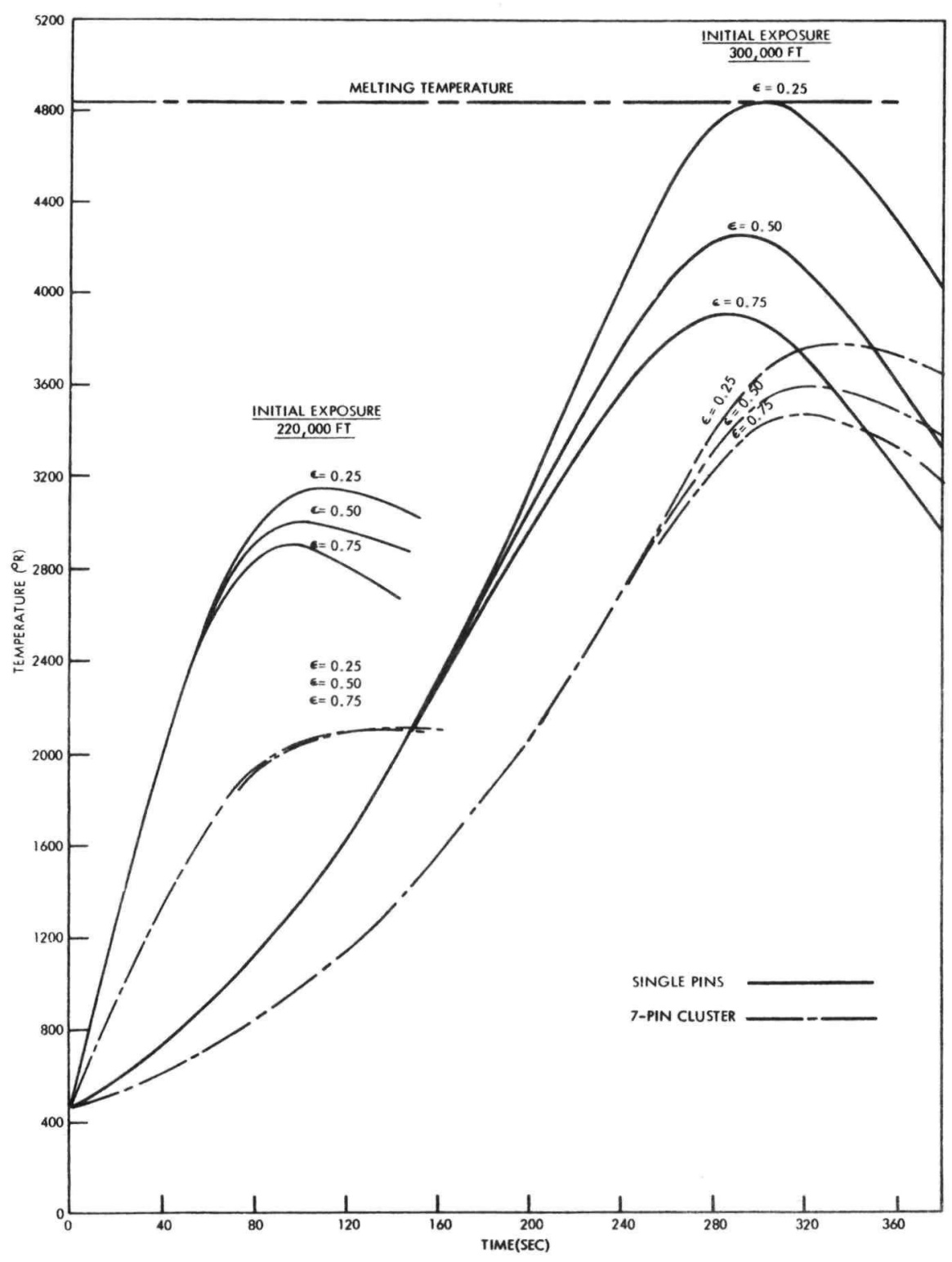

Figure 25. Pin and cluster temperature at different emissivities 
Escape Rocket System -- In the event of a launch abort, the reactor could fall to earth with a velocity of 100 to 700 feet per second, depending upon terminal height and drag. From the viewpoint of both safety and economy, it would be desirable to find a way to recover the nuclear system rather than destroy it, or at least to minimize any excursion resulting from impact. Such a system would be even more desirable if it could play a functional part in a normal mission. This reasoning leads to consideration of an auxiliary rocket ejection system for the nuclear system, similar to that used in the Mercury program for emergency ejection of a manned capsule from an aborted launch booster.

The proposed ejection system would separate the nuclear power system from the vehicle and bring it back to earth by means of a drogue parachute. As in the Mercury vehicle, it would be mounted forward of the reactor by means of a space frame. One possible use for such a system on a normal mission would be to remove the main aerodynamic fairing in space, when reactor startup begins. While this solution is excellent in principle, the penalty paid in launch weight must be balanced against the possible gain. The weight of such an ejection system was calculated to be about 900 pounds, or 30 percent of the original power-system weight.

Neutron Poisons -- In theory, neutron-poison materials placed in or around the reactor could prevent or reduce the magnitude of possible excursions as a result of earth impact or water immersion. In practice, it is found that poison materials are generally ineffective for fast spectrum reactors because the average neutron energy in such reactors is greater than the energies at which neutron absorption resonances are found in the poisons. For water immersion, it might be expected that neutron-energy degradation by collision with hydrogen nuclei would improve poison-material effectiveness. However, it was found that enclosing the reactor pressure vessel with liners of various materials did not prevent criticality when the reactor was completely immersed.

The substitution of natural lithium (93 percent Li-7, 7 percent Li-6) for Li-7 as the reactor coolant yielded more favorable results. The launch-ready reactor with natural lithium coolant was calculated to be subcritical upon water immersion, provided water does not penetrate to the core. The use of natural lithium poses several disadvantages, however. Replacement of $\mathrm{Li}-7$ with natural lithium requires that more fue 1 be added to the core, thus increasing reactor weight and size, and hence shield weight also. In addition, neutron absorption by Li-6 results in a buildup of tritium which may react with structural materials. However, based solely on nuclear safety considerations, the use of natural lithium appears to be an effective hazards countermeasure for water immersion accidents and thus deserves more careful study and evaluation.

Destruct Mechanisms -- Destruct mechanisms could be used to dismantle the reactor in the event of a launch abort and thus prevent a criticality accident. However, there is some question about the reliability of this procedure since abort not the result of command destruct could conceivably disarm the destruct system. In addition, the laumch-destruct mechanism would have to be ejected from the reactor system before reactor startup to prevent inadvertant detonation because of high temperature and exposure to nuclear radiation. Hence, it is not clear at present whether or not the use of a launch reactor-destruct system is advisable.

\section{Re-Entry}

Countermeasures to re-entry hazards can be grouped into three categories: (1) disposal of the reactor by injecting it into a solar orbit, (2) destruction of the reactor in space, and (3) destruction of the reactor or control of its point of landing upon re-entry into the earth's atmosphere. For each category, the countermeasure system employed could be internal, i.e., part of the reactor system when launched, or externa1, i.e., sent up to rendezvous with the reactor on command. Hence, there are six general re-entry countermeasure systems possible. 
1. Solar Orbit Injection: Internal System -- If the system is used for a manned or orbital mission, the system will be in the vicinity of earth upon completion of its mission, and hence energy must be supplied to it to cause escape from the earth's gravitational field. Velocity increments of about 15,000 feet per second are necessary to escape from earth orbits less than 1000 nautical miles high. For a 3000-pound system, this implies an impulse of about $1.5 \times 10^{6} 1 \mathrm{~b}-\mathrm{sec}$. This impulse could be supplied by a high thrust over a short period, e.g., by an AGENAclass rocket engine, or by a low thrust over a long period such as by an ion propulsion engine.

Although it seems to be a "clean" disposal method, there are some serious questions on solar orbit injection. First, is it feasible and/or desirable to carry along a heavy disposal system throughout a nuclear mission? Second, will the disposal system operate reliably after long exposure (more than 1 year) to the combined radiation and space environments? Both questions must be answered affirmatively before the method can be seriously considered.

2. Solar Orbit Injection: External System -- An external system of solar orbit injection has the same advantages as the previous one but without the weight addition and long term reliability problems. It has some unique difficulties of its own, however. Most obvious is the rendezvous problem: accurate and reliable rendezvous techniques must be proved before this method could be considered. Secondly, the reliability of the disposal rocket engine and guidance system requires verification. (It is considered unlikely that an external, low-thrust device would be used.)

3. Reactor Destruction in Space: Interna1 System -- If the reactor were destroyed in space, i.e., broken up into pieces small enough to be melted and/or widely dispersed upon re-entry, the radiological hazard from it would be no greater, and probably much less, than that from the existing atmospheric fission product fallout resulting from weapons testing. Possible methods of reactor destruction include the use of explosive charges and planned nuclear excursions. The questions on the added weight and long-term reliability of such countermeasure systems apply to this method also.

4. Reactor Destruction in Space: External System -- It is conceivable that a shaped explosive charge or a low-yield nuclear explosive could be made to rendezvous with and destroy the reactor after completion of its mission. However, rendezvous techniques must be proved, and the efficacy and advisability of using explosive destruct systems must be shown before consideration is given to this method.

5. Re-Entry Destruction: Internal System -- Since the countermeasures discussed above are not fail-safe, atmospheric re-entry of the reactor is the ultimate consequence of an orbital mission. Reactor destruction by use of its kinetic and potential energy during re-entry is thus the last line of defense against radiological hazards. Postulated destruction methods include the use of low-me1tingpoint materials in various parts of the reactor and use of additives to materials to enhance oxidation. However, such methods are generally incompatible with the high temperatures required for good system performance.

6. Controlled Re-Entry: External System -- Re-entry hazards could be avoided if the reactor were guided by some means to a harmless landing place, such as a remote, deep-water location. The necessary velocity increments are much less than those required for solar orbit disposal. However, the questions of rendezvous technique and control system reliability apply to this case as well. 
Conclusions

The requirement for high operating temperature, high fissile inventory, and minimum shield weight for power levels about a few hundred kilowatts necessitates the use of a liquid-metal-cooled, ceramic-fueled fast reactor with refractory metal cladding and structure. The preliminary operational safety and hazards analysis of such a reactor leads to the following conclusions:

1. Potential nuclear hazards do exist up through the prelaunch and assembly operation. However, by the use of well-disciplined and planned procedures and proper facilities and handling equipment, all potential incidents can be eliminated.

2. Liftoff, pitchover and final stage separation are the most critical operations, and significant nuclear incidents can occur as a result of launch aborts followed by ground impact, water immersion, or rocket-fuel immersion of the reactor.

3. Excursion yield is directly related to the specific heat of reactor materials as a function of temperature and the heats of fusion and vaporization of these materials. Such data is very sparse for temperatures above $900^{\circ} \mathrm{K}$ for ceramic fuels and refractory metals. Consequently, basic physical properties must be estimated over wide temperature ranges in order to perform excursion calculations, and the accuracy of such calculations is no greater than that of the physical property estimates.

4. For space power reactors, there is a potential for very large reactivity insertion rates because of the high velocities associated with missile aborts either on or above the launch pad. Rates on the order of 1000 dollars per second are possible because of water immersion or earth impact following a fall of about 100 feet to the pad or its environs. These rates are approximately a factor of 10 higher for a downrange impact at terminal velocity.

5. Reactor excursions possible during launch operations can be grouped into three general categories with final core configuration and approximate nuclear yield as follows: (1) reactor control malfunction, core partially melted, 50 mwsec; (2) booster abort on pad causing reactor to fall to pad, core partially vaporized, $100 \mathrm{mw}-\mathrm{sec}$; and (3) booster abort above pad or downrange causing reactor to impact with terminal velocity, core totally vaporized, $1000 \mathrm{mw}-\mathrm{sec}$.

6. The heat release from chemical reactions of vaporized or molten core materials following an excursion can be of the same order as, or even exceed, the nuclear yield.

7. For the worst nuclear yield considered, under inversion meteorological conditions, emergency exposure guides would not be exceeded for unprotected individuals located beyond about 2100 feet directly downwind and environmental dose levels would be below the general population peacetime exposure guides at distances beyond about 3 miles downwind from the accident.

8. Safety devices such as control rod lockouts and Mercury-type escape rockets and parachutes can be used to minimize launch hazards. In addition, use of proper exclusion areas and procedures and availability of a trained cleanup crew can reduce the hazards.

9. Atmospheric or ground contamination following re-entry appears to be a potential problem area because it is unlikely that the core can be made to burn up by aerodynamic heating during re-entry. Novel countermeasures must be devised to solve this problem. 
References

1. D. L. Cochran and K. E. Buck, "Boiling vs Non-Boiling Liquid Metal Cooled Reactors in Rankine Cycle Space Power Plants, Progress in Astronautics and Rocketry," Space Power Systems, Vo1. 4, N. W. Snyder, ed., New York Academic Press, 1961.

2. K. P. Johnson, Performance Comparison of Nuclear Electric Space Power Plants, Aerojet General Nucleonics-TP-73, February 1963.

3. J. Belle, ed., Uranium Dixoide: Properties and Nuclear Applications, USAEC Publication, 1961.

4. F. A. Rough and W. Chuff, An Evaluation of Data on Nuclear Carbides, BMI-1441, May 1960 .

5. D. R. Stu11 and G. C. Sinke, "Thermodynamic Properties of the Elements," American Chemical Society, Advances in Chemistry Series, No. 18, 1956.

6. Dow Chemical Co., JANAF Thermochemical Data, Midland, Michigan.

7. R. R. Hultgren, et a1., Selected Values of the Thermodynamic Properties of Metals and Alloys, New York, John Wiley \& Sons, Inc., 1963.

8. E. Jahnke and F. Emde, Tables of Functions, 4th edition, New York, Dover Publications, 1945.

9. L. J. Koch, et a1., Hazard Summary Report EBR-II, ANL-5719, May 1957.

10. R. O. Brittan, et al., Hazard Evaluation Report on the Fast Reactor Zero Power Experiment ZPR III, ANL-6408, October 1961.

11. "Permissible Dose From External Sources of Ionizing Radiation," Nationa1 Committee on Radiation Protection, NBS Handbook No. 59, June 5, 1959.

12. Exposure to Radiation in an Emergency, National Committee on Radiation Protection and Measurements, Report No. 29, January 1962.

13. Federa1 Register Title 10, Part 100, Reactor Site Criteria, Apri1 $12,1962$.

14. Background Material for The Development of Radiation Protection Standards, Federa1 Radiation Council Staff Report No. 1, U. S. Government Printing Office, Washington 25, D. C., May 13, 1960.

15. Background Materia1 for The Development of Radiation Protection Standards, Federal Radiation Council Staff Report No. 2, U. S. Government Printing Office, Washington 25, D. C., September 1961.

16. W. G. Marley and T. M. Fry, "Radiological Hazards from an Escape of Fission Products and the Implications in Power Reactor Location," Geneva Conference Paper No. 394, 1955.

17. B. Carlson, et a1., The DSN and TDC Neutron Transport Codes, LAMS-2346, October 1959 .

18. G. A. Graves, "Radiation Problems in the ROVER Program," Paper No. 849-59, presented at the ARS Semiannual Meeting, June 18-11, 1959, San Dięgo, California.

19. A. C. Chamberlain, "Aspects of Travel and Deposition of Aerosol and Vapour Ciouds," AERE, HP/R 1261, September 17, 1953. 
20. 0. G. Sutton, "A Theory of Eddy Diffusion in the Atmosphere," Proc. Roya1 Society, London, Vo1. 135, Series A, 1 February, 1932, p. 143.

21. W. F. Hilsmeier and F. A. Gifford, Graphs for Estimating Atmospheric Dispersion, OR0-545, July 1962.

22. Meteorology and Atomic Energy, U. S. Dept. of Commerce Weather Bureau; USAEC, AECU-3066, July 1955.

23. G. J. Hine and G. L. Browne11, Radiation Dosimetry, Academic Press, 1956.

24. G. H. Anno, P. J. Dubois, T. P. Wilcox, and J. K. Whithaus, "Radiological Inhalation Safety Code, (RISC)," AN-TP-44, Paper presented at the Annua1 Meeting of the ANS, Salt Lake City, Utah, June 1963.

25. J. F. Perkins and R. W. Kine, Nuclear Science and Engineering, $3: 726$ (1958).

26. K. Z. Morgan and M. R. Ford, "Developments in Internal Dose Determinations," Nucleonics, 12:6, (June 1954).

27. K. Z. Morgan, W. S. Snyder, and M. R. Ford, "Maximum Permissible Concentration of Radioisotopes in Air and Water for Short Period Exposure," Geneva Conference Paper No. 379, August 1955.

28. K. Z. Morgan, "Report of ICRP Committee on Permissible Dose for Internal Radiation," (1959) Health Physics, Vo1. 3, June 1960.

29. J. C. Couchman and A. H. Chura, "Safety Analysis Program Review for NuclearPowered Vehicles," NARF-60-13T, FZK-9-148, Apri1 16, 1960.

30. G. Roupe and E. H. Miller, The Effect of Varying Re-Entry Angle and Re-Entry Velocity on Re-Entry Heating, AFSWC-TDR-61-83, October 1961.

31. J. W. Clark, "The Ignition of Columbium and Selected Alloys," Columbium Metallurgy, D. L. Douglass and F. W. Kung, eds., AIMMEE, Metallurgical Society Conferences, Vo1. 10, New York, Interscience Pub1ishers, 1961.

32. AVCo Corporation, Investigation of Re-Entry Destruction of Nuclear Auxiliary Power Plant, AFSWC-TR-61-69, October 1961.

33. W. H. McAdams, Heat Transmission, 3rd edition, New York, McGraw-Hi11, 1954.

34. Batte11e Memoria1 Institute, Oxidation of Tungsten, DMIC 155. 


\section{BLANK}




\section{SESSION III}

NUCLEAR SAFETY ASPECTS OF PROPULSION REACTOR DESIGN

Chairman

Ralph S. Decker, Chief, Safety Branch

Space Nuclear Propulsion Office

Division of Reactor Development, USAEC

At the first session, Harold B. Finger emphasized that the achievement of reliability is the first essential step in realizing safety. This follows from the fact that there is no inherent danger in the flight operation of space vehicles employing either nuclear propulsion or power reactors. A failure or accident must occur before even the possibility of a hazardous situation arises. While the achievement of extremely high reliability has been demonstrated by many space systems, the slim but finite chance of failure requires the use of countermeasures to eliminate or at least minimize any resultant threat to health and safety.

But all the speakers at the first session, and Dr. Bradbury in particular, admonished that we were not to lose our balance. Not only is absolute safety an impossibility but an overzealousness in providing countermeasures can easily defeat its purpose by detracting from reliability. We are not to become safety hypochondriacs!

This does not mean, of course, that we are to sit on our hands and do nothing. We are morally obliged to do all in our power to eliminate every unnecessary risk-to seek the safest balance between reliability and countermeasure. To do this without impairing payload or operational flexibility is the trick, a trick no less difficult and challenging to the scientist and engineer than the exploration of space itself. The authors of this session stand in the midst of those who have taken up this challenge.

Session Coordinator

W. R. Stratton

Los Alamos Scientific Laboratory 


\section{BLANK}




\section{SAFETY OF RIFT VEHICLE LAUNCH AND FLIGHT OPERATIONS}

Major R. C. Hock, USAF

Launch Operations Center

Introduction

The Reactor-In-Flight-Test (RIFT) Project was initiated in June 1962 to develop a nuclear stage and vehicle capable of performing advanced missions in space. The RIFT flight test program consists of a series of ballistic flight tests at the Merritt Island Launch Area - Atlantic Missile Range (MILA-AMR) to demonstrate this capability.

The Marsha11 Space Flight Center is charged with the design, development, fabrication, system integration, and static tests of the RIFT vehicle. The Launch Operations Center will conduct launch operations at MILA. The Lockheed Missiles and Space Company was selected as the prime contractor for RIFT stage design, development, etc. NERVA engine development is the responsibility of the Space Nuclear Propulsion office (SNPO), and Aeroject-General Corporation has the contract for the engine development with a subcontract to Westinghouse for reactor development.

The RIFT development and test program involves not only about a11 the comp1ications of a large chemical stage development but also the problems arising from the potential hazards of a nuclear reactor capable of producing very high power leve1s. Safety, therefore, must be an important and integral part of the program from conception through design, development, and test.

RIFT Stage and Vehicle Description

The RIFT vehicle configuration, Figure 26, consists of the S-1C stage, S-11 stage, S-N stage, instrument unit, and nose cone. The RIFT stage is 33 feet in diameter, and 80 feet long; the total SATURN V/RIFT vehicle length is over 350 feet.

The S-1C booster now being developed for the SATURN V launch vehicle is approximately 140 feet long, uses five Rocketdyne F-1 engines producing a total of $7.5 \mathrm{mil}-$ lion pounds thrust, and has a propellant capacity of approximately 4.5 million pounds of LOX and RP-1.

The S-11 stage will be included as a dummy in the RIFT flight test to provide structural and dynamic simulation. The S-11 is approximately 80 feet 1 ong and will be ballasted for propellant-weight simulation on the RIFT flights. For operational missions, the S-11 stage would be powered by five Rocketdyne J-2 engines producing a total thrust of approximately 1 million pounds and would have a total prope 11 ant capacity of approximately 900,000 pounds of $\mathrm{LOX}$ and $\mathrm{LH}_{2}$.

The RIFT S-N stage is approximate1y 80 feet 1 ong and consists of a prope11ant tank, nuclear engine, and interstage. Liquid hydrogen contained in the welded aluminum tank will be forced through the reactor by a combination of tank pressure and engine turbopump action, absorbing heat from the reactor before passing into the thrust chamber as hot hydrogen gas. The RIFT stage propellant capacity is approximately 100,000 pounds, but for operational missions the tank size may vary between 100,000 and 200,000 pounds depending upon the specific mission. 


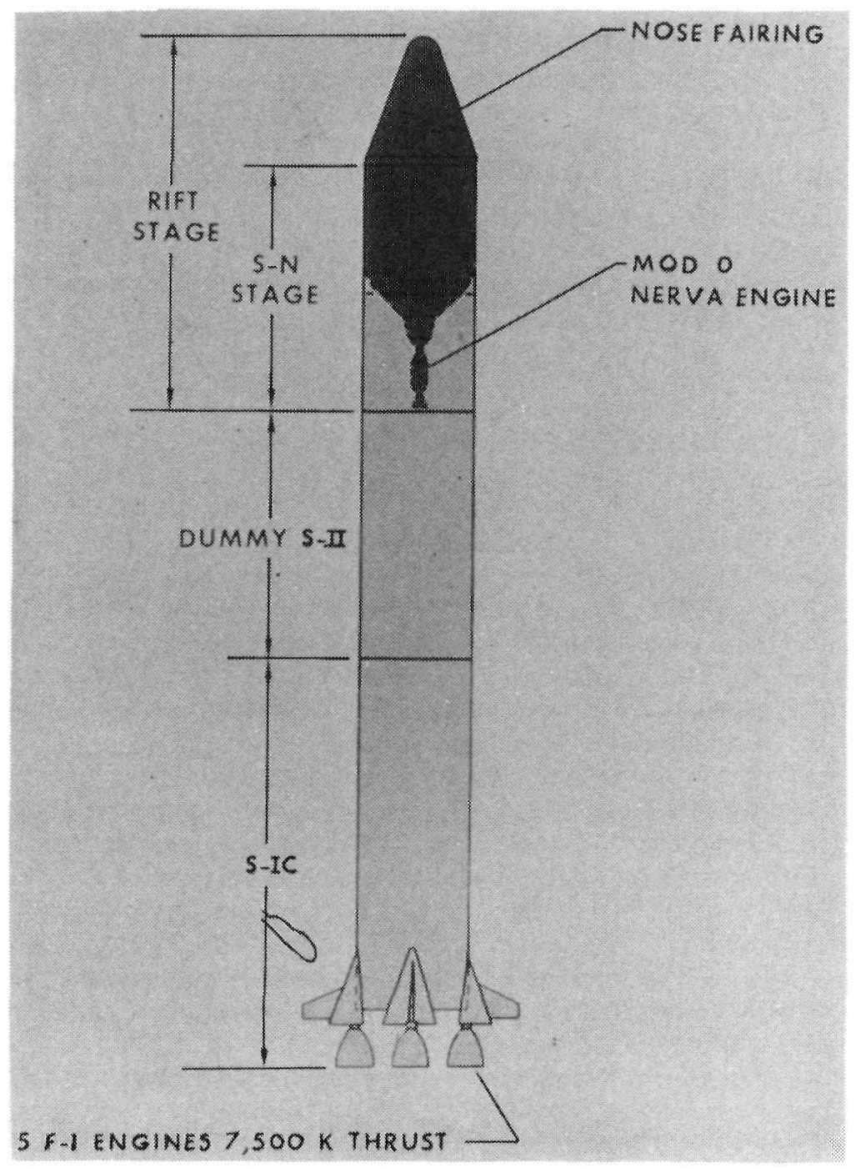

Figure 26. SATURN V/RIFT vehicle

The Instrument Unit (IU) containing the guidance and controls for the vehicle is 3 feet long and is mounted between the $\mathrm{S}-\mathrm{N}$ stage and the nose cone which projects above the IU to a length of 50 to 60 feet along a half angle of 15 degrees.

\section{S-N Stage Safety Systems}

The S-N stage safety systems, in addition to the SATURN V vehicle safety systems, are designed to reduce to a minimum the potential hazard associated with the flight of a nuclear-powered rocket. To provide maximum safety and reliability for the reactor-in-flight tests, the flight system must be capable of responding to all foreseeable malfunctions and of achieving an acceptable termination of the flight program at any point within the defined flight span.

Major S-N stage safety systems are as follows:

Criticality monitoring system

Propellant prevalve

Stage-Engine operational sequence safety system

Stage $\mathrm{GN}_{2}$ purge system

Engine purge system

Engine safety system

Stage destruct system 
A radiation monitoring system with detectors at strategic locations throughout the stage will provide information on neutron count and gamma radiation on a continuous basis. Alarm circuits will be triggered if preset levels are exceeded.

An isolation valve, referred to as the propellant "prevalve," will be located at the propellant tank outlet to prevent leakage of liquid hydrogen into the reactor system before scheduled thrust buildup. This valve consists of a stainless-stee1 disc surrounded by an annular ring of shearable metal alloy which provides a hermetic seal to the tank outlet line.

In-flight initiation of the $\mathrm{S}-\mathrm{N}$ stage operations requires that specific functions be accomplished in sequence with appropriate safety interlocks to ensure the safe startup, operation, and shutdown of the reactor/engine system. This function is performed by the stage-engine operational sequence safety system.

An inert-gas purge system will be used to reduce or eliminate undesirable gases such as oxygen from the propellant tank, interstage and forward equipment areas, and engine system. Reducing oxygen to less than 1 percent by volume in the inert gas will eliminate the oxygen/hydrogen explosive hazard.

Several engine safety systems are being considered. An anticriticality poison system would incorporate poison wires in the reactor to prevent reactivity buildup in case of inadvertent control-drum operation or immersion of the reactor in water. An anticriticality destruct system in combination with the stage destruct system would destroy the reactor in case of in-flight malfunction after booster separation and before engine power increase from 1-percent power hold to 100-percent power. A postoperational destruct system would fragment a radioactive engine and reduce the core to particles fine enough to reduce radiation to an acceptable level.

The stage destruct system will initiate engine shutdown and propellant tank destruction upon receipt of a properly coded RF signal. High reliability is achieved through use of two independent redundant circuits powered from separate electrical power buses. A common antenna system and common ordnance components are used because of their inherent reliability.

\author{
Prelaunch Testing
}

Nuclear rocket flight test stages, unlike chemical stages, will not have been test fired before flight because of the fission-product buildup and the induced radioactivity that such testing would produce. It is therefore mandatory that the development test program for RIFT include extensive prelaunch testing, effective quality assurance procedures, and as much simulation of flight conditions as practicable.

The RIFT program includes tests at the Propellant Tank Facility and the Cold Flow Facility and captive testing at the Nuclear Rocket Development Station (NRDS). Twenty to thirty test firings, simulating in-flight conditions, and functional sequences are to be conducted at NRDS before the first RIFT flight.

Preflight Operations

The safety record of chemical rocket operations involving large quantities of explosive and toxic materials at the Atlantic Missile Range has been outstanding. This record has been achieved through careful planning, thorough training, and adequate facilities and equipment.

The introduction of a nuclear-powered stage requires a new and complete examination of the elements which have contributed to the safety of chemical rocket operations plus additional study of the problems peculiar to the nuclear system. 
The Merritt Island Launch Area and the Atlantic Missile Range are we11 suited for nuclear launch operations with ample space for facilities and required exclusion areas. MILA and Launch Complex No. 39 (LC-39) from which the SATURN V, and therefore RIFT, will be launched, are shown in Figures 27 and 28. Three laumch pads are located along the ocean 8730 feet apart. This distance is sufficient to prevent damage to a vehicle in the event of an explosion of another vehicle on an adjacent pad during simultaneous checkout operations. The Vertical Assembly Building (VAB) in which the chemical stages will be checked out and erected is located approximately 3-1/2 miles west of the southernmost launch pad. A Nuclear Assembly Building (NAB) will be located approximately $1 / 2$ mile north of the VAB.

The closest public habitation to the LC-39 pads is along Highway US 1, and at Titusville, 10 to 11 miles away. Access to the VAB will be by barge, railroad, or highway.

The AMR extends from Cape Canaveral, Florida, into the Indian Ocean beyond South Africa and includes island tracking stations, instrumented ships and aircraft, and a11 necessary equipment for data acquisition and reduction incident to longrange missile and space vehicle operations.

A brief examination of the prelaunch operation which the SATURN V/RIFT vehicle will probably go through at MIIA will furnish the basis for more detailed consideration of potential hazards. The SATURN V stages and RIFT will be shipped to MILA by ocean-going vesse1s. Arriving at the canal terminus near the VAB, the S-1C and S-11 will be rolled off on their transporters and towed to the VAB, Figure 29. There, the S-1C will be erected on the Launcher Umbilical Tower (LUT) and the S-11 wil1 be taken to the low-bay area of the VAB for checkout. The RIFT stage will be towed on its transporter to the NAB for checkout and mating with the engine.

The reactor, engine, and RIFT stage will each be subjected to detailed inspections for shipping and handling damage, followed by functional checkout as required. The reactor will be mated to the engine and the subsequent checkout will probably include a criticality test to verify control-drum calibration and core reactivity. Following this test, the integrated NERVA engine/RIFT stage will be checked out and prepared for transportation to the VAB.

At the VAB high bay, the S-11 will have been erected on the booster and fina1 mating of the RIFT stage and the Instrument Unit (IU) will take place. After the mechanical mating and alignment of the stages and IU, the stages are mated to the LUT Ground support Equipment (GSE) and limited-stage/GSE checks performed before electrically mating the stages with each other. Following the completion of the stage-GSE compatibility tests, the stages will be electrically mated and the launchvehicle systems test performed.

When the complete vehicle is in a ready condition, the crawler-transporter, Figure 30 , is moved into position under the LUT. Hydraulic jacks will lift the LUT and vehicle and move out the crawlerway to the launch pad where the LUT wil1 be positioned onto prepared pedestals. The crawler will then move the arming tower, Figure 31, into position at the launch pad for ordnance installation and final servicing, Figure 32 .

At the pad, the LUT and space vehicle services such as digital data link communications circuitry, pneumatic and propellant lines, environmental controls, and power supply lines will be connected, the vehicle aligned, and ordnance installed.

The launch-pad program will consist of the following:

Limited subsystem verification check from the Launch Control Center (LCC)

Checkout of hardwire backup circuits to LCC

Tank pressurization test

Propellant loading test

RF systems test

Simulated flight test 

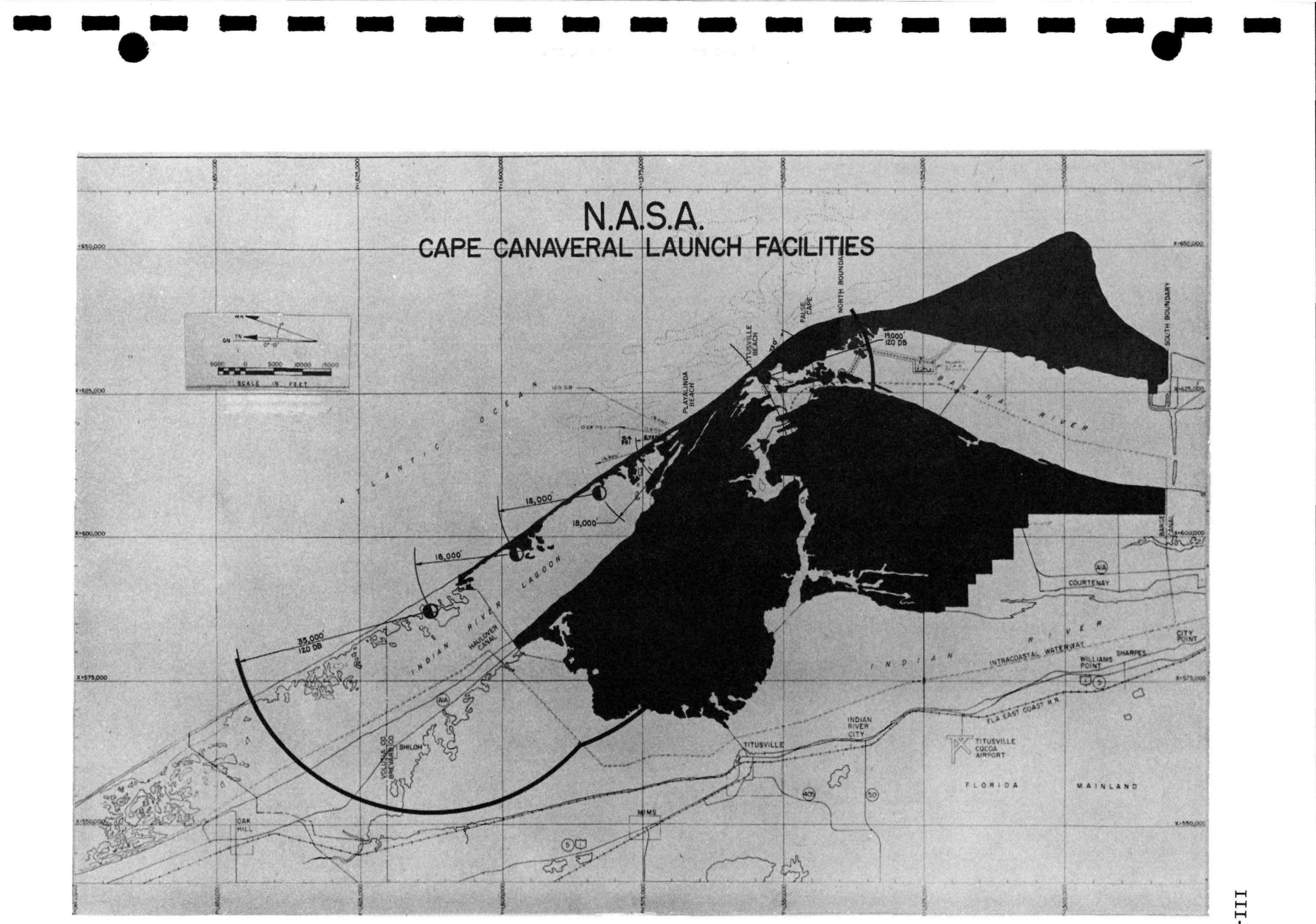


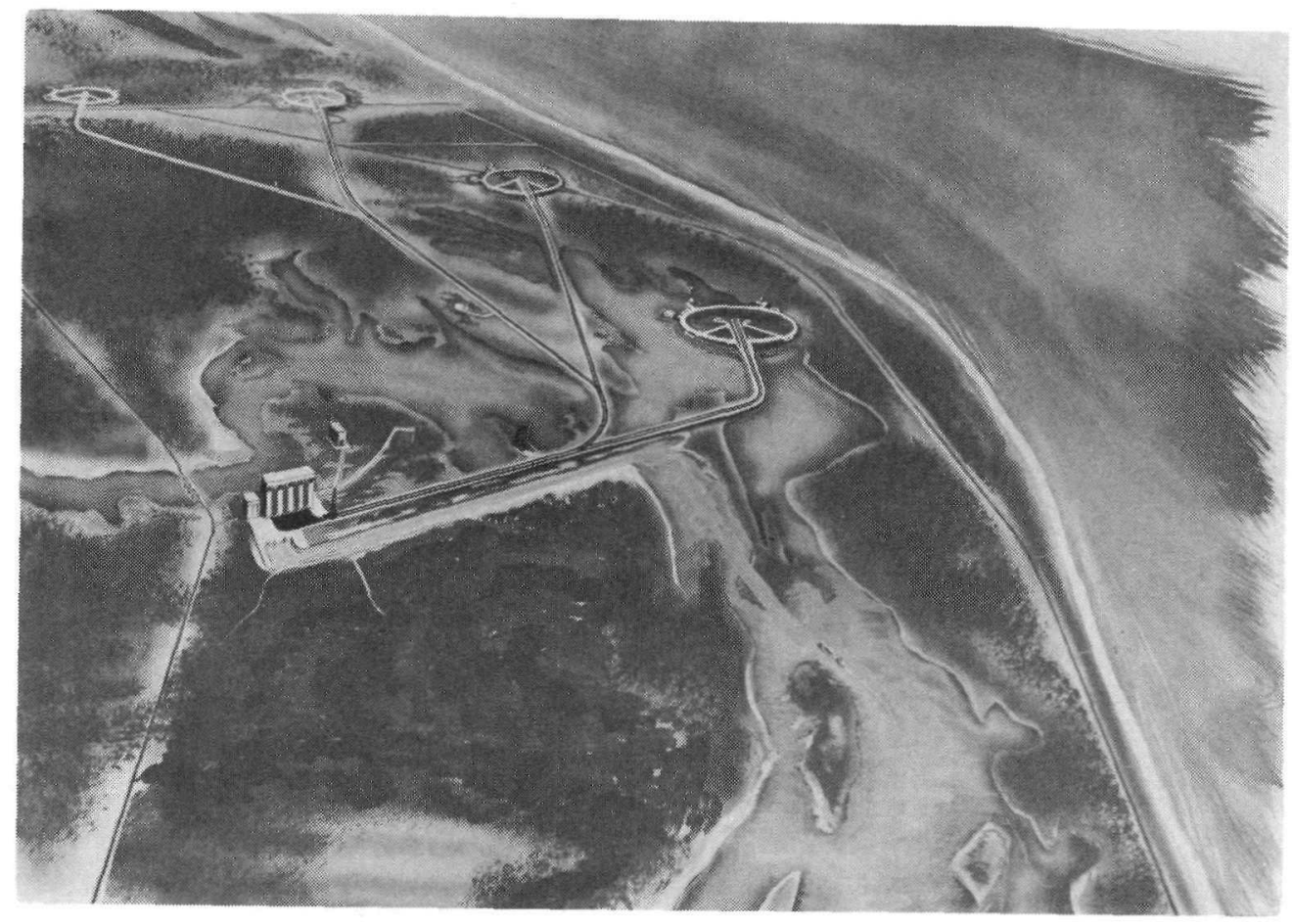

Figure 28. Launch Complex 39

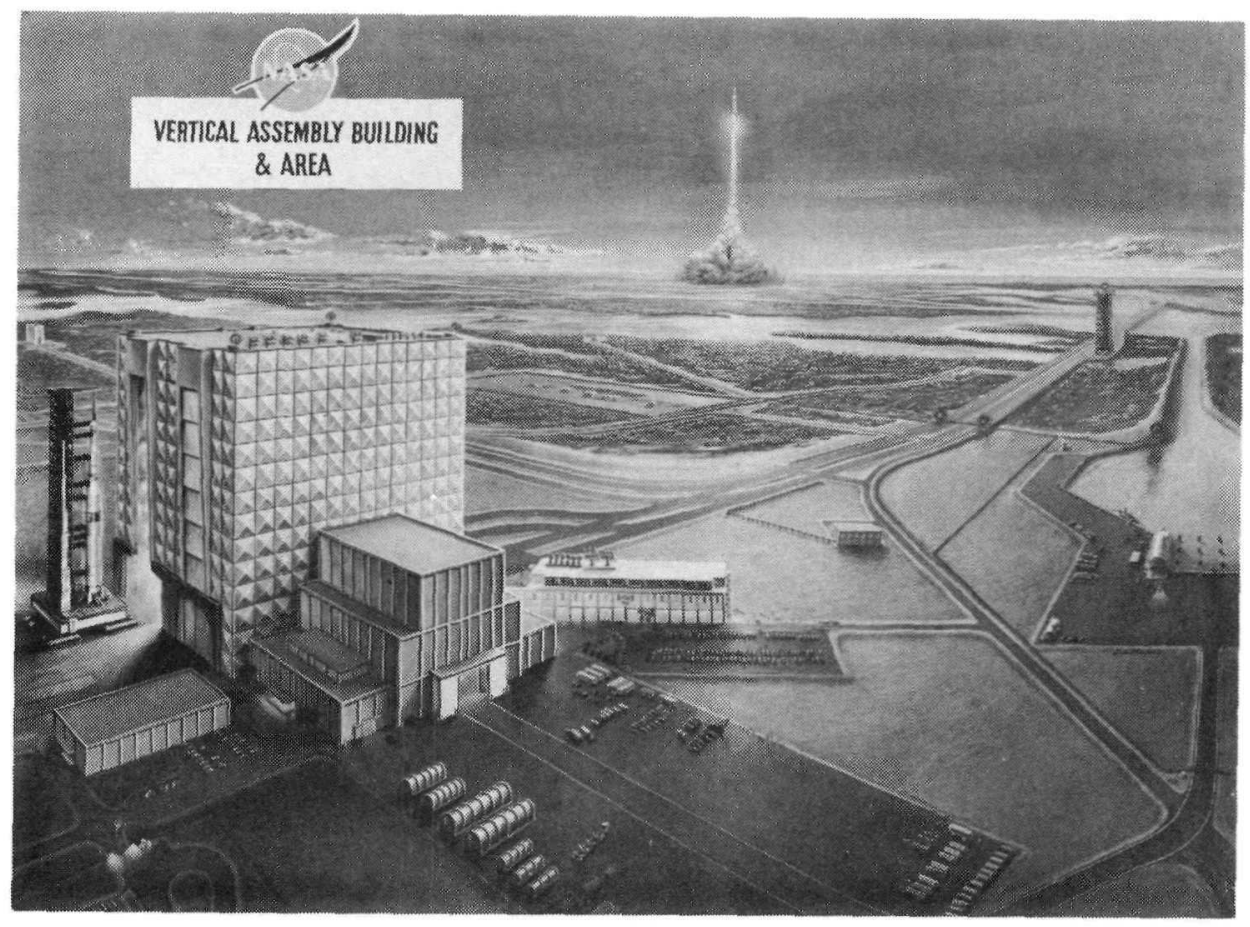

Figure 29. Vertical assembly building 


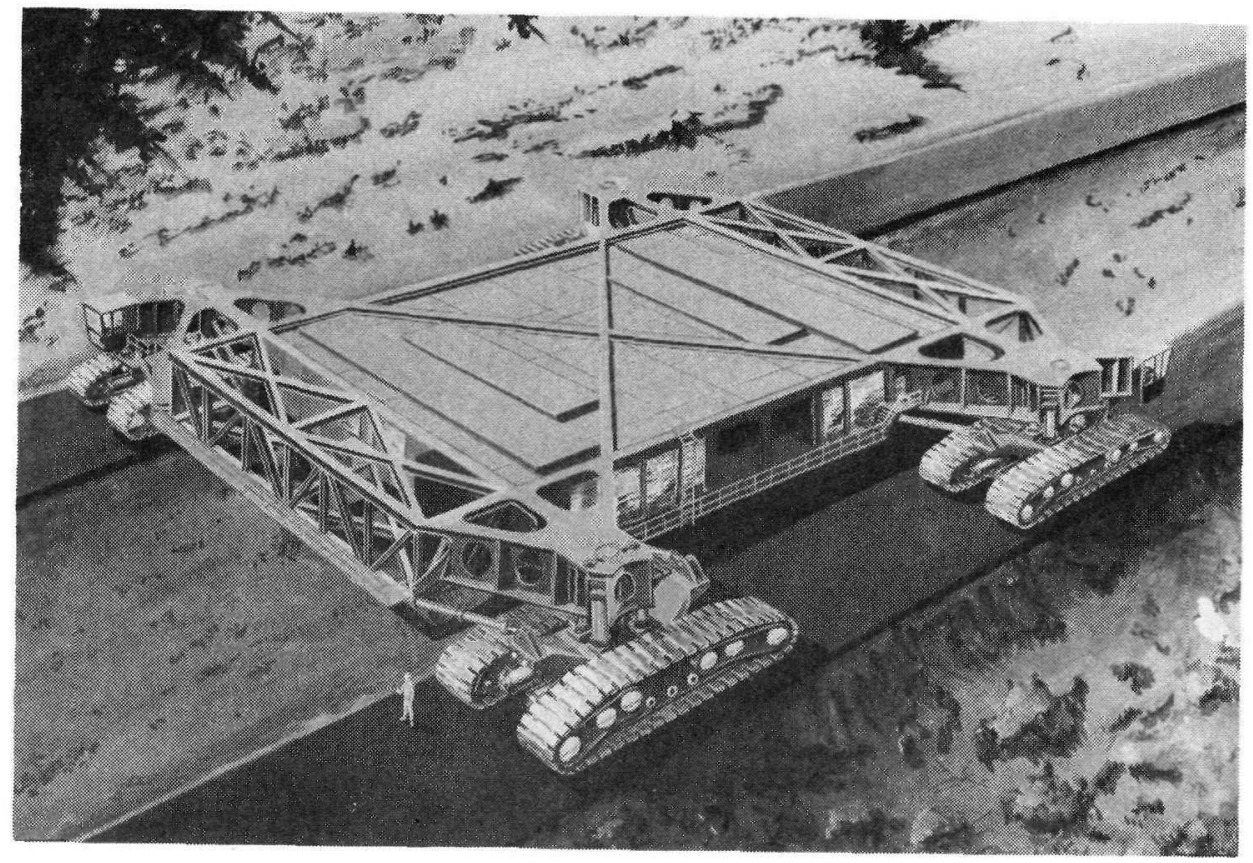

Figure 30. Crawler-transporter

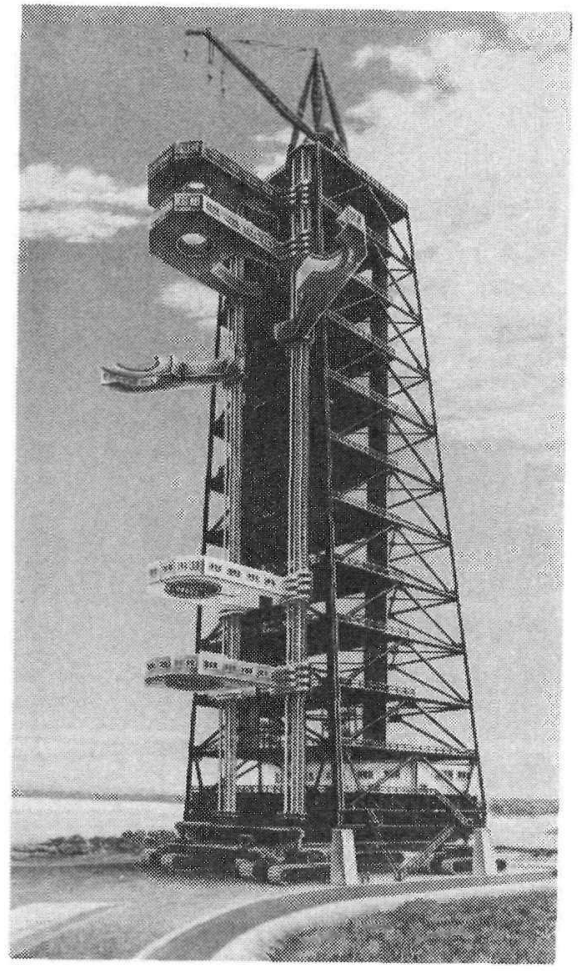

Figure 31. Arming tower

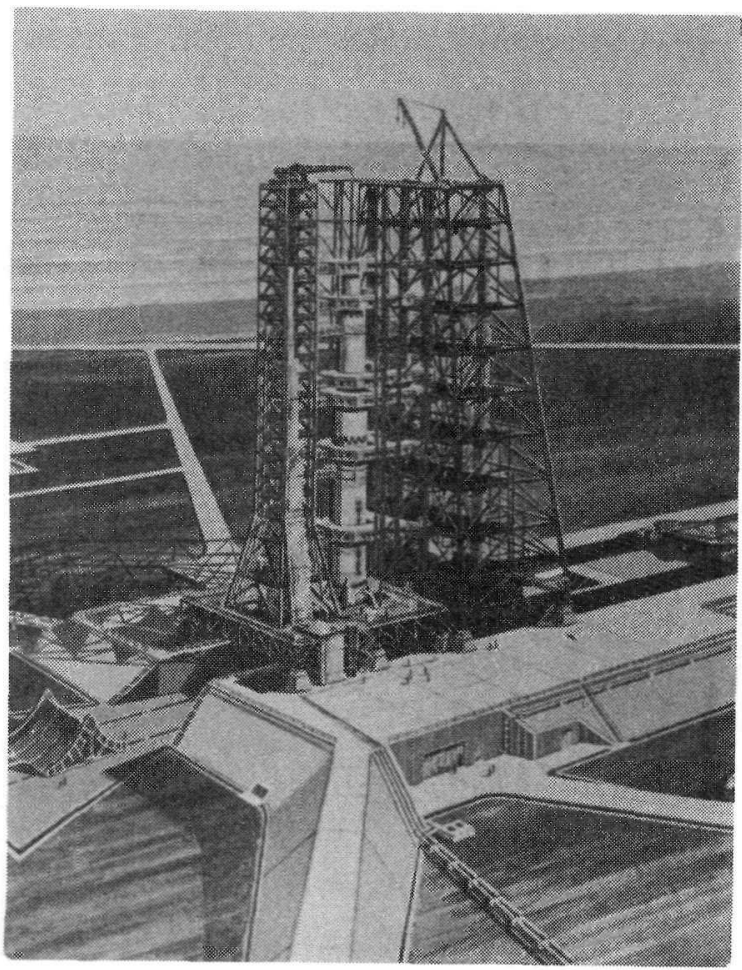

Figure 32. Launch site - LC39 
Following a successful simulated flight test, the vehicle is ready to enter the 10-hour countdown preparatory to launch.

Flight Operations

A typical trajectory for the RIFT mission is shown in Figures 33 and 34 . The NERVA engine will operate through programmed cycles and cool down before final impact in the deep ocean area beyond the Blake escarpment.

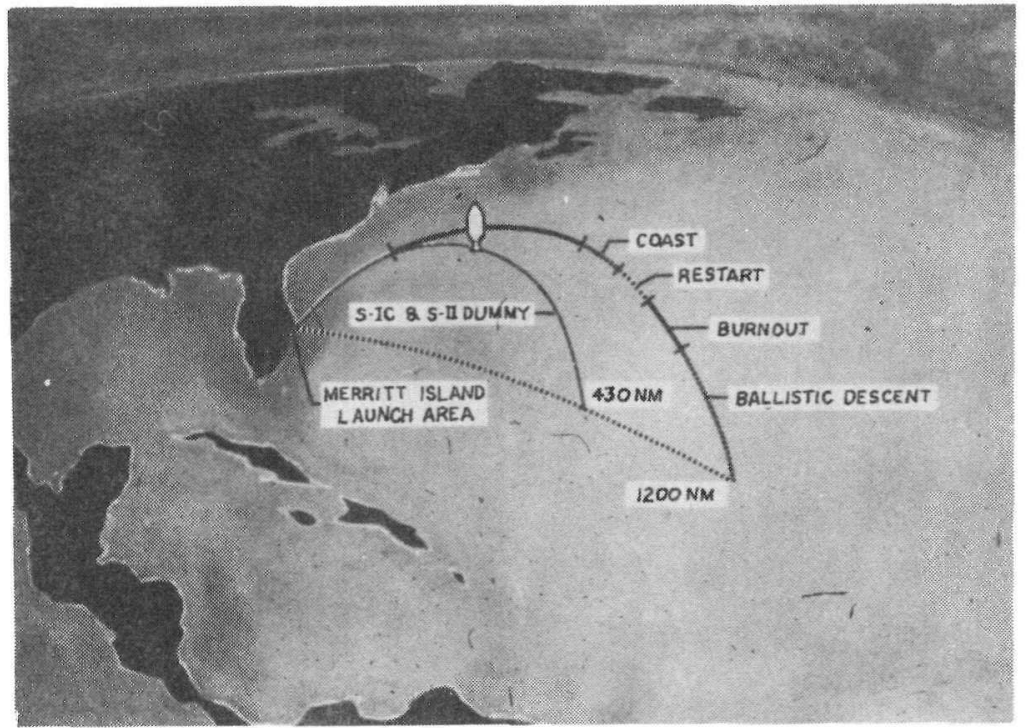

Figure 33. RIFT trajectory - Lob

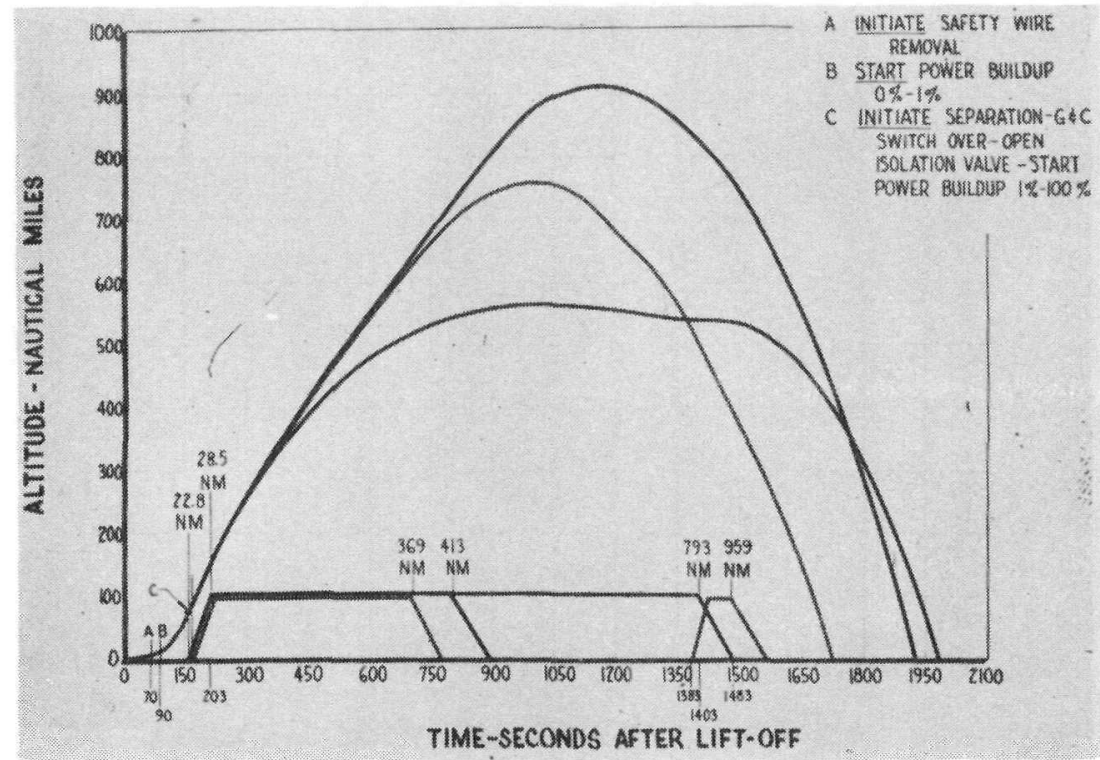

Figure 34. RIFT trajectory - Ballistic 
Safety Considerations

Before attempting to identify steps in the SATURN V/RIFT operation which could lead to a nuclear hazard, it is necessary to consider the conditions under which a nuclear excursion is credible. Several such conditions are readily identifiable:

\author{
Contro1-drum runout \\ Hydrogen filling of reactor \\ Core compaction from impact or explosion \\ Water immersion \\ Immersion in $\mathrm{RP}-1$
}

With the above conditions in mind, a step-by-step examination of the proposed SATURN V/RIFT operation at LC-39 will readily identify potentially hazardous conditions. Such a qualitative procedure, although necessary, can be misleading since the probability of occurrence of some of these so-called "credible accidents" may be so low as to make their consideration unrealistic. It will therefore be necessary to subject this sequence of operations to a quantitative analysis before judging the safety of the operation.

The reactor for the NERVA engine will arrive at MILA with full shipping poisons in place and can probably remain in this condition until it is mated with the engine. The type of poison system to be employed throughout the operation at MILA is a problem that is under active consideration at this time and will not be discussed in this paper although the final poison system selection will have a major effect on safety problems. During all ground checkout operations except reactor criticality and related tests, the reactor will contain at least enough poison to prevent inadvertent control-drum operation from causing a nuclear incident. The ultimate goal is to include sufficient poison to prevent the reactor from becoming critical under any conceivable circumstances.

\title{
NAB Operations
}

A review of the safety of operations as proposed within the NAB shows that only two of the accidents described previously merit any further consideration since no explosive propellants or liquid hydrogen will be present in the NAB. Consideration is therefore limited to control-drum runout and reactor deformation because of ground impact. Control drums will be locked and the core at least partially poisoned during the reactor/engine mating operation and during transit within the NAB. Thus, from a handling standpoint, the worst conceivable accident would be a drop of the partially poisoned core from a height of, at most, 20 feet during the initial operation of picking up the core for mating with the nonnuclear engine assembly. Preliminary analysis indicates that the dropping of a partially poisoned core from 20 feet will not result in a nuclear incident. Drop-test experiments will be conducted on scale reactor models to provide data from which core deformation calculations can be made.

Contro1-drum override poisons and drum locks must, of course, be removed during the performance of criticality checks and control-drum calibration in the reactor/engine checkout area. Thus, the safety of the system is degraded to its lowest level at this point in the operation. Criticality tests will be remotely performed in a controlled area from a shielded control room which would protect test personnel from direct radiation and fission-product dispersal in the event of a nuclear incident. The probability of a nuclear incident is quite remote since a large number of similar operations will have been performed, the particular core under test will have undergone a similar test before shipment, and a complete transit history will be available to give any indication of abnormal conditions or potential difficulties. Even so, the possibility of a control-drum runout at this point cannot be ruled out completely. 
The NAB will have a detailed personnel rad-safe protection program, an enclosedarea monitoring system, emergency protection equipment, and possibly a continuous engine/reactor monitoring system. All areas associated with reactor, reactor/engine, and engine/stage mating operations will be controlled, with limited access only to authorized personne1. These areas will be equipped with extensive detection equipment monitoring each area at several locations for air contamination, gamma rays, and neutrons. These systems will be coupled with an audible alarm system preset to actuate at a given radiation level. These fixed monitoring systems will be augmented by portable detection systems in critical areas such as the reactor and reactor/ engine assembly areas.

\section{Transport NAB to VAB}

The VAB is approximately 3000 feet from the NAB. Since transfer time may be scheduled to avoid unfavorable weather conditions, an accident does not appear credible that could result in a nuclear incident during this operation. Core poison is installed, drums are mechanically locked, and since there is no water along the route, water immersion is not credible.

\section{Operation in the VAB}

Before arrival of the RIFT stage, the S-11 stage will have been checked out and erected on the S-1C. The RIFT stage on its transporter will be positioned under the 250-ton crane in the high bay, removed from the transporter for mating to the interstage, and then hoisted into position on the S-11 stage.

Inasmuch as the drum locks and core poisons are not removed in the VAB, a drumrunout accident is not likely. Handling during the mating of the RIFT stage to the S-11 stage appears to be the only area in which an accident could occur. Although the possibility of such an incident seems extremely remote, the core compaction resulting from dropping the stage from an engine gimbal height of approximately 275 feet must be analyzed to determine the credibility of a nuclear incident.

\section{Transport from VAB to Launch Pad}

The distance from the VAB to the launch pad of 3-1/2 to 4-1/2 miles (depending on which pad is used) is traversed by the crawler at a maximum speed of 1 mile per hour. It can move at this speed against a steady wind of 40 knots. Winds greater than 99-percent probability during the strongest wind month (54-knot peak winds at 400 feet) necessitate immediate stoppage of the operation. A forecast of hurricane conditions would necessitate transfer back to the VAB, which is designed for hurricane protection. The crawler maintains the entire launcher platform level with \pm 10 minutes of arc over the entire distance, including the 300-foot transition curve to the pad.

During the operation, the only hazard apparent is the abundance of water on either side of the 150-foot crawlerway. It would be possible for the nuclear stage to be immersed in shallow water if the entire vehicle were tipped or blown over during the transit phase of the pad. If the poison system devised for the reactor core is found to be sufficient to prevent an excursion even in the event of water immersion, then this ceases to be a problem for consideration. The nuclear consequence of tipping the entire vehicle over into shallow water with the reactor partially poisoned and the control drums locked requires detailed analysis. If it is found that an excursion could result, the magnitude of such an accident would then have to be weighed against the probability of such an accident ever occurring and the costs of land filling 300 feet on both sides of the crawlerway. When the equipment to be used in this operation and the experience that will have been amassed in several years of SATURN V operations are considered, the possibility of such an accident seems extremely remote. 
Launch-Pad Operations

Overall operations at the pad before launch are expected to take approximately 2 weeks. Upon arrival at the pad, a11 LUT and vehicle service interconnects between the launch facility and LCC will be made. They include all digital data links, communications, pneumatic and propellant supply lines, environmental controls, and power distribution cables. All electrical interfaces are made at the launch facility distributor located at the pad terminal connection room. After all connections are made, overall vertical alignment of the vehicle is accomplished. The crawler then moves over to the arming tower (parked 7000 feet away from the pad) and moves it into position around the vehicle, thus providing 360 degrees of access to the vehicle for ordnance installation and special servicing requirements.

Installation of all ordnance that could not be installed in the VAB because of safety considerations is performed concurrently with other pad operations. (Note that although ordnance is installed, it is not armed until the day of launch.)

The overall launch-pad program, including the simulated flight test, is conducted preparatory to the launch countdown.

The simulated flight test will include a complete launch-day simulation. Compatibility with the range is verified at this time. This test is conducted through the high-speed data link between the LCC and LUT, the same link used in the VAB simulated flight tests. The hardwire system uses battery-powered independent circuitry as a backup link between the LCC and pad for safing and monitoring of the launch vehicle at the pad in the event of data-link failure. Critical reactor and engine control circuits for the RIFT stage will be monitored through this system. Up to this time, all of the pad operations discussed have been performed with the reactor control drums still mechanically locked and the reactor core poison in position.

Upon completion of a successful overall simulated flight, the vehicle is ready to enter the 10-hour countdown phase of the launch operation.

Up to launch day, the overall launch-pad checkout should not provide any greater degree of hazard from the nuclear state than that present during the VAB high-bay checkout because the drum locks and core poisons are still in place. The safety of the overall system is somewhat degraded as the countdown progresses by the connection of ordnance initiators and arming of the reactor destruct system. Removal of core poisons (if required) and removal of manual control-drum locks degrades the engine/reactor system safety to the level existing during the performance of criticality checks in the NAB. Propellant loading further degrades the system safety from an explosive hazard standpoint. All of the accidents previously postulated could occur at the launch pad including possible impact of the reactor in shallow water as a result of an early flight failure. Thus, the nuclear hazards associated with the following conditions must ultimately be analyzed in detail:

Gross control-drum runout during the latter phases of countdown (after removal of poison and manual locks).

Immersion of the reactor in liquid hydrogen or $\mathrm{RP}-1$ as a result of an explosion rupturing propellant tanks. (Injection of liquid hydrogen into the core through an engine valve failure or leak is precluded because of the prevalve used.) on the pad.

Implosion of the reactor core as the result of an explosion

Impact of the nuclear stage in shallow water as the result of an early flight failure.

As indicated, the time period during which these accidents could occur in the launch-pad area is quite small (approximately from T-5 hours up to launch time and immediately thereafter). To provide for these possible accidents, the following personne1, equipment, and procedures will be available for support in the launch-pad area: 

system.

An extensive launch-complex radiation detection and warning

Salvage vehicles and equipment.

Trained salvage crews for cleanup operations (protective clothing, portable radiation-detection devices, etc.) will be available.

Methods, equipment, and facilities for disposal of radioactive waste material.

Emergency plan for predicting affected areas.

Plans, based on detailed environmental surveys, for control of on- and off-site areas.

The equipment and planning will be based on the philosophy that even though the postulated accidents are not likely to occur, a11 credible eventualities must be provided for.

\section{F1ight}

The most hazardous phase of any rocket operation, and particularly one containing any kind of a nuclear device, is the period immediately following ignition and continuing into the early flight phase. In conjunction with the vehicle destruct system, the reactor destruct system previously described can be actuated by the range safety officer as soon as a vehicle deviates from its planned trajectory. The incorporation of a reactor poison system capable of in-flight actuation would provide further backup to the reactor destruct system.

Impact of the reactor off-shore does not constitute any more of an immediate hazard to personnel than an accident in the vicinity of the launch pad. Such an impact may, however, require continuing surveillance to protect the populace from contaminated marine life or from radioactive material carried by ocean tides and currents.

Downrange activity during a typical RIFT flight will be supported by stations in the Bahama Island chain (Grand Bahama, San Salvador, and Grand Turk Islands), instrumented ships, and aircraft. The ships will be on station 5 hours and the aircraft 1 hour before launch to cover re-entry and impact. Additional ships and instrumented aircraft will be required for the RIFT flights to monitor the fate of airborne and seaborne fission products released by the postoperational destruct of the NERVA engine. The same airborne and surface craft requirements exist to monitor and record radioactivity in case of the impact of an expended NERVA engine into deep water.

\section{Conclusions}

The RIFT vehicle, typical RIFT trajectories, prelaunch, launch and flight operations and their related safety considerations, based on current planning, have been described. It should be emphasized that the launch of the RIFT vehicle is several years away and the potential hazards of the operation have been subjected to only preliminary study.

The evaluation of the safety of RIFT operations is and will continue to be of prime importance as NERVA and RIFT designs mature and as test data evolve. Much work has been done in support of the RIFT flight-safety program, and these efforts are being intensified to ensure satisfactory solution of the related safety problems before flight testing begins. 
Current data and analyses lead to the conclusion that the probability of a nuclear incident of any kind as a result of planned RIFT operations at Cape Canaveral is remote and that the dangers involved should such an incident occur are acceptably low. 


\section{BLANK}




\section{A BRIEF DESCRIPTION OF THE ROVER-TYPE REACTOR-- ITS INHERENT SAFETY PROBLEMS AND TEST PROGRAMS}

$$
\text { L. D. P. King }
$$

Los Alamos Scientific Laboratory

Introduction

The Rover program has associated with it three principal phases and pieces of hardware. These programs are known as Kiwi (a flightless New Zealand bird), NERVA (Nuclear Engine for Rocket Vehicle Application), and RIFT (Reactor-in-Flight Tests). Since the inception of the program, the Los Alamos Scientific Laboratory has been closely associated with the design and development of the basic reactor configuration called Kiwi. As the name implies, this part of the program was never supposed to produce a flyable device. The engineering of this reactor into a flyable engine, the NERVA program, is being carried out by Aeroject-General and Westinghouse in a series of engine tests known as NRX. The fully designed engine will then be integrated into the complete flight vehicle stage by the Lockheed Missiles and Space Company in the RIFT program.

In his paper, Maj. Hock (see Paper III-1) confined his remarks to the overall vehicle problems as seen by personnel responsible for the successful launch of the RIFT vehicle. In this paper, I will give a brief description of the Rover-type reactor and its inherent safety problems and then describe a few of the test programs.

\section{Reactor Description}

Reactors designed for space applications fall into two general categories: (1) those intended to provide electrical power for equipment or propulsion, and (2) those intended for propulsion by means of a direct cycle heat exchanger. The Rover program is in the latter category.

In this paper I will describe the reactor itself and then give a brief survey of the current development effort. As can be seen from Figure 35, my description will be limited, since details of the reactor design and its performance are still considered classified.

The previous Kiwi series of reactor tests has been carried out at the Nuclear Rocket Development Center in Nevada to proof test a number of possible core designs. The Kiwi B-4 and NRX series of hot tests, planned for early next year, represent the most promising design from which approximately 50,000 pounds of thrust per 1000 megawatts of reactor power is expected.

The principal Kiwi-B4 reactor components are:

1. numerous uranium graphite bearing fuel elements with multiple coolant passages,

2. an external composite reflector,

3. a series of control rods within the reflector region, 
4. a pressure vesse1, and

5. a nozzle for proper gas expansion.

The critical mass is several hundred kilograms of $\mathrm{U}^{235}$.

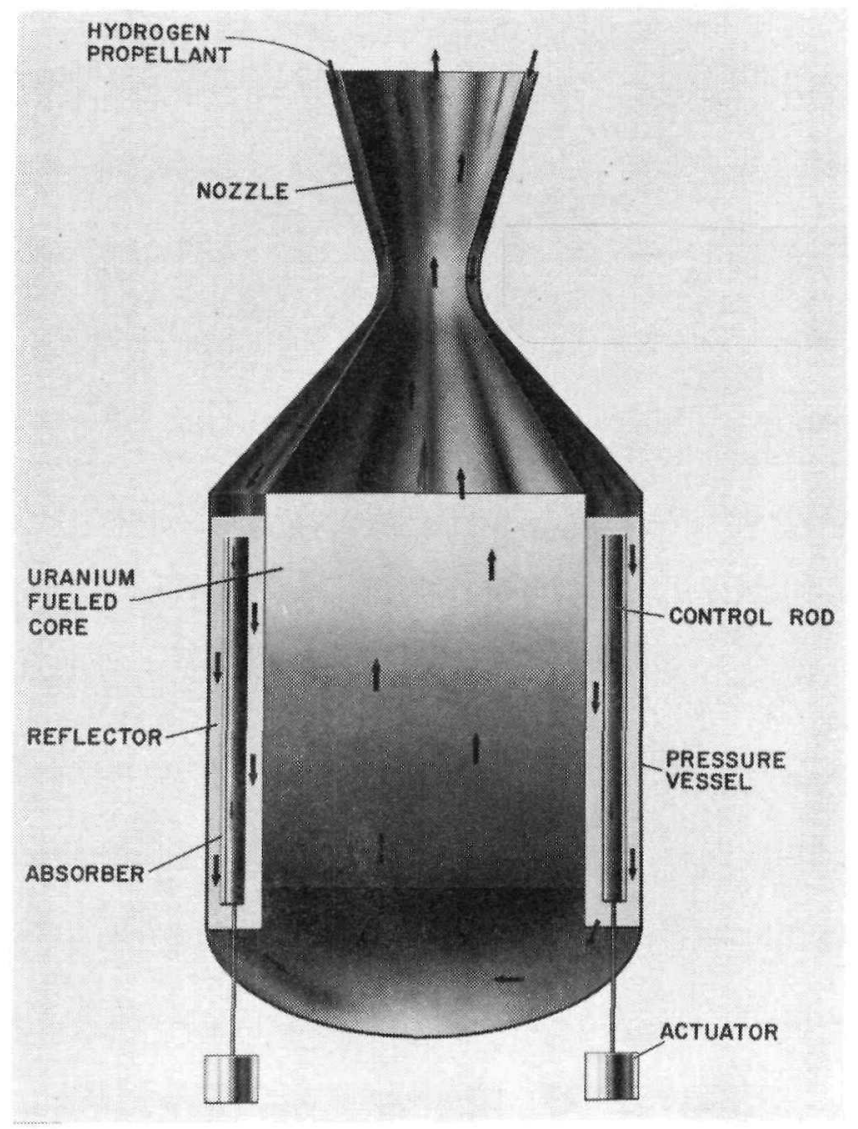

Figure 35. Schematic reactor

Liquid hydrogen serves both as a coolant and propellant. The propellant enters the system by flowing through the nozzle shell for regenerative cooling. It then flows through the coolant passages in the reflector surrounding the core and along the inner surfaces of the pressure vessel. Vaporization takes place in this zone. The flow from the reflector assemblies is directed along the pressure vessel dome and through a plenum chamber which distributes the coolant through the multiple passages in the fuel elements. The thermal power of the reactor is absorbed in this region. The propellant is then discharged at very high temperature and velocity through the nozzle.

More details can be seen in Figure 36, an external view of the reactor in the disassembly building after operation. Extending below the pressure vesse 1 are the contro1-rod actuators.

Figure 37 shows the reactor on the test stand at the Nevada Reactor Test Site. This figure also shows the method of introducing the liquid hydrogen into the nozzle. 
III-2

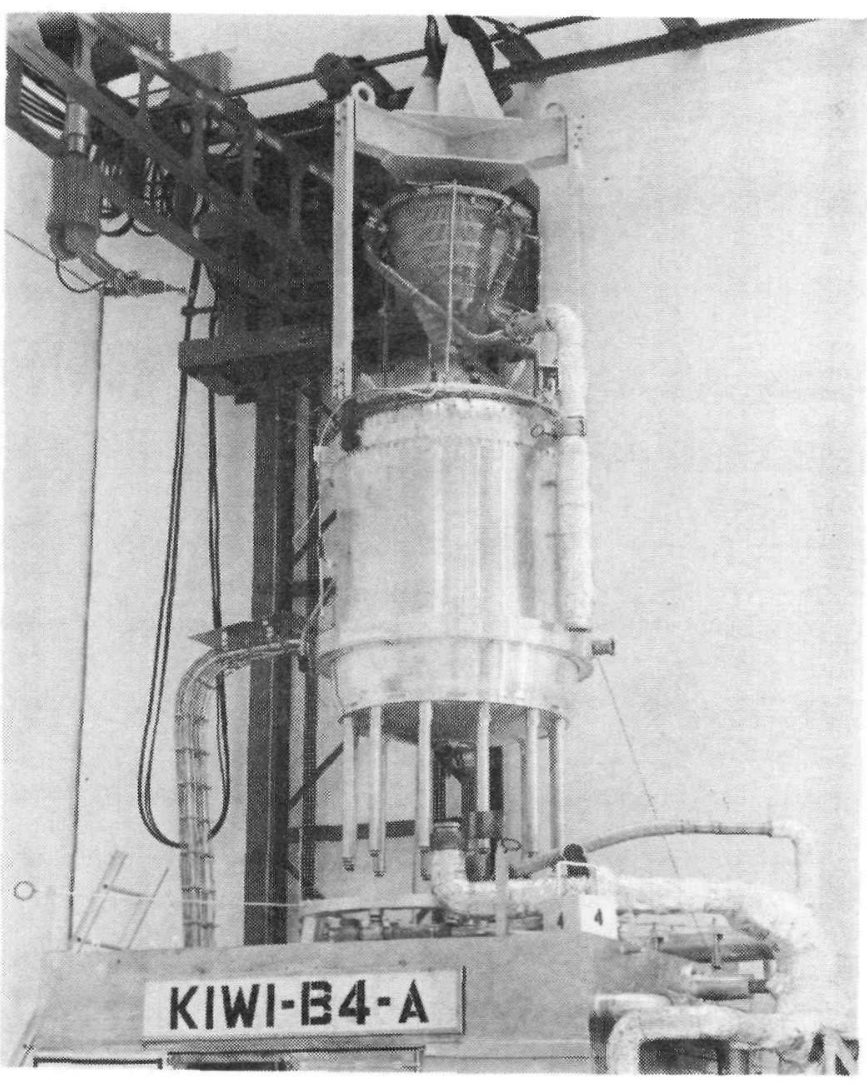

Figure 36.

Kiwi B4-A

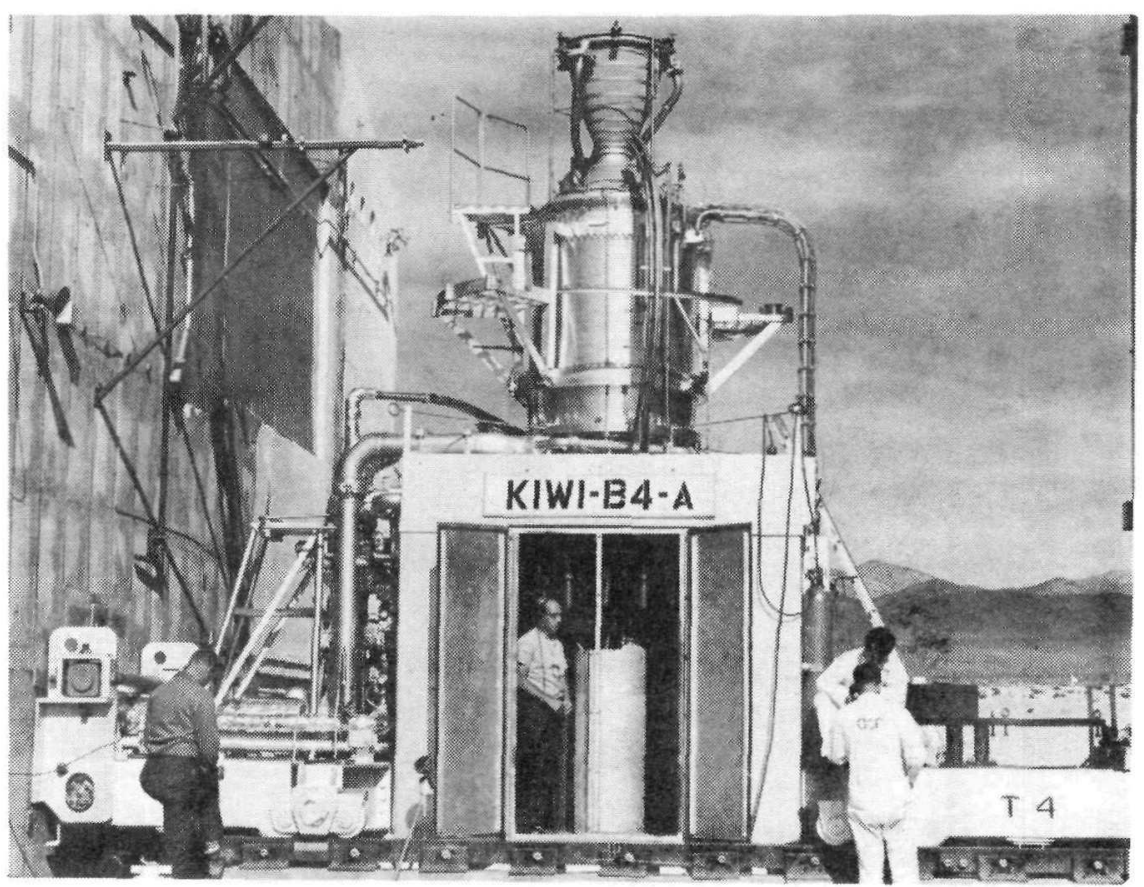

Figure 37. Kiwi B4-A on test stand 
The use of nuclear rockets has required additional safety analysis in the following areas: (1) the determination of the magnitude, the probability, and the consequences of nuclear incidents on or near the launch pad and the means of preventing such potential accidents, and (2) the disposal after reactor operation of the highly radioactive core in a manner which does not expose the general public to undue hazards.

\section{Test Programs}

An extensive safety program sponsored by the joint AEC/NASA Space Nuclear Propulsion Office is now in progress to cope with these problems. A Rover Flight Safety Panel has been appointed by this office to act as an advisory group. Membership includes the principal government and industrial participants in the Rover program.

Overa11 safety work now in progress includes detailed studies and experiments to determine such items as

1. safe reactor assembly and transport to Cape Canavera1,

2. reactor checkout and mating to the engine,

3. assembly of the nuclear stage to the overall vehicle,

4. trajectory studies for optimum safety,

5. anticriticality and poison systems for the safe handling and launch of the reactor,

6. destruct and disposal schemes to eliminate any hazard to the general public after reactor operation,

7. a study of the overal1 radiation problems associated with the use of nuclear rockets, and

8. the magnitude and consequences of the principal types of potential nuclear accidents. analysis.

Let us now look at the first principal area requiring additional safety

\section{Analysis of Launch-Pad Accidents}

A number of different accidents are conceivable during the vehicle assembly at the launch pad. An extensive analytical program has been in progress at Los Alamos to evaluate the magnitude of the more probable and those of large potential hazard. More about this work will be given in the following paper.

Initial results indicate that some of these may have an appreciable nuclear yield. Serious consideration has therefore been given to the use of a complete reactor poison system which will remove the possibility of a nuclear incident. More details of such a system are given in Paper III-4, Flight Operational Safety Systems for NERVA, by R. I. Unger.

A survey of the many possible causes for nuclear excursions on or near the launch pad has led to selection of the following general types for more detailed analysis. 
1. Dry excursions (i.e., not involving water or propellants).

a. Inadvertent control-rod motion.

b. Land impact of the reactor with collapse of the core into a more critical geometry.

2. Wet excursions (propellants or water immersion).

a. Core flooding by water or propellant.

b. Core implosion from a booster-propellant explosion.

\section{Dry Excursions}

The reactor response to control-rod motion is in general we11 understood from the design and testing of the reactor. The probability of accidental rod motion can be reduced to a very low value by proper design and by use of prescribed handling procedures.

It is more difficult to determine the consequences of a core impact since the yield will depend on the rate of density increase in the core region. Two scale experiments have just been completed to assist in the evaluation of such accidents. One experiment consisted of dropping a 1/3-scale core 75 feet onto a steel slab; another simulated a 300-foot drop by impacting the core following rocket-sled acceleration.

Figure 38 illustrates the sled setup used by the Sandia Corporation to produce a 140-foot-per-second impact velocity.

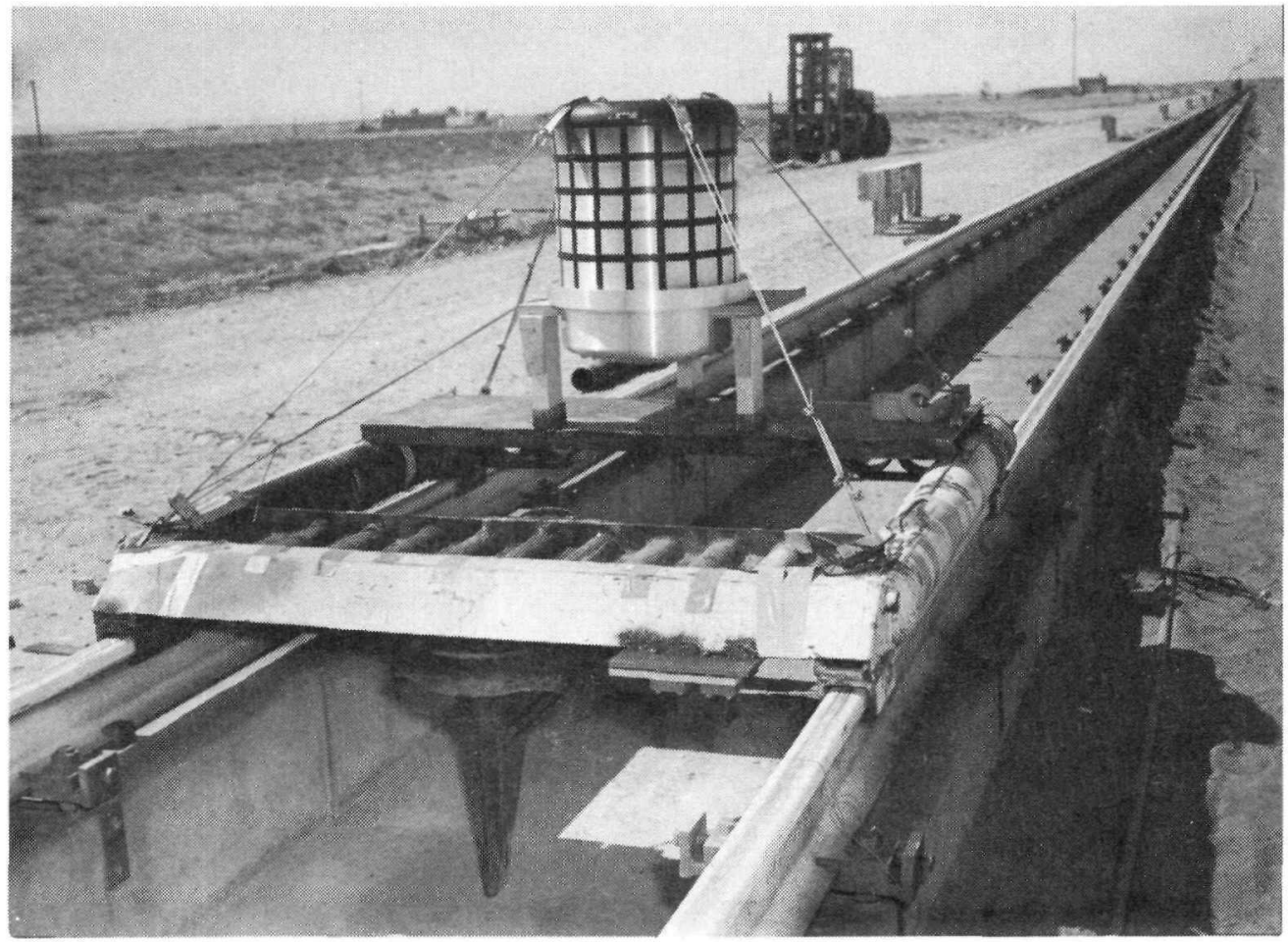

Figure 38. Reactor impact test setup 
Figure 39 shows a composite view of the scale reactor at the moment of impact and about 1 millisecond later when the compression was at a maximum.
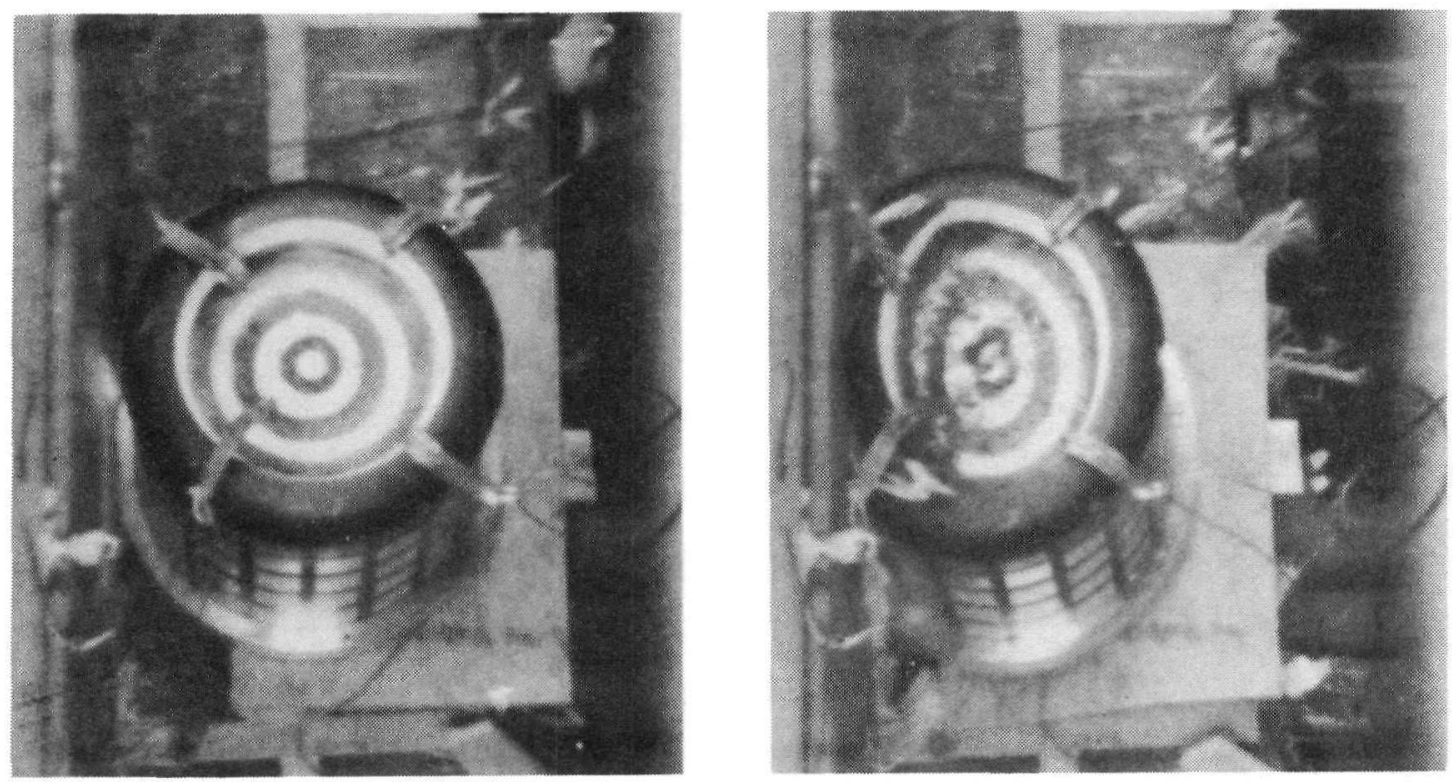

Figure 39. Reactor impact

Density as a function of time is determined by a number of simultaneous gammaray transmission measurements together with high-speed photography of the change in core geometry during impact. No density increase was observed in the 75-foot drop test; the 300-foot equivalent drop indicated a definite density increase of 5 percent or less. Estimates of the nuclear yield based on these recent measurements will be given in the following paper.

\section{Wet Excursions}

Let us now consider the wet type of nuclear incidents. The principal causes are (1) flooding of the core by water or propellant, and (2) core implosion produced by a booster-propellant explosion.

The probability of core flooding either from the handling of the engine in the vicinity of the large amounts of hydrogenous materials existing at the launch area or from booster failure is appreciable. The detonation of large amounts of $\mathrm{LH}_{\mathbf{2}}, \mathrm{LO}_{\mathbf{2}}$, and RP-1 can result in large overpressures. This type of incident appears to provide the largest potential yield with estimates in the range of $10^{21}$ to $10^{22}$ fissions. The use of a poison system will prevent this type of nuclear excursion on the launch pad.

Since predictions of the size of accidents can never be any better than the assumptions which must be made in the calculations, it is of importance to obtain experimental information where possible as a check. A number of experiments are in progress at LASL to determine the magnitude of a nuclear incident produced by water entering the core.

Calculations and measurements were made to determine if it might be possible for a nuclear engine to continue operation for extended times if it were subjected to gradual, accidental water or fuel flooding. These included measurements of the heat-transfer properties between water and uranium-graphite fuel material at elevated temperatures as we11 as estimates of fuel life for water immersion at temperatures 
from $500^{\circ}$ to over $2000^{\circ} \mathrm{C}$. Heat-transfer rates between fuel and water were found to vary by over a factor of 17 in this temperature range. The fue 1 material was surprisingly resistant to attack by water until very high temperatures were reached. On the other hand, estimates indicate that only very low power levels can be tolerated without reaching excessive temperatures since cooling can only take place by conduction from the external surfaces of the reactor to the water. These results make it appear extremely unlikely reactivity conditions could ever be such that a reactor could operate in a "chugging" or semistable condition and thus build up an appreciable fission product inventory. The most probable result is an almost instantaneous nuclear incident which fragments the core and prevents further operation. If immediate destruction does not occur, the reactor will tend to build up extreme internal temperatures because of poor heat conduction out of the core. The result is destruction by rapid erosion, vaporization, and melting of reactor components.

Accurate prediction of the fission yield and kinetic energy release of wettype excursions is difficult. The reactivity coefficient as a function of temperature is not known under transient conditions. One does not have a good knowledge of the equation of state for graphite in the important region from the point of vaporization to beyond the triple point $\left(-4000^{\circ} \mathrm{K}\right.$ at 100 atmospheres), and the detailed behavior of the uranium-graphite fuel under rapid transient conditions is not we 11 known.

A number of experiments are planned to aid calculations in such accident estimates. In particular, a full-scale reactor excursion will be carried out at NRDS in Nevada in about 1 year.

This experiment is aimed at obtaining a number of important parameters which will assist in understanding excursions in a nuclear rocket engine. Since the wettype excursion is expected to produce the largest yield and the disposal of the reactor in the ocean is permissible during the RIFT program, it appears desirable to obtain first-hand information for this type of nuclear incident. It is therefore planned to place the reactor immediately above a large water basin and deliberately inject water into the coolant channels under well known conditions.

The experiment is aimed at releasing about $10^{21}$ fissions with a possible kinetic energy release of a few hundred pounds of $\mathrm{HE}$ equivalent.

Data from this test, known as "SWET," for Simulated Water Entry Test, should provide the following:

1. A check on the predicted yield and on the assumptions made in the calculations. This will permit a greater reliance on calculational predictions for other possible nuclear transients.

2. A detailed study of the dispersal of fission products in air and water. Fission product dispersal is highly dependent on the cloud rise, and this experiment will determine the type of cloud rise to be expected from an excursion at low altitude over water.

3. The kind of missile damage and the cleanup which an excursion requires.

4. Data for postoperational disposal by a nuclear transient.

The upper limit of a water-impact incident depends on how fast water can be introduced into the core. This can be determined by measurements now in progress on the breakup of the fuel elements and collapse of the nozzle as a function of water-impact velocity. 
Postoperational Reactor Disposal

The second major safety problem is the disposal of the nuclear engine after successful operation or in case of some malfunction after startup. A nuclear incident because of re-entry before reactor startup can always be avoided by the use of an explosive system which will break the reactor up into pieces that will not go critical upon water immersion, i.e., an anticriticality destruct system. The REON* Division of Aerojet-General is working on such a system.

The problem becomes somewhat more difficult if the reactor has operated and built up an appreciable fission product inventory, which may be in the range of $10^{6}$ to $10^{7}$ curies. In the present RIFT program, which uses a ballistic trajectory over a controlled deep-water area, disposal of the reactor as a whole is permissible under the present rules. It is thought to be highly desirable, however, to test disposal techniques, which would be required on any nuclear space mission, during the RIFT program. A number of disposal systems have been thought of to take care of such a situation:

1. the use of an auxiliary chemical propulsion system to place the nuclear rocket in orbit in case of failure,

2. starting the nuclear rocket only after achieving orbit,

3. chemical attack on core materials,

4. chemical explosives for reactor fragmentation, and

5. nuclear explosion for reactor fragmentation.

Marshal1 Space Flight Center and the Lockheed Missile and Space Company have investigated the feasibility of the first two methods. Both are possible but result in a considerable loss in payload.

Chemical explosives for reactor fragmentation have shown some promise in work performed at LASL, Aerojet-General, and the Aberdeen Proving Grounds. It appears difficult, however, to achieve complete fragmentation. Objections to this disposal scheme are that (1) some fragments appear to remain with volumes of several cubic centimeters, and (2) the weight of the necessary projectiles and launchers is large.

The use of chemical additives to weaken or disintegrate the core materials has shown some promise. In particular, this approach in conjunction with one of the other schemes may enable more complete fragmentation or enhance the burnup of the fragments on re-entry.

The fifth method is under active investigation at LASL. Calculations and inpile experiments have been carried out which indicate that some types of Rover fuel can be fragmented into very sma11 pieces by a rapid, deliberate nuclear transient. Experiments resulting in fuel fragmentation have been performed both by rapid electrical heating as we11 as in Argonne Laboratories' TREAT Reactor Facility. These experiments as we11 as calculations have shown that fragmentation is quite dependent on the detailed fuel composition as well as on the speed of the nuclear transient.

Additional in-pile fuel experiments for testing the nuclear destruct concept are planned in the near future in reactors being tested to destruction in the SPERT and STEP programs being carried out by the Phillips Petroleum Company at Arco, Idaho.

This concept for reactor disposal appears to have several possible advantages since calculations indicate that a hydrogenous projectile can produce a very rapid nuclear transient.

\footnotetext{
Rocket Engine Operations - Nuclear
} 
1. The launching mechanism may be lighter and simpler and the projectile is less sensitive to radiation damage.

2. The fragmentation promises, on the basis of recent in-pile tests, to be much more complete.

3. Residual activity of the fragments should be lower. Since the uranium particles and their immediate surroundings are heated to the highest temperature, most of the fission products should be vaporized and escape in space or be deposited on the surface of fragments where they can be lost by ablative processes during re-entry.

Experiments directed toward understanding the direct radiation hazard from the escape of fission products under a variety of normal and accidental reactor conditions have been performed at LASL. Such experiments include the leaching rates of fission products from fuel samples under a variety of water-immersion conditions, the escape of fission products from the fuel under normal full-power operating conditions, and the escape of fission products from the fuel under abnormal situations of extreme reactor temperature and rapid transient conditions.

The Nava1 Radiological Defense Laboratory is performing more detailed work on the release of fission products into water. Nuclear Utilities Services is under contract with the Space Nuclear Propulsion Office to conduct an evaluation of the overall environmental safety aspects of nuclear flight operations at Cape Canaveral. One item under study in this contract is the problem of returning reactor fragments after disposal in space. In particular, the size requirements which will satisfy all public health and safety requirements is under detailed investigation.

Conclusions

At the present time it appears that there are no insurmountable safety problems created by the application of nuclear power for rocket propulsion. The use of a poison system in the reactor core during all assembly and launch procedures will completely remove all safety worries in handiing a reactor on or near the launch pad. Such a system now appears quite feasible.

The problem of postoperational disposal has been attacked in a number of ways with the promise that one or several schemes will satisfy all safety requirements. 


\section{BLANK}




\author{
ROVER REACTOR TRANSIENT ANALYSES* \\ W. R. Stratton \\ C. G. Chezem \\ Los Alamos Scientific Laboratory
}

Introduction

This paper reports on the methods used and the current capabilities for estimating the power history, fission energy release, and dynamic behavior of a Kiwi-B4 reactor when it is subjected to abnormal changes of reactivity. Conceptual accidents that are considered arise from (1) assumed malfunction of the control vanes, (2) the lack of complete reflection (immersion in water), (3) the undermoderated character of the core (water or liquid-hydrogen flooding), and (4) the existence of void space in the core (compaction following impact on concrete or implosion within chemical propellants). A special and related case is that of the purposeful destruction of the reactor in orbit about the earth following full power operations.

The information seemingly required for various hazards studies includes (1) the total fission yield, (2) the kinetic or explosive energies, (3) the final state of the core material (temperature, solid, vapor, etc.) and (4) distribution of corematerial particle sizes. In addition, any calculational scheme must allow for arbitrary inputs of reactivity and arbitrary alterations of the flux density within the core. These requirements are considerably greater than can be satisfied with, for example, the energy mode $1^{2}$ of a prompt power excursion; to attempt to supply the information, recourse is made to detailed computation by digital computers. Not a11 of the above requirements are satisfied.

The philosophy adopted has been to find a means to describe a generalized accident and use this to provide a framework within which each accident type with its special characteristics may be fitted. The codes employed are the we11-known RTS, which numerically integrates the neutron kinetic equations, and the relatively new RAC, which, though not completed, is designed to follow changes in the core geometry and physical state of the material.

Codes

\title{
$\underline{\text { RTS } \text { Code }^{2}}$
}

The RTS code integrates the reactor kinetic equations with no approximations beyond the usual space-independent and one-velocity assumptions involving the introduction of an effective delayed-neutron fraction and an effective prompt-neutron generation time. For Kiwi-B4 reactors, the delayed fraction $\beta$ 3 and prompt generation time, $\boldsymbol{\ell},{ }^{4}$ are $7.8 \times 10^{-3}$ and $2.5 \times 10^{-5}$ second, respectively. Input to the RTS code may include a completely arbitrary reactivity function and either a constant or

\footnotetext{
*Presented by Dr. Stratton
} 
time-varying energy coefficient of reactivity* such that

$$
\delta k(t)=\delta k_{0}(t)+b E^{f}(t)
$$

In Eq. (1), $\delta k_{\mathrm{O}}(\mathrm{t})$ is the imposed reactivity function, $\mathrm{E}^{\mathrm{f}}$ is the fission energy density at time $t$, and $b$ is a negative energy coefficient of reactivity appropriate to the reactor of interest. Given these inputs, the code returns the resulting period, power response, energy density, and compensated reactivity as a function of time. To obtain results pertinent to any given reactor, additional assumptions must be formulated about spatial flux densities, constancy of the reactivity coefficients over the range of interest, and the physical state of the reactor-core material during the transient. This code is most useful for Rover purposes in the reactivity region between delayed critical and somewhat above prompt critical.

The RTS code has been used to simulate power transients initiated by extreme contro1-vane motion. It is assumed that a maximum of 5 dollars over delayed critical is available, that all vanes move together at 90, 45, or 22-1/2 degrees per second, and that the transients start at delayed critical and room temperature. The reactivity in dollars as a function of time in seconds can be represented by

$$
\Delta k_{0}(t)=3.927 t-0.177 t^{2}-0.26825 t^{3}
$$

for the 45-degree-per-second case, which may be scaled for the other two rates.

The power response and integrated powers are illustrated as a function of time in Figures 40 and 41 . Maximum reactivities during the transients are 1.97, 1.67, and 1.46 dollars relative to delayed critical for 90,45 , and $22-1 / 2$ degrees per second, respectively, while the maximum alphas (inverse periods) are 296, 206, and 142 seconds $^{-1}$. Following the initial power spike, the power is sustained at the high leve1 of $\sim 3000$ megawatts by the delayed neutrons and the continuing rise in reactivity.

Typical problem running times for this code are 3 to 5 minutes on the IBM 7094.

\section{$\underline{\text { RAC } \text { Code }^{5}}$}

The RAC code is relatively new and is a first attempt ${ }^{* *}$ to describe in some detail the dynamic behavior of a Rover reactor during a power transient. For calculational purposes, the core is imagined to be homogeneous (solid core of density 1.57) and divided into an arbitrary number (usua11y 10) of squat, adjacent cylinders with a flux (or fission) density assigned to each such region. This arbitrary distribution can be forced to simulate, for example, either a control-rod transient with a normal cosine-type flux or a water-penetration-type transient with a very peaked flux at the end of the core subjected to flooding. Given an assumption on the imposed reactivity function (step or ramp), the code then cyclically generates fission energy in each region (or mass point), increasing temperatures and internal pressures as demanded by heat capacities, and an assumed graphite equation of state.

*The terms "energy coefficient of reactivity" and "temperature coefficient of reactivity" will be used interchangeably. The connection between the two is through the core heat capacity. Thus, for Kiwi systems, for which $\mathrm{b} \cong 0.75$ dollar per $1000^{\circ} \mathrm{C}$ is a reasonable value,

$$
\mathrm{b}=0.75 \times 10^{-3}\left(\frac{\mathrm{do} 1 \mathrm{ar}}{{ }^{\circ} \mathrm{C}}\right) \cdot \frac{1}{\mathrm{M}(\mathrm{gm})} \times \frac{1}{\mathrm{Cp}\left(\mathrm{erg} / \mathrm{gm}^{\circ} \mathrm{C}\right)}=0.75 \times 10^{-3} \frac{1}{\mathrm{MCp}} \frac{\mathrm{do} 11 \mathrm{ar}}{\mathrm{erg}}
$$

where, $\mathrm{M}$ is the core mass and $\mathrm{Cp}$ the specific heat.

\footnotetext{
${ }^{* *}$ Similar codes have been used to attempt descriptions of fast-reactor power excursions 6,7 .
} 
During each time cycle, each region is also allowed to perform thermodynamic work $\left(\int \mathrm{Pdv}\right)$ on its neighbors through the common interface, thus relieving internal pressures (thermal expansion), and in extreme cases physically to set the core mass into motion. The fundamental equation for each region is

$$
\frac{\mathrm{dE}(\mathrm{T}, \rho)}{\mathrm{dt}}=\frac{\mathrm{dE}^{\mathrm{f}}}{\mathrm{dt}}-\mathrm{P} \frac{\mathrm{dv}}{\mathrm{dt}}
$$

and for each interface is

$$
\frac{\mathrm{d}^{2} \mathrm{R}}{\mathrm{dt^{2 }}}=\frac{1}{\rho} \frac{\partial \mathrm{P}}{\partial \mathrm{R}}
$$

where $\mathrm{E}(\mathrm{T}, \rho)$ is the internal energy (assumed to be a function only of density and temperature), $E^{f}$ is the fission energy, $P$ is the pressure, $v=1 / \rho$ is the specific volume, and $\mathrm{R}$ is the interface coordinate. Reactivity is decreased as the core expands; the amount of the decrease is assumed to be proportional to a weighted sum of the change of length of each region. The weighting factor is the assumed flux density. The prompt approximation is assumed throughout; delayed neutrons are not entered into the code. If delayed neutrons should prove of importance (as is sometimes the case), recourse is made to the RTS code. The pertinent equations are formulated in plane geometry, and thus, axial, but not radial, expansions are allowed.

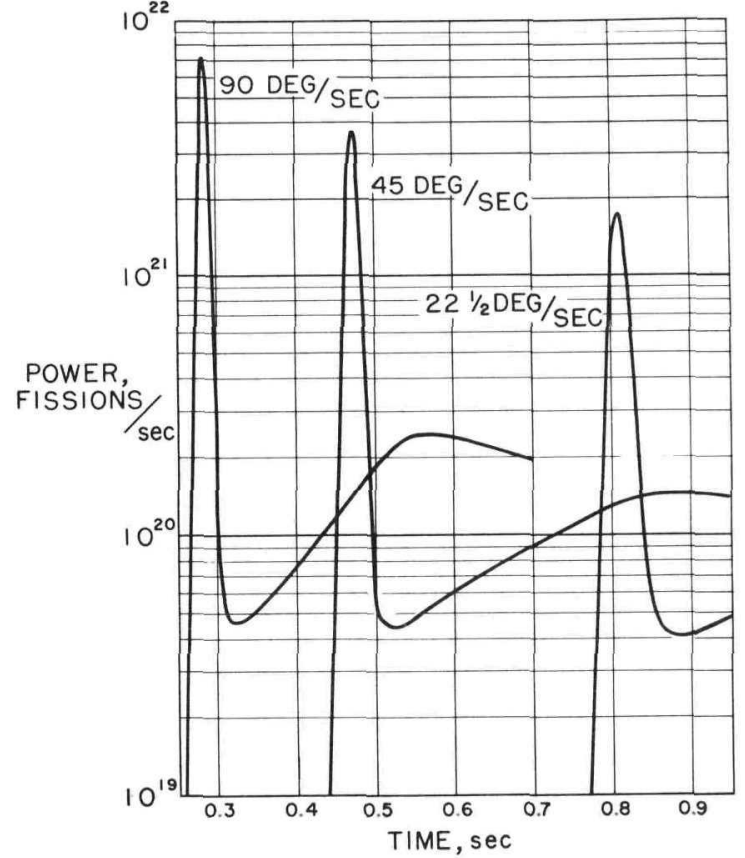

Figure 40. Reactor power versus time for three control vane accidents as calculated by the RTS code. All vanes are assumed to be rotating together at 90,45 , and $22-1 / 2 \mathrm{deg} / \mathrm{sec}$. The exact time dependence is given by $\mathrm{Eq}$. (2) of the text.

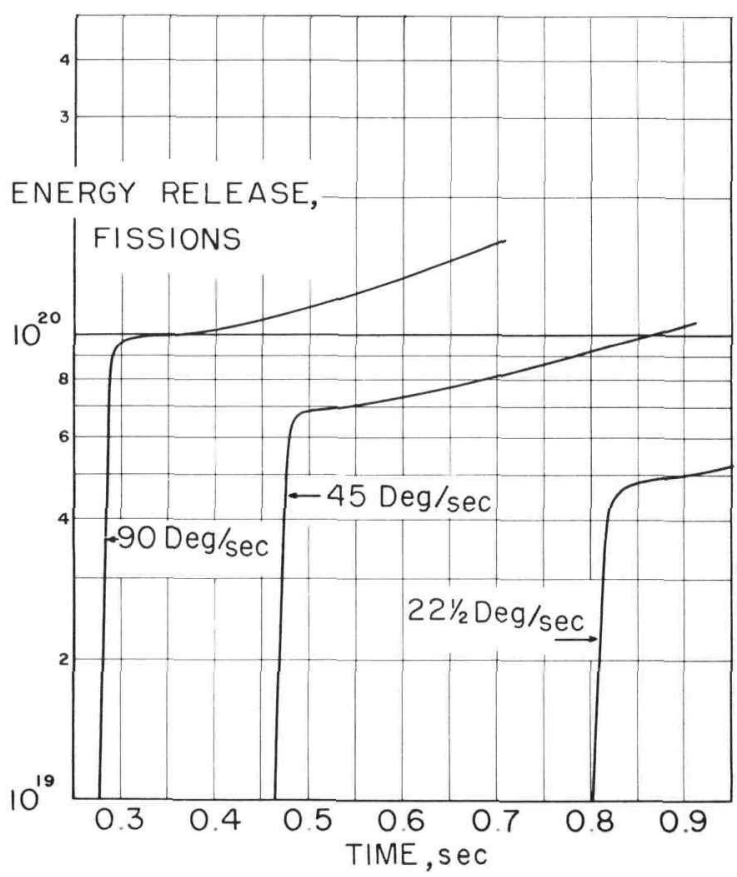

Figure 41. Integrated powers for the three accidents illustrated in Figure 40 . 
Assumptions about the graphite equation of state are of most importance in this type of calculation. The low-temperature function is a linear combination of temperature and density change of the form,

$$
\mathrm{P}(\rho, \mathrm{T})=\mathrm{C}_{1}\left(\mathrm{~T}-\mathrm{T}_{\mathrm{O}}\right)+\mathrm{C}_{2}\left(\rho-\rho_{\mathrm{O}}\right) / \rho
$$

where $C_{1}=2.41 \times 10^{5}$ and $C_{2}=6.43 \times 10^{10}$ are constants related to graphite therma1 expansion and compressibility. These constants are adjusted such that a zero pressure is calculated for the equilibrium state along with a proper change of reactivity (assumed to be $\sim 0.75$ dollar per $1000^{\circ} \mathrm{C}$ ). Negative pressures are allowed to simulate tensions; but a maximum allowable tension is defined beyond which a rupture is assumed, and the pressure in the given region is no longer allowed to assume negative values. At low temperatures, this "breaking tension" is -300 atmospheres, but above $\sim 3600^{\circ} \mathrm{K}$ its magnitude decreases and is zero at and above the assumed triple point $\left(3960^{\circ} \mathrm{K}\right)$. Above $\sim 3600^{\circ} \mathrm{K}$, the graphite vapor pressure becomes significant, and at about $3960^{\circ} \mathrm{K}$, the graphite triple point, the equilibrium vapor pressure is 100 atmospheres. One form of the graphite P-T diagram ${ }^{8}$ for this temperature range is illustrated in Figure 42. Credence in this figure is limited; the triple-point pressure seems to be better established than is the temperature. The code allows for the production of graphite gas (latent heat of sublimation, L, equal to 172 kilocalories per mole), 9 but, for temperatures at or below $3960^{\circ} \mathrm{K}$, the vapor pressures are not allowed to exceed a limiting function

$$
\mathrm{P}=\mathrm{C}_{3} \mathrm{e}^{-\frac{\mathrm{C}_{4}}{\mathrm{RT}}}
$$

in which $\mathrm{C}_{3}=2.739 \times 10^{29}$ and $\mathrm{C}_{4}=3.877 \times 10^{5}$. The limiting values of Eq. (6) do not apply to Eq. (5). If temperatures exceed $3960^{\circ} \mathrm{K}$, a second limiting function similar to Eq. (5) is used, but in this temperature regime another heat sink is possible--the conversion of solid to liquid, for which the latent heat is estimated to be $11 \mathrm{Kcal} / \mathrm{mole}$. It is assumed that Eq. (5) is descriptive of the liquid as wel1 as the solid state, except that tensions are disallowed. When a given core region reaches (or slightly exceeds because of the finite differencing) the triple-point temperature and pressure, it is further required that additional energy must go only into producing liquid at constant temperature and pressure until that region contains only two constituents. When this process is completed, the temperature may continue to rise, accompanied by further vaporization.

To gain an understanding of characteristics and general behavior, some results taken from a series of problems with appropriate constants for a Kiwi-B4 are illustrated in Figures 43, 44, 45, and 46. These problems were initiated by use of a step increase of reactivity, a scheme that reasonably approximates very fast control-rod motions, abrupt changes of reflection, moderation, etc. The fission energy release for a wide range of initial reactivities (relative to prompt critical) is illustrated in Figure 43. Maximum internal graphite vapor pressures are shown in Figure 44 , while explosive energies (kinetic energies) are seen in Figures 45 and 46 . The initial prompt $\alpha$ (reciprocal period) for any reactivity may be obtained with reasonable accuracy from

$$
\alpha=\frac{\delta k_{\mathrm{p}} \beta}{\ell}
$$

where $\delta \mathrm{k}$ is the initial reactivity in dollars relative to prompt critical. A coefficient of reactivity equivalent to 0.75 dollar per $1000^{\circ} \mathrm{C}$ has been used for this survey. 


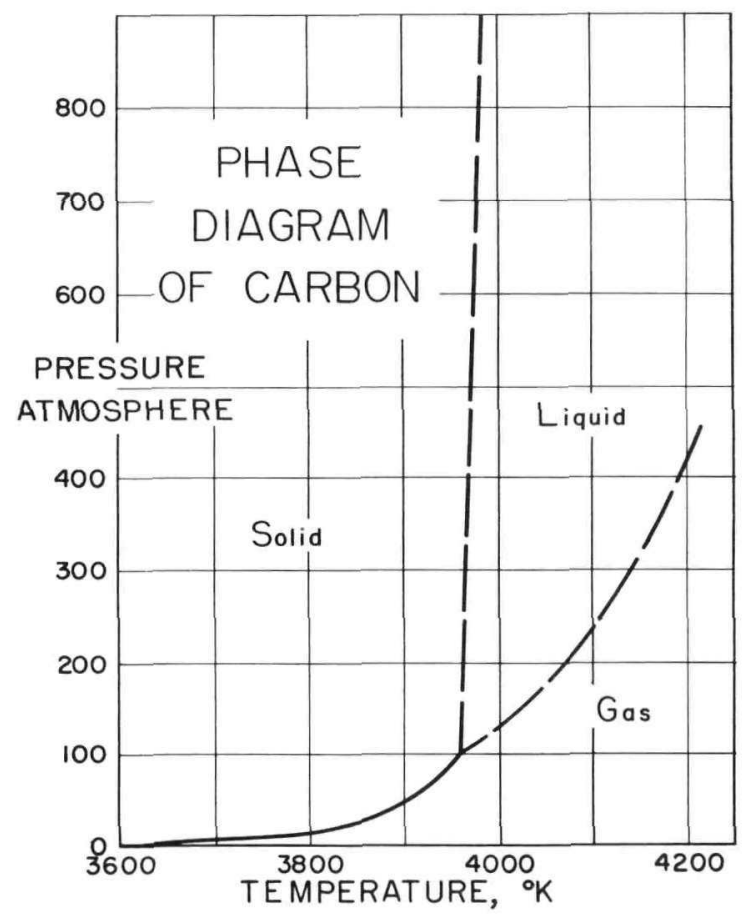

Figure 42.

The graphite pressure-temperature diagram. The triple point is assumed to be at $3960^{\circ} \mathrm{K}$ and 100 atmospheres.

Figure 43.

Energy release versus step increase of reactivity relative to prompt critical as calculated by the RAC code. The change in slope at about one dollar is caused by some graphite vaporization in the core.

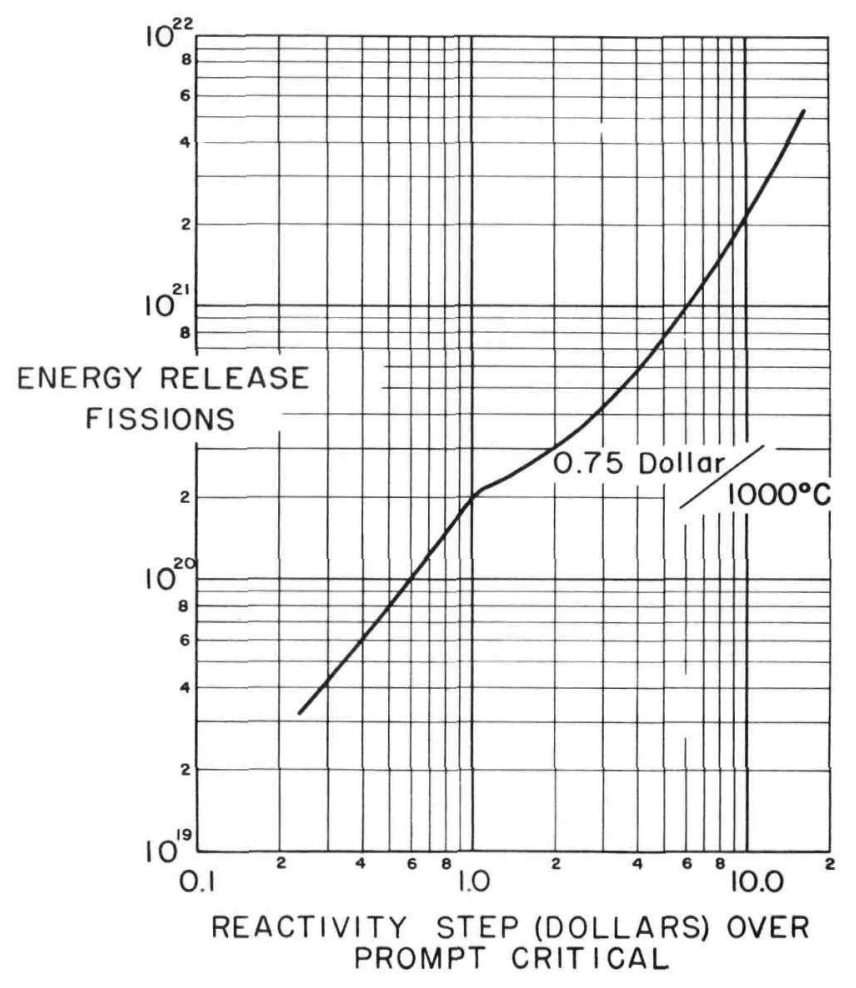




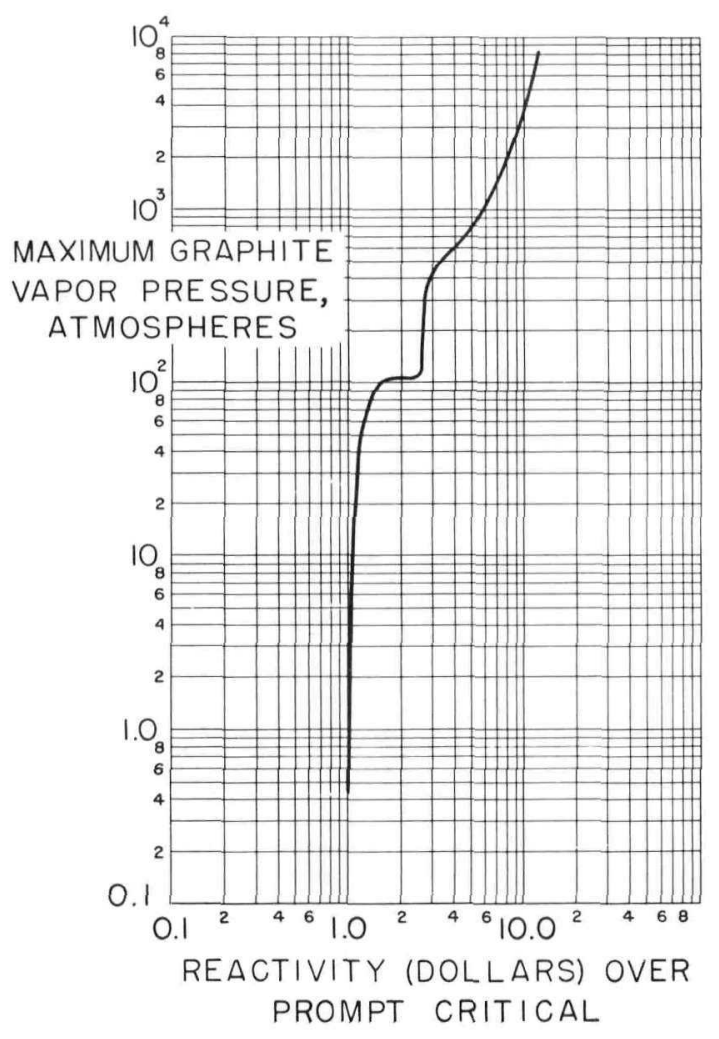

Figure 45.

The kinetic or explosive energies for the problems illustrated in Figure 43 .
Figure 44 .

Maximum internal graphite vapor pressures for the problems illustrated in Figure 43. The knee of the curve is associated with the graphite triple point.

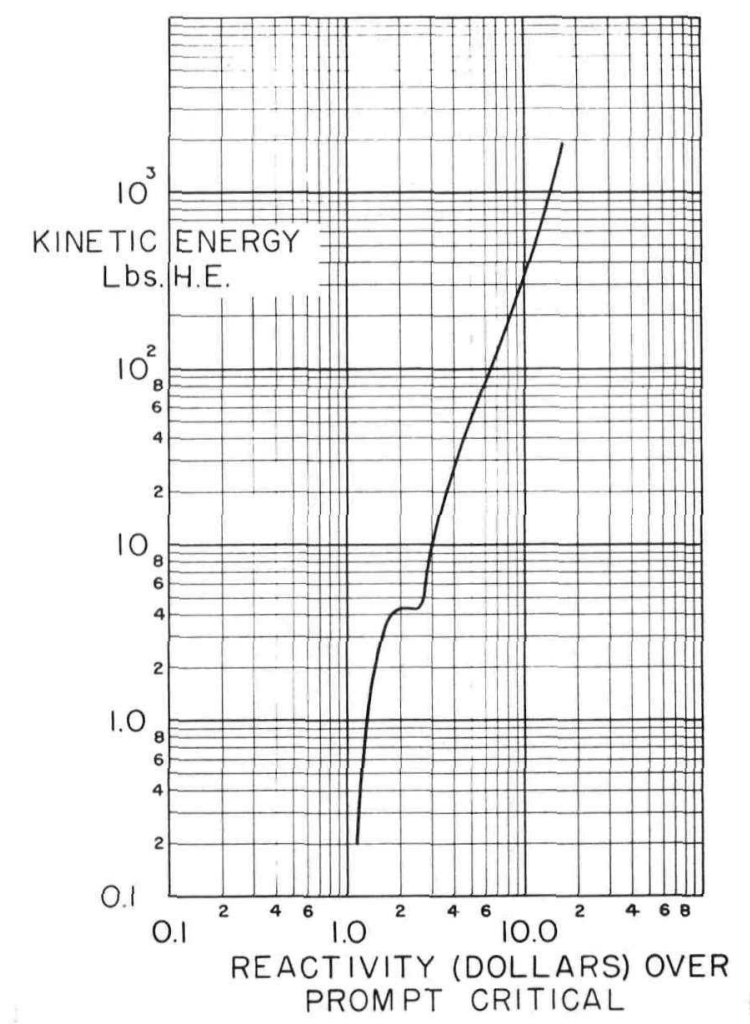




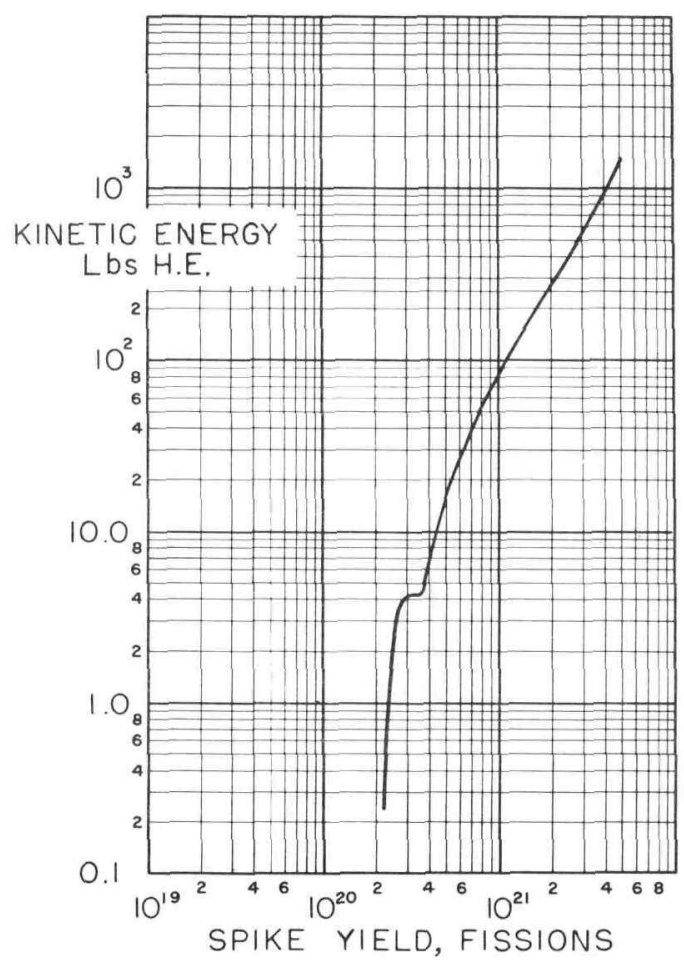

Figure 46.

The kinetic or explosive energies for the problems of Figure 43 plotted as a function of the total fission energy. This presentation eliminates some of the dependence on the reactivity coefficient.

The principal uncertainty in the fission energy release and kinetic energy for a given reactivity change arises from a lack of knowledge of this coefficient of reactivity as a function of temperature or energy density.

For initial reactivities somewhat less than $\sim 1.0$ dollar over prompt critical, the fission yield is nearly proportional to the excess reactivity; the core expansion is in near-equilibrium with the fission rate, and no physical explosion should be expected. However, above this initial value and depending on the value of the energy coefficient of reactivity, the maximum central temperatures and pressures are found to be in the neighborhood of the triple point and some portion of the core will vaporize or melt. The resulting high internal pressures (Figure 44) produce a more effective quenching mechanism leading to an asymmetry in the power spike. This effect produces a fission yield somewhat less than that expected from an extension of the yield line from the lower reactivities (Figure 43). At still larger step inputs, the core expansion lags the energy release and the total fissions increase at a higher power of the initial reactivity.

The introduction of a high-pressure gas can impart significant kinetic energy to the core and a physical explosion might be expected. These results from the RAC code are illustrated in Figures 45 and 46 as functions of the initial reactivity and the total fission energy release, respectively, for a temperature coefficient of reactivity of 0.75 dollar per $1000^{\circ} \mathrm{C}$. The latter presentation removes some of the uncertainty in the value of the temperature coefficient of reactivity. The kinetic energy (in units of pounds of high explosive equivalent) shows a distinct and sharp threshold at about 1.1 dollars or $2.1 \times 10^{20}$ fissions; the knee of the pressure and kinetic energy curves near 2.0 dollars and the sharp rise at $\sim 2.5$ dollars are associated with the triple point and the liquification of graphite at the center of the core. These estimates of kinetic or explosive energy are highly suspect; an undertainty factor of five would not be unduly generous even if the calculation of the fission energy were exact.

Since for many conceptual accidents a step increase of reactivity is unrea1istic, accident magnitudes for a series of ramp insertions are illustrated in 
Figure 47. These problems also start at room temperature and near-zero power; the ramp commences with no time delay and continues indefinitely. For insertion rates less than 10 dollars per second (not illustrated), the energy release is closely proportional to the square root of the insertion rate; below about 4 dollars per second delayed neutrons become of importance, and recourse is made to the RTS code.

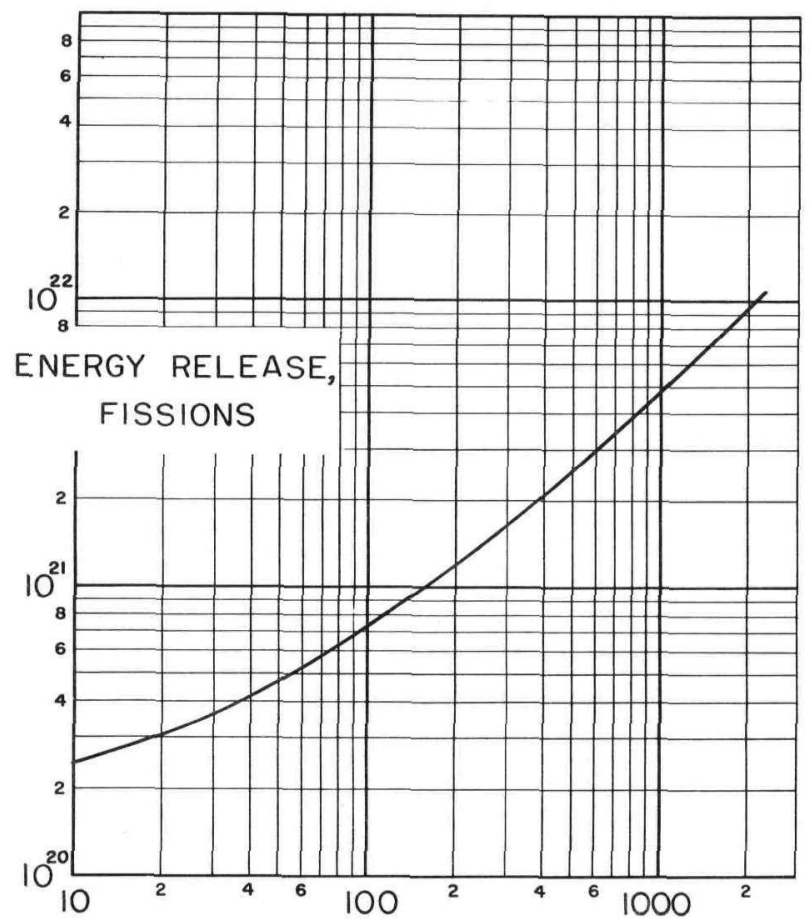

Figure 47.

Fission energy release as a function of an uncontrolled reactivity insertion rate in dollars/sec as calculated by the RAC code. Corresponding kinetic energies may be obtained from Figure 46 with reasonable accuracy.

REACTIVITY INSERTION RATE, DOLLARS/sec

Some comments appropriate to the assumptions of a homogeneous core and a specific graphite equation of state seem worthwhile. In effect, the assumption of homogeneity is equivalent to the supposition that the vapor pressures shatter the loaded graphite and plug the flow channels for times at least of interest to the problem (on the order of milliseconds). If such vapors can diffuse from the graphite matrix and escape (or deposit on cooler surfaces) the fission energy release would be larger for those initial reactivities greater than 1.1 dollars. Since large pressures would be absent, kinetic energies could be drastically reduced from the values illustrated in Figures 45 and 46 .

Additional variations of the equation of state question are possible and of interest in establishing limits of total fissions and kinetic energy. If change of phase should be ignored entirely, the yield curve would follow an extension of the energy releases calculated for steps less than 1 dollar (Figure 43). This must be the upper limit of energy release in this region, assuming that 0.75 dollar per $1000^{\circ} \mathrm{C}$ is correct. Kinetic energies would be much smaller. If the liquid phase were ignored (but gas production allowed and the assumption retained that gas stays where it is created), the yield curve (Figure 43) above 1.1 dollars would be 1ower, 25 to 30 percent as a guess. For a given reactivity, the kinetic energy would be larger.

An assumption implicit in these calculations is that the graphite matrix contains no absorbed gases. This situation is unlikely; and, when through auxiliary experiments (TREAT and SPERT reactor experiments, chemical analyses, etc.), the amount and nature of possible absorbed gases are known, some reasonable assumptions may be incorporated into the RAC code to allow for this. The effects will be similar to those from graphite vapor pressures but will most 1ikely occur at lower 
temperatures and fission energy densities. The magnitude of explosive energies will depend on the volume and nature of absorbed gases and the rate at which they are released.

The code allows for the fact that at large energy densities there are limits to the amount of liquid and vapor that can be created. Thus, at $\sim 8$ dollars sufficient energy has been accumulated to liquify most of the core, and at 15 dollars vaporization of the core is nearly complete.

Typical running times for this code are from 1 to 10 minutes on the IBM 7094. Contemplated improvements such as two-dimensional hydrodynamics can only drastically increase this running time.

\section{Conceptual Accidents}

The accidents discussed on this section will be of the type and in the order presented in the introduction. In discussing these possibilities, it is worth noting that the most uncertain factor is the imagined reactivity history. Often the guessing accuracy is scarcely good to within a factor of four or five. Given the reactivity history, the next most uncertain factor is the temperature coefficient of reactivity. The value used $\left(0.75\right.$ dollar per $\left.1000^{\circ} \mathrm{C}\right)$ is probably accurate to within a factor of two.

\section{Contro1-Vane Failure}

To calculate the maximum accident from control-vane motion, simultaneous failure, which is improbable, of the servocontrol system, the scram circuit, and the safety springs of all vanes is assumed along with the appearance of a signal which forces them to add reactivity at the maximum possible rate. We assume for the Kiwi-B4 that all vanes are programmed to move together at 45 degrees per second. The power history and fission energy release for this case are illustrated in Figures 40 and 41. The energy release for the initial power spike is $\sim 7 \times 10^{19}$ fissions.

As was noted above, at least $1.2 \times 10^{20}$ fissions are required to bring the central portion of the core to vaporization temperatures. Thus, a graphite gas explosion is not expected, but some small explosive force could occur from the sudden release of absorbed gases.

If the core should survive the initial power spike, the plateau power of 3000 megawatts could last only a short time (seconds) before causing severe damage to the core and reducing reactivity to the point that the power level would drop to a low value.

\section{Water Reflection}

For this case, we imagine water surrounding the pressure shell and nozzle end of the core. By generalizing several Los Alamos experiments, the reactivity worth of water surrounding the reactor in this fashion is about 5 dollars. If before submersion the reactor were just critical, it would be 4 dollars over prompt critical with the additional reflection, and, from Figure 43, the energy release could be $5.9 \times 10^{20}$ fissions, with kinetic energies of the order of 26 pounds high explosive equivalent. If the liquid phase were ignored, some 13.7 percent of the core could be vaporized.

These numbers must be overestimates, since full reflection could not be achieved in any manner short of several seconds.

If the control vanes were in the full-poison position, the excess reactivity would be between 0 and 1 dollar. In this case the power could rise to several hundred megawatts and would slowly decrease as the temperature rose and core support members softened and lost strength. An analysis has not been attempted. 
Liquid Insertions

Water Insertion -- The number of possibilities for water insertion is extremely large. One can imagine cases ranging from impact from high altitudes to slow and smooth flooding of the core in shallow water. Only one case will be discussed here, the order-of-magnitude result for the reactor falling nozzle down from very high altitudes. Both WANL and LASL experiments have shown that for the reactor core striking water at high velocities, the water jetting up into the flow channels can be moving at least four to five times faster than the downward reactor velocity. Thus, if the reactor should fall from 300 to 400 feet, some water could move through the core in less than 10 milliseconds. If this water is $\sim 1 / 10$ normal density and distributed throughout the core, the increase in reactivity (essentially a step increase) would be about 12 dollars, or 11 dollars relative to prompt critical. From Figure 43, the energy release is $2.5 \times 10^{21}$ fissions.

This number is thought to be large, but experiments and calculations now in progress are not sufficiently advanced or analyzed to allow a substantially better estimate. Upwards of $10^{21}$ fissions is a reasonable guess for the worst case of this type of accident.

Under certain circumstances, the additional internal pressures arising from steam or dissociation of water should be included in the calculation. This factor would not appreciably influence the fission yield but could change the kinetic energy considerably.

Liquid Hydrogen Insertion -- The accident caused by the sudden flow of liquid hydrogen into the reactor system can be overestimated by making some grossly simplified assumptions. It is assumed that the hydrogen in the core is worth about 2 dollars per pound and that the pump can start the flow of 1iquid hydrogen at the rate of 70 pounds per second with no time delay whatsoever. In addition, it is postulated that the flow is directed into a room-temperature reactor (no cooldown) and that no choking in the nozzle, reflector, or pressure she11 occurs.

With these assumptions, the energy release from a transient created by a steady insertion of 140 dollars per second is $9.3 \times 10^{20}$ fissions as taken from Figure 47. The kinetic energy is about 70 pounds $\mathrm{HE}$ equivalent.

This energy release must be a gross estimate for reasons cited above but also because some exploratory calculations with the RAC code in which the axial fission density is highly peaked at one end of the core show a lower fission yield (compared to a normal distribution) for the same insertion of reactivity. The necessary reduction factor cannot be estimated now.

\section{Implosion and Impact}

Implosion Within Chemical Propellants -- This conceptual accident is most improbable, but, regardless, some calculations are in progress to provide an estimate of the change of density if the reactor should be centered within an exploding mass of chemical propellants. Preliminary results suggest that at least the core void space may be lost, but also that the shock-wave transient times may be quite short. Results to date are not complete enough to allow a reasonable estimate of densities or the time of supercriticality.

Impact on a Hard Surface -- Recently, experiments have been completed in which 1/3-scale mode1, inert Kiwi-B4 reactors were dropped from 75 feet and impacted upon a concrete surface with a velocity equivalent to that obtained during a 300-foot drop. (See Paper III-2, p 149.) During the time of impact, gamma-ray attenuation experiments were performed in order to detect changes in density resulting from the shock. The data are not as yet fully analyzed, but the indications are that the average change in core density is not greater than 5 percent. 
An estimate of the consequences of this accident may be obtained immediately if we accept $\delta \mathrm{k} / \mathrm{k} \approx 1 / 2 \delta \rho / \rho^{10}$. Then, for $\delta \rho / \rho=0.05, \delta \mathrm{k}$ in dollars is 3.3 and from Figures 40 and 45 the fission yield is $3.3 \times 10^{20}$ and the kinetic energy is 4.3 pound $\mathrm{HE}$ equivalent.

\section{References}

1. G. E. Hansen, Burst Characteristics Associated with the Slow Assembly of Fissionable Materials, Los Alamos Scientific Laboratory Report, LA-1441 (1952).

2. G. R. Keepin, Nuclear Science and Engineering, 8, 670 (1960).

3. G. E. Hansen, LASL, private communication.

4. J. D. Orndoff, LASL, private communication.

5. C. G. Chezem and W. R. Stratton, A Computer Program for Reactor Accident Calculations, Los Alamos Scientific Laboratory Report LAMS-2920, August, 1963.

6. W. R. Stratton, T. H. Calvin, and R. B. Lazarus, "Analysis of Prompt Excursions in Simple Systems and Idealized Fast Reactors", Proceedings of the Second International Conference on the Peaceful Uses of Atomic Energy, Volume 12, page 196.

7. D. Okrent, J. M. Cook, D. Satkus, R. B. Lazarus, and M. B. We11s, AX-1, A Computing Program for Coupled Neutronics - Hydrodynamics Calculations on the IBM-704, ANL-5977, May, 1959.

8. M. T. Jones, National Carbon Research Laboratories Report PRC-3.

9. American Institute of Physics Handbook, McGraw-Hi11, 1957.

10. J. D. Orndoff, LASL, private communication. 


\section{BLANK}




\section{FLIGHT OPERATIONAL SAFETY SYSTEMS FOR NERVA}

R. I. Unger

Aerojet-Genera1 Corporation

Introduction

Safety and reliable operation are the engine contractor's foremost considerations in the development and use of the NERVA engine. The engine control system incorporates interlocks and malfunction detectors and alternate or redundant controls to ensure programming and operation of the engine in a safe manner. In addition, flight safety and destruct systems complete with associated controls and actuation subsystems are required on the engine. They must function both as an anticriticality safety system and as a postoperational safety system. These systems must function upon receipt of an internal signal or a range safety command signal.

The anticriticality safety system must render the reactor essentially harmless in the event of an accident or malfunction of the engine before its operation. This system may be (1) passive, i.e., poison is inserted in the reactor core, (2) active, i.e., a destructive force is used to fragment the reactor core into pieces and distribute them in a noncritical pattern, or (3) a combination of the passive and active types.

The postoperational safety system must disintegrate or disperse the reactor core and the core-retained fission products to such an extent that the particles will not constitute a health hazard. The system may utilize nuclear, chemical, or explosive reactions.

\section{Anticriticality Safety Systems}

The objective of the anticriticality safety system is to prevent inadvertent criticality of the reactor in the event of an accident or malfunction of the NERVA engine before its operation. The requirement for an anticriticality safety system is clearly established by the possibility of a nuclear excursion of the cold engine in the launch area or shallow water as an aftermath of vehicle failures occurring early in the launch sequence. It is conceivable that a power excursion and the associated release of contaminating fission products would result if an accident caused the NERVA engine to be compacted, as in a fall back to land during launch or to be immersed in water or hydrogen, both of which are highly moderating, as in a fall into the tank of $\mathrm{LH}_{2}$ propellant on the chemical booster rocket.

Two approaches to the design of a countermeasure have been taken: a destruct system which would fragment and disperse the core over a sufficient area so that the submerged fragments would be subcritical, and a poison system which would provide sufficient in-core poison to maintain the submerged core subcritical. For the destruct system, a conservative approach is taken in which core fragments are required to fall into the water in a manner that will under no circumstances yield the water-uranium ratio for a minimum critical mass. 
Design Requirements -- The anticriticality destruct system must function, therefore, to fragment the reactor core into pieces of various sizes and to disperse these pieces so that none of the portions could combine in a geometry which could become critical in the moderating environment. Thus, it was necessary to determine a minimum critical mass for uranium-graphite water systems. This calculation was performed and the factors which were most influential in determining the minimum critical mass were determined, resulting in a numerical value for this mass. The value of this mass was reduced an arbitrary amount to provide a factor of safety and then related to an equivalent weight of fuel elements. Since the determination of this minimum critical mass could be area-related, it was possible to express this minimum critical mass in terms of a given weight of fuel elements within the confines of a circular area of fixed diameter. These number relationships formed the basis for the tentative anticriticality destruct criteria.

Description -- In the ordnance type of anticriticality destruct system (ACDS), the directed high energy of explosive is employed to destroy the geometry of the reactor and disperse the mass in accordance with the destruct criteria.

Several explosive ACDS concepts were considered and have been subjected to preliminary testing and evaluation. These concepts employ different types of linear shaped (cutting) charges, conical shaped charges, and projectile (burster type) charges, separately or in combination. One combination that has shown particular promise is shown in Figure 48. This system, which is ejectable, consists of a linear cutting charge array consisting of longitudinal linear cutting charges and circumferential curvilinear cutting charges distributed over the exterior of the pressure vessel in combination with a single conical or hemispherical shaped charge directed through the nozzle or positioned around the aft head. The external cutting charges open the pressure vesse1, the residual energy being used to fragment the core material. The large conical or hemispherical shaped charge then (after a slight firing delay) further fragments and disperses the core material according to the tentative anticriticality destruct criteria. This first ejectable system was successfully tested in the simplified, lighter-weight version shown in Figure 49.

This modified concept differs from the original concept in that it employs conical shaped charges located diametrical1y opposite each other at the outer periphery of the nozzle throat and directed toward the center of the engine core. In addition, the concept uses only a circumferential curvilinear cutting charge in combination with longitudinal cutting charges.

This system must be ejectable before engine start-up because of the intense radiation environment. Further, it would not be desirable to carry the additional parasitic weight of this system once it was no longer required. Figure 50 shows the details of one concept for providing the required ejection.

In addition to the concepts of ejectable ACDS's, a concept of a nonejectable system, Figure 51, has been evolved. This concept consists of one or more explosive projectiles launched from tubes or guns located forward of the reactor shield. The explosive projectile would first penetrate the reactor core after which an internal burster type explosive wculd detonate to provide fragmentation, opening of the pressure vesse1, and dispersion of the core material. 
III-4

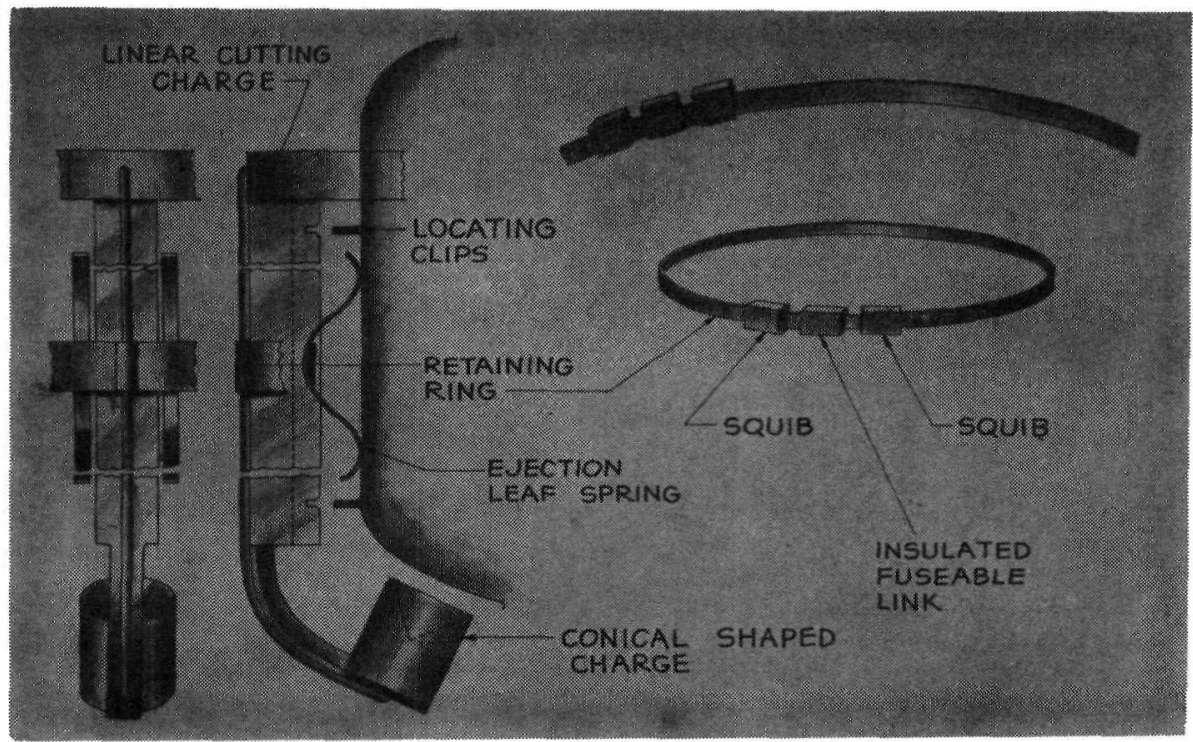

Figure 50. Details of Mark A ejectable concept

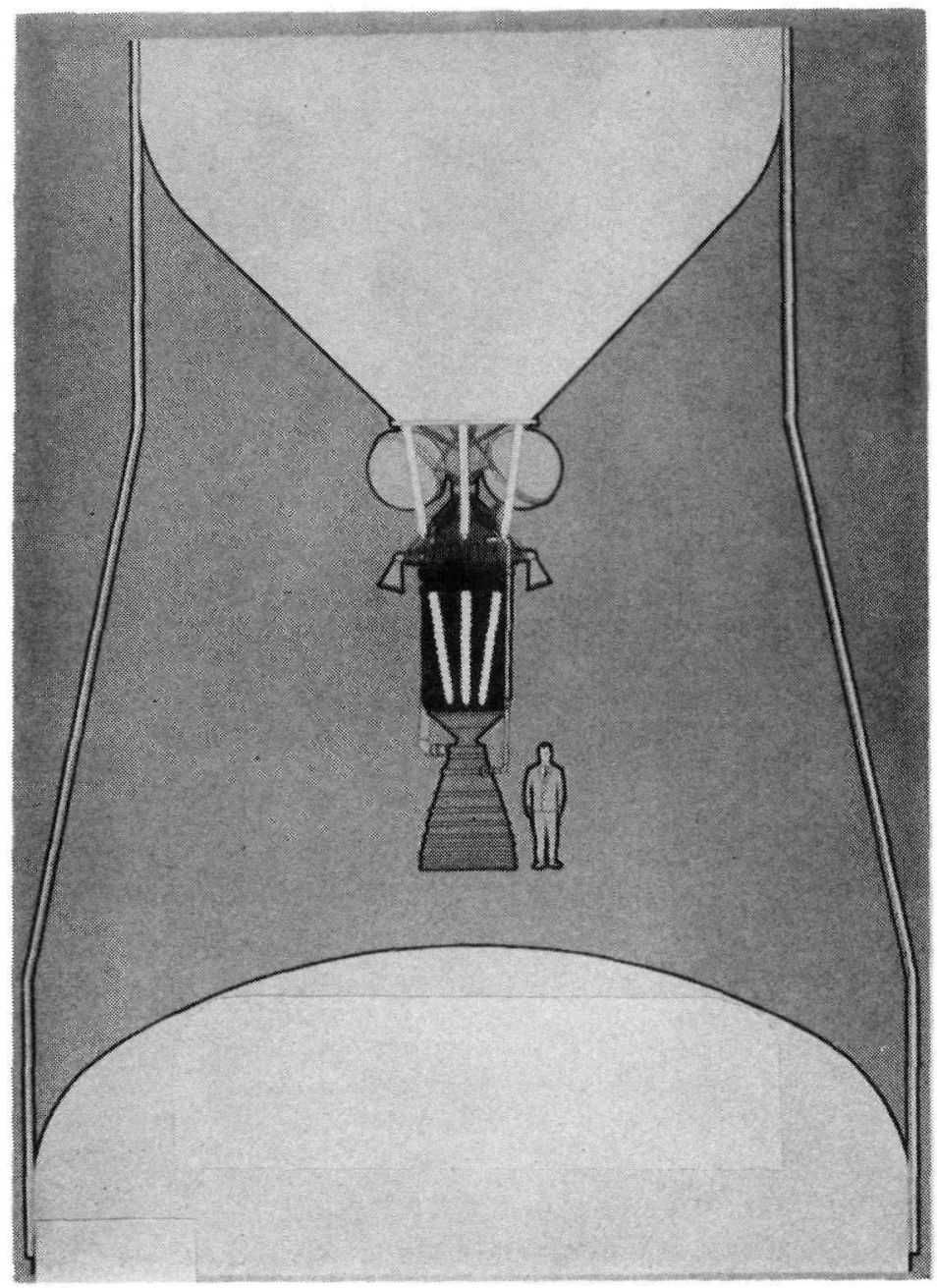

Figure 51.

Projectile-inserted internal burster charges 


\section{Anticriticality Poison System}

The second approach to a countermeasure to prevent criticality of the reactor because of an accident or malfunction of the NERVA engine before operation is that of a poison-wire safety system.

Design Requirements -- The primary requirement of the flight poison system is the requirement for the NERVA core to be subcritical following accidental immersion in water. This requirement can be met by adjusting the poison loading required for the flooded core. In addition, a number of other design criteria must be satisfied in order to arrive at a practical system. These criteria would include the following items :

1. The effectiveness of the nuclear poison must not be compromised by a propellant fire.

2. After a successful launch, the poison must be removed from the core before second-stage separation.

3. The poison withdrawal apparatus must be mounted without a rigid connection to the nozzle and in such a manner that the nozzle is clear after separation.

4. The poison must remain in the core if the second stage is prematurely separated from the nuclear stage.

5. The removal of the poison must not cause core damage.

6. The system must be able to withstand the environment of a powered flight.

Description -- The search for a system that would satisfy these design criteria led to a scheme in which poison wires are inserted in an appropriate fraction of the core through the nozzle end. This method has the advantage of presenting a minimum of development problems, good structural strength, and mechanical integrity. The major design problems of this system involve the possibility of damage to the fuel and a suitable method for holding a multiwire pull head in the nozzle without fasteners.

Figure 52 shows a conceptual version of a pull head mounted in the nozzle throat. The poison wires are clustered into groups, each group being ba11-andsocket mounted in a retaining plate. The plate is fastened to a pul1 head and the assembly held in place by a spring leaf structure. The spring characteristics of these leaves will be determined by the $g$ force during ascent and the combined mass of the head and wires. If necessary, the nozzle throat will have an overlay to minimize abrasion of the nozzle during retraction of the head and wires. Shown beneath the pull head is the top of an actuator which would be attached to the second stage and which could be inserted by gas pressure to a position just beneath the pull head during countdown. In this position it could help support the pull head from below but would break away without the pull head if the second stage or interstage failed. After the proper altitude was reached, an enabling signal would raise the actuator into the pull head without engaging; an arming signal would engage the main plungers with the pull head. On signal, high-pressure gas to the actuator would effect withdrawal of the pull head and wires. Figures 53a, b, and c show actuator concepts, single, double, and multiple.

An analytical study has been undertaken to establish the optimum distribution of poison wires in the core in terms of poison effectiveness and pull force. Furthermore, an experimental program has been initiated to determine the most desirable arrangement of wire characteristics, wire-bundling schemes, and pull forces. Final design of a poison-wire system will be possible only when the required poison distribution is experimentally verified and the relation between radial position and pull force is firmly established. 


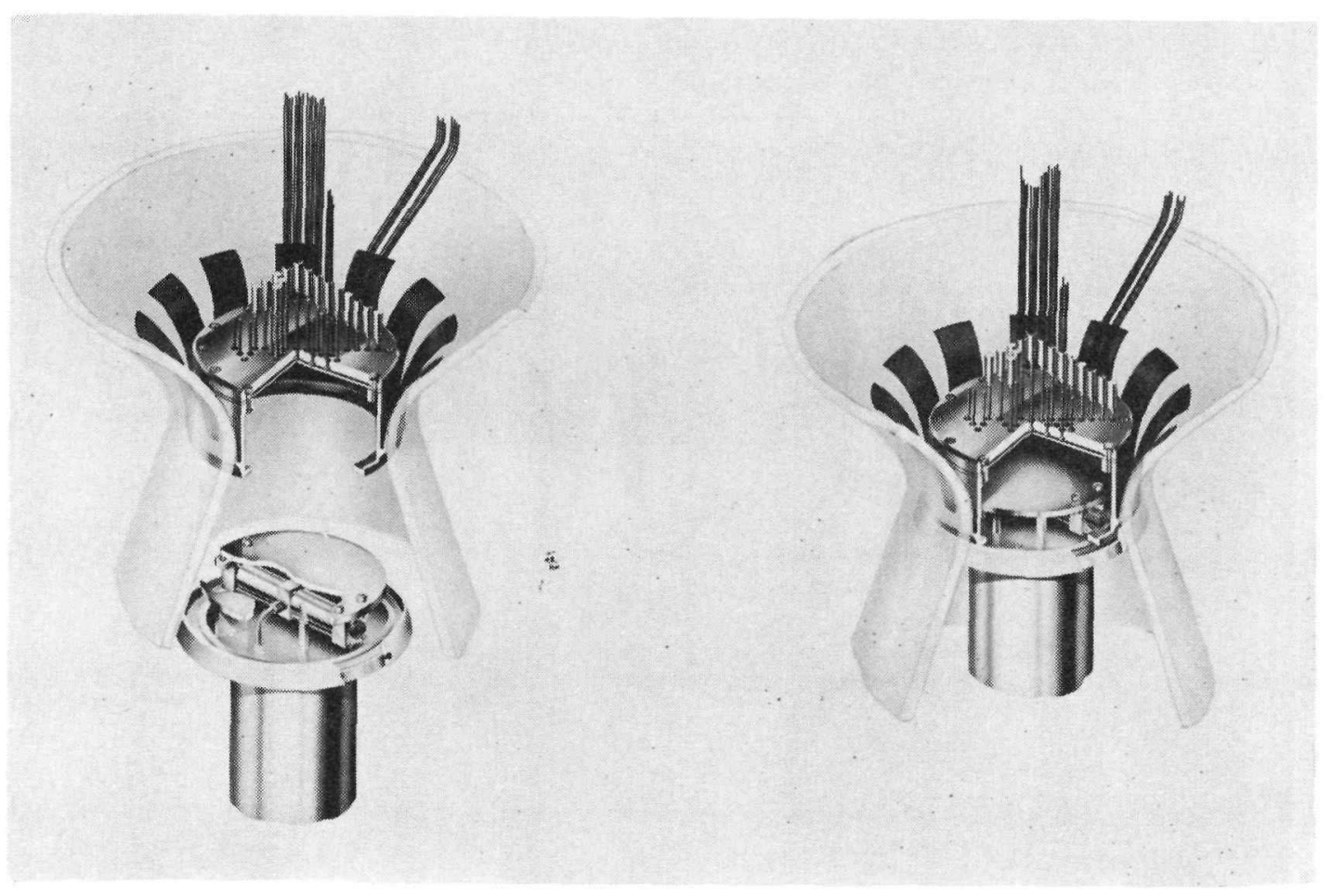

Figure 52. Poison system wire pull head

\section{Postoperationa1 Destruct Systems}

\section{General Considerations}

In considering the feasibility of a postoperational destruct system, it is necessary to assess the extent of surface contamination of the earth and the concomitant radiological hazards which would result from the use of such a system. Such an evaluation requires an integrated study of many governing factors as follows:

1. Trajectory

2. Reactor operating history

a. Reactor temperature history, during and after operation.

b. Fission product diffusion during and after operation.

3. Time, altitude, vehicle orientation, latitude and longitude at the time of destruct

4. Nature of destruct mechanism

a. Are particles created? If so, what are their sizes, space orientation, and velocities?

b. If fission products are removed by reactor excursions, what percentage leave the core as gases?

c. If the core is weakened, at what altitudes of re-entry does the core fragment and what particle sizes are created? 


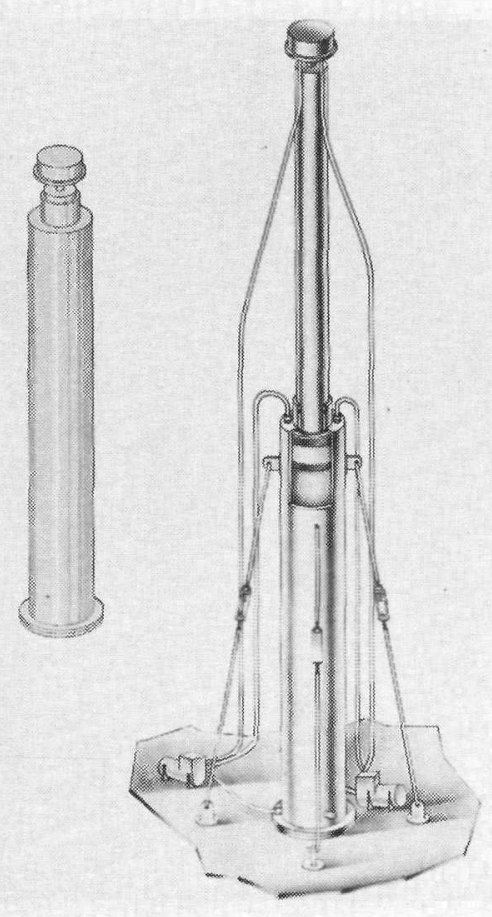

a. Single stage

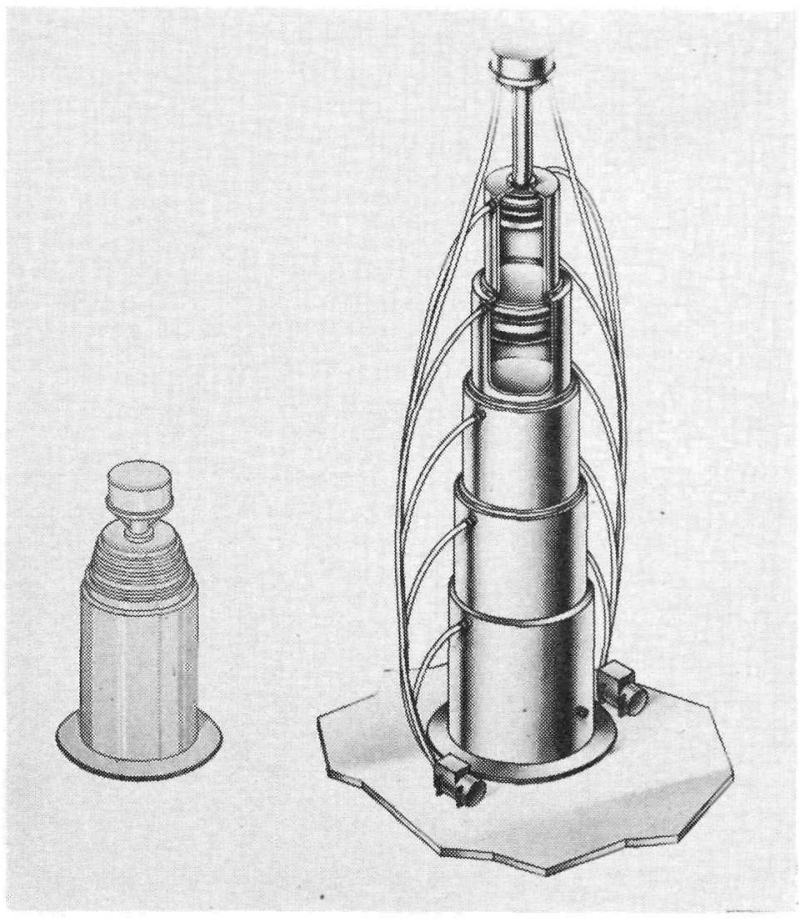

c. Multiple stage

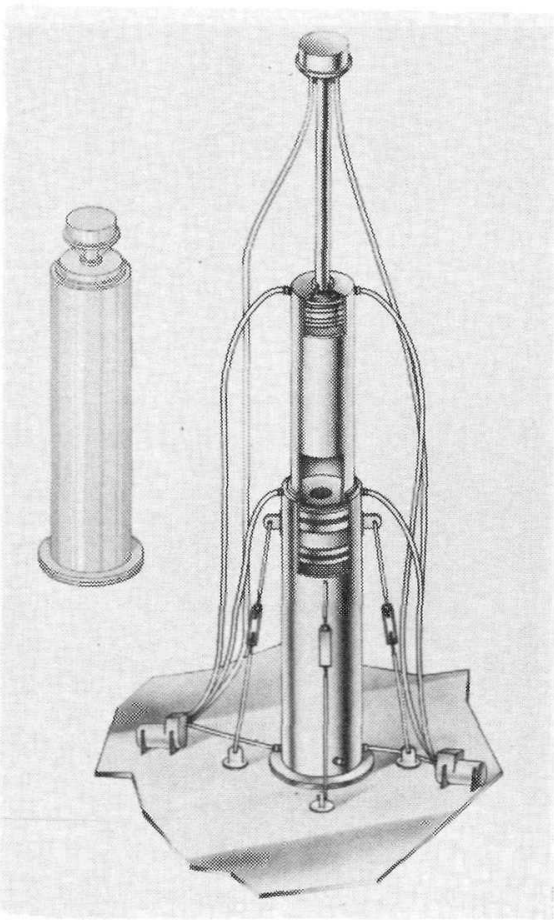

b. Double stage

Poison system actuators 
5. Particle consideration

a. It has been tentatively determined that particles 25 microns or smaller will be retained in the atmosphere for appreciable lengths of time. What percentage of particles are within this range?

b. What are the velocities and re-entry angles of the reentering particles?

c. What is the effect of particle shape and surface condition?

d. What is the extent of the burnup of particles on re-entry?

e. What is the rate of loss of fission products during re-entry?

f. From the fission product history, what is the particle source strength?

\section{Meteorologica1 conditions}

A number of techniques using nuclear, chemical, or explosive destruct methods or a combination, have been considered as potential postoperational safety systems. The postoperational safety system was desired to function in a manner which would disintegrate the reactor core and distribute the fragments and retained fission products to such an extent that the resultant particles would not constitute an unpredictable health hazard.

\section{Chemical Destruct System}

In concept, a chemical destruct system would have a reagent stored in a separate tank, the shut-off valves, and the control circuitry. Following reactor shutdown, the core preconditioning would be programmed by a master programmer and the chemical introduced. The master programmer may be arranged either to require a common ground signal or to cause the preconditioning and chemical addition events to occur in sequence following an indication of some critical operating condition.

\section{Nuclear Destruct System}

The current concept of a possible nuclear destruct system that is most favored would involve firing materials into the reactor core by methods similar to those employed in the anticritically destruct system. These materials may provide extra moderation or extra fuel as necessary to make the NERVA reactor go prompt critical and thus cause an explosive rise in temperature. In any event, it will be necessary to ensure ground safing of the system by a delay device operating at some minimum time. In actual practice it might be ground safed by means of an arm/safe device and a baroswitch to ensure that arming would occur at a safe altitude, and only after the receipt of a safe guidance signal.

\section{Combined Destruct System}

A multitude of combined destruct schemes are possible. These include preconditioning the core with limited circuits of chemical reagent before destruct by nuclear or explosive means, use of a soft excursion before chemical destruct, or compaction by explosive means. However, until more detailed data are available on the characteristics of the nuclear and explosive systems, the full need or use of a combined approach will not be realized.

\section{Ordnance Destruct System}

The task of a postoperational ordnance destruct system would be to fragment the reactor into particles small enough to remain aloft as aerosols, to be burned up upon re-entry into the earth's atmosphere, or to have so little activity upon reaching the earth's surface that they do not present a hazard. 
The principal concepts considered for postoperation destruct systems employ either the directed energy from high-explosive shaped charges in suitable arrays and combinations in various positions around the core assembly or the use of explosive internal burster type techniques, as shown in Figures 54 and 55 . The explosive shaped charges introduce energy in the form of hypervelocity fragments as the mechanism for transferring shock energy to the reactor core for its desired disintegration. Basically, the shaped charges consist of a cylinder of explosive within a specifically designed geometrical cavity such as a cone. This cavity is lined with metals of various types and thicknesses for the different types of charges, depending upon the function and action desired. This metal liner collapses under the pressure of detonation and ejects a portion or portions of the metal liner as a jet of molten particles traveling at velocities in the range of 25,000 to 30,000 feet per second. Penetrating the core simultaneously at many points and at high velocity, these hypervelocity jets create intense shock waves within the core material and cause it to fragment. Most of the concepts being considered employ various types of linear shaped (cutting) charges, conical shaped (nozzle head entry) charges, projectile penetrating (burster) charges, and explosive panel sheet charges in various combinations and configurations.

Tests have shown the concept of multiple internal-burster charges to be the most promising. In this concept, core-length projectiles, Figure 51, are fired from launch tubes rearward through the forward head structure into the core. This concept has additional merit in that it can also function as an anticriticality destruct system through use of one or more of the projectile units.

The penetrating projectile designed to carry the explosive charge into the core creates a highly confined explosion within the core. This causes the graphite elements to be crushed against the massive engine pressure vessel and reflector structures. Since the core material has exhibited high energy-absorption characteristics, especially under lateral attacks in the NERVA engine design, the explosive effects contributing to core breakup are somewhat different from concepts employing externally positioned explosives. The explosive energy is used in a manner which provides effects such as the following:

1. intense local explosive shockwaves produced by the detonation of high explosives,

2. intense local pressure and temperature regions produced by great volumes of hot expanding explosive gases momentarily confined by the massive pressure vessel and reflector structure,

3. mechanical impact by sma11 fragments from the explosiveprojectile container that are propelled at high velocity through the core material by the action of the explosive gas pressure, and

4. subsequent high-velocity collision and interaction between neighboring core fragments, causing further fragmentation.

Investigations conducted with the explosive postoperation destruct system technique have strongly indicated that a satisfactory solution to the postoperation safety problems can be achieved. This indication is based upon the particle size and distribution obtained from basic fragmentation and subscale and full-scale testing. The burnup of the core fragments and the problems of the fragment size and their effects are the subjects of other papers. 
A fragmentation program was performed in support of larger scale tests using crudely simulated models and full-scale simulated engine targets. Subscale tests were performed in the development of explosive components to be employed in the demonstration of destruct concepts. Tests with full-scale simulated engine targets were performed to indicate the feasibility of selected explosive destruct concepts. An important objective of the basic fragmentation research program was to obtain data and information on the mechanism of fracture and the shock attenuation characteristics of the core material. The initial portion of this support work attempted to determine qualitatively the efficiency with which energy could be transferred to a target from a quantity of explosive, through the various mechanisms of application, to achieve the breakup desired. A large number of subscale tests were conducted to develop the various component explosive charges. The angles of charge liners of different shapes, types of liner material, liner thicknesses, weights of explosives, types of explosives, and standoff distances were tested in the development of large conical shaped charges. Likewise, tests were conducted in the development of large linear shaped charges. Some targets simulated different sections of the NERVA engine. Other targets consisted of stacks of metal plates shich were useful in comparing the cutting capability of different massive linear charges. The results of this testing effort were used in the design of charges employed in demonstrating different concepts on full-scale engine models. The feasibility of internally placed explosive charges to produce the fragmentation of core material was demonstrated in the subscale tests and further demonstrated in full-scale tests with different sizes and numbers of explosive charges simulating explosively loaded projectiles.

A series of tests has been conducted to determine the penetration of graphite targets as a function of projectile velocity. These tests provided data relating penetration to kinetic energy and to the impact area and tensile strength of the target. This data provided good approximations of projectile velocities required for the penetration of various types of graphite target arrays. The feasibility of delivering at least one projectile into a full-scale simulated engine target has been demonstrated also. This was done by firing one projectile from a standard tank gun at a distance of 50 feet from a target containing three similar statically emplaced projectiles. Delay circuitry capable of causing simultaneous detonation of the projectiles was developed. The problem was to cause the detonation of fastmoving projectiles to occur when properly positioned in the target. In these tests, projectiles fired from a tank gun penetrated a simulated target and then impacted against a sandwich-type armor target which closed a circuit when pierced by the nose of a projectile. Switch closure caused the start of an electronic delay, and detonators then caused the fuses to function. Two major tests were subsequently conducted in which the dynamic implantation of a single armor-piercing explosive projectile into a full-scale target that contained additional static implanted charges was successfully achieved. In the first test (APG-1), the core quadrant used as a target for the dynamic projectile was filled with solid graphite rods. Longitudinal receptacle holes were provided for the insertion of projectiles, each containing explosive and centrally located in the other quadrants. Solid graphite rods also filled the quadrants where the static charges were placed. A standard tank gun placed 44 feet away was used to deliver the projectile to the target. Impact against the rear armor target by the nose of the projectile initiated electronic timing circuitry used to control the firing of al1 projectiles. The degree of fragmentation achieved was similar to that experienced in previous tests where a11 charges were in a static condition.

The second test (APG-2) was significant since it represented the first attempt to compare, in a full scale test, the degree of fragmentation. The target in this test was similar to that in APG-1 except that the 90-degree quadrant into which the moving projectile was fired was loaded with Kiwi-type fuel. The other quadrants were filled with graphite rods. An analysis of core fragment size after this test revealed that a considerably better fragmentation of the Kiwi fuel was achieved than when solid round rods were used.

It would be possible to conclude from this data that:

1. The feasibility of a penetrating-explosive destruct system for NERVA has been demonstrated, and a design basis now exists for hardware development. 
2. System performance in terms of graphite fragment size is influenced to a large extent by graphite geometry.

3. There is a need for data on the influence of explosive weight on graphite fragment size with fuel elements so the system design may be optimized.

\section{Future Studies}

Much work remains to be accomplished in the evaluation of the relationship of particle sizes, obtained by explosively induced fragmentation, to their potential hazard as expressed in terms of dose rate. Basically, two factors will determine the maximum health hazard, namely the mass of the particle at the time it reaches the ground and its residual inventory.

A number of factors exert a marked influence on the variation and terminal dose rates remaining with fragmented particles:

1. The particle sizes obtained, with reference to size and geometry.

2. The velocity increment imparted to the fragmented particles which in turn affects the fission-product inventory and/or orbital residence time.

3. History of the fragmented particle as related to:

a. The fission-product inventory in the reactor at the time the destruct system is initiated.

b. The fission product boil-off during re-entry.

c. The radioactive decay during orbital lifetime. 


\section{BLANK}




\section{NUCLEAR RAMJET MISSILE FLIGHT SAFETY*}

W. J. Hesse

J. E. Standefer

Ling-Temco-Vought, Inc.

Introduction

The intent of this paper is to show that nuclear-ramjet missiles may be safely flight tested without increasing present levels of contamination and without exposing personnel to radiation in excess of those levels recommended by organizations such as the Federal Radiation Council. The opinions and conclusions of this paper do not necessarily represent those of the Air Force, the Department of Defense, or the Atomic Energy Commission.

The ramjet powered vehicle, (see Figure 56) depends upon its forward movement at supersonic speed to force air into the engine inlet, thence into a heat exchanger and through a nozzle, producing thrust. Initial flight speed is achieved with a booster rocket. Ramjet thrust is equal to the change in momentum of the air passing through the ramjet. ${ }^{2}$

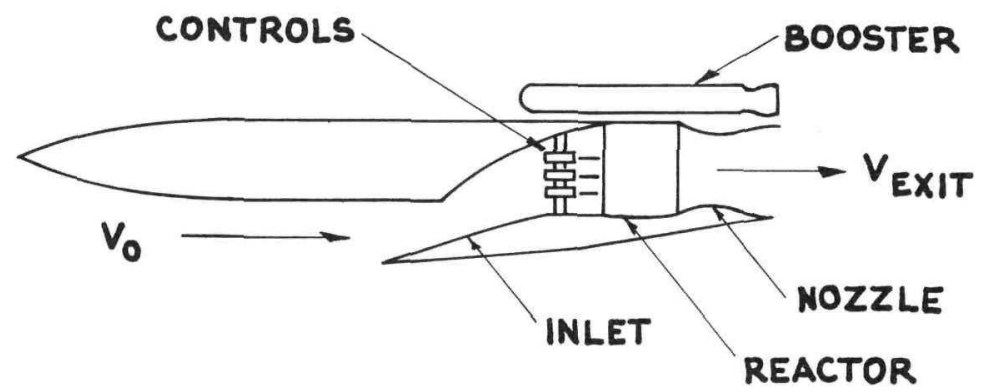

THRUST $=\frac{w_{a}}{g} V_{\text {EXIT }}-\frac{w_{a}}{g} V_{0}$

Figure 56. Nuclear Ramjet

(1 1b uranium equivalent

to $2 \times 10^{6}$ lbs jet fue1)

In a nuclear ramjet, a reactor is substituted for the conventional combustion chamber and serves as a single-pass-straight-through heat exchanger. Although the nuclear-ramjet engine and vehicle could be designed for almost any altitude up to about 100,000 feet, the system possesses a unique capability for supersonic flight at low altitudes for very long ranges with large payloads.

*Presented by Mr. Hesse 
A reactor for nuclear-ramjet engine application has been developed by the Lawrence Radiation Laboratory under contract to the Atomic Energy Commission. The reactor development program is referred to as the Pluto program. Two reactors have been developed, the Tory IIA and Tory IIC. Both are intermediate-neutron-energy reactors using $\mathrm{BeO}$ and $\mathrm{UO}_{2}$.

On May 14, 1961, the Tory IIA, Figure 57, was operated at 40 megawatts thermal for about 200 seconds at temperatures in excess of $2000^{\circ} \mathrm{F} .^{2},{ }^{3}$ Full power operation was achieved on three separate occasions during September and October 1961. The Tory IIC reactor design power, temperature, size, controls, and reflector are those necessary for a propulsion system to permit low-altitude supersonic flight. It is planned to begin testing the Tory IIC in $1963 .{ }^{4}$

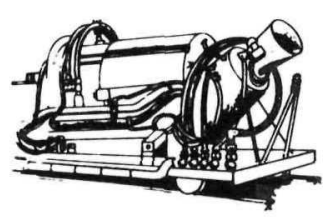

\author{
$196 I$ - REACTOR FEASIBILITY DEMONSTRATION \\ - FLIGHT POWER DENSITY EXCEEDED \\ - Flight temperature exceEded \\ - FUEL ELEMENT INTEGRITY DEMONSTRATED
}

TORY IIA

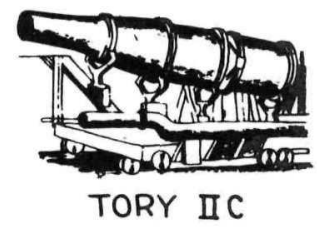

\title{
1963- FULL SCALE REACTOR DEMONSTRATION \\ - LONGER RUN TIMES \\ - improved fuel elements \\ - FLIGHT tYPE REFLECTOR \\ - Flight tyPe controls
}

Figure 57. Pluto Reactors

The Air Force is conducting a technology program to investigate the problems associated with sea-level flight at Mach numbers of about 3 and is investigating the timing and cost of future ground engine tests, flight tests, and weapon-system development. ${ }^{4}$ Ling-Temco-Vought, Inc., is prime contractor to the USAF for these investigations, and the Marquardt Corporation is the propulsion system subcontractor.

One problem under investigation is that of realistically, economically, and safely flight testing a supersonic, low-altitude, nuclear-ramjet missile.

The various phases in a flight-test/training program and the flights required for each phase are shown in Figure 58. Early studies indicated that the range required to accomplish these tests was very large and therefore should be laid out over an ocean area. Shown in Figure 59 is a conceptual layout of such a range.

There is no possibility of increasing the present level of worldwide contamination from operation of a nuclear-ramjet missile, as shown in Figure 60. Reactor excursions would not affect these comparisons, as seen in Figure 61, which compares the strontium-90 produced during reactor excursions with the production during a norma1 flight.

The problem, then, is one of limiting to safe levels the radiation exposures to personnel at the launch site and in the flight-test area, of controlling the flight path of the missile, and ensuring safe disposal of the missile debris upon termination of flight.*

\footnotetext{
"The information reported below was generated with the help of our colleague, Mr. Tom Johnson, and his contribution is gratefully acknowledged.
} 


\begin{tabular}{|c|c|c|c|c|c|}
\hline PROGRAM PHASE & \multicolumn{5}{|c|}{ NUMBER OF FLIGHTS/YEAR } \\
\hline $\begin{array}{l}\text { BOOSTED } \\
\text { SHELL TESTS }\end{array}$ & 4 & & & & \\
\hline $\begin{array}{l}\text { PROPULSION, } \\
\text { AERODYNAMIC } \\
\text { STABILITY \& CONTROL, } \\
\text { PERFORMANCE } \\
\text { TESTS }\end{array}$ & $\sum_{6}^{\text {FIRST }}$ & UCL & EAR & FLIGHT & \\
\hline $\begin{array}{l}\text { INERTIAL GUIDANCE, } \\
\text { FIXTAKING, } \\
\text { TERRAIN } \\
\text { AVOIDANCE, } \\
\text { ARMAMENT TESTS }\end{array}$ & & 3 & 12 & 9 & \\
\hline $\begin{array}{l}\text { TRAINING } \\
\text { FLIGHTS }\end{array}$ & \multicolumn{5}{|c|}{$\begin{array}{l}\text { NUMBER OF FLIGHTS PROPORTIONAL } \\
\text { TO MISSILE FORCE SIZE, MAX. OF } \\
38 / \text { YEAR ASSUMED FOR THIS STUDY }\end{array}$} \\
\hline
\end{tabular}

Figure 58. Typical flight test program

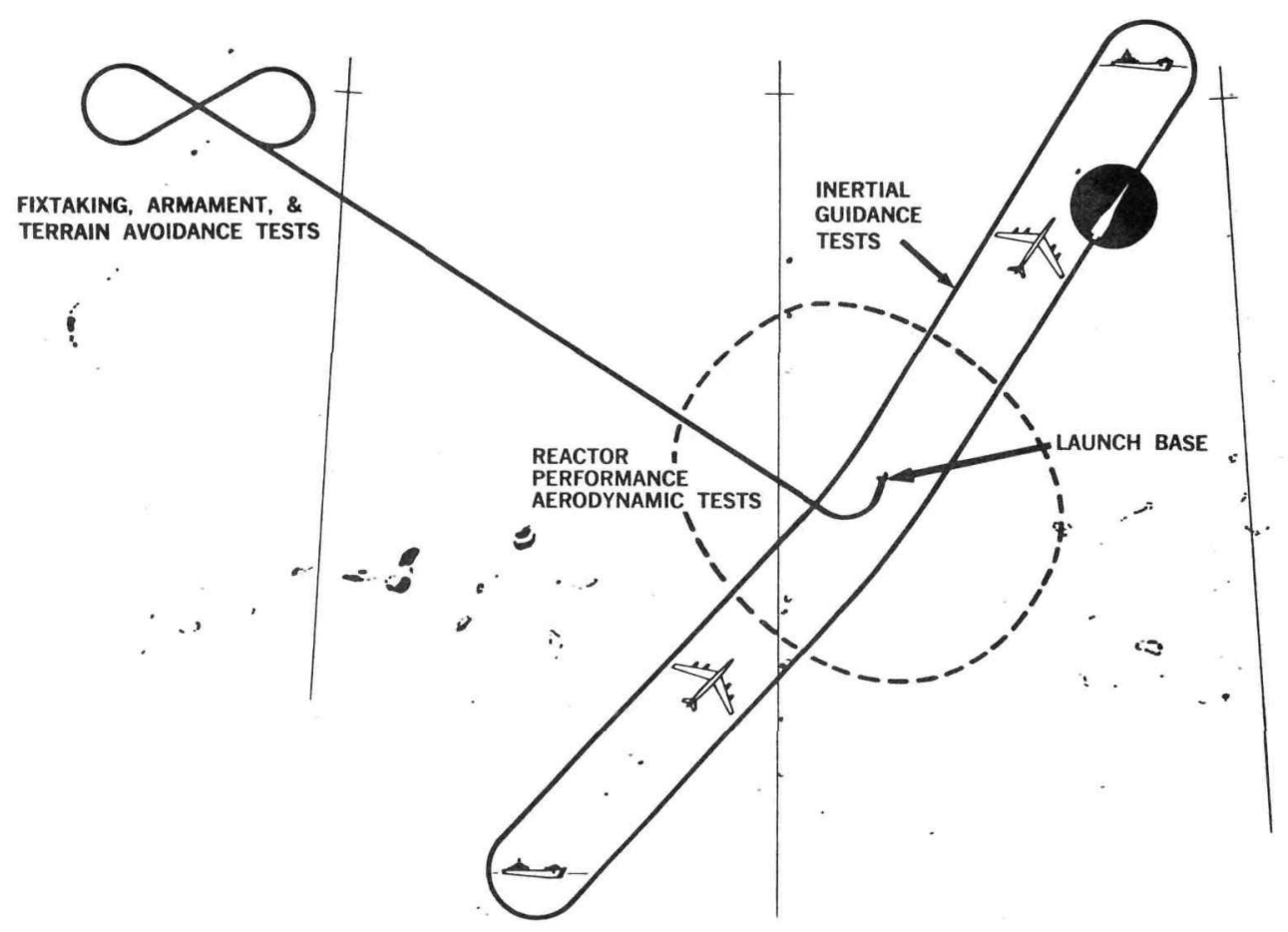

Figure 59. Flight test range concept 
RELEASED TO AIR/FLIGHT

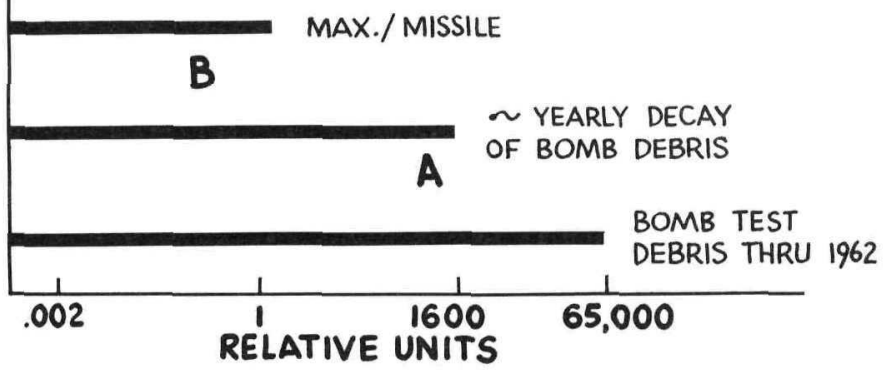

Figure 60.

Sr-90 comparisons

$\frac{A}{B}=1600$ MISSILES $/$ YR. WITHOUT

INCREASING PRESENT INVENTORY!

Figure 61.

Potential excursion events

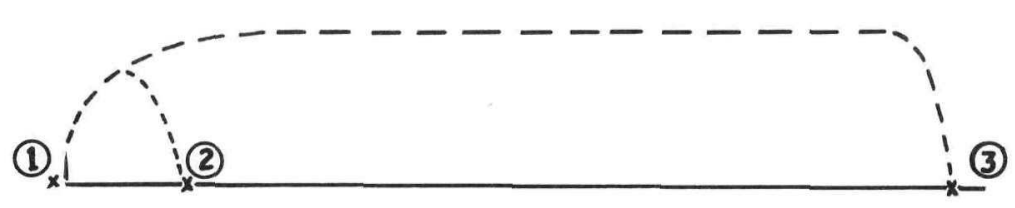

EVENT

(1) LAUNCH PAD EXCURSION

(2) IMMERSION, LAUNCH FAILURE

(3) IMMERSION, HOT REACTOR

NORMAL FUGHT

\section{SP ${ }^{90}$ PRODUCTION}

(RELATIVE NUMBERS)

0.002

0.012

0.006

1.0

Launch Base Exclusion

Consideration of external whole-body and internal radiation exposure versus distance from normal operations, of the effects of a reactor excursion, of long-term ground contamination, and of possible booster explosion (Figure 62) led to a recommended exclusion radius of $1 / 2 \mathrm{mile}$ for protection of project personne 1 and $1 \mathrm{mile}$ for protection of civilian personnel. The effluent from normal startups is considered to be a continuous point source at ground level, and diffusion is treated by the generalized Gaussian plume formula. ${ }^{5}$ The effluent from an excursion is considered to be an instantaneous point source at ground level and diffusion is treated using similarity theory of turbulence. ${ }^{6,7}$ 


\section{NORMAL OPERATION}

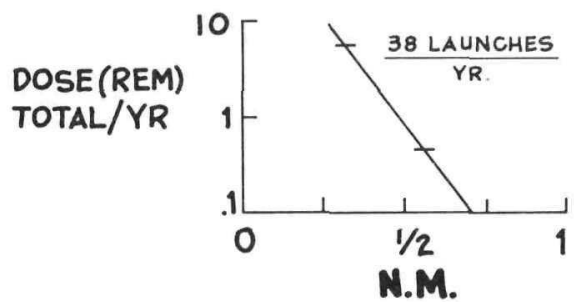

10 YR. PROGRAM PLUS ACCIDENT

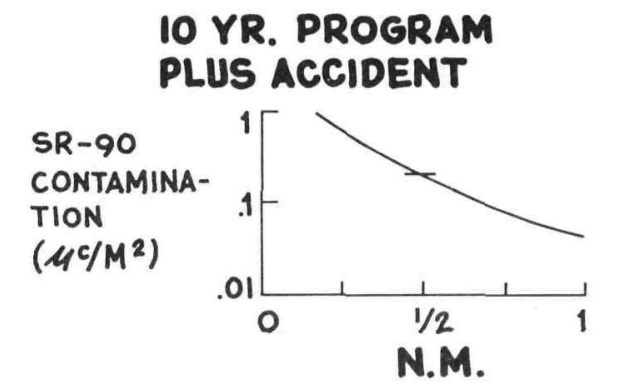

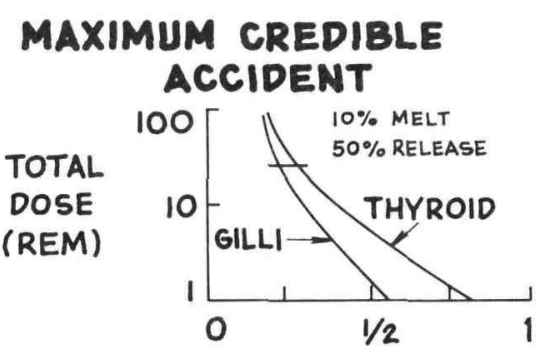

N.M.
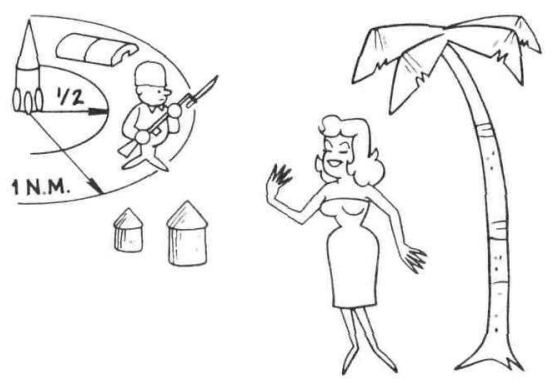

Figure 62. Launch base exclusion

Precautions at FAT Island

Fixtaking, armament, and terrain-avoidance proof tests require that the vehicle fly over an island ("FAT Island") of particular terrain roughness and altitude, Figure 63. Precautions will include complete evacuation of civilians from the FAT island before a test. Test personnel will either be on ships a safe distance off shore or in massive protective bunkers. First tests of the vehicle and s'bsystems, which will be flown above simulated terrain over the open ocean, will lower the probability of impacting on the FAT island. Thorough monitoring of the environment before and after the tests will ensure that no residual radiation hazard goes undetected.

Preflight Precautions

Before each test flight, extensive precautions would be taken to ensure safe operation (see Figure 64). These precautions include requiring good weather and sea conditions to minimize the chances of an accident and to mitigate the results should one occur. Good weather and smooth seas facilitate thorough radar and visual scouting of the range before the flight. In addition, the missile will be held on the pad until the boosters have developed thrust and are operating properly. Once the vehicle is released, it is highly probable that it will land downrange in deep water should the reactor not develop sufficient thrust to sustain flight. 
- EVACUATION DURING TEST

- TEST PERSONNEL ON SHIPS AT SAFE DISTANCE

- >.988 PROBABILITY OF

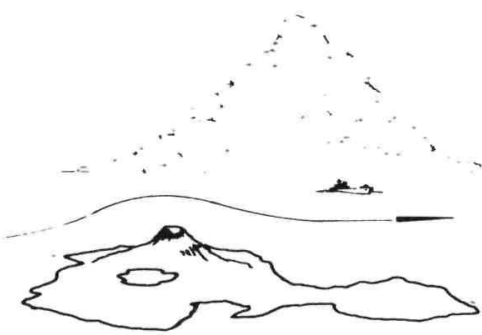
NO IMPACT / 36 PASSES

- THOROUGH MONITORING

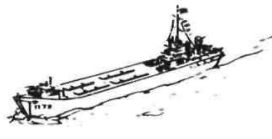

Figure 63. Precautions at FAT island

- GOOD WEATHER AND SEA CONDITIONS

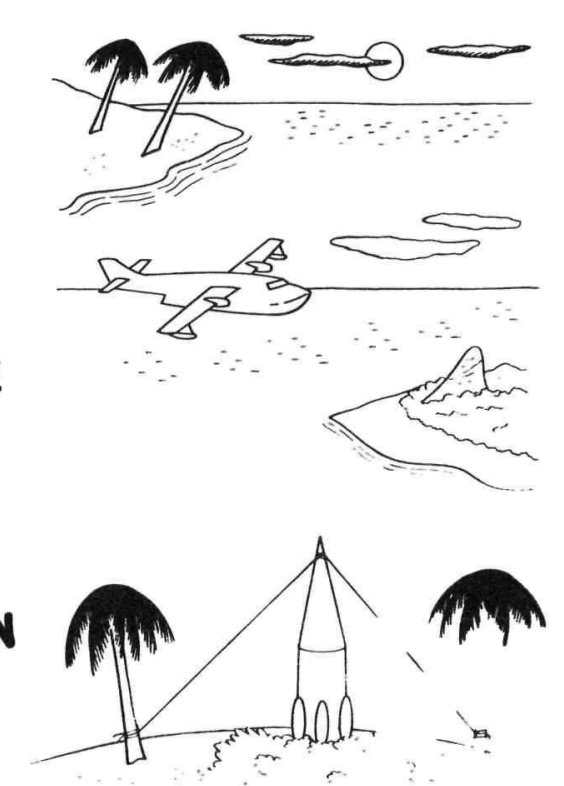

- RANGE SURVEILLANCE

- BOOSTERS HELD DOWN UNTIL OPERATING PROPERLY

Figure 64. Preflight precautions 
F1ight Precautions

Figure 65 lists certain flight precautions. The cardinal principle for nuclearpowered missile flight-test operations is full-time, line-of-sight radar tracking and radio command-control in conjunction with multiple, fail-safe flight-termination systems to permit selection of the missile flight path and to prevent the missile from running away.

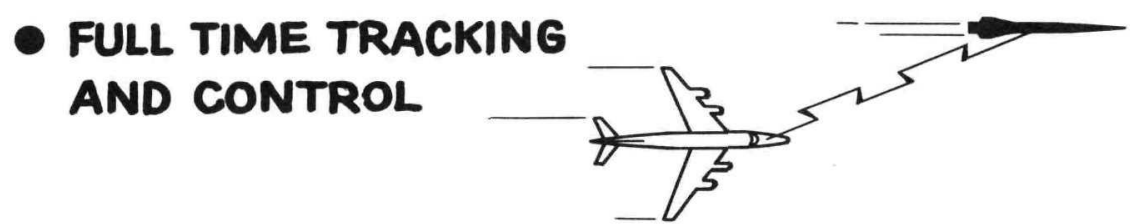

\title{
AUTOMATIC, REDUNDANT, FAIL-SAFE FLIGHT TERMINATION
}

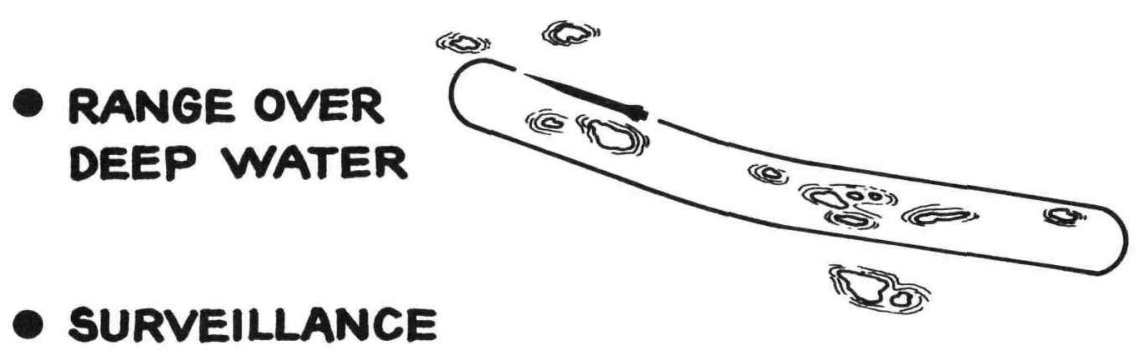

Figure 65. F1ight precautions

\begin{abstract}
Airborne range stations ${ }^{8}$ provide increased radio line-of-sight and flexibility to translate in a downrange direction with the missile. The number of airborne range stations to maintain full-time tracking and control is much lower than that of surface range stations, for large dollar savings.
\end{abstract}

With the exception of a sma11 area near the launch base and a small area around the terrain-avoidance test island, the entire flight test range will be situated over a very deep ocean area. There will be no need to fly over the inertial-guidance-test islands, and the missile will be flown away from shipping and aircraft that might enter the area.

Each flight test will be planned so that in the event a missile breaks up in flight, no debris will fal1 on land, in shallow water, or on a ship. Debris trajectories have been calculated and are shown in Figures 66 and 67.

\section{Positive Flight Termination}

The signal for flight termination can originate at several sources, Figure 68. Multiple sources of destruct commands are incorporated into all range stations. There are multiple fail-safe destruct devices aboard the missile in case command signal is lost. The launch base can redirect the flight of the missile either for immediate destruct or for flight to a predesignated disposal area. The mechanisms for terminating a test flight include reactor shutdown, disruption of reactor, aerodynamic zoom-sta11 or dive, and "explosive destruct." Reactor disruption and/or explosive destruct would probably consist of pneumatic decoupling of sections. 


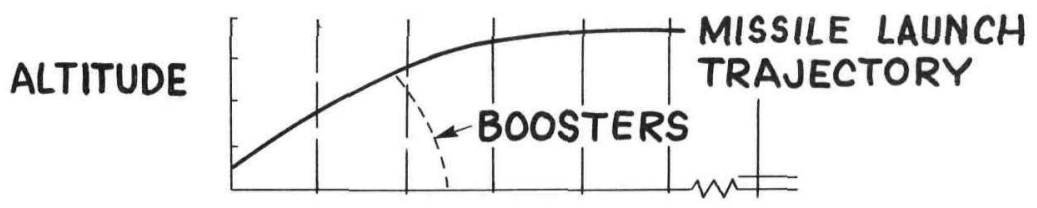

Figure 66.

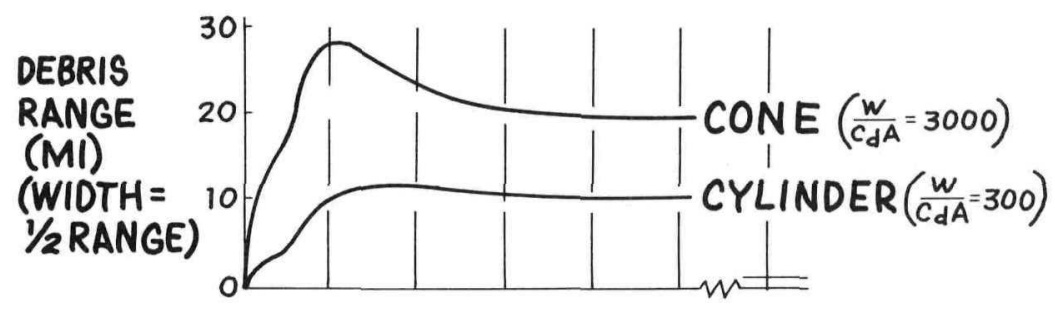

Debris trajectory

Figure 67.

Latera1 debris range
10 SEC. MAX.

BEFORE AUTOMATIC

DESTRUCT

3 R.F. LINKS - A)DRIMARY COMMAND CONTROL

B) TRACKING BEACON

C) INDEPENDENT DESTRUCT LINK

FAIL SAFE - LOSS OF CARRIER IN A \& B - LOSS OF ELECTRICAL POWER IN MISSILE

Figure 68.

Positive flight termination

\section{MULTIPLE METHODS -REACTOR DISRUPTION \\ - AERODYNAMIC MANEUVER \\ - REACTOR SHUTDOWN \\ - EXPLOSIVE CHARGE}


Ocean Impact

It has been stated that the flight path will be over deep water. But how deep is deep? The upper mixing layer, Figure 69, where photosynthesis takes place, where most of the life of the sea is found, and where turbulent action causes relatively rapid mixing, extends to an average depth of about 600 feet. Commercial or sport fishing rarely extends below 600 feet. Upwelling, the relatively rapid rising of water to the surface from depth, is perhaps significant to depths of 1500 feet, but below this vertical diffusion is very slow. Forage for fish commonly caught migrates to perhaps as deep as 2400 feet. Three thousand feet is thus taken as the definition of deep, i.e., that depth below which it is judged safe to abandon missile and reactor debris. ${ }^{9}$ However, in accordance with the conservative recommendations of a committee of the National Academy of Sciences - National Research Council for disposal off the California coast, deliberate disposal of missile or reactor debris will be in water deeper than 7200 feet. Test ranges that have been recommended to the USAF are such that almost the entire flight paths may be over water deeper than 7200 feet.

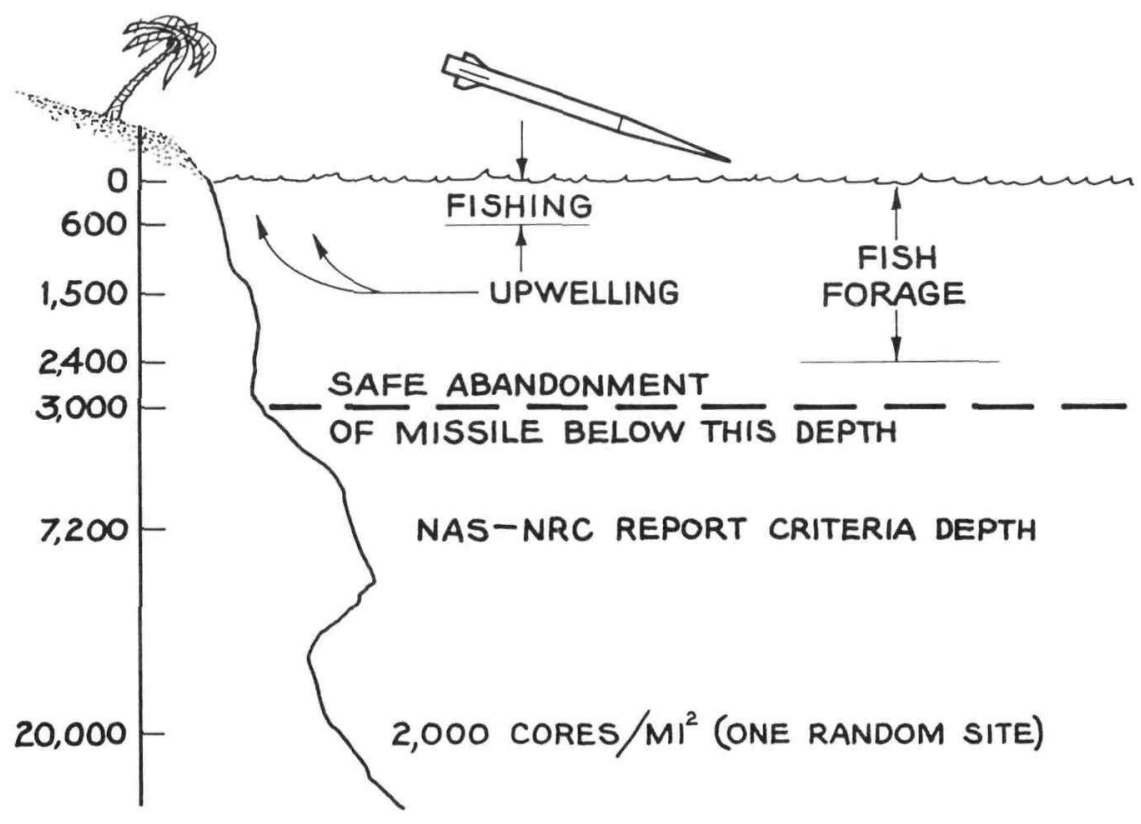

Figure 69. Ocean impact

If the missile impacts in deep water either accidently or deliberately at the end of a test flight, the debris will be abandoned. Factors supporting the safety of this procedure are these:

1. Fuel elements do not shatter when quenched in cool water from operating temperature.

2. Fuel elements will sink through the important upper 600 feet of the ocean in approximately 10 minutes. This time was calculated from the density of sea water and fuel elements, assuming zero velocity on entrance into the water and the maximum reasonable drag of a fuel element.

3. Beryllium oxide is extremely inert in sea water. 
4. It takes perhaps 300 years for water to exchange between the deep layers of the ocean and the surface. Areas for deliberate disposal may be selected so that the exchange rate is slower than this.

5. Using the conservative requirements for disposal off the California coast ${ }^{10}$ and the best estimate of the corrosion rate of beryllium oxide, it was calculated that more than 2000 Pluto reactors, each having flown a typical mission, may safely be disposed of in an area 1 nautical mile square and 6000 meters deep.

Impact at the launch point or FAT island would require continued isolation of the area until the debris decays or until the debris can be salvaged and the area decontaminated.

\section{Diffusion in the Ocean}

Any radioactivity released into the surface layer of the ocean following a missile impact will quickly diffuse, as shown in Figure 70. The lower curve corresponds to the fractional loss expected in the surface layer of the ocean from the quenching of fuel elements. The diffusion model used is the one developed by okubo for an instantaneous point source. ${ }^{11}$ The average value found in Reference 11 for the diffusion parameter is used. The maximum permissible concentration shown is that for drinking water and is extremely conservative for the transient condition considered here. Dose to man from this transient condition will be calculated in the near future. In any event, the missile impact point will be controlled so that any such release will not cause a problem to commercial fisheries.

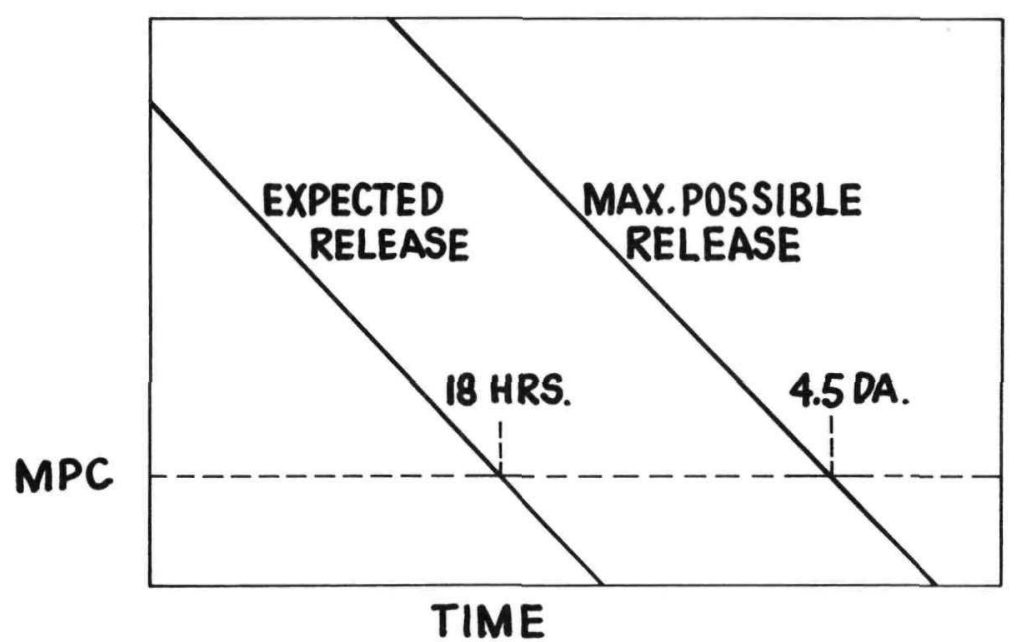

Figure 70. Diffusion in ocean surface layer 
The capacity of the oceans to accept radioactive materials has been estimated. ${ }^{10}$ Figure 71 illustrates that capacity in terms of nuclear-ramjet missiles. It appears that each year, $10^{6}$ nuclear-ramjet missiles could be disposed of in the ocean depths without exceeding that total capacity. It was previously assumed, Figure 62 , that no more than 38 missiles would be flown in any one year.

\section{DEPTHS OF OCEAN CAN ACCEPT 90 TONS - F.P. /YR. ( NAS-NRC, OTHERS )}

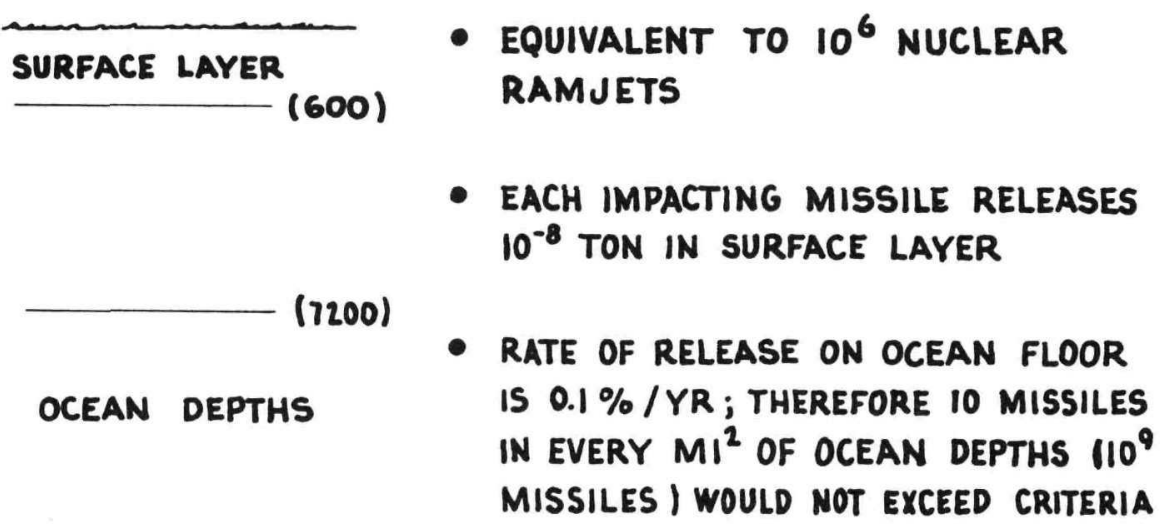

- EACH IMPACTING MISSILE RELEASES $10^{-8}$ TON IN SURFACE LAYER

- RATE OF RELEASE ON OCEAN FLOOR OCEAN DEPTHS IS $0.1 \% / Y R$; THEREFORE 10 MISSILES IN EVERY $M I^{2}$ OF OCEAN DEPTHS $110^{9}$ MISSILES I WOULD NOT EXCEED CRITERIA

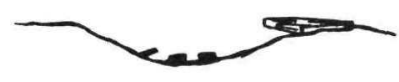

Figure 71. Ocean capacity

Conclusion

Great care must be exercised in the application of nuclear energy, but there should be no doubt that a nuclear-ramjet missile can be safely flight tested.

The emotion that seems to grip people at mention of radioactivity is a problem that burdens a11 nuclear programs. It is sincerely hoped that the information contained in this paper will help separate emotional reactions from the true facts of a program to flight test nuclear missiles. 
1. W. J. Hesse, Jet Propulsion, Pitman Publishing Corporation, 1958.

2. Volume 4, No. 7, Nuclear News, American Nuclear Society, July 1961.

3. J. R. Morgan, PLUTO Branch, USAEC, personal communication.

4. Hearings before the Subcommittee on Research, Development, and Radiation of the Joint Committee on Atomic Energy, Congress of the United States, Space Nuclear Power Applications, September 13, 14, and 19, 1962.

5. F. A. Gifford, Jr., "Use of Routine Meteorological Observations for Estimating Atmospheric Dispersion," Nuclear Safety, June 1961.

6. F. A. Gifford, Jr., "Relative Atmospheric Diffusion of Smoke Puffs," Journa1 of Meteorology, Volume 14, 1957.

7. E. M. Wilkins, "Observations on the Separation of Pairs of Neutral Ba11oons and Applications to Atmospheric Diffusion Theory," Journal of Meteorology, Volume 15, 1958.

8. W. J. Hesse and L. J. Boyer, Airborne Range Stations for Control of Nuclear Ramjet Missile Test Vehicles, Princeton University Conference on Prospects for Nuclear Aerospace Propulsion, February 15-16, 1962.

9. P. L. Horrer, Marine Advisers, Inc., personal communication.

10. J. D. Isaacs, et. a1., Disposa1 of Low-Leve1 Radioactive Waste Into Pacific Waters, National Academy of Sciences - National Research Council, Publication 985, 1962 .

11. A. Okubo, Horizontal Diffusion from an Instantaneous Point Source Due to Oceanic Turbulence, Chesapeake Bay Institute, Technical Report 32 , December 1962 . 
SESSION IV

ENVIRONMENTAL FACTORS

Chairman

Joseph A. Lieberman

Assistant Director for Nuclear Safety

Division of Reactor Development, USAEC

Session Coordinator

Capt. Robert A. Meisenheimer

Air Force Weapons Laboratory 


\section{BLANK}




\author{
MARINE SCIENCES RELATED TO AEROSPACE \\ USES OF NUCLEAR POWER \\ Arnold B. Joseph \\ Environmenta1 Sciences Branch, USAEC
}

Introduction

The benefits of nuclear power in aerospace applications loom potentially large. But the very thing that makes nuclear power beneficial--the release of atomic energy-carries with it a risk to human safety. By defining and controlling these risks the users of atomic energy can more freely derive the benefits. This paper deals almost exclusively with studies to define the risks of radioactivity in the marine environment. An important by-product of such studies is that, once the risks have been defined, steps or procedures may be designed to control or overcome them.

Oceanography is a young science. Even in 1963 we know very little about the ocean compared to what we need to know. Historically, developments in the field are mostly tied to man's uses of the sea. In the days before diesel engines, navigation aids were probably the principal need; charts were therefore developed to show dominant wind and surface current systems and bottom obstructions. More recently, submarines and other military needs have created a demand for much more detailed information on underwater currents, sound transfer, chemistry, and biology. The military needs perhaps more than any other factor have boosted oceanography into the 1imelight. of course, getting food from the sea has occupied man for a long time and many of man's discoveries relating to the sea came as a result of fishing. However, until recently man could always catch enough fish in shallow water close to home and had no need for information beyond this area. The global population increase is changing this picture. It is now recognized that in the not-too-distant future man will farm the ocean for food much as he farms the land. This means he will need to know what makes it "tick." For defining risks of using nuclear power, we also need to know what makes the ocean "tick." Thus, in a way, we are neck and neck with the fishermen and much of our oceanographic research is, by circumstance, work of exploration and discovery .

\title{
Source-Term Studies
}

The risk of introducing radioactivity into this environment varies with the amount and kind of activity introduced, the time and place of introduction in relation to the dynamics of the environment, the resources exposed to the activity, and man's subsequent contact with the resources.

To define a risk, it is necessary to measure--physically and chemically-exactly what it is that may create the risk. While one can easily calculate or measure the radioactivity in a nuclear power source, the calculation gives only a number which may or may not describe the possible exposure realistically. For example, in the SNAP-7 series there may be kilocuries of strontium-90. However, strontium in the form of the titanate is not very soluble in sea water and very little would be available to enter the marine ecological cycle. Aerospace reactors are another example. Even though one may undergo an excursion, all of the fission fragments are not necessarily released; some may be bound up in a matrix of insoluble fuel materials. 
However, if the physical and chemical form of the activity is such that when released to the water it stays in solution or suspension and thus is available to marine 1ife, then a calculation of activity can be made to give an upper limit to the definition of risk.

Laboratory experiments are being undertaken by the U. S. Naval Radiologica1 Defense Laboratory, Atomics International-Phillips Petroleum Co., Los Alamos Scientific Laboratory, and others to describe the physical and chemical characteristics in relation to sea water of nuclear materials used in SNAP devices and the nuclear propulsion reactors.

With SNAP isotope units, samples of the radioactive source material, prepared in the same way as the actual fuel material, are subjected to prolonged corrosionleaching immersions in sea water. Actual sea water flowing past the sample is used whenever possible. Besides prolonged exposure to water, an effort is also made to determine radiation effects on solubility of the source material and on containment materials used in the devices. Another objective is to determine if the materials behave differently after many years of radiation history.

With the reactor units, marine source-term work involves looking at two different cases: (1) the characteristics of the radioactivity in a normally operated core and (2) the characteristics of the activity in core materials subject to a transient. In the first case, samples of an operated prototype core, or a simulation, are subjected to leaching experiments as in the case of the SNAP isotope units. In the second case, samples of core fuels, encapsulated in a suitable pressure vesse1, are subjected to a burst of neutrons in a reactor like the TREAT at NRTS or the Triga of General Atomics. The effect on the sample is that of a transient with its accompanying temperature and pressure evolutions. The fuel sample can be immersed in air or water or a combination of both while undergoing the transient. The chemical and physical characteristics of the fission products released to the water can be measured directly. Of importance are determinations of the soluble and insoluble fission products and particle size distributions with and without associated but unaffected core materials. Subsequently, measurements can be made of the fission products leached from a fuel matrix over a longer period. Activation products are being looked at only theoretica1ly at present. When designs are frozen, i.e., materials selected, marine source-term studies of some activation products may be indicated. A11 of this marine source-term work is important to an understanding of the possible risks and is needed to reduce or eliminate uncertainties in the definition of risks. To examine possible effects in the ocean environment, one should study the characteristics of the activity in sea water--not freshwater, not air--but sea water.

\section{Marine Studies}

To give a better framework for subsequent discussions of research studies, I will first go briefly into a general concept and touch upon the structure of the ocean. What is known about the oceans, at least for our purposes here? We know that the ocean environment is dynamic. An early concept was that the deep waters of the ocean were like a stagnant pool and the ocean bottom was a thick, soft ooze. This concept was quickly discarded when tools were lowered, water movements measured, and samples collected. Waters in deep chasms, abyssal deeps, enclosed basins, and even the floating ice caps of the polar regions all have some movement. Topographically, the ocean floor is found to be much like the surface of the land. The oceans of the world are interconnected, they are chilled at the poles, they absorb the major share of the sun's energy received by the earth, and they are acted upon by gravitational and wind forces; their dynamic nature is therefore to be expected even if not fully understood.

Another early concept was that the ocean was constant, a concept derived, I should guess, from the presence of saltiness everywhere and the lack of visible superstructure. Actually, it is far from constant: the salt content varies from shore to shore, from top to bottom, and from pole to pole. It has had geologic ages to come to equilibrium and still has not reached it. Miliions of observations have 
shown that the ocean bottom has about as many variations in topography as the land surface, i.e., mountains, valleys, and plains.

We also know that the ocean environment is mother and home to tens of thousands of different species of organisms ranging from microscopic bacteria and phytoplankton to harvestable fish and animals. The evidence indicates that the biology is related to the chemistry which in turn is related to the physics of the environment.

Figure 72 (from Reference 1) illustrates the interrelationship of physical, chemical, and biological processes taking place in the sea. A theoretically ideal objective for a marine studies program would be to put numbers to these processes. I have no doubts that this will be done some day. However, practical limitations of time and money dictate another course, that of seeking out and identifying the processes that are known or suspected to relate most directly to man, i.e., the shortest routes back to man of the materials of risk. For example, it has been found that fish and certain kinds of plants will take materials out of solution or suspension and in some cases concentrate them to a high degree. Thin films of dead or decomposing organic materials floating at the surface have an exchange capacity and may return activities to the shore. By wind or wave action, these films or slicks can be driven on to the beach to be filtered out by beach sands. Organic debris on the beaches is ready evidence of this.

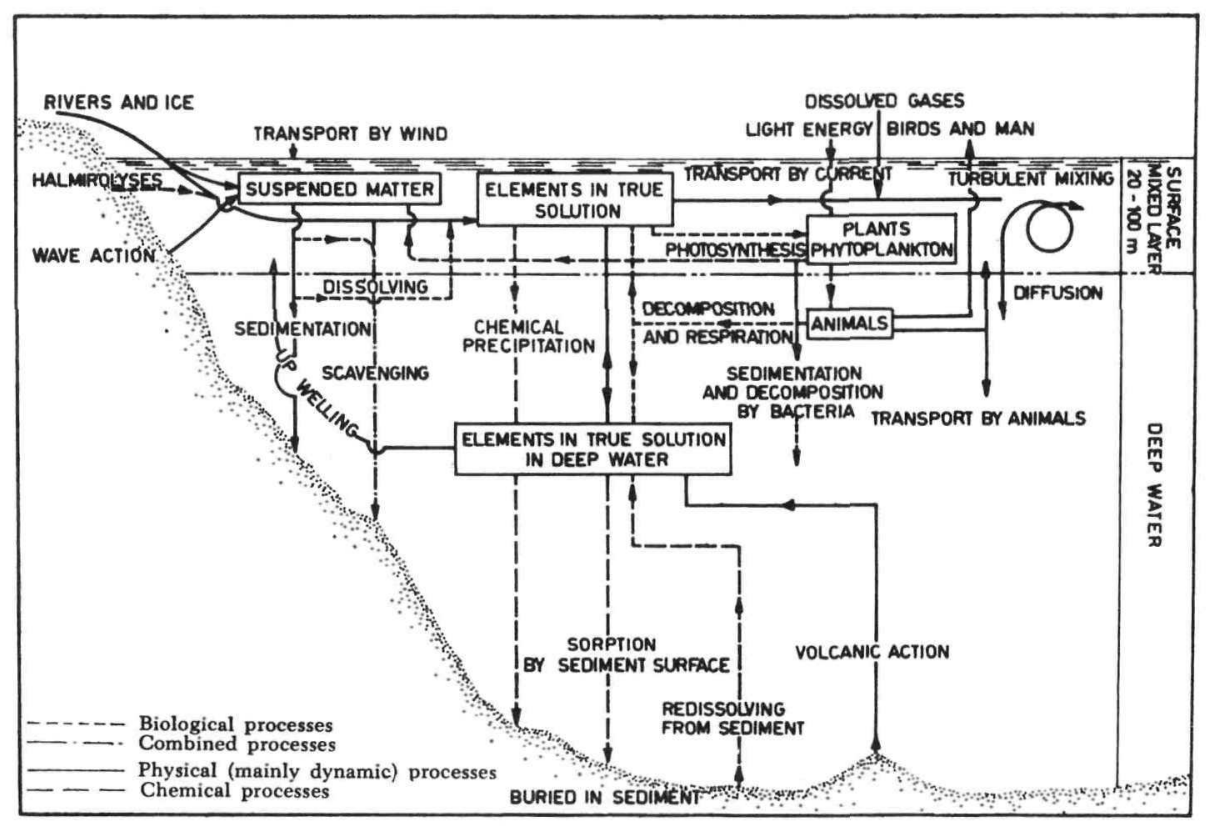

Figure 72. Scheme of major physical and geological processes in the sea

Much more is known about man's activities than his environment: where he fishes, what kinds of fish he takes and eats or otherwise uses, and which beaches he uses. These uses of the sea tell something of the area of concern and where one should be aware of direct return processes. For identifying future risks there is also the benefit of some limited but direct experience with fission products in the ocean and from studies of biological systems in the laboratory. 
Structure of the Ocean Environment

In vertical profile, the ocean has several distinct physical separations in addition to air and land interfaces. I have already mentioned the existence of an organic surface film noticeable in inshore waters. Next is the upper layer of the ocean known as the mixed layer or the photosynthetic zone, i.e., the mass of water penetrated by solar radiation. About 100 meters thick, it is well mixed by wind and wave action. In this upper mixed layer, sunlight provides energy for photosynthesis, and over 95 percent of the biota are produced here.

The temperature gradient top to bottom takes a sharp dip at about the bottom of the mixed layer. This dip, which is called the thermocline, is also representative of a slight change in water density. Above the thermocline, water is less dense, below the thermocline more dense. The thermocline is observed to be in effect a physical barrier to chemical exchanges between the surface waters and those below it.

Let us turn our attention to the water at the other boundary, near the bottom. (The layers between the top and bottom of the sea are rather too complex for a limited discussion such as this.) In the deepest parts of the Atlantic and Pacific Oceans in the Southern Hemisphere lies cold and dense water formed in the Antarctic Ocean; in both it flows generally to the north, but with this the similarity between the Atlantic and Pacific ends. The Atlantic Ocean at the north is in communication with the Arctic Ocean where cold waters are formed in winter and generally move southward. These polar waters clash or mix in the equatorial region. The time for the top to bottom circulation in the Atlantic Ocean has been estimated to take between 100 to 500 years. The Pacific on the other hand is connected to the Arctic Ocean only through the Bering Strait, a relatively small channel. As a result, movement of Pacific bottom waters is not nearly as distinguishable as in the Atlantic. It is believed top to bottom circulation in the Pacific takes between 1000 and 5000 years. But even with such long times of exchange, it is notable that stagnant bottom waters are very rare.

Currents in the ocean are caused by lunar and gravitational forces (tida1), wind forces, and density differences. The Coriolis force causes a clockwise circulation in the Northern Hemisphere and counterclockwise in the Southern Hemisphere. The continental land masses mold currents into patterns of convergences and divergences, i.e., changes in shape, direction and intensity. Seasonal and annual changes in climate superimpose a variable effect on current patterns as do intense disturbances like storms. When it comes to considering questions of possible dilution values and transport directions and rates, it is almost impossible to generalize. Hence it is necessary next to turn to direct observations and measurements in the region of concern.

Physical Studies

The AEC is supporting physical and biological oceanographic studies of the ocean areas off both the Florida and California missile launch facilities. The ocean area of most concern is the relatively shallow mixed layer, the photosynthetic zone. It is here that most of the ocean's biological productivity takes place and where man comes in contact with the ocean and its contents. The objectives of the physical studies are to determine the extent, direction, and rate of possible diffusion and transport. Since chemical interactions and plant and animal life may modify this picture, it is necessary to study these factors in concert with the purely physical factors.

There are several largely empirical formulae to describe diffusion of soluble materials in the ocean. Schonfeld, ${ }^{1}$ Pritchard and Carpenter, ${ }^{2}$ and Okubo ${ }^{3}$ have reviewed the merits and demerits of equations by Joseph and Sendner, ${ }^{4}$ Ozmidov, and Obukhov as we11 as some they derived. Basically these are similar to the Fickian distribution equation: 


$$
S(r, t)=\frac{M}{4 k t} e^{-r^{2} / 4 k t}
$$

where

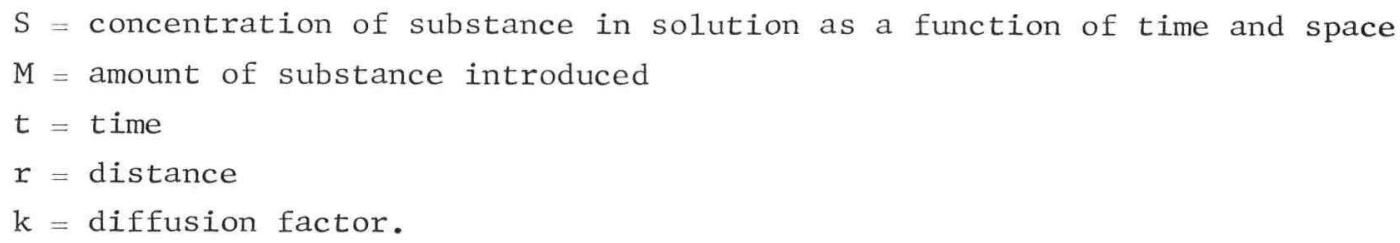

The experts do not agree on any single model to be used to predict or describe al1 cases of oceanic diffusion. Their disagreements are concerned primarily with the units of the diffusion factor, $k$. Depending on whose formula is used, $k$ has dimensions of $\mathrm{L} / \mathrm{T}, \mathrm{L}^{2} / \mathrm{T}$ or $\mathrm{L}^{2 / 3} / \mathrm{T}$. When compared to measured concentrations in coasta1 waters, the different formulae give answers that vary by factors of 10 or more. However, the experts are in agreement in noting that diffusion undoubtedly does vary from place to place and time to time depending on boundary conditions, depth, vertical stability (temperature and salinity distributions), and tidal and wind-driven currents and that the best obtainable measure of diffusion is the direct observation. For the open ocean (i.e., away from boundary effects), they further agree that the Joseph and Sendner formula would give a reasonable estimate (plus or minus a factor of 10) of diffusion of materials in solution. This formula is as follows:

$$
s(r, t)=\frac{M}{2(P t)^{2}} e^{-r / P t}
$$

where

$$
\begin{aligned}
& \mathrm{S}=\text { concentration of substance introduced } \\
& \mathrm{M}=\text { amount of substance introduced in smal1 area } \\
& \mathrm{P}=\text { diffusion velocity }=1.16 \mathrm{~cm} / \mathrm{sec} \text { or } 1 \mathrm{~km} / \mathrm{day} \\
& \mathrm{t}=\text { time after introduction } \\
& \mathrm{r}=\text { distance from origin to edge of cloud. }
\end{aligned}
$$

Equations (1) and (2) both treat concentrations in a simplified way, i.e., in two dimensions. The key feature of the Joseph and Sendner formula is the estimate of a diffusion velocity (based on a limited number of observations) of the order of 1 kilometer per day. Extrapolating freely on this observation, one may say that the average radius of a diffusing cloud enlarges by 1 kilometer per day. We know too by observation that vertical mixing is much slower than horizontal and depends upon which portion of the vertical profile is being considered. In a wind-mixed surface layer, the mixing time to the thermocline can be brief as observed in the dyediffusion experiments off Cape Canaveral described below. In the thermocline, the vertical mixing is slow or almost nil; below the thermocline, data are lacking, but vertical mixing rates are presumed to be low also.

In confirming their formula or those of others for diffusion in coastal waters, oceanographers are making direct measurements using the rhodamine dye tracer technique developed by the Chesapeake Bay Institute and described by Pritchard and Carpenter. ${ }^{2}$ In studies supported by AEC, a series of dye releases in the coasta1 waters off Cape Canaveral were made in March and April 1962, and again in August 1962. In both series, spring and summer, three releases of 200 pounds of dye each were made at different distances off-shore. In the spring series, the waters were well mixed vertically to the bottom and water motion was dominated by some rather 
brisk winds. In the summer release, a strong thermocline existed at about 25 feet and the tracer, released in the upper waters, was mixed in the upper 25 feet and did not penetrate below the thermocline (see Figure 73). In the spring, strong winds pushed the waters at velocities up to 5 knots and in the summer at 0.1 to 0.5 knot, yet measured diffusion during the summer period was within a factor of two of the spring measurements.

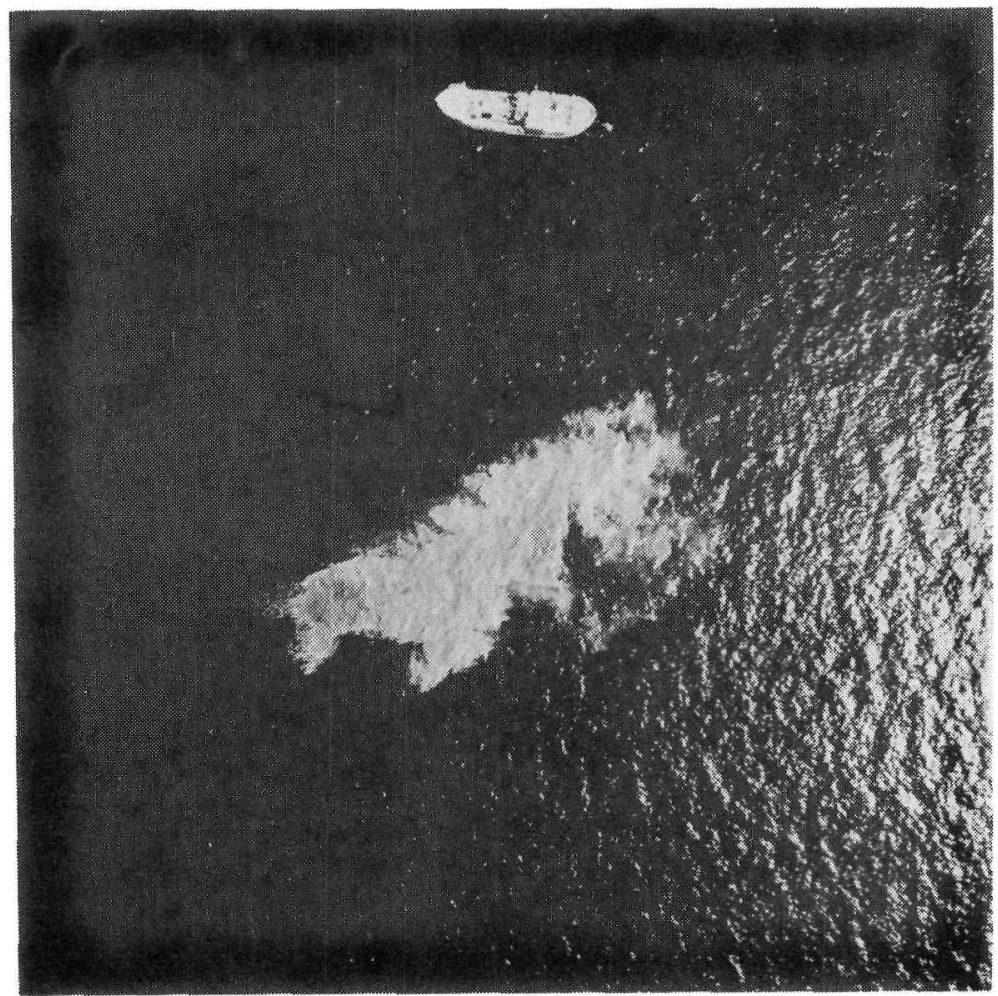

Figure 73. Diffusing cloud of rhodamine-B dye as observed by aircraft at about 500 foot altitude. (Photo courtesy of Chesapeake Bay Institute)

The data of Table I indicate that if a source were introduced to these waters, if it went into solution, and if it was not affected by other factors, e.g., biological retention or co-precipitation, it would be diluted by a factor of "about '10 10 in a period of 4 days.

\section{TABLE I}

Ratio of Peak Concentration to Amount Introduced at Various Times

\begin{tabular}{cc}
$t$ (hrs) & $\mathrm{g} / \mathrm{m}$ (grams $/ \mathrm{m}^{3}$ per gm released) \\
\hline 1 & $5.4 \times 10^{-4}$ \\
10 & $5.4 \times 10^{-7}$ \\
24 & $3.9 \times 10^{-8}$ \\
48 & $4.9 \times 10^{-9}$ \\
100 & $5.4 \times 10^{-10}$
\end{tabular}


Simultaneous with the diffusion experiments, a series of observations and measurements were made on current velocities and their variation in profile and direction. The resulting data are being correlated with surface wind observations. The data on currents are considered important, for if the source does not go into solution rapidly but diffuses out slowly, say at the bottom, there will be a basis to indicate what to expect in the way of diffusion and transport.

Similar dye diffusion and current measurements will begin this year in studies of conditions off Point Argue11o.

\section{Biologica1 Studies}

Two kinds of biological programs are supported by AEC. They can be differentiated by time requirements as long term and short term. Short-term studies are survey programs that identify and characterize the biota in the area of concern. They are largely taxonomic and provide simple biological inventories of the area. Long-term studies are those dealing with such factors as productivity, mechanisms of ingestion, metabolism of nutrient and trace elements, ecological relationships, and biological effects in and on the organisms.

A first step in defining the risks of releasing radioactivity in a given environment is to identify the populations that may be exposed. Fisheries biologists of the Bureau of Commercial Fisheries are performing this task in cooperative studies with AEC. They are gathering and compiling information and data on important sport and commercial fishes taken in and around the ocean areas adjacent to both East and West Coast launch facilities. The data will include information on the food organisms important to the fish. In a short-term study, the data will be analyzed for age distributions of species in an effort to determine how much of their lives are spent in the area of concern.

In another study of fish population dynamics supported by AEC, a team headed by Dayton L. Alverson is making some important findings on seasonal and age distributions of species and their variance with depth. Alverson finds that species of bottom-dwelling organisms like crab and flounder have regular migrations up and down the continental she1f (see Figures 74 and 75).

In an unpublished report, ${ }^{5}$ Heyamoto and Pereyra have given some examples of changes in distribution:

"Dover sole [Figure 74] showed a greater availability on the inshore grounds from June through September and virtually disappeared from the stations during December and March, the winter months. They reappeared again during survey number six at the same depths they were found in the summer and fall of the previous year. This appearance on the inshore grounds during the summer and disappearance in the winter is not a new discovery, for it has been observed that these fish concentrate in restricted spawning areas in deeper water during the winter, much like the petrale sole. Thus far, concentrations of spawning Dover sole have not been encountered at the deeper stations.

"[Figure 75] shows the changes in the bathymetric and temporal distribution pattern of male and female Tanner crabs. In the spring (June) the sexes are almost completely separated with the mode of the male distribution centered at 275 fathoms and the female distribution at 350 fathoms. As winter approaches there is a gradual shift of the male population into deeper water to join the female populations where mating occurs. Rapid separation of the male and female segments of the population occurs after mating.

"It has been discovered that the bathymetric distribution of juvenile Tanner crabs extends to 1000 fathoms. The juvenile crabs appear to be abundant at depths from 375 to 800 fathoms. Very few 
juvenile crabs were found at the depths of maximum adult abundance. Whereas the adult population segregated by sex, male and female juvenile crabs were always found together in almost similar numbers.

"Intermediate sized crabs (50 - $90 \mathrm{~mm}$.$) were found to be con-$ centrated in sma11 numbers at depths from 450 to 600 fathoms. Most of the females in this group were non-ovigerous with the males usually smaller than those in the adult population. Whenever large individuals were encountered in these depths, they were nearly all softshe11ed."

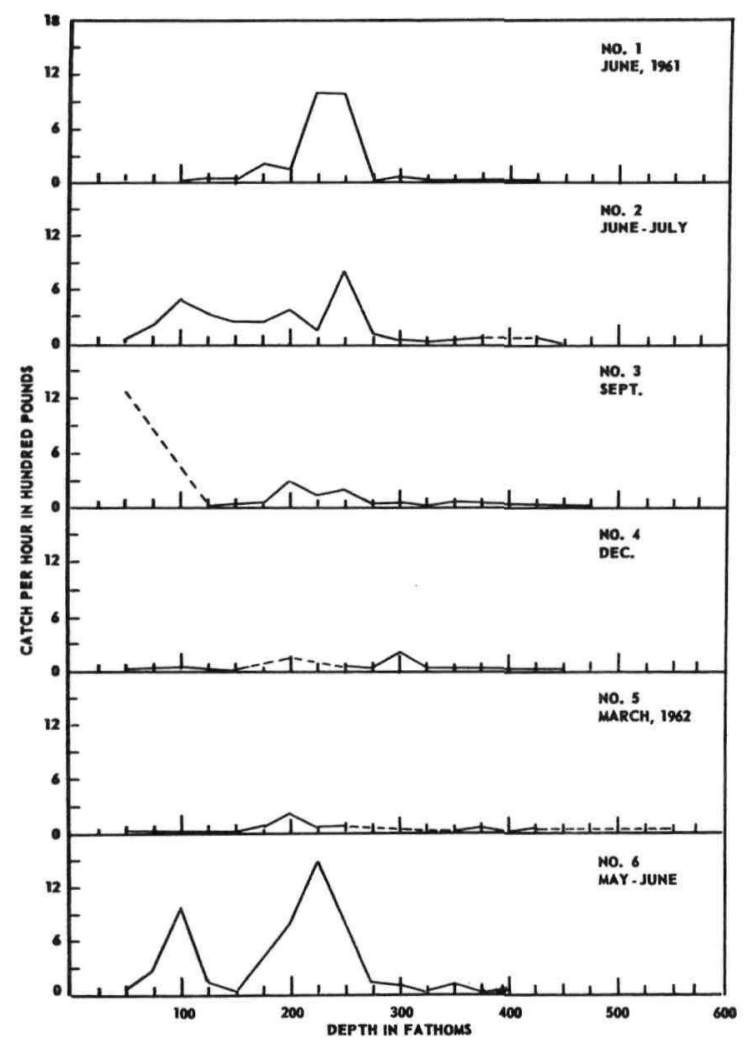

Figure 74. Dover sole catch-per-hour by 25 -fathom depth intervals --after Heyamoto \& Pereyra

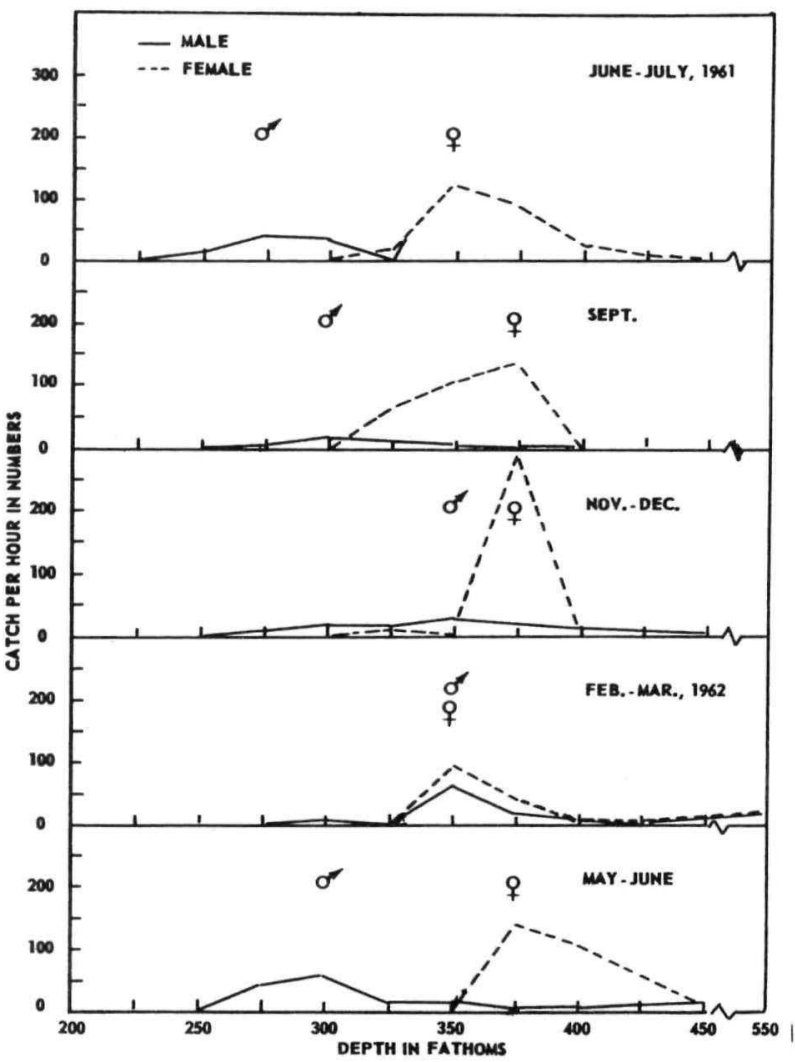

Figure 75. Catch-per-hour in numbers of mature male and female Tanner crabs by 25 -fathom depth intervals--sex symbols represent modes of distribution-after Heyamoto \& Pereyra

How does radioactivity in the water get into the marine food web and ultimately in the fishes man uses? One observed mechanism involves plankton, microscopic plants and animals ubiquitous in the photosynthetic zone. (The word "plankton" is from the Greek "planktos", meaning wandering or drifting.) The primary producers known as phytoplankton are able to use carbon dioxide, water, and the sun's energy in converting nutrient elements and other trace elements in solution into plant materials. These tiny organisms are observed to undergo dramatic changes in productivity which correlate with the seasons and with changes in available nutrients. 
Although ubiquitous, they vary greatly in concentration thriving more frequent1y in shallow coastal waters enriched by nutrients washed out to sea from land. Some mid-ocean areas away from the influence of land are quite barren in comparison. Identifying the barren areas and their inherent conditions would be a short-term project, but studies of conditions and combinations of nutrients including trace elements necessary to sustain optimum growth is a longer term, multiple-1aboratory effort. AEC supports such studies as well as studies of specific organisms and specific elements to determine uptake rates and retention levels. Table II presents some data developed by the Radiobiologica1 Laboratory of the Bureau of Commercial Fisheries at Beaufort, North Carolina.

TABLE II

Distribution of $\mathrm{Zn}^{65}$ in the Organs of the Bay Scallop After a Two-Hour Immersion in Water Containing $10^{-9} \mathrm{c}$ per gram*

\begin{tabular}{|lcc|}
\hline \multicolumn{1}{|c|}{ Tissue } & $\begin{array}{c}\mathrm{Zn}^{65} / g \\
\left(\mathrm{x}^{6} 0^{-9}\right)\end{array}$ & $\begin{array}{c}\text { Tota1 Curies } \\
\left(\mathrm{x} 10^{-9}\right)\end{array}$ \\
\cline { 3 - 4 } Kidney & 1384 & 824 \\
Liver & 243 & 507 \\
Gills & 218 & 857 \\
Testes and ovaries & 138 & 193 \\
Foot & 131 & 25 \\
Rectum & 120 & 8 \\
Heart & 105 & 13 \\
Adductor muscle & 100 & 375 \\
Mantle & 92 & 321 \\
\hline After Chipman, et a1 & & \\
\hline
\end{tabular}

The importance of investigations of the organs in which isotopes concentrate as we11 as factors of concentration should be obvious: man seldom consumes al1 of the organs. Present efforts include studies of other animals and other elements of interest as well as studies of the mechanisms involved in uptakes. Much of the early basic data have been summarized in Ptblication 551 of the National Academy of Sciences.?

There has been some limited but direct experience following the weapons tests of the 1950's in the Pacific. This work exemplifies an earlier statement that much of the present work in oceanography is that of exploration and discovery. Most of the activity entered the ocean as fallout from island shots, and it remains to be demonstrated that the physical and chemical forms of these sources can be likened to the source terms of aerospace devices. Nevertheless, some lessons learned in the test program can be of benefit to any program of identifying risks. For example, it was learned that radionuclides enter the food web rapidly and with certain isotopes and organisms to a surprisingly high degree. The extent of distribution of activity both horizontally and vertically was also a discovery of interest and utility.

Fission and activation product activities were measured in plankton at very short intervals of time after the events--as soon as it was safe to approach the target area, usually hours. Rapidity of uptake is substantiated by Chipman's 1aboratory experience. He reports "immediate and great" uptake for $\mathrm{Ru} \& \mathrm{Y} .{ }^{8}$ In the Pacific work, Donaldson et $\mathrm{al}^{9}$ report average concentration factors in plankton (over that concentration in the water) of about 7000 based on gross beta-gamma counting. Gamma spectroscopy tentatively identified isotopes of Mo, Ru, I, Ba, La, and, less positively $\mathrm{Zr}$ and Ce. Earlier, Palumbo had discovered that a species of red algae had concentrated I-131 by a factor of about 18,000 times. ${ }^{30}$ Chipman reports concentration factors in phytoplankton of several thousand less than an hour after introduction. ${ }^{8}$ 
Several surveys were made of the Pacific following the nuclear tests. One such survey was Operation Troll conducted in March and Apri1 1955, following the tests of May and June 1954.11 Low concentrations of activity occurred over most of the Pacific, presumably widespread from atmospheric fallout. There were higher concentrations on the western side of the Pacific in the direction of currents prevailing from the test area. The highest activities were in the upper hundred meters where the concentration was about twice that at 500 meters. Seymour, et a1, ${ }^{12}$ using more sophisticated analytical techniques, determined radioisotopes of $\overline{\mathrm{Sr}}, \overline{\mathrm{Ba}}, \mathrm{De}, \mathrm{Pr}$, $\mathrm{Ru}, \mathrm{Rh}, \mathrm{Zr}, \mathrm{Co}, \mathrm{Zn}, \mathrm{Fe}$, and rare earths in plankton following a 1956 test series.

The next step up the food chain from the phytoplankton is comprised of a group of plankton generally larger in size called zooplankton or nonnoplankton. Zooplankton are the smallest known marine animals. They feed on phytoplankton. This group, which is based on the size of the organisms, also includes eggs and larval forms of fish. Zooplankton have some swimming or propulsion ability but move mainly in the vertical, their horizontal range being limited. Many of the animals in this group are nocturnal feeders coming up from below the thermocline to graze at night and return to the depths in daylight hours. This feeding habit is considered by Ketchem and Bowen ${ }^{13}$ as an import mechanism causing a vertical distribution of activity below the thermocline. These animals, and their effects on the vertical transport of radionuclides, are being studied by AEC investigators.

Near the top of the marine food chain, at the trophic level which uses the zooplankton, are the nekton, or fish. No attention is paid in this brief account to the roles played by many other organisms in converting inorganic elements to available organics and vice versa. Certainly such organisms as worms and bacteria play a role in the cycling of elements. Plankton do not live only until they are consumed, and they do have chemical exchanges with their environment, i.e., they metabolize certain substances and they also return substances to the environment, if only their body elements when they die and decompose. There are also short circuits in this chain of phytoplankton to zooplankton to fish. Some fishes like menhaden and herring feed directly on the phytoplankton. And fish can sorb anions and cations and particulate material directly from the water without ingesting it. It should also be noted that animals like the shellfish and certain other bottom-dwelling forms can feed directly on radioelements in particulate form since their feeding mechanisms consist of strainers or filters.

Concentration Guides for Sea Water

Several study groups under the auspices of the National Academy of Sciences have established concentration guides for maximum permissible concentrations (MPC's) of radioisotopes in sea water. ${ }^{1}$ These were developed because the MPC's for drinking water were considered as not applicable to the marine environment for two reasons. One, fish can concentrate radioelements over the concentration found in the water, and, two, the stable elements normally in solution in the sea offer isotopic dilution that can diminish effects of associated radioelements. These NAS studies were based on the health physics considerations of the National Committee on Radiation Protection and the International Commission on Radiological Protection, i.e., on the designations by these organizations of critical organs and maximum permissible body burdens for each of the isotopes.

These NAS guides offer two approaches to deriving MPC's. The first considers concentration factors in fish and is equilibrated to a permissible intake rate of water at MPC. The second employs a consideration of a quasi-specific activity. This latter approach may be used when the isotope is known to concentrate in a specific part or organ of the body. The specific activity approach says that if the specific activity as calculated by dividing the maximum permissible body burden in the critical organ by the total amount of the stable element in the organ is not exceeded in any portion of food ingested or at any step in the food chain or in the marine environment (concentration in the sea water) it will not be exceeded in the critical organ. Mathematically, the specific activity approach for MPC's is 


$$
I=\frac{\operatorname{Irb}}{\operatorname{Inb}} \operatorname{Ine}\left(1+\frac{\mathrm{K}}{\mathrm{B}}\right)
$$

where

$$
\begin{aligned}
\mathrm{I} & =\text { MPC (in sea water) } \\
\mathrm{Irb} & =\text { MPC } \text { in critical organ } \\
\text { Inb } & =\text { concentration of stable element in critical organ } \\
\text { Ine } & =\text { concentration of stable element in sea water } \\
\mathrm{K} & =\text { decay factor }=0.69 / \mathrm{T}_{1} / 2 \text { (half } 1 \text { ife) } \\
\mathrm{B} & =\text { biological factor }=0.69 / \mathrm{T}_{\mathrm{b} 1 / 2} \text { (biological half } 1 \text { ife) }
\end{aligned}
$$

Again, the fish concentration factor approach for MPC's is

$$
I=\frac{10(\mathrm{MPC})_{\mathrm{W}}}{\mathrm{F}}\left(1+\frac{\mathrm{K}}{\mathrm{B}_{\mathrm{f}}}\right)
$$

where

$$
\begin{aligned}
(\mathrm{MPC})_{\mathrm{W}} & =\text { maximum permissible concentration in drinking water } \\
\mathrm{F} & =\text { concentration factor in marine organism } \\
\mathrm{B}_{\mathrm{f}} & =\text { biological half-life factor in fish }
\end{aligned}
$$

The factor of 10 relates the consumption of fish to intake of water.

Where concentration factors are known fairly we11, MPC's computed by this means compare very closely with MPC's computed by the specific activity approach. A shortcoming in the specific activity approach is that it calls for a quantitative knowledge of the elemental composition of specific organs and of the carrier or diluting stable element in sea water--and such details have not been accumulated for a11 elements and a11 organs and a11 kinds of diets. Some radioelements have no natural stable element counterpart, for example, plutonium and tellurium. Table III compares MPC's derived by both methods with MPC's or drinking water.

\section{Summary}

The marine environment with its complex and interrelated physical, chemical, and biological factors poses a few problems when it comes to predicting the ultimate pathways radionuclides may take and how long they will remain in the biosphere. A number of research studies are being undertaken and perhaps a few more are indicated. These will provide information needed to assess the safety of operating nuclear devices in the oceans. 
TABLE III

Comparison of Some Permissible Sea Water Concentrations with MPC Values for Drinking Water ${ }^{14}$

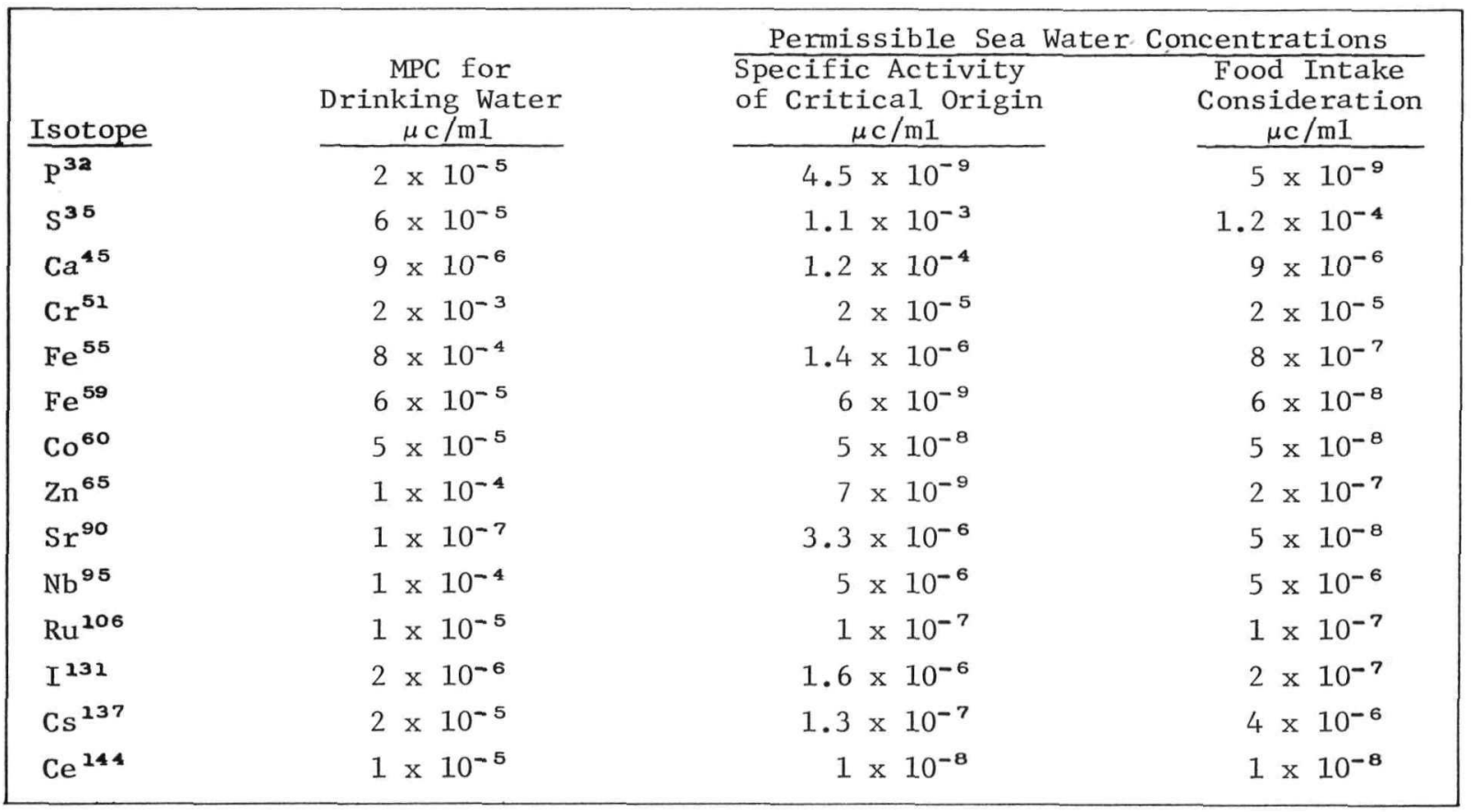

References

1. "Radioactive Waste Disposa1 Into the Sea," Safety Series No. 5, Internationa1 Atomic Energy Agency, Vienna, 1961.

2. Pritchard and Carpenter, "Measurement of Turbulent Diffusion in Estuarine and Inshore Waters," Proceedings of Symposium on Tidal Rivers, Helsinki, July 1960.

3. A. Okubo, A Review of Theoretical Models for Turbulent Diffusion in the Sea, Chesapeake Bay Institute Technical Report 30, 1962.

4. "Horizontal Diffusion in the Sea," J. Joseph, R. H. Sendner, Deutsche Hydrographische Zeitschrift, Volume II, No. 2, 1958, pp. 49-77.

5. H. Heyamoto and W. T. Pereyra, Deep Water Marine Explorations, Progress Report No. 2 for Period Jan.-July 1962, U. S. Bureau of Commercial Fisheries, Seattle, Washington (unpublished).

6. W. A. Chipman, F. R. Rice and T. J. Price, Uptake and Accumulation of Radioactive Zinc by Marine Plankton, Fish and Shellfish, Fishery Bulletin 135, Volume 58 of the U. S. Fish and Wildlife Service, Department of Interior, 1958.

7. The Effects of Atomic Radiation on Oceanography and Fisheries, Publication No. 551 of the National Academy of Sciences - National Research Council, 1957.

8. W. A. Chipman, "Biological Aspects of Disposal of Radioactive Wastes in Marine Environments," Proceedings of Conference on Disposal of Radioactive Wastes, Volume 2, Monaco, 1959. 
9. L. R. Donaldson, et al, Survey of Radioactivity in the Sea Near Bikini and Eniwetok Atolls, June 1956, AEC Report UWFL-46, July, 1956.

10. R. F. Palumbo, Uptake of I-131 by the Red Alga Asparagopsis Tax formus, AEC Report UWFL-44, November 1955.

11. J. H. Harley, Editor, Operation Troll, AEC Report NYO 4656, March 1956.

12. Survey of Radioactivity in the Sea and in Pelagic Marine Life West of the Marsha11 Islands in 1956, AEC Report UWFL-47 dated March 1957.

13. B. H. Ketcham and V. T. Bowen, "Biological Factors Determining the Distribution of Radioisotopes in the Sea," Proc. Second International Conference on Peaceful Uses of Atomic Energy, Geneva 1958, Volume 18, pp. 429-433.

14. "The Biologica1 Effects of Atomic Radiation," Summary Reports, National Academy of Sciences-National Research Council, 1960. 


\section{BLANK}




\author{
METEOROLOGICAL STUDIES AS RELATED TO \\ AEROSPACE NUCLEAR SAFETY \\ Isaac Van der Hoven \\ U. S. Weather Bureau
}

Ironic as it may seem, a major environmental problem in the use of nuclear rocket engines is at or near the launch pad before flight has been attained. This paper discusses the meteorological aspects of this localized aerospace nuclear safety problem, leaving to the following paper the very important problem of atmospheric fallout of nuclear debris during early aborts or after orbital flight has been att'ained.

Meteorology as applied to the hazards of static nuclear rocket engine tests and launches of missiles having a nuclear stage may involve horizontal distances on the scale of tens of miles or may be limited to an area within a few thousand feet of the test point, depending upon the radioactive source strength and the prevailing atmospheric dispersion condition. The meteorological studies aimed at providing the necessary information for the nuclear hazard evaluation can be divided into three problem areas; the initial source configuration; the mean atmospheric transport; and the effect downwind, at the surface, of atmospheric diffusion and deposition.

\title{
Source Configuration
}

One of the more important input parameters of an atmospheric dispersion model is the source configuration. By this is meant whether the source of the spreading radioactivity is in gaseous or particulate form, the particle size distribution, the stabilized height and shape of the effluent cloud, and the spatial distribution of the various particle sizes. It is recognized that obtaining this information is difficult but nonetheless necessary since the accuracy of any dispersion model is a direct function of the accuracy of the source term.

Since a postulated nuclear excursion at or near the launch pad involves a simultaneous rocket-fuel explosion, pertinent source configuration data can be obtained from field experiments with rocket-propellant explosions. In other words, the initial cloud rise and volume can be correlated with the energy released in the burn and the thermodynamic state of the ambient atmosphere. This type of information is available from a series of liquid-rocket-propellant burns conducted by the Meteorology Group of the Brookhaven National Laboratory and the Atlantic Research Corporation. Amounts of fuel up to 400 pounds were burned, the clouds rose as high as 2000 feet, and one puff was tracked for 40 miles by airplane. A formal report on this work which will include appropriate meteorological data, is expected within the next few months. A similar study has just been started at Edwards Air Force Base. Sponsored jointly by the Air Force Missile Test Center and the Marshall Space Flight Center, the study will employ burns of from 200 to 25,000 pounds of prope1lant. It is hoped that appropriate meteorological measurements can be arranged to be taken during the burns.

A second approach to obtain source term data is the studies in the deliberate nuclear excursion tests such as the proposed simulated water entry test (SWET) to be conducted by the Los Alamos Scientific Laboratory at the Nevada Test Site. Numerous meteorological measurements are already being taken, among which are measurements on 
the 1500-foot tower in Yucca Flats about 25 miles northeast of the experiment site. An elaborate sampling array out to 25 miles is being planned by LASL as we 11 as aerial tracking and sampling of the effluent by aircraft and the tracking by radar of constant-level balloons. It is hoped that this type of reactor-destruct test will fill a gap in important environmental information on potential hazards in the reactor-in-flight-test (RIFT) program. Similar tests such as the controlled environmental radioiodine test (CERT) and the special power excursion reactor test (SPERT I destruct test), which were conducted in Idaho, are designed to yield important sourceterm data.

Mean Atmospheric Transport

The second problem area in nuclear rocket hazard evaluation is the determination of mean atmospheric transport. This requires not only a detailed climatology of the launch site area but also a working knowledge of the meso-meteorological type of circulation peculiar to the region. For example, during one of the attempts to run the SPERT I destruct tests, a mesoscale shear line existed just to the north of the test as shown in Figure 76. To the observer at the site, a considerable period of favorable southerly winds might have been erroneously suggested. Although this type of circulation is almost impossible to predict in advance, at least an awareness of its existence as shown by the telemetered wind measurement network at the National Reactor Testing Station is necessary. The WIND (Weather Information Network and Display) system at Cape Canaveral and at Vandenberg Air Force Base are similar examples of data telemetry used for an evaluation of the transport and diffusion of toxic effluents.

Two computer programs have recently been developed by which conventional punchcard hourly weather reports are used to obtain an estimate of the diffusion climatology of an area such as a missile launch site. The first program is based on wind speed, cloud height and amount, and sun elevation angle which are classified by a method developed by Turner ${ }^{1}$ using the Pasquil1 ${ }^{2}$ diffusion indices. An example of such a computation using 18 months of Cape Canaveral hourly weather reports is shown in Figures $77 \mathrm{a}$ and $\mathrm{b}$ in which the cumulative frequencies of Categories $\mathrm{A}$ (very good diffusion) to $G$ (very poor diffusion) are plotted as a function of time of day. Of interest is the rapid transition from poor to good diffusion at sunrise during the summer season, while during the winter season large frequencies of neutral stability (Category D) occur. Data of this nature are useful for planning purposes.

Another attempt at a more realistic definition of atmospheric diffusion conditions is a computer program using standard hourly wind values to compute the probability that the wind will persist within a sector of $22-1 / 2,67-1 / 2$, and 112-1/2 degrees centered on a given wind direction for a given number of hours. Figure $78 \mathrm{a}$ shows the wind persistence for the 67-1/2-degree sector for Daytona Beach for winter and summer. It is to be noted that at the 10-percent probability leve 1 winds tend to persist for about 10 hours and are most persistent from the northwesterly directions in winter. The longest single event of persistence in this sector for 5 years of data was a period in summer of 125 hours centered on ESE. The overal1 persistence values for Daytona Beach may be compared with those of Point Mugu (Figure 78b) where persistence is somewhat less, since the 10-percent line is considerably below the 10-hour value. A definite peak persistence in the seaward and landward directions is indicated, however. 


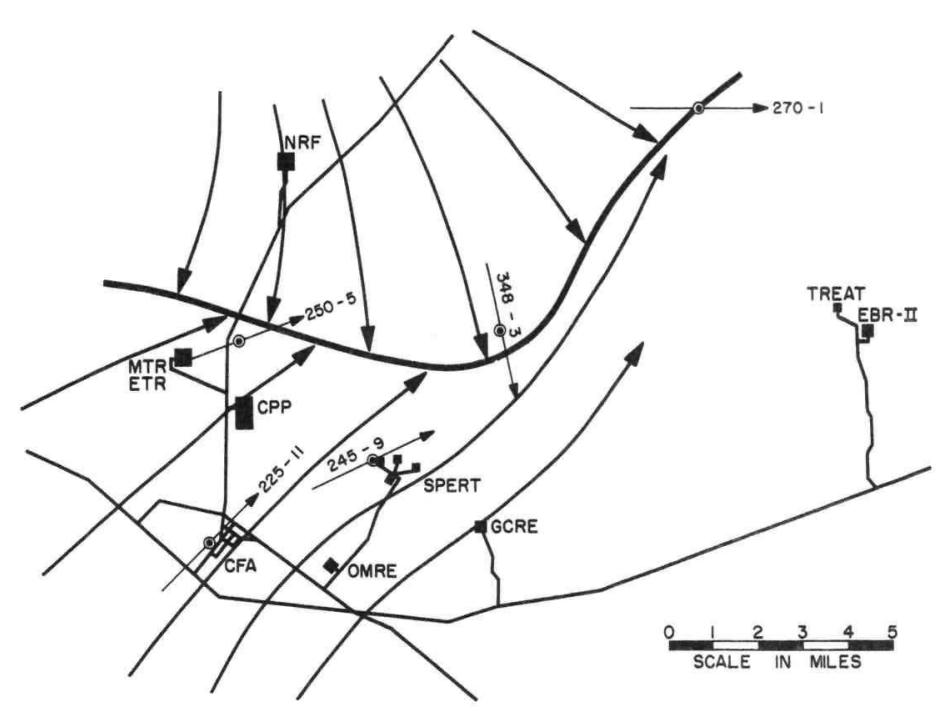

a. $1540-1550$

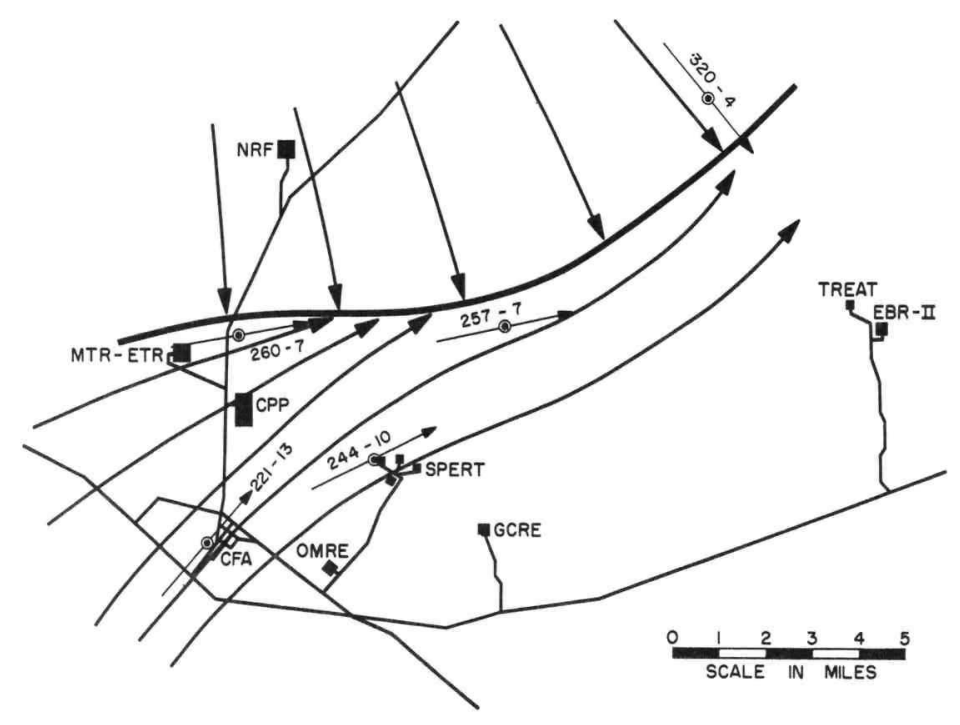

b. $1550-1600$

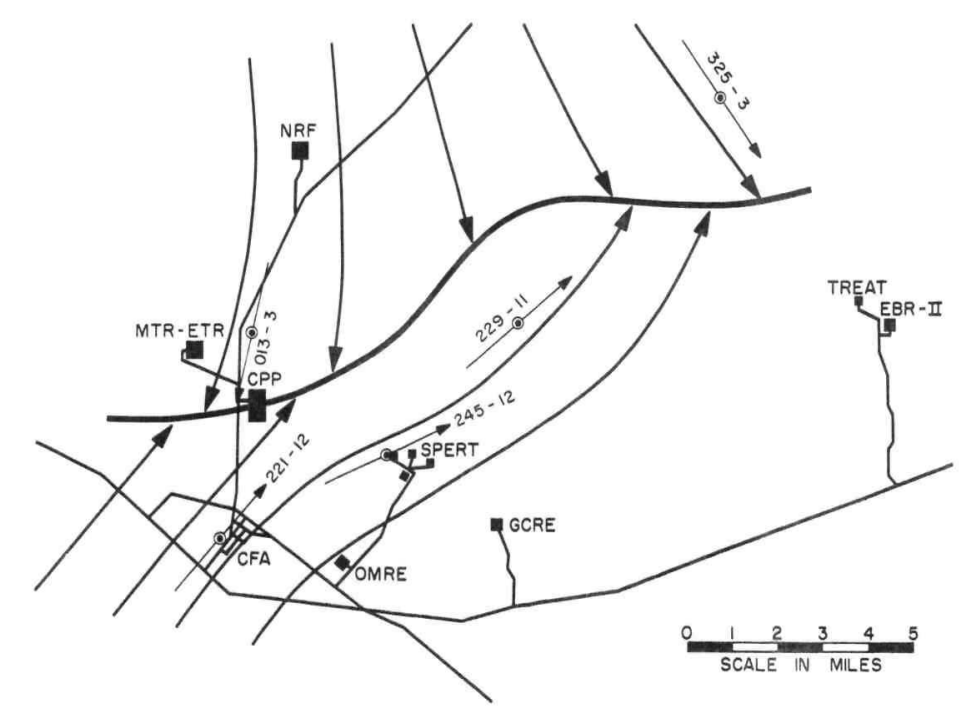

c. $1600-1610$ 


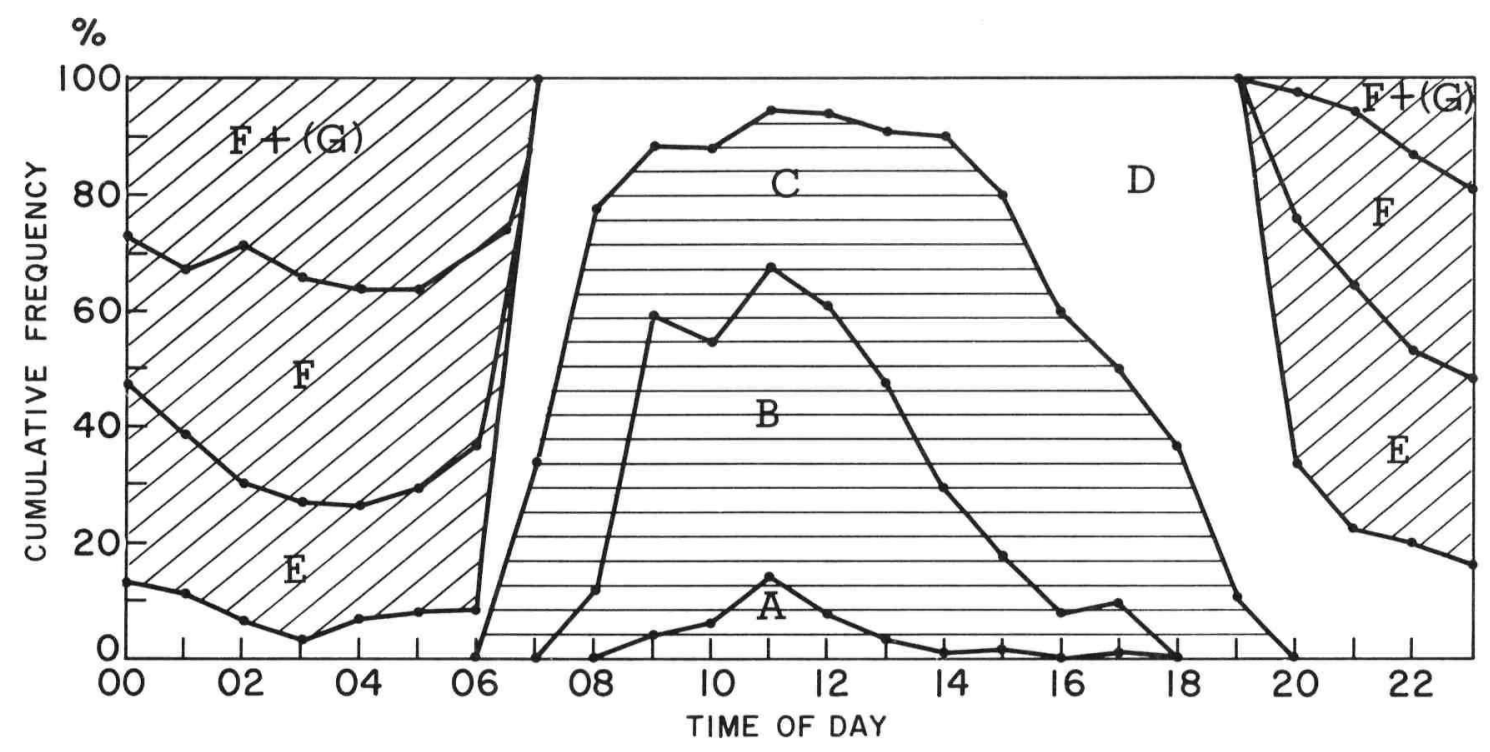

a. Summer (July, Aug. 1958 -

June, July, Aug. 1959)

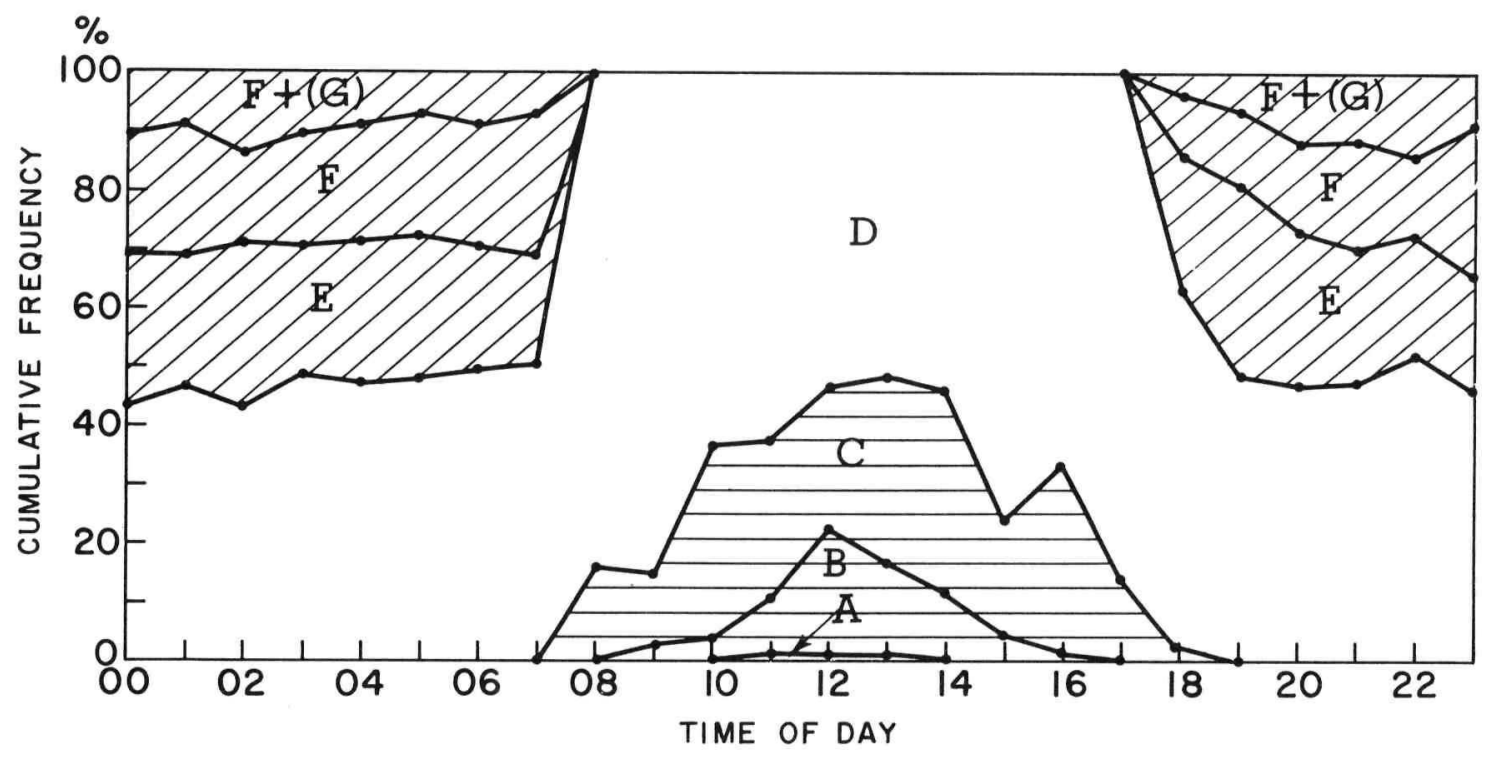

b. Winter (Dec. 1958 - Dec., Jan., Feb. 1959)

Figure 77. Diffusion indices for Cape Canaveral 


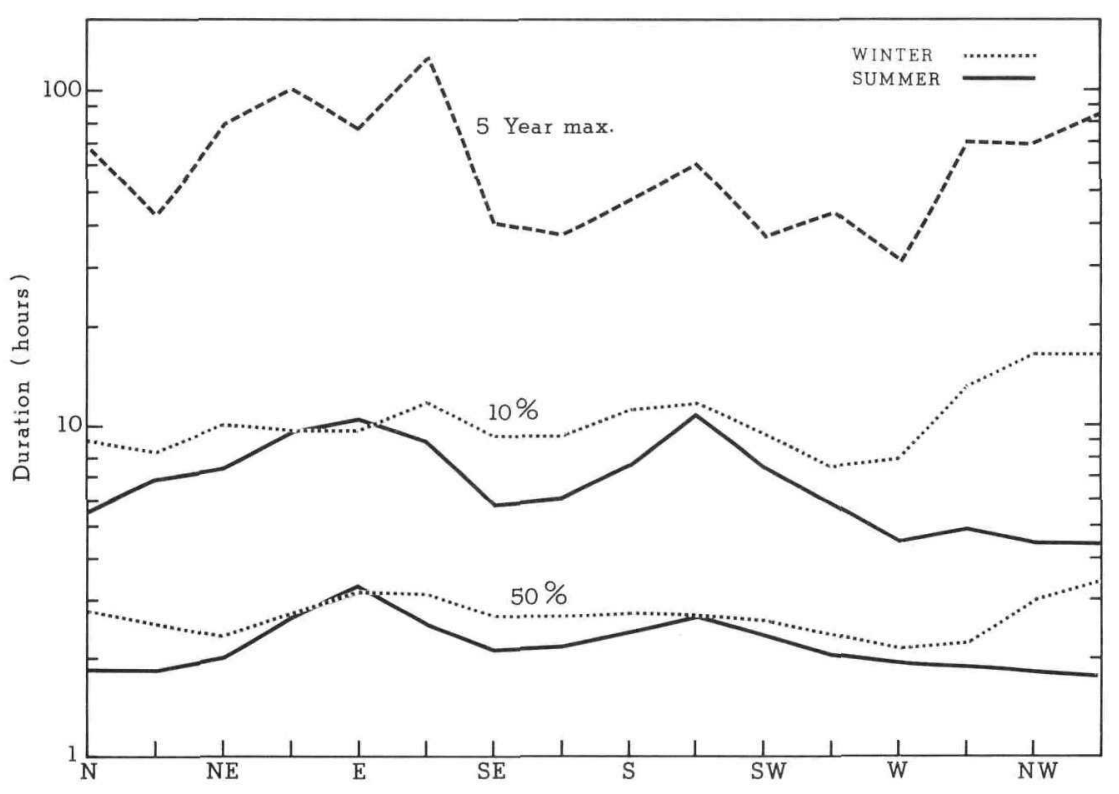

a. Daytona Beach

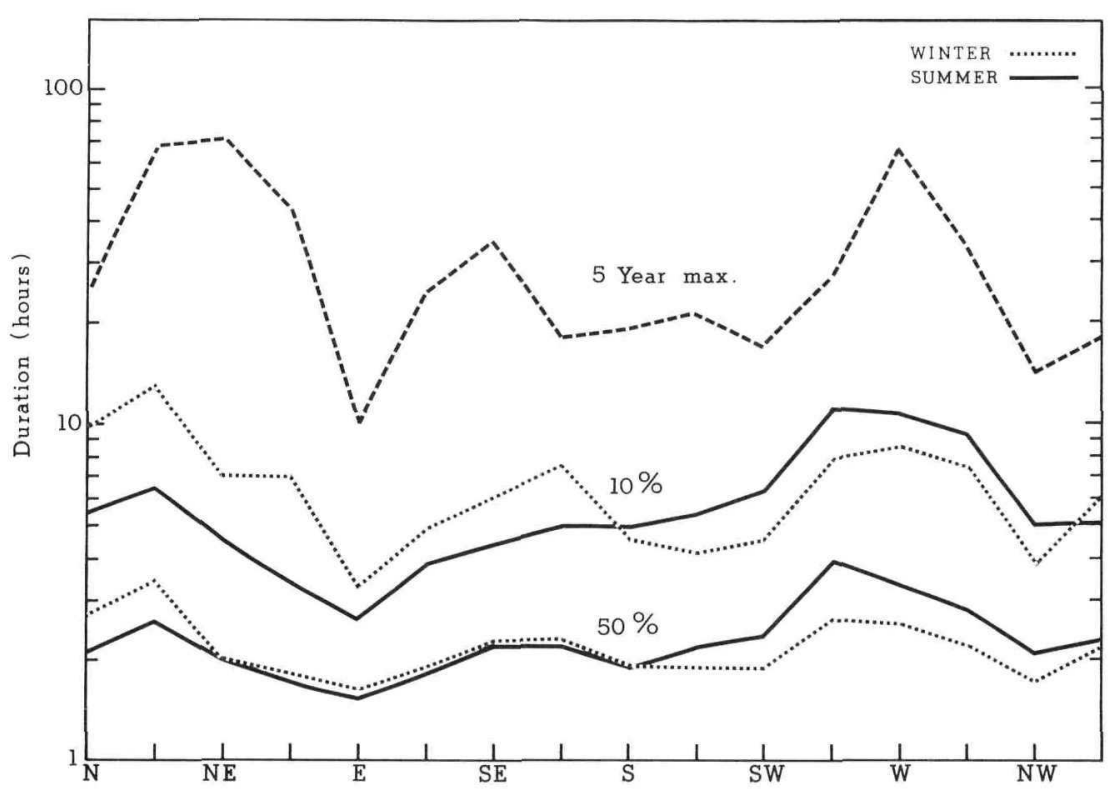

b. Point Mugu

Figure 78. Wind direction persistence

(67-1/2-degree sector) 
Still another attempt to systematically define air trajectories near the surface is through the use of tetrahedral-shaped constant-volume balloons (Figure 79). Since these "tetroons" tend to float at predetermined constant-density levels, they provide an indication of atmospheric flow at a given height. A series of 88 tetroon trajectories over a 1-month period using the Weather Bureau Surveillance Radar at Catalina Island are described in a recent report by Pack and Ange11. ${ }^{3}$ For tracking, a 5-ounce transponder carried by the tetroon emits a signal when triggered by a ground-based radar. The return signal, which is unique and therefore distinguishable from ground clutter, is fed directly into the video circuit of the radar. Figure 80 shows a composite of a11 the tetroon releases from Long Beach which were over 2 hours in length. A11 were below the marine inversion at about 1000 feet above sea leve1. The trajectories at first sight appear chaotic but upon close inspection (Figure 81) the trajectories show a definite diurnal fluctuation, seaward during the night and landward during the day. In trajectory 30, the tetroon was released at 10:20 PM PST, traveled inland until 3:40 AM, then went out over the ocean until 1:40 PM, and again returned inland until it was lost in mountainous terrain at about 5:00 PM.

The tetroon-transponder-radar system is being considered as a means of defining the meso-scale sea-breeze circulation at Cape Canaveral.

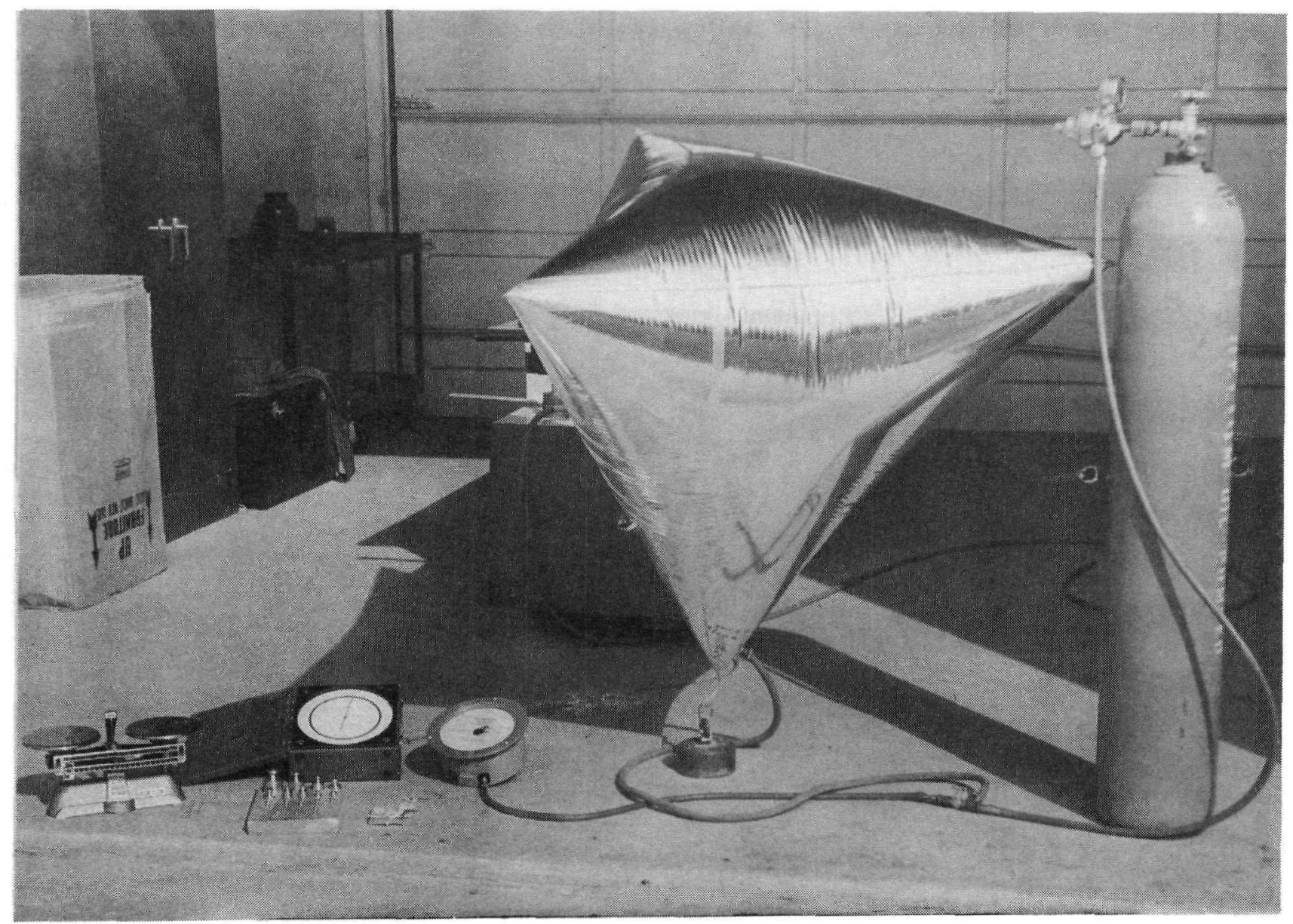

Figure 79. Tetrahedral Constant-Volume Balloon ("Tetroon") 


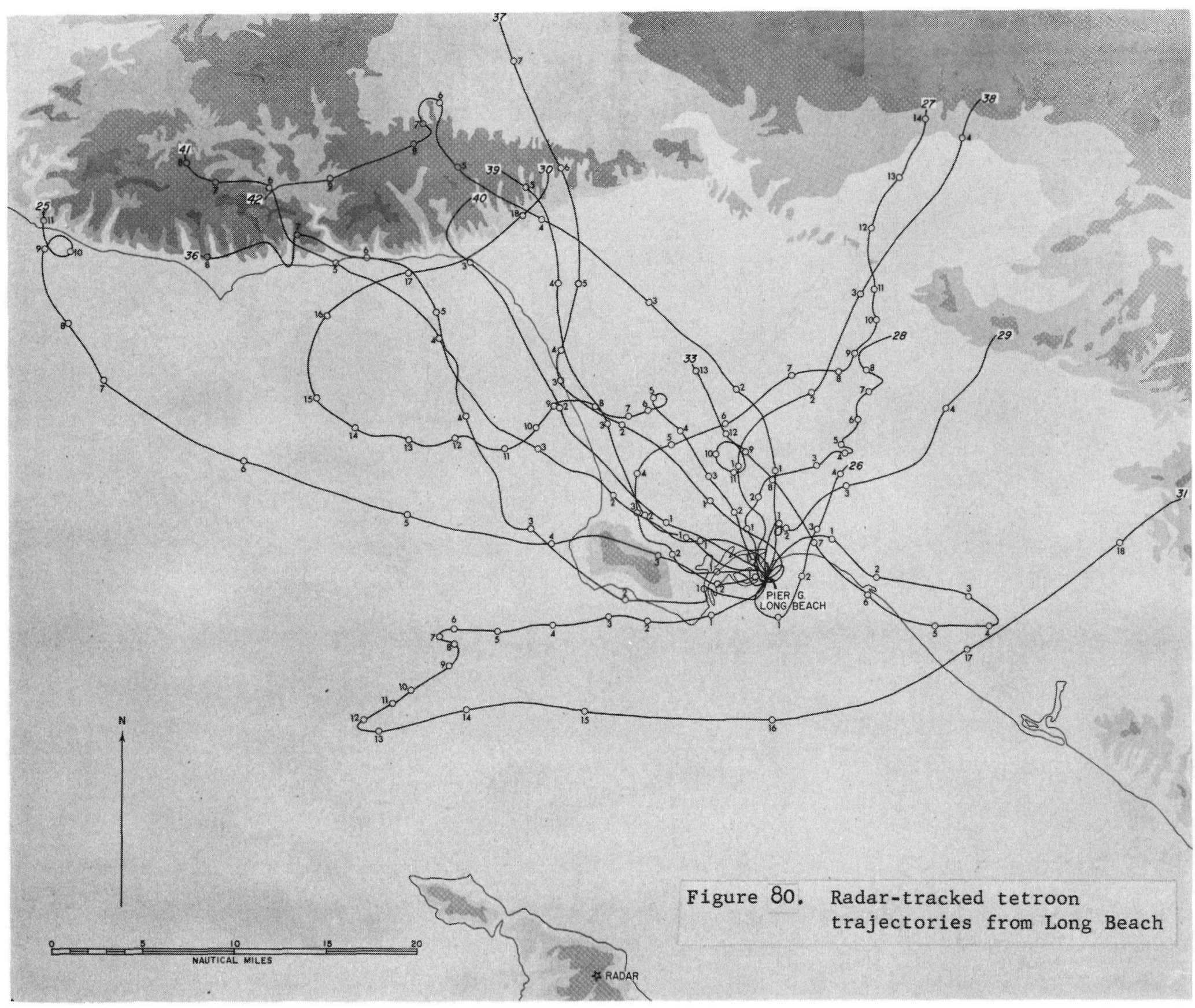




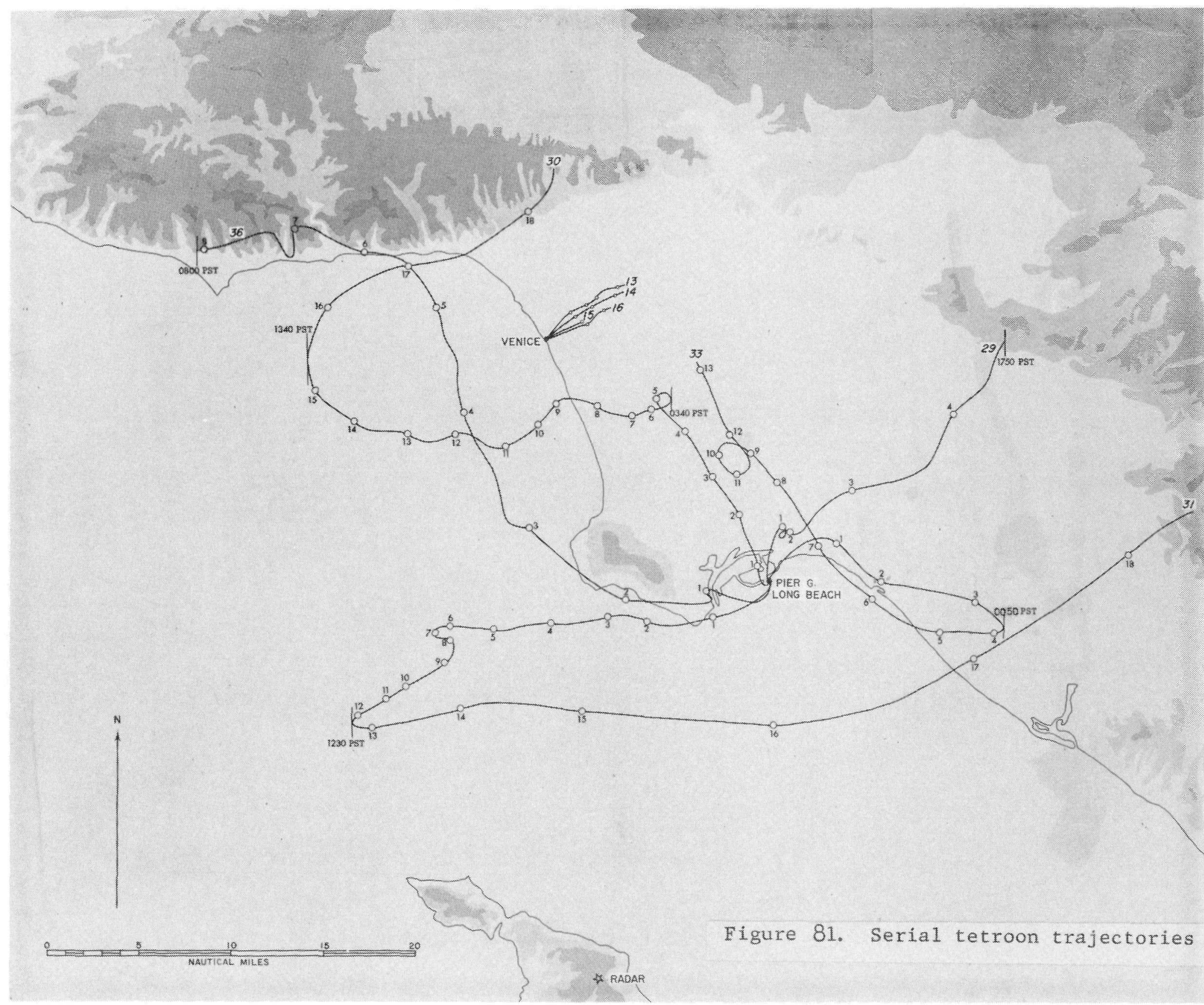


The third problem area to be considered is the effect at the surface of the diffusion and deposition of an effluent along its trajectory. The "Ocean Breeze" and "Dry Gulch" diffusion experiments at Cape Canaveral and Vandenberg Air Force Base are two examples in which the end result was an empirical continuous pointsource diffusion equation applicable to the site in question. The important parameters proved to be the standard deviation of the horizontal wind direction, the vertical temperature structure, and the distance downwind. The addition of wind speed as a parameter did not seem to improve the prediction equation significantly.

Since a launch-pad excursion will probably involve a large puff of radioactivity, the more general question of the diffusion of an instantaneous source as compared to a continuous source needs to be experimentally verified. What is needed is a classical gaseous-diffusion field study in which the effect of terrain is largely eliminated by choosing flat topography with no pronounced vegetation and in which the continuous and instantaneous sources can be detected downwind to distances of tens of miles. Part of the problem of conducting such a study is obtaining an adequate gaseous tracer. The Atomic Energy Commission's Division of Reactor Deve1opment is currently supporting a contract for the evaluation and development of atmospheric tracer methods with sufficient sensitivity to be detected out to 10 miles. Hopefully, a demonstration of such a method may be carried out in the summer of 1964 at the National Reactor Testing Station. Another approach in obtaining information on the diffusion of puffs is through the use of tagged particles. A floating tetroon approximates a tagged particle and thus lends itself very well to such an experiment. If a series of pairs of tetroons were released simultaneously, the mean separation distances of the tetroon pairs could be related to puff diffusion, provided that average atmospheric conditions did not change.

As mentioned previously, the studies of downwind diffusion of deliberate nuclear excursions can be applied to launch-pad nuclear hazards. For example, Figure 82 shows the crosswind distribution of air concentration of mixed fission products for the SPERT I destruct test at several downwind distances. This information along with the appropriate meteorological data is helpful in explaining and predicting atmospheric diffusion.

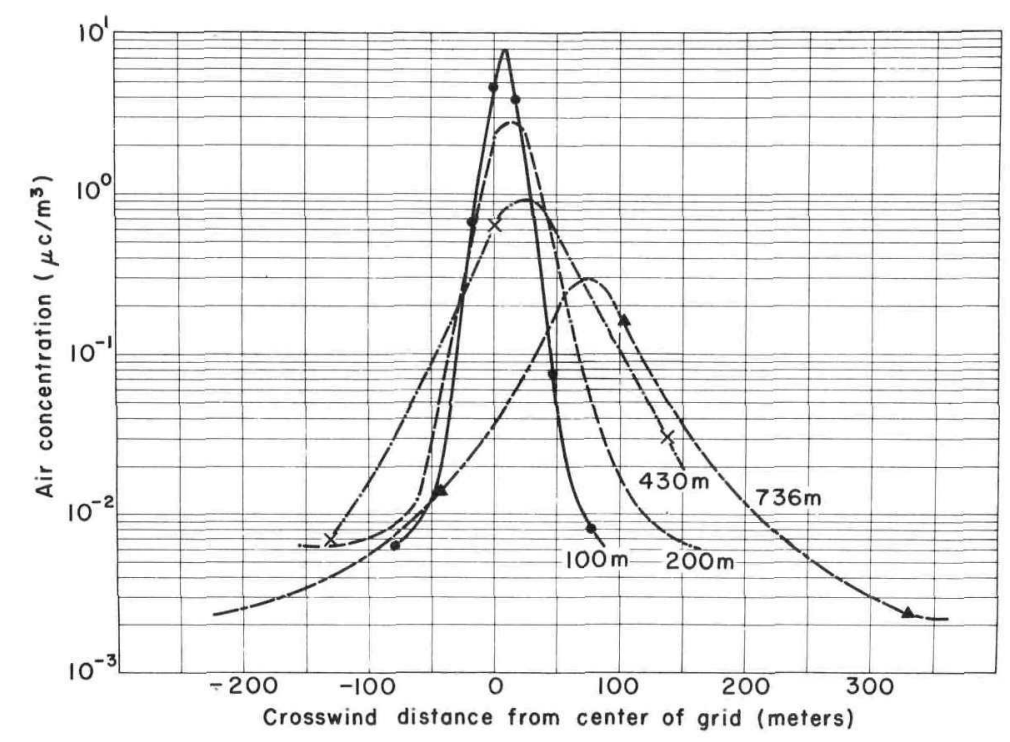

Figure 82. Crosswind distributions of air concentration of mixed fission products for SPERT I Destruct Test 
The study of deposition has principally concentrated on the deposition velocities of the radioiodines. The previously mentioned controlled environmental radioiodine test (in which a known amount of I-131 was released over a desert pasture upon which cattle were grazing and which included meteorological, air concentration, and deposition measurements as well as the eventual uptake of iodine in the milk of the cows) is an example of the type of data which is needed to evaluate the iodine hazard from a reactor excursion. However, the application of deposition measurements taken over desert-1ike vegetation to the dense vegetation characteristic of the Florida peninsula needs extensive study.

In a launch-pad explosion-excursion, the deposition of larger particles with diameters of more than 10 microns can be treated by one of two techniques. One is a diffusion-deposition mode $1^{4}$ in which the particles are diffused according to a statistical model such as the Sutton diffusion equation and are at the same time settling. The other is an analog scaling procedure using fallout patterns observed from previous reactor excursions or from nuclear weapon detonations of low yield on the surface or in a tower. For the first technique a knowledge of the particlesize distribution and configuration is needed, while for the second it is assumed that the postulated excursion has the same particle-size distribution and fissionproduct inventory as the analog.

In conclusion, it would appear that much atmospheric environmenta1 data pertinent to aerospace nuclear safety is now available or is being obtained. The principal gaps in information on launch-pad hazards are the initial cloud rise, the iodine deposition rate, and the atmospheric diffusion rates at distances of tens of miles. The aim of all these meteorological studies is to obtain realistic values of the parameters which describe atmospheric transport and diffusion rather than to assume the most extreme hazards evaluation. It is essential, in order to properly evaluate atmospheric conditions at the time of launch, that rather extensive measurements involving meteorological networks and soundings be taken during the launch countdown period.

\section{References}

1. D. B. Turner, "Relationships Between 24-hour Mean Air Quality Measurements and Meteorological Factors in Nashville, Tennessee, (Appendix: A Stability Classification Using Hourly Airport Observations)," Air Pollution Control Association Journa1, 11, 1961, 483-489.

2. F. Pasqui11, Atmospheric Diffusion, Van Nostrand Company, London, 1962.

3. D. H. Pack and J. K. Ange11, "A Preliminary Study of Air Trajectories in the Los Angeles Basin as Derived from Tetroon Flights," submitted to Monthly Weather Review for publication.

4. I. Van der Hoven, "A Diffusion-Deposition Model for Particulate Effluents from Ground-Tested Nuclear Engines." To be published in the Internationa1 Journal of Air and Water Pollution. 


\section{FALLOUT PREDICTION TECHNIQUES* \\ J. Z. Holland \\ A. W. Klement, Jr. \\ Division of Biology and Medicine \\ U. S. Atomic Energy Commission}

A great deal of attention has been given to the fallout of radioactive debris injected into the atmosphere during past nuclear weapons tests. With nuclear power units and nuclear propulsion systems beginning to be used in aerospace devices, problems of environmental safety could arise similar to those of weapons tests. In aerospace programs, as in other programs using nuclear energy, it is necessary to predict possible and probable effects of such programs on the environment, and on man. Both normal and abnormal situations must be considered. As with any new problem, a review of basic scientific data and past experience is a first step toward its solution. Concurrently, knowledge of the potential source of nuclear contamination is required. With these, useful estimates can be made of the magnitude of fallout problems to be encountered in aerospace programs.

Early aborts of devices containing nuclear components could release radioactivity into the troposphere and, perhaps, the stratosphere. Releases at or near the launch pad would produce puffs or plumes of gases and particulates which would drift downwind, accompanied by diffusive spreading and deposition on the surface. The behavior of such clouds has been the subject of intensive micrometeorological and mesoscale meteorological studies during the past decade. Valuable experience applicable to the problem of launch pad accidents has been gained from many tracer experiments on diffusion, from work on fallout prediction, from monitoring of 1owyield surface and subsurface nuclear weapons tests, from reactor tests and operations, and from studies of diffusion and deposition of chemical processing plant effluents. This type of problem was discussed in Dr. Van der Hoven's paper (IV-2, above, pp 209 to 218) and will not be treated further here.

An abort above the tropopause as well as burnup on re-entry, either planned or accidental, could release radioactivity in the stratosphere or higher atmospheric regions. High-yield and high-altitude nuclear weapons tests have provided experience on which fallout predictions for such events can be based until experience with specific aerospace devices is built up. Some of the approaches to fallout predictions which have been useful for weapons tests and which are also applicable to aerospace problems will be discussed here.

In order to estimate rates of deposition and distribution of nuclear debris injected into the atmosphere, it is necessary to know or, in the absence of know1edge, to make assumptions on the amount, altitude, and initial spatial distribution of the debris. Once these are quantitatively translated into initial concentration estimates, they immediately place limits on the problem. Another factor of considerable importance is initial particle-size distribution, since this determines what fraction can be treated as a stable aerosol and what fractions will be deposited by sedimentation at various rates. The choice of methods used in predicting fallout from releases of interest here may be determined by these initial conditions. These conditions may differ widely among the various nuclear devices and the various test and operating conditions. In many cases, these may be largely unknown at present so that only gross estimates within wide ranges are available on which to base fallout predictions.

\footnotetext{
*Presented by Dr. Holland
} 
The radionuclides involved and their chemical and physical form determine the most likely modes of radiation exposure and therefore the predictions required. Surface air concentrations are important where inhalation is likely to be a hazard, as, for example, plutonium in fine particles. Total deposition and deposition rate per unit area of the earth's surface is of interest where external radiation may be of importance, as, for example, gamma-emitting nuclides. These and levels of specific nuclides in animal and human diets and in the human body are prediction steps where internal radiation may be important, as, for example, Sr9o. In some cases, e.g., large gross fission-product releases, all of these must be considered.

Three principal methods are employed in predicting fallout from such releases. They are based on (1) gravitational settling and turbulent diffusion of particles, (2) distribution of the total debris into a finite number of atmospheric reservoirs, and (3) analogy with the observed distributions from specific nuclear detonations or groups of detonations. Following deposition on the surface, estimates of dietary and human levels may be made on the basis of a variety of empirical models embodying the available research results.

\section{Gravitational Settling and Turbulent Diffusion of Particles}

Where particle diameters are predominantly greater than 20 microns or where releases are within the troposphere, settling and diffusion models are applicable. Point, line, or discrete-volume sources are assumed. For this method, surface distributions for ranges of particle sizes are calculated from equations which include gravitational settling velocities and the resultant of the wind vectors characteristic of the atmospheric layers through which the particles fall. Precipitation can, of course, alter the resulting patterns considerably. If the initial cloud is large (i.e., many miles in diameter) and if the particles are of the order of 100 microns or larger, turbulent diffusion can be neglected. From the total mass deposited, estimates are made of the radioactivity in a given area at various times. This type of method is essentially that used for predicting local fallout from surface bursts of nuclear weapons.

\section{Distribution Into Atmospheric Reservoirs}

The type of approach to fallout prediction based on distribution of the total debris into a number of atmospheric reservoirs is useful for small particles which have attained a relatively broad-scale distribution. Each atmospheric reservoir is characterized by a mean residence time, or by exchange coefficients with adjacent reservoirs. From these, deposition rates and cumulative deposition levels of nuclear debris can be estimated. Such a simple model has obvious faults since a number of the inherent assumptions are known to be wrong. For example, reservoirs are not necessarily we11 mixed and the boundaries between them, such as the tropopause, are not permeable membranes. Movements between reservoirs are therefore not exponential, as the model assumes, but are subject to changes in apparent residence time as the distribution within each reservoir changes. Nevertheless, there are discontinuities in mixing rate which are useful in differentiating among regions of the atmosphere for prediction purposes.

It is we11 known that the mean residence time of suspended particles in the troposphere is of the order of weeks to a month or two. That of the stratosphere is one to two orders of magnitude longer. However, it makes a great deal of difference whether a cloud of contaminant is introduced at the top or bottom of the troposphere or in a rainstorm. Similarly, in the stratosphere it appears that injections not far above the tropopause in winter or early spring at middle or polar latitudes might be largely discharged into the troposphere within a few months, while gaseous or submicron particulate debris stabilizing in the upper stratosphere near the equator might take several years.

The altitude range in which re-entering bodies tend to burn up or ablate, about 100,000 to 300,000 feet, is the least known both from the standpoint of its circulation and from the standpoint of its radionuclide content. As a result of 
studies of the $\mathrm{Rh}^{10 a}$ tracer data and $\mathrm{Ce}^{144} / \mathrm{Sr}^{90}$ ratios from the 1958 high-altitude shots Teak and Orange, limits of about 5 and 20 years (Stebbins) have been put on the residence time for this region. The cloud from the USSR 55- to 60-mt shot in October 1961 seems to have risen into this altitude region but at a high polar latitude. This shot seems to have produced most of the Fe ${ }^{55}$ and $\mathrm{Mn}^{54}$ now in the atmosphere. We are now analyzing these nuclides in balloon, aircraft, and surface samples to follow the pattern of movement and fallout. It appears that this debris also has a very long residence time compared to that injected into the lower stratosphere. We also have made some tenths of a megacurie of $\mathrm{Cd}^{\text {109 }}$ in the 1962 Johnston Island rocket shot Starfish, which we hope will be analyzed by many laboratories so as to add to our experimental basis for predicting fallout of high-altitude debris. Even now, however, some fallout predictions based on reservoir-residence-time methods may be useful for cases somewhat nonspecific as to initial spatial configuration and location. A requisite is that the release be in the form of vapor or submicron particles.

The use of the simple reservoir model for burnup of a hypothetical device containing 100 kilocuries of $\mathrm{Sr}^{90}$ on random re-entry may be used as an example. Many of the factors concerning such re-entry and burnup are unknown at present. However, let us assume for this example a complete burnup at 200,000 feet resulting in dispersion of submicron particles of radioactive material. Let us assume half-residence times of 10 years for the mesosphere, 5 years for the stratosphere, and 20 to 30 days for the troposphere. Table I shows the estimated amount of material remaining in the mesosphere and stratosphere and deposited on the surface at various times. The tropospheric residence time can be ignored in making this calculation. Further estimates of deposition rate, deposition rate per unit area, total deposition per unit area, and concentration in the various atmospheric compartments can be derived from these figures by dividing by the appropriate times, areas, or volumes.

TABLE I

Example of Reservoir Calculation

\begin{tabular}{|ccccc|}
\hline $\begin{array}{cccc}\text { Year } \\
0\end{array}$ & Mesosphere & & Stratosphere & Surface \\
\hline 1 & 100 & 0 & 0 \\
2 & 91 & 6 & 0 \\
3 & 83 & 11 & 1 \\
4 & 76 & 14 & 3 \\
5 & 69 & 17 & 5 \\
\hline 10 & 63 & 18 & 7 \\
\hline 15 & 39 & 19 & 20 \\
\hline 20 & 24 & 16 & 29 \\
\hline 25 & 15 & 11 & 34 \\
\hline 30 & 10 & 8 & 36 \\
\hline 35 & 6 & 5 & 36 \\
\hline
\end{tabular}

From the estimates of deposition rate and cumulative deposition, we can estimate levels of $\mathrm{Sr}^{90}$ in milk and other foods and in human bone using empirical relationships which have been determined from the studies of weapons test fallout. Average levels of $\mathrm{Sr}^{90}$ in milk and other dietary constituents, (Mpc/g Ca) are expressed by the relationship:

$$
\mathrm{M}=\mathrm{AS}+\mathrm{BR},
$$


where $\mathrm{A}$ and $\mathrm{B}$ are constants determined by climatic region and food item, $\mathrm{S}$ is cumulative $\mathrm{Sr}^{90}$ deposition $\left(\mathrm{mc} / \mathrm{mi}^{2}\right)$ and $\mathrm{R}$ is deposition rate (mc/mi $\left.{ }^{2}-\mathrm{yr}\right)$. Monthly levels are determined similarly, using for monthly deposition rates the average for the month in question and the previous month. A simplified estimate of average total dietary levels may be obtained by using 1.5 times milk levels. Levels in new human bone are, on the average, about one-fourth the total diet levels.

The reservoir model can be refined to incorporate our improved knowledge of atmospheric transport. By the use of computers, the number of compartments can be greatly increased, flux both into and out of each reservoir can be accounted for, and translatory circulations as we11 as diffusive transport coefficients can be included.

In the limit, such programs become finite-difference approximations to a continuum. Their properties can be determined by both empirical and theoretical considerations and can be made consistent with the current understanding of the dynamics of atmospheric circulation. The Weather Bureau and the Defense Atomic Support Agency as well as several university research groups are working on the development of such computer models.

\section{Analogy With Debris From Nuclear Detonations}

The third fallout prediction technique is based on observed distributions from specific weapons detonations or groups of detonations. This technique could we11 have been applied to the situation exemplified above, since much weapons test fallout data for $\mathrm{Sr}^{90}$ is available. From weapons test fallout studies we have good evidence for a nonuniform distribution of nuclear debris on the earth's surface. It is now possible to make realistic estimates of annual deposition by latitude, climatic region, and season from the conditions and amount of release in the atmosphere. From ratios of total source strengths of the particular weapons detonations selected as the analog to that of the aerospace injections for which the prediction is being made, we would predict deposition from observed test fallout. of course, this method is only applicable to the degree that the aerospace injections can be assumed to resemble those for weapons test debris. However, by the use of fissionproduct ratios for dating and of various induced activities as unique tracers, it has been possible to resolve fallout samples into components originating in the equatorial mesosphere, low equatorial stratosphere, high polar stratosphere, and low polar stratosphere. Figures 83 to 88 , which were prepared by Dr. L. Machta's group in the Weather Bureau, illustrate the two-dimensional patterns of global surface distribution, altitude versus latitude, and altitude versus time for selected components.

The great advantage of the analog method is that it provides information on both the systematic and random variability of the fallout in time and space, even though the mechanisms may not be understood or may not even be reducible to a quantitative mathematical model. For chemically similar radionuclides, it even permits direct estimates of levels in the food chain and in man. Its disadvantages, of course, derive from the same deficiencies which favor its use, namely, incompleteness of past observations and uncertainty as to the degree to which observed patterns will repeat themselves.

This technique may be applicable to the complete burnup of reactors or specific nuclide power devices. Since some data from weapons test fallout have been obtained for a number of specific nuclides, comparison of nuclear test and aerospace fallout can be made for a wide range of specific nuclides. A SNAP device powered by $\mathrm{Pu}^{238}$ is a recent practical example. Fallout deposition data are available for a few locations for three plutonium isotopes, the most plentiful data being, of course, for $\mathrm{Pu}^{239}$. Although predictions are less reliable for such cases involving somewhat unusual nuclides, some estimates for these based on experience are useful. Using ratios of $\mathrm{Sr}^{90} / \mathrm{Pu}^{238}$ which were available and assuming constant ratios produced in detonations, one could arrive at estimates of existing $\mathrm{Pu}^{238}$ deposition levels. 


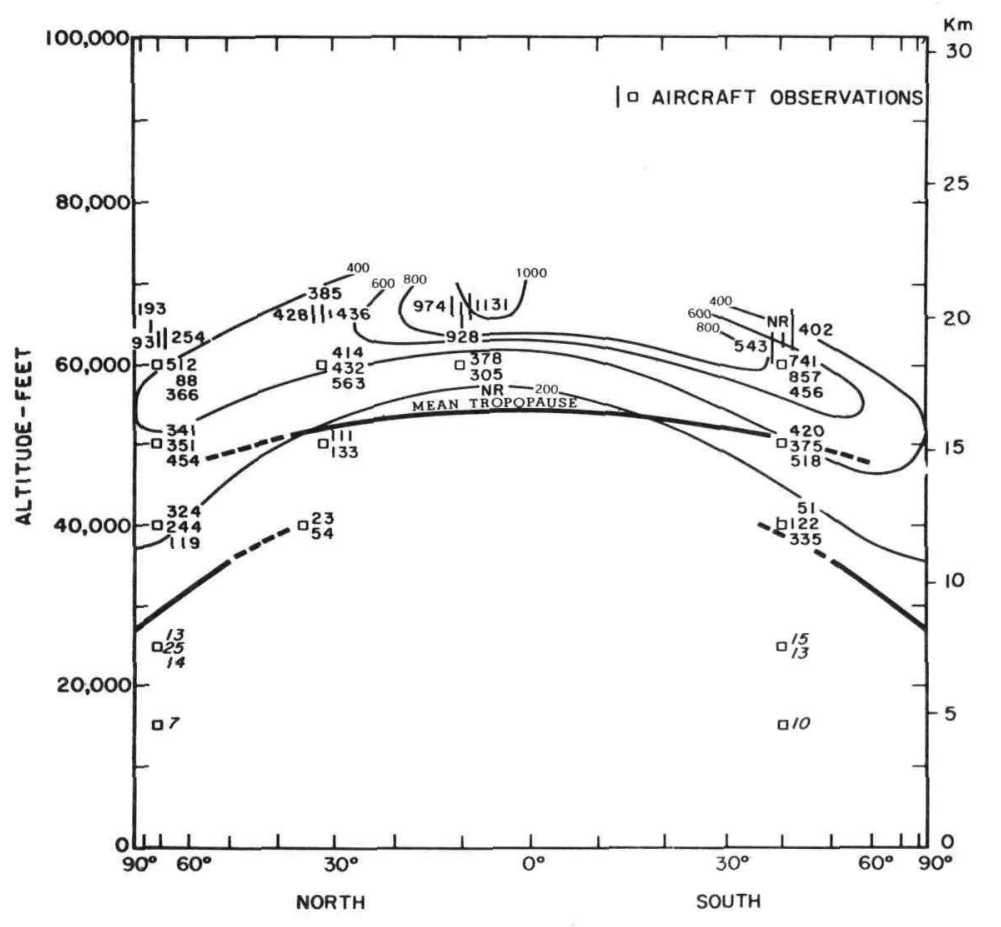

Figure 83 .

Observed concentrations of $\mathrm{W}^{181}$ (dpm/1000 S.C.F.) in the stratosphere by latitude November 1960 (corrected for decay to August 15, 1958)

Figure 84.

Observed concentrations of $\mathrm{W}^{185}$ in ground-leve 1 air along the $80^{\circ} \mathrm{W}$ meridian, January-May 1959

(from data of L. B. Lockhart, Jr. et al., Naval Research Laboratory)

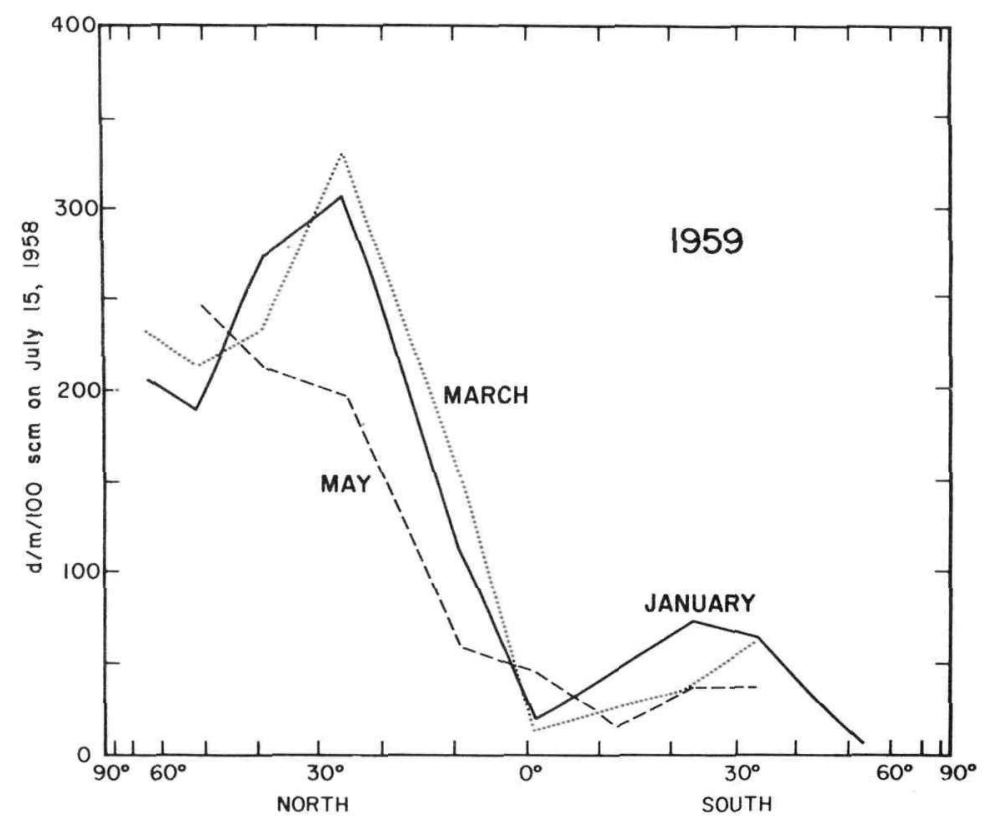




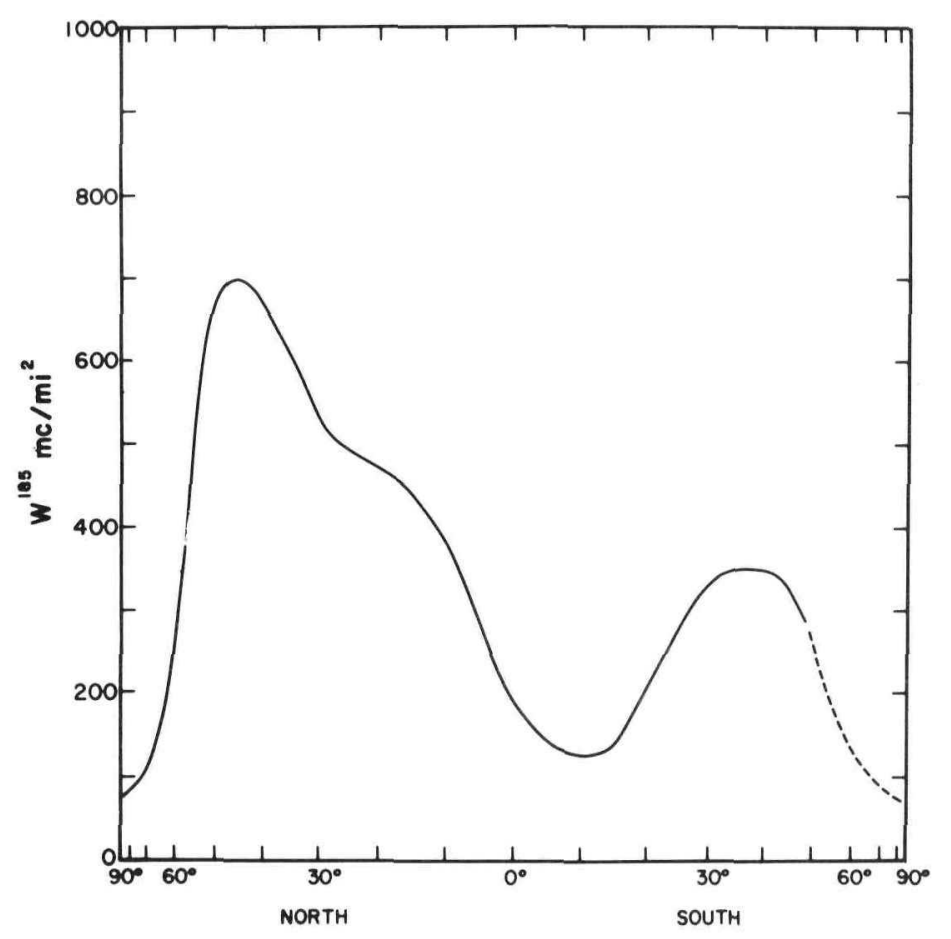

Figure 85.

Deposition of $W^{185}$ by latitude, January-June 1959 (estimated from fallout collection data of the AEC Health and Safety Laboratory)

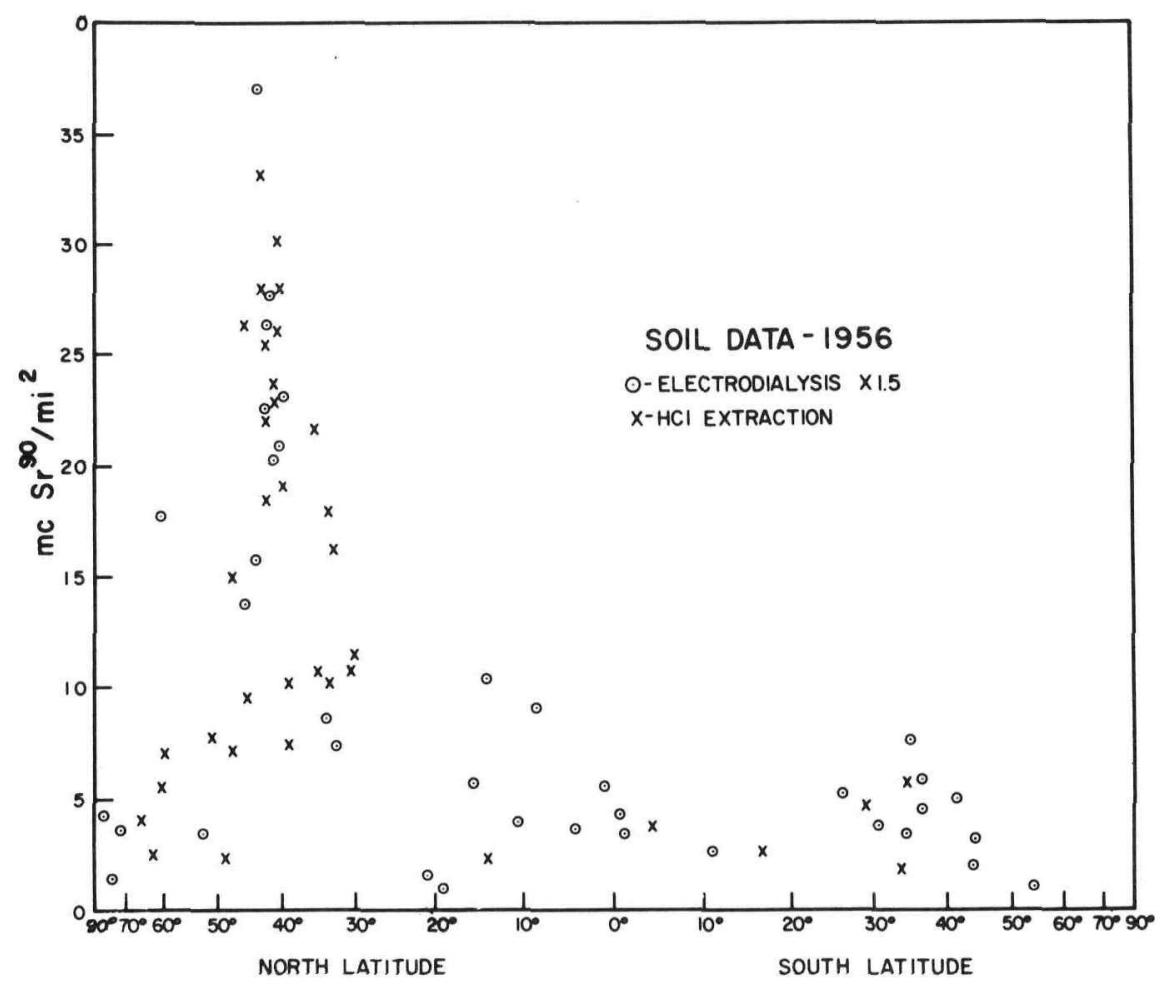

Figure 86. Deposition of $\mathrm{Sr}^{90}$ by latitude, 1956 (from the worldwide soil-sampling network of L. T. Alexander et al., USDA, and the AEC Health and Safety Laboratory) 


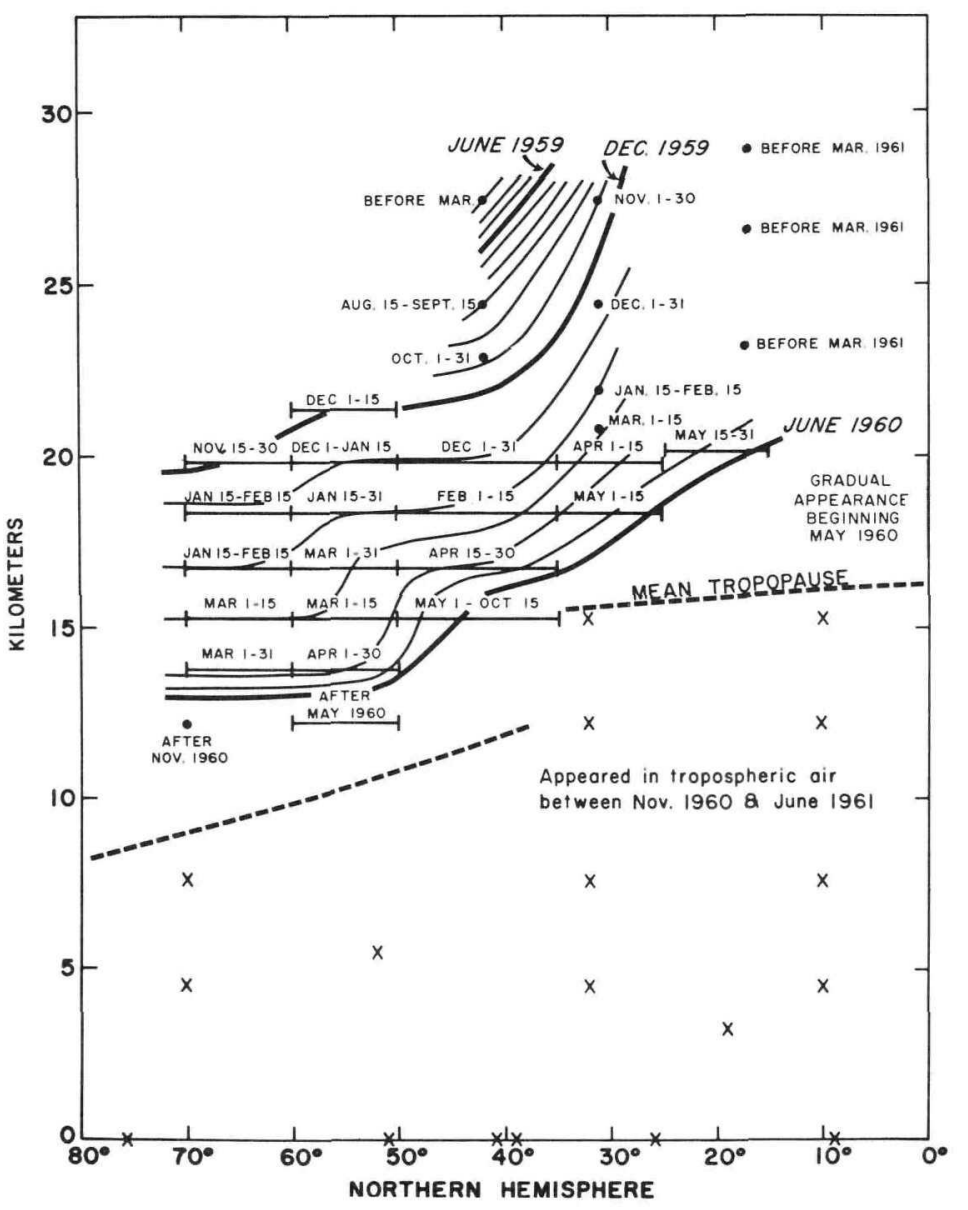

Figure 87. Time of arrival of TEAK-ORANGE debris as a function of altitude and latitude (Courtesy of R. G. List and K. Telegadas, U. S. Weather Bureau)

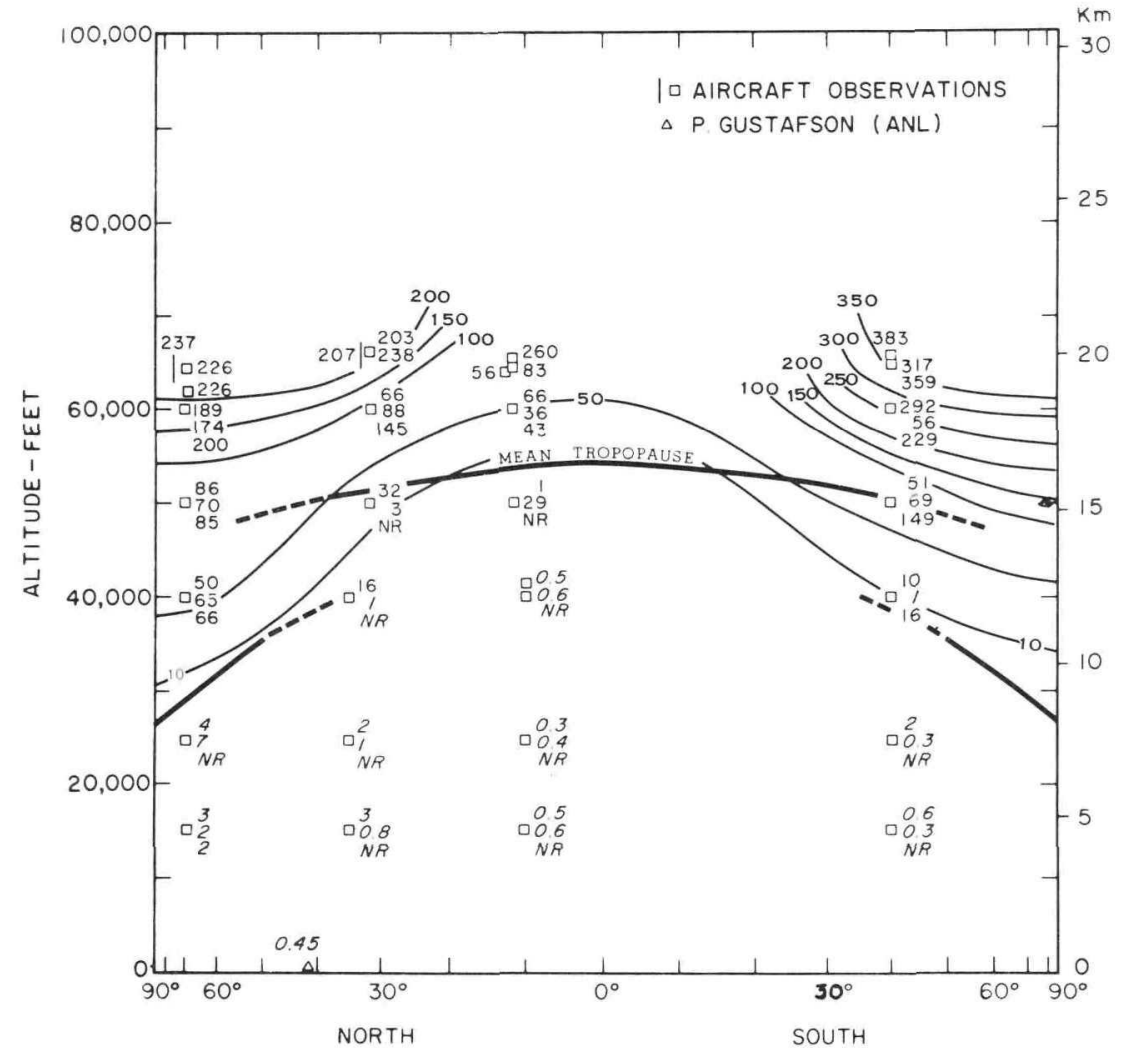

Figure 88. Atmospheric concentrations of $\mathrm{Rh}^{102}$ (dpm/1000 S.C.F.), May-June 1961

(corrected for decay to August 12, 1958) 
Distributing the assumed injection of $\mathrm{Pu}^{238}$ in accordance with the observed distribution of $\mathrm{Sr}^{90}$, an estimate of the addition of new $\mathrm{Pu}^{238}$ to the pre-existing $\mathrm{Pu}^{239}$ background can be made. Furthermore, with even fragmentary data on existing $\mathrm{Pu}^{239}$ levels in the diet and human tissues it is possible to place some order-ofmagnitude limits on the levels of $\mathrm{Pu}^{238}$ likely to occur in the body, provided the particle size and chemical form of the $\mathrm{Pu}^{233}$ fallout from the re-entering SNAP unit can be assumed to resemble those of the $\mathrm{Pu}^{239}$ from weapons test fallout.

Clearly an important task in attempting to resolve these uncertainties is to follow up the high-altitude debris currently present in the atmosphere from past tests. We are supporting intensive efforts to develop techniques which we hope will improve high-altitude sampling capabilities considerably within the next year. These include extension of balloon sampling from the present ceiling of about 110,000 feet to about 130,000 or 140,000 feet and development of rocket sampling capabilities for the region up to 200,000 feet or higher. Sandia Corporation, the Air Force Special Weapons Center in Albuquerque, and the Air Force Cambridge Research Center are cooperating in these efforts. Figures 89 to 96 illustrate the status of these high-altitude sampling techniques.

From this brief discussion it is seen that gross fallout predictions, at least, can be made for a number of aerospace situations involving nuclear debris. There may be opportunities in the future for obtaining better specific data from which better prediction models can be made. Currently an area where better information is needed is in the source data. Little is known of particle-size distribution, spatial distribution of debris, and chemical form of radionuclides which may result in the injections of debris from the various aerospace activities. In some cases, species and quantities of nuclides may not be known. Continued research in a11 of these areas will undoubtedly assist in improvement of our fallout prediction techniques.

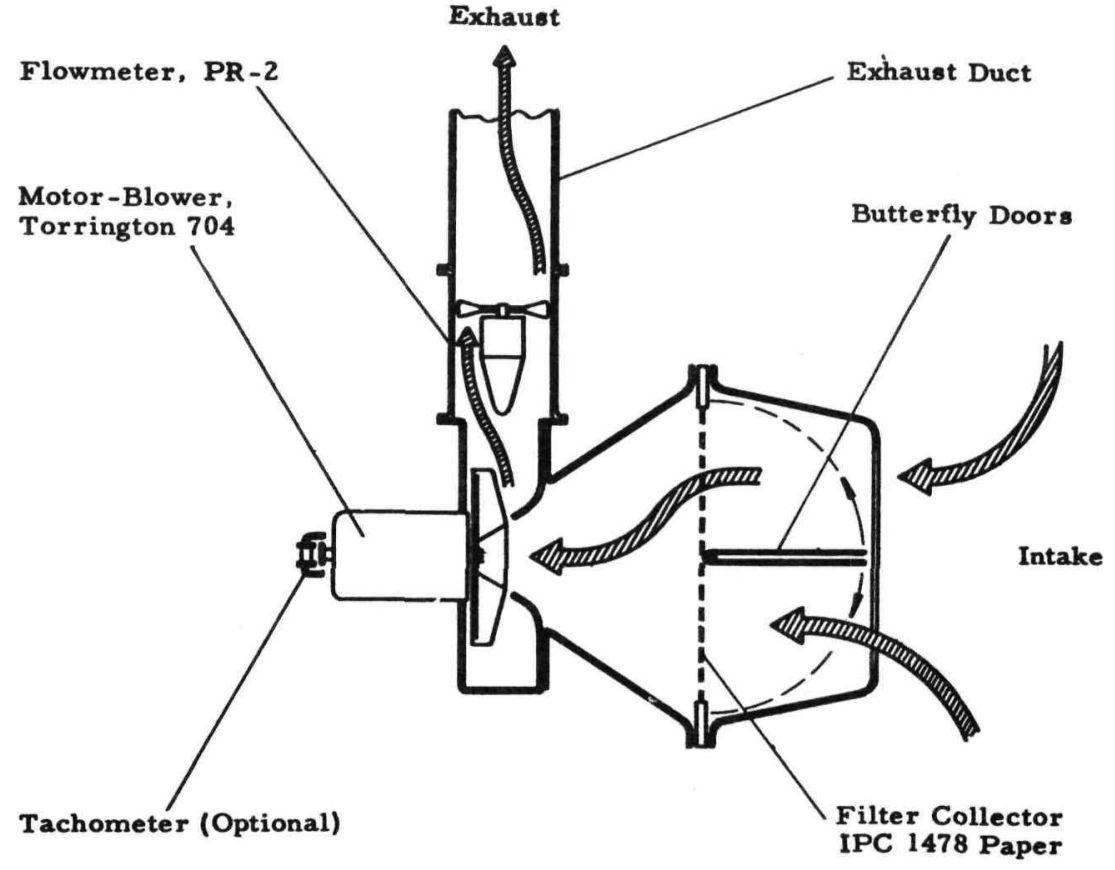

Figure 89. Schematic diagram of a direct-flow aerosol sampler developed by General Mills, Inc. 


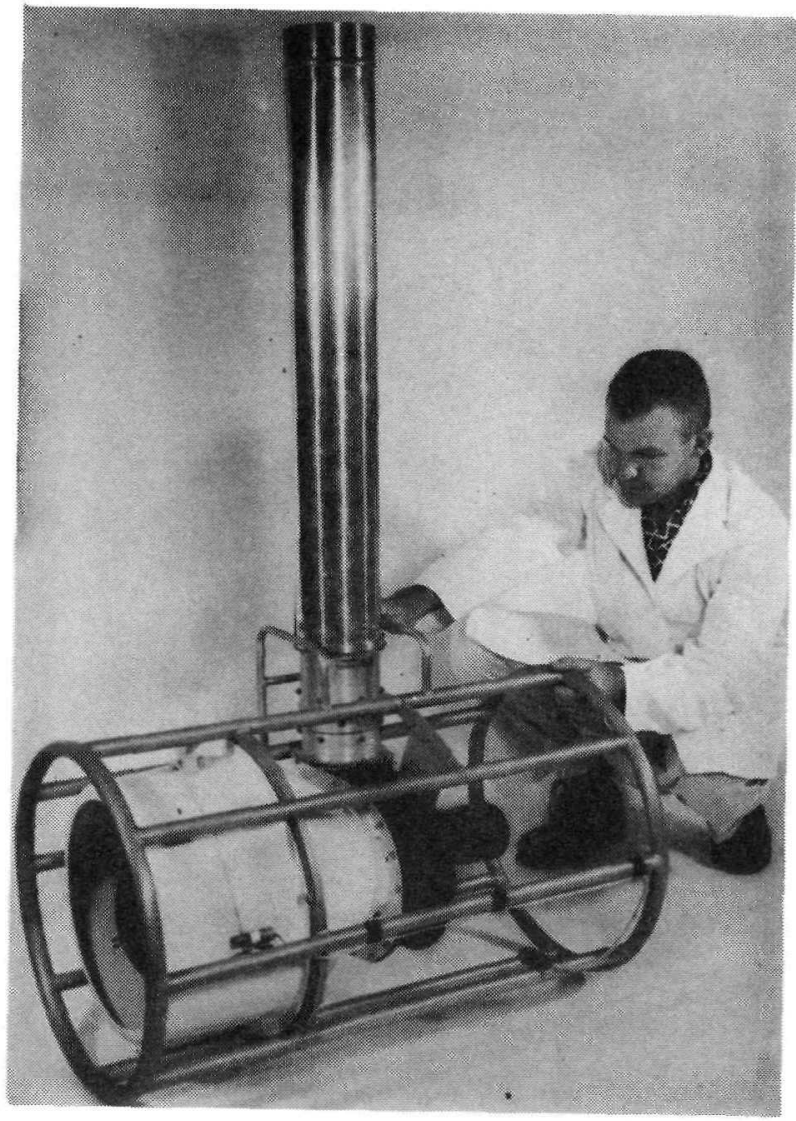

Figure 90.

Direct flow aerosol sampler

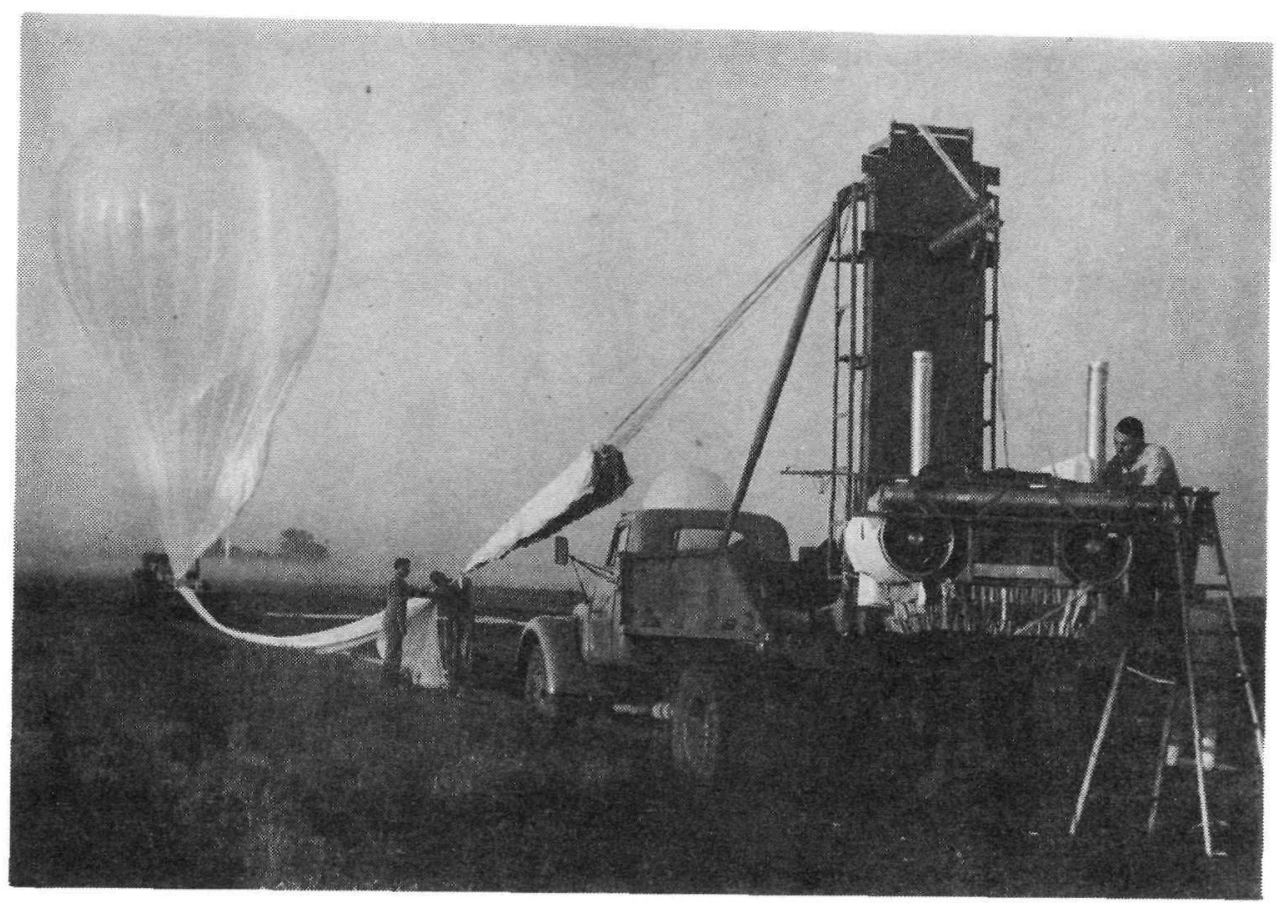

Figure 91. Launching of balloon carrying direct-flow aerosol samplers and an electrostatic precipitator sampler 
IV -3
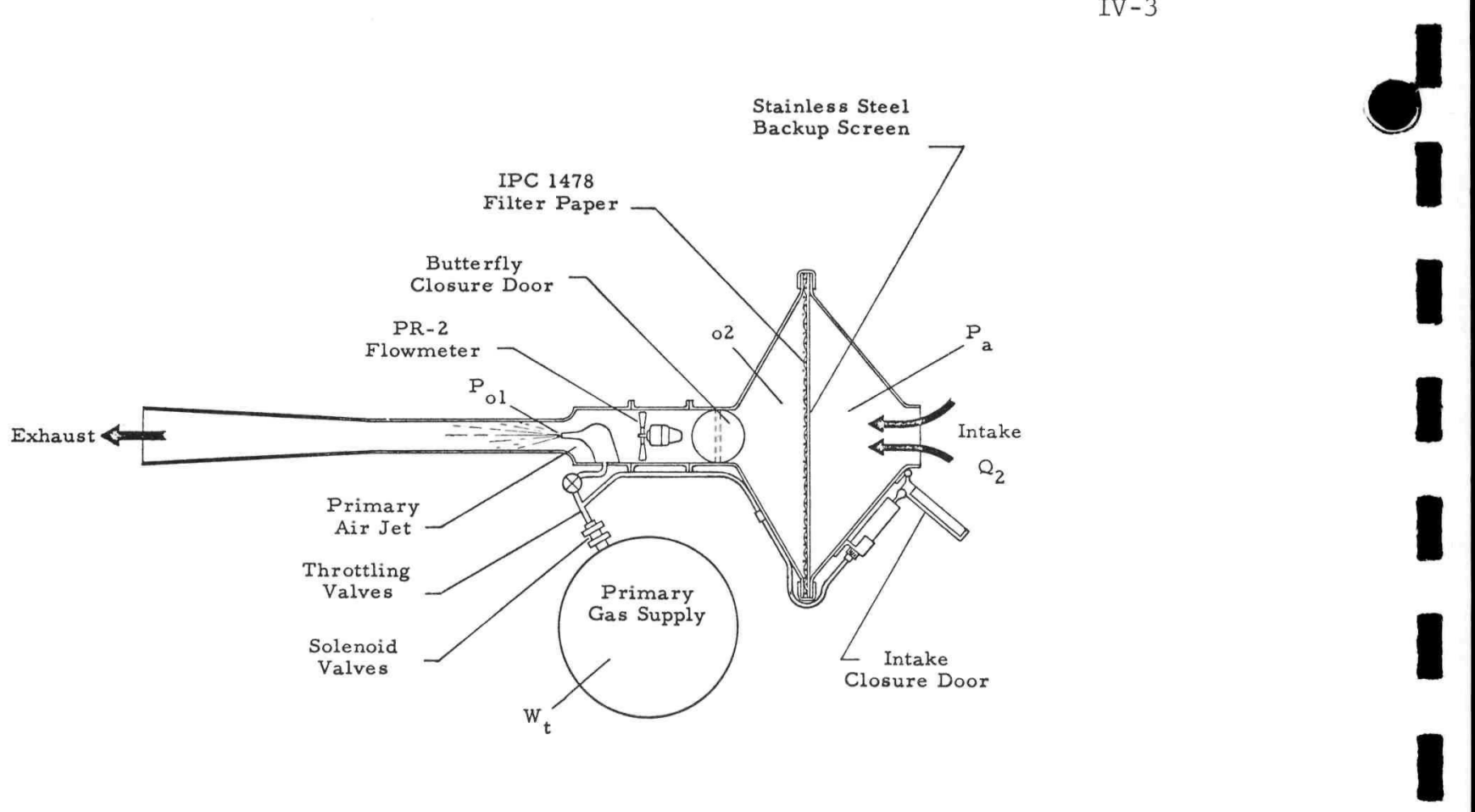

Figure 92. Schematic diagram of ejector-powered aerosol sampler developed by Genera1 Mills, Inc.

Figure 93.

Ejector-powered aerosol sampler

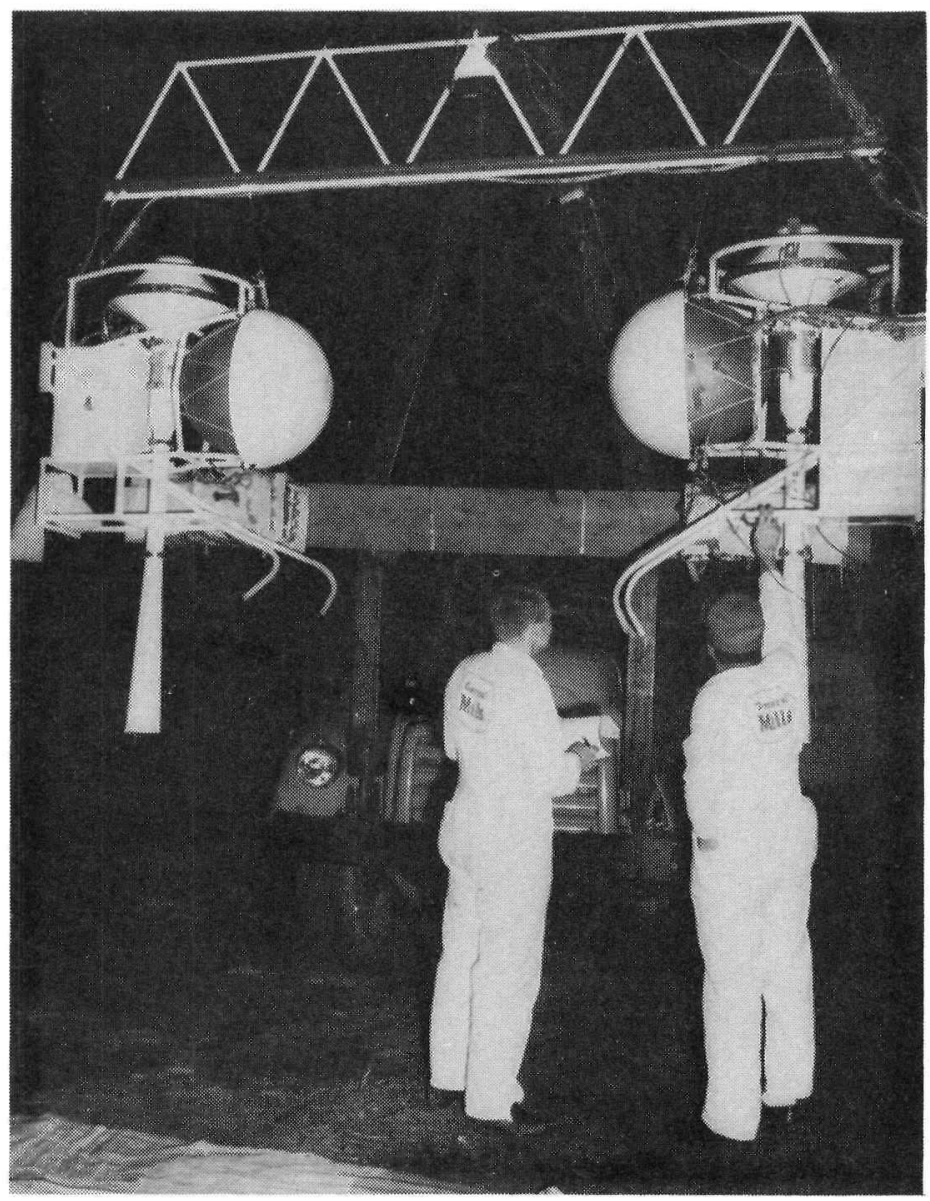




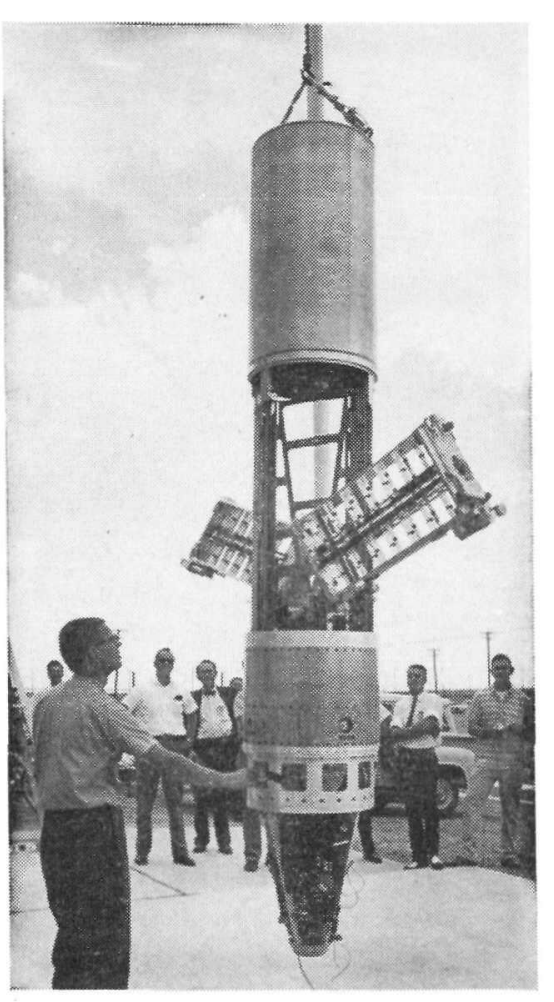

Figure 94 .

SAND-LO rocket sampler being developed by Sandia Corporation--beginning of blade extension

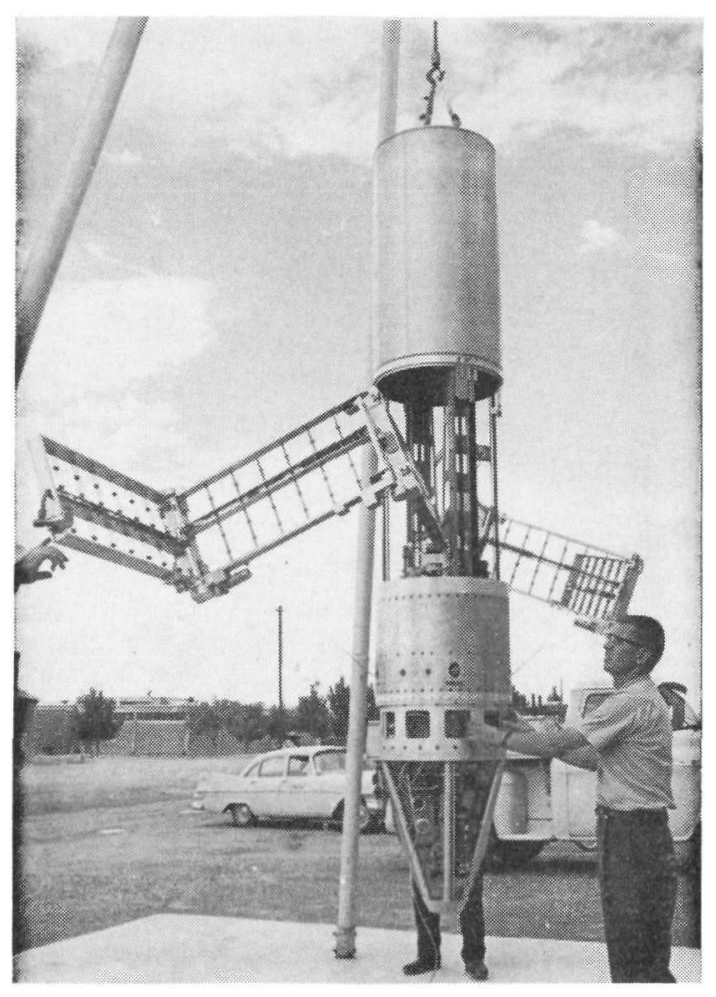

Figure 95.

SAND-LO rocket sampler-blades being extended

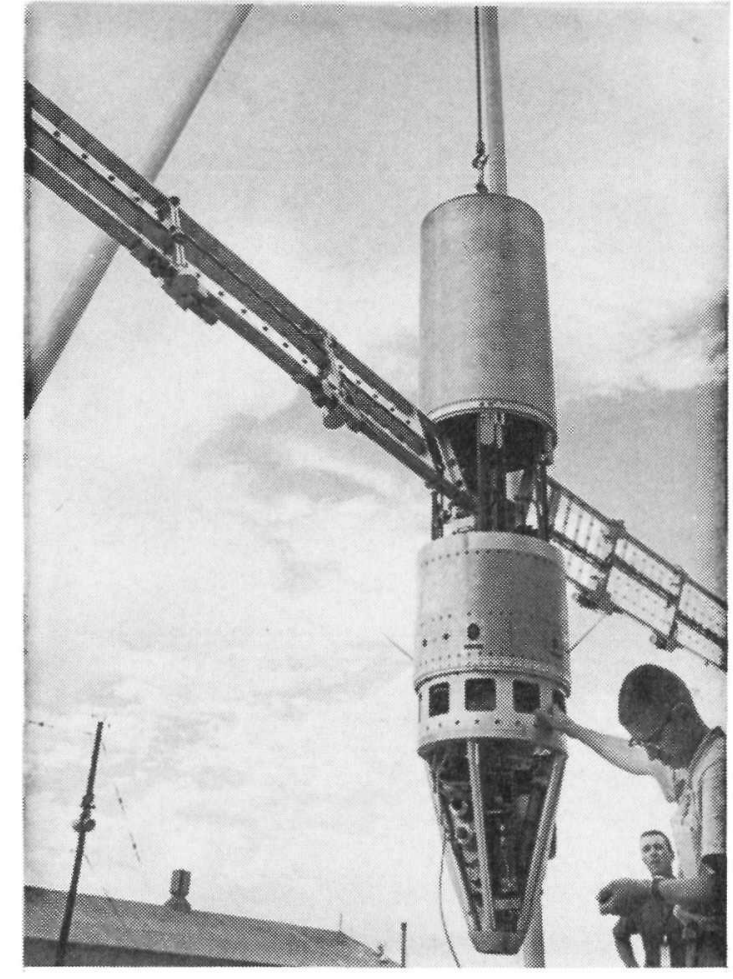

Figure 96.

SAND-LO rocket sampler-blades in sampling position 


\section{BLANK}




\title{
ENVIRONMENTAL SAFETY ASPECTS OF ROCKET FLIGHT OPERATIONS*
}

\author{
M. I. Goldman \\ C. R. McCullough \\ Nuclear Utility Services, Inc.
}

Introduction

Previous papers in this meeting have described the pertinent characteristics and safety problems associated with the first generation of nuclear rocket reactors as we 11 as the approaches under study to solve the safety problems. (Papers III-1, III-2, and III-3, pp 131 to 166.) In this session on environmental factors, previous speakers have described the character of the marine and atmospheric environments and the role played by these media in the transport of radioactive materials from nuclear aerospace devices. (Papers IV-1, IV-2, and IV-3, pp 195 to 230.) A11 of the speakers have emphasized present uncertainties in both nuclear rocket and environment which will be resolved as the program develops.

It is the intent of this paper to describe by "precision guesswork" the significant routes of radiation exposure which could occur with a nuclear rocket system which is unprotected by safety systems and the effect of environmenta1 parameters on the resulting doses. This is not, however, a hazard evaluation since it applies to a system which as yet does not have a final design and whose characteristics therefore are not well defined. It is conservative, as befits the role of "professional pessimists" in order to highlight the problems which may arise in the event of malfunction and which should be avoided either by more reliable design or engineered safeguards.

To avoid the necessity of describing a series of precise accident situations, a meaningless exercise at this stage, the approach taken here considers the way in which material is released to the environment and the identity of that segment of the environment in which the release takes place. For the present study, launch site releases are assumed to fall into one of the following three environmental cases:

1. a release to the atmosphere as a result of an inadvertent criticality occurring on or near the launch site from controlrod malfunction, dropping and compacting of the core, reflection by water, etc.,

2. a release to the atmosphere from a nuclear excursion near the launch pad concurrent with the detonation of the booster propellant, and

3. a release to the marine environment from an early abort of the booster in which the nuclear stage drops into nearby waters.

Each of these three types of occurrences produce transport and dose effects which differ greatly from the others.

In examining cases occurring away from the launch site, other types of problems are revealed, particularly those resulting from premature re-entry of radioactive fragments, or for that matter, of the reactor as a whole. The remainder of

*Presented by the authors 
the paper deals with both launch-site and re-entry hazards specifically associated with the application of nuclear rockets but which may, with appropriate differences recognized, serve to highlight similar problems in other aerospace nuclear applications.

Launch-Site Hazards

Accidents occurring at or near the launch site may have significant dose effects primarily because of the nature of the power source. In contrast to more conventional reactors, nuclear rocket engines are essentially unshielded and uncontained reactors in rather close proximity to large quantities of highly flammable materials. Of great importance is the neutronic behavior of the reactor when immersed in a moderator such as water or liquid hydrogen or when compressed by impact or by propellant detonation.

If, either because of its basic design or because of engineered safeguards, no nuclear excursion can occur under these circumstances, then there should be no launch-site hazard other than that normally considered in the assembly and checkout of a reactor. This hazard can be made minimal, as it has for reactors in general, by the design of the facility itself and by following prepared, rigid, procedural safeguards in the assembly and testing of the nuclear stage.

On the other hand, if a nuclear excursion is possible during work at the pad, during launch, or in early flight, then the amount and nature of the radioactive material released will depend primarily on the properties of the core with the environmental factors possibly limiting the extent of the resulting hazard. In this regard, such reactors are similar in many ways to other more conventional ones, yet the differences can create situations which are essentially unique to aerospace nuclear applications. For example, with no significant power history, the reactor will not contain a fission-product inventory and hence any accident will be dominated by short-lived fission products in contrast to the usually considered case of power reactors.

In the event of a criticality incident at or near the launch site which was unaccompanied by a large release of chemical energy, a core designed to operate at high temperatures would resist melting, as indicated by Stratton, (Paper III-3) and fractionation of the fission-product inventory would result. The release would consist chiefly of the more volatile fission products, notably the noble gases and halogens. In an essentially uncontained system, such elements would be released to the environment and dispersed, duplicating to some extent the recognized problems from conventional reactor hazards. However, some rather more severe problems may arise in this case since containment essentially does not exist. For this excursion, a magnitude of 10,000 megawatt-seconds ( $3 \times 10^{20}$ fissions) has been selected as representative of the credible range described by Stratton.

The first environmental uncertainty in evaluating radiation hazards lies in selecting the model to be used in estimating atmospheric transport. As indicated by previous speakers, the transport of materials by the atmosphere is perhaps the most significant. It is certainly the most rapid method for a dose to be carried to people. Of the atmospheric diffusion models in common use, the Pasquill model ${ }^{1}$ was selected as probably the most representative of those relationships in the absence of definitive dispersion studies. The basis for this choice is indicated in Figure 97, which shows centerline dilution factors for a number of these models under stable conditions. It can be noted that about an order of magnitude difference exists between the greatest and the least concentration values and that the Pasquil1 model provides (for the assumptions made) a median value between maximum and minimum. Without exhaustive and definitive dispersion testing at specific sites, it is felt that the Pasquill relationship provides the best approach to a general estimate of diffusion presently available. It is neither as conservative as the Sutton model nor apparently as radical as the Couchman relationship, as indicated on this figure. 


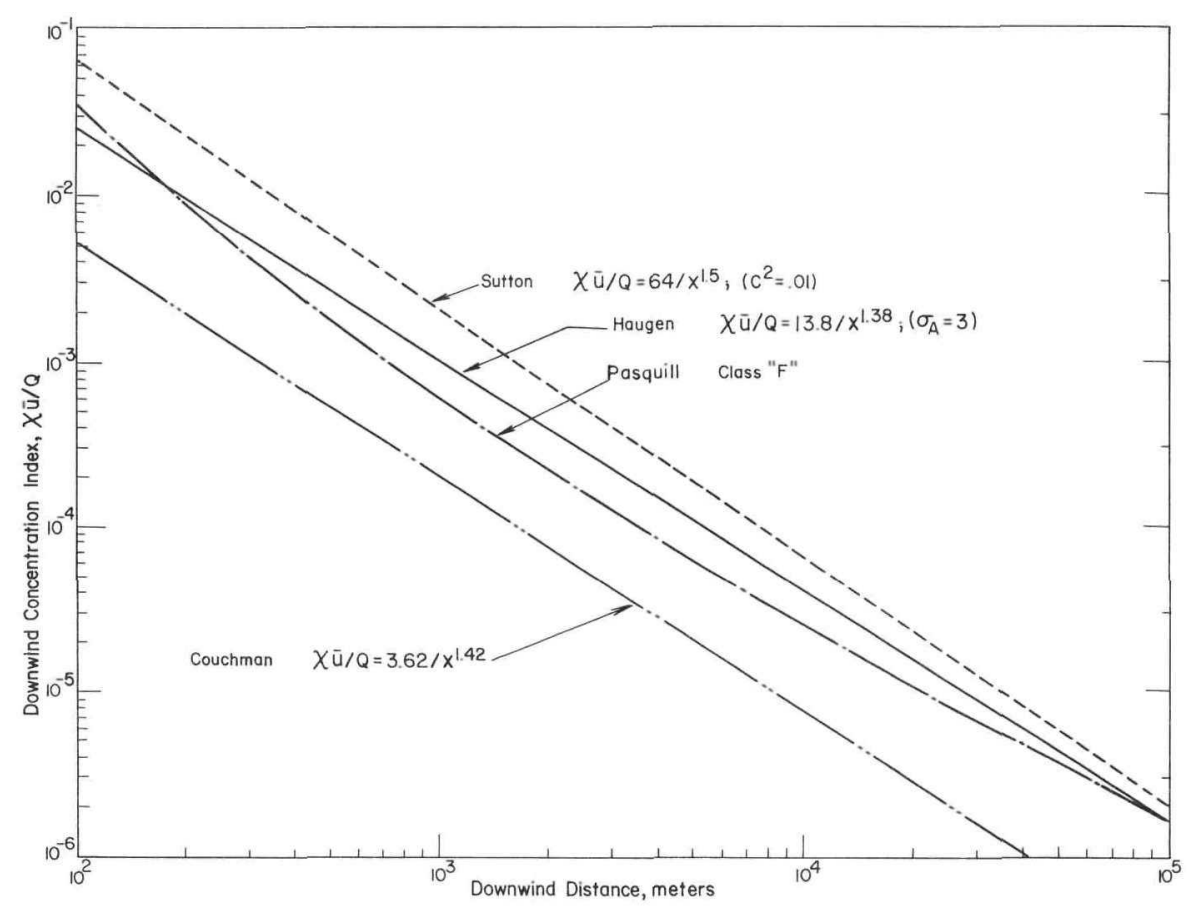

Figure 97. Comparison of calculated downwind concentrations for the stable atmosphere

The results of an analysis using this atmospheric diffusion model and the excursion indicated previously are not unanticipated. As expected, radioiodines create the major difficulty. However, one effect of interest arises from the depositon velocity mentioned by Dr. Van der Hoven (Paper IV-2). Figure 98 indicates the effect of the deposition velocity assumption on the thyroid dose resulting from inhalation along the cloud centerline. This figure illustrates the inhalation dose as affected by deposition velocities ranging from 0 to 1 centimeter per second for two atmospheric stability cases. It indicates that the deposition velocity plays a relatively minor role in the unstable or lapse atmospheric condition but plays a rather significant role in the stable or inversion case. The difference increases as the distance becomes greater, reaching a factor of 10,000 at a downwind distance of 60 miles, that is, between no deposition and deposition at the rate of 1 centimeter per second. These data indicate the importance of this parameter in assessing the thyroid doses from radioiodines that may occur at rather substantial distances from the site of the accident.

This factor plays an additional role in the milk contamination problem. It has been calculated that continued consumption of milk from a single deposition of I-131 to the extent of about $0.2 \mu \mathrm{c}$ per square meter of pasture will result in an integrated thyroid dose of 1.5 rad to a child's thyroid in 1 year. This is the FRC figure for permissible peacetime exposure to a sensitive individual in the population. In Figure 99 the effect of deposition velocity on I-131 contamination is shown for the stable and neutral conditions as a function of deposition velocity and downwind distance. Under stable conditions, it will be noted for example that the distance within which milk may be contaminated in excess of the indicated acceptable value is in the range of 20 to 40 miles, depending upon the value of the effective deposition velocity. Under neutral conditions the range might extend from about 7 to 15 miles depending upon the value of this parameter. A 1 ocal shower raining through the iodine-containing cloud could result in contamination of a small area with very high concentration and a reduction of the distance to reach 
the specified concentration by dry depletion of the cloud; it could also extend the distance for unacceptable contamination by enhancing the dry deposition out to a distance of a hundred miles or so. These results, of course, do not consider restriction on the pasture feeding of cows or distribution of milk.

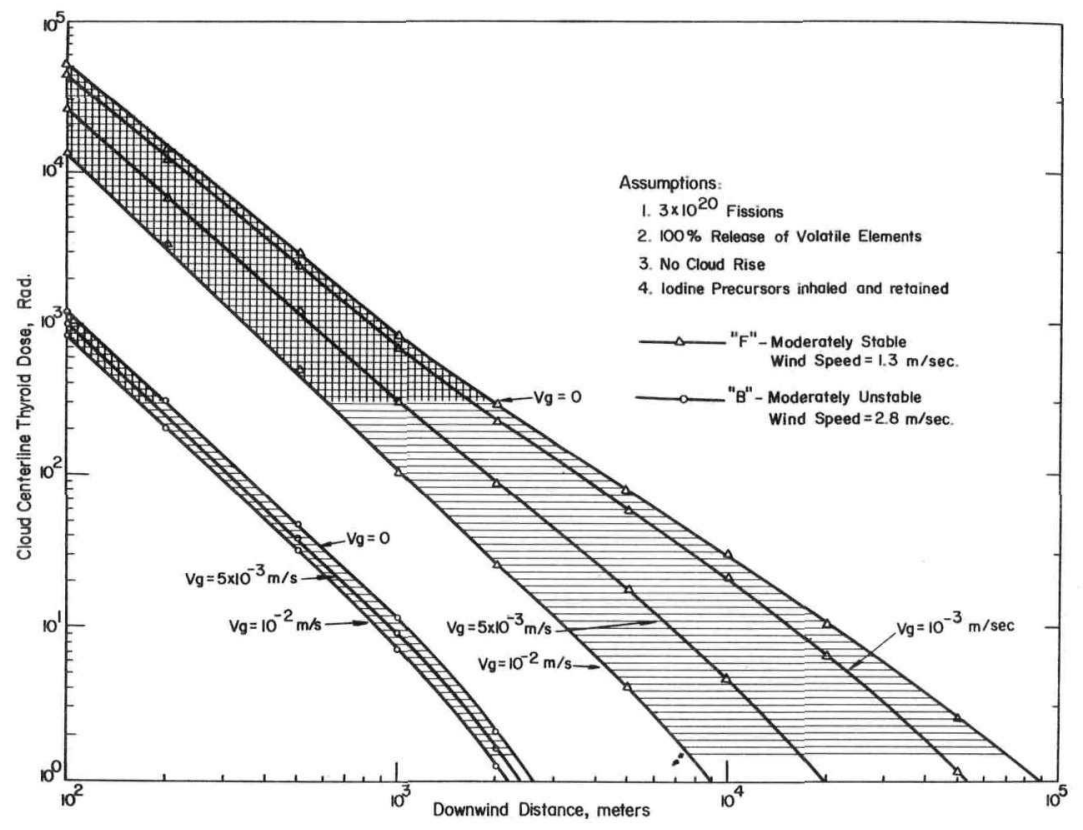

Figure 98.

Effect of deposition velocity on thyroid dose
Figure 99.

Effect of deposition velocity on I-131 deposition

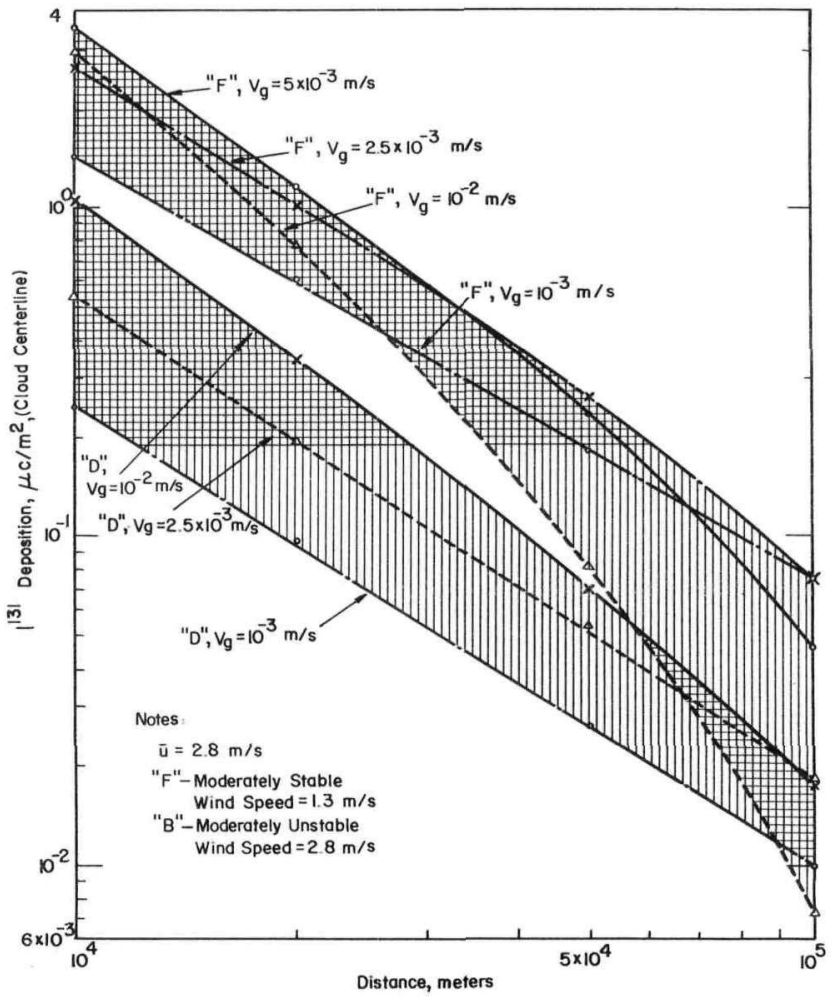


Other factors which must be considered in this type of accident are those associated with prompt radiation, cloud gamma doses, and contaminated surface exposures. Prompt gamma and neutron doses, for example, would be fatal within about 200 meters of the unshielded reactor, and other doses, under the most restrictive meteorological conditions, would be 25 rads whole-body gamma dose from cloud passage at 100 meters downwind and an infinite gamma dose from surface contamination of about 10 rads at 350 meters downwind. The on-site iodine inhalation dose to thyroid would be about 300 rads at 600 meters downind under these conservative meteorological conditions.

Consider next the types of exposures and the significance of the environment in the booster explosion case. If large amounts of chemical energy accompany or initiate a nuclear excursion, problems of a more novel sort may occur. Particularly with a vehicle in which propellant quantities are large, detonation on or just above the pad may create a severe fallout problem with an unprotected reactor against which launch-site boundaries may not provide adequate protection. Blast overpressure estimates range up to the order of $100,000 \mathrm{psi}$, and at these values it is possible to postulate compression of the reactor core followed by fragmentation and dispersion into the atmosphere. Immersion in propellant might result in the same nuclear effect.

For this hypothetical case, an excursion of 100,000 megawatt-seconds ( $3 \times 10^{21}$ fissions) in magnitude is assumed to occur (see Paper III-3) concurrently with a booster explosion. An explosion of sufficient magnitude to compress the core and create an excursion of this size will induce a rather large thermal rise of the cloud, perhaps on the order of 3000 to 4000 meters. In this case, the dispersion of fission products which are volatilized and boiled off from the core will be adequate to prevent their creating a substantial immediate hazard at the earth's surface, although long-range, food-chain contamination may we11 occur. On the other hand, nonvolatile fission products from this number of fissions will create substantial activities in the fragments returning to earth.

Residual fission-product beta power is shown in Figure 100 for an excursion of this order of magnitude. "Nonvolatile" elements are $\mathrm{Zr}$, $\mathrm{Nb}$, Mo, Tc, Ru, and $\mathrm{Rh}$; all others are assumed to be volatile under these conditions. On the basis of articles in Nucleonics, ${ }^{2}, 3$ a nuclear reactor of $1200 \mathrm{mw}$ power delivering 60,000 pounds of thrust and a specific power of $100 \mathrm{mw}$ per cubic foot is assumed. A void volume of 25 percent is assumed, resulting in a volume of core solids of 9 cubic feet. Assuming a core material density of two, the dose rates at the surface of spherical particles can be estimated as a function of particle diameter from the residual beta power using methods described in the literature. ${ }^{4}$ These dose rates are shown in Table $I$ as a function of time after the incident. As noted in the table, the surface dose rates are extremely high. For example, about 16 hours after the event, dose rates range from 200,000 rads per hour for a 6 -millimeter particle to 1700 rads per hour for a 25 -micron particle.

Although the larger particle sizes would not be expected to be carried offsite under low-wind conditions, the smaller particles, 100 to 200 microns and less, might very we11 be carried beyond the confines of the launch area. If one estimates that the skin receives significant exposure at the rate of only one-tenth that at the surface of the particles themselves, severe skin damage can be seen to be done by exposure for a matter of a few hours to one of the smaller particles. Ranges of travel of such fragments created in a detonation of this magnitude have been computed and distributions with distance of the particles using this model are presented in Table II. In this table it will be noted that particles ranging from 25 to 75 microns in diameter will be present in significant concentrations per square meter at distances of 100 kilometers from the site of the accident. Since 25 -micron particles can still deliver more than 1000 rads per hour 16 hours after their creation, it is obvious that these particles can create substantial difficulties off-site.

It is important to re-emphasize that this large excursion is based on the assumption that the unprotected reactor core is subject to compression from pressures of the order of $100,000 \mathrm{psi}$ or immersed in propellant. The probability of such an occurrence may be low, but further study is required to make a more quantitative estimate. 


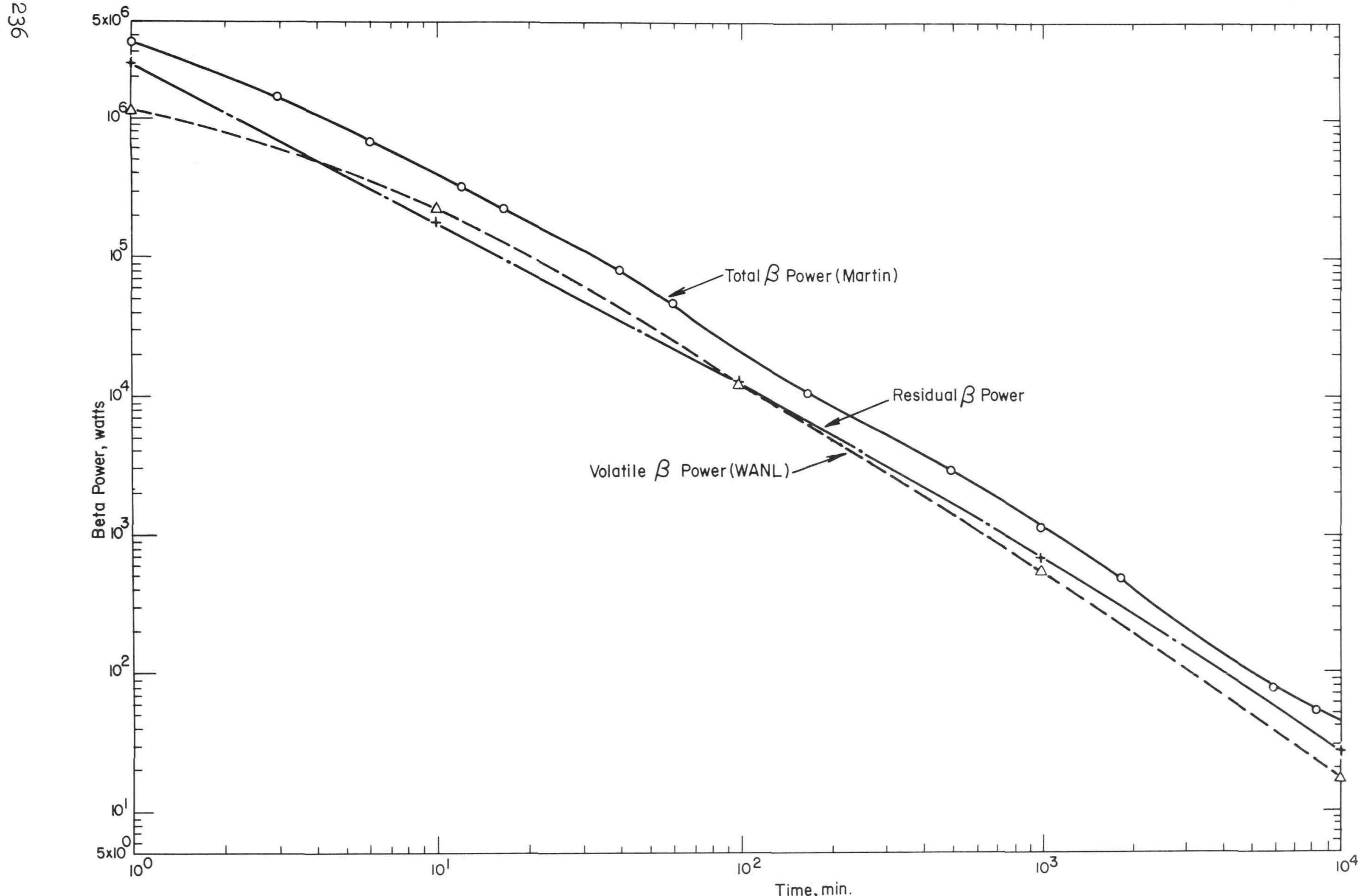

Figure 100. Residual fission product beta power $\left(3 \times 10^{21}\right.$ fissions $)$ 
TABLE I

Dose Rates at the Surfaces of Spherical Particles

\begin{tabular}{|c|c|c|c|c|}
\hline \multirow{2}{*}{ Particle Diameter, $\mu$} & \multicolumn{4}{|c|}{ Surface Beta Dose Rate, rad/hr } \\
\hline & $\underline{T}=10 \mathrm{~min}$ & $I=10^{2} \mathrm{~min}$ & $\underline{T}=10^{3} \mathrm{~min}$ & $\mathrm{~T}=10^{4} \mathrm{~min}$ \\
\hline 6000 & $4.4 \times 10^{7}$ & $3.3 \times 10^{6}$ & $2.0 \times 10^{5}$ & $9.0 \times 10^{3}$ \\
\hline 2000 & $2.0 \times 10^{7}$ & $1.6 \times 10^{6}$ & $1.2 \times 10^{5}$ & $7.7 \times 10^{3}$ \\
\hline 1000 & $9.9 \times 10^{6}$ & $8.5 \times 10^{5}$ & $7.1 \times 10^{4}$ & $6.5 \times 10^{3}$ \\
\hline 600 & $6.0 \times 10^{6}$ & $4.9 \times 10^{5}$ & $3.9 \times 10^{4}$ & $5.0 \times 10^{3}$ \\
\hline 200 & $2.0 \times 10^{6}$ & $1.7 \times 10^{5}$ & $1.3 \times 10^{4}$ & $2.1 \times 10^{3}$ \\
\hline 100 & $9.9 \times 10^{5}$ & $8.5 \times 10^{4}$ & $7.1 \times 10^{3}$ & $1.2 \times 10^{3}$ \\
\hline 75 & $7.3 \times 10^{5}$ & $6.3 \times 10^{4}$ & $5.0 \times 10^{3}$ & $7.5 \times 10^{2}$ \\
\hline 50 & $5.2 \times 10^{5}$ & $2.1 \times 10^{4}$ & $3.2 \times 10^{3}$ & $4.8 \times 10^{2}$ \\
\hline 25 & $2.5 \times 10^{5}$ & $2.1 \times 10^{4}$ & $1.7 \times 10^{3}$ & $2.8 \times 10^{2}$ \\
\hline \multicolumn{5}{|l|}{ Assumptions: } \\
\hline Beta power, w/g & 0.35 & 0.025 & 0.0014 & $5.3 \times 10^{-5}$ \\
\hline \multicolumn{5}{|c|}{1 watt $/$ gram $=3.6 \times 10^{8} \mathrm{rad} / \mathrm{hr}$} \\
\hline \multicolumn{5}{|c|}{ Material density $=2$ grams $/ \mathrm{cm}^{3}$} \\
\hline \multicolumn{5}{|c|}{ Residual beta power from $3 \times 10^{21}$} \\
\hline
\end{tabular}

TABLE II

Centerline Particle Density

\begin{tabular}{|ccr|}
\hline Distance, $\mathrm{km}$ & No. $/ \mathrm{m}^{2}$ \\
\cline { 2 - 3 } 10 & 1500 \\
& $75-200$ & 330 \\
& $50-75$ & 800 \\
50 & $75-100$ & 100 \\
& $50-75$ & 250 \\
$25-50$ & 400 \\
100 & $50-75$ & 170 \\
& $25-50$ & 280 \\
\hline Assumptions: & \\
12 cubic-foot core, 25-percent voids & \\
Log norma1 distribution; median $=2.5 \mathrm{~mm}$ & \\
Surface wind speed $=1.3 \mathrm{~m} / \mathrm{s}$ & \\
Neutral stability & \\
\hline
\end{tabular}


The final considerations in launch-area problems are those associated with the introduction of radioactive material into the marine environment. Problems in this area are primarily those associated with the uptake of material by biota in the marine environment and the subsequent reconcentration of such materials through the food chain until they reach man. As a basis for evaluation, concentrations have been estimated for the introduction of all of the fission products of a $10^{4}$ megawatt-second excursion into the marine environment and assuming a11 are soluble. The peak concentrations of the diffusing cloud mixed in a 10-meter deep layer are compared with maximum permissible concentrations in sea water as developed by the Isaac's Committee ${ }^{5}$ of the National Academy of Sciences-National Research Council and are shown in Table III. Although almost all of the fission products listed exceed the permissible concentrations at about 16 hours after their introduction, with one exception (that of ruthenium-103) they are a11 below the maximum permissible concentration within a week after their introduction. Thus it would appear that the control of off-shore waters into which such fission products were to be introduced would not be required for periods extending much beyond the order of a week. In confined waters, the problem would, of course, be more severe.

\section{TABLE III}

Significant Fission-Product Concentrations in Sea Water $\left(3 \times 10^{20}\right.$ fissions $)$

\begin{tabular}{|c|c|c|c|}
\hline \multirow[b]{2}{*}{ Nuc1ide } & \multirow[b]{2}{*}{ MPCC,$\mu \mathrm{c} / \mathrm{kg}$} & \multicolumn{2}{|c|}{ Peak Concentration, $\mu \mathrm{c} / \mathrm{kg}$} \\
\hline & & $10^{3}$ minutes & $10^{4}$ minutes \\
\hline Sr-89 & $8.7 \times 10^{\circ}$ & $2.7 \times 10^{-3}$ & $2.4 \times 10^{-5}$ \\
\hline Sr-90 & $3.4 \times 10^{-2}$ & $1.6 \times 10^{-5}$ & $1.6 \times 10^{-7}$ \\
\hline$Y-91$ & $7.0 \times 10^{-2}$ & $8.0 \times 10^{-4}$ & $1.1 \times 10^{-5}$ \\
\hline $\mathrm{Zr}-95$ & $6.0 \times 10^{-4}$ & $2.7 \times 10^{-3}$ & $2.5 \times 10^{-5}$ \\
\hline $\mathrm{Nb}-95$ & $5.0 \times 10^{-3}$ & $7.1 \times 10^{-6}$ & $1.6 \times 10^{-6}$ \\
\hline Ru-103 & $1.6 \times 10^{-5}$ & $4.3 \times 10^{-3}$ & $3.8 \times 10^{-5}$ \\
\hline Ru-106 & $2.0 \times 10^{-6}$ & $3.0 \times 10^{-5}$ & $2.9 \times 10^{-7}$ \\
\hline $\mathrm{Cd}-115 \mathrm{M}$ & $1.5 \times 10^{-5}$ & $4.4 \times 10^{-7}$ & $4.2 \times 10^{-9}$ \\
\hline Sn-125 & $3.5 \times 10^{-5}$ & $3.7 \times 10^{-5}$ & $2.3 \times 10^{-7}$ \\
\hline I-131 & $1.6 \times 10^{-3}$ & $7.5 \times 10^{-3}$ & $4.4 \times 10^{-5}$ \\
\hline Cs-137 & $1.5 \times 10^{-1}$ & $1.6 \times 10^{-5}$ & $1.5 \times 10^{-7}$ \\
\hline Ba-140 & $6.0 \times 10^{-4}$ & $1.4 \times 10^{-2}$ & $9.7 \times 10^{-5}$ \\
\hline $\mathrm{La}-140$ & $2.0 \times 10^{-4}$ & $3.5 \times 10^{-3}$ & $1.0 \times 10^{-4}$ \\
\hline Ct -141 & $9.0 \times 10^{-4}$ & $6.6 \times 10^{-3}$ & $6.2 \times 10^{-5}$ \\
\hline Ct-144 & $1.0 \times 10^{-4}$ & $6.2 \times 10^{-4}$ & $6.2 \times 10^{-6}$ \\
\hline
\end{tabular}

Another problem is introduced if the beach is of such a nature that the washup of particles can occur from material introduced in the near off-shore area. This, however, depends to an extremely sensitive degree on the nature of the shore area itself and upon the density of the reference core material. As a generalization, it is not possible to meaningfully treat this in detail. 
For RIFT flights directed along a ballistic trajectory into isolated ocean impact zones, radiation hazards should be minimal. On entry of the intact subcritical reactor or reactor fragments in these areas, the radiological problems, although not insignificant, would be relatively minor, provided that the waters were not heavily fished. On the other hand, entry of a reactor with an accompanying excursion on impact may create significant downwind exposures for distances upward of 100 miles, depending upon the distribution of material between the water and atmosphere. Since the area should be isolated, only personnel on tracking vessels need be considered, and these ships can be positioned upwind from impact.

Operational vehicles can present somewhat different problems. Although the obvious use of nuclear stages is for missions extending beyond the confines of the earth, the premature entry of a reactor with a few minutes of power history can create substantial problems.

A meaningful evaluation of potential safety problems for this case must await information currently being generated in the "source term" program described by Kraig in Paper V-5. However, a preliminary judgment of the severity of the problem to be solved, again in a pessimistic vein, can be gained by merely considering the magnitude of the fission-product inventory generated in 15 minutes of operation of the reference design described above, over 1 million megawatt-seconds. If fragments can return to earth promptly and retain their inventory, significant radiation hazards may be generated from external whole body and skin doses and from ingestion and inhalation of small fragments impacting on land.

As indicated previously, however, the loss of fission products from the graphite by diffusion and decay before earth impact and the spatial and temporal distribution of the fragments on the earth's surface can improve the outlook presented above by many orders of magnitude. Unger, Kraig, and King describe approaches currently under study for engineering solutions to the problem in Papers III-4, V-5, and III-2, respectively. Operationa11y, the problem can be resolved by restricting power operation to high orbits which incorporate within them sufficient decay time to eliminate such hazards in the event of malfunctions.

\section{Summary}

This paper has indicated some of the environmental safety aspects of nuclear rocket flight. This is a new application of nuclear energy, and it is not surprising that it has some new problems. These problems must be faced, examined in detail, and methods derived for limiting the hazards to acceptable levels, whether by inherent characteristics designed into the reactor, engineered safeguards, or operating procedures. It has been mentioned in earlier papers, for example, that work is in progress on a poison system which may obviate nuclear excursions at or near the launch site. Moreover, we must realize that we are in the early stages of development of nuclear rockets, and it is reasonable to expect restrictions for the first few flights which are not tolerable for repeated operational flights. It should be noted, for example, that the iodine and particle fallout problems for early flight conditions are of minimal consequence if the wind direction is out to sea. The radioactive contamination of the water around the launch site might require restrictions on the consumption of sea food for a week or even longer. Such a restriction is tolerable to consider for an improbable accident in the early stages of development.

The re-entry case is a somewhat more difficult problem or, at least it seems so at this stage of development. For RIFT flights, it presents no substantial public hazard by selection of the impact location. Engineered safeguards and operational controls are being studied for the operational situation also, but it is too soon to attempt to assess the magnitude of this hazard to the environment. 
Fortunately, the managers of the nuclear rocket program have had the wisdom to start the study of the safety problems and the possible impact of accidents on the environment at an early stage of the program. There is time to study them and devise safeguards, if necessary, so that nuclear rockets can be used without undue hazard to the public.

References

1. F. Pasqui11, "The Estimation of the Dispersion of Windborne Materia1," Meteorology Magazine, 90 (1063) 33-49 (February 1961).

2. F. E. Rom, A. F. Lietzke, and P. G. Johnson, "Nuclear Rockets for Unmanned Missions," Nucleonics 20, 11, 1962.

3. M. M. Levoy and J. J. Newgard, "Rocket Reactor Design," Nucleonics 16, 7 , 1958.

4. G. J. Hine and G. L. Browne11, Radiation Dosimetry, Academic Press, Inc.

5. Disposal of Radioactive Wastes in Pacific Coastal Waters, Publication 985, National Academy of Sciences - National Research Council, Washington, D. C., 1962 . 


\author{
THE SPACE ENVIRONMENT AND \\ ITS IMPLICATIONS FOR SPACECRAFT DESIGN* \\ J. B. Rittenhouse \\ F. J. Clauss \\ Lockheed Missiles and Space Company
}

Introduction

Special problems on the behavior of materials in outer space arise from both the absence and the presence of surrounding matter, that is, from vacuum and from particles in space. Although much information has been gained in the last few years on the nature of the space environment and the effect it has on materials, many gaps still remain in our knowledge. Yet, in order to design and build operating satellites, space probes, and manned space vehicles, engineering judgments must be made on the basis of existing information.

The space environment is not homogeneous. (The region of space considered extends from the minimum altitude of an earth satellite, out about 125 miles, to deep space.) The gas composition at an altitude of 125 miles is significantly different from that at a half-million miles. The micrometeoroid concentration will differ by a factor of $10^{4}$; the electron flux varies by a large factor over smal1 distances. Therefore, we can state that the space environment is a range of environments rather than a single one.

Vacuum Effects

One of the factors in the space environment that has received much attention is that of vacuum effects. The pressure at the earth's surface is about 10 ${ }^{3}$ torr; at 125 miles it is about $10^{-6}$ torr; at 4000 miles the pressure drops to $10^{-12}$ torr. The pressure in a good usable vacuum system on earth is about $10^{-5}$ to $10^{-7}$ torr, and the best vacuum ever achieved in small laboratory apparatus is about $10^{-12}$ torr. The gas temperature falls in the first 5 miles to very low values (about $-40^{\circ} \mathrm{C}$ ), but then it rises to around $1000^{\circ} \mathrm{C}$ at 125 miles. However, these gas temperatures in space have no significant effect upon the spacecraft because heat balance depends upon radiation received from the sun, earth, and moon, upon the heat generated by power supplies and other internal sources aboard the spacecraft, and upon the energy radiated by the spacecraft.

One obvious effect of the low gas pressure in space is the evaporation, or sublimation, of the more volatile constituents of components. Sufficient data are available on the vapor pressures of elements and simple inorganic compounds to permit a conservative approximation of the evaporization rates (conservative because the rates obtained in this manner are usually high). Table I presents such an approximation. The values for cadmium, however, have been verified in the laboratory.

\footnotetext{
*Presented by Mr. Rittenhouse
} 
TABLE I

Sublimation of Metals and Semiconductors in High Vacuum

\begin{tabular}{|c|c|c|c|c|c|c|}
\hline \multirow{2}{*}{ Sublimation Rate } & \multicolumn{2}{|c|}{$1000 \AA$ \&/year } & \multicolumn{2}{|c|}{$\begin{array}{c}10^{-3} \mathrm{~cm} / \text { year } \\
(0.0004 \text { in./year })\end{array}$} & \multicolumn{2}{|c|}{$\begin{array}{l}10^{-1} \mathrm{~cm} / \text { year } \\
(0.04 \mathrm{in} \text { / /year })\end{array}$} \\
\hline & ${ }^{\circ} \mathrm{F}$ & ${ }^{\circ} \mathrm{C}$ & ${ }^{\circ} \mathrm{F}$ & ${ }^{\circ} \mathrm{C}$ & ${ }^{\circ} \mathrm{F}$ & ${ }^{\circ} \mathrm{C}$ \\
\hline Cadmium & 100 & 40 & 170 & 80 & 250 & 120 \\
\hline Selenium & 120 & 50 & 180 & 80 & 240 & 120 \\
\hline Zinc & 160 & 70 & 260 & 130 & 350 & 180 \\
\hline Magnesium & 230 & 110 & 340 & 170 & 470 & 240 \\
\hline Te1lurium & 260 & 130 & 350 & 180 & 430 & 220 \\
\hline Antimony & 410 & 210 & 520 & 270 & 570 & 300 \\
\hline Bismuth & 470 & 240 & 600 & 320 & 750 & 400 \\
\hline Lead & 510 & 270 & 630 & 330 & 810 & 430 \\
\hline Indium & 760 & 400 & 940 & 500 & 1130 & 610 \\
\hline Silver & 890 & 480 & 1090 & 590 & 1300 & 700 \\
\hline Tin & 1020 & 550 & 1220 & 660 & 1480 & 800 \\
\hline Aluminum & 1020 & 550 & 1260 & 680 & 1490 & 810 \\
\hline Bery11ium & 1140 & 620 & 1300 & 700 & 1540 & 840 \\
\hline Copper & 1160 & 630 & 1400 & 760 & 1650 & 900 \\
\hline Gold & 1220 & 660 & 1480 & 800 & 1750 & 950 \\
\hline
\end{tabular}

It can be seen that such metals as cadmium and zinc, commonly used as platings, will sublime appreciably at temperatures (approximately $150^{\circ} \mathrm{F}$ ) 1ikely to be encountered by spacecraft. For this reason, cadmium-plated fasteners are not recommended for use in space applications. Selenium, sometimes used in photocells and rectifiers, also may sublime. Magnesium, used extensively for spacecraft structural components and electronic packaging, can lose around 0.0004 inch per year at about $340^{\circ} \mathrm{F}$ (an insignificant loss); at about $470^{\circ} \mathrm{F}$, its 1 oss may be as much as 0.040 inch per year, a loss which could be of structural significance. Other metals, like aluminum, and semiconductors, like silicon and germanium, will not lose amounts significant for structural considerations except at high temperatures.

Most polymeric compounds used in spacecraft degrade in vacuum, not by evaporation, but by scission into smaller fragments. Direct experimental measurements of weight loss of polymers have been used for data of their degradation behavior (Figures 101 and 102).

Plots of the time for a given weight loss of interest (say 10 percent per year) versus temperature are shown.

Commercial plastics are much more complex than pure polymers. Polymerizing catalysts, plasticizers, mold lubricants, etc., used to help fabrication and to modify mechanical properties, are sometimes detrimental to vacuum stability. Other factors that affect the vacuum stability of polymers are degradation inhibitors, antioxidants, and formulation and curing procedures. A11 of these influence the behavior of polymers. Trade names usually do not identify a particular polymer; they merely serve to identify the manufacturer.

In thicknesses up to 0.5 inch and in times up to 48 hours, weight loss does not depend upon surface area but rather upon total volume or weight. This indicates that the decomposition mechanism is the rate-limiting process in vacuum degradation rather than the diffusion of decomposition products through the solid. 


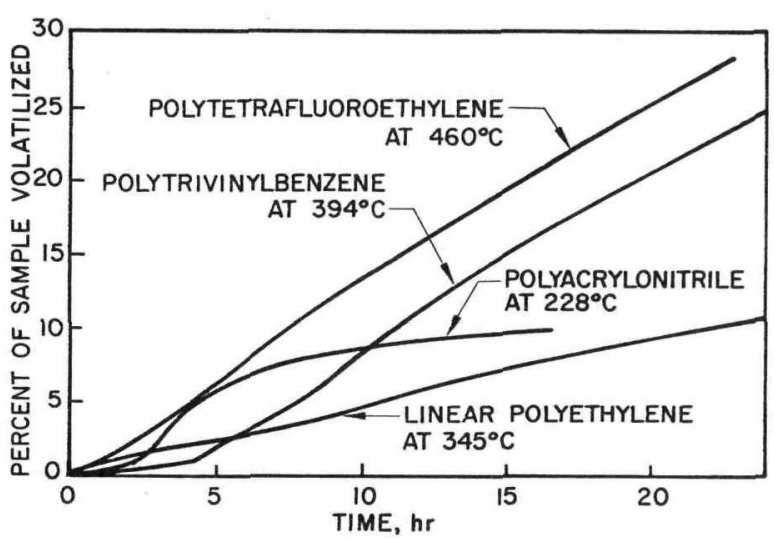

Figure 101. Typical curves for weight loss of polymers in vacuum as a function of time

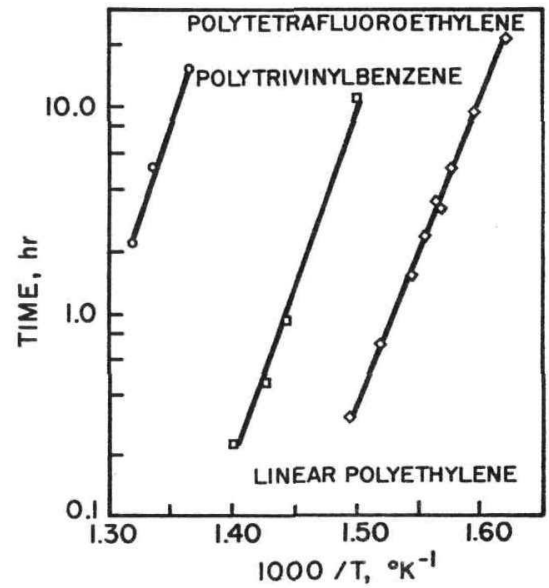

Figure 102. Time-temperature relation for 10 percent weight loss of polymer in vacuum

The temperatures given in Tables II and III for polymer degradation rates do not indicate the polymers' usable range for structural purposes. That is, the material may lose strength at a temperature lower than that at which it loses weight, and, through loss of strength, may be more limited in its applications.

One factor in favor of polymer and plastic stability in vacuum is the absence of oxygen for recombination. The upper limiting temperature for useful service in air is lower than the temperatures indicated in Tables II and III. These lower temperatures can, therefore, be used for conservative design in vacuum.

TABLE II

Decomposition of Polymers in High Vacuum

\begin{tabular}{|l|c|c|c|}
\hline \multirow{2}{*}{ Polymer } & \multicolumn{2}{|c|}{$\begin{array}{c}\text { Temp for } 10 \% \text { Wt } \\
\text { Los }\end{array}$} & \multirow{2}{*}{$\begin{array}{c}\text { Quality } \\
\text { of Data }\end{array}$} \\
\cline { 2 - 3 } & ${ }^{\circ}$ F & ${ }^{\circ}$ C & \\
\cline { 1 - 2 } $\begin{array}{l}\text { Isobutylene-isoprene } \\
\text { (buty1 rubber) }\end{array}$ & 250 & 120 & D \\
Melamine & 380 & 190 & E \\
Methy1 methacrylate & $220-390$ & $100-200$ & A \\
Methy1 pheny1 silicone & & & \\
$\quad$ resin & 710 & 380 & B \\
Nylon & $80-410$ & $30-210$ & A \\
Phenolic & $270-510$ & $130-270$ & B-D \\
Rubber, natural & 380 & 190 & B \\
Silicone elastomer & 400 & 200 & D \\
Styrene & $270-420$ & $130-220$ & A \\
TFE & 710 & 380 & A \\
Urethane & $150-300$ & $70-150$ & C \\
Vinyl chloride & 190 & 90 & A \\
\hline
\end{tabular}


TABLE III

Decomposition of Polymers in High Vacuum

\begin{tabular}{|c|c|c|c|}
\hline \multirow[t]{2}{*}{ Polymer } & \multicolumn{2}{|c|}{$\begin{array}{l}\text { Temp for } 10 \% \mathrm{Wt} \\
\text { Loss per Year }\end{array}$} & \multirow{2}{*}{$\begin{array}{l}\text { Quality } \\
\text { of Data }\end{array}$} \\
\hline & ${ }^{\circ} \mathrm{F}$ & ${ }^{\circ} \mathrm{C}$ & \\
\hline Acrylonitrile & 240 & 130 & A \\
\hline $\begin{array}{l}\text { Butadiene-acrylonitrile } \\
\text { (NBR rubber) }\end{array}$ & $300-450$ & $150-230$ & $B-D$ \\
\hline $\begin{array}{l}\text { Butadiene-styrene } \\
\quad(\text { SBR rubber) }\end{array}$ & 460 & 240 & B \\
\hline Cellulose & 350 & 180 & A \\
\hline Cellulose acetate & 370 & 190 & A \\
\hline $\begin{array}{l}\text { Cellulose acetate } \\
\text { butyrate }\end{array}$ & 340 & 170 & $\mathrm{C}$ \\
\hline Epoxy & $100-460$ & $40-240$ & $\mathrm{~B}-\mathrm{C}$ \\
\hline Ethylene, high density & 560 & 290 & A \\
\hline Ethylene, low density & $460-540$ & $240-280$ & $\mathrm{~A}$ \\
\hline $\begin{array}{l}\text { Ethylene terephthalage } \\
\text { (Mylar, dacron) }\end{array}$ & 400 & 200 & $\mathrm{~A}$ \\
\hline
\end{tabular}

We have a fairly extensive history of successful performance of polymeric materials in spacecraft. Epoxy-glass laminates are used for circuit boards and for the outer shells of the Transit and Anna satellites. In Pioneer III and IV, these laminates performed well for the battery lifetime of a few days. Phenolic-cloth bulkheads were used in Explorers I, III, and IV which transmitted for several months. Explorer VII had a polyester-glass laminate secondary structure. This satellite performed satisfactorily for over a year. The Echo balloon satellite was an 0.5-mil-thick aluminized Mylar film. This satellite also performed we11 for over a year. Silicone-based paints are used for temperature-control purposes on the external surfaces of spacecraft. These are but a few of the many examples of satisfactory applications based on sound engineering judgment of polymeric materials in operating spacecraft.

One problem resulting from the absence of an atmosphere is that of friction and wear of rubbing or sliding surfaces in contact. Operating mechanisms in spacecraft require bearings, gears, and sliding electrical contacts. Lubrication is needed to reduce friction and thereby minimize the power required to drive the mechanisms. Without an atmosphere for heat transfer by convection, radiation and conduction across point contacts are the only means for dissipating heat in a mechanism. Thus, increased friction and the consequent overheating can cause seizure of moving parts. In the environment of the earth's atmosphere, exposed solid surfaces quickly absorb films of oxygen and water vapor. These films tend to keep clean metal surfaces apart just as oils and greases separate clean metal surfaces in boundary lubrication. These absorbed layers, once removed by wear or evaporation in the high vacuum of space, will not be re-established. Thus the clean metal surfaces in contact have been known to weld together, and increasing friction of rubbing or sliding parts have caused seizure.

Low-vapor-pressure petroleum-, ester-, and silicone-based oils and greases have been used successfully with 440C stainless steel R-3-type ball bearings in vacuum tests at pressures of $10^{-6}$ to $10^{-7}$ torr for several thousand hours (Table IV). In order to prevent loss of oil by evaporation and to minimize the tendency of oils to creep over clean metal surfaces in vacuum, the best design would be based on a vacuum-tight seal around moving parts. This consideration is probably not desirable, or even possible for all applications. However, shielded bearings with proper clearances and selected lubricants have performed satisfactorily both in tests and 
in space. A diester oil, for example, was used in the shielded ball bearings in the tape recorder in Explorer III. A similar oil was used successfully for several months in the radiometer ball bearings in Tiros II. Close shaft clearances and sintered nylon sleeves impregnated with oil used directed capillary flow to provide adequate passage of oil to the places where it was needed. This was accomplished by good mechanical design. Good design is probably just as important as the selection of materials in solving lubrication problems in space.

TABLE IV

Bearing Tests in Vacuum of Several Lubricants

\begin{tabular}{|c|c|c|c|c|}
\hline \multicolumn{5}{|c|}{ Performance in vacuum at $180^{\circ} \mathrm{F}$} \\
\hline Type & $\begin{array}{l}\text { Number } \\
\text { Tested }\end{array}$ & Material & Lifetime hr & Remarks \\
\hline Oi1 & 21 & $\begin{array}{l}\text { Apiezon K } \\
\text { Versilube F50 }\end{array}$ & $\begin{array}{l}18297(\mathrm{SR})^{\mathrm{a}} \\
13652\end{array}$ & High torque failed \\
\hline Grease & 11 & $\begin{array}{l}\text { Versilube G300 } \\
\text { Versilube G300 } \\
\text { Versilube G300 }\end{array}$ & $\begin{array}{l}8255 \text { (SR) } \\
8244 \quad(\mathrm{SR}) \\
4352\end{array}$ & $\begin{array}{l}\text { Temp } 220-230^{\circ} \mathrm{F} \\
\text { Failed temp } 300^{\circ} \mathrm{F}\end{array}$ \\
\hline $\begin{array}{l}\text { Molybdenum } \\
\text { disulfide }\end{array}$ & 7 & $\begin{array}{l}\text { Everlube } 811 \\
\text { Hi-T-Lube }\end{array}$ & $\begin{array}{l}2213 \\
1533\end{array}$ & $\begin{array}{l}\text { Data scattered life- } \\
\text { times are reduced by } \\
\text { start-stop-reverse }\end{array}$ \\
\hline Metal & 1 & Silver & 2600 & \\
\hline Teflon & 2 & $\begin{array}{l}\text { Duroid } 5813 \\
\text { Rulong }\end{array}$ & $\begin{array}{l}5110 \\
2699\end{array}$ & $\begin{array}{l}\text { Lifetimes reduced by } \\
\text { high loads and stop- } \\
\text { start-reverse }\end{array}$ \\
\hline Misc. & 7 & Sinitex & 2727 & \\
\hline
\end{tabular}

Solid lubricants such as laminar solids and thin, soft-metal films have been considered as solutions to the problem of loss of liquid lubricants in space vacuum. Moreover, these materials are not as susceptible to radiation damage as organic lubricants. One problem exists, however. These materials have a finite thickness and after wearing away cannot be resupplied in space. Laminar solid molybdenum disulfide has been used in many applications. However, problems of bonding the material to the substrate, establishing exact clearances in bearings to account for the finite thickness of the surface layer of the material, and consequent run-in requirements (along with the wear-away of the layer, and resultant lack of an adequate method of unattended resupply) can limit the usefulness of molybdenum disulfide coatings. With the correct finish and treatment of the underlying surface, clearances, and run-in periods, up to 2000 hours of running time $(10,000 \mathrm{rpm}$, $\left.150^{\circ} \mathrm{F}\right)$ have been obtained in vacuum $\left(10^{-6}\right.$ to $10^{-7}$ torr). The film thickness, particle size, and bonding of the molybdenum disulfide coatings must be done under carefully controlled conditions. Usually, in the case of ball bearings, the molybdenum disulfide is applied to the ribbon-metal ball retainers, or else synthanetype retainers are impregnated with it. Sodium silicate bonded films appear to provide longer lifetimes than epoxy, phenolic, or ceramic-bonded types.

Bearing testers have been flown on spacecraft. A friction experiment was conducted on Ranger I and Ranger II spacecraft; and, although neither achieved its highly eccentric orbit but became low-altitude, short-lived earth satellites, some data from the friction experiment were obtained. Meaningful data were obtained from Ranger I flight. Friction in space was, in general, only slightly higher than in laboratory vacuum. At the altitude of Ranger $I$, the vacuum was of the order of $10^{-8}$ torr. 
Sliding electrical contacts usually consist of noble-metal sliders on plated silver or copper slip rings. Sometimes silver-impregnated graphite sliders are used. These devices are used in electromechanical commutators, switches, timers, etc. Fortunately, in some applications they can be sealed. Table V shows some vacuum tests on typical slip-ring materials and the results of introducing just a film of oil on the electrical noise produced.

\section{TABLE V}

Electrical Noise Behavior of

Meta1-to-Meta1 Contacts in Vacuum

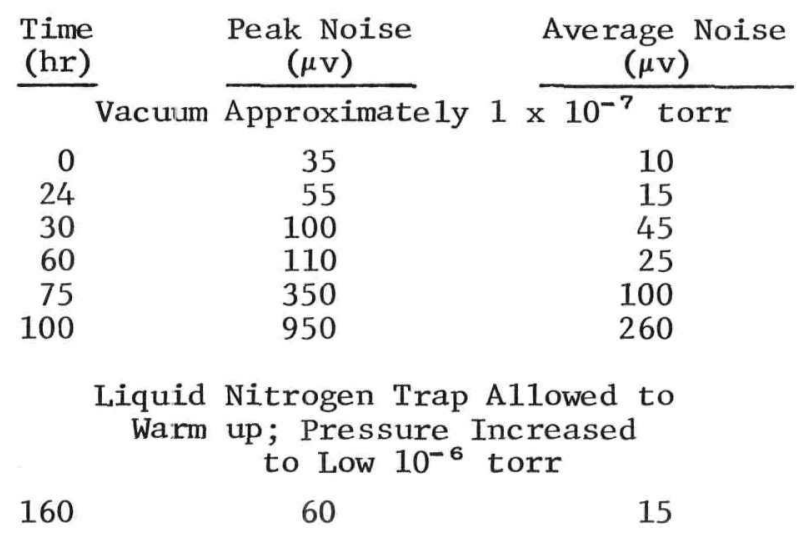

Vacuum Re-established at Approximate1y $1 \times 10^{-7}$ torr

$\begin{array}{rrr}170 & 90 & 65 \\ 190 & 100 & 60 \\ 215 & 250 & 50\end{array}$

Brushes -- Formed ribbon, 0.008-inch thick $\times 0.020$-inch wide, of Paliney 7 alloy

Rings -- Fine silver with gold overlay

Brush pressure -- 3 grams

Sliding velocity - 51 inches per minute

Brush current -30 milliamps

Vacuum $\quad-2 \times 10^{-7}$ to $8 \times 10^{-8}$ torr, produced by a diffusion pump using Dow-Corning No. 704 silicone fluid; system provided with a liquid nitrogen trap.

\section{Radiation Effects}

Radiation damages metals and semiconductors when the impinging charged particle displaces atoms in the target material. Damage to organic materials occurs primarily by ionization. Inorganic insulator materials may be affected by both displacement and ionization. (The mechanisms of radiation damage are of course very complex and this account is considerably oversimplified.)

It is doubtful that cosmic radiation, protons, and light and heavy nuclei originating from the galaxies will cause radiation damage in spacecraft. Similarly, away from earth, little damage will be caused by sputtering (incident ions and gas atoms may erode a thickness of about $10^{-8}$ centimeter per year off exposed surfaces).

The sun is the primary source of electromagnetic radiation in the solar system. At 1 astronomical unit, the total solar electromagnetic energy flux is 
0.140 watt $/ \mathrm{cm}^{2}$. Approximately 50 percent of the energy of sun1ight 1ies in the infrared and radiofrequency regions, 40 percent in the visible ( $4000 \AA$ to $7000 \AA$ ) and 10 percent in the ultraviolet and X-ray spectral regions (Figure 103). Most of the ultraviolet $f 1 u x$ is at about $3000 \AA$ to $4000 \AA$; about 1 percent of the total energy is below $3000 \AA$. At the orbit of Venus, the intensity of solar radiation wil1 be 1.9 times that at earth; at Mars, it will be about 0.4 of the intensity of earth. The threshold for atomic displacement by photons (electromagnetic radiation) is above $100 \mathrm{kev}$ corresponding to wavelengths below $10^{-1} \AA$ (X-rays). The threshold for ionization is from 12 to. $25 \mathrm{ev}$, which corresponds to wavelengths of $1000 \AA$ to $500 \AA$. Sunlight above $3000 \AA$ is not likely to damage engineering materials, since materials that cannot withstand sunlight on earth are not of engineering interest. Incident electromagnetic radiation can affect the properties of a material only if it is absorbed by the material; for major changes to occur, it must be strongly absorbed, giving a high dose rate per gram. This strong absorption means that the radiation will probably penetrate the material only shallowly. Accordingly, changes in materials induced by electromagnetic radiation in space are primarily to spacecraft external surfaces and coatings and to exposed optical surfaces.
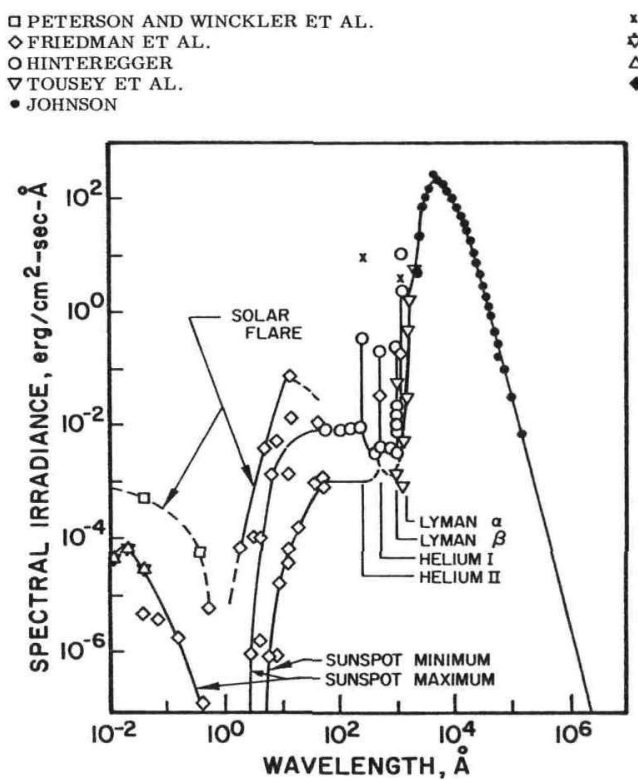

Figure 103. Solar spectra
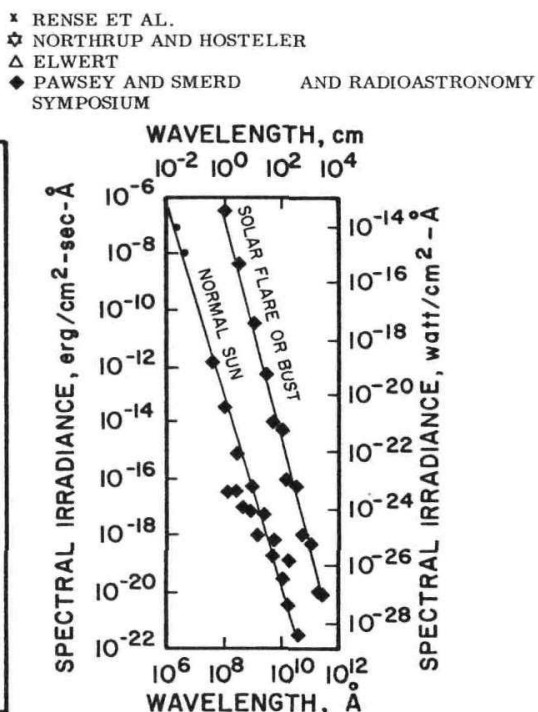

Electromagnetic radiation in the $100 \AA$ to $1000 \AA$ spectral region (short ultraviolet) of intensity $10^{8} \mathrm{erg} / \mathrm{cm}^{2}$-year produces an ionization dose of $10^{12}$ to $10^{15}$ erg/gm-year, which can seriously damage insulating materials. Increased optical absorption and surface electrical conductivity may also be produced. Changes in dimensions and mechanical properties of materials will be confined to a thin surface layer and, therefore, will not be too important.

The flux of solar radiation from $1000 \AA$ to $3000 \AA$ (1ong ultraviolet) is $5 \times 10^{21} \mathrm{erg} / \mathrm{cm}^{2}$-year and does not produce damage in metals or semiconductors. Damage to insulators can result from the formation of color centers.

Irradiation of polymers by ultraviolet above $1000 \AA$ can cause darkening and cross-linking, and, consequently, embrittlement. At exposures corresponding to about 14 days in space, plastics like polyethylene, Mylar, vinyl, and Teflon have discolored and lost much of their strength, elongation, and flexibility. 
Most glasses are sensitive to discoloration and consequent los of optical transmission when exposed to radiation in space. This discoloring can be minimized by using high-purity fused silica or sapphire. Sapphire solar-cell covers were used on Telstar I and II, and on Anna IB solar-array test panels.

The damage to materials is commonly expressed as the weight of material per unit area through which atomic particles penetrate. In the inner radiation belt (Figure 104), the engineering properties of organic and semiconductor materials, and the optical transmission properties of inorganic insulators may be damaged in less than a year to a depth of $1 \mathrm{mg} / \mathrm{cm}^{2}$. As an example, Transit 4B suffered a 7-percent power degradation in 55 days in a 700-mile orbit. It was estimated that a total flux of $8 \times 10^{10}$ protons $/ \mathrm{cm}^{2}$ with an energy of greater than 4 mev was experienced by the $\mathrm{p}$ on $\mathrm{n}$ silicon solar cells covered with 0.006 -inch glass and $420 \mu$ filter.

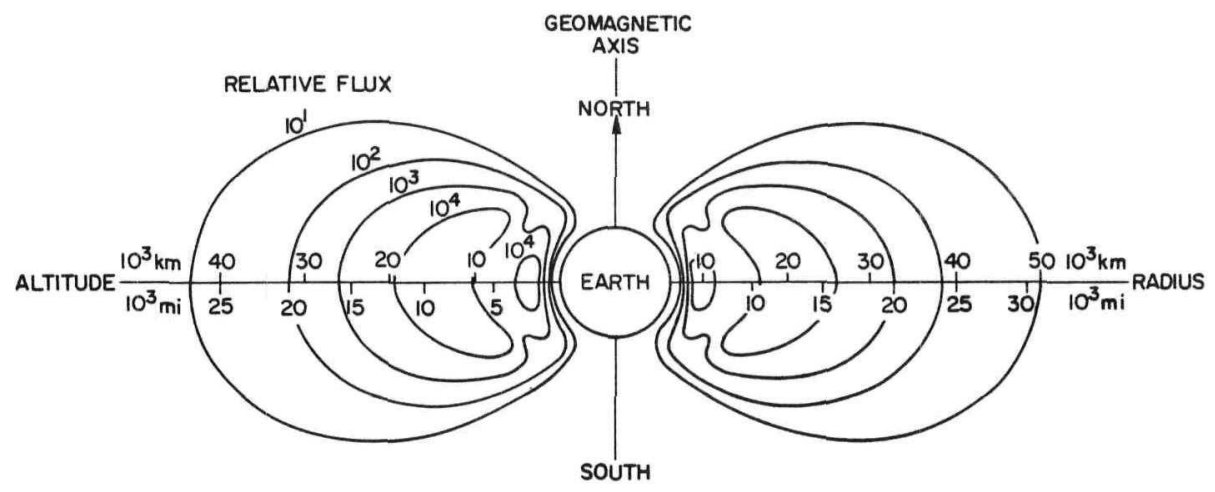

Figure 104. Contours of constant integrated flux in the Van Allen trapped radiation belts

In the outer radiation belt, the properties of organic and optical materials will be affected within a year to a depth of $1 \mathrm{mg} / \mathrm{cm}^{2}$. The minority carrier properties of semiconductors, and the electrical and mechanical properties of inorganic insulators will be affected; metals will not be changed. Explorer VI, after 18 days in an orbit of apogee 26,500 miles and perigee 130 miles, experienced a total flux of $7.5 \times 10^{13}$ electrons $/ \mathrm{cm}^{2}$ with energies greater than $200 \mathrm{kev}$. A 27 -percent power degradation in the $\mathrm{p}$ on $\mathrm{n}$ silicon solar cells without glass covers was reported.

It is wel1 known that Telstar I experienced some solar-cel1 power degradation after the high-altitude nuclear test (Starfish) of July 9, 1962, (Figure 105) which created an artificial intensification of the inner magnetosphere. The flux was about $10^{23}$ electrons $/ \mathrm{cm}^{2}$; the energy was about $1.5 \mathrm{mev}$. Transit and TRAAC showed a power degradation of 17 percent 9 days after the test and each ceased transmission because of degradation of the solar cells on August 2 and August 5, 1962, respectively.

Similarly, the orbiting solar observatory (OSO) spacecraft suffered considerable degradation of power output after the series of high-altitude nuclear tests.

Beyond the radiation belts, the steady and flare emissions of the sun are predominant. During solar flares, bursts of protons having energies of 1 mev to 10 bev with total fluxes of $5 \times 10^{7}$ to $3 \times 10^{10}$ protons $/ \mathrm{cm}^{2}$ are emitted, and electron intensity reaches its peak in the solar plasma. The solar steady emission is probably composed of low-energy protons and electrons. 


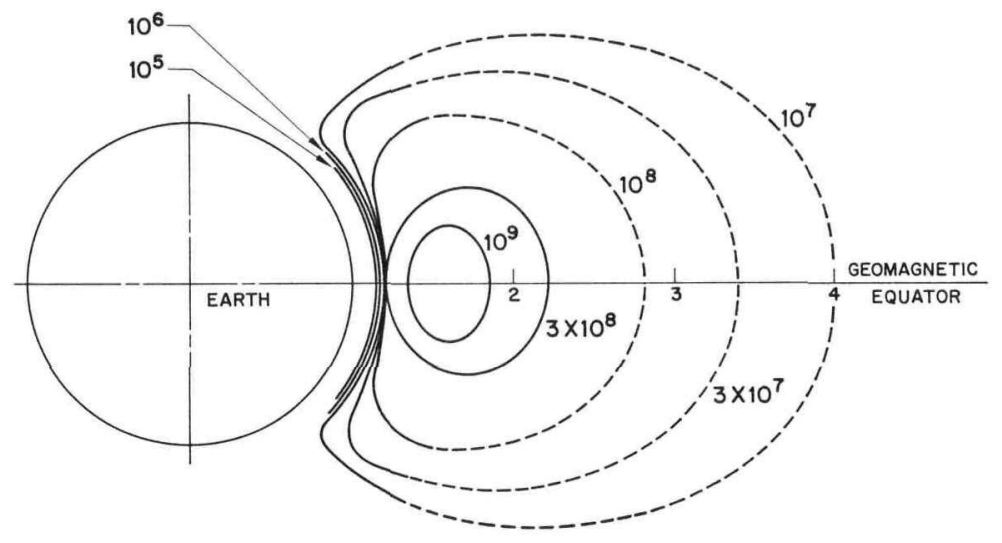

Figure 105. Contours of constant flux (electrons $/ \mathrm{cm}^{2}-\mathrm{sec}$ ) of artificial (Starfish) electrons having energies greater than 0 mev. Dashed lines indicate extrapolations; radial distance is in earth radii (= 3440 nautical miles)

Material of $1 \mathrm{mg} / \mathrm{cm}^{2}$ will shield out most low-energy particles. Through this thickness the minority carrier properties of the more sensitive semiconductors, optical transmission of some glasses, and the properties of the more sensitive polymers will be affected. During solar flares, the electrical conductivity of insulators will increase temporarily.

In Explorer XII, after three days at an apogee of 48,000 miles, the unprotected $\mathrm{p}$ on $\mathrm{n}$ silicon solar cells suffered a 50-percent power degradation. Ce11s with 0.006 -inch, 0.003 -inch, and 0.020 -inch glass covers experienced no power degradation. The solar proton flux was $5.4 \times 10^{18} \mathrm{p} / \mathrm{cm}^{2}$ with energies of $120 \mathrm{kev}$ to $4.5 \mathrm{mev}$.

Recently data from Anna 1B have shown that $n$ on $p$ silicon solar cells are more radiation resistant than $p$ on $n$ types. Summaries of radiation effects on materials are shown in Tables VI and VII. 
TABLE VI

Radiation Dosages: Ionization and Displacement Produced by Atomic Particles in Space

\begin{tabular}{|c|c|c|}
\hline Radiation & $\begin{array}{l}\text { Energy } \\
(\mathrm{ev})\end{array}$ & $\begin{array}{c}\text { Range } \\
\left(\mathrm{gm} / \mathrm{cm}^{2}\right)\end{array}$ \\
\hline $\begin{array}{l}\text { Inner radiation belt } \\
\text { Protons } \\
\text { Electrons } \\
\text { Bremsstrahlung }\end{array}$ & $\begin{array}{l}10^{3}\left(\text { ?) to } 7 \times 10^{8}\right. \\
<2 \times 10^{4} \text { to } 1 \times 10^{6} \\
<2 \times 10^{4} \text { to } 1 \times 10^{6}\end{array}$ & $\begin{array}{l}10^{-6}(?) \text { to } 10^{3} \\
10^{-3} \text { to } 10^{\circ} \\
10^{-1} \text { to } 10^{1}\end{array}$ \\
\hline $\begin{array}{l}\text { Outer radiation be } 1 t \\
\text { Electrons } \\
\text { Bremsstrahlung }\end{array}$ & $\begin{array}{lllll}2 \times 10^{4} & \text { to } 5 \times 10^{6} \\
2 \times 10^{4} & \text { to } 5 \times 10^{6}\end{array}$ & $\begin{array}{ll}10^{-3} & \text { to } 10^{\circ} \\
10^{-1} & \text { to } 10^{1}\end{array}$ \\
\hline $\begin{array}{l}\text { Solar-flare high-energy particles } \\
\text { Protons } \\
\text { Electrons } \\
\text { Bremsstrahlung }\end{array}$ & $\begin{aligned} 2 \times 10^{7} & \text { to } 10^{9} \\
\sim & 5 \times 10^{4} \\
\sim & 5 \times 10^{4}\end{aligned}$ & $\begin{array}{l}10^{\circ} \text { to } 10^{3} \\
10^{-2} \\
10^{\circ} \text { to } 10^{1}\end{array}$ \\
\hline $\begin{array}{l}\text { Solar-flare low-energy particles } \\
\text { Protons } \\
\text { Electrons } \\
\text { Bremsstrahlung }\end{array}$ & $\begin{array}{l}5 \times 10^{2} \text { to } 2 \times 10^{4} \\
2 \times 10^{-1} \text { to } 10^{1} \\
2 \times 10^{-1} \text { to } 10^{1}\end{array}$ & $\begin{array}{l}10^{-6}(?) \text { to } 10^{-5}(?) \\
10^{-8} \\
10^{-6}(?) \text { to } 10^{3}\end{array}$ \\
\hline $\begin{array}{l}\text { Steady solar emission } \\
\text { Protons } \\
\text { Electrons } \\
\text { Bremsstrahlung }\end{array}$ & $\begin{array}{l}10^{\circ} \text { to } 10^{3} \\
10^{\circ} \\
10^{\circ}\end{array}$ & $\begin{array}{l}10^{-8} \text { to } 10^{-6}(?) \\
10^{-8} \\
10^{-7}\end{array}$ \\
\hline $\begin{array}{c}\text { Cosmic rays } \\
\text { Protons }\end{array}$ & $10^{8}$ to $10^{19}$ & $>10^{-1}$ \\
\hline
\end{tabular}

TABLE VII

Radiation Leve1s That Produce Appreciable Property Changes

\begin{tabular}{|c|c|c|c|}
\hline Materia1 & $\begin{array}{c}\text { Properties or } \\
\text { Characteristics Measured }\end{array}$ & $\begin{array}{l}\text { Ionization } \\
\text { (ergs/gm) }\end{array}$ & $\begin{array}{l}\text { Fraction } \\
\text { of Atoms } \\
\text { Displaced }\end{array}$ \\
\hline $\begin{array}{r}\text { Ceramics } \\
\text { Glass }\end{array}$ & $\begin{array}{l}\text { Optical transmission } \\
\text { Dimensions, mech. properties } \\
\text { Electrical }\end{array}$ & $\begin{array}{l}10^{5} \\
10^{-11} 10^{10} \\
10^{11}\end{array}$ & $\begin{array}{l}10^{-31}-10^{-7} \\
10^{-7}-70^{-7}-10^{-6}\end{array}$ \\
\hline Fused silica & Optical transmission & $10^{7}-10^{11}$ & $10^{-9}-10^{-5}$ \\
\hline Crystalline ceramics & $\begin{array}{l}\text { Optical transmission } \\
\text { Dimensions, mech. properties } \\
\text { Electrical }\end{array}$ & $\begin{array}{l}10^{-5}-10^{11} \\
10^{11} \\
10^{11}\end{array}$ & $\begin{array}{l}-10^{-4} \\
-10^{-1} \\
-10^{-1}\end{array}$ \\
\hline Elastomers & Mechanical & $10^{8}-10^{10}$ & -- \\
\hline Meta1s & $\begin{array}{l}\text { Ferromagnetism } \\
\text { Mechanical } \\
\text { Electrical }\end{array}$ & $\begin{array}{l}-- \\
-- \\
--\end{array}$ & $\begin{array}{l}10^{-6}-10^{-5} \\
10^{-4}-10^{-3} \\
10^{-3}-10^{-2}\end{array}$ \\
\hline Oils and greases & Lubrication, consistency & $10^{9}-10^{12}$ & -- \\
\hline $\begin{array}{l}\text { Plastics } \\
\quad \text { Tetrafluoroethylene }\end{array}$ & $\begin{array}{l}\text { Mech., elec. in air } \\
\text { Mech., elec. in air-free atm }\end{array}$ & $\begin{array}{l}10^{6}-10^{7} \\
10^{7}-10^{9}\end{array}$ & -- \\
\hline Other plastics & $\begin{array}{l}\text { Optical transmission } \\
\text { Dimensions, mech. elec. }\end{array}$ & $\begin{array}{l}10^{6}-10^{11} \\
10^{7}-10^{11}\end{array}$ & -- \\
\hline Semiconductor materials & $\begin{array}{l}\text { Minority carrier effects } \\
\text { Majority carrier effects }\end{array}$ & -- & $\begin{array}{l}10^{-12}-10^{-10} \\
10^{-9}-10^{-6}\end{array}$ \\
\hline
\end{tabular}


The earth is surrounded by a cloud of meteoritic dust which extends beyond the moon. The density of these particles is high close to earth and diminishes away from earth. At low satellite altitudes, material lost by meteoritic erosion will be about $200 \AA$ per year. Erosion will be in the form of sma11 hemispherical pits about 10 mils (or less) in diameter. In brittle materials like glass and some plastics, each pit will be surrounded by cracks or by a splintered crater several times the pit diameter.

Figure 106 shows the meteoritic flux versus their mass, as found by several investigators; in addition, Figure 106 indicates that the flux decreases with mass. Furthermore, the chance for a large meteorite to strike a spacecraft near earth is sma11. Their velocities relative to those of a spacecraft, and usually in the same direction as earth, are about $20 \mathrm{~km} / \mathrm{sec}$, although occasionally velocities are as high as $72 \mathrm{~km} / \mathrm{sec}$.

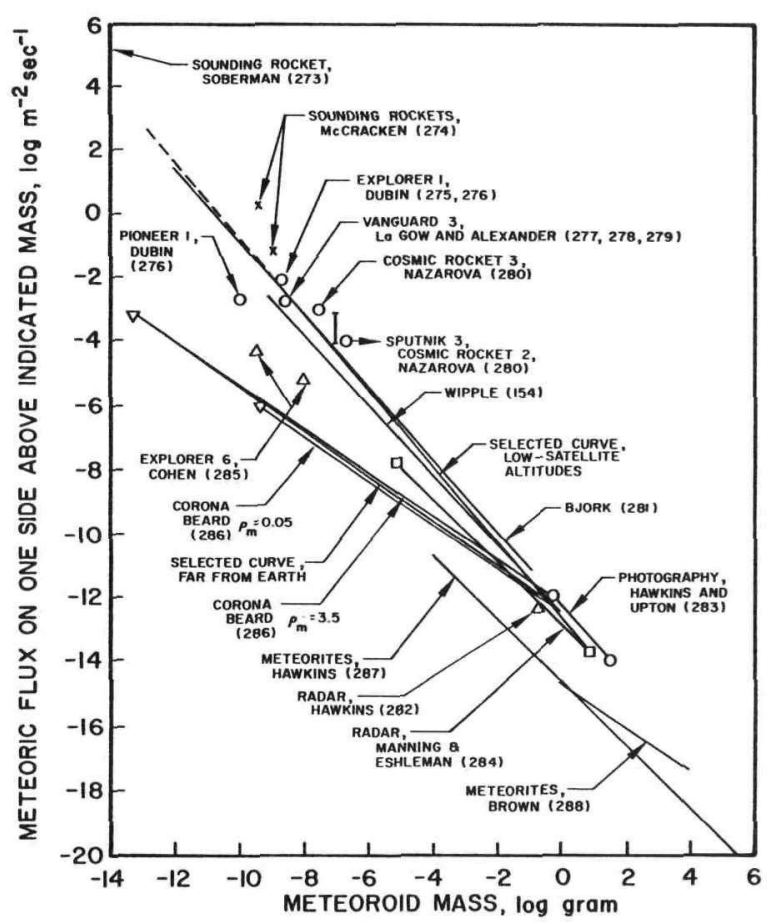

Figure 106. Meteoric flux in vicinity of earth's orbit

The estimated frequency of perforation of iron and aluminum sheet by meteoroids is shown in Figure 107. The next figure (Figure 108) shows the estimated frequency of spalling, or back surface fracturing after impact.

When a meteoroid with its high velocity strikes a plate, both the meteoroid and the plate behave hydrodynamically so that a strong compressive shock, starting at the outer surface, is reflected off the inside surface as a tensile stress which causes pieces of the inside surface to be ejected at high velocity. Spalled areas (Figure 108) are greater by about a factor of 3 than the size of the perforation, and the thickness in which spalling will occur will be two or three times greater than thicknesses which are adequate to prevent perforation. 


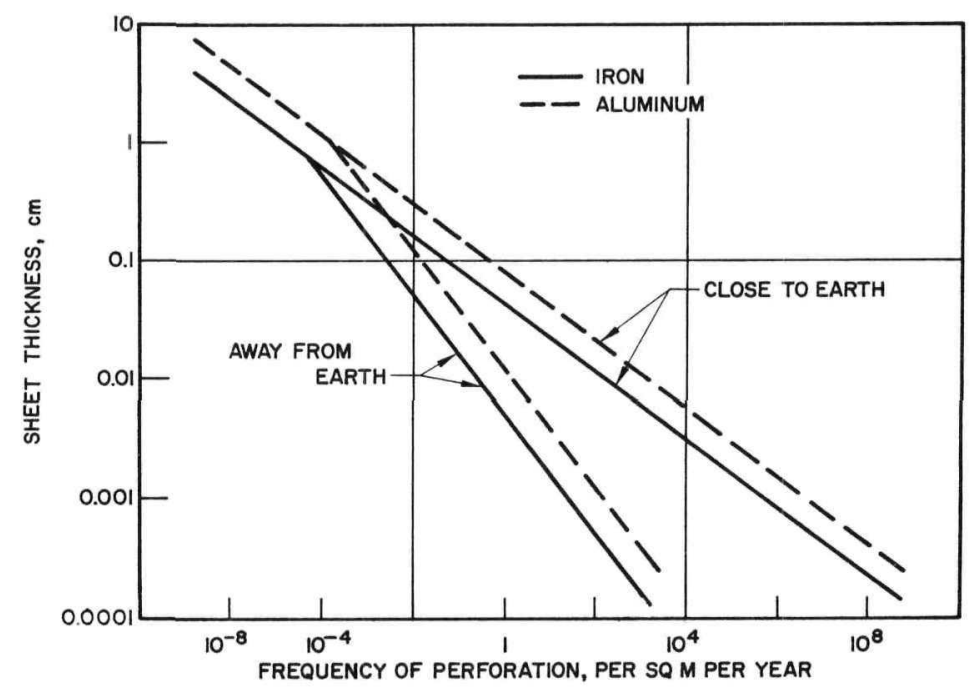

Figure 107. Frequency of perforation of metals by meteoroids

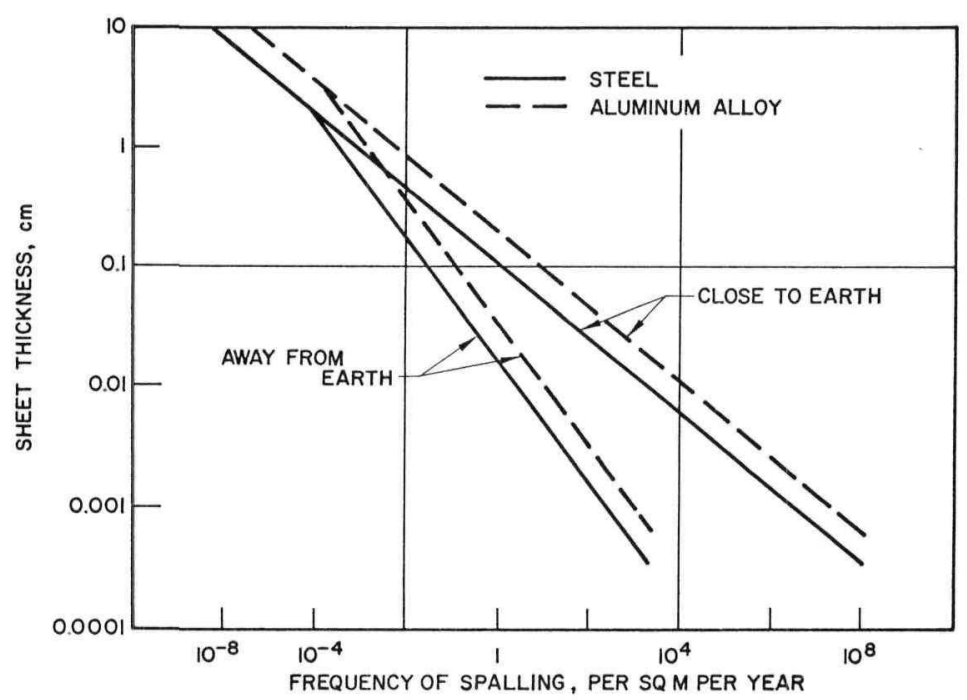

Figure 108. Frequency of spalling of metals by meteoroids

Meteoroid damage can be reduced by as much as $2 / 3$ by using a thin wall spaced in front of the main wall. This thin wall shatters the impinging meteoroid, thus absorbing some of its kinetic energy so that a smaller particle strikes the main wa11. Impact is thus reduced. The space armor, or bumper, should be thin (about 1 percent of the main wa11) and spaced out about 12 times the main wal1 thickness to reduce weight and to provide effective protection to the spacecraft skin. 
We have attempted to give a review of the space environment and its implications upon spacecraft design. It is obvious that the space environment is complex; thus it can be inferred that its effects on materials of spacecraft construction will be complex. We have treated each phase of the environment and its effects, in most cases, singly with only limited reference to the combined environment. In most instances these have dealt primarily with laboratory simulation studies which at best only give indications of the expected behavior in space. The final criterion and goal of the spacecraft designer is to achieve long-term reliable operation in space. The present plans place stringent demands for reliable, man-rated operating lifetimes of at least a year on spacecraft design. Only through a thorough study of the behavior of materials actually used in successful space flights coordinated with we11-conceived laboratory simulation tests and studies on the physics of failure modes can these reliable spacecraft designs be achieved.

\section{References}

L. D. Jaffee and J. B. Rittenhouse, "Behavior of Materials in Space Environments," ARS J, March 1962.

C. G. Geotze1 and J. B. Singleton, Editors, Space Materials Handbook, Lockheed Missiles and Space Company, Air Force Contract AF 04(647) -673, January 1962.

F. J. Clauss, Lubrication Under Space/Vacuum Conditions, Lockheed Missiles and Space Company, Tech. Report 5-10-62-47, October 1962, Air Force Contract AF 04 (647) -727. 


\section{BLANK}




\author{
Supplementary Paper* \\ OFF-SITE RADIOLOGICAL MONITORING PROCEDURES \\ FOR MISSILE TEST RANGES \\ M. W. Carter \\ R. D. Coleman \\ D. J. Ne1son, Jr. \\ Division of Radiological Health \\ U. S. Public Health Service
}

Introduction

Public health considerations in the launch of aerospace systems which carry radioactive material either in the form of radionuclides or in the form of fissionable material dictate the need for an extensive and comprehensive off-site radiological health and safety program at each launch complex. In cooperation with state and local health agencies and responsible Federal agencies at the launch sites, the Public Health Service through its Division of Radiological Health Laboratories at Las Vegas, Nevada, and Montgomery, Alabama, has established surveillance programs on environmental radioactivity at the Pacific Missile Range (PMR) and Atlantic Missile Range (AMR), respectively. These operational surveillance programs are designated as the Off-Site Radiological Safety Program (OSRSP). The objectives of this program may be summarized in three broad categories: surveillance, liaison, and emergency capabilities.

\title{
Surveillance
}

The first objective of the OSRSP is to measure and document environmental radiation levels in the off-site area before and following launches employing nuclear power or propulsion devices. These records also provide a basis for planning and implementing any necessary countermeasures and for a sound and effective public information program. To attain this objective, trained Public Health Service teams are stationed in the off-site area during launches where the source material is an important component. These teams are available for consultation and advice on radiological safety. The techniques they use in surveillance are as follows.

1. A ground survey is conducted using portable radiation monitoring instruments, as determined by conditions in the off-site area. However, monitoring teams are prepared to go beyond the off-site boundaries if necessary.

2. Air sampling for radioactivity is conducted in populated offsite areas. Each sample generally represents a 24 -hour collection period. Whenever possible these stations are operated at selected governmental installations or health departments or on mobile units. Where such facilities are not available, services of other local government officials are solicited. If an incident occurred, aerial monitoring would be performed.

\footnotetext{
*Because of the number of papers to be presented, the following paper could not be included among the formal presentations. However, the importance of the subject has led to its inclusion in these Proceedings.
} 
3. Water, milk, foodstuffs, crop, and vegetation samples are collected from selected locations in the off-site area; the type depends on local conditions. Soil samples are collected where vegetation is not present.

4. Laboratory and ancillary support for processing and analyzing the various environmental samples for radioactivity is provided by the PHS laboratory facilities augmented with equipment and personne1.

5. Data from existing environmental sampling networks operated by the PHS, such as the Radiation Surveillance Network, are transmitted by telephone to the off-site area to complement local measurements. During operational periods, environmental sampling is also coordinated with existing similar state or local programs.

6. Personnel specializing in medical and other radiological health fields are available for use as required. The personnel who conduct the sampling and monitoring are trained in similar test activities and in the public relations aspects of such tests.

The radiological safety equipment supplied and used by the PHS in this program consists of the following: (1) Mobile land monitoring units including highvolume air samplers with millipore filters, survey meters capable of measuring alpha and low-energy gamma radiation, sample containers and devices, shipping cartons, and necessary supplies for complete documentation and identification of field activities. These units are used primarily during the launching period; however, the same types of equipment are also used singly or in combination for emergency monitoring and for background monitoring such as air, water, and vegetation sampling at selected locations before and after the launch. (2) Aerial monitoring units: two $\mathrm{C}-45^{\prime} \mathrm{s}$, light aircraft which have been adapted to the collection and rapid field analysis of samples of airborne gaseous releases resulting from an incident during a launch. And, (3) a radiochemistry trailer unit, used to supplement the laboratory facilities and especially to provide a means for determining quickly the approximate radiation levels in the field, contains the equipment necessary for rapid radioanalysis of environmental samples. The aerial and trailer units are presently available for use during the program at PMR; the other equipment is used at both missile ranges.

\section{Liaison}

A second objective is to maintain close cooperation and liaison between the AMR, PMR, and pertinent public health officials at the local, state, and Federal levels and to assure the public that all reasonable steps are being taken to protect it. Consultation on radiological safety matters is also provided to on-site safety groups.

Public Relations -- To conduct such a program properly, the OSRSP maintains flexibility in dealing with pertinent state and local health officials and with the public. Experience has strongly indicated the need and desirability of adequately informing the public of the steps which are being taken in the health and safety field. Within security and public relations criteria, the PHS conducts the offsite field surveillance in an unclassified manner and as inconspicuously as possible, describes and discusses its program with a11 interested groups and individuals, and solicits their active support of the program. In all cases, specific questions from the public are answered as concisely and accurately as possible. Should an accident or contamination occur which would require additional sampling or restriction of certain civilian activities, the need would be presented on a scientific and precautionary basis.

State Relationships -- Close cooperation and liaison is maintained with principal state and local health officials and between these officials and other Federal 
agencies; these officials are kept informed of the PHS activities within the state. This includes prompt information following each event and, if it appears an area will be affected, the steps underway to handle the situation. In addition results of this program are made available to interested official health agencies and their personne1.

\section{Emergency Capability}

The third objective is to maintain an emergency capability should an emergency occur. In a true emergency, additional personnel and equipment are available within a few hours. A more likely problem is that of intense public concern rather than an emergency. This situation is not predictable but can be adequately covered by personnel and equipment located within the off-site area.

Off-site contamination could occur in the launch sequence or in early ascent phases. In cases of a suspected emergency situation, it is desirable to determine, as quickly as possible, at least approximate radiation deposition levels on environmental media. For the launches recently monitored, the major health concern has been the level of alpha radioactivity. Therefore, rapid field methods for estimating gross alpha activity in sea water, natural water, soil, vegetation, and leafy flora samples have been developed and can be performed by the radiochemistry trailer unit during surveillance activities or emergency conditions. These methods, depending on the type of sample, involve either a precipitation, leaching, or ultrasonic cleaning procedure to remove radionuclides from the sample, followed by evaporation and alpha counting.

The basic criterion for the control of population exposure to long-1ived alpha radioactivity in off-site areas is to reduce the alpha contamination levels to as low a level as practicable. The basic field measuring instrument is the alpha survey meter. When significant levels are detected by means of these instruments, evacuation or restriction of access may be required. The personnel of each monitoring team have been trained in the use of these instruments and in the health significance of alpha radioactivity in the environment. They are prepared to make evaluations and recommendations of whether evacuation, restriction of access, or decontamination procedures should be employed. These evaluations, recommendations, or other considerations are relayed to appropriate officials, and the teams are prepared to direct necessary remedial actions.

\section{Description of OSRS Program Operations}

A general guide to the off-site geographical area of interest is that land area adjacent to Federally controlled property; at the AMR it is considered as that area outside the Cape Canaveral Missile Annex and within a radius of approximately 50 miles from Canaveral, Florida. However, it might be anticipated that a situation requiring appropriate action by the off-Site Radiological Safety Program may arise at a considerable distance from this area.

Since 1960, the USPHS has been conducting environmental surveillance studies in the Cape Canaveral area to document seasonal variations in radioactivity levels. This program in the form of air, water, shellfish, and silt sampling, has provided a useful record of existing environmental radioactivity levels and is continuing as a part of the overall environmental surveillance efforts in the Florida area.

The first operational PHS off-site radiological safety coverage was provided during the launch of two satellites from Cape Canaveral in June and November 1961. These launches were the first and second use of a radioisotope-fueled SNAP device as an electrical power source for a satellite. Before and after the launch, environmental sampling was performed and the event was covered by mobile survey teams. 
In this type of operation, the activity level in air is perhaps the best early indicator of environmental contamination. Before each launch, 11 air-sampling stations were set up in peripheral lines approximately 5 and 30 miles inland from the launch site. At these stations, high-volume air samplers were operated continuously from $\mathrm{T}-1$ to $\mathrm{T}+1$ days and from $\mathrm{T}-2$ to $\mathrm{T}+1$ days, for the two launches, respectively. The alpha activity was below the limit of detection. This was within the range of values determined from background samples previously collected in the area before the launch.

Subsequent to the first event, two air samplers were operated in the area for several weeks and data was collected on the background levels in addition to that collected immediately before the launch. Through the cooperative efforts of state and local health department officials, other environmental samples (milk, water, and food) were collected as a part of the general surveillance activities in the AMR area. These samples were analyzed to obtain information on the background levels of radioactivity.

During the actual launches, mobile monitoring units were located in or near off-site communities on a stand-by basis and were in contact with a PHS officer stationed at Cape Canaveral. If a mishap had occurred, these units were prepared to define the limits and approximate amounts of any contamination.

During both launch periods, liaison was maintained with the state health officials, who were informed promptly of activities leading up to and following each launch. Both launches proceeded normally as scheduled and the surveillance operations detected no contamination that could be attributed to the event.

Off-site radiological safety coverage by PHS has also been provided during a launch of a satellite using a radioisotope-fueled SNAP device from Point Arguello, a launch complex at the Pacific Missile Range, in late 1963. Approximately one month before the launch, air, soil, natural vegetation, fresh water, ocean water, milk, and crop samples were collected from the off-site area with the assistance of local health department officials and agricultural agents, and were analyzed for radioactivity. At the same time, a background survey was conducted with an alpha survey instrument. Immediately preceeding the event, an air-sampling station was established and operated continuously. Also in preparation for the launch, the radiochemistry trailer containing equipment for rapid analysis of environmental samples was stationed at a convenient and accessible location. During the 1aunch, mobile monitoring teams were located in a convenient and accessible place on a stand-by basis and in communication with a PHS officer stationed at the launch complex. After the launch, several vegetable samples were again collected because of the amount of truck farming in the off-site area of the Pacific Missile Range. No radioactivity attributable to the launch operation was detected.

Summary

The major emphasis of Public Health Service activities has been directed toward the determination of current base levels of significant fission products and selected radionuclides of heavy elements which exist in the AMR and PMR off-site areas. The monitoring systems were adapted to measure specifically alpha radioactivity, since the radionuclide of concern in the SNAP launches has been plutonium238. However, the systems are capable of detecting other radionuclides of health significance as required.

To date, aerospace nuclear safety programs have been effective. The off-site program during the launches involving SNAP devices at both PMR and AMR have shown no radioactivity above preoperationa1 background leve1s. 


\section{SESSION V}

RE-ENTRY AND POSTMISSION DISPOSAL

\section{Chairman}

V. E. Blake, Jr., Manager

Aerospace Nuclear Safety Department Sandia Corporation

\section{Session Coordinator}

Mr. A. J. Clark, Jr. Sandia Corporation 


\section{BLANK}




\author{
COMBUSTION AND DISINTEGRATION OF ZIRCONIUM \\ HYDRIDE-URANIUM EUEL RODS* \\ F. E. Littman \\ A. E. Levy-Pascal $* *$ \\ Astropower, Inc.
}

Introduction

Nuclear auxiliary power systems will be carried by many satellites to operate their instruments. If the satellites are designed to return to earth at the end of their mission, the nuclear reactor containing radioactive products constitutes a potential hazard. Of the several possible means of disposal, incineration during re-entry seems the most promising, particularly if the resulting combustion products are finely divided and widely dispersed before finally falling out.

A series of investigations was initiated by the Air Force Weapons Laboratory to answer the questions raised by this problem. The work reported in this paper concerns itself, on one hand, with the combustion behavior of relatively massive pieces of fuel elements and, on the other, with the behavior of small molten droplets resulting from a primary breakup of the fuel elements during re-entry.

Background Information

Combustion of Fue1 Rods

This study was part of a cooperative effort carried out by a number of contractors under the direction of the Air Force Weapons Laboratory. Thus the conditions to be examined were decided upon by mutual agreement of the investigators, and the model trajectories were calculated by General Dynamics/Astronautics.

The pertinent conditions adapted for this investigation are those encountered by an object re-entering from a polar orbit; starting re-entry at the north pole; and having a velocity of $25,680 \mathrm{ft} / \mathrm{sec}$, a zero entering angle, and a ballistic parameter, $\mathrm{W} / \mathrm{C}_{\mathrm{D}} \mathrm{A}$, of 20 (rod normal to trajectory) and 300 (rod axial) $1 \mathrm{~b} / \mathrm{sq} \mathrm{ft}$. It was further assumed that for each ballistic parameter the ejection of the fuel rods would occur at each of the following altitudes: 400,000, 300,000, 250,000, $200,000,150,000$, and 100,000 feet. For convenience, the trajectories were designated the "a" and "b" series according to the scheme shown in Table I. In the heat transfer calculations, a cold wall temperature of $500^{\circ} \mathrm{R}$ was assumed. The flux and pressure conditions of the two families of trajectories are shown in Figures 109 and 110. The $5 \mathrm{a}, 4 \mathrm{~b}$, and $5 \mathrm{~b}$ trajectories were not included in the experimental approach because in those trajectories the total integrated heat content drops to a very low figure, as was pointed out by Philbin ${ }^{1}$ in the listing shown in Table II. The amount of heat required to melt a 1.25-inch fuel element is of the order of 2400 Btu. ${ }^{2}$

\footnotetext{
*Presented by Dr. Littman

**Present address: Lockheed Corporation, Palo Alto, Calif.
} 
TABLE I

Trajectory Designations

\begin{tabular}{|ccc|}
\hline \multirow{2}{*}{$\begin{array}{c}\text { Ejection Height } \\
(1000 \mathrm{ft})\end{array}$} & & \multicolumn{2}{c|}{ Trajectory } \\
$4 / \mathrm{C}_{\mathrm{D}} \mathrm{A}=20$ & $\mathrm{~W} / \mathrm{C}_{\mathrm{D}} \mathrm{A}=300$ \\
300 & $\mathrm{a}$ & $\mathrm{b}$ \\
250 & $1 \mathrm{a}$ & $1 \mathrm{~b}$ \\
200 & $2 \mathrm{a}$ & $2 \mathrm{~b}$ \\
150 & $3 \mathrm{a}$ & $3 \mathrm{~b}$ \\
100 & $5 \mathrm{a}$ & $4 \mathrm{~b}$ \\
& $5 \mathrm{a}$ & $5 \mathrm{~b}$ \\
\hline
\end{tabular}

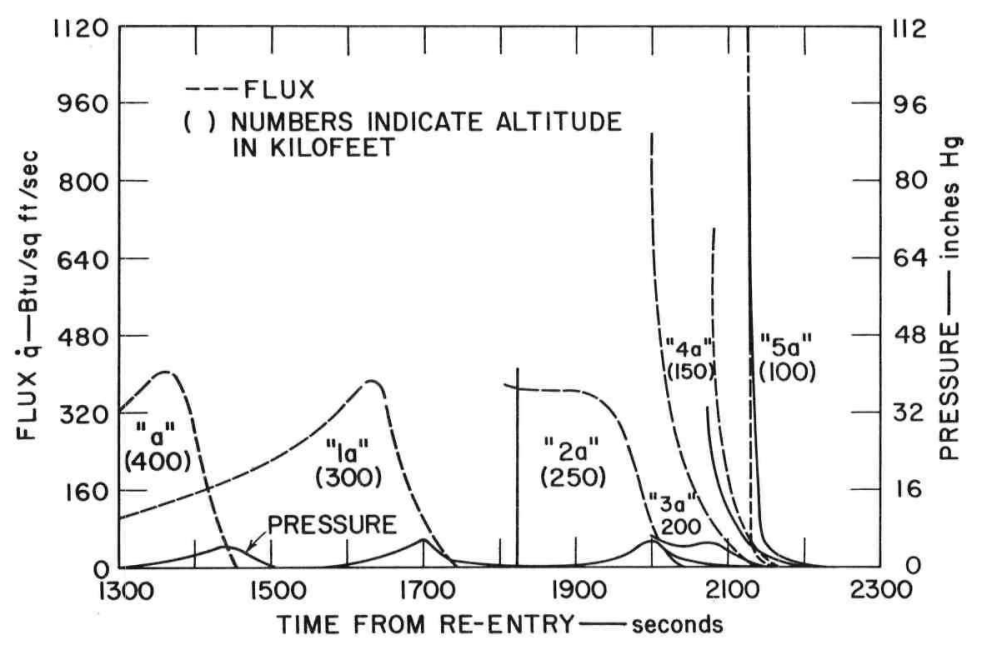

Figure 109. "a" Trajectories $\left(\mathrm{W} / \mathrm{C}_{\mathrm{D}} \mathrm{A}=20 \mathrm{lb} / \mathrm{sq} \mathrm{ft}\right)$

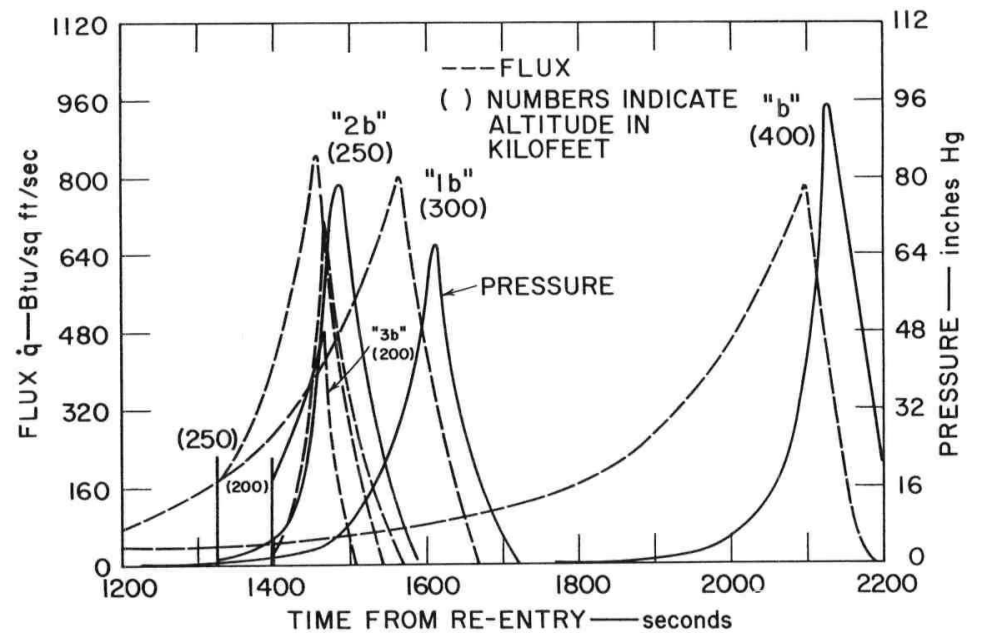

Figure 110. "b" Trajectories (W/C $\mathrm{D} A=3001 \mathrm{~b} / \mathrm{sq} \mathrm{ft}$ ) 
TABLE II

Total Stagnation-Point Heating of Exposed Fue1 Elements

\begin{tabular}{|c|c|c|c|}
\hline Trajectory & $\begin{array}{l}\text { Tota1 Heating } \\
\quad\left(\mathrm{Btu} / \mathrm{ft}^{2}\right) \\
\end{array}$ & Trajectory & $\begin{array}{c}\text { Total Heating } \\
\left(\mathrm{Btu} / \mathrm{ft}^{2}\right)\end{array}$ \\
\hline $\mathrm{a}$ & $60 \times 10^{3}$ & b & $202 \times 10^{3}$ \\
\hline $1 a$ & $61 \times 10^{3}$ & Ib & $153 \times 10^{3}$ \\
\hline $2 a$ & $42 \times 10^{3}$ & $2 b$ & $89 \times 10^{3}$ \\
\hline $3 a$ & $22 \times 10^{3}$ & $3 b$ & $29 \times 10^{3}$ \\
\hline $4 a$ & $9 \times 10^{3}$ & $4 b$ & $3 \times 10^{3}$ \\
\hline $5 a$ & $2 \times 10^{3}$ & $5 b$ & $0.1 \times 10^{3}$ \\
\hline
\end{tabular}

For experimental simulation of the trajectories, both the flux and the pressure values were averaged over periods of time ranging from 300 to 20 seconds, depending on the slope of the curves, as shown in diagrams below (e.g., Figure 120a).

\section{Particle Disintegration}

The pressure and temperature conditions for the particle disintegration study were less well defined. It was assumed that the particles were formed by the initial melting of the re-entering fuel rod and ejected by an undefined mechanism. In this study (which was preliminary in nature and is still continuing), the particle size was fixed at 50 to 200 microns, the particles were to be molten, and the pressures were to range from $10^{-2}$ to 1 atm. No attempts were made to simulate actual trajectories, since the conditions of particles ejected into the wake of a reentering object are not we11 enough known.

Equipment and Procedures

\section{Combustion Study}

The major piece of equipment used for this study was an arc image furnace equipped with 14-inch elliptical mirrors. This apparatus, a lineal descendant of the mirror system used by Archimedes in 212 B. C. to burn the ships of the invading Roman navy at Syracuse, consists of a carbon arc system as a source of energy and a pair of elliptical mirrors whose function is to collect and transfer this energy to another plane, the "furnace" area. Flux densities of the order of $900 \mathrm{Btu} / \mathrm{sq} \mathrm{ft}-$ sec can easily be obtained by commercial equipment and maintained for 20 to 30 minutes (the lifetime of a carbon electrode). These flux densities correspond to a blackbody temperature of over $5000^{\circ} \mathrm{R}$. Control of the flux density can best be achieved by decreasing the area of the subtended angle of the secondary mirror by means of continuous or step diaphragms.

The sample rested on a zirconia colum which was contained in a borosilicate glass exposure chamber. For experiments at less than atmospheric pressure, a thinwalled, spherical container, which did not absorb a measurable amount of radiant energy, was used. For high-pressure experiments, a thick-walled glass container was used which reduced the incident energy by about 20 percent. Figure 111 shows a schematic diagram of the equipment, Figure 112 an overal1 view, Figure 113 the highpressure container, and Figure 114 a closeup of a typical sample.

The furnace was calibrated with a radiometer developed by the Naval Defense Radiological Laboratories. This meter consists essentially of a small blackened 
silver disk to which a thermocouple is connected. The disk is embedded in a watercooled copper block, which constitutes an infinite heat sink. The temperature reached by the black target is directly proportional to the heat input; the instrument is calibrated in terms of millivolt output per Btu/sq ft-sec flux having a constant of $41.6 \mathrm{Btu} / \mathrm{sq} \mathrm{ft}-\mathrm{sec}-\mathrm{mv}$.

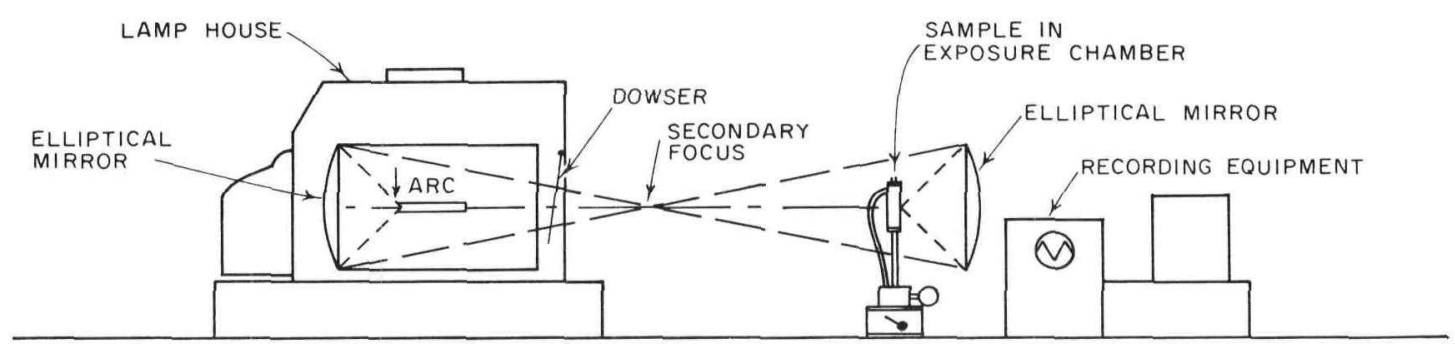

Figure 111. Arc image furnace (schematic diagram)

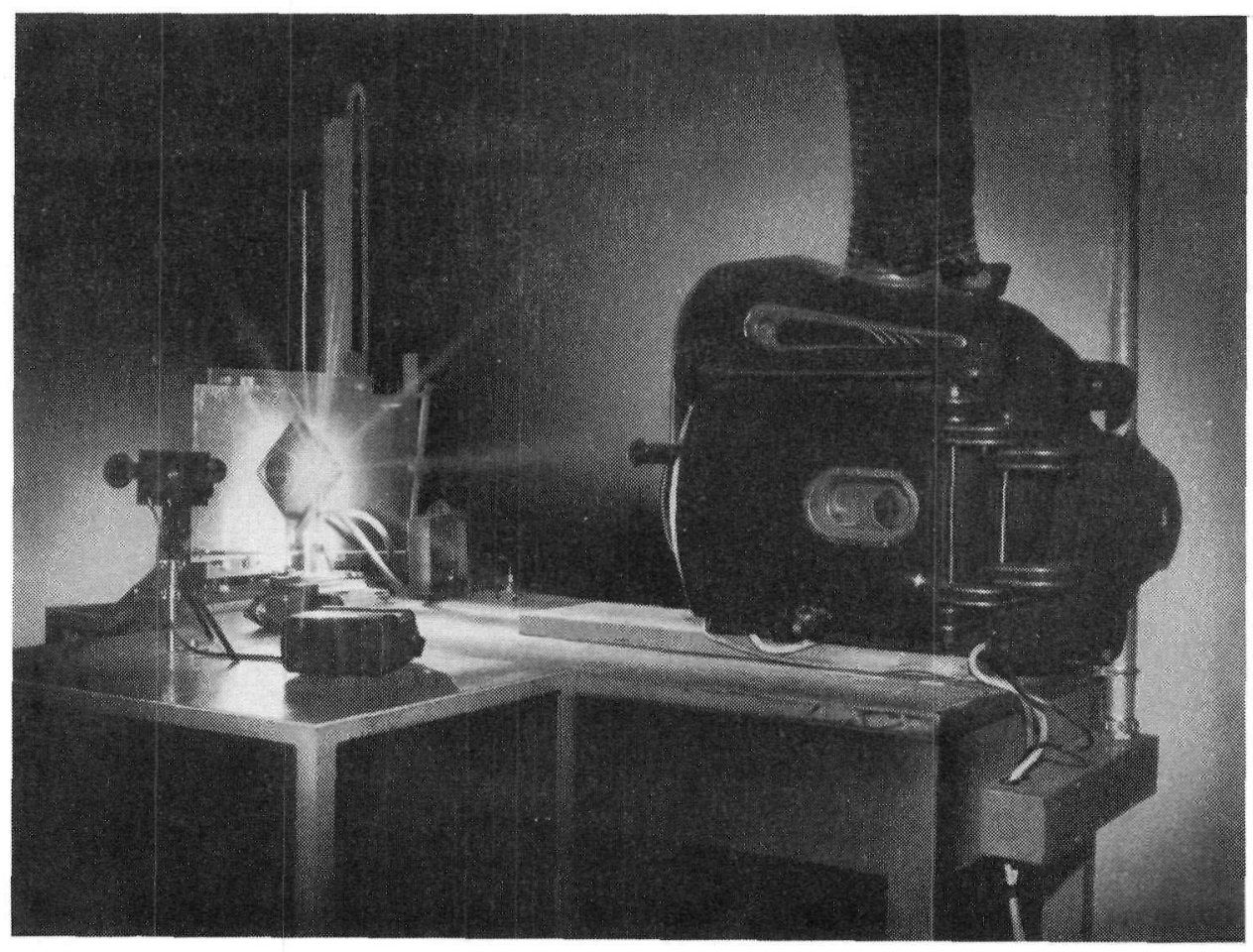

Figure 112. Arc image furnace 


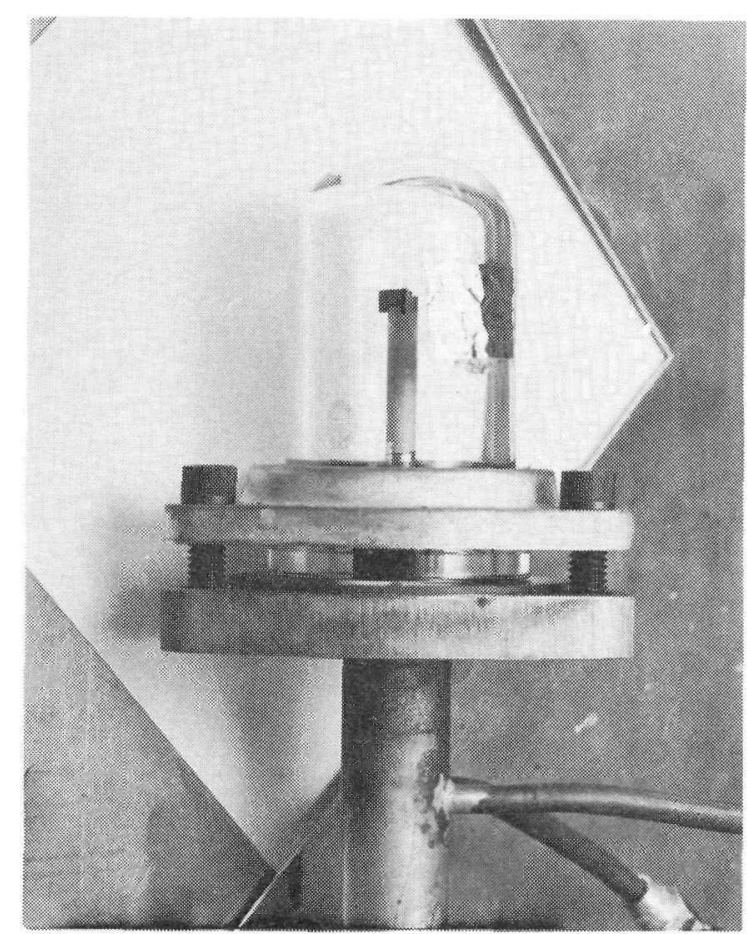

Figure 113. Sample in high-pressure container

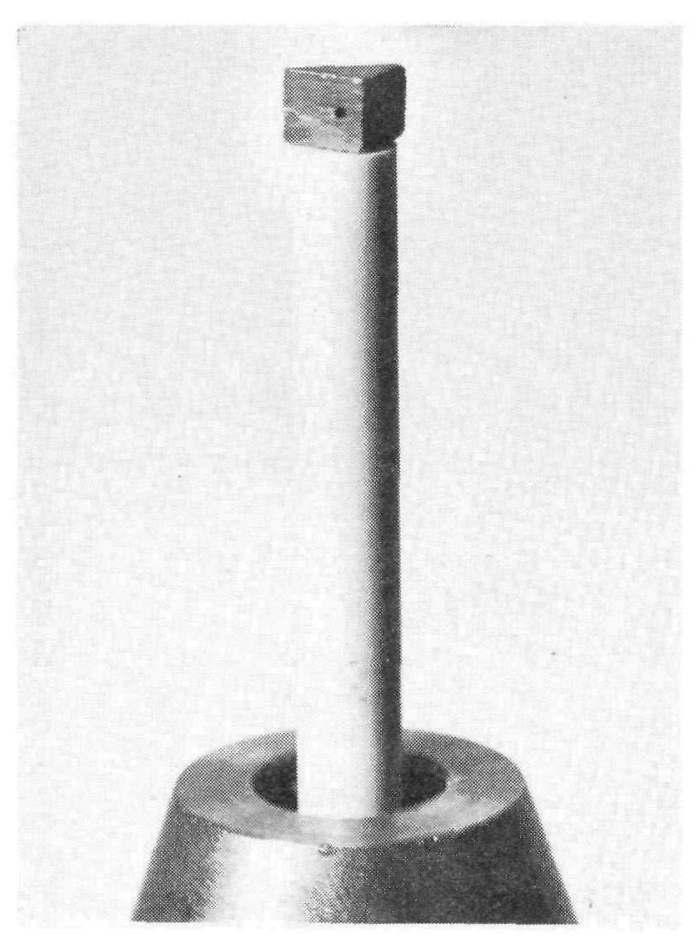

Figure 114. Sample used in combustion study

Pressures were measured with an assortment of gages, depending on the desired range. A McLeod gage was used for pressures up to 0.1 inch, a manometer up to atmospheric pressure, and a Bourdon gage for higher pressures. Pressure, as we11 as flux, was changed stepwise, as indicated on the diagrams representing the several trajectories.

Optical measurement of temperatures proved to be quite difficult because reflection of the arc on the surface of the sample resulted in high readings. The problem was eventually solved by using a Micro Optical Pyrometer, which was focused on a hole 0.025 inch in diameter and 0.150 inch deep that was drilled into the side of the sample. The hole can be seen clearly in Figure 114. (Drilling holes into the hydrided samples was exceedingly difficult but was eventually accomplished with a supersonic drill.) The temperature readings thus obtained closely approximate blackbody temperatures, since it can be shown that an apparent emissivity of 0.99 results with a hole having a depth of 2.6 diameters and a surface emissivity of $0.75 .3^{3}$

Once the furnace was calibrated, the sample resting on the zirconia column was positioned in the exact focus by means of a jig. The pressure was adjusted to correspond to the first step of the trajectory which was to be simulated, and the proper flux was ensured by a corresponding setting of the diaphragm. The arc was then 1it, and exposure was begun by raising the dowser. Changes from one level of flux and pressure to the next were made as rapidly as possible by adjusting a bleeder valve and the diaphragm, without dowsing the arc.

Temperature readings were taken at frequent intervals and an average reading was recorded for each step. The sample was closely observed through the telescope of the Micro Optical Pyrometer during the run. The actual flux used was increased 
by 50 percent over the calculated value in most runs to compensate for two factors: the experimental conditions, which permitted the heating of one face of the sample only, while at the same time it was radiating from five sides; and, offsetting this to some extent, the reduction of stagnation-point flux to average flux by a factor of three because of the tumbling of the rod. Assuming that the sample is at uniform temperature and that all heat loss is by radiation, the requirement of heat input by the arc image furnace equal to that by stagnation heating is given by the relation

$$
\Sigma \dot{q}_{i} A_{i}=\frac{1}{3} q_{s} A_{t}
$$

where $\Sigma$ is the emissivity, $\dot{q}$ is heat flux, A is area, and the subscripts $i, s$, and $t$ refer to arc image input, stagnation, and tota1. Assuming $\Sigma=0.8$ and our particular wedge-shaped sample $\left(\mathrm{A}_{i} / \mathrm{A}_{\mathrm{t}}=0.275\right)$, we find $\mathrm{q}_{i}=1.5 \dot{\mathrm{q}}_{\mathrm{S}}$, requiring a 50 percent increase in incident flux.

\section{Particle Disintegration Study}

The key to this study was an RF plasma torch. This device is capable of producing an intensely hot, entirely inert "flame" which was successfully used to melt particles of fuel-rod material.

The equipment consisted of a $7.5-\mathrm{kw}$, dual-range radiofrequency generator.* The RF power generated by this machine was coupled directly to the ionized gas, usually argon, to produce an intensely hot "thermal" plasma. The plasma was contained in a cylindrical tube made of quartz, Vycor, or even Pyrex, through which a flow of gas was maintained.

Since argon is initially not ionized and therefore not capable of conducting a current, the plasma must be started by first ionizing a portion of the gas. This was accomplished by using an externally mounted Tesla coil. Once started, a stable condition can be achieved by judicious manipulation of gas-flow rates, input power, and frequency.

The powdered fue1-rod material was fed into the plasma by means of a concentric powder feed tube leading from an agitated hopper. As shown in Figure 115, the molten particles were then passed through an orifice into the reaction zone, where they were brought into contact with reactive gases such as oxygen, nitrogen, or air.

The initial temperature of the particles was not determined; they were, however, molten, as evidenced by the splattering of droplets on a microscope slide located just below the orifice.

The reaction chamber could be maintained at subatmospheric pressures by a vacuum pump without affecting the pressure of the plasma torch, which remained at about 1 atmosphere.

A great deal of development work was necessary to obtain reliable, reproducible operation of the plasma torch, which originally was patterned after Reed's equipment.4 A more recent pattern is shown in Figure 116.

The reacted particles were quenched and collected in a chemically inert liquid (poly trifluorochloroethylene). They were first separated from the 1iquid and then washed and dried for visual and metallographic inspection.

\footnotetext{
*Manufactured by Lepe1 Laboratories, New York, N. Y.
} 


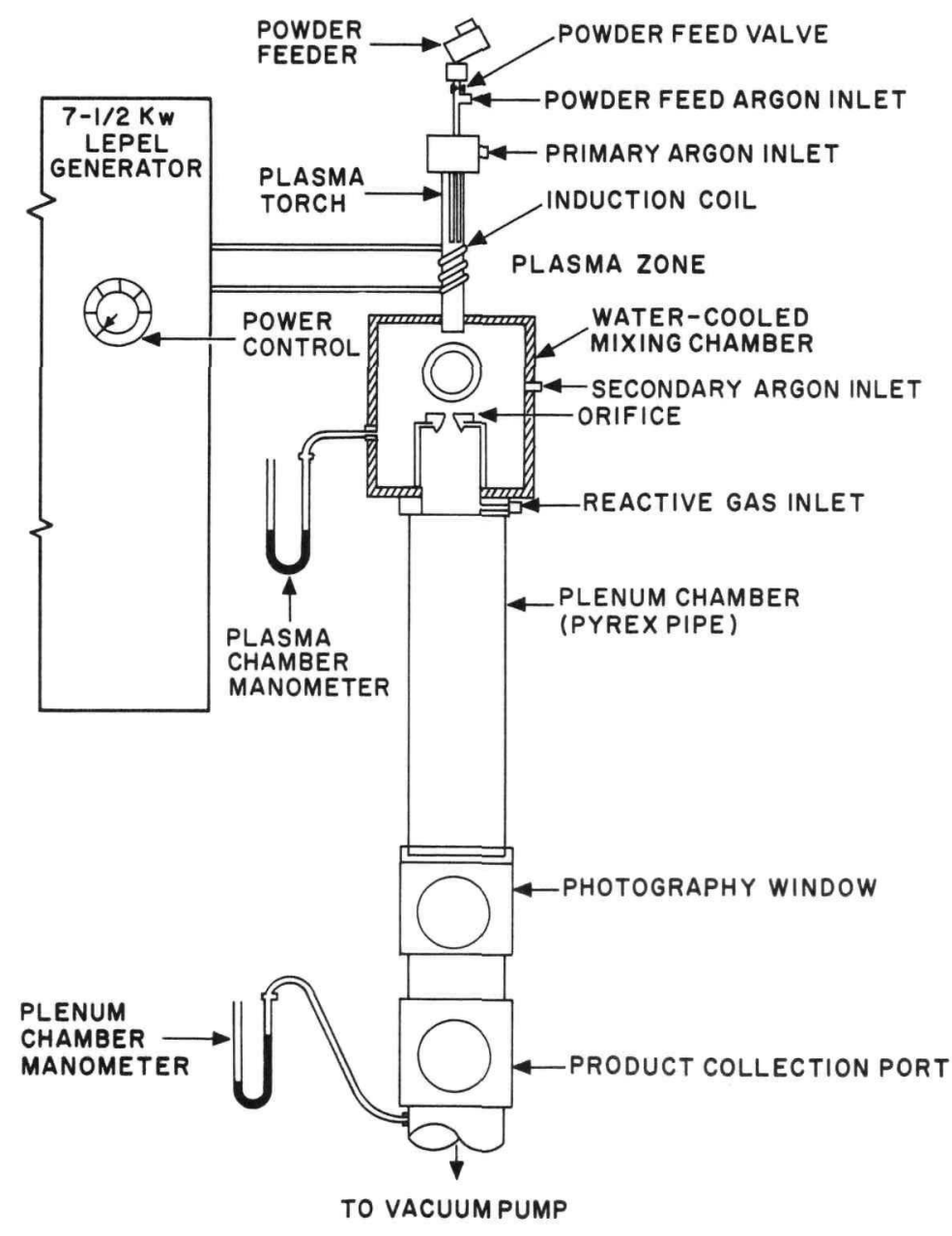

Figure 115. Plasma apparatus

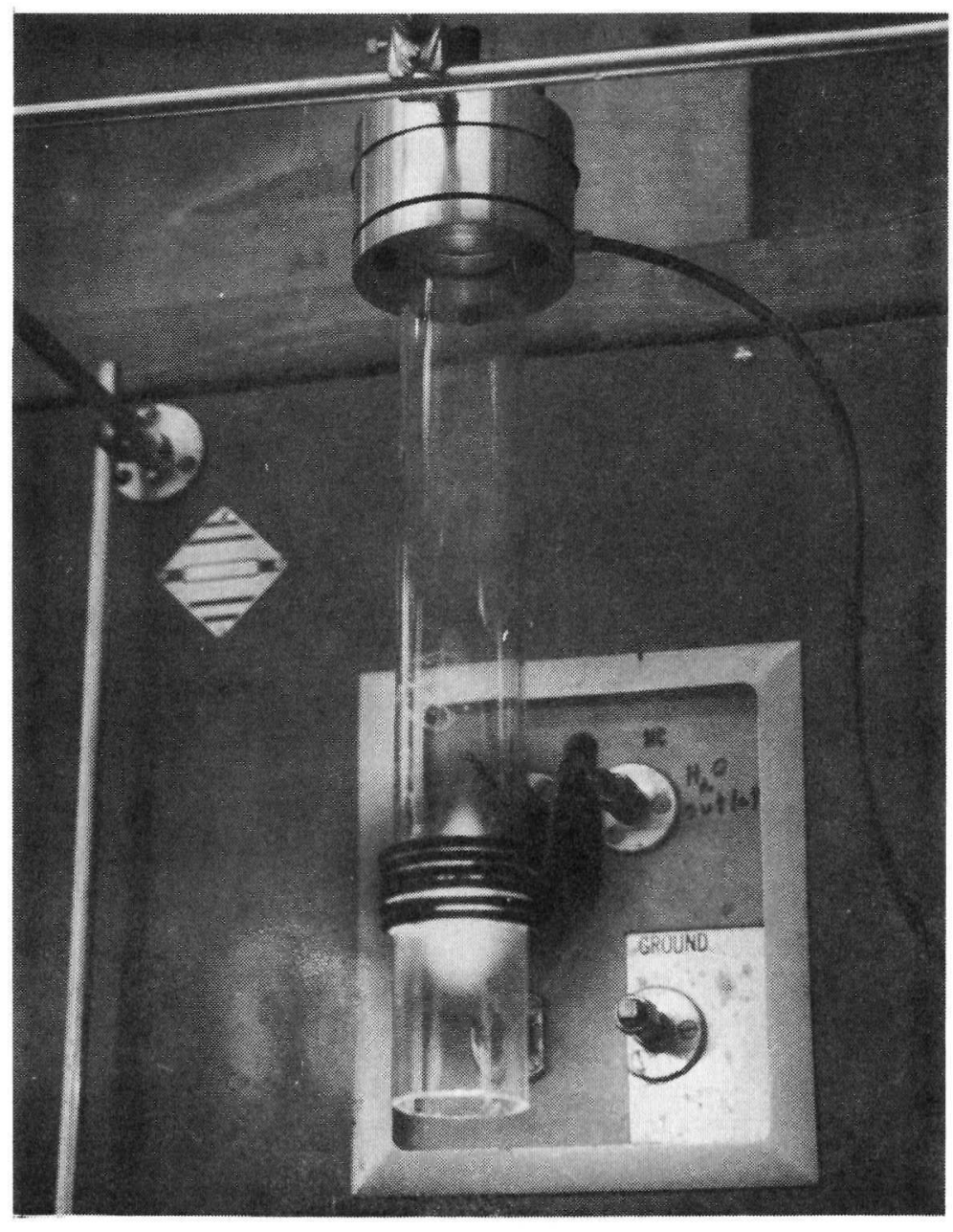

Figure 116. Plasma torch 


\section{Sample Preparation}

Both studies required careful sample preparation. For the combustion study, wedged-shaped columns about $3 / 16$ inch on edge were cut on a milling machine. Two types of material were used: zirconium-10\% uranium alloy, and hydrided material of the same starting composition containing about 1.9 atoms of hydrogen per atom of zirconium. Since the uranium was not enriched, no special handling precautions were were required. Typical photomicrographs of the starting material are shown in Figures 117 and 118. The alloy has a very fine crystal structure without characteristic markings. The hydrided material shows very large, banded crystals characteristic of hydrides containing more than 1.6 atoms of hydrogen per atom of zirconium.
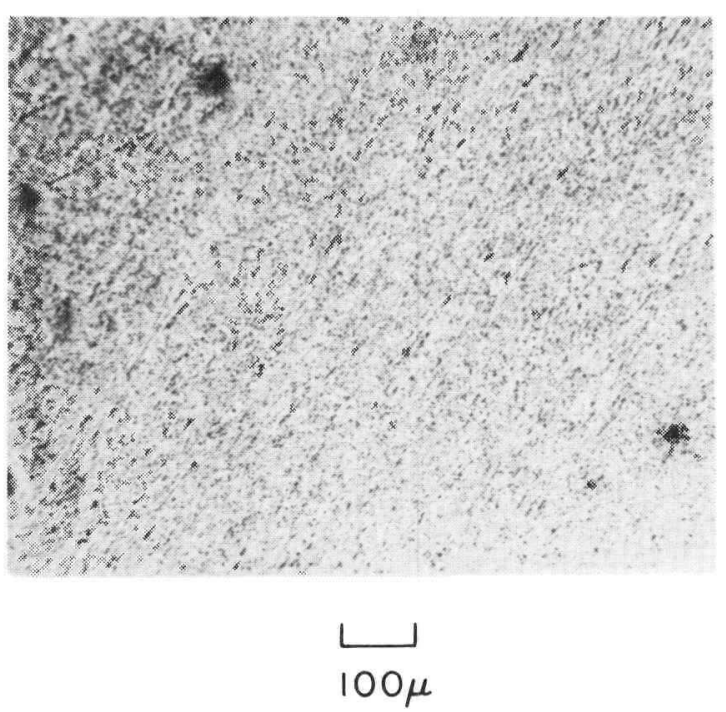

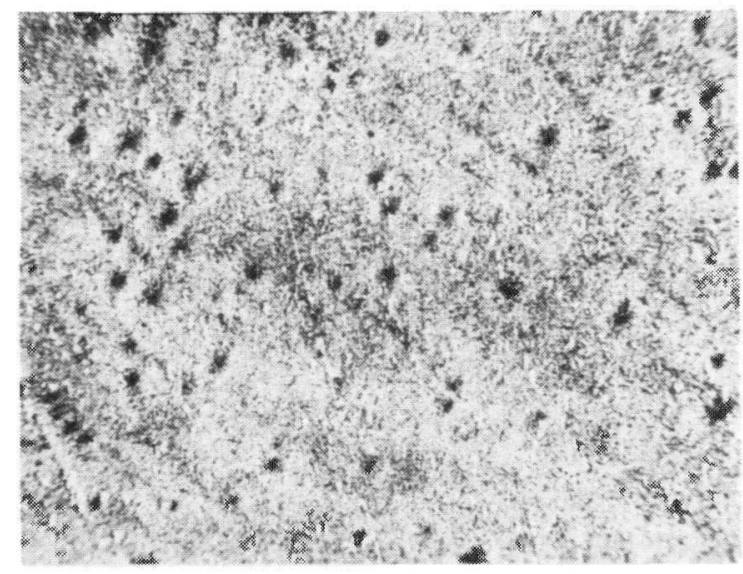

$\underset{25 \mu}{L}$

Figure 117. Zirconium-10\% uranium alloy
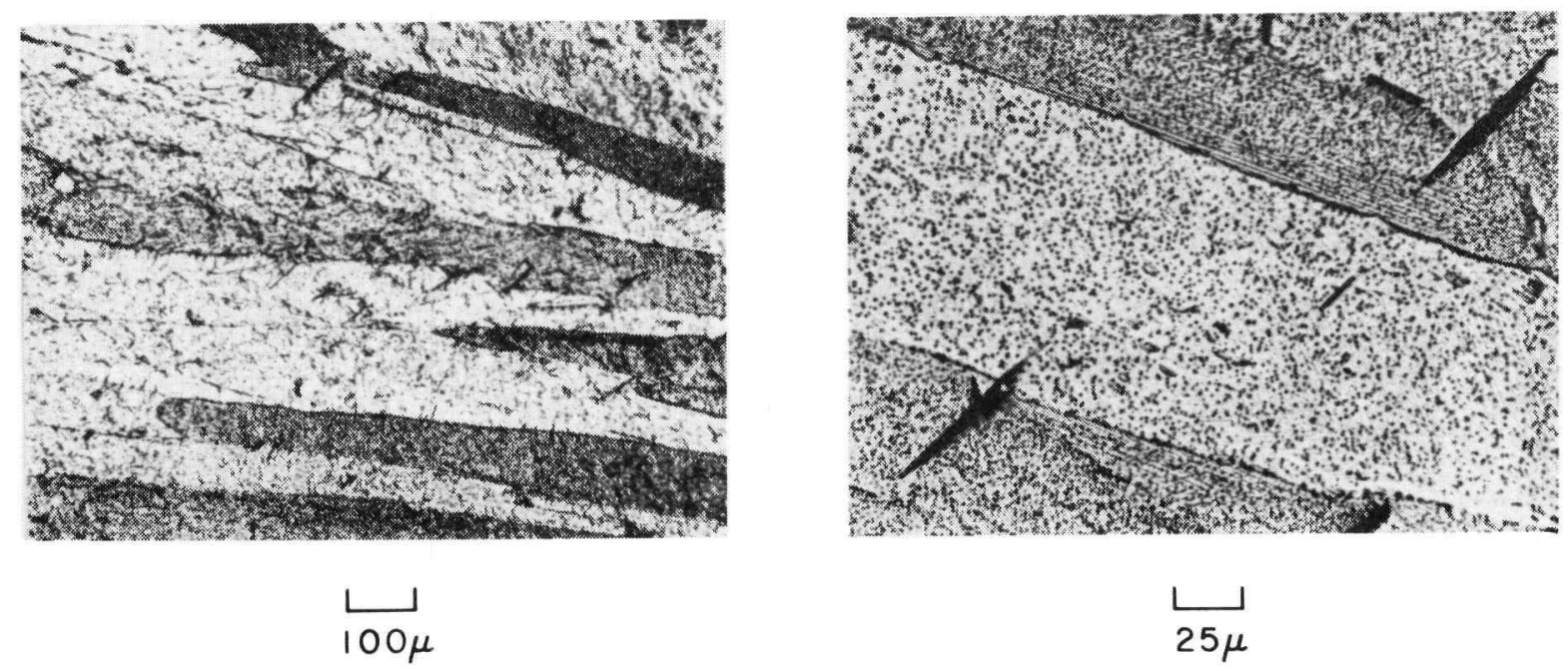

Figure 118. Zirconium hydride-10\% uranium 
The alloy was easily cut and drilled by conventional cutting tools. The hydride, being hard and brittle, was cut with a wet carborundum wheel and drilled with a supersonic drill, as mentioned above. The filings of hydrided material were pyrophoric; the alloy did not appear to possess this characteristic.

Samples for the particle study were prepared by filing a fuel rod. This operation was performed in a dry box containing argon. The filings were screened and classified into three groups having nominal sizes of 50, 100, and 200 microns. Because of the irregular, elongated shape of the filings, (Figure 119), this classification was only very rough. The sized particles were transferred into the hopper while still in the dry box. The closed hopper was then attached to the powder feed mechanism of the plasma torch.

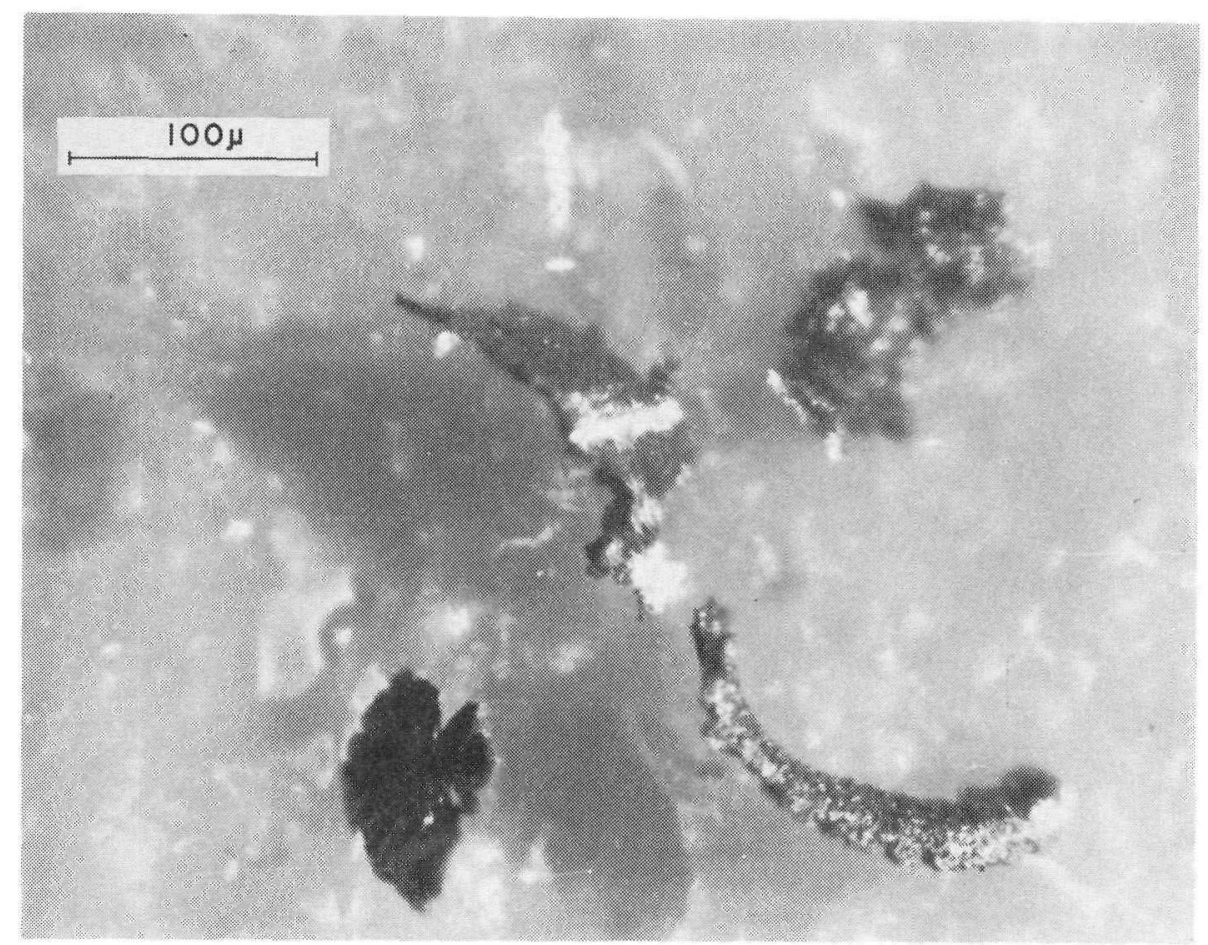

Figure 119. Fuel rod filings

Photography and Metallography

Both standard and high-speed motion picture photography were used to document the particle-disintegration study. A $16 \mathrm{~mm}$ Bolex reflex camera (Model $\mathrm{H}-16$ ) and a Fastax camera were employed. The tracks obtained on both records were produced by radiation from the particle and did not show the actual particle.

Metallographic procedures used for both studies were quite similar. For the larger particles obtained in the combustion study, the following technique seemed to give the best results:

The samples were mounted in cold-set plastic, about 1/16 inch was ground off to remove strained material, and the resulting face was polished on 600-grit silicon carbide paper. The polish marks were removed with a chemical etch consisting of 47-percent nitric acid (65 percent), 5-percent hydrofluoric acid (48 percent), and 48-percent hydrogen peroxide (3 percent). The etching solution was applied 
with a cotton swab and rinsed off after 10 to 15 seconds with distilled water. If necessary, the etching was repeated until the desired surface was obtained. The sample was then rinsed in methanol and dried with warm air. It was necessary that samples be examined within 1 to 2 hours, since an oxide coating seemed to form overnight.

Essentially the same procedure was used for the smaller particles resulting from the disintegration study. An etching solution consisting of 50cc of lactic acid, $10 \mathrm{cc}$ of $\mathrm{HNO}_{3}$, and 3 to 5 drops of $\mathrm{HF}$ was used alternatively.

Results and Discussion

The results of the combustion study, which simulates the conditions encountered by a re-entering fuel rod, show a strong dependence on the specific trajectory conditions.

In general, the maximum surface temperatures reached were we11 below the melting point of the alloy (about $3800^{\circ} \mathrm{R}$ ). The slower the rate at which the peak temperature was reached, the less likely meltdown became. This appeared to be due to the fact that we were dealing with two simultaneous processes: aerodynamic heating and reaction with air (primarily oxidation). Though the oxidation released a great deal of heat (the heat of combustion of zirconium is about $260 \mathrm{Kcal} / \mathrm{mole}$ ), the resulting oxide had an extremely high melting point (about $5340^{\circ} \mathrm{R}$ ). Gradual heating favored the formation of an oxide she11, which retarded further reaction.

Tests were run on both hydrided and unhydrided material. Of the two, the results obtained with hydrided zirconium-uranium alloy are directly pertinent; the test with unhydrided alloy merely served to point out the differences between the two.

The first step was a dehydrogenation of the hydrided material. This appeared to be strongly endothermic. As a result, the temperatures obtained by hydrided samples under otherwise identical conditions tended to be 100 to $200^{\circ} \mathrm{F}$ lower than those reached by the unhydrided alloy. As compared to the alloy, the dehydrogenation hindered or helped oxidation, depending on the duration of the run and the ambient pressure of air. Dehydrogenation provided access to the interior of the sample through numerous fissures but in the initial stages prevented oxidation, probably both by creating a diffusion barrier and by scavenging oxygen near the surface. Formation of water from the combination of hydrogen with oxygen was observed.

Depending on specific conditions, more or less complete oxidation of the fuel rod occurred. Some characteristic results are shown in Figures 120 to 122 , together with the trajectory conditions which produced them. Oxidation varied from almost none ("a" trajectory, Figures $120 \mathrm{a}$ and 120b) to almost complete ("4a" or "2b" trajectories - see Figures 121 and 122). Violent disintegration was not observed in these runs; however, it is believed that eruptions of liquid metal can and do occur under some conditions, particularly with larger samples and high heating rates.

Such eruptions of liquid metal from the inside of a heated sample (rather than from an external liquid layer, as was first assumed) provide the starting conditions for the particle disintegration study. The behavior of zirconium hydrideuranium particles was studied in detail by dropping them through an inert plasma into argon, argon and nitrogen, and argon and oxygen. 


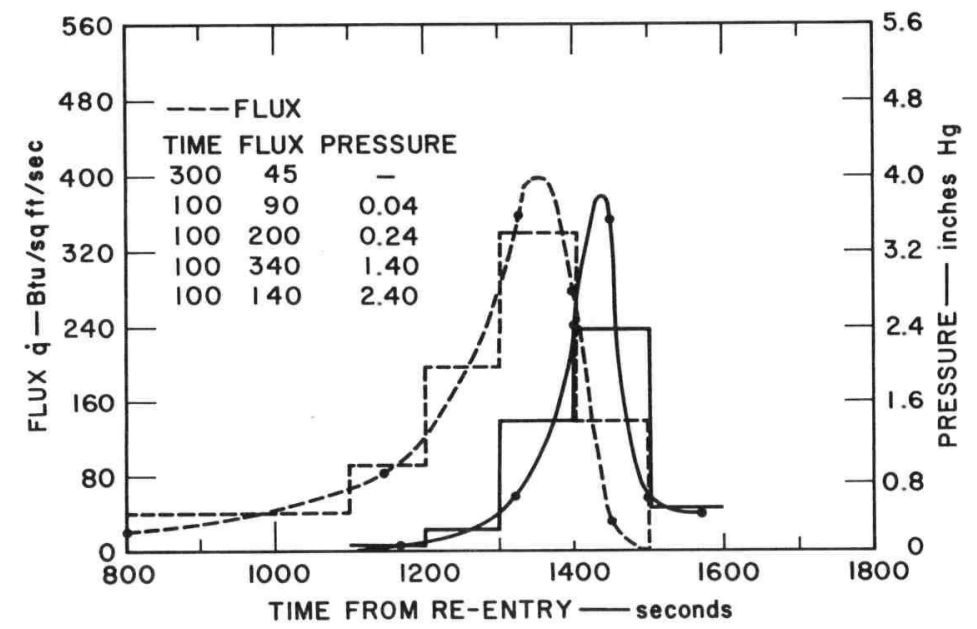

Figure 120a. "a" Trajectory

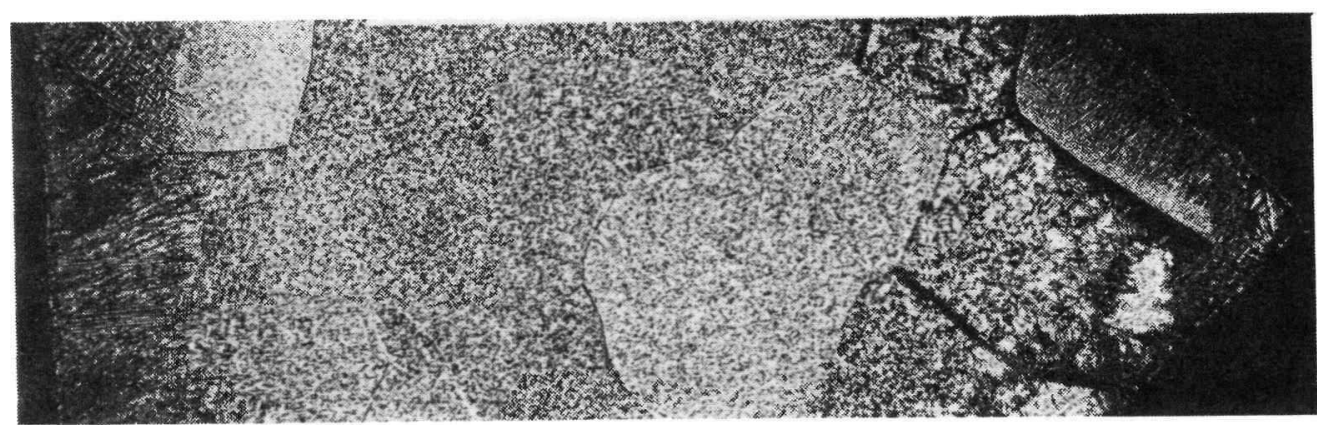

MATERIAL: ALLOY RUN No.: $a-7 \quad 135 \mu$

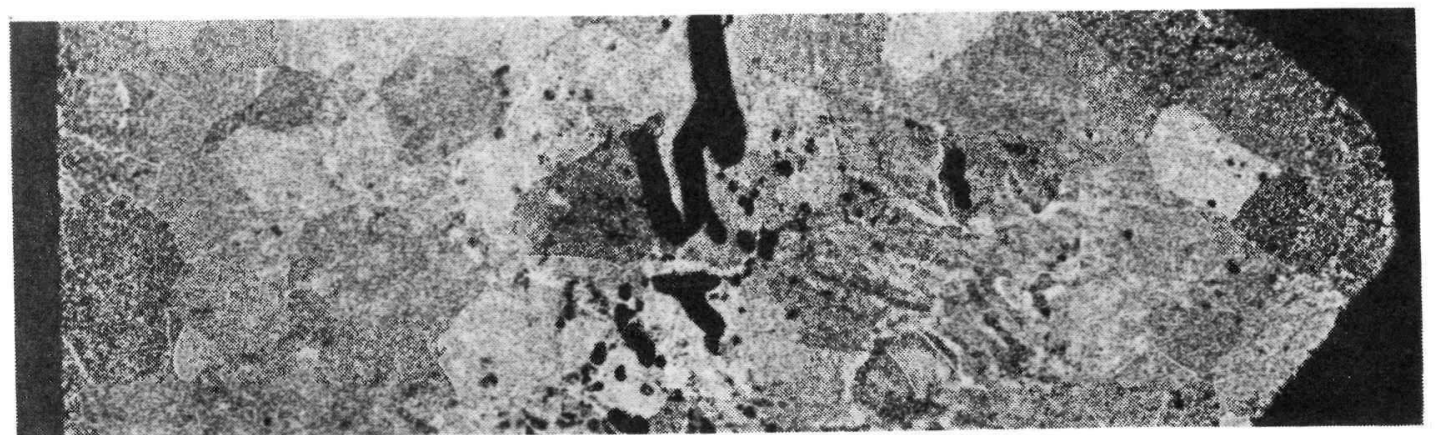

MATERIAL: HYDRIDE RUN No: $a-9 \sqrt{135} \mu$

Figure 120b. "a" Trajectory samples 


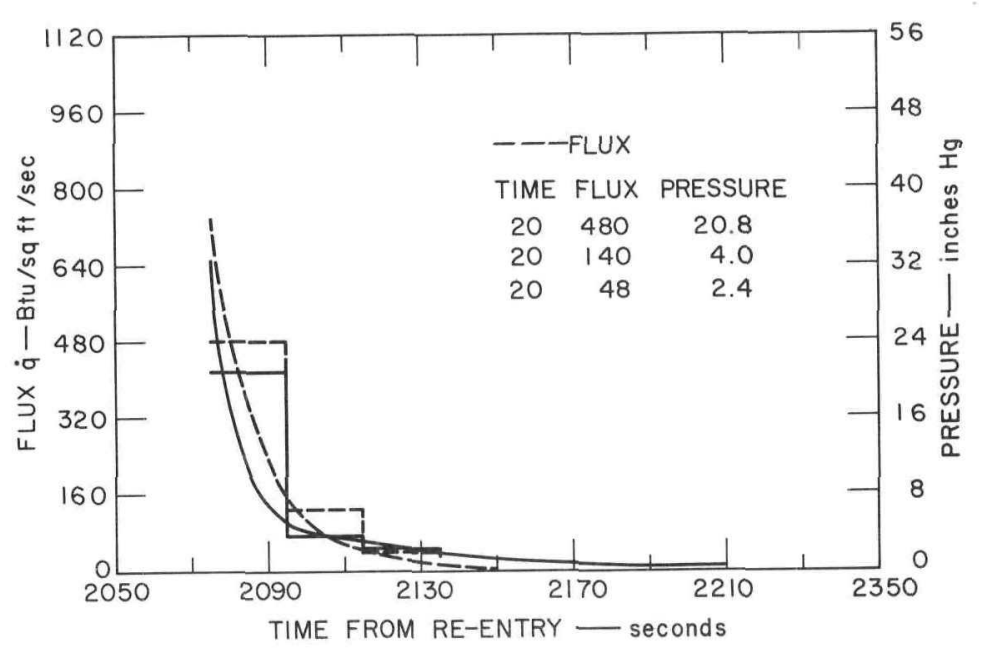

Figure 121a. "4a" Trajectory

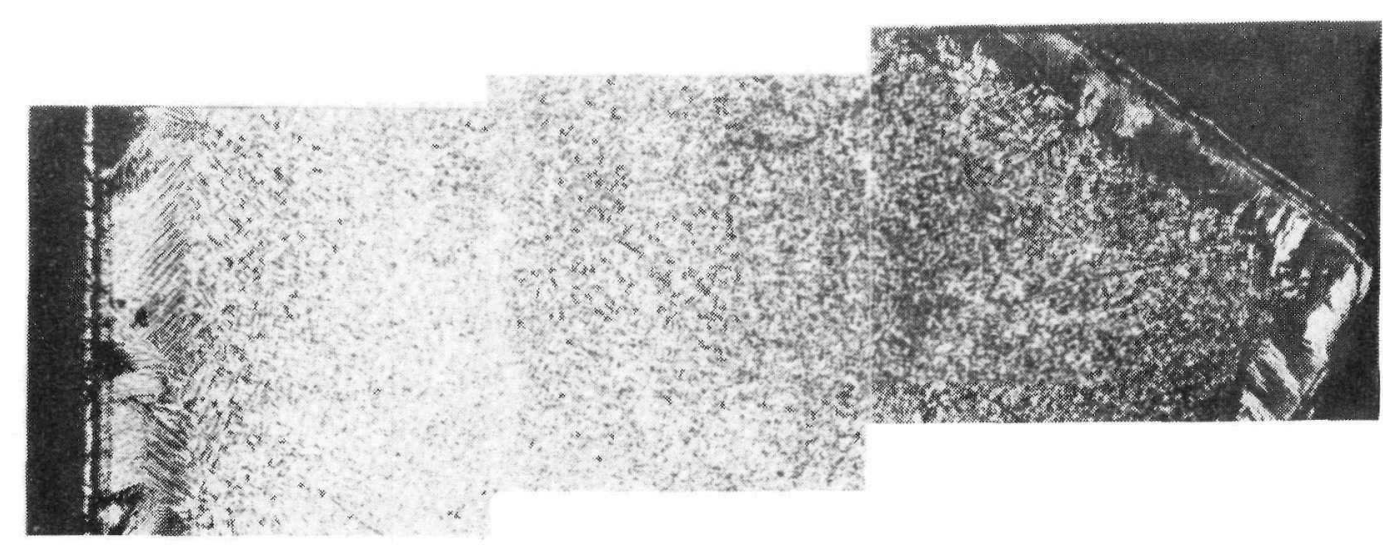

MATERIAL: ALLOY RUN No: $4 a-2 \quad \sqrt{35} \mu$

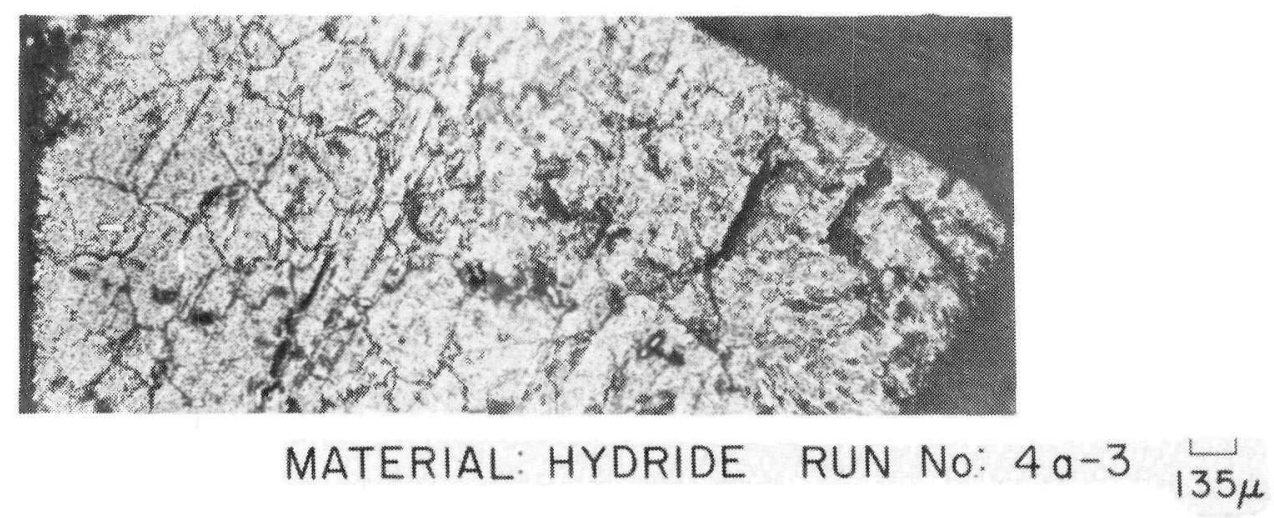

Figure 121b. "4a" Trajectory samples 


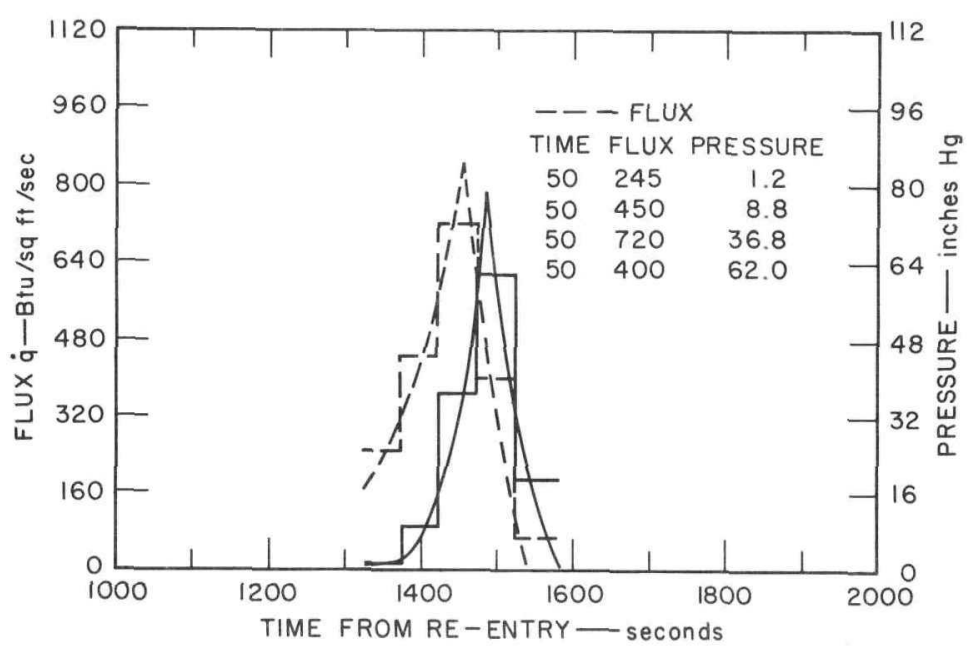

Figure 122a. "2b" Trajectory
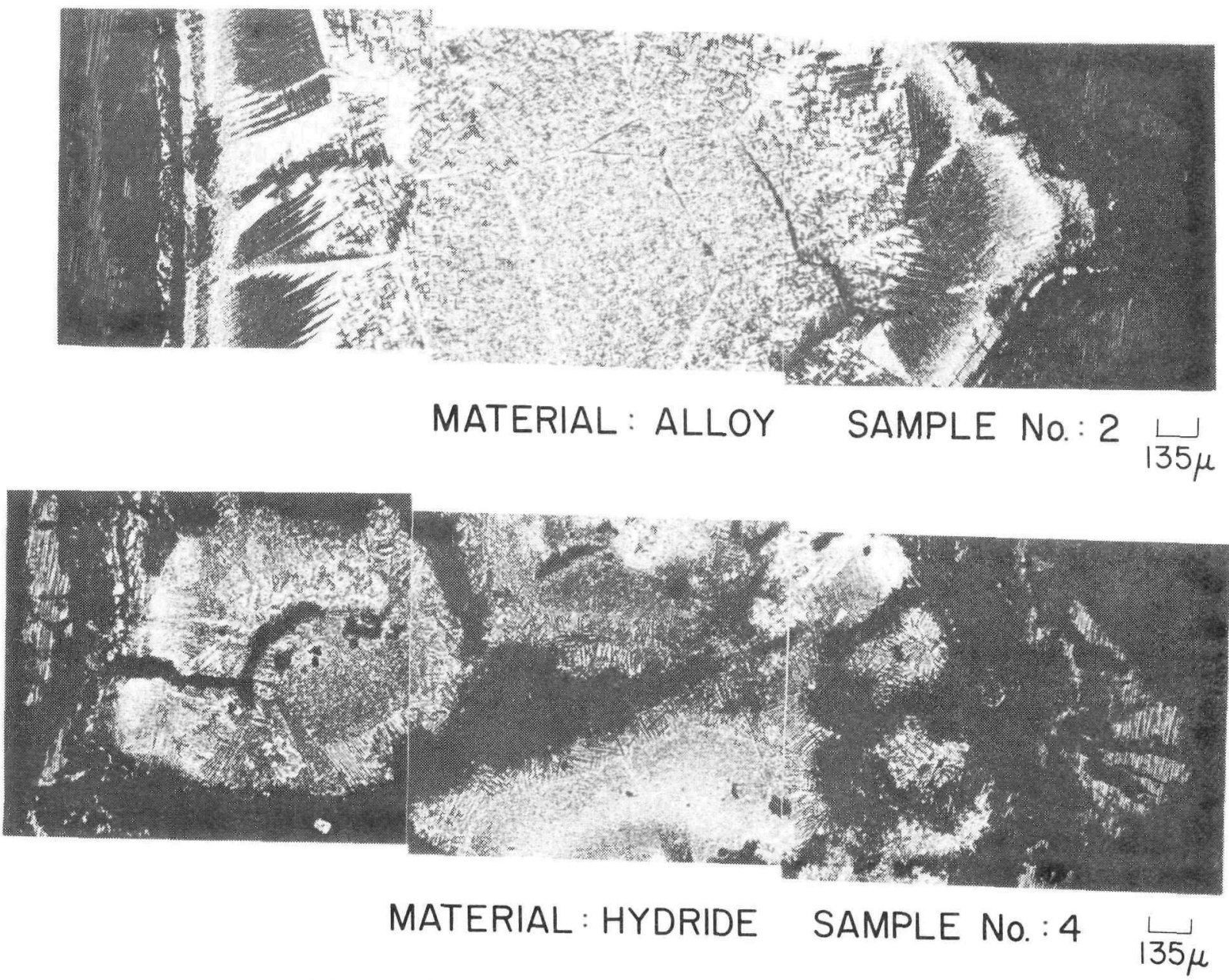

Figure 122b. "2b" Trajectory samples 
In the absence of reactive gases, the particles were melted and spherodized (Figure 123). In the presence of nitrogen, the results were similar, but a thin nitride case and precipitation of nitride along the grain boundaries could be detected. The surfaces of the particles tended to be gold colored and shriveled in appearance (Figures 124 and 125). Reaction with oxygen gave the most interesting results. The majority of the collected particles consisted of yellow, glossy spheres of about the same diameter as the original particle. Microsections of these spheres indicated that most of them were completely oxidized (Figure 126) and solid. Some were oxidized only on the surface (Figure 127) and contained a metallic core. Still others (Figure 128) had large cavities, with or without residual metallic cores. In addition large, thin-shelled particles were found whose diameters were several times greater than those of the original particles.

The mechanism of formation of these particles is not entirely clear. The oxidation appears to be diffusion-controlled in some cases, while the complete oxidation and the "balloon" formation indicate a different mechanism.

High-speed motion pictures indicated that occasionally the reaction of the particles was terminated by an explosion which fragmented the particle into smaller pieces. These explosions seemed to occur principally at pressures less than 1 atm. A terminal sequence is shown in Figure 129 .

We attempted to correlate the initiation time before explosion with particle size, but the results were inconclusive because of the uncertainties in particle size. There seemed to be a trend toward size reduction, but definite data on this point remains to be obtained. In addition, the fate of larger particles is of much interest, since the primary disintegration of the fuel rod is likely to produce fairly large pieces.

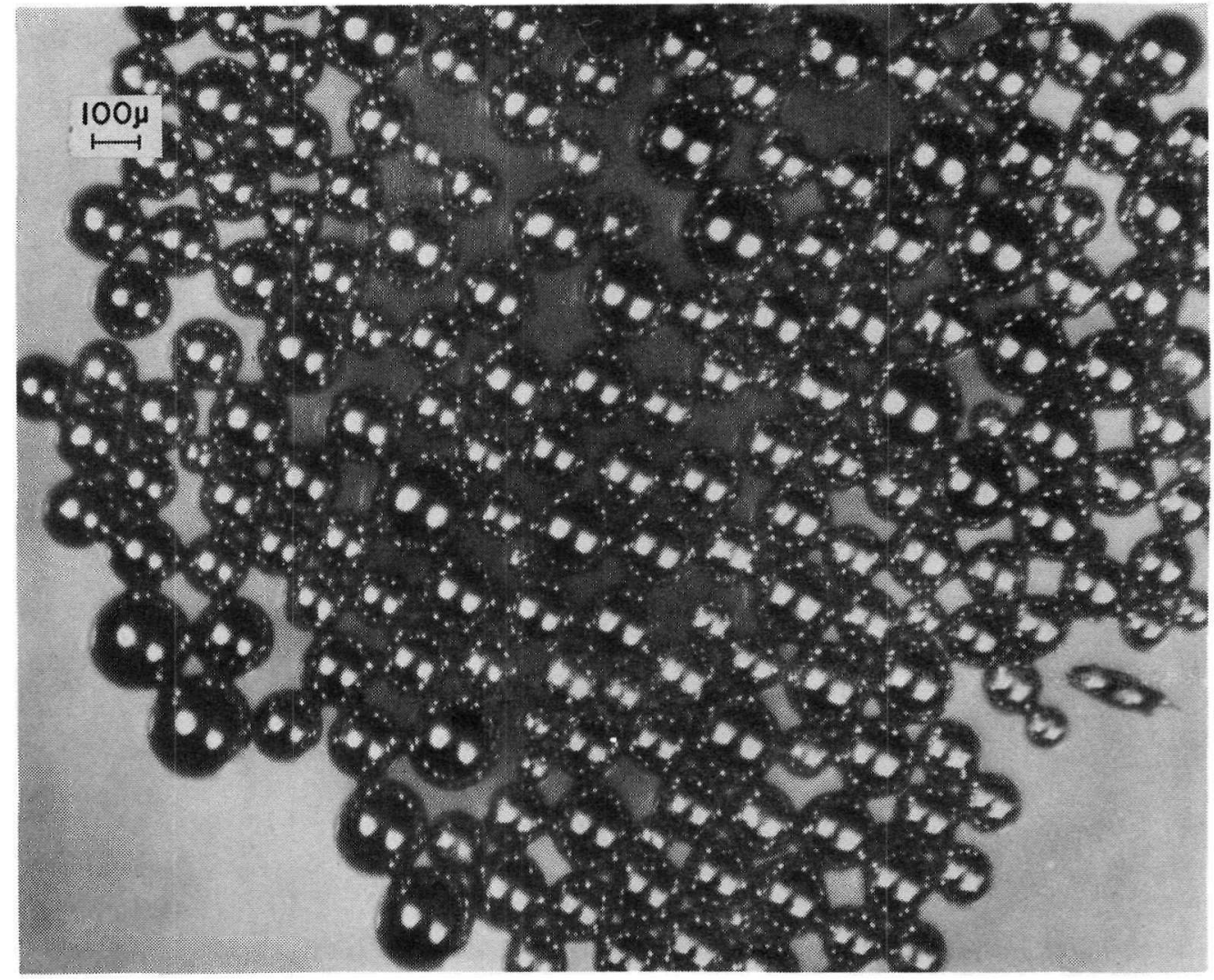

Figure 123. Spherodized particles 


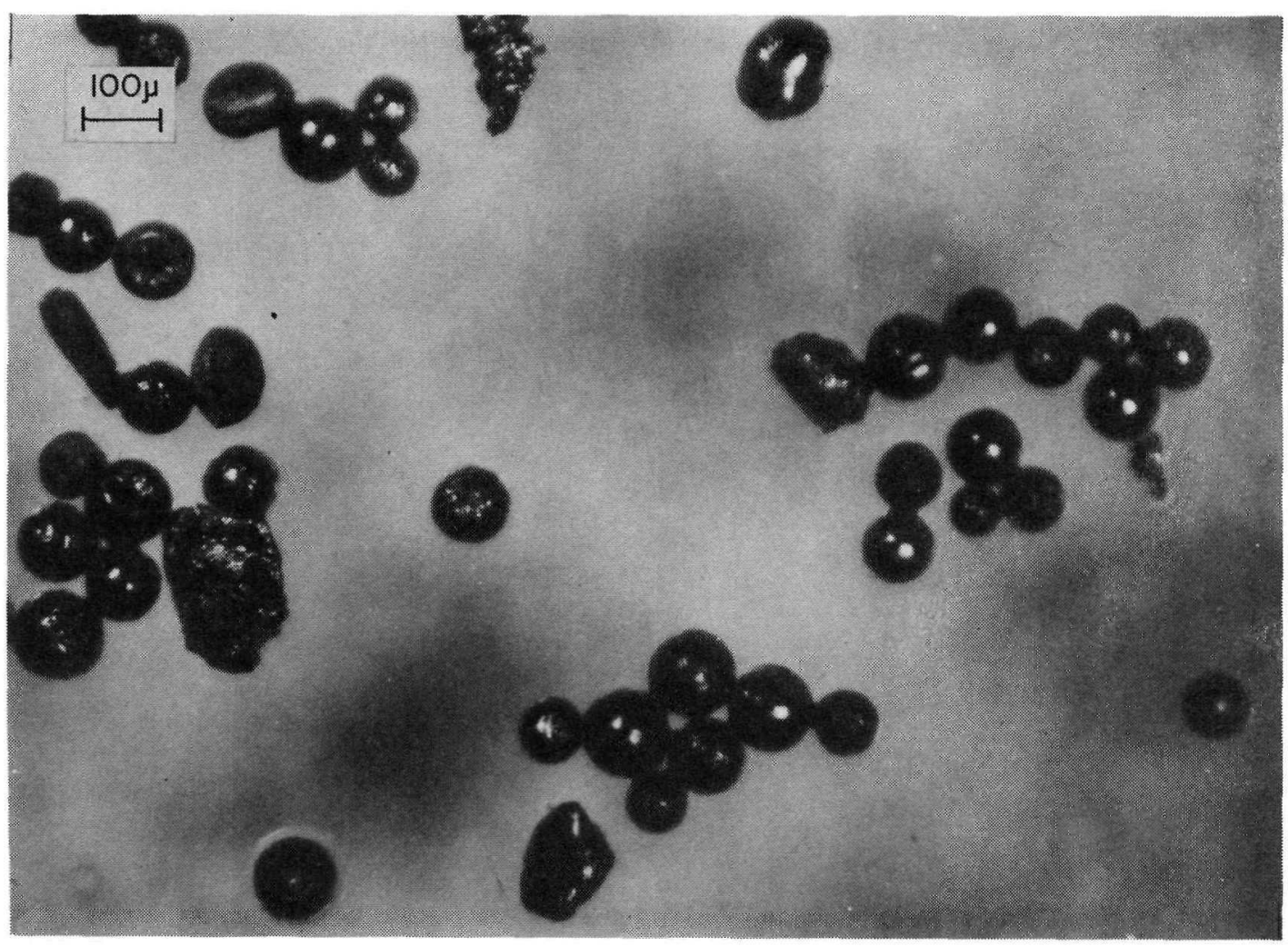

Figure 124. Nitrided particles

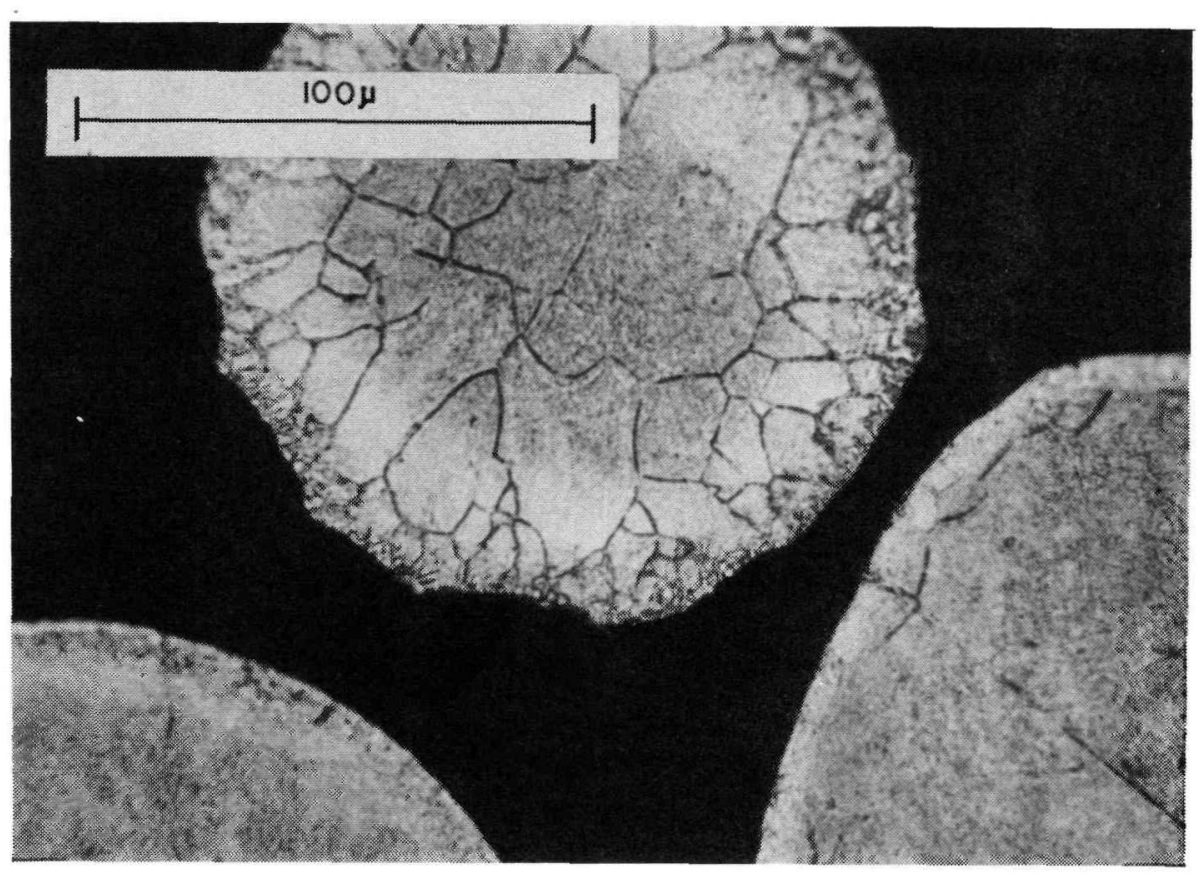

Figure 125. Nitrided particles (microsection) 


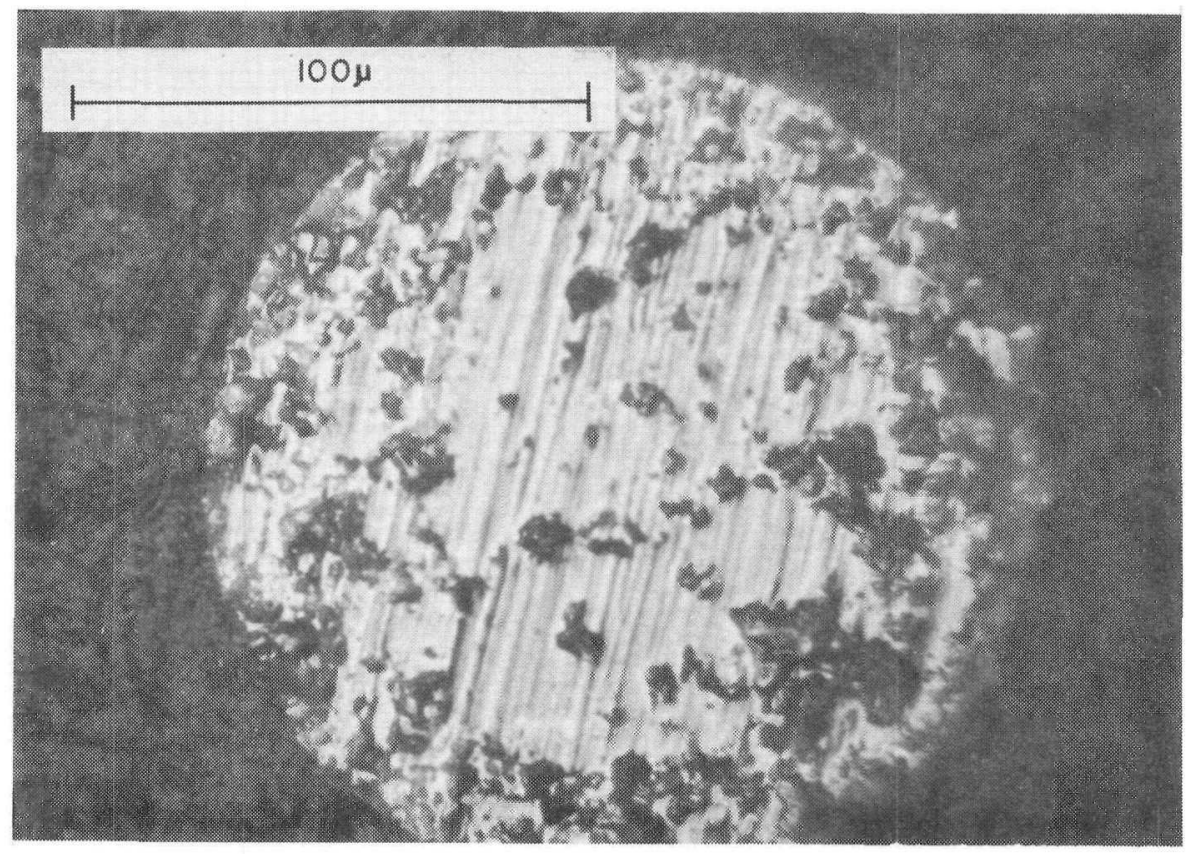

Figure 126. Fully oxidized particle

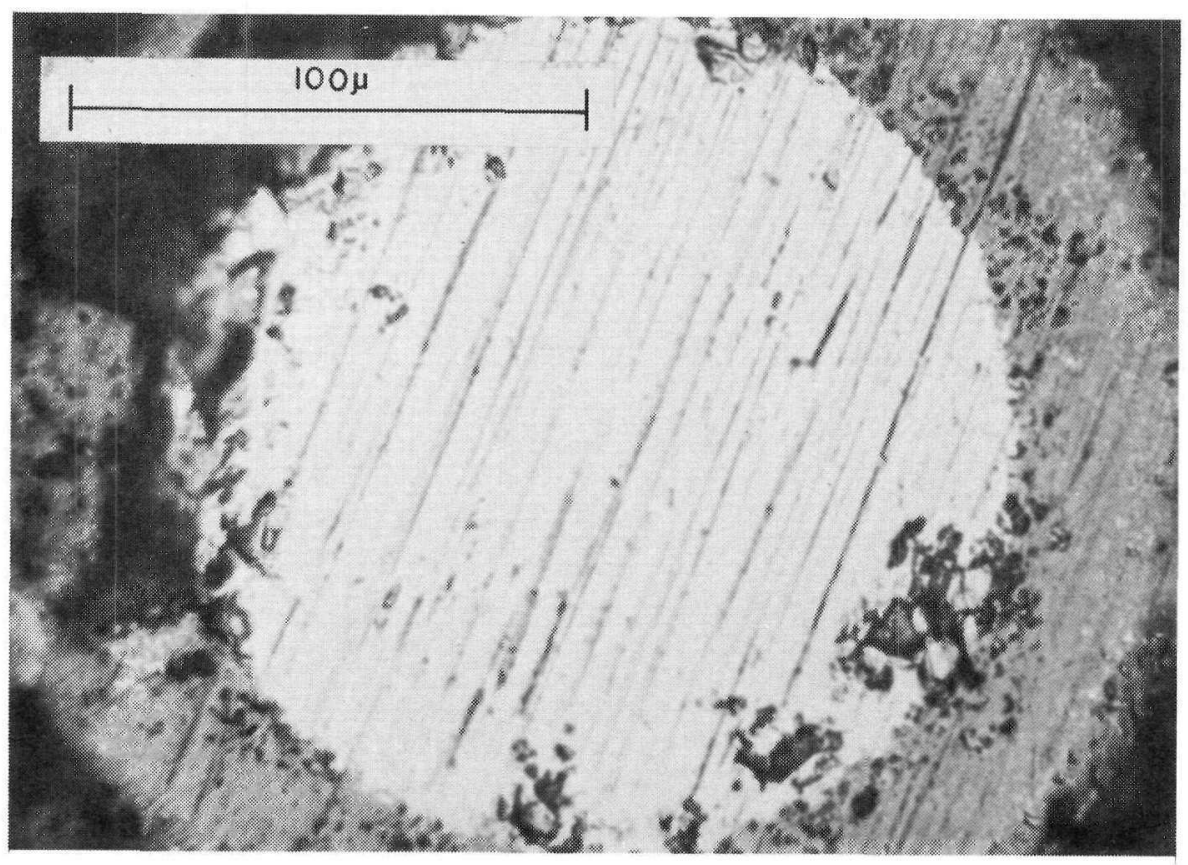

Figure 127. Partially oxidized particle 


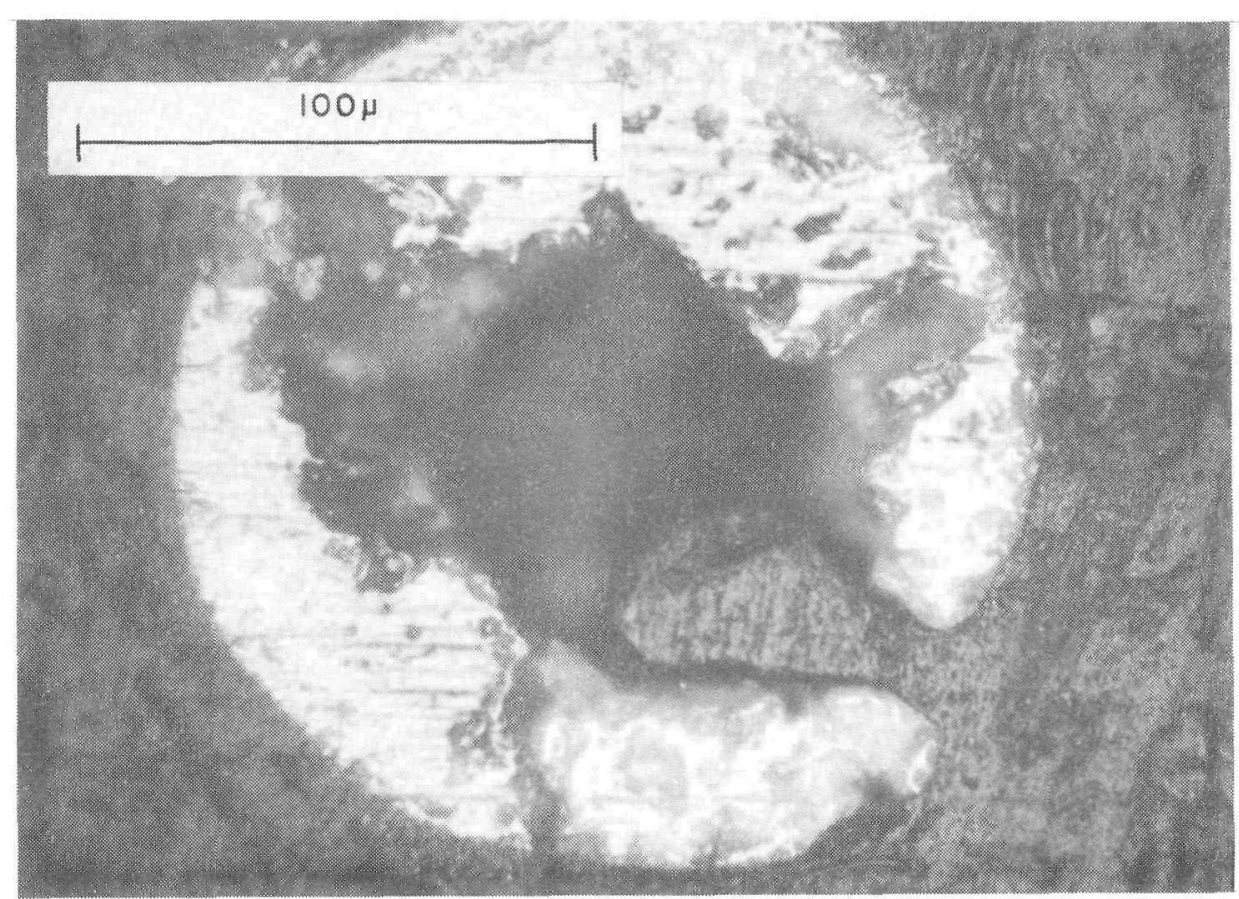

Figure 128. Oxidized particle with hollow center

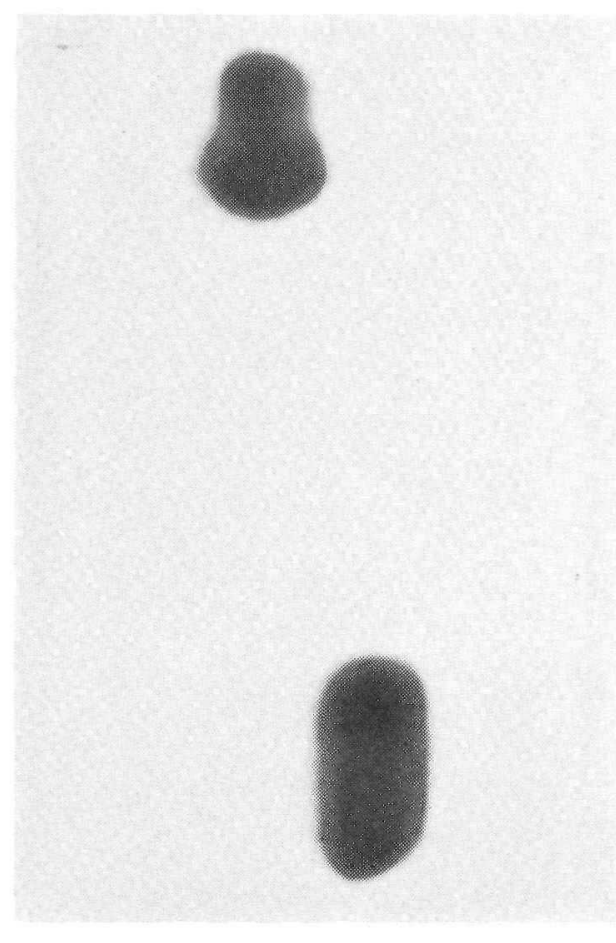

a. Upper particle swelling

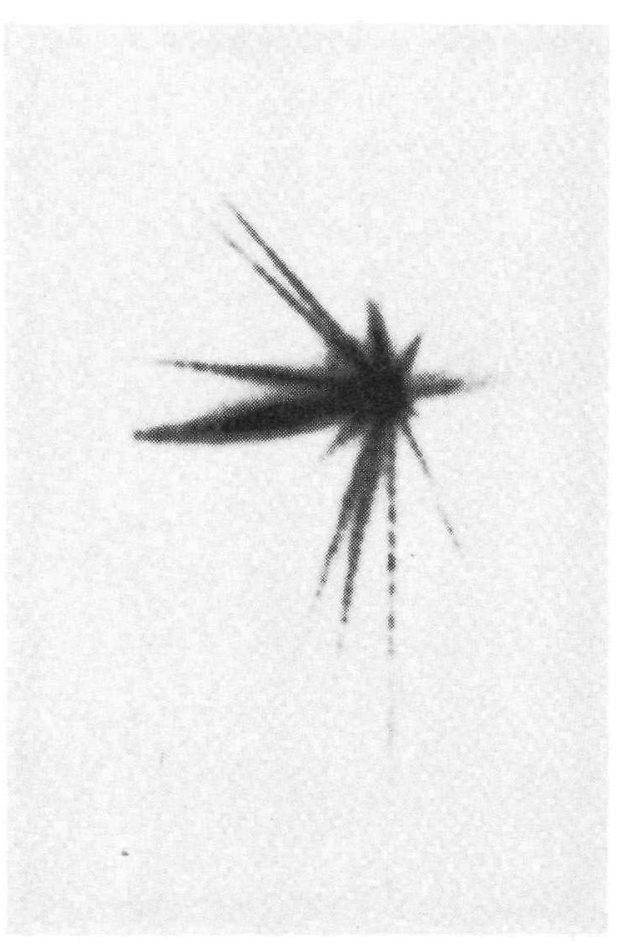

b. Same particle fragmenting Figure 129. Fragmentation of single particle 
The results of these studies suggest that the probable mode of disintegration of zirconium hydride-uranium fue 1 rods is a strong function of their re-entry trajectory, which in turn depends primarily upon the ejection altitude. The disintegration may include some or a11 of the following steps:

1. gradual heating of the more or less intact fuel element, resulting in a stripping of the cladding and loss of hydrogen,

2. continued aerodynamic heating leading to more rapid oxidation, which in turn releases more heat. As a result, a fairly coherent oxide layer is created that contains a molten metalif core,

3. ejection of the molten material by release of hydrogen or fission products, or mechanical failure of the fuel rod as a structure, and

4. further reaction and disintegration of the molten material resulting, under favorable circumstances, in a complete, explosive disintegration.

Thus the elements exist for adequate dispersal of fuel rod materia1. The proper sequence of events, the mechanisms leading to more complete dispersa1--indeed, all quantitative relationships--remain to be determined.

\section{References}

1. E. J. Philbin, Re-Entry and Disposa1 Phenomena for NAPS, Third Quarterly Report (AE 62-0683), General Dynamics/Astronautics.

2. M. Zlotnick, et a1., Investigation of Re-Entry Destruction of NAPS, AFSWC-TR-61-69, AVCO Corp., Wilmington, Mass. (RAD-TR-61-28).

3. E. M. Sparrow, "Radiation Characteristics of Cylindrical Enclosures," J. Heat Transfer, 1962, pp 73-81.

4. T. B. Reed, "Growth of Refractory Crysta1s," J. App1. Phys., 32, 12 (Dec 1961). 


\title{
AEROSPACE NUCLEAR SAFETY RE-ENTRY \\ FLIGHT TEST PROGRAM
}

\author{
A. J. Clark, Jr. \\ Sandia Corporation
}

The complex satellites and spacecraft of recent years demand larger amounts of auxiliary electrical power than can be readily or economically produced by batteries, solar cells, or chemical means. Long-1ived orbital vehicles, especially the manned versions now under development, accentuate the demands for space power.

Nuclear power sources offer the obvious solution for some of these power requirements. Research work, initiated several years ago under contracts from the AEC and DOD, has resulted in the development of functional nuclear systems for the production of power for these applications. There are two general types of Systems for Nuclear Auxiliary Power (SNAP's): radioisotopic systems and nuclear reactor systems.

Radioisotope-fueled generators rely on the decay process of special radioisotopes to produce thermal energy. Through the thermoelectric process this thermal energy is converted directly into usable electric energy without the aid of rotating generating equipment. Systems of this type are currently limited to relatively low power outputs (several hundred watts).

Reactor power supplies use nuclear reactors to produce thermal energy. This thermal energy is converted into electrical energy either by direct thermoelectric conversion or by rotating-type generators. Systems of this type are capable of producing hundreds or thousands of watts.

Also under development are systems for propulsion using heat-transfer rockets that derive their heat from nuclear reactors. The two main examples of these systems are Rover, a series of nuclear rocket engines currently being tested, and Pluto, a nuclear ramjet power plant for an Air Force weapons delivery system.

Because of the radiation hazards and peculiar environments inherent in the use of nuclear space power sources, the AEC decided to designate a specific group to study the safety aspects of these devices. In March 1962, Sandia Corporation accepted the responsibility for the Aerospace Safety Program for the Atomic Energy Commission, as described in Paper II-3 by J. L. Colp. This program includes the responsibility for safety flight tests of all aerospace nuclear systems.

Initial tests are being directed toward studies of re-entry burnup characteristics. Re-entry burnup of SNAP units and their attached payloads may be investigated by one or more of the following three methods:

1. simulation of the re-entry burnup of SNAP units in ground test facilities,

2. theoretical analysis of the re-entry burnup of SNAP units, and

3. re-entry flight tests of SNAP units.

At present, full simulation of all aspects of the re-entry burnup of SNAP units is impossible using ground-based test facilities. Ground-based test facilities, however, can be and are being used to investigate many specific areas of interest in the re-entry burnup problem. 
The theoretical analysis of re-entry burnup requires knowledge of the reentry trajectory and attitude of the SNAP-unit/payload combination. Information is also required on the aerodynamic heat transfer to the combination and the structural modes of failure of the combination. Since the power-supply/payload combination is generally of a complex shape with a complex internal structure, many simplifying assumptions in the analysis of structural burnup and breakup are required. Even in the best theoretical analysis, additional experimental results are often needed for use in the theory.

Because of the present limitations in ground test facilities and theoretical methods, re-entry flight tests of nuclear power supplies are required. The re-entry flight tests will (1) investigate nuclear power supply disassembly characteristics and burnup, (2) obtain data on basic re-entry burnup not obtainable in ground facilities, and (3) obtain experimental re-entry burnup data for correlation with the results of ground-test facilities and theoretical analyses.

The overall flight-test program is presented in chart form in Figure 130 . Flight testing embraces three areas of endeavor: re-entry system design and deve1opment, flight-test launch and range operations, and flight-test data analysis. These areas are further subdivided as indicated in Figure 130.

Launching of the first flight-test system in this safety program occurred in May 1963. This system, which was refered to as Re-Entry Flight Demonstration No. 1 (RFD-1), was conducted on a NASA SCOUT missile flown from Wallops Island past Bermuda.

The SNAP-10A reactor, designed and developed by Atomics International, was selected for the first re-entry flight demonstration since it is currently scheduled to be the first reactor-type nuclear auxiliary power supply for space application. The RFD-1 investigated pertinent aspects of the proposed re-entry burnup of the reactor to determine the effectiveness of this method for core disposal.

The design philosophy adopted by Atomics International for the first SNAP-10A system includes certain mechanical disassembly features to a1low early exposure of the reactor core to re-entry heating. The sequence necessary to expose the core is as follows:

1. separation of a fusible link to eject the beryllium reflector assembly,

2. burnoff of the NaK pipe and pump radiator,

3. separation of the core-can lid by melting of a lip weld, and

4. separation of the fuel-element from the can by inertial forces.

The primary objective of the flight test was to provide experimental evidence to support the effectiveness of the reactor disassembly design. Ejection of the fuel elements into the air stream at a high altitude should result in exposing individual elements to a maximum amount of heat and should provide the best opportunity for complete burnup.

Preliminary calculations indicated that aerodynamic heating alone would be insufficient to ensure complete ablation of the ejected simulated SNAP-10A fuel element. The fact was recognized, however, that the aerodynamic heating effect could be negligible compared to the exothermic chemical reactions of uranium and zirconium with the air. The lack of knowledge and the ultimate importance of uranium-zirconium hydride (UZrH) fuel burnup suggested that a fue1-burnup experiment be included in this flight test. Hence, a secondary objective, to be included only if it would not interfere with the primary objective, was an experiment to attempt to evaluate the ablation of full-scale UZrH fuel elements containing depleted uranium. This experiment served to evaluate optical instrumentation techniques. 
Sandia Safety Flight-Test Program

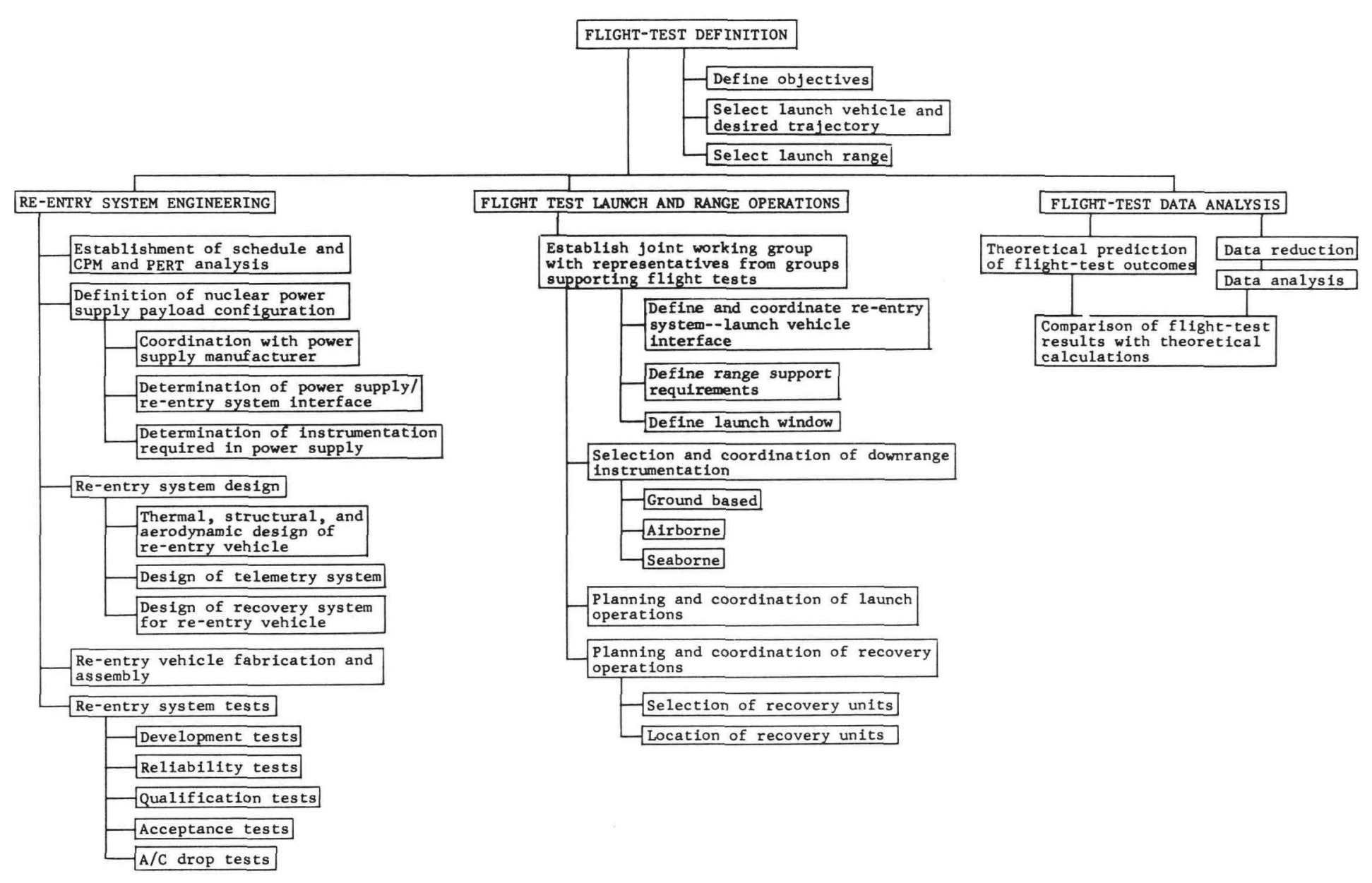


To accomplish this secondary objective, the re-entry system included two groups of simulated fuel rods.* A group of 12 full-scale, simulated SNAP-10A fuel rods which were hollow and filled with a tracer material was ejected from the RFD-1 re-entry system at the start of re-entry. The second group of fuel rods consisted of three short cylinders of simulated fuel-rod material mounted on the SNAP-10A reactor base ring. Recovery of the re-entry system would have permitted examination of these samples after they had experienced re-entry heating.

Inability to simulate closely the heating from an orbital decay trajectory (because of the limitations of the carrier vehicle and available ranges) will necessitate extrapolation of the results of this flight test to orbital decay re-entry.

The following flight requirements were defined as necessary for RFD-1:

1. The flight must result in the re-entry of a full-scale SNAP-10A reactor mockup attached to a re-entry vehicle and instrumented to investigate reactor disassembly and burnup resulting from reentry aerodynamic heating.

2. Simulated SNAP-10A fuel rods must be ejected from the re-entry vehicle at high altitude to permit investigation of burnup resulting from re-entry aerodynamic heating.

3. The re-entry velocities must be close to orbital.

4. The re-entry angle must be as shallow as possible consistent with range and instrumentation limitations and launch-vehicle guidance accuracy.

5. The re-entry burnup portion of the trajectory must occur near an island suitable for installation of ground-based instrumentation including radars, telemetry receivers, and optical equipment.

6. A11 radioactive reactor components must be simulated by nonradioactive materials to preclude nuclear hazards.

7. Recovery of the SNAP-10A re-entry system should be accomplished for visual evaluation of the reactor, the attached fuel samples, and the re-entry vehicle (RV) after re-entry.

A planning sketch of the RFD-1 flight presented in Figure 131 shows planned trajectory and downrange instrumentation.

During the RFD-1 flight, the re-entry system was tracked by radars located on Bermuda and Wallops Island. Optical coverage of the burnup of the re-entry vehicle and the external fuel rods, which contained tracer material for determination of burnup time, was provided by optical instrumentation located on Bermuda and in three aircraft along the flight path. The flight was therefore at night and, to improve coverage, was made during the dark of the moon. Telemetry transmission from the re-entry system was received by stations on Bermuda, in three aircraft, and on two surface ships.

Recovery of the re-entry vehicle was to be effected by three surface ships, with aid in locating the RFD-1 re-entry system being furnished by two aircraft.

"'Simulated fuel rods" refers to rods of depleted uranium-zirconium hydride. 


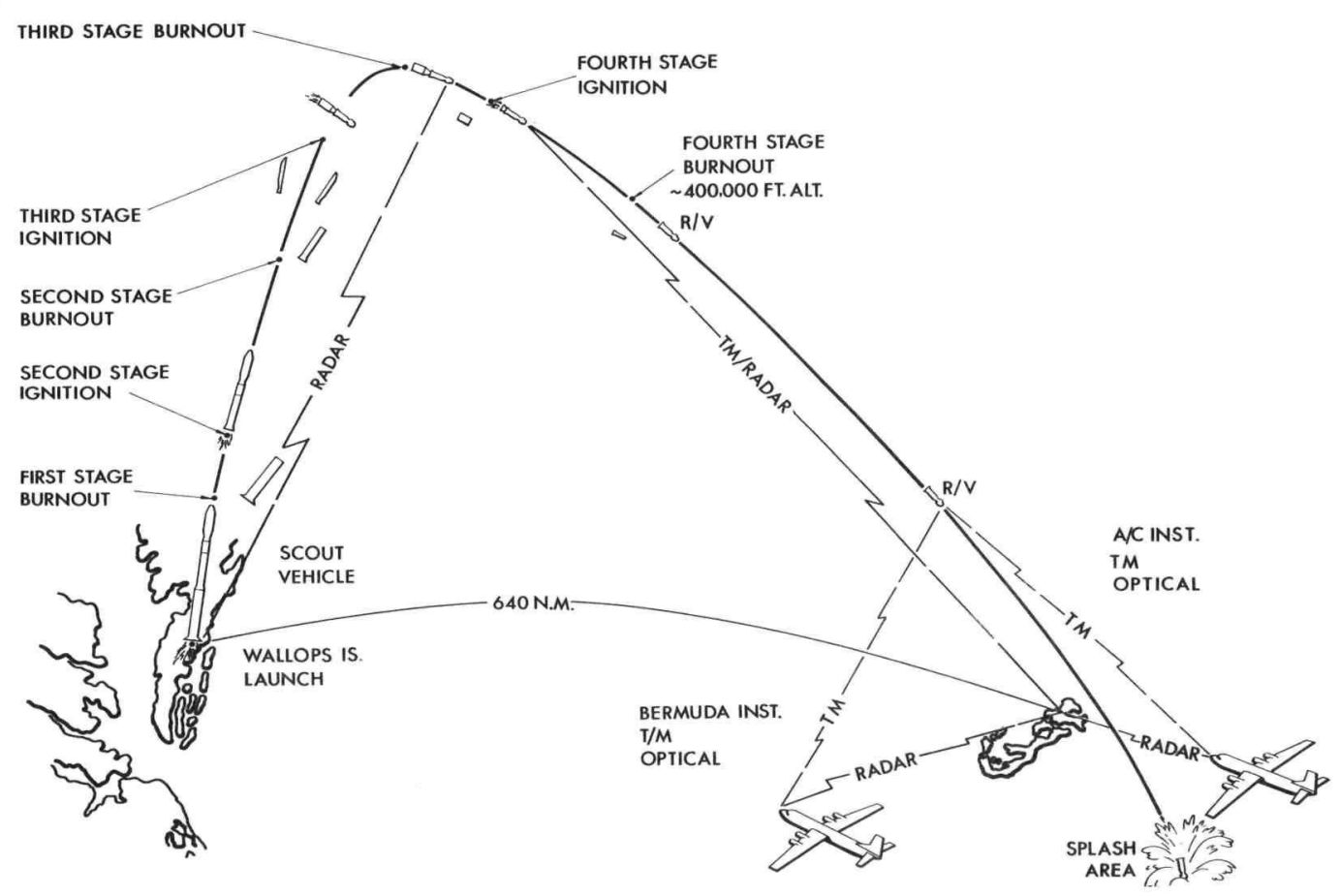

Figure 131. SNAP-10A safety flight test

Important factors among those considered in the selection of a launch vehicle for RFD-1 were vehicle performance, vehicle availablility, and budget limitations. The vehicle had to be able to place an adequate payload into a shallow angle reentry at high velocities, and it had to be available for a launch in the first quarter of 1963. The NASA four-stage, solid-propellant Scout launch vehicle was selected for the RFD-1 launch vehicle because it was the most economical launch vehicle which met the requirements (see Figure 132). In addition, NASA had been using the Scout for re-entry flight tests impacting southeast of Bermuda in a flight plan similar to that for RFD-1.

The re-entry system (Figure 133) developed to accomplish the flight objectives of RFD-1 consisted of a SNAP-10A reactor mockup, the re-entry vehicle with telemetry, the ejection and recovery system, and the external fuel-rod experiment.

The ful1-scale SNAP-10A reactor mockup was fabricated and instrumented by Atomics Internationa1. By joint agreement between Atomics International and Sandia Corporation, the reactor-RV interface and instrumentation requirements were defined and the required deviations from an operational SNAP-10A reactor were determined. Actual SNAP-10A reactor parts were used wherever possible, with the following deviations:

1. The beryllium reflectors and control drums were replaced by aluminum components which were designed to simulate the shape and the clearance from the core can.

2. The NaK coolant was omitted from the system to reduce weight, to prevent obscuring of the tracer material in the external fue1-rod experiment with the large NaK flare, and to prevent adverse effects of the extension of the region of RF blackout. 


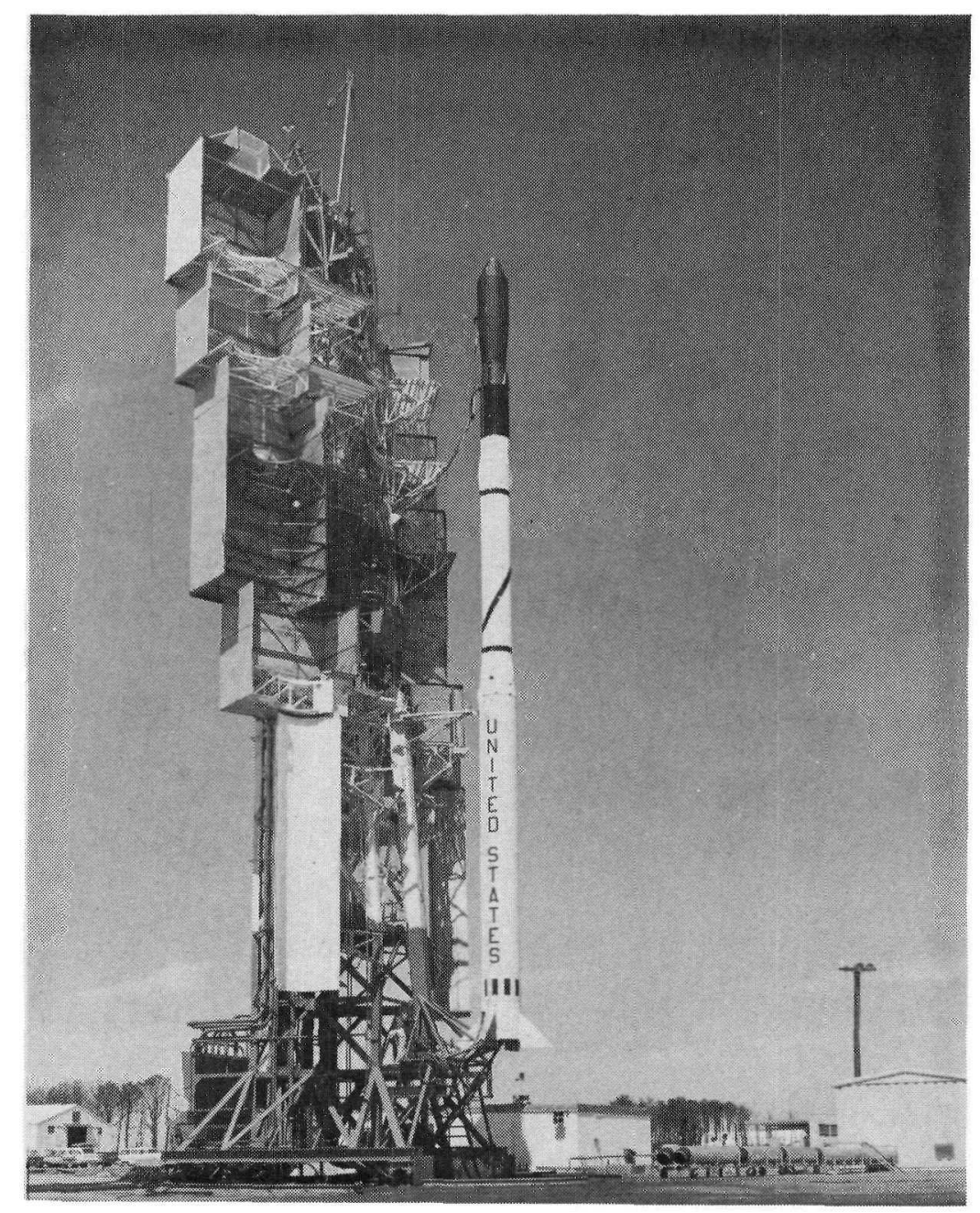

Figure 132. Scout vehicle

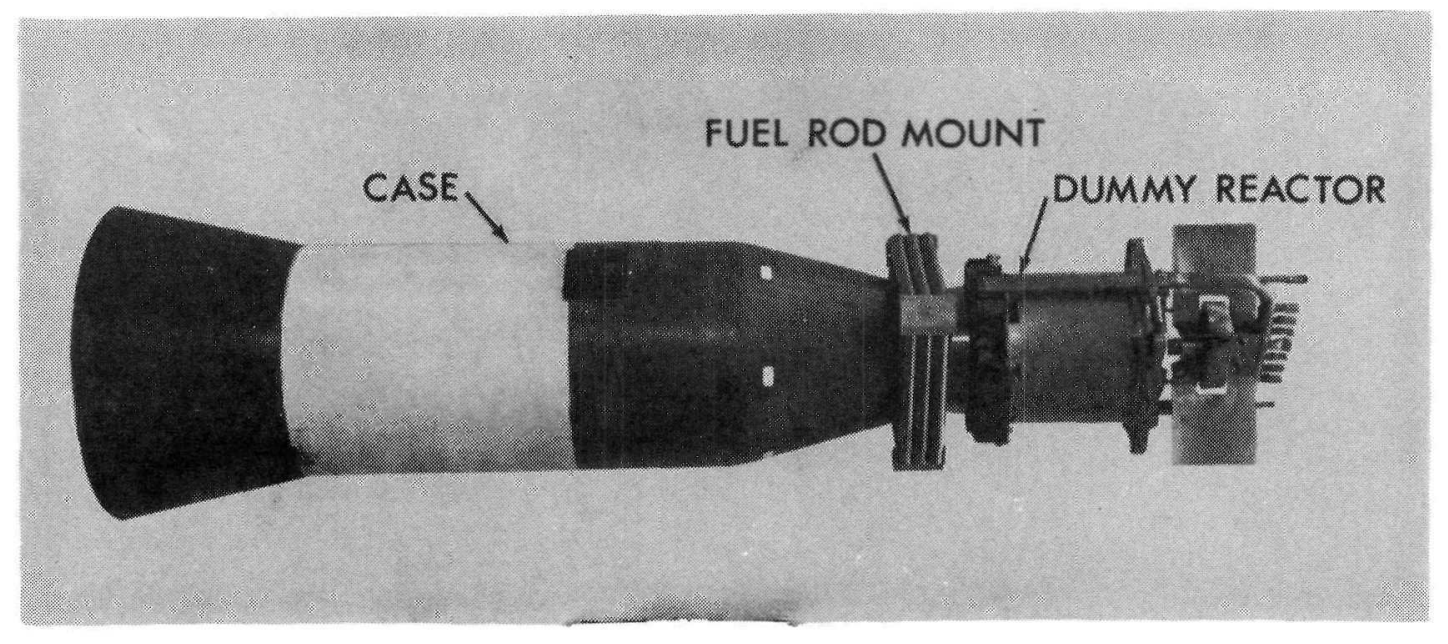

Figure 133. RFD-1 re-entry system 
3. The fuel-rod complement and internal beryllium reflector were also removed from the core can. These components were removed since theoretical studies showed that their removal would not appreciably affect the heat transfer to the core can.

The elimination of these components permitted the inclusion of the external fue1-rod experiment on RFD-1.

The reactor was extensively instrumented with 21 thermocouples to measure temperatures on the fusible band, the band support, the band weld, the band standoff, the fins, the NaK tube, the base of the NaK pump, the lip weld, the core vessel wall, and the heat meter attached to the reactor base ring. Six switches were mounted to monitor the reflector ejection and core vessel disassembly. Three cylindrical pieces of nonradioactive material were attached to the base of the reactor to simulate the reactor fuel rods. Two pieces were 1-1/4 inches in diameter, and one piece was $1 / 2$ inch in diameter and 1-1/4 inches 1ong. A copper heat meter 1-1/4 inches in diameter and 1-1/4 inches 1ong was fastened to the reactor base. These cylinders were added to permit recovery of simulated fuel rods that had experienced re-entry heating. Since the cylinders had to be mounted where they would not interfere with the main objective of investigating reactor disassembly, a heat meter was required in the same location to determine the re-entry heat input at this location. tem were:

Complicating factors in the design and development of the RFD-1 re-entry sys-

1. stringent volume and weight limitations imposed by the scout launch vehicle and its heat shield;

2. an early launch date requiring tightly scheduled design, development, and testing efforts;

3. requirements to build the re-entry vehicle around the fourthstage motor and still attain an adequately stable aerodynamic shape, and to keep an acceptable center-of-gravity location by ejection of the fourth-stage motor;

4. severe aerodynamic heating inputs to the re-entry system;

5. a complex reactor shape making burnup analysis difficult; and

6. large changes in re-entry system shape, weight, center of gravity, and aerodynamic coefficients during re-entry resulting from reactor burnup and re-entry vehicle ablation.

Re-entry system (RS) design was initiated by a theoretical study to select the most stable re-entry vehicle shape compatible with the Scout heat-shield requirements. Once this shape had been selected and defined, layouts and RS design began. Computations were initiated on trajectories based on theoretical aerodynamic coefficients. Aerodynamic force tests were conducted on scale models of the reentry system for several stages of reactor disassembly in the Sandia transonic (Mach 0.5 to 3.0) and hypersonic (Mach 7) wind tunnels and the Comell Aeronautical Laboratory 40-inch shock tunnel (Mach 11 to 20) (Figure 134). The objective of these tests was to determine aerodynamic coefficients for stability analysis and trajectory calculations. Aerodynamic heating tests were conducted on full-scale and quarter-scale models (Figure 135) in the Arnold Engineering Development Center (AEDC) 100-inch hotshot facility (Mach 17 to 21) to determine heating inputs to the RS. The quarter-scale model was later tested in the Rhodes and Bloxsom 60-inch hotshot tunnel for confirmation of test results. 
V-2
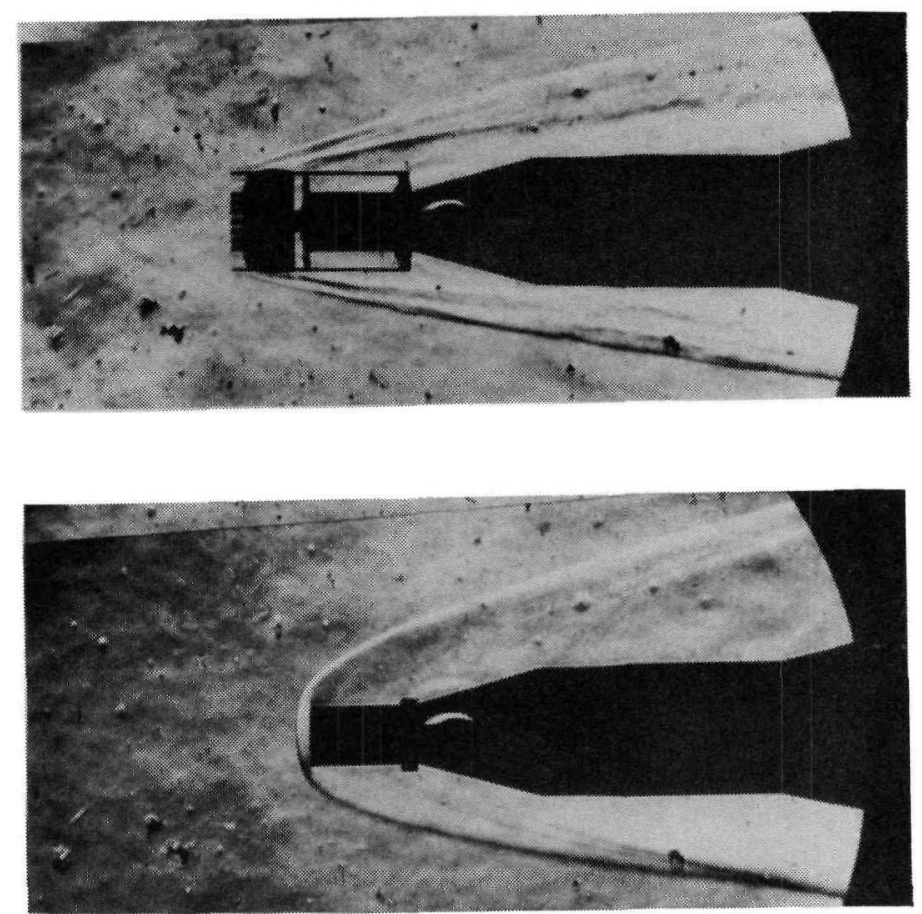

Figure 134. Aerodynamic test models

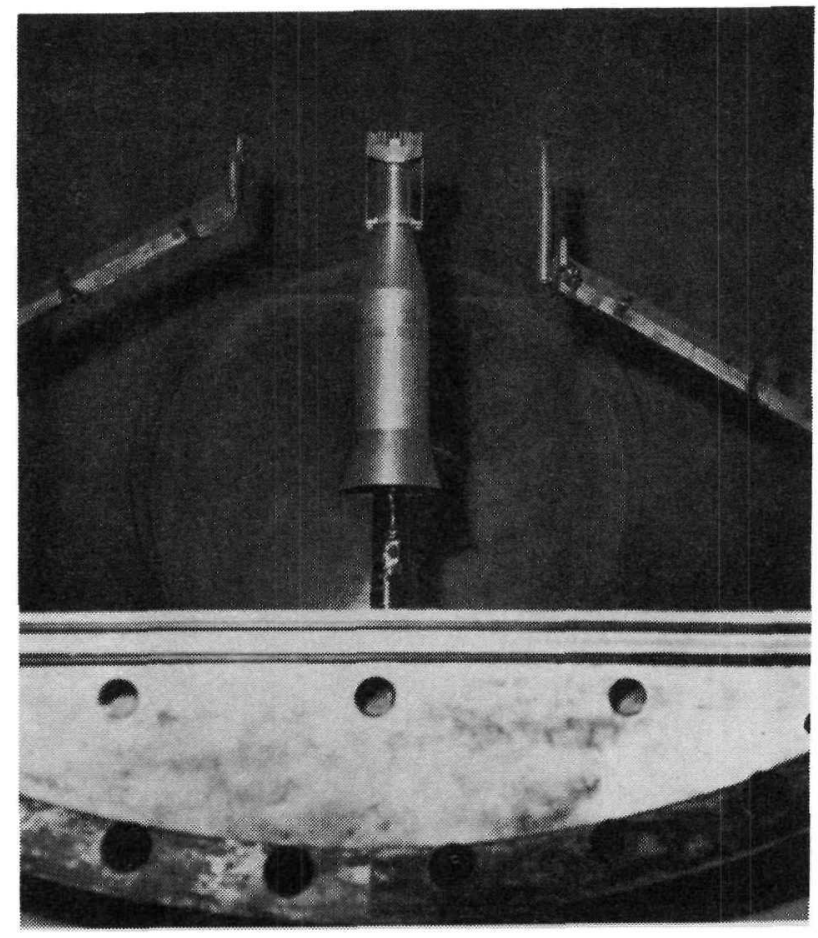

Figure 135. Aerodynamic heating test of quarter-scale model 
The re-entry vehicle was designed to perform several functions:

1. to provide a mounting to support the reactor and a location for mounting the external fuel-rod experiment,

2. to telemeter data from the thermally protected telemetry package and antennas,

3. to prevent reactor tumbling by means of an aerodynamically stable shape,

4. to eject the fourth-stage motor after burnout, and

5. to provide parachute deceleration before water impact and recovery aids after water impact.

The major systems of the re-entry vehicle were the re-entry vehicle she11, the motor ejection system, the recovery system, the telemetry system, and the external fuel-rod experiment.

Testing of RV designs was conducted in the plasma jet and radiant heat facility at Sandia to simulate the heating rates expected during re-entry. The thickness requirements for the ablation materials were based on theoretical calculations made on the Sandia thermoanalog (passive analog computer). Although early studies were based on theoretical aerodynamic heating rates, final calculations used the measured heat inputs from the AEDC 100-inch hotshot tunnel tests (Figure 135).

The RV was made up of an outer ablation she11, a layer of insulation, and the support structure. As is the normal practice, the insulation acted as part of the support structure. The ablation and support structure material could be bonded into a single unit because of the similarity in thermal expansion of the two materials and the use of the same resin in both parts. This integral design simplified manufacture, reduced weight, and eliminated the need for a flexible bond between the ablation material and the support structure. Since RF cannot be transmitted through charred phenolic fiberglass, a clean-ablating teflon sleeve was used for thermal protection over the telemetry and $\mathrm{c}$-band antenna areas. Because of the higher thermal expansion of teflon, a cored RTV-11 bond was required to attach the teflon antenna window to the case. A phenolic fiberglass retaining sleeve was bonded with FM-1000 over the forward edge of the teflon to maintain a smooth transition surface and prevent aerodynamic forces from loosening the teflon. A phenolic fiberglass mount for attaching the reactor was provided on the forward end of the RV. The fiberglass provides adequate thermal protection for the instrumentation cables from the reactor through the nose of the RV. Thin ablative and insulating coatings were applied to the antenna, the parachute door cover, the 0.04-inch fiberglass liner, and the flare area. To obtain information on the re-entry she11 ablation during flight, two ablation depth sensors at different depths were installed at two locations on the vehicle.

Since ejection of the fourth-stage motor from the re-entry vehicle was required to obtain a re-entry system center of gravity that would render the system aerodynamically stable, this design was incorporated in the re-entry system. Important requirements in the design were high reliability, simplicity, small size, and light weight.

The separation device was designed to serve as the structural link between the fourth-stage motor of the Scout launch vehicle and the re-entry system. The separation system consisted of a motor adapter, a coil spring between the motor adapter and the re-entry system structure, a Marmon clamp with explosively actuated nuts to hold the re-entry system structure to the motor adapter, and two 1-KS 40 Atlantic Research Corporation retrorockets.

The requirement for recovery was added after initiation of the re-entry vehicle design. Important factors affecting the design of the recovery system were: 
1. extremely small volume available for the recovery system, and

2. the necessity of placing most of the recovery system in the flare portion of the she11. Since this requirement tended to move the CG of the $R V$ rearward, the recovery system weight had to be kept down to prevent an adverse CG location.

The recovery system was designed to include a solid-canopy parachute, drogue gun, flotation bag, gas bottles, flashing light, dye marker, search and Recovery and Homing (SARAH) beacon, and whip antenna. The 7-foot-diameter, solid-canopy parachute was selected after drop tests and sled tests on the Sandia sled track designed for testing parachute deployment and flotation bag inflation. The parachute was reefed at the skirt with a 2 -foot line to reduce loads at parachute deployment. The drogue gun was a gun-type device that provided operative energy by the firing of a steel slug. The gas bottles were thermally insulated to prevent a large buildup in pressure from re-entry heating. The SARAH beacon is a highly shock resistant unit (in excess of $100 \mathrm{~g}$ 's) transmitting on a frequency of $235 \mathrm{mc}$.

The recovery system was designed so that at an altitude of approximately 21,000 feet two barometric switches, or timer signals from the TM package, would simultaneously fire the drogue gun and the gas-bottle explosive squib. Firing of the drogue gun would eject the parachute cavity cover, deploy the parachute, and energize the flashing light. Deployment of the parachute would initiate three Holex pyrotechnic cutters to cut the reefing line 10 seconds after deployment. Ejection of the parachute cover would then allow the SARAH beacon antenna to extend. Firing of the explosive squib would permit the compressed $\mathrm{CO}_{2}$ from the gas bottle to in flate the flotation bag to fill the cavity vacated by the ejected fourth-stage motor. The parachute would decelerate the descent of the RS from approximately 700 fps to approximately $100 \mathrm{fps}$ at water impact. At water impact, the SARAH beacon would be energized by two salt water switches or an impact deceleration switch wired in parallel. After water impact, the RS would float in a near vertical position with approximately the rear third of its length extending above the water.

The telemetry system (see Figure 136) for RFD-1 was designed to gather and transmit data on the following:

1. the condition of the SNAP-10A reactor,

2. the orientation of the re-entry vehicle,

3. the vibration and acceleration induced in the re-entry vehicle by the Scout missile,

4. the condition of the shell of the re-entry vehicle, and

5. the pressure in the fourth-stage motor chamber (requested by NASA).

Integral with the telemetry system were a C-band beacon for radar acquisition and tracking, and an elapsed time generator and programmer to control the fourthstage motor separation, the separation of the external fuel-rod experiement, and the sequence of the operations of the recovery system.

Factors affecting the design of the telemetry system were:

1. limited volume and weight,

2. severe vibration during fourth-stage booster burning,

3. high-altitude trajectory, requiring sealing of the telemetry compartment,

4. 1oss of RF transmission during re-entry because of ionization in the vehicle plasma sheath, 
5. development of telemetry and $\mathrm{C}$-band beacon antennas to survive re-entry heating, and

6. shielding and isolating millivolt signals (thermocouples) from effects of $\mathrm{RF}$ radiation and ionization during re-entry.

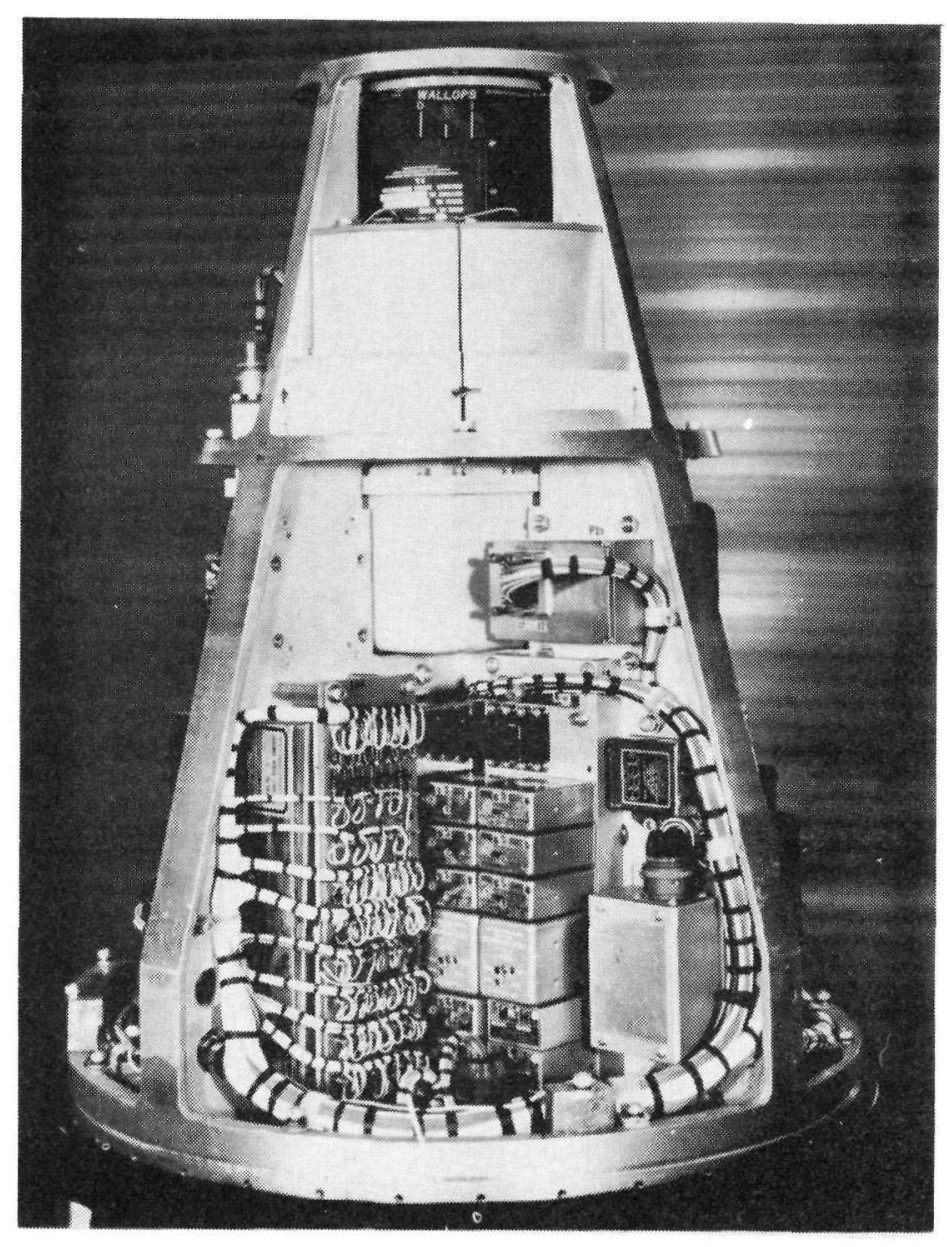

Figure 136. RFD-1 telemetry system

The external fuel-rod experiment consisted of an aluminum, aluminum-magnesium mounting structure attached to the re-entry vehicle nose and containing 12 simulated SNAP-10A dumy fuel rods. The structure was restrained from sliding forward by a torus-shaped, sintered tungsten ring weight. Explosive bolts and a wire cutter were used to release the two halves of the mounting structure. The structure and rods were deployed by the re-entry vehicle spin rate of approximately 2 revolutions per second upon a timer signal at an altitude of about 350,000 feet.

The fuel rods were identical in size and shape to SNAP-10A fuel rods except for a longitudinal hole filled with tracer material (Figure 137). The 12 fuel rods consisted of four groups of three identical rods. Each group had a different wall thickness and used a different tracer material. The tracer elements (gold, silver, barium, and strontium in order of decreasing wall thicknesses) were chosen with the overal1 experimental objective in mind. First, the experiment required elements 
for which the spectra were simple and easily identifiable. Because of the distance and the resulting lack of intensity for the re-entry test, the radiant energy had to be contained in the minimum spectral lines. In addition, the large number of other elements present during re-entry dictated a simple spectrum. It was necessary that the tracer elements not be present in other bodies undergoing the re-entry, either as intentional parts of the bodies or as impurities in the materials. Fina11y, the tracer elements had to be physically compatible with the fuel rods during re-entry.

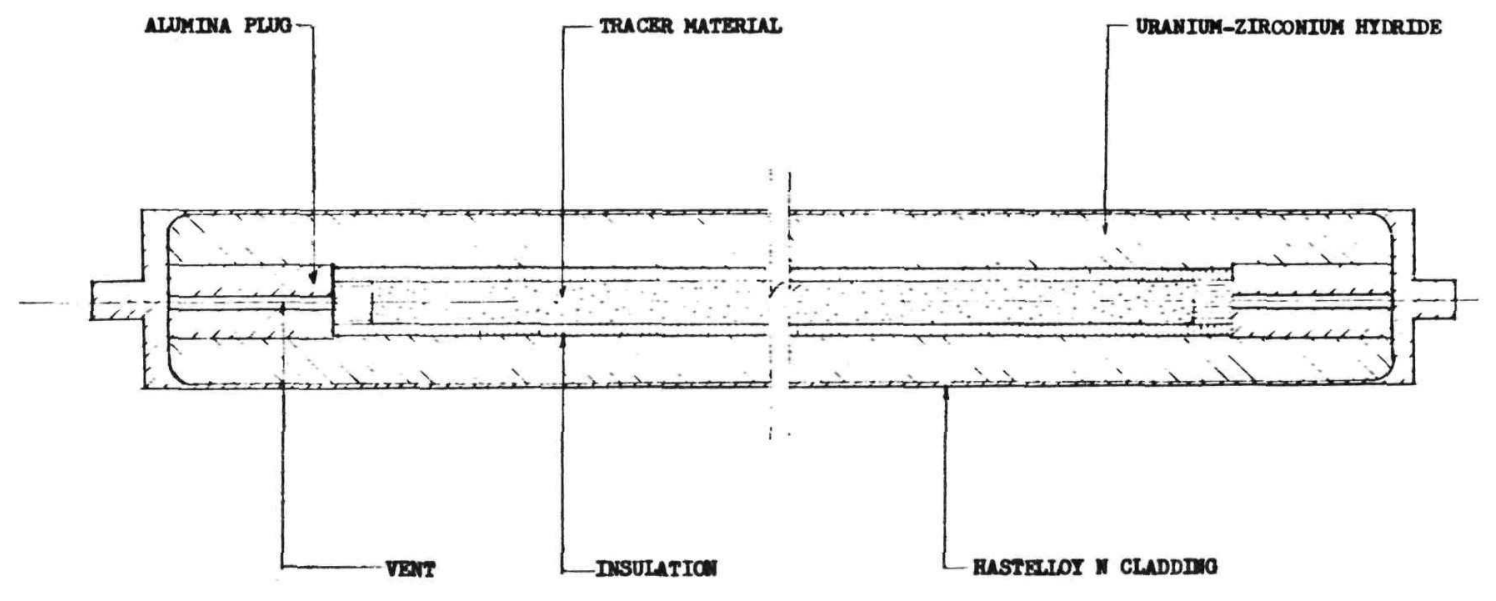

Figure 137. Fue1-rod experiment

Data on fue1-rod ablation was provided by optical instrumentation to determine the altitudes at which the rods burn through to the tracer material and by spectroscopic methods to permit determination of the tracer materials that were ignited and burning.

The RFD-1 was launched on the moonless night of May 22, 1963. Radar plots indicated that the trajectory was very close to normal except for being at a somewhat higher altitude. The RV was possibly as much as 10,000 feet higher than planned at apogee. Injection angle and velocity appear to have been close to the predicted values. The overall scout performance appeared good.

The payload performance was excellent. Telemetry and C-band blackout occurred at altitudes of about 200,000 and 178,000 feet, respectively, which were much later than predicted. No postblackout data was obtained from either telemetry or C-band equipment. Aircraft acquired SARAH signals but for only 20 seconds. The payload was not recovered. Figure 138 compares the actual events along the trajectory path with those predicted analytically with the aid of wind-tunnel tests. Radar data, temperature profiles, switch actuation, plate-camera photos, motion pictures, spectroscopic data, and changes in pitch and roll rates were used as cross checks in the determination of the times for events.

Reactor-temperature data appeared to be good through 350 seconds after launch with thermocouples reading high enough to permit comparison with anlytical studies. Figure 139 shows such a comparison for the aluminum pump fins. A11 thermocouples did not reach the failure temperature of the surrounding material before 1oss of telemetry, but a11 rose to a sufficiently high temperature to permit extrapolation to failure.

Figure 140 is a reproduction of a plate-camera exposure taken from Bermuda of the RFD-1 re-entry. Enlargements of these plate-camera photographs have provided valuable information on burnup and disassembly sequence. Chopped platecamera photographs have provided information for extending the trajectory beyond the point at which the $\mathrm{C}$-band beacon blacked out and radar tracking was lost. 


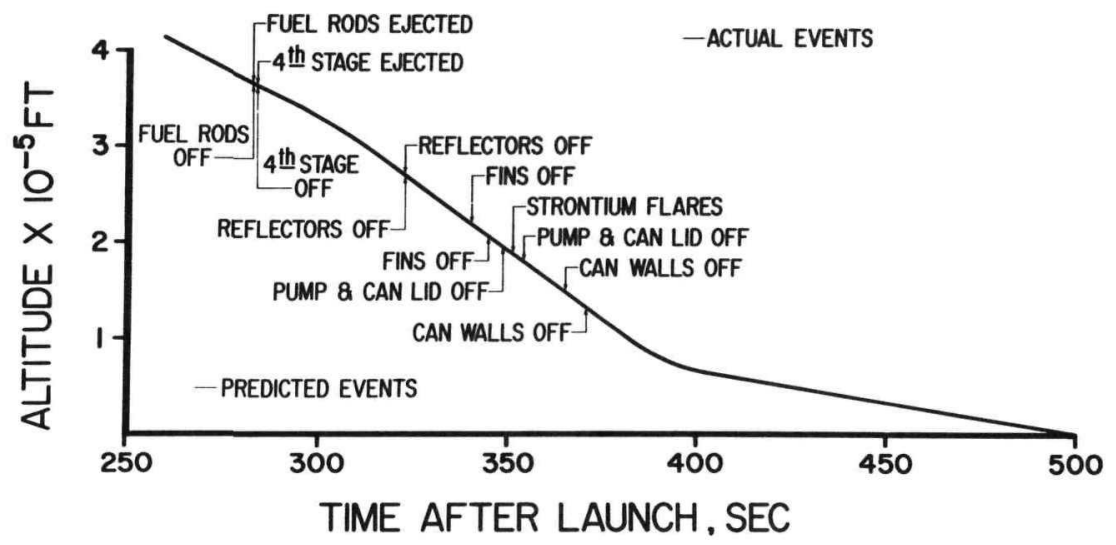

Figure 138. Trajectory (actual versus predicted events)

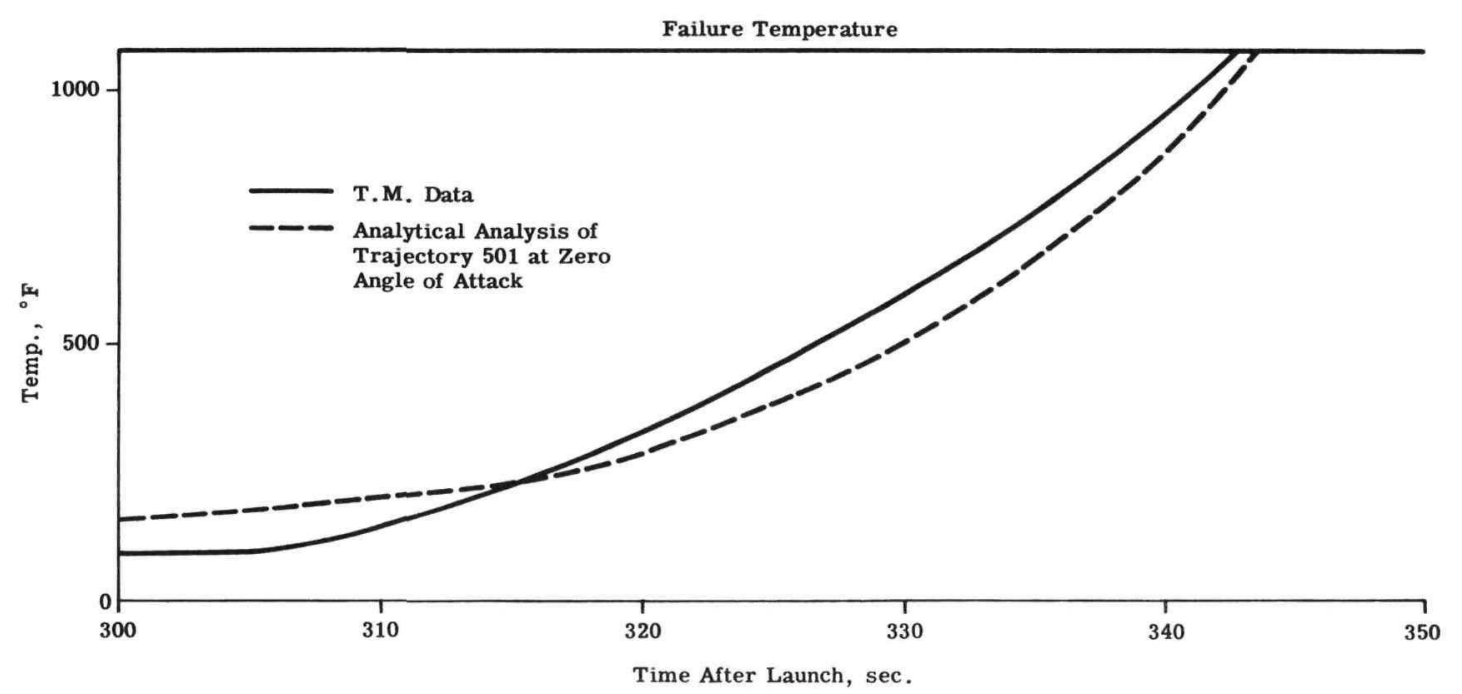

Figure 139. Time-temperature plot of the fins during re-entry

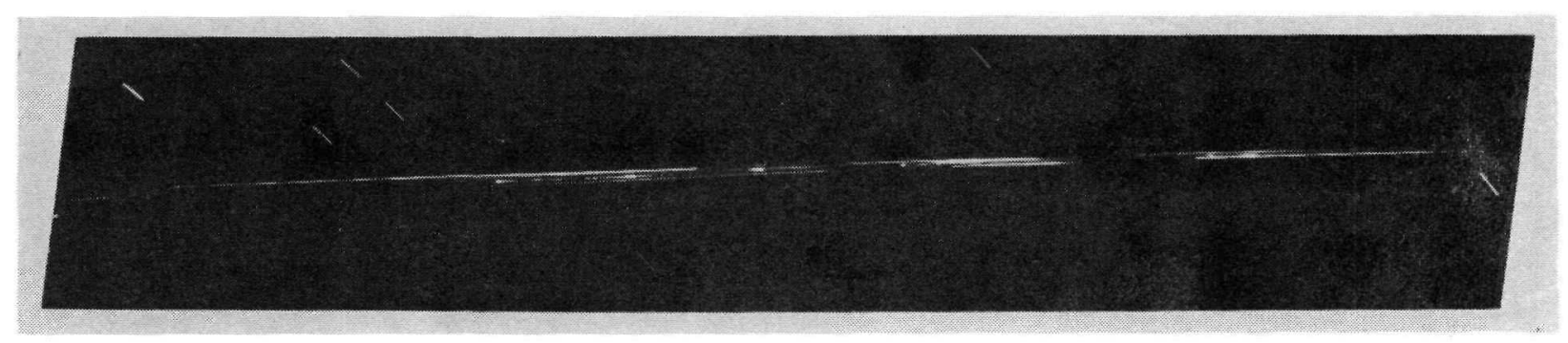

Figure 140. Plate-camera photograph of RFD-1 re-entry 
Design of a re-entry system for a second flight test has been initiated. It is tentatively planned to launch this second re-entry flight in the spring of 1964 . Figure 141 is an artist's conception of the system presently under development.

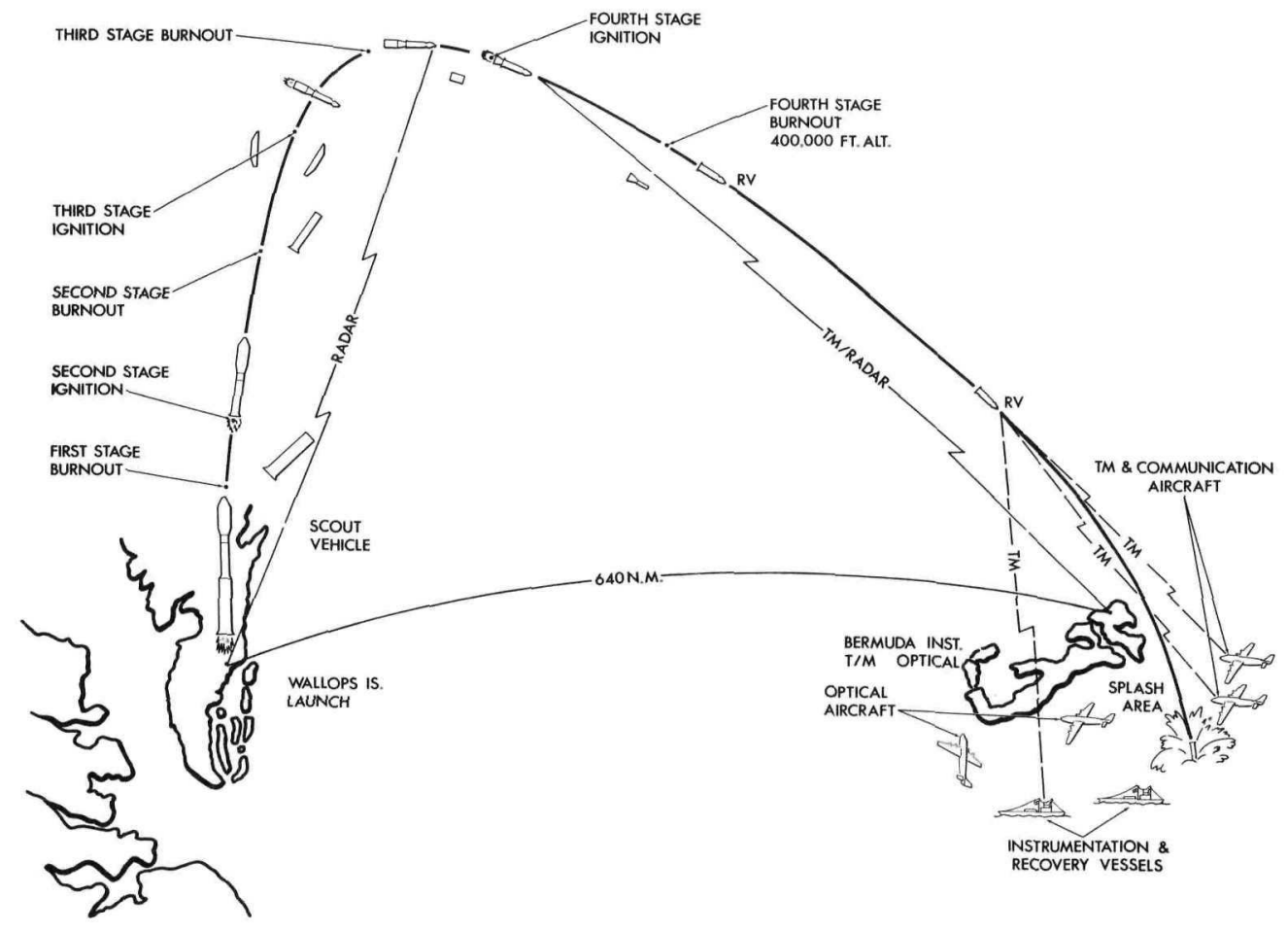

Figure 141. RFD-2 safety flight test

The payload, or nuclear power supply under investigation, will consist of a specially designed experiment based on a study of re-entry burnup of isotopic generators. The first objective of this flight will be to correlate actual thermal responses and disassembly events measured during the re-entry flight test with the calculated information. Thus, the test will aid in improving present analytical techniques for predicting re-entry burnup.

The second objective will be to determine burnup rates of fuel capsules used in present and proposed future isotopic generators. Optical coverage of the test, including a photometer and spectrograph used in conjunction with flare materials inserted in the fuel capsules, will be employed to determine burnup rates.

Additionally, it is hoped to attach some fuel and other material samples from which relative ablation rates and oxidation characteristics can be obtained when the re-entry vehicle is recovered.

For future nuclear safety flight testing, an attempt is being made to avoid demonstration-type flights except where these are necessary. It appears advantageous to perform re-entry flight tests to provide basic technical safety data that will be of a more general nature and may be applied to all re-entry studies.

Development effort for future flight tests for re-entry burnup information is being expended on particle collection systems. It is obvious that from a safety 
standpoint complete fuel burnup, in itse1f, is not sufficient information. To completely evaluate ground hazards, a knowledge is required of resulting particle size and distribution. The estimation of particle size is most difficult. It is planned to provide the unknown information from future flight tests.

Nuclear safety of some future aerospace devices is being assured by a design for intact re-entry. Future flight tests will be necessary to examine this concept adequately.

In conclusion, all of these aerospace nuclear systems may be used in earth orbital applications or for lunar missions, or even interplanetary missions. For each type of mission, a different range of re-entry trajectories and initial velocities must be investigated to provide the technical information required to evaluate the safety of each system. Thus, it appears that many and varied types of aerospace nuclear safety flight tests will be forthcoming to answer the myriad of technical questions on aerospace nuclear safety. 


\section{BLANK}




\section{RE-ENTRY BURNUP ENHANCEMENT OF HYDRIDED \\ ZIRCONIUM URANIUM ALLOY FUEL}

E. L. Foster, Jr.

Batte1le Memoria1 Institute

Introduction

A $\mathrm{ZrH}-$ uranium fuel element re-entering the atmosphere is influenced by many coupled effects, e.g., heat transfer to fuel elements, accelerations of the fuel elements, and the resulting molten-layer instabilities that are generated. The buildup of the instabilities in the molten layer is approximately inversely proportional to the kinematic viscosity of the molten material. In addition, the shedding of the molten material is directly proportional to the instabilities generated, and, thus, the liquid layer decreases in thickness as the instabilities increase. When the thickness of the liquid layer decreases, the heat transfer to the solid portion of the fuel rod increases. The shed molten material forms molten droplets whose size is directly dependent on the surface tension of the material. In general, the safe dispersal requirement of 1 -micron particle size or less may be achieved direct1y or by ignition and oxidation of the droplets that are produced. These processes would be enhanced by an increased surface area per unit mass (or volume). When the surface-area-to-volume ratio increases, the total heat capacity of the drop is smaller and the aerodynamic heating effects increase, thus encouraging gas-phase reactions with the infinite oxidizing atmosphere. A high vapor pressure also tends to encourage gas-phase reactions.

The objective of the Battelle study reported here was to determine the feasibility of changing the properties of the $\mathrm{ZrH}$-uranium fuel by use of certain additives in such a way that will enhance the atmospheric burnup upon re-entry from orbit. The effects of additions to the fuel, particularly those that could produce smaller droplet sizes during its re-entry melting, were investigated by both analytical and experimental methods.

Preparation and Hydriding of Alloys

Selection of Alloying Additions

Criteria used in the selection of the type and quantity of additions to be made to the zirconium-uranium fuel alloy were thermal-neutron cross section, difficulties in making the additions, and cost and availability of the additions. Elements not considered in this study were those totally insoluble in the fuel alloy, rare and extremely expensive, highly toxic, and/or very reactive and difficult to alloy. Also not considered were elements possessing thermal-neutron cross sections greater than 0.084 square centimeter per gram. The quantity of alloying additive was limited to amounts which would not add more than 0.00084 square centimeter per gram of alloy to the cross section of the fuel.

Twenty-seven alloying elements were chosen for study: lead, bismuth, magnesium, cerium, tin, silicon, aluminum, barium, calcium, niobium, strontium, yttrium, thallium, zinc, molybdenum, thorium, antimony, copper, chromium, nickel, vanadium, tungsten, tantalum, titanium, nitrogen, oxygen, and carbon. Four 
combinations of these alloying additions were also chosen:

1. barium and niobium,

2. tin and niobium,

3. tin and lead, and

4. tin and barium.

Selection of combinations of elemental additions was based upon results of initial tests. Two different procedures were used in combining the alloying elements with the fuel alloy. The Group 1 additions, which comprised the majority of the elements, were combined by supplying elemental additions directly to the molten alloy. The Group 2 additions, oxygen, nitrogen, and carbon, were added by mixing powders of the uranium compounds of these elements with $\mathrm{ZrH}_{2}$ powder and pressure bonding the mixtures.

\section{Melting Technique}

Zirconium-uranium alloys of Group 1 were prepared from reactor-grade materials as small buttons, each weighing approximately 120 grams, by inert-electrode arcmelting techniques. To produce satisfactory shapes for further fabrication and, at the same time, to measure the "castability" of the molten alloys, which reflects surface tension and viscosity, a special copper mold was designed and constructed. Each alloyed button was placed on the hearth of this mold and was heated until it became molten and dropped into the multisection cavity below. The extent of the metal flow into each horizontal section appended to the main cavity then defined semiquantitatively the castability of each molten alloy. The length of lateral penetration into each cavity was measured in sixteenths of an inch, the total number of sixteenths being designated the fluidity index of each alloy. The special test mold that was constructed is shown along with a typical casting in Figure 142.

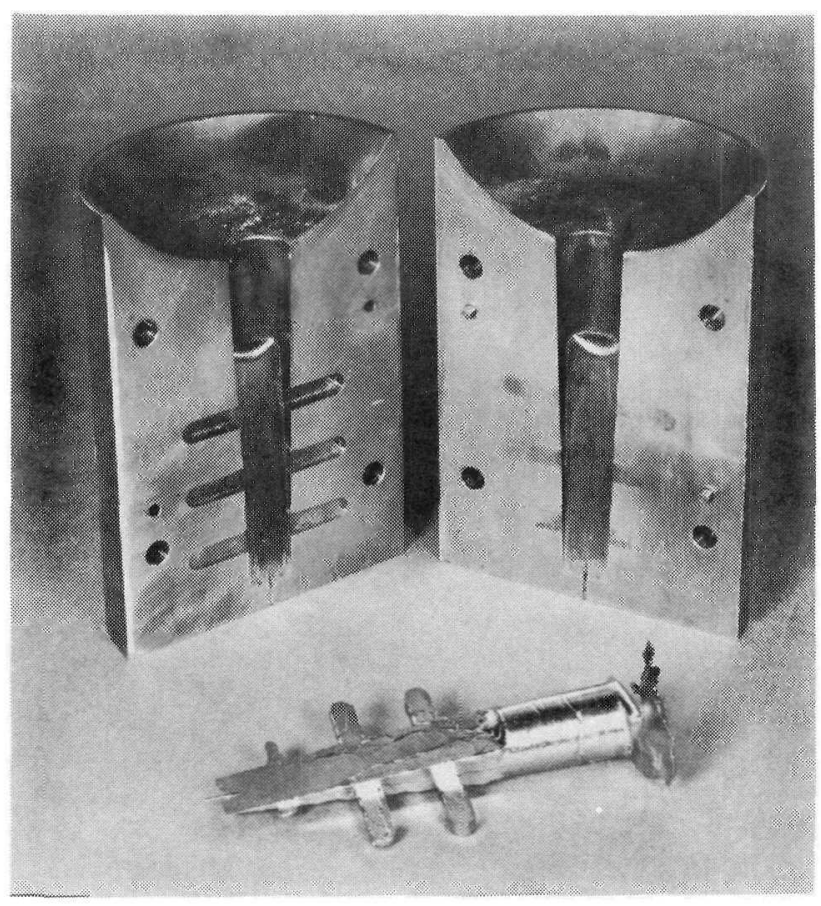

Figure 142. Fluidity test mold and sample casting 
Machining and Fabrication of the Alloys

After each alloy was cast and evaluated for its castability, it was radiographed to determine its soundness of structure. On completion of the X-ray examination, the riser and appendages were removed from each casting and its surface was machined to remove all cold shuts or surface irregularities. Each casting was then hot rolled to $1 / 4$-inch-diameter rod. The alloys were heated to $800^{\circ} \mathrm{C}$ for $1 / 2$ hour in an argon atmosphere before rolling. Approximately 18 passes and 8 reheats were necessary to reduce the castings satisfactorily to a 1/4-inch diameter. Each rod thus produced had a length of approximately 10 inches. The ability of each alloy to be fabricated was closely noted, and hardnesses were taken on each material with a standard Rockwell hardness tester after fabrication. A small sample was removed from each fabricated rod, mounted, polished, etched, and examined metallographically.

\section{Hydriding of Fabricated Alloys}

Alloy rods, after fabrication, were prepared for hydriding by filing the surfaces to remove cracks that might be present. Samples in lengths of $1 / 4$ inch and 1 inch were cut from each rod and given a final polish with dry 400-grit silicon carbide paper. Samples were then sealed in a Vycor reaction tube of a modified Sieverts apparatus, and the apparatus was evacuated to less than 0.05-micron pressure of mercury. A resistance furnace at $900^{\circ} \mathrm{C}$ was placed around the reaction tube, and the sample was degassed until pressure returned to that before heating. The temperature was then lowered to $875^{\circ} \mathrm{C}$, and hydrogen additions were begun. The hydrogen was produced by the thermal decomposition of $\mathrm{UH}_{3}$.

Evaluation of Alloys and Alloy Hydrides

$\underline{\text { Alloys }}$

The results of the castability tests and comments on the appearance and on the fabricability of the castings are given in Table I. The castability-test results indicated that additions which appeared particularly promising for increasing the fluidity of the base alloy were tin, niobium, cerium, barium, copper, lead, bismuth, vanadium, tungsten, calcium, and combinations of additions of barium and niobium, tin and niobium, and tin and lead. Elemental additions which appeared to decrease the fluidity of the alloy markedly were molybdenum, aluminum, chromium, thallium, and zinc.

The addition of certain alloying elements to the base fuel alloy greatly affected its fabricability. Additions of tin, yttrium, thallium, chromium, tungsten, calcium, and combinations of tin and barium and of tin and lead appeared to improve its fabricability. Additions of silicon, molybdenum and titanium, on the other hand, made fabrication more difficult, and the fuel alloy rods produced with these additions possessed extremely rough surfaces and numerous cracks.

The hardnesses for the alloys varied from $55.5 \mathrm{R}_{\mathrm{A}}$ for the $\mathrm{Zr}-10 \mathrm{U}-5 \mathrm{Sn}-1.6 \mathrm{Ba}$ a1loy to $71.5 \mathrm{R}_{\mathrm{A}}$ for the Zr-10U-2Mo a11oy. The base fuel a11oy (unhydrided) showed a hardness of $59.0 \mathrm{R}_{\mathrm{A}}$. With the exception of alloys containing barium, yttrium, and thallium, all alloys had hardnesses equal to or greater than that of the base alloy. Noticeable changes in the microstructure of the fuel alloy occurred with the addition of alloying elements. Increased grain size, the presence of mixed grain sizes, and varying amounts of second phases are some of the changes that occurred.

The hardnesses and descriptions of the microstructures of the base-fuel a1loy hydride and its modifications are presented in Table II. In general, upon hydriding the hardnesses of the alloys decreased and the alloys became somewhat embrittled. Several hydrides were so brittle that hardness readings could not be taken. Hardnesses for the hydrides ranged from 43.5 to $61.5 \mathrm{R}_{\mathrm{A}}$; the base ZrH-10U materia.1 exhibited a hardness of $49.0 \mathrm{R}_{\mathrm{A}}$. 
TABLE I

Castability and Fabricability of Zirconium 10 Weight-Percent Uranium Alloys, With and Without Additions

\begin{tabular}{|c|c|c|c|c|}
\hline Sample & $\begin{array}{c}\text { Alloy Composition } \\
\text { (Balance Zirconium) } \\
\text { wt } \%\end{array}$ & $\begin{array}{c}\text { Castability } \\
\text { Ratinga } \\
\end{array}$ & $\begin{array}{r}\text { Genera1 } \\
\text { Appearance } \\
\text { of Casting } \\
\end{array}$ & Fabricability \\
\hline 1 & $10 \mathrm{U}$ & 40 & Good & Satisfactory \\
\hline 2 & $10 U$ & 32 & Good & Satisfactory \\
\hline 3 & $10 U$ & 39 & Good & Satisfactory \\
\hline 4 & $10 \mathrm{U}$ & 38 & Good & Good \\
\hline 5 & $10 \mathrm{U}$ & 38 & Good & Satisfactory \\
\hline 6 & $10 \mathrm{U}$ & 45 & Good & Satisfactory \\
\hline 7 & $10 \mathrm{U}$ & 33 & Good & Satisfactory \\
\hline 8 & 10U & 38 & Good & Satisfactory \\
\hline 9 & $10 \mathrm{U}-1 \mathrm{Nb}$ & 20 & Good & Satisfactory - fair \\
\hline 10 & $10 \mathrm{U}-2 \mathrm{Nb}$ & 55 & Exce1lent & Satisfactory \\
\hline 11 & $10 \mathrm{U}-5 \mathrm{Nb}$ & 41 & Good & Satisfactory - fair \\
\hline 12 & $10 \mathrm{U}-2 \mathrm{Sn}$ & 36 & Good & Good \\
\hline 13 & $10 \mathrm{U}-4 \mathrm{Sn}$ & 34 & Good & Exce1lent \\
\hline 14 & $10 U-5 S n$ & 56 & Exce1lent & Excellent \\
\hline 15 & $10 \mathrm{U}-2 \mathrm{Mo}$ & 17 & Fair & Satisfactory \\
\hline 16 & $10 \mathrm{U}-5 \mathrm{Mo}$ & 39 & Good & Poor \\
\hline
\end{tabular}

TABLE II

Hardnesses and Microstructures of Zirconium 10 Weight-Percent Uranium Alloy Hydrides

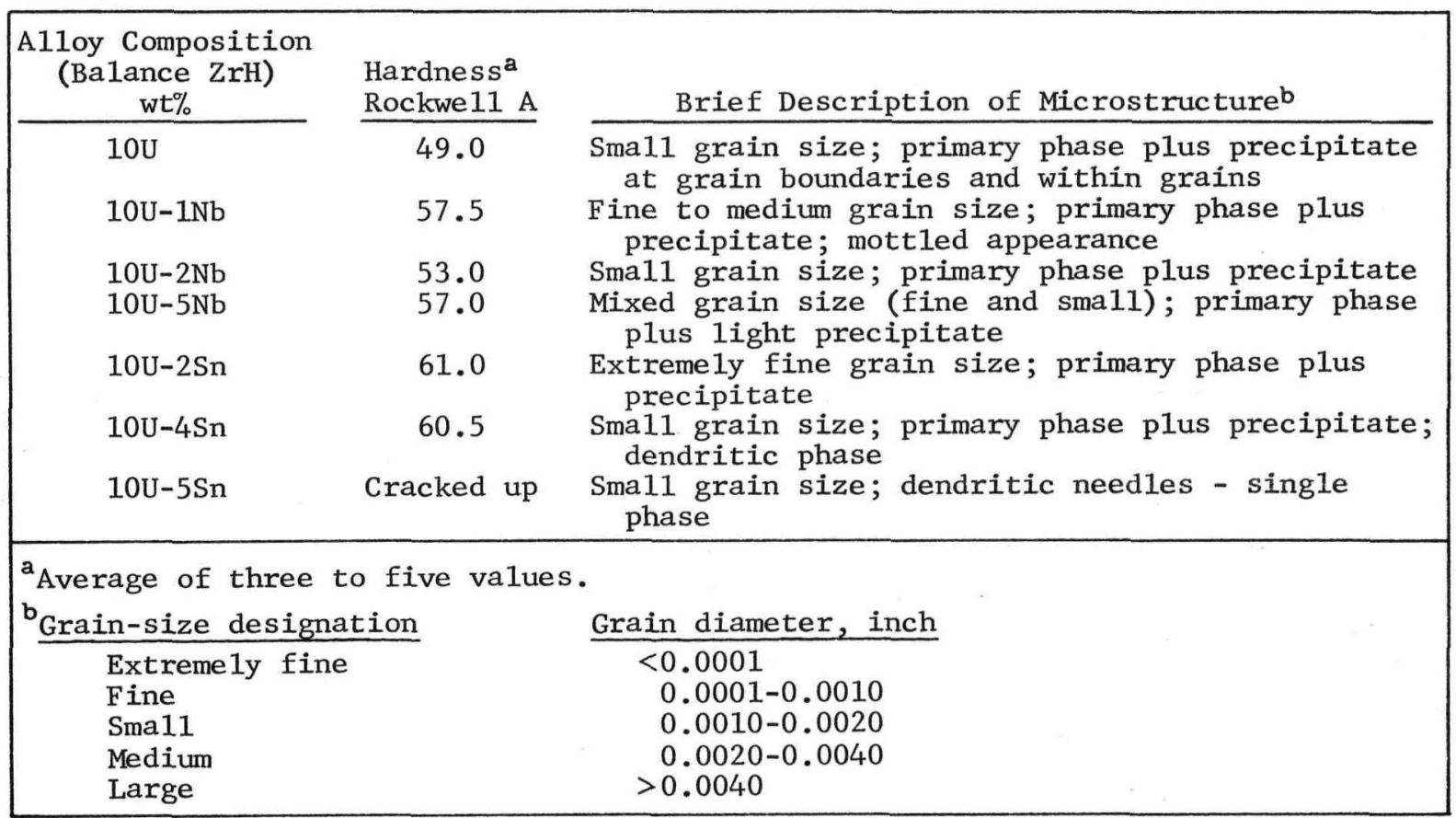




\section{$\underline{\text { Plasma Tests }}$}

A second test with a radio frequency plasma device was devised to examine the me1ting characteristics of the alloys and to see if there was any correlation between the results of the fluidity tests and the melting properties of the alloys in the plasma. Specimens, 2 inches long and $1 / 4$ inch in diameter, of unmodified and modified unhydrided alloys, of zirconium hydride, and of unmodified ZrH-uranium fue 1 were exposed to a plasma for times up to 20 seconds. An atmosphere consisting of 5.2 weight-percent oxygen, 28.4 weight-percent helium, and 66.4 weight-percent argon was used. The maximum heat flux on the specimens was estimated to be approximately 100 to 150 Btu per square foot. The results of these tests were as folloirs:

1. Portions of the $\mathrm{Zr}-10 \mathrm{U}$ alloy and most of the modified alloys melted and dripped off in less than 10 seconds under the test conditions.

2. Times before first drippings occurred in these tests were noted for each material. These times appeared to correlate very well with the extent of metal penetration into the molds in the fluidity tests.

3. Zirconium hydride and the ZrH-uranium fuel behaved similarly. Little melting occurred in these specimens for 10 to 15 seconds; then with a dazzling burst, these specimens flashed continuously (not unlike a sparkler). Very small particles, estimated to be somewhat less than 1 milimeter in diameter were dispersed in a11 directions. Although some of the particles were collected below the plasma device, most were lost on the walls of the device.

4. Examination of the microstructure of the remaining fue 1 alloy after testing showed that a series of structures existed that were very similar to those seen in zirconium hydride specimens exposed to a plasma.

\section{Ablation Testing}

In order to evaluate experimentally the effect of alloying additions on the ablation of fuel-element materials and the characteristics of the ablation products, tests were carried out in a rocket test facility. The collection and analysis of the ablation products are discussed in the following section of this paper. To ensure proper evaluation of the materials' performance, the experimental fuel-element exposure conditions were chosen in a manner to provide simulation of critical reentry parameters. The primary re-entry parameters are considered to be heat flux to the specimen surface, concentration of gas-phase chemical reactants, and shearstress leve1.

\section{Selection of Test Conditions}

The basic experimental tool used in this portion of the program was an $\mathrm{O}_{2}-\mathrm{H}_{2}$ rocket motor. This motor operates with gaseous propellants and is water cooled. Propellant flow is accurately controlled by critical flow orifices. The module design of the motor permits replacement of the exhaust nozzle to satisfy particular test requirements.

Experimental fuel-element materials fabricated in the form of 1/4-inchdiameter rods were evaluated. It was decided that, for comparative analysis, all experimental fuel elements would be evaluated in a fixed position with axis normal to the exhaust-gas flow direction. Possible rocket-motor operating conditions were evaluated for chamber pressures between 50 and 150 psia for an exhaust pressure of 1 atmosphere and also for chamber pressures between 10 and 100 psia with exhaust into a tank maintained at a pressure of $1 / 4$ atmosphere. 
Figure 143 shows the variation in heat flux and shear stress in the stagnation region with chamber pressure in the rocket motor. In all instances, the rod is cross-axially aligned to the flow. Results are shown for 2-, 5-, 10-, 15-, and 20percent oxygen in the exhaust, the remainder of the exhaust being $\mathrm{H}_{2} \mathrm{O}$. The shear stress is given for only 20-percent oxygen; the change in shear stress with variation in exhaust composition is sma11. In the calculations of heat flux to the specimen in the rocket tests, the magnitude of the net radiative heat transfer was considered to be sma11 compared to the convective flux and was therefore neglected.

Figure 144 shows the correlation of heat flux and shear stress for both free-flight and rocketmotor conditions. Figure 144 shows that the shear stress in the rocketmotor facility is higher than desired for the corresponding heat flux to the $3500^{\circ} \mathrm{R}$ specimen surface. Although the given range of rocketmotor conditions shows a peak heat flux to $530 \mathrm{Btu} / \mathrm{sq} \mathrm{ft}-\mathrm{sec}$, higher values can be obtained by the use of chamber pressures above 100 psia.

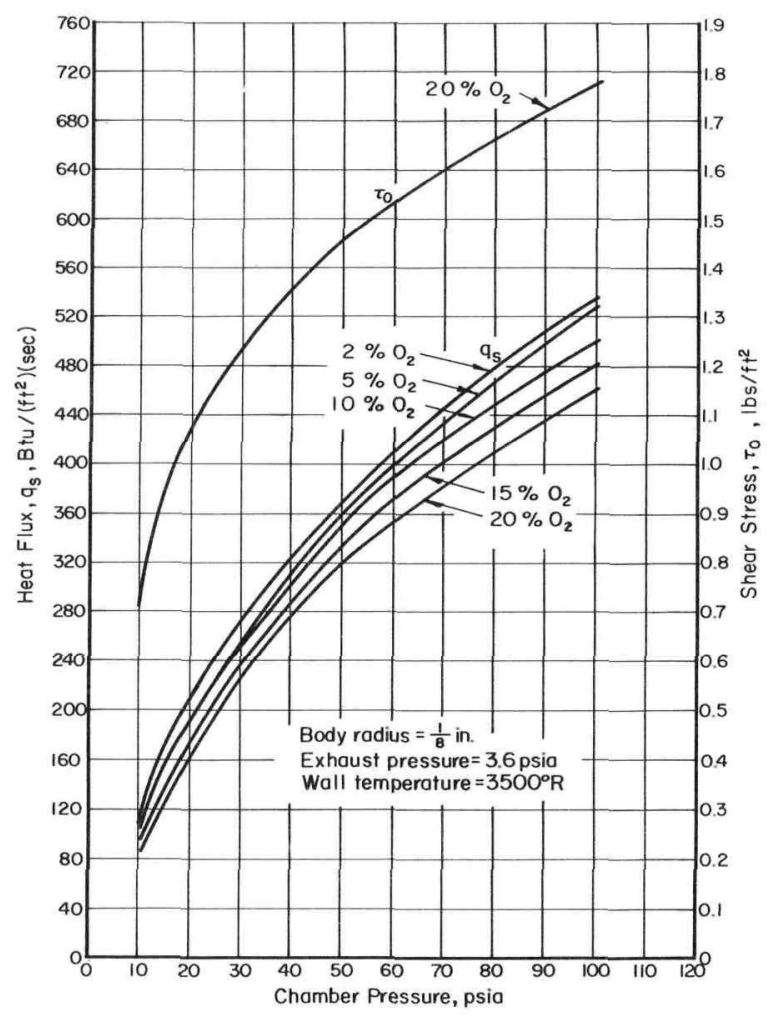

Figure 143. Variation of stagnation-point heat flux and wall shear stress with combustion-chamber pressure of rocket motor.

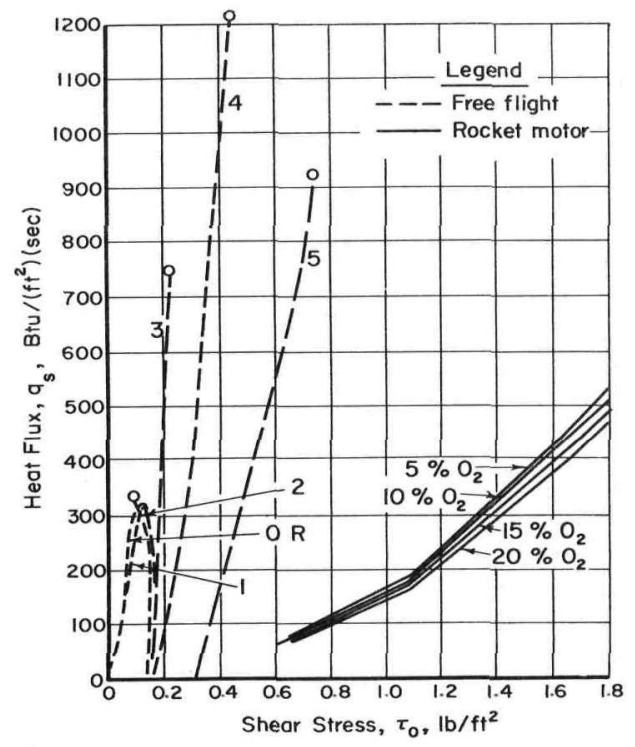

Free-flight conditions: Body radius $=5 / 8$ in. axia1 alignment of vehicle, cross-axial exposure of rods

Rocket-motor conditions:

Cross-axial exposure of rods Exhaust pressure $=3.6 \mathrm{psia}$ Body radius $=1 / 8$ in

\begin{tabular}{ccc} 
& & \multicolumn{2}{c}{$\begin{array}{c}\text { Rod-Release } \\
\text { Trajectory }\end{array}$} & Altitude, ft \\
\cline { 1 - 1 } Orbita1 Release (O.R.) & & 400,000 \\
1 & & 298,562 \\
2 & 252,312 \\
3 & 204,676 \\
4 & 158,325 \\
5 & 109,380
\end{tabular}

Figure 144. Heat flux as a function of shear stress for free-flight conditions and for conditions in the rocket motor 
Figure 145 shows the correlation of applied heat flux and oxygen number density at the $3500^{\circ} \mathrm{R}$ specimen surface without gas-surface reactions for both freeflight and rocket-motor conditions. Adequate simulation of these two flow characteristics can be achieved simultaneously. This is shown in Figure ; the rocketmotor curves of constant mixture ratio are shifted to the left as the percentage of oxygen in the exhaust is decreased. As the oxygen percentage continues to decrease even further, the rocket-motor curve will ultimately span a range in oxygen number density common to nearly all trajectories.

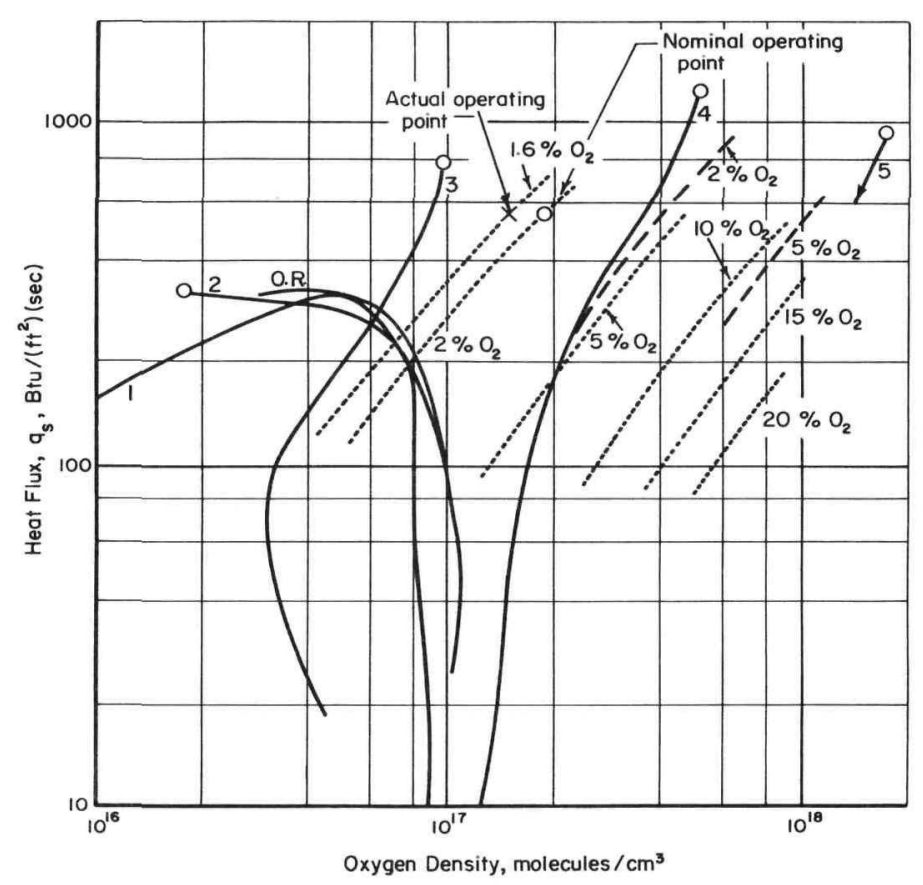

Free-Flight Trajectories

\begin{tabular}{cc}
\hline Trajectory No. & Release Altitude, ft \\
\hline Orbita1 Release (O.R.) & 400,000 (Orbit) \\
1 & 298,562 \\
2 & 252,312 \\
3 & 204,676 \\
5 & 158,325 \\
5 & 109,380
\end{tabular}

\begin{tabular}{l} 
Rocket Motor Simulation \\
\hline- One atmosphere rocket exhaust \\
pressure
\end{tabular}

Figure 145. Correlation of heat flux with oxygen density for free-flight and rocket-motor test conditions

After the significant ablation characteristics had been adequately investigated, efforts were directed toward the design of experimental equipment. A desirable supersonic flow nozzle was first considered. The complexities peculiar to partial vacuum exhaust operation led to consideration of the feasibility of operation at atmospheric pressure. However, it became apparent that atmospheric pressure operation would require less than 1-percent oxygen in the exhaust.

On the basis of the data presented in Figure 145, test conditions were selected with a stagnation heat-flux level of approximately $370 \mathrm{Btu} / \mathrm{sq} \mathrm{ft}-\mathrm{sec}$ being achieved at a combustion chamber pressure of 50 psia, with a nominal 2-percent excess oxygen 
in the exhaust, and with 1/4-atmosphere exhaust pressure. These operating conditions were chosen arbitrarily as being representative of high-heat-flux flight conditions and within reasonable rocket-motor operating limits. The nominal operating point is indicated by the circle in Figure 145. Following fabrication and installation of the critical flow orifice, flow calibrations implied that the actual operating point corresponded to 1.6-percent excess oxygen. This point is also shown in Figure 145.

Figure 146 is a schematic drawing of the facility used for simulating re-entry conditions. The combustion products expand through the nozzle and impinge on the model fuel element. The nozzle is so designed that optimum expansion can be obtained from a chamber pressure of 50 psia to a test chamber pressure of $1 / 4$ atmosphere. This nozzle also provides parallel gas flow at the test section. Water is injected downstream from the test specimen to condense the steam in the exhaust gases and to remove the ablation products from the gas stream. The water and ablation products are collected in the large tank and are then removed from the water by filtration following the test.

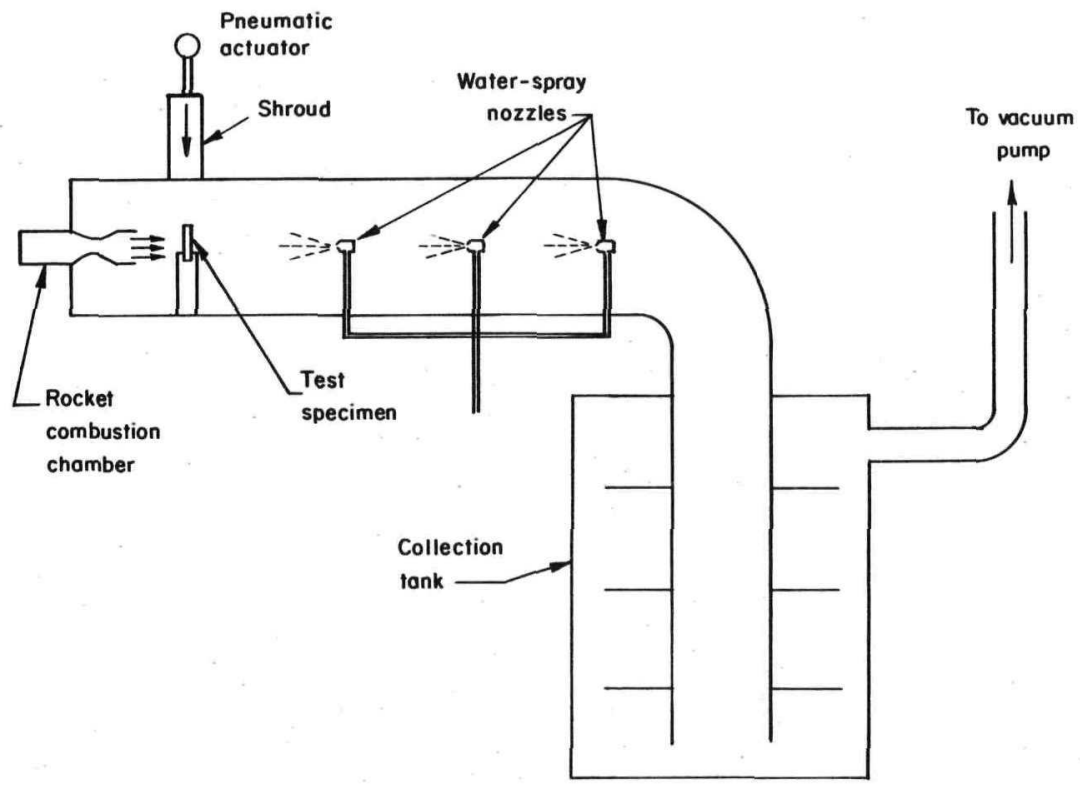

Figure 146. Schematic of rocket-motor test setup

During start-up and shutdown operations, the model fuel element is protected by a shroud. The normal rocket-motor start-up procedure is to spark-ignite a low flow of oxygen and hydrogen and then to turn on the full propellant flow as soon as combustion in the chamber is obtained. It was found during initial trials with the equipment that the low-flow ignition could not be accomplished satisfactorily when the test section was at reduced pressures. (During low-pressure start-up, an explosion occurred that damaged the collection tank and associated equipment.) Therefore, the start-up procedure was revised, and ignition was attained with low rates of propellant flow at atmospheric pressure in the test section. The system was then evacuated to $1 / 4$-atmosphere pressure.

The full propellant flow is turned on after the operating static pressure is attained. The model fuel-element specimen is shrouded during the entire low-flow operating period (approximately 10 minutes) in order to prevent undesirable heating of the specimen. 
To ensure that the shrouded test specimen is unaffected by the 10-minute period of low-flow operation of the rocket motor, a $\mathrm{ZrH}_{1}$.80 model specimen was kept within the shroud for a 10-minute low-flow period. No visual change was noted. Hydrogen analyses indicated no change in the hydrogen content of the specimen.

During a later trial run, difficulty was experienced in the ignition of the rocket motor. The difficulty resulted from improper control of propellant flow rates during ignition. In this run, an explosion again occurred, bending the top of the stainless stee 1 tank and causing some significant damage to associated equipment. Following this explosion, the equipment was repaired and modified to ensure future safe operation. Modifications were made in the propellant control system and sensors were added to the system to sense the presence of a flame in the chamber and the hydrogen content of the gases in the collection tank. Following these modifications, the facility was operated without incident for the remainder of the program.

\section{The Testing Program}

When it was completely assured that all equipment was functioning satisfactorily, the testing program was begun. The first part of this program, termed preliminary testing, included 24 separate test firings. The purpose of these tests was (1) to establish the exposure times of samples to the rocket exhaust to obtain enough ablation to be able to satisfactorily compare one fuel material with another, and (2), more importantly, to evaluate a large number of materials in a relatively short time. Materials were selected for evaluation from the results of the fluidity tests and from consideration of their fabrication and hydriding properties. During the preliminary tests, no efforts were made to evaluate the particulate ablation products. Although samples were taken of rinse water before each firing and of collector water containing particulate products immediately after firing, nothing was done with these. Instead, in this phase, emphasis was placed upon determining weight loss of each material during testing and upon examining the remaining bulk samples after tests.

The second part of the testing program consisted of five tests in which detailed evaluations of both the remaining bulk samples and the particulate products were made. The selection of samples to be exposed in tests was made principally from the results obtained in the preliminary studies. All samples in this phase of testing were exposed to identical conditions.

In the third phase of the program, three samples of unmodified ZrH-uranium fue1, taken from material supplied by Atomics International, were exposed to the rocket exhaust tests for $2.5,5$, and 8 seconds. The principal purpose of these tests was to examine the different stages of ablation that occur under the test conditions.

\section{Ablated Particle Collection}

For this study it was believed that a representative sample of the ablation products could be obtained by the use of a scrubbing system. A scrubbing system has two principal advantages over a direct gas-filtration system: (1) it can provide a means of rapidly cooling the particulate matter, thus reducing the prolonged exposure of particles to a high-temperature oxidizing atmosphere, and (2) it can effectively eliminate an air-pollution problem by retaining the particles and soluble gases in the scrubbing solution. Direct gas-filtration of the ablated particles is not feasible owing to the lack of a suitable filtering medium, since the present high-efficiency medium will not stand the moisture and temperature requirements. In addition, because of the large surface area of the media required for low pressure drop, it would be difficult to remove a suitable sample for particle-size analysis. 
Design and Construction of Collection System

The collection system was designed to provide a fine spray through which the ablation products would pass, a collection tank to hold the water containing the particles, and suitable baffling within the tank to prevent re-entrainment of the aerosol. A11 these items were constructed of stainless steel.

The scrubber tank was constructed of 1/8-inch-thick stainless stee1 and was approximately 4 feet in diameter and 4 feet high. The top of the tank was removable and had four pressure-relief valves. The bottom of the tank was dished to promote drainage of the water and particles. The tank was designed to operate under a vacuum.

The nozzle housing assembly was attached to the scrubber tank with a reducing elbow. The aerosol entered the scrubber through a 4-inch pipe which extended to the bottom of the tank. Holes in the bottom of this pipe permitted the noncondensed gaseous phase to bubble through the collecting liquid. The entrance pipe also served as a columnar support. Attached to this pipe were two circular baffles containing holes which impelled any gaseous phase leaving the system to make abrupt changes in direction. The baffles were essentially of the same diameter as the inside diameter of the tank.

\section{Procedures Followed in Collecting Samples}

At the beginning of the program it was decided that the particle-size analysis of the ablated material could be determined with the Coulter counter. In this method, the number and size of particles suspended in an electrically conductive liquid are determined. In operation of the coulter counter, a measured volume of suspension is allowed to flow through a small aperture having an immersed electrode on either side. The concentration of the particles in the suspension is maintained low enough so that the particles pass through the aperture substantially one at a time. The particle-size range of the device is limited to between approximately 1 and 30 microns.

As each particle passes through the aperture, it displaces electrolyte which causes a momentary change in resistance between the electrodes. The change in resistance creates a voltage pulse of magnitude proportional to the particle volume. The resultant series of pulses is electronically amplified, scaled, and counted.

In this approach, the collecting liquid must be relatively free of extraneous particles and all surfaces which come in contact with the collecting fluid must be clean. For this reason, efforts were made to have as clean a system as possible. Initially, it was found that the distilled, deionized water which was available contained an abundance of the ion-exchange resin. Special filters were used to reduce greatly this source of contamination.

Evaluation of Products of Ablation

\section{Preliminary Tests}

Results -- As stated previously, 24 tests were performed in the first formal phase of the testing program. In these tests, the following materials were studied:

1. One unmodified ZrH-uranium fuel sample (prepared by casting and hydriding at Batte1le).

2. Eighteen different fuel samples modified by single-element additions of barium, niobium, copper, vanadium, calcium, cerium, tungsten, tantalum, aluminum, bismuth, antimony, strontium, thorium, nickel, silicon, and chromium (prepared by casting and hydriding. 
3. Two different fuel samples modified by double additions--bariumniobium and tin-niobium (prepared by casting and hydriding).

4. Three fuel samples modified by additions of oxygen, nitrogen, and carbon (prepared by isostatic compaction).

A summary of the first three tests performed is outlined below:

TABLE III

Test Summary

\begin{tabular}{|c|c|c|c|}
\hline Test & $\begin{array}{c}\text { Material } \\
\text { Tested }\end{array}$ & $\begin{array}{l}\text { Time of Exposure to } \\
\text { Simulated Re-Entry } \\
\text { Conditions, seconds } \\
\end{array}$ & Results \\
\hline 1 & $\mathrm{ZrH}-10 \mathrm{U}-2 \mathrm{Ba}$ & 4.1 & $\begin{array}{l}\text { Ablation was initiated but } \\
\text { loss of material was not } \\
\text { appreciable }\end{array}$ \\
\hline 2 & $\mathrm{ZrH}-10 \mathrm{U}-2 \mathrm{Nb}$ & 6.0 & $\begin{array}{l}\text { Ablation was initiated but } \\
\text { weight change was not large }\end{array}$ \\
\hline 3 & $\mathrm{ZrH}-10 \mathrm{U}-5 \mathrm{Sn}$ & 8.0 & $\begin{array}{l}\text { Ablation occurred with a } \\
\text { notable weight loss }\end{array}$ \\
\hline
\end{tabular}

From the results of these tests, 8 seconds appeared to be a satisfactory exposure time and was used in the remaining tests in Phases 1 and 2 .

F:lotomicrographs and photographs of all specimens tested in Phase 1 are shown in Figures 147 through 150 (Sample 3, a Phase 2 test, is included in this group of specimens). The exterior surfaces of specimens exposed to the heat flux are shown in the photographs; cross sections of each fuel sample normal to the direction of heat flux are shown in the photomicrographs. Weight changes of a11 samples run in tests are given in Table IV.

Discussion -- The samples fell into three classifications: those which 1ost a large amount of weight upon exposure (greater than 0.800 gram); those which lost a limited amount of weight $(0.200$ to $0.300 \mathrm{gram})$; and those which lost 1ittle or no weight or actually gained weight during test $(+0.001$ to 0.070 gram $)$. 0f the 24 samples run, 13 were seen to exhibit a large weight loss. These included the unmodified $\mathrm{ZrH}-\mathrm{U}$ fuel and $\mathrm{ZrH}-\mathrm{U}$ fuel samples modified with additions of vanadium, tungsten, tantalum, aluminum, bismuth, antimony, strontium, silicon, carbon, oxygen, nitrogen, and tin-niobium.

The top sections of samples containing oxygen, carbon, and nitrogen (produced by isostatic compaction) sheared off during the early stages of heat up, owing probably to thermal shock and/or shear forces. Metallographic examination of large sections of these samples found downstream after tests disclosed that essentially no ablation occurred. Fracture surfaces on specimens containing additions of 5 weight-percent antimony and 2 weight-percent tin/2 weight-percent niobium also revealed that large sections were sheared or broken away from these materials during tests. 


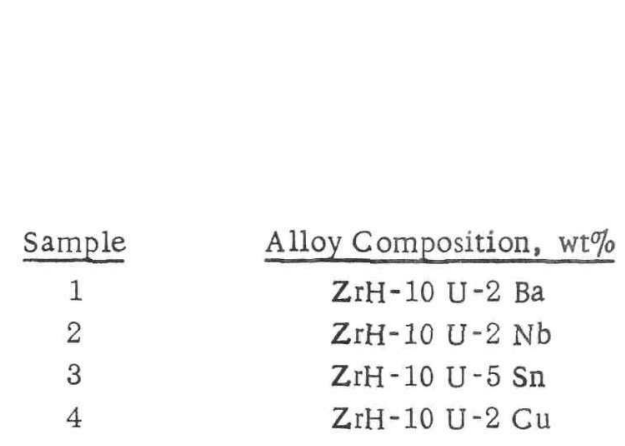

$2 \mathrm{X}$

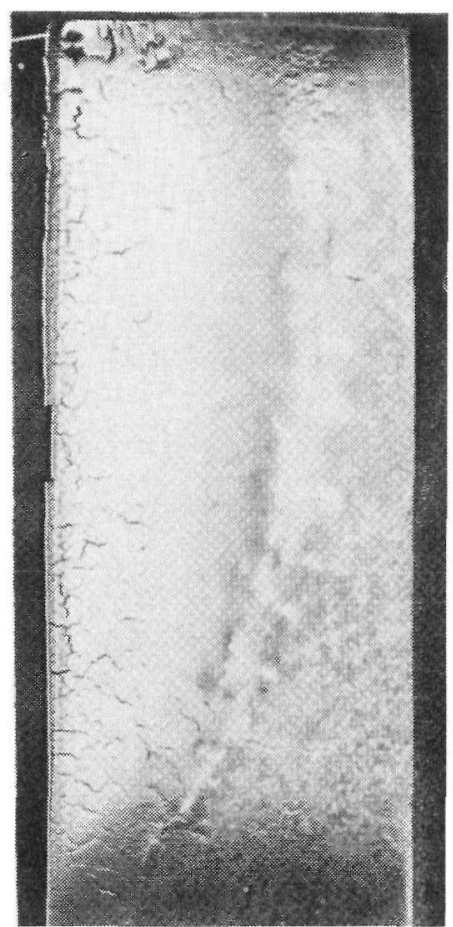

Sample 1

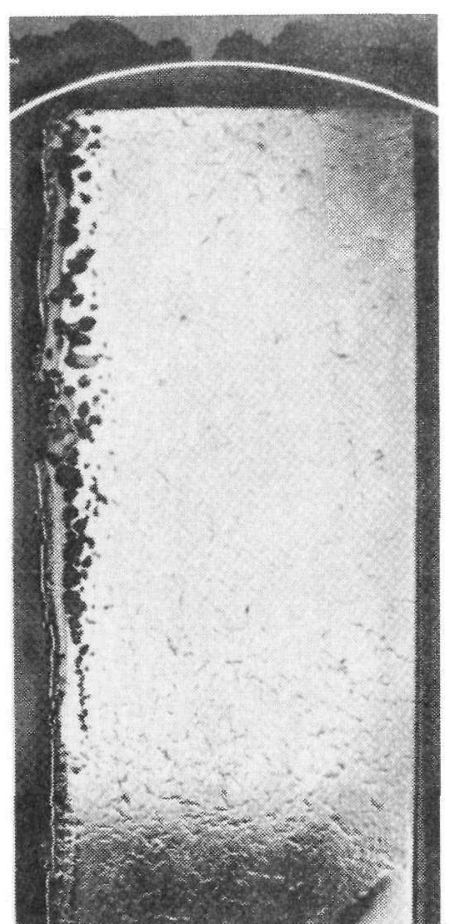

Sample 2
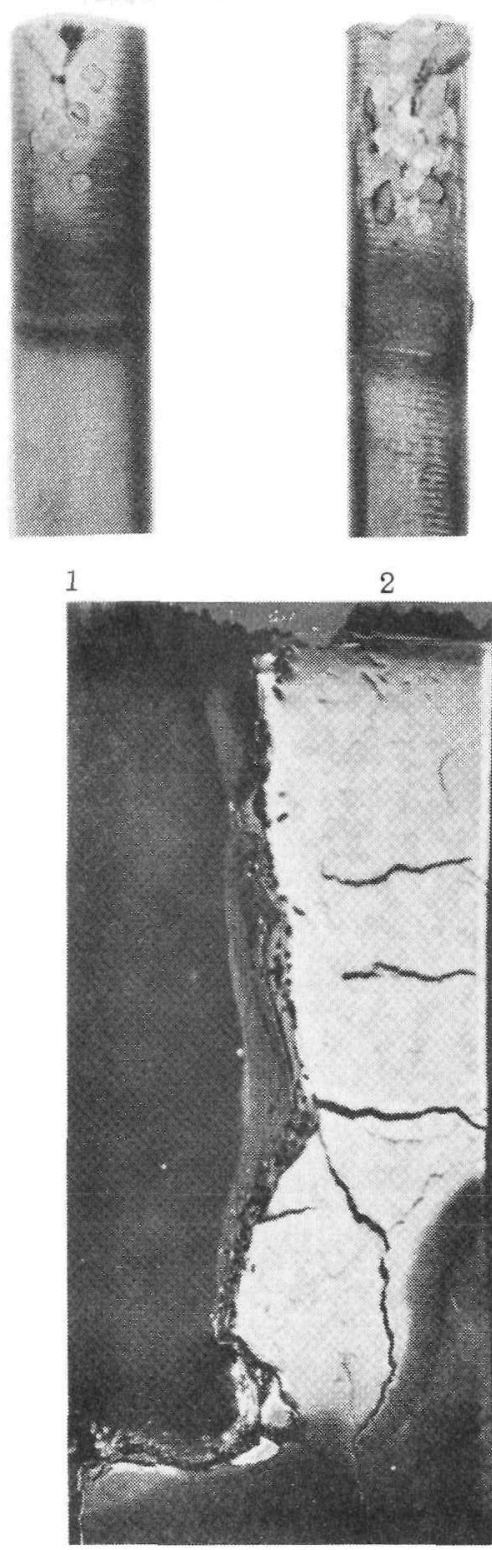

Sample 3

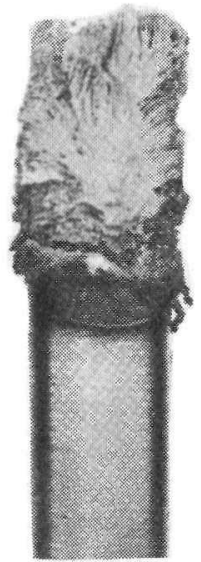

3

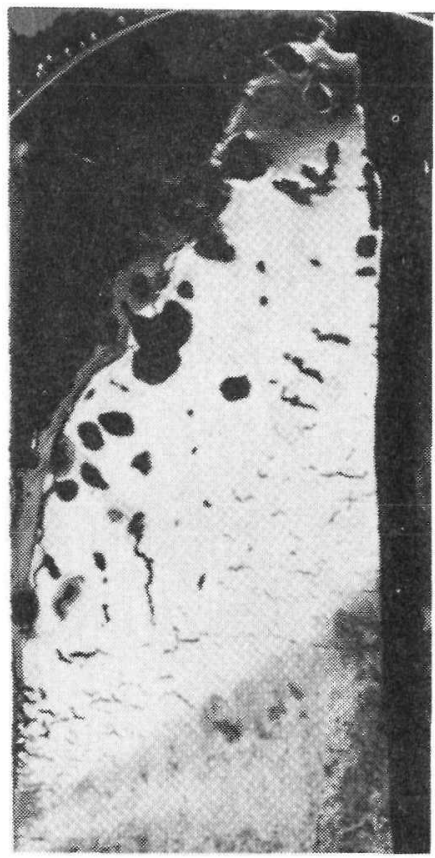

Sample 4

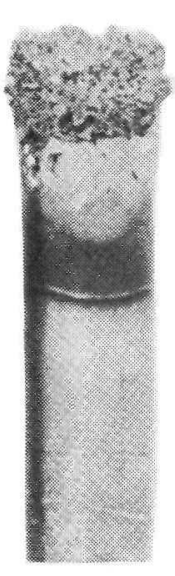

4

Figure 147. Photographs and photomicrographs of ablated ZrH-uranium fuel

samples modified with additions of barium, niobium, tin, and copper 

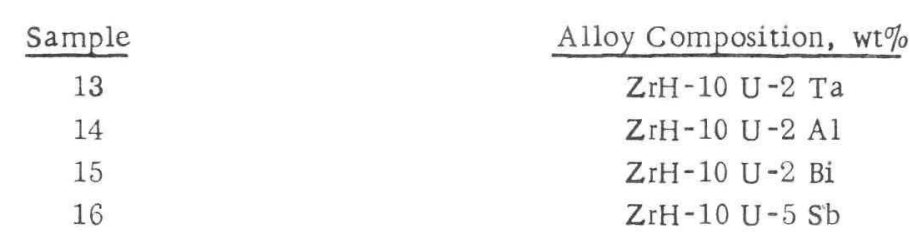

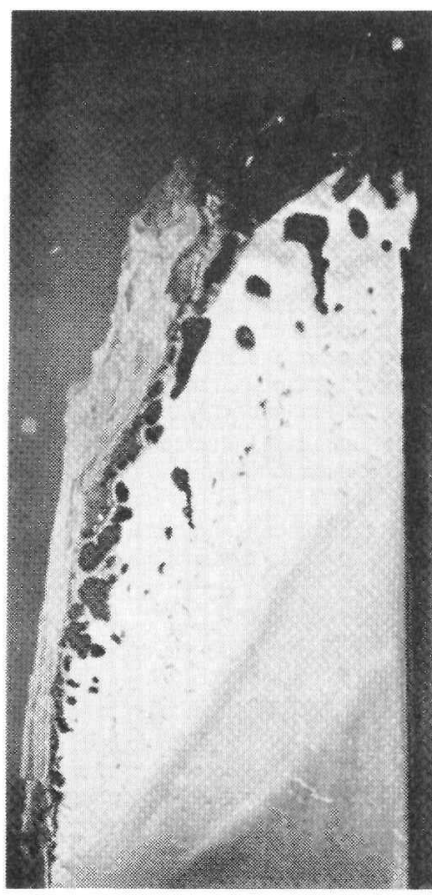

Sample 14

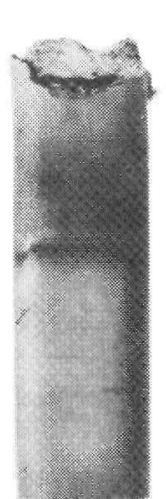

$2 \mathrm{X}$

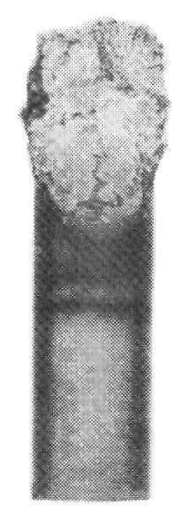

14

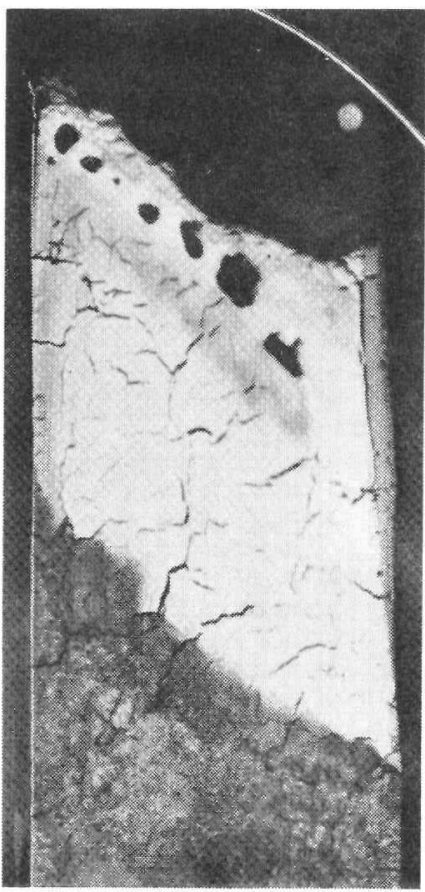

Sample 15
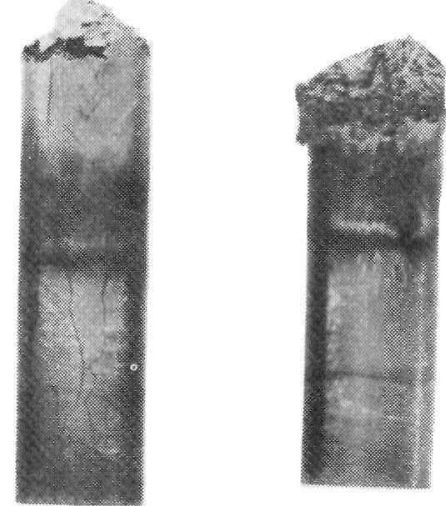

16

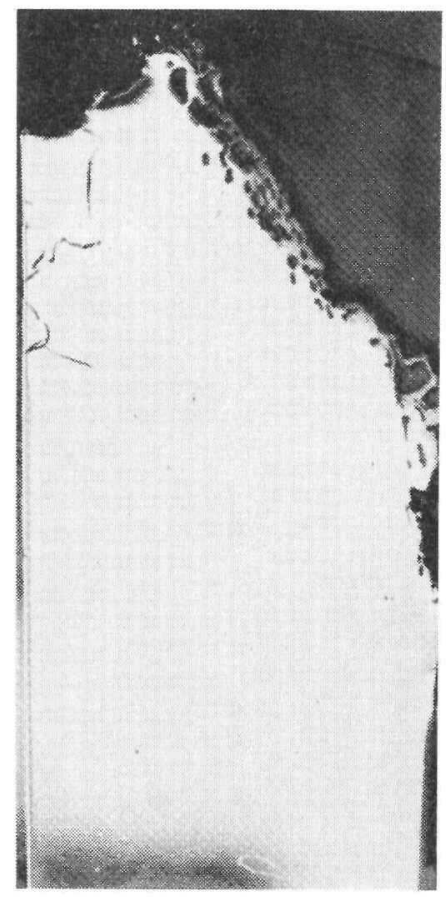

Sample 16

Figure 148. Photographs and photomicrographs of ablated ZrH-uranium fuel samples modified with additions of tantalum, aluminum, bismuth, and antimony 
Sample

17

18
19

20

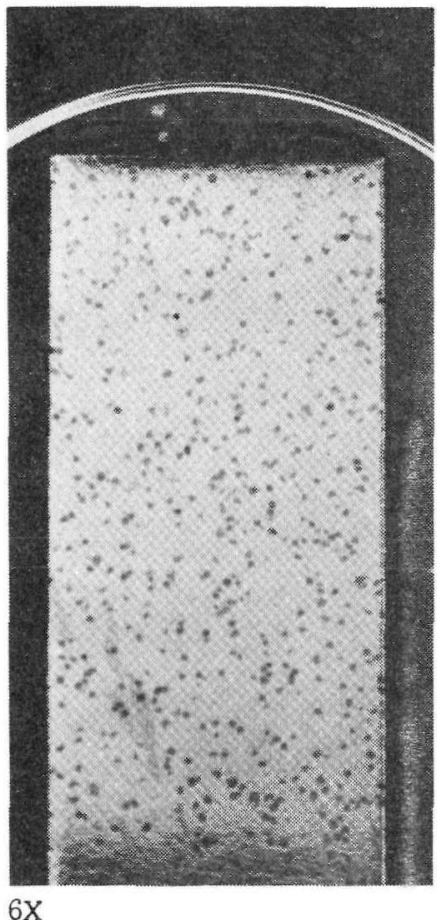

Sample 17
Alloy Composition

$\mathrm{ZrH}_{2}-\mathrm{UO}_{2}$

$\mathrm{ZrH}_{2}$-UC

$\mathrm{ZrH}_{2}$-UN

$\mathrm{ZrH}-10 \mathrm{U}-2 \mathrm{Si}$

$2 \mathrm{X}$
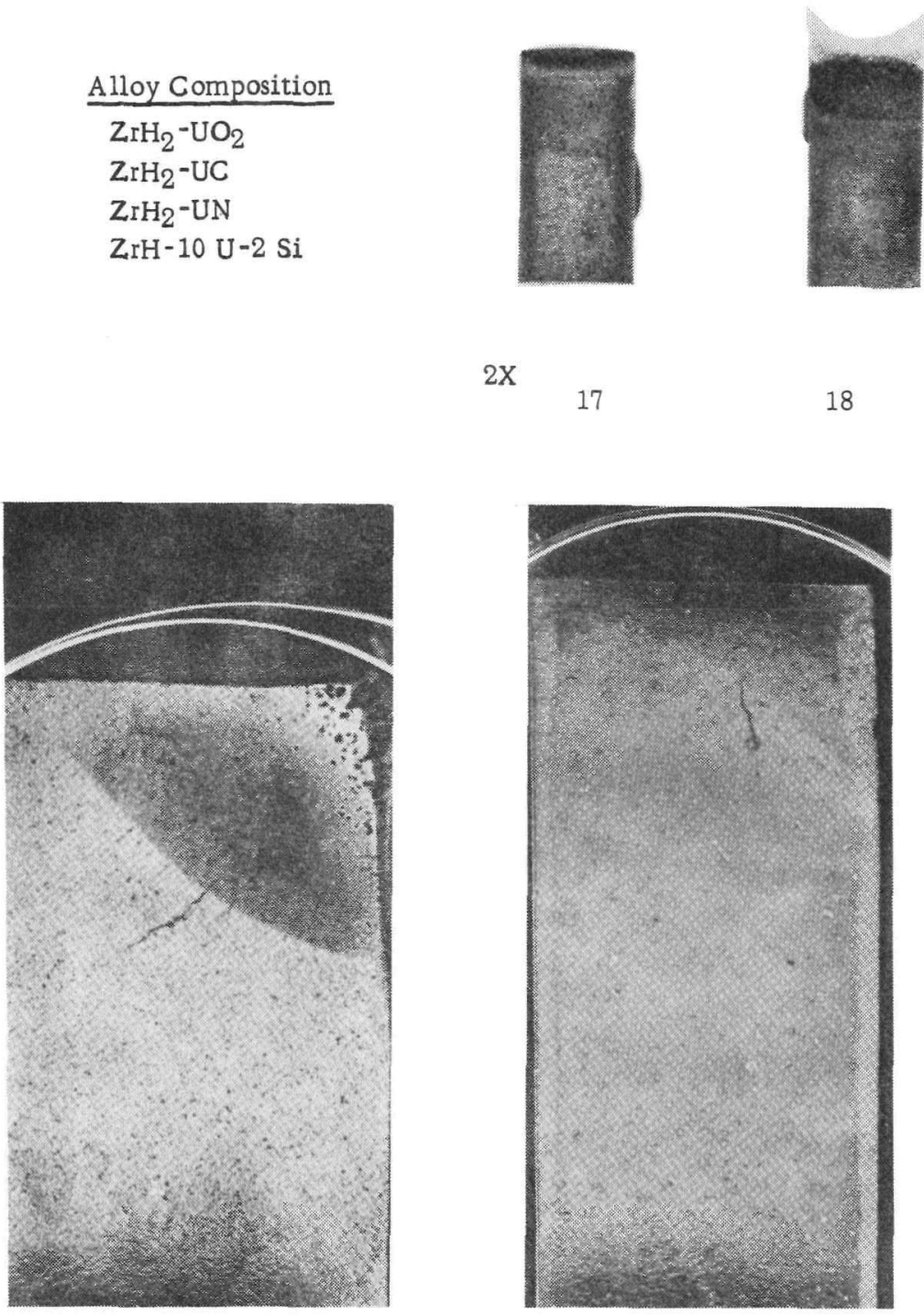

Sample 18

18

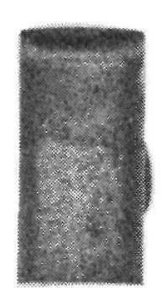

17

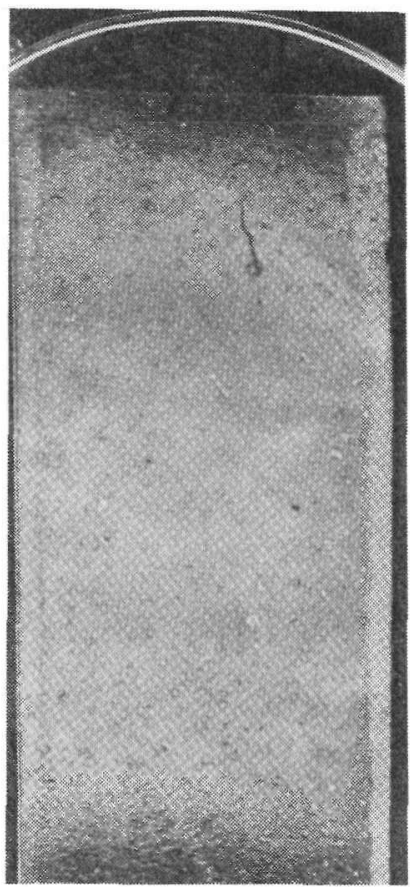

Sample 19
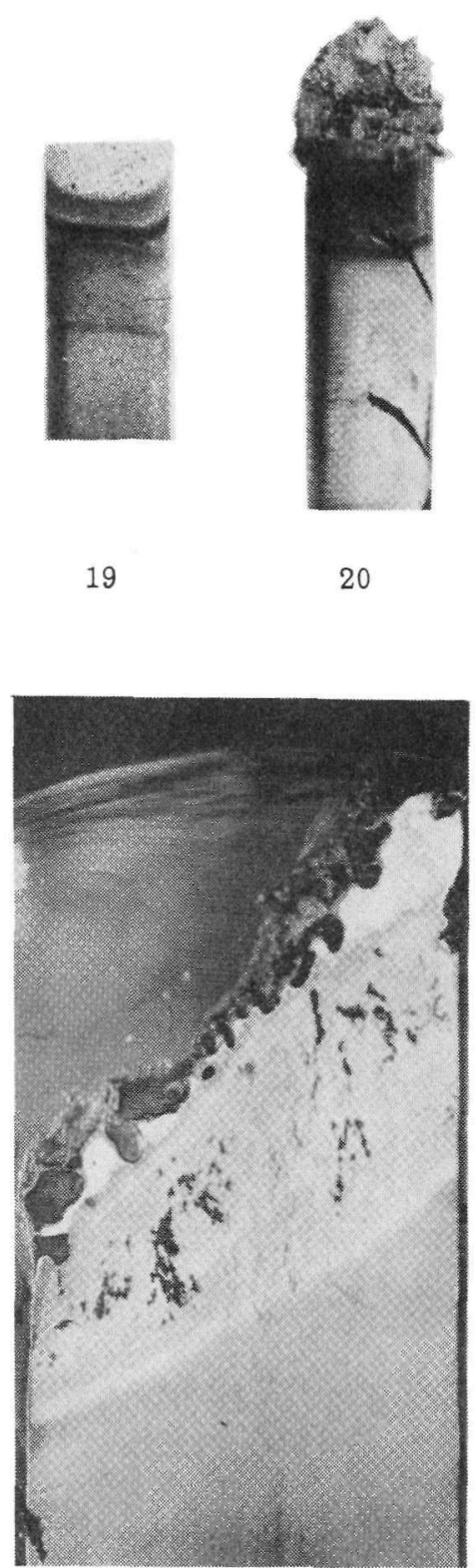

Sample 20

Figure 149. Photographs and photomicrographs of ablated ZrH-uranium fuel samples modified with additions of oxygen, carbon, nitrogen, and silicon

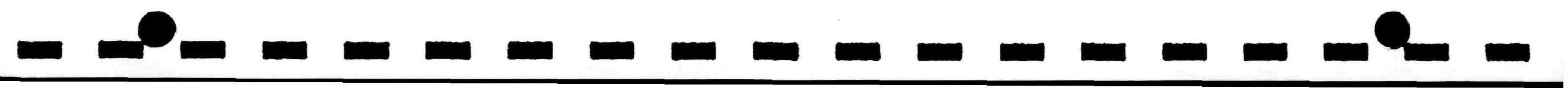



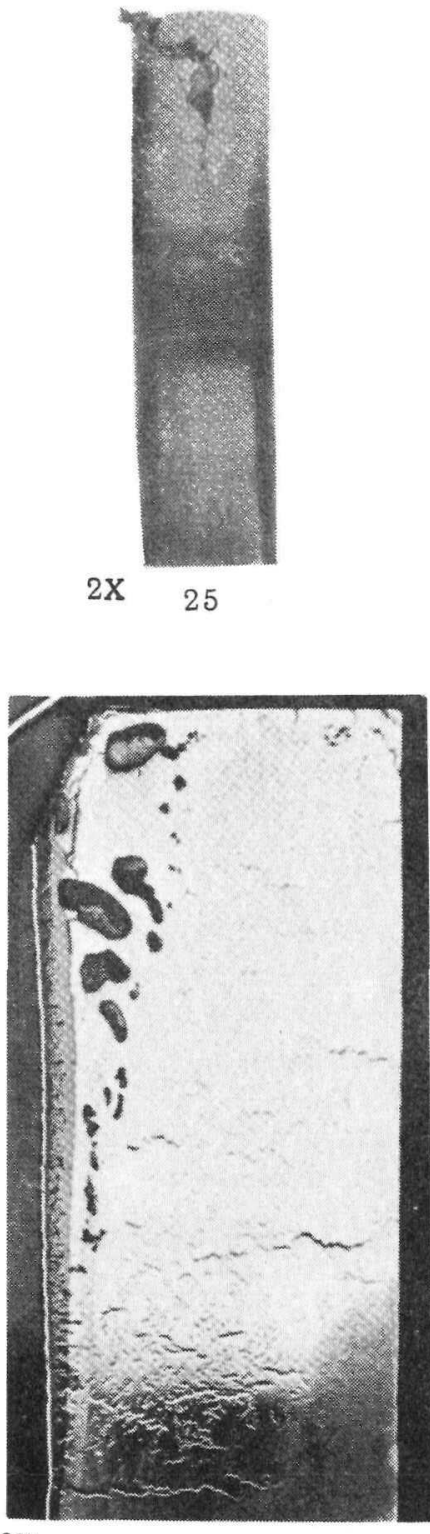

Sample 25
The photomicrograph below shows the thick, tenacious oxide that was seen on the calcium-modified specimen

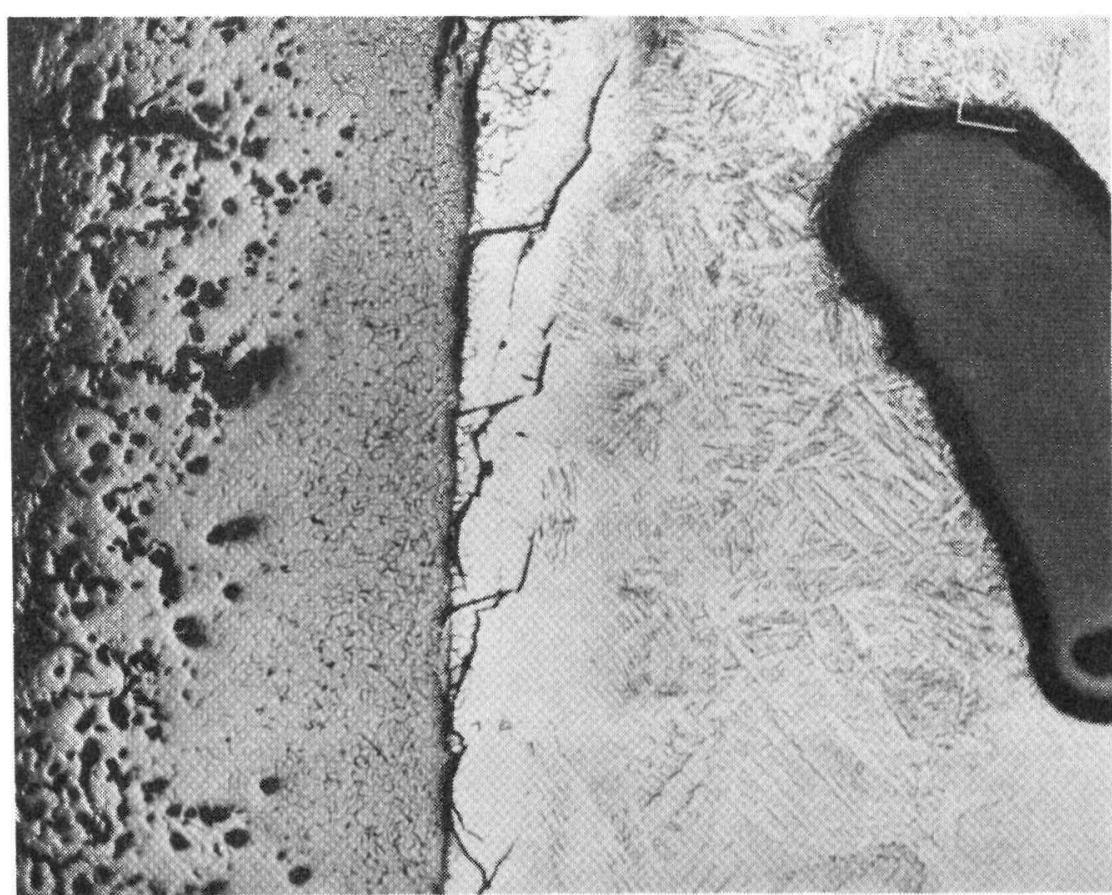

$100 \mathrm{X}$

Figure 150. A photograph and photomicrographs of an ablated ZrH-uranium fuel sample modified with an addition of 2 weight-percent calcium 
TABLE IV

Results of Ablation Tests on Unmodified and Modified ZrH-Uranium Fuel Alloys

Weight Change

Exposure

Time

A11oy Composition

$\mathrm{ZrH}-10 \mathrm{U}$

$\mathrm{ZrH}-10 \mathrm{U}-2 \mathrm{Ba}$

$\mathrm{ZrH}-10 \mathrm{U}-2 \mathrm{Nb}$

$\mathrm{ZrH}-10 \mathrm{U}-2 \mathrm{Cu}$

$\mathrm{ZrH}-10 \mathrm{U}-2 \mathrm{~V}$

ZrH-10U-2Ca

ZrH-10U-2Ba-2Nb

$\mathrm{ZrH}-10 \mathrm{U}-2 \mathrm{Sn}-2 \mathrm{Nb}$

$\mathrm{ZrH}-10 \mathrm{U}-5 \mathrm{Ce}$

$\mathrm{ZrH}-10 \mathrm{U}-1 \mathrm{Ba}$

$\mathrm{ZrH}-10 \mathrm{U}-2 \mathrm{~W}$

ZrH-10U-2Ta

ZrH-10U-2AI

ZrH-10U-2Bi

$\mathrm{ZrH}-10 \mathrm{U}-5 \mathrm{Sb}$

ZrH-10U-2Sr

$\mathrm{ZrH}-10 \mathrm{U}-5 \mathrm{Nb}$

ZrH-10U-5Th

$\mathrm{ZrH}-10 \mathrm{U}-2 \mathrm{Ni}$

ZrH-10U-2Si

$\mathrm{ZrH}-10 \mathrm{U}-2 \mathrm{Cr}$

$\mathrm{ZrH}_{2}-\mathrm{UO}_{2}$

$\mathrm{ZrH}_{2}-\mathrm{UC}$

$\mathrm{ZrH}_{\mathbf{2}}-\mathrm{UN}$

$\mathrm{ZrH}-10 \mathrm{U}$

ZrH-10U-2V

$\mathrm{ZrH}-10 \mathrm{U}-2 \mathrm{~A} 1$

$\mathrm{ZrH}-10 \mathrm{U}-2 \mathrm{~W}$

$\mathrm{ZrH}-10 \mathrm{U}-5 \mathrm{Sn}$

$\mathrm{ZrH}-10 \mathrm{U}$

$\mathrm{ZrH}-10 \mathrm{U}$

ZrH-10U of Specimen

During Ablation (grams)

Series 1

$-1.148$

$-0.004$

$-0.002$

$-0.210$

$-0.915$

$-0.069$

$-0.019$

$-1.419$

$-0.014$

$-0.008$

$-1.487$

$-1.320$

$-0.836$

$-0.803$

$-1.452$

$-0.905$

$-0.249$

$+0.001$

$-0.251$

$-1.185$

$+0.001$

$-2.150$

$-1.521$

$-1.807$

Series 2

$\begin{array}{ll}8.0 & -1.581 \\ 8.0 & -1.686 \\ 8.0 & -1.414 \\ 8.0 & -1.021 \\ 8.0 & -1.036\end{array}$

Series 3

$+0.006$

$-1.258$

$-1.622$
Comments

Material prepared at Battelle

Top section appaared to have sheared off

Section appeared to have sheared off

Whole top section sheared off Whole top section sheared off Whole top section sheared off

MateriaI prepared at AI

Material prepared at AI Material prepared at AI Material prepared at AI

Appearances of the microstructures of the various ZrH-uranium fuel samples indicate that during their exposure to simulated re-entry conditions several important processes occur simultaneously. The rate at which these processes occur, the manner in which they occur, and the properties of the initial material and the intermediate and final products all are extremely important in determining how much ablation occurs (how much weight loss occurs) and the size and shape of the particles that are ablated. Factors that appear to be most important in determining the ablation rate are:

1. The rate of oxidation of the exposed surface of the fuel. 
2. The strength, tenacity, and thermal conductivity of the oxides that are formed.

3. The rate of hydrogen diffusion through the lattice of the fuel.

4. The rate and manner in which the hydrogen is released.

5. The melting points of the fuel alloy and the oxides that are formed.

6. The viscosity and surface tension of the fuel alloy and the oxides.

7. The strength and thermal-shock properties of the hydride and the dehydrided alloy.

The importance of the various factors mentioned above can be seen in the photomicrographs in Figures 147 through 150. In Sample 1, for example, the initia1 stages of ablation are shown. A relatively thick layer of oxides has already formed, and hydrogen has been released (although probably not in large amounts) from regions extending approximately $1 / 8$ inch in from the exposed surface. The oxide does not appear to have had high strength since the small amount of hydrogen released readily blistered and fractured it. No melting can be noted in this sample.

In Sample 2, a greater amount of hydrogen probably has been released. Apparently, hydrogen in most samples diffuses initially to the grain boundaries and then toward the hot exposed surface. This second sample shows a fairly thick oxide layer probably relatively low in strength. Melting beneath this oxide layer has occurred, and hydrogen diffusing toward the hot surface has collected in pools in this molten region. The diffusion of hydrogen through the oxide layer apparently is slow. It may be pointed out that after a certain time, gas pressure can be expected to build up beneath the oxide layer to a level where the oxide can no longer retain it. This will then give rise to the "sparkler" effect which was noted earlier in the program.

Two different types of ablation that occurred are typified by Samples 14 and 15, modified alloys containing 2 weight-percent aluminum and 2 weight-percent bismuth, respectively. In both cases, the majority of the hydrogen in the upper portions of the samples has been released, and both samples contained molten regions during testing. Sample 15 differed from Sample 14, however, in two respects. A thick, tenacious oxide was seen on the former sample compared to a thin, loose oxide on the latter (the gray area shown on the left of the ablated surface in Figure 148 is below the surface of the mount; clear epoxy resin was used as the mounting material). In addition, the ablated surface of the former in the direction of the heat flux was concave as compared with a convex surface for Sample 14. Three important factors, the rate of oxidation, the properties of the oxide, and the fluidity of the molten alloy, appear to be primarily responsible for these structures. For the sample containing bismuth, the rate of oxidation was high and resulted in an oxide so strong and tenacious that a large portion of it remained even after much of the molten alloy behind it ablated. The molten alloy containing bismuth undoubtedly had relatively high fluidity; castability tests conducted earlier in the study suggested that this is true.

Little can be said about the initial oxide that was formed on the sample containing aluminum. The fluidity of the alloy, however, appears to have been low since a large molten region was built up and was retained on the specimen. Again, this agrees well with the castability test results obtained earlier.

\section{$\underline{\text { Detailed Studies }}$}

Results -- The particulate ablation products and remaining sections of five fuel samples, unmodified ZrH-uranium (A.I. materia1) and ZrH-uranium alloys containing additions of vanadium, tungsten, aluminum, and tin, were studied in some detail. In these studies, efforts were made (1) to collect representative samples of 
particulate products and to determine their particle size and volume distributions, to examine them both macroscopically and microscopically, and to determine their compositions; and (2) to examine the microstructures of the remaining sections and to obtain a hydrogen, oxygen, and nitrogen profile across one sample.

Particle Size and Volume Distribution -- Owing to the shape of the downstream chambers of the collection system, particulate ablation products were separated into two distinct size ranges. Larger particles were collected upstream and were removed through the specimen-holder orifice; smaller particles suspended in water were obtained from the exit of the collector tank. Three separate, approximately 1-liter water samples were taken during each test. The first sample was taken before the run to establish the base impurity leve1 of the water in the system. The second sample was drawn inmediately after the specimen was exposed. The third sample, termed an integrated sample, was made up of smaller samples removed randomly from the 16 gallons of water which passed through the system during a run.

The particle size and volume distribution for the unmodified ZrH-uranium fuel and the fuels modified with additions of aluminum and vanadium have been plotted in Figures 151 and 152. Figure 151 shows the distribution of the number of particles obtained during the ablation of fuel samples as a function of particle size; Figure 152 shows the manner in which the total volume of ablation products was distributed over the particle size range.

Samples of ablation products were weighed and compared with the weight losses of specimens during tests. Assumptions of uniform ablation, uniform distribution of ablation products in the water samples, of composition of the ablation products, and of the amount of contamination in the system made accurate analyses impossible. Nevertheless, all calculations indicated that essentially all material ablated from the samples was collected.

Macroscopic and Microscopic Examination of Ablated Particles -- Larger particles were collected upstream during the ablation tests of the unmodified fue1 samples and the samples modified with aluminum and vanadium. Figures 153, 154, and 155 show these larger particles. From macroscopic and microscopic examinations, it was seen that particles collected from the unmodified and vanadium-containing samples were of two types. The first type, making up greater than 95 percent of the total volume, consisted of spherical particles ranging from about 5000 microns to less than 1-micron in diameter and possessing a gray color with a meta11ic luster. Larger particles were more irregular in shape. The second type of particle seen was yellow or gold in color and angular in shape. These latter particles appeared to be sections of oxide that initially formed on the front exposed surface of the samples. The particles collected from the aluminum-containing specimen were much less numerous, in general much larger in size, and more irregular in shape than those particles collected from the unmodified and vanadium-modified samples.

The larger particles were mounted, polished, and examined metallographica11y. Most of the particles possessed a dehydrided alloy core with a thick, oxide case. Other particles were seen to be completely oxidized. Figures 154, 155, and 156 show some of the structures that were seen.

Smaller particles which were collected in water samples obtained from the collector tank exit were examined also. A typical sample of particles that were collected from a 1-liter sample of water is shown at high magnification (750X) in Figure 155. Note the spherical nature of the particles. X-ray analyses of small particles collected from modified and unmodified fuel samples showed structures consisting almost entirely of monoclinic zirconia. Although the overall appearances of the particles were examined in detail, no efforts were made to mount, polish, and examine the internal structures of these particles because of their extremely sma11 size. 


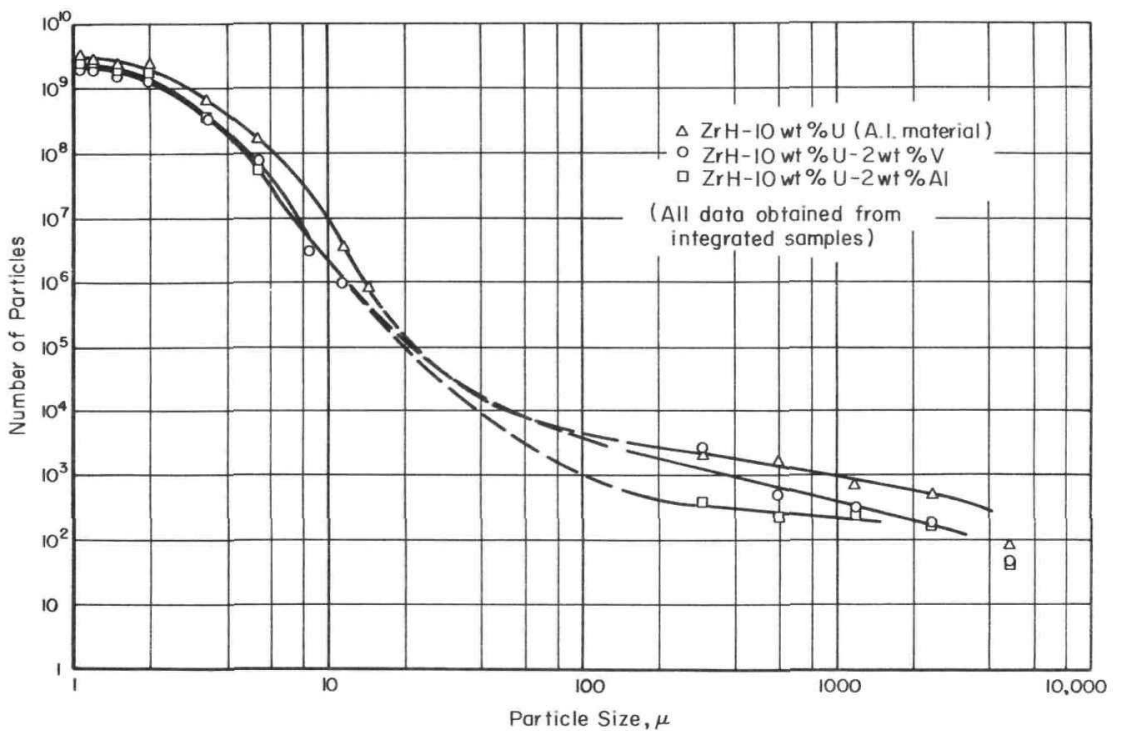

Figure 151. Distribution of the number of particles obtained during the ablation of three fuel samples as a function of particle size
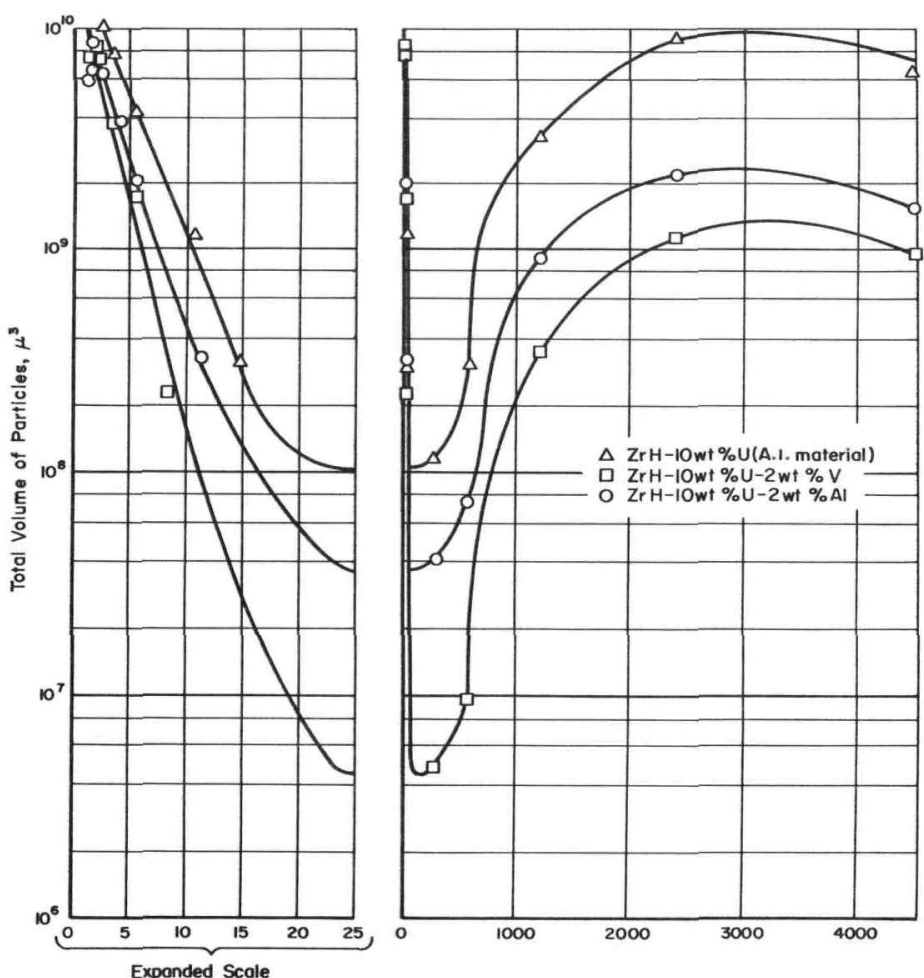

Particle Size, $\mu$

Figure 152. Volume distribution of particles obtained during the ablation of three fue 1 samples 


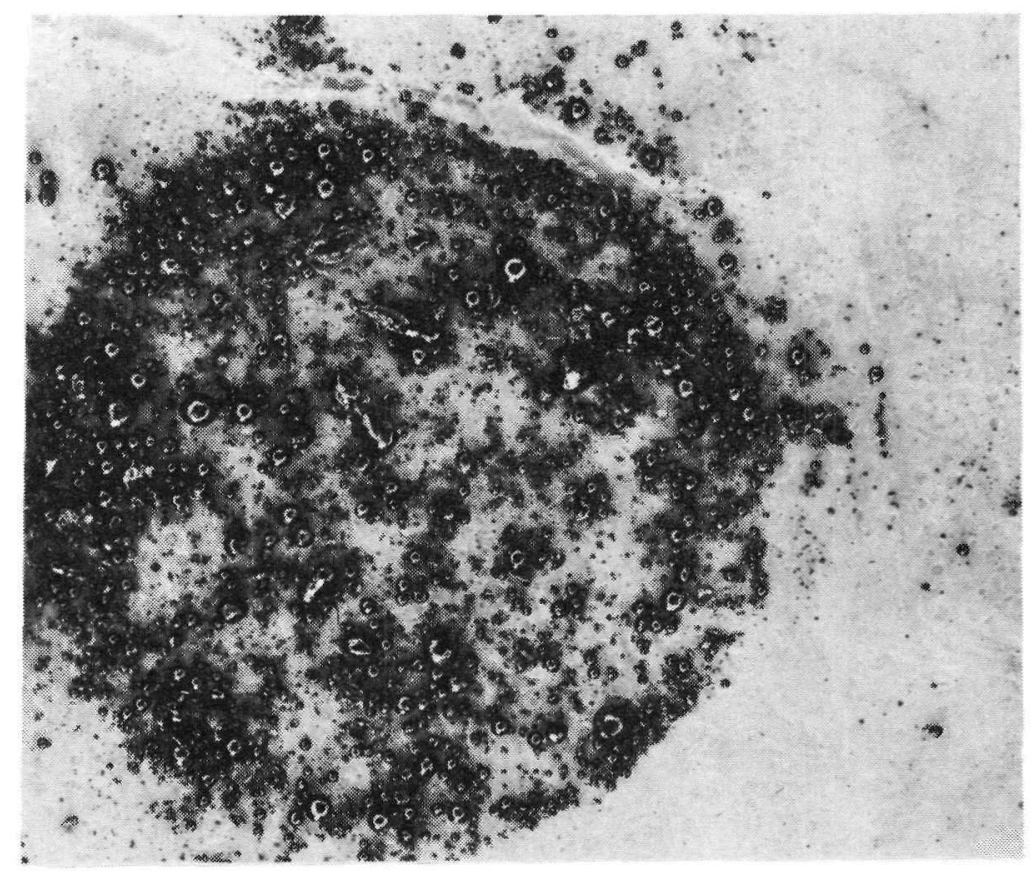

Figure 153. Collection of large particles obtained during the ablation of a 2 weight-percent vanadiummodified ZrH-uranium fuel

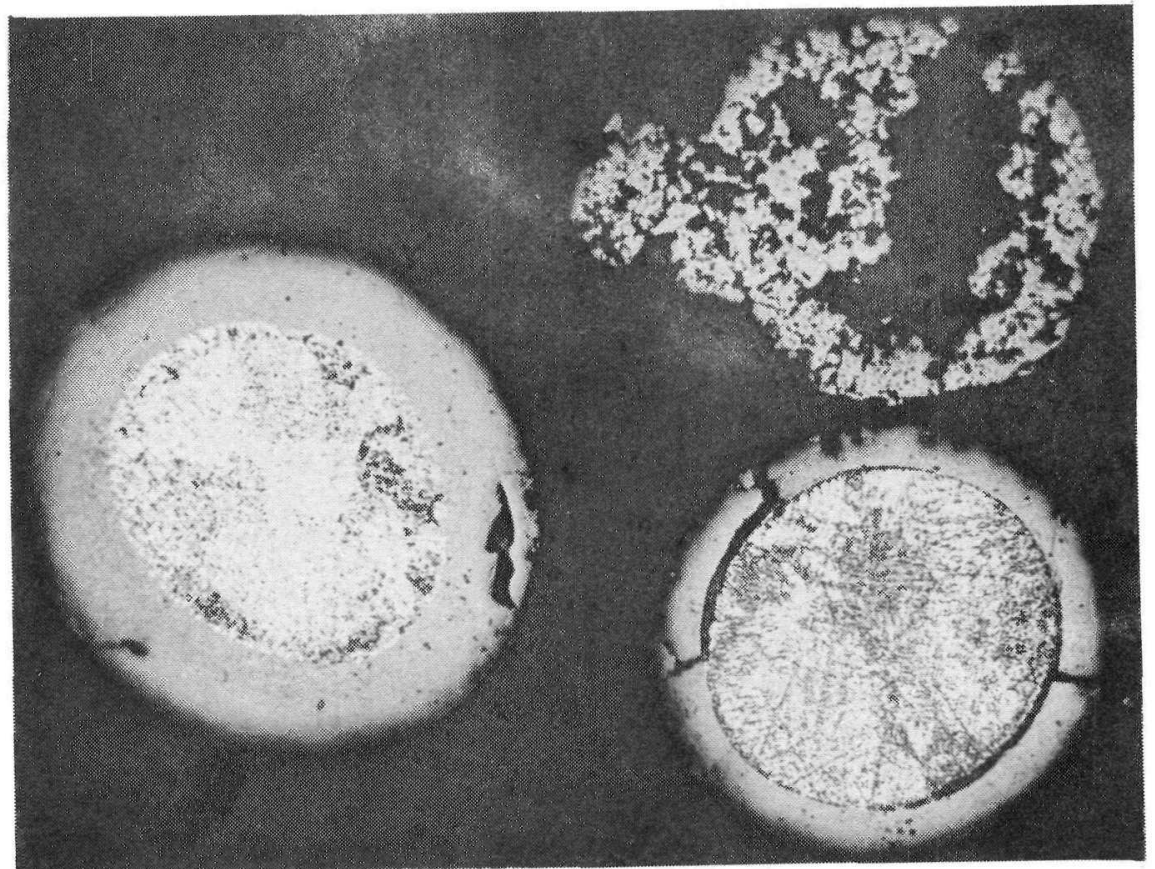

Figure 154. Microstructure of several large particles collected during the ablation of a 2 weightpercent vanadium-modified $\mathrm{ZrH}$-uranium fuel 


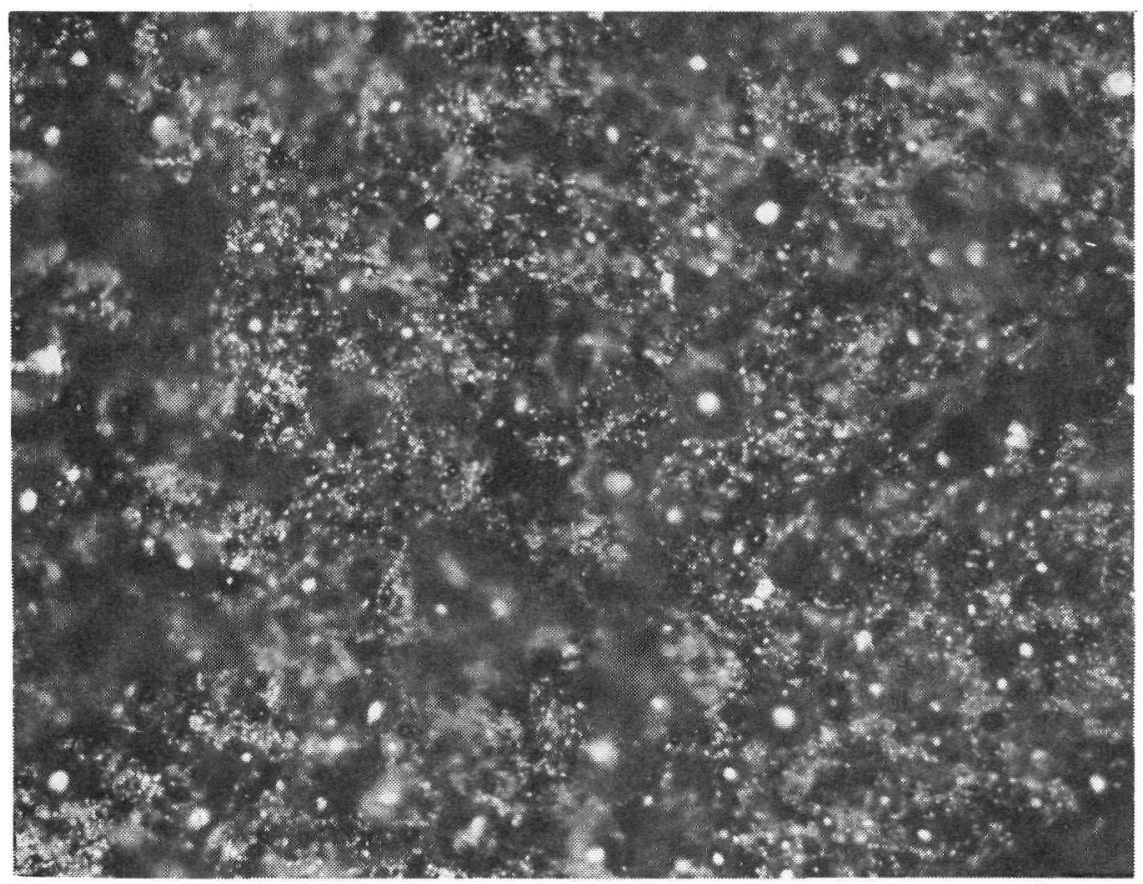

Figure 155. Smal1 particles collected during the ablation of an unmodified ZrH-uranium fuel sample

Composition of Ablated Particles -- To determine what elements were present in the spherical ablation products, three samples of the larger particles and two samples of the smaller particles were analyzed qualitatively. An emission spectrograph was used to perform these analyses. Owing to the manner of analysis, very rough approximations of the amounts of the various elements present in the particles were also disclosed. The results of these analyses are given in Table V. One sample of the larger particles (ZrH-uranium) and two samples of the smaller particles ( $\mathrm{ZrH}-$ uranium and $\mathrm{ZrH}-$ uranium-aluminum) were then examined quantitatively for uranium by fluorescent analyses. The results of these analyses are given in Table VI.

TABLE V

Results of Qualitative Analysis of Ablated Fuel Particles

\begin{tabular}{|c|c|c|c|c|c|c|c|c|}
\hline \multicolumn{2}{|c|}{ A11oy } & $\mathrm{Zr}$ & $\mathrm{U}$ & $\mathrm{A} 1$ & V & $\mathrm{Si}$ & $\mathrm{Fe}$ & $\mathrm{Cu}$ \\
\hline \multicolumn{9}{|c|}{ Large Particles } \\
\hline \multirow{3}{*}{\multicolumn{2}{|c|}{$\begin{array}{l}\mathrm{ZrH}-10 \mathrm{U} \\
\mathrm{ZrH}-10 \mathrm{U}-2 \mathrm{~V} \\
\mathrm{ZrH}-10 \mathrm{U}-2 \mathrm{~A} 1\end{array}$}} & $\mathrm{H}$ & M & $\mathrm{T}$ & $\mathrm{L}$ & $\mathrm{T}$ & $\mathrm{T}$ & $\mathrm{T}$ \\
\hline & & $\mathrm{H}$ & M & $\mathrm{T}$ & M & $\mathrm{T}$ & $\mathrm{T}$ & $\mathrm{T}$ \\
\hline & & $\mathrm{H}$ & M & L & $\mathrm{T}$ & $\mathrm{T}$ & $\mathrm{T}$ & $\mathrm{T}$ \\
\hline \multicolumn{9}{|c|}{ Sma11 Particles } \\
\hline \multirow{2}{*}{\multicolumn{2}{|c|}{$\begin{array}{l}\mathrm{ZrH}-10 \mathrm{U} \\
\mathrm{ZrH}-10 \mathrm{U}-2 \mathrm{~A} 1\end{array}$}} & $\mathrm{H}$ & M & $\mathrm{T}$ & $\mathrm{T}$ & $\mathrm{L}$ & $\mathrm{T}$ & $\mathrm{T}$ \\
\hline & & $\mathrm{H}$ & M & $\mathrm{L}$ & $\mathrm{N}$ & $\mathrm{T}$ & $\mathrm{T}$ & $\mathrm{T}$ \\
\hline \multicolumn{9}{|c|}{$\begin{array}{l}\text { Note: } \mathrm{H} \text { denotes high concentration (1 to } 100 \mathrm{wt} \%) \text {. } \\
\mathrm{M} \text { denotes medium concentration }(0.1 \text { to } 10 \mathrm{wt} \%) \text {. } \\
\mathrm{L} \text { denotes low concentration }(0.01 \text { to } 1.0 \mathrm{wt} \%) \text {. } \\
\mathrm{T} \text { denotes trace present }(<0.01 \mathrm{wt} \%) . \\
\mathrm{N} \text { denotes none detected. }\end{array}$} \\
\hline
\end{tabular}


TABLE VI

Results of Quantitative Fluorescent Analysis for Uranium

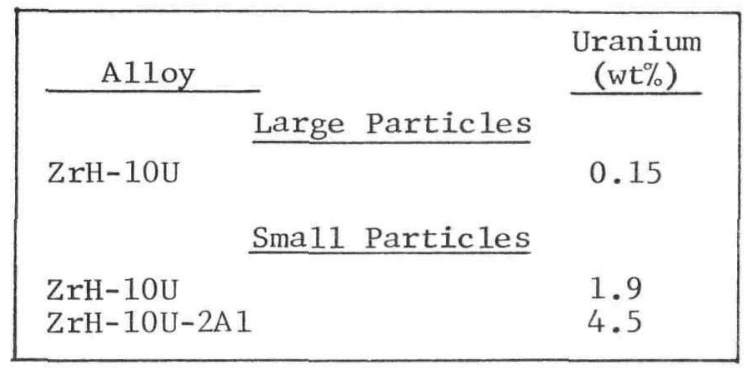

Examination of Remaining Samples -- Several observations were made in examining the microstructures of the remaining sections. Voids at grain boundaries were seen in the interior regions of most samples. Figures 156, 157, and 158 show examples of these voids. The presence of these voids supports the postulate that hydrogen first diffuses to the grain boundaries before leaving the specimens. In addition to the voids, an acicular phase within the grains was also noted.

Figure 159 shows the microstructure of an area at the top surface of the $\mathrm{ZrH}$ uranium-tungsten sample. Of interest here are the alternate layers of metal and oxide. A structure such as this can only indicate either that alternate layers of molten oxide and molten metal were laid down or that molten metal was splashed over the oxide intermittently with oxidation occurring in the interim.

Various phenomena occurring at the surface of samples are shown in Figures 160,161 , and 162. Sections of the dark gray phase appearing on the surface were removed from several samples, and the structure of these sections was determined by $\mathrm{X}$-ray spectroscopy. In al1 cases, the results showed that only single-phase monoclinic zirconia $\left(\mathrm{ZrO}_{2}\right)$ was present.

Also present in many of the samples beneath the zirconia layer was a "suboxide" or second phase. Figure 160 shows a good example of the suboxide that was seen on the tin-modified fuel after exposure. Curiously enough, no suboxides were seen in the structures of unmodified samples. It may be that the alloying elements play some part in the formation of this phase.

Figure 161 presents examples of large gas pockets trapped within or just behind the oxide layer. The shape of the gas pockets indicates that much or all of this area was molten during testing. Figure 162 is an interesting photomicrograph of the surface of the ZrH-uranium-vanadium sample showing a variety of structures, internal voids at the grain boundaries, a needlelike phase, a gray surface oxide (zirconia), the presence of a suboxide, gas pockets, etc.

Analysis of the Remains of the Unmodified ZrH-uranium Sample -- Five sections, approximately 0.050 -inch thick, were taken from the unmodified fuel sample. Each was cut paralle1 to the exposed surface as shown in Figure 163. The sections were analyzed for their oxygen, hydrogen, and nitrogen contents by vacuumfusion techniques. The results of these analyses are given in Table VII. 


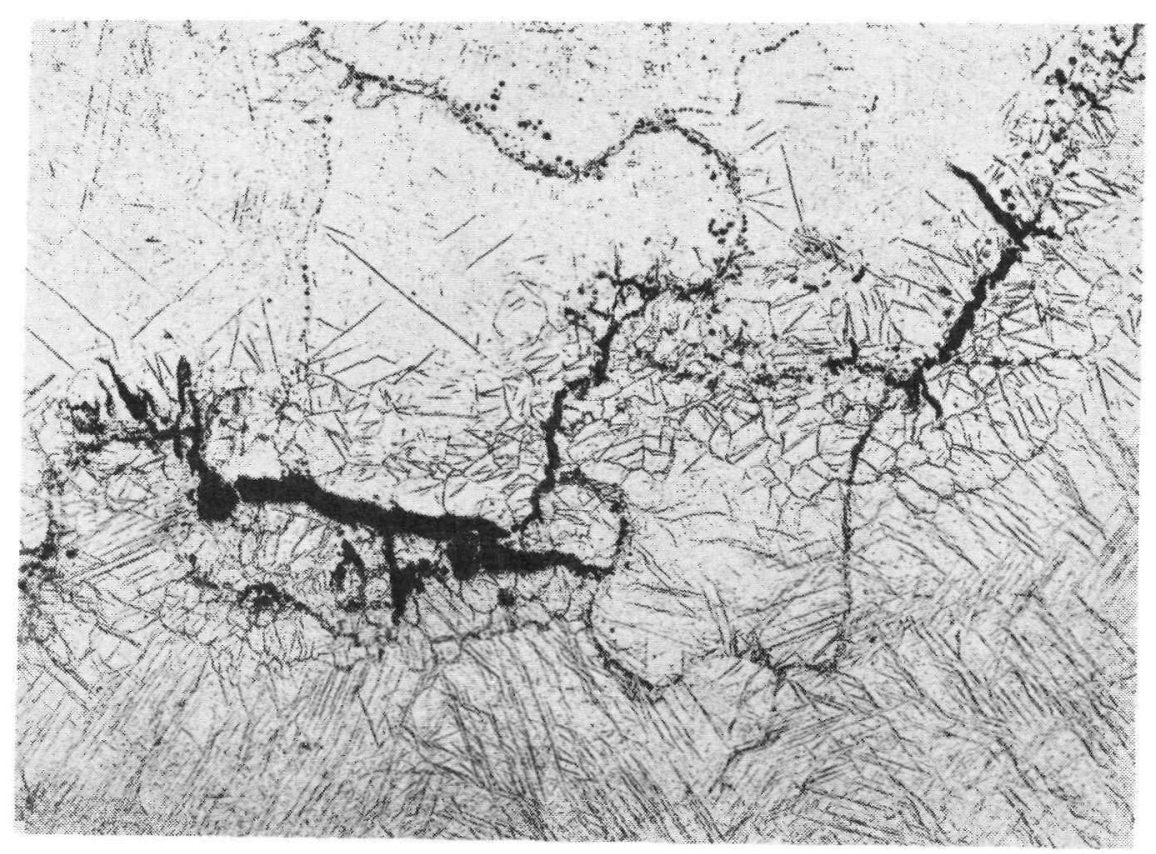

Figure 156. Voids in the interior of an exposed unmodified ZrH-uranium fuel sample

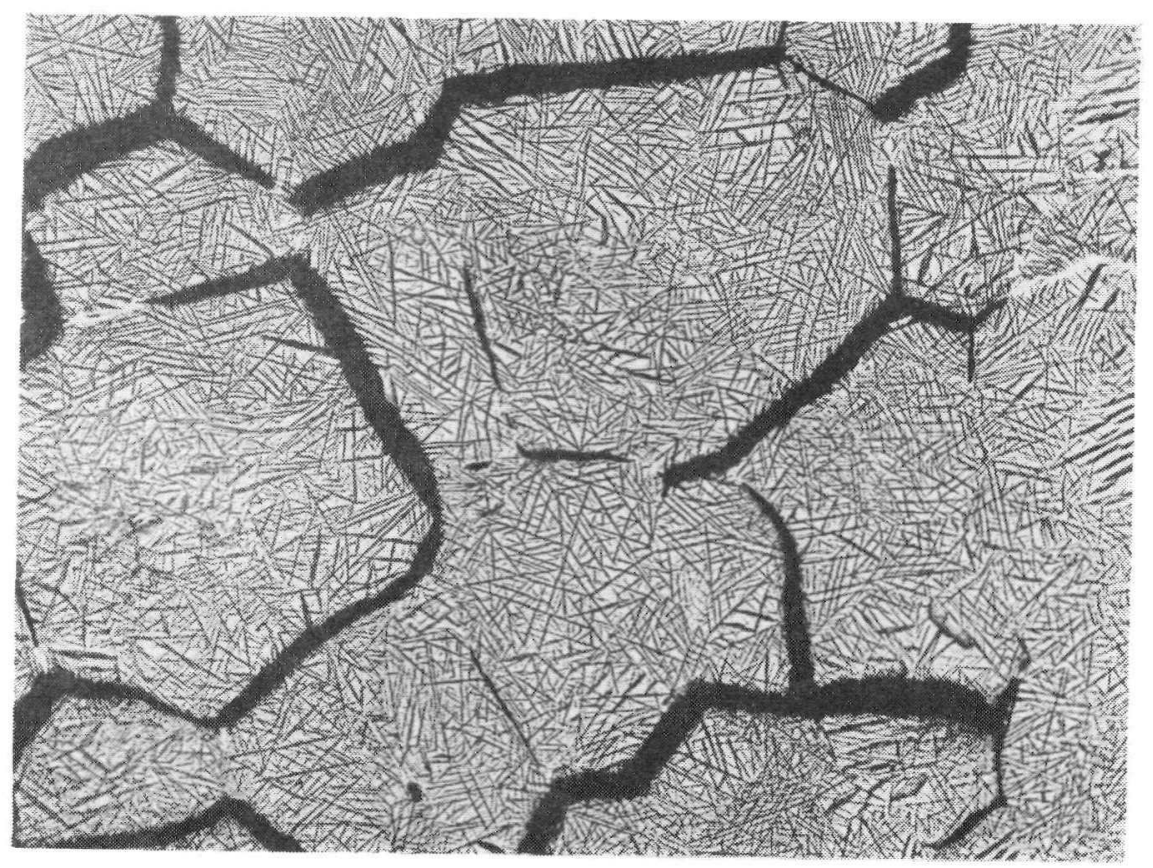

Figure 157. Voids in the interior of an exposed vanadium-modified $\mathrm{ZrH}$-uranium fuel sample 


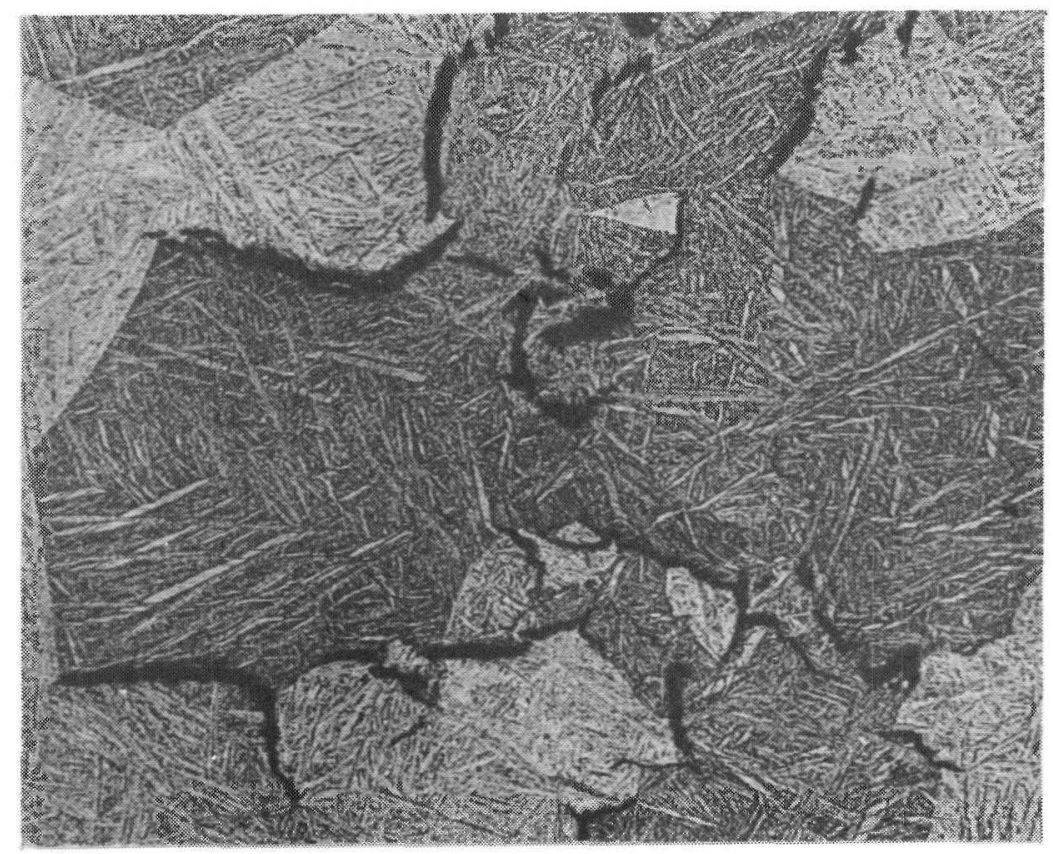

Figure 158. Voids in the interior of an exposed tin-modified ZrH-uranium fuel sample

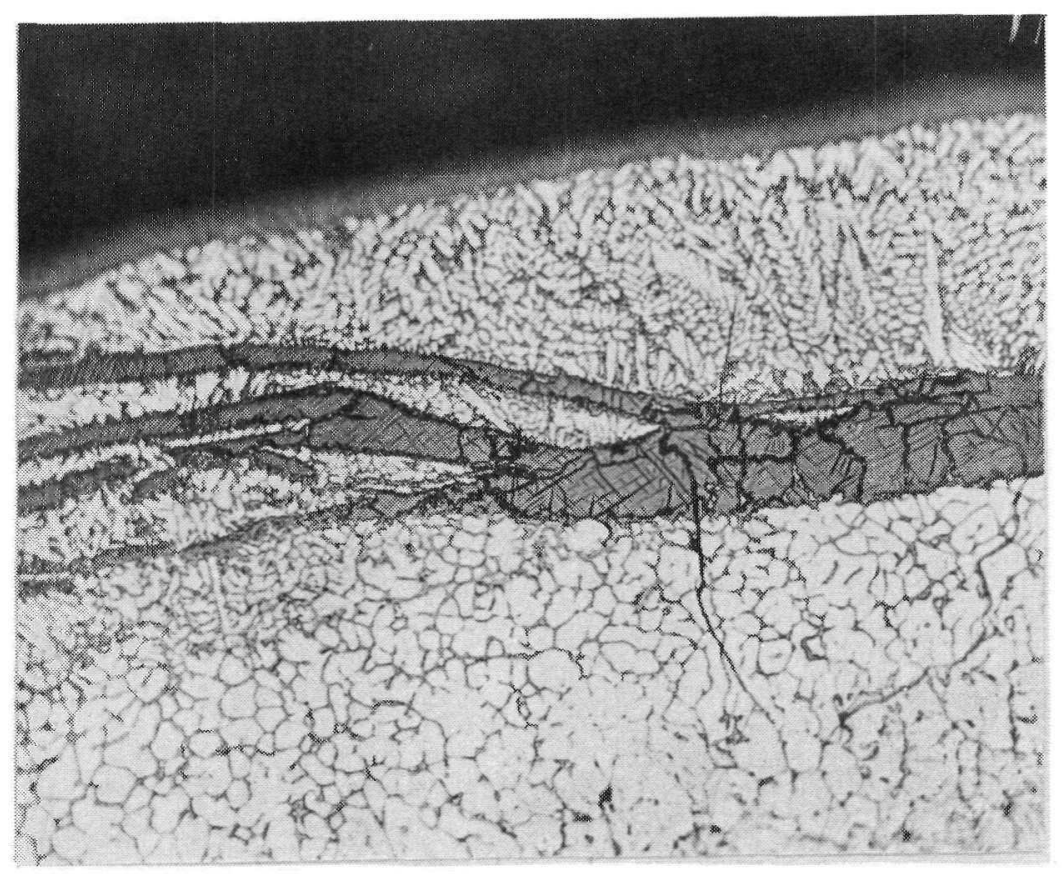

Figure 159. A region along the top surface of an exposed tungsten-modified $\mathrm{ZrH}$-uranium fuel sample 


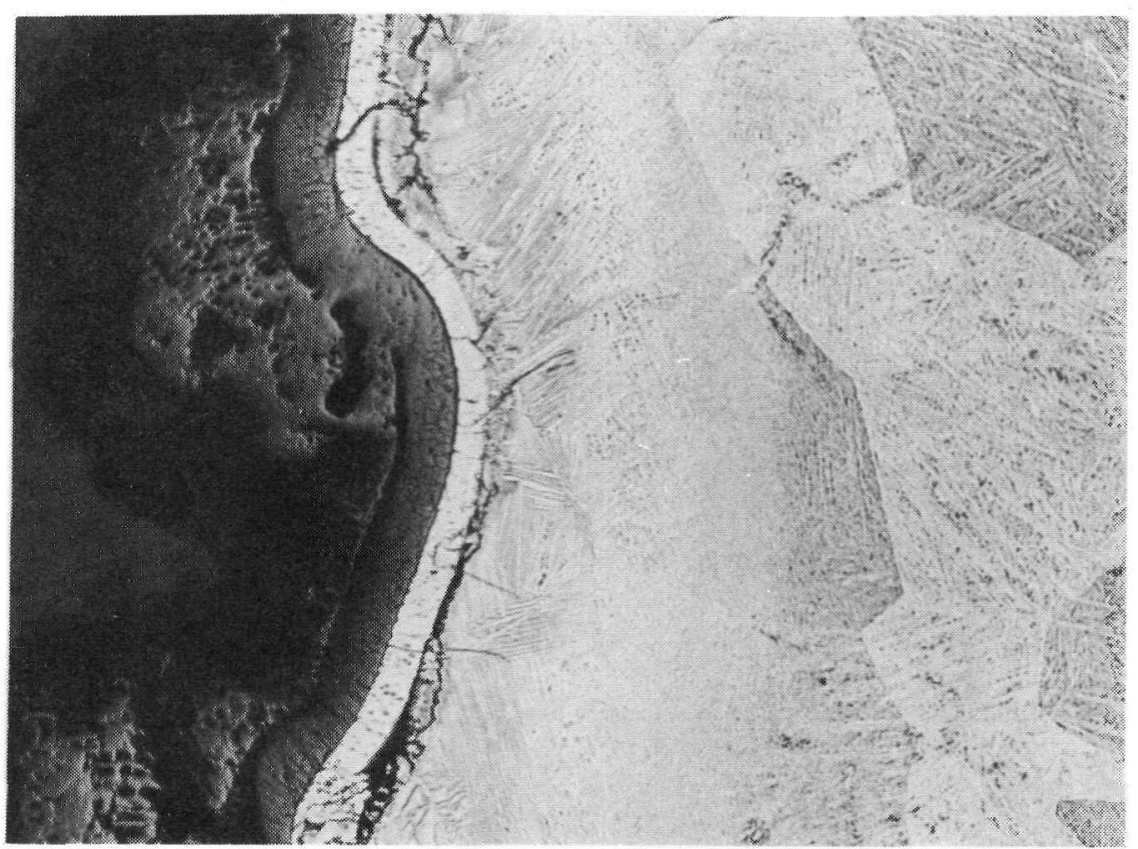

Figure 160. Exposed surface of a tin-modified fuel sample displaying a suboxide

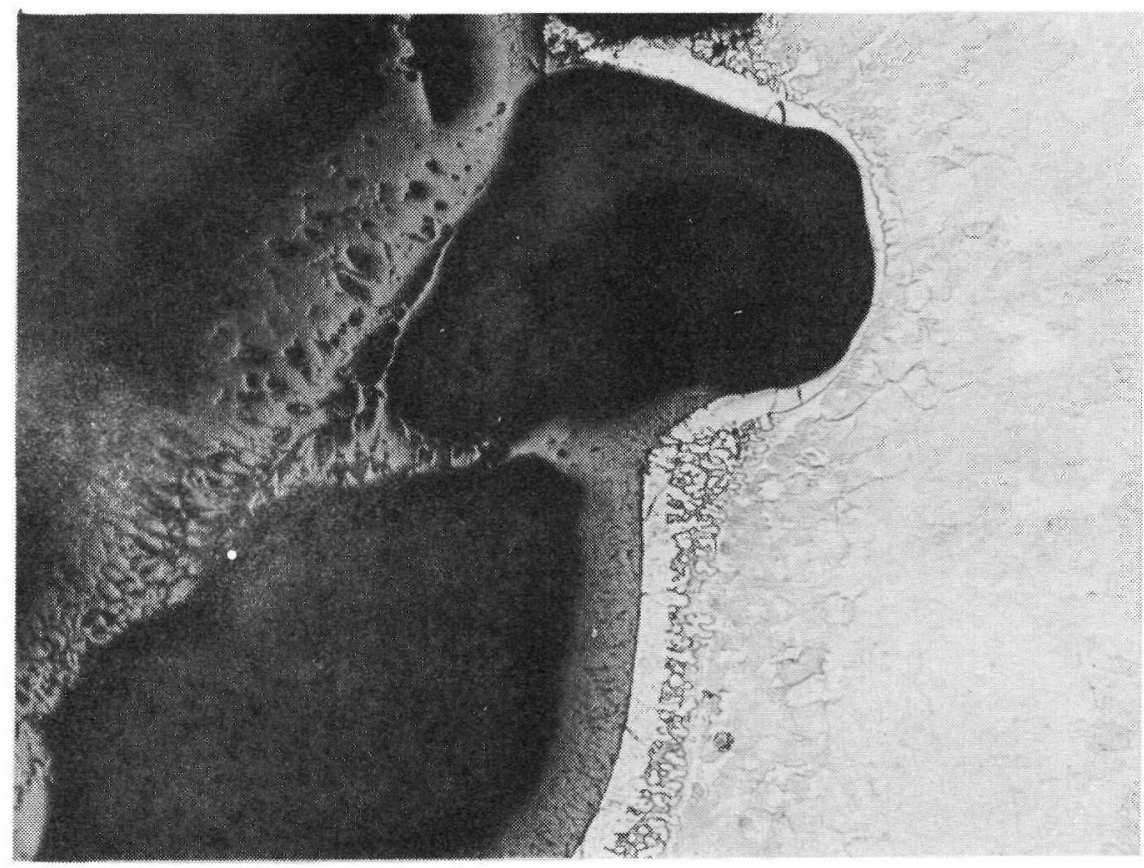

Figure 161. Large gas pockets within and beneath the surface oxide of an exposed aluminummodified fuel sample 


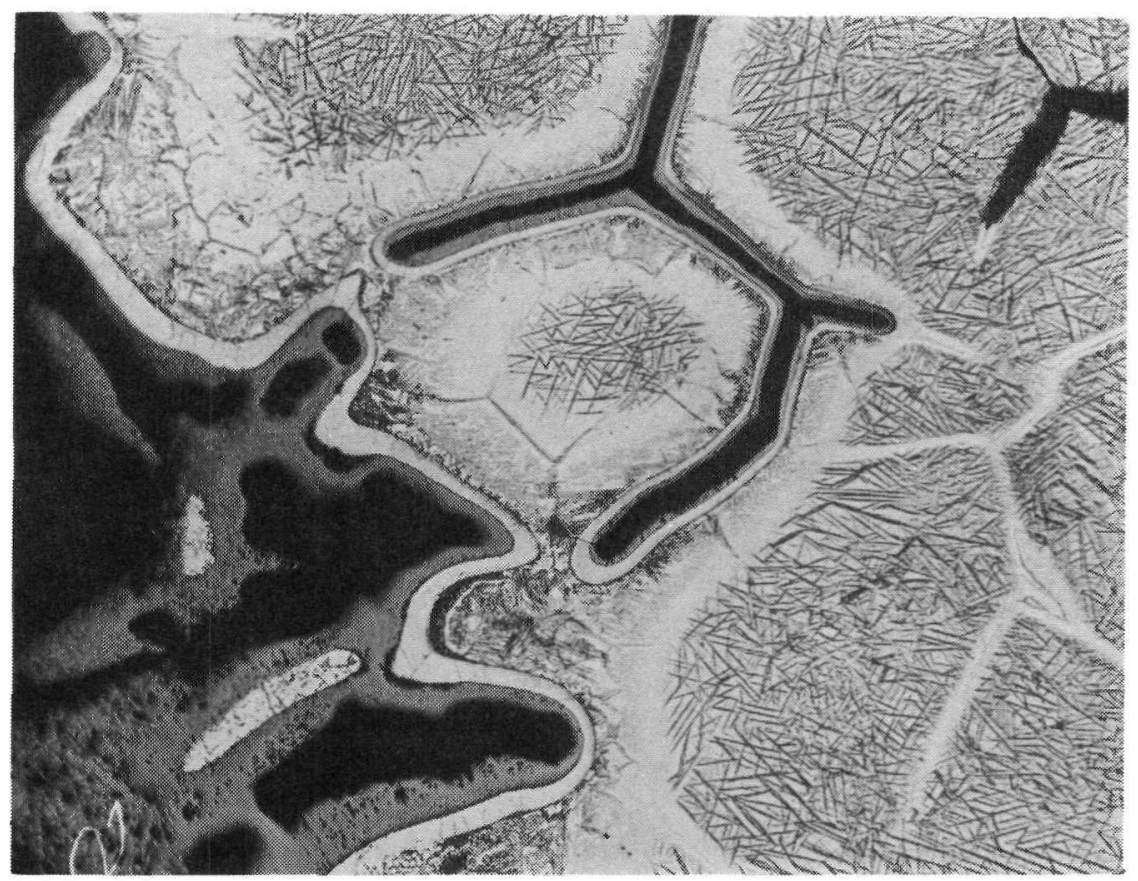

Figure 162. Structures near the surface of an exposed vanadium-modified $\mathrm{ZrH}-$ uranium fue 1 sample

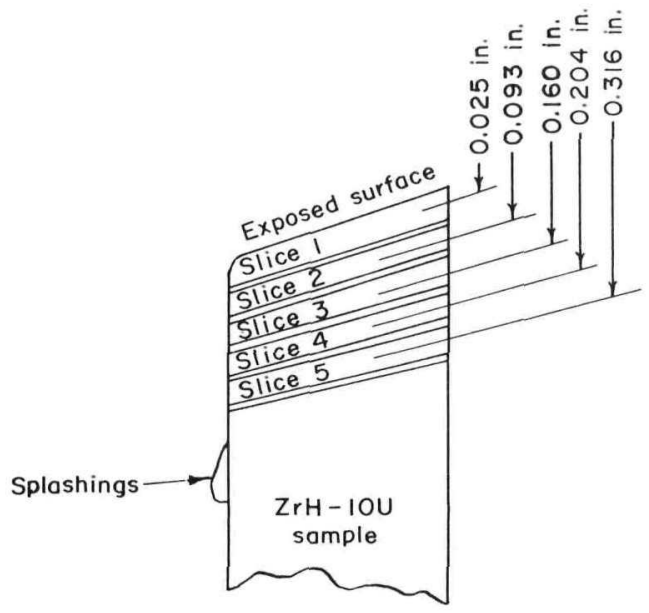

Figure 163. Sectioning of zirconium hydride uranium samples
TABLE VII

Analysis of an Ablated ZrH 10 WeightPercent Uranium Fuel Sample for Oxygen, Hydrogen, and Nitrogen

\begin{tabular}{|c|c|c|c|}
\hline \multirow[b]{2}{*}{ S1ice } & \multicolumn{3}{|c|}{ Analysis, ${ }^{\mathrm{a}}$ percent } \\
\hline & $\mathrm{O}_{2}$ & $\mathrm{H}_{2}$ & $\mathrm{~N}_{2}$ \\
\hline 1 & 2.43 & 0.071 & 0.099 \\
\hline 2 & 2.78 & 0.655 & 0.041 \\
\hline 3 & 1.26 & $0.167^{b}$ & 0.045 \\
\hline 4 & 0.398 & 1.915 & 0.062 \\
\hline 5 & 0.283 & 1.810 & 0.146 \\
\hline Splashings & 16.3 & 0.022 & 0.083 \\
\hline
\end{tabular}

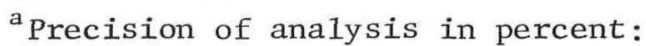
$\pm 0.03 \mathrm{O}_{2}, \pm 0.004 \mathrm{H}_{2}, \pm 0.003 \mathrm{~N}_{2}$.

${ }^{b}$ No explanation is available for this low value. 
Discussion

From the data plotted on the graphs in Figures 151 and 152, it can be seen that, although the number of particles produced in each test decreased rapidly with increase in size, the majority of the volume of ablated particles fel1 into two distinct size ranges. The first range consisted of particles with diameters greater than approximately 1000 microns; the second consisted of particles with diameters less than 5 microns. It can be seen further that the curves designating tota1 volumes for the different fuels varied somewhat. These occurrences would indicate that alloying elements affect the volume distribution of particles produced during ablation.

Chemica1 analysis of sections taken at various locations across the ZrH-10U sample after ablation showed that, in general, hydrogen rapidly diffused out of the sample, oxygen rapidly diffused into the sample, and the nitrogen content remained fairly constant. No nitrogen pickup would be expected in the tests that were performed since essentially no nitrogen was present in the rocket test environment.

Investigation of the Stages of Ablation of an Unmodified ZrH-Uranium Fuel

Three samples of unmodified $\mathrm{ZrH}-$ uranium were exposed to identical conditions in the rocket test for times of $2.5,5.0$, and 8.0 seconds, and the remaining sections were examined in an effort to define more fully the manner in which the unmodified fuel ablates. The weight changes that occurred in the samples are given in Table IV; photographs and photomicrographs of samples are given in Figure 164. From the weight-change data and the photomicrographs, it can be seen that:

1. After 2.5 seconds' exposure, a thin oxide layer had formed on the sample, hydrogen had been released, and some melting beneath the oxide had begun. No loss of bulk material, however, had yet occurred. Oxidation was undoubtedly responsible for the weight increase noted in the specimen.

2. After 5.0 seconds' exposure, a large amount of the specimen had been ablated, and a molten surface layer about 1/16-inch thick was present on the sample. A microprobe analysis for uranium across the cross section of this sample after test (see Figure 165) showed that the concentration of uranium decreased from the surface to a region approximately 0.017 inch into the fuel sample. A minimum concentration of 7.0 weight-percent uranium was noted there, and the concentration then increased in going further into the sample until the initial concentration of the fuel was obtained.

3. After 8.0 seconds' exposure, al1 materia1 in the direct line of maximum heat flux had ablated. The top surface of the remains of the sample contained a thick oxide layer, and the remaining hydride material within the specimen holder was beginning to decompose. If an exposure time of 10 seconds or longer had been used, it is expected that the entire specimen along with a large portion of the specimen holder would have melted and been carried away. Such dissolution did take place during early trials in the rocket device when a zirconium hydride sample was exposed for 10 seconds. 

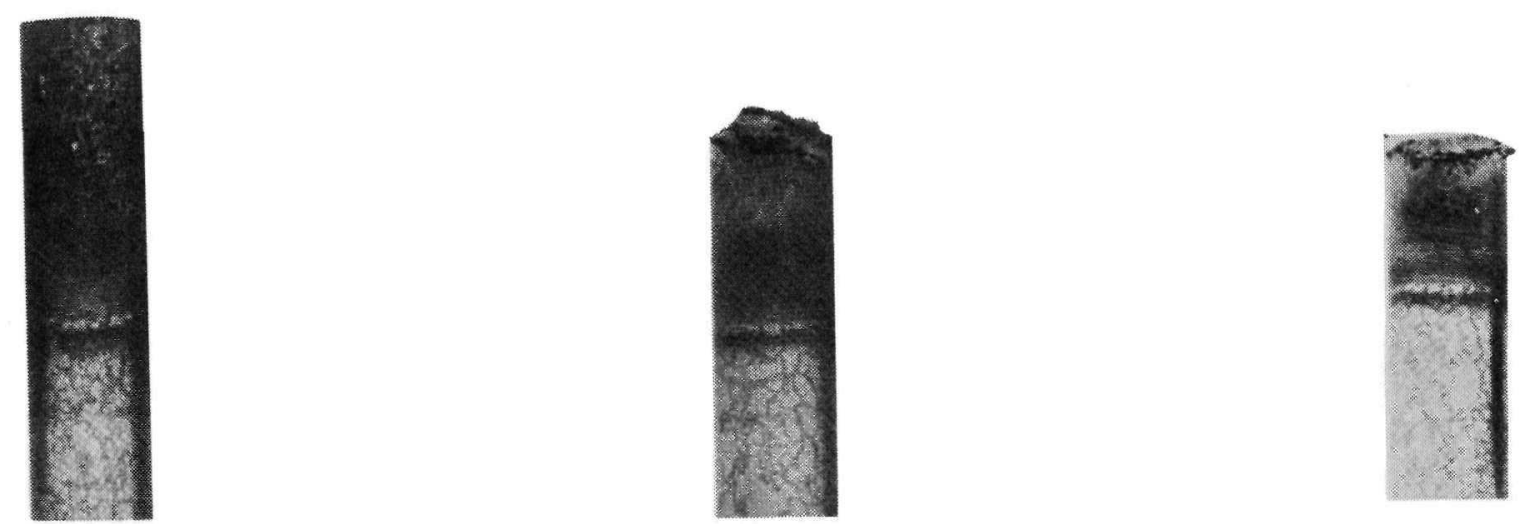

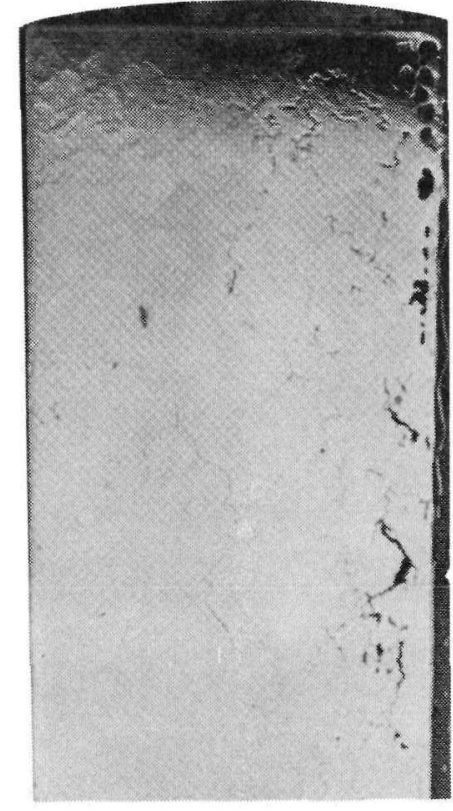

2.5 Seconds

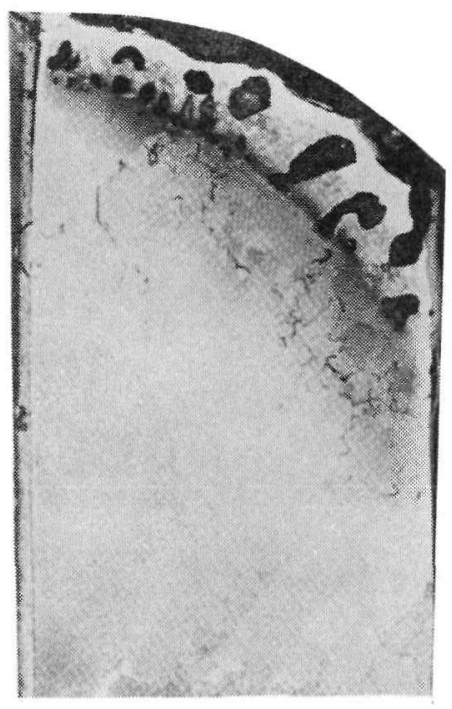

5. 0 Seconds

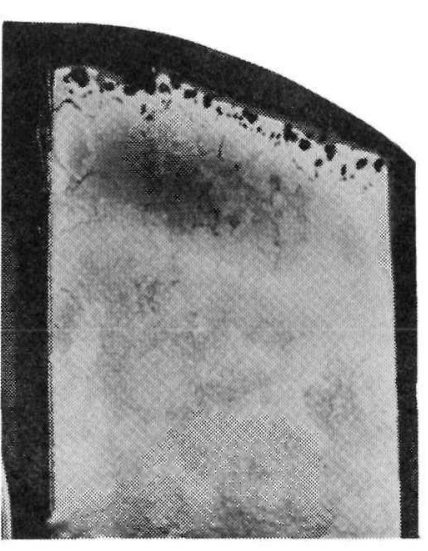

8.0 Seconds

Exposure Time

Figure 164. Photographs and photomicrographs of unmodified ZrH-uranium fuel samples exposed to re-entry conditions for various times 


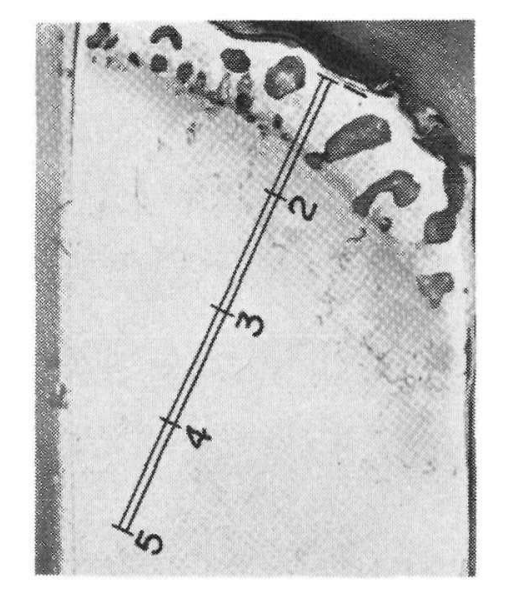

ZrH-Uranium Specimen (A.I. Material)

Exposed in Test for 5 Seconds

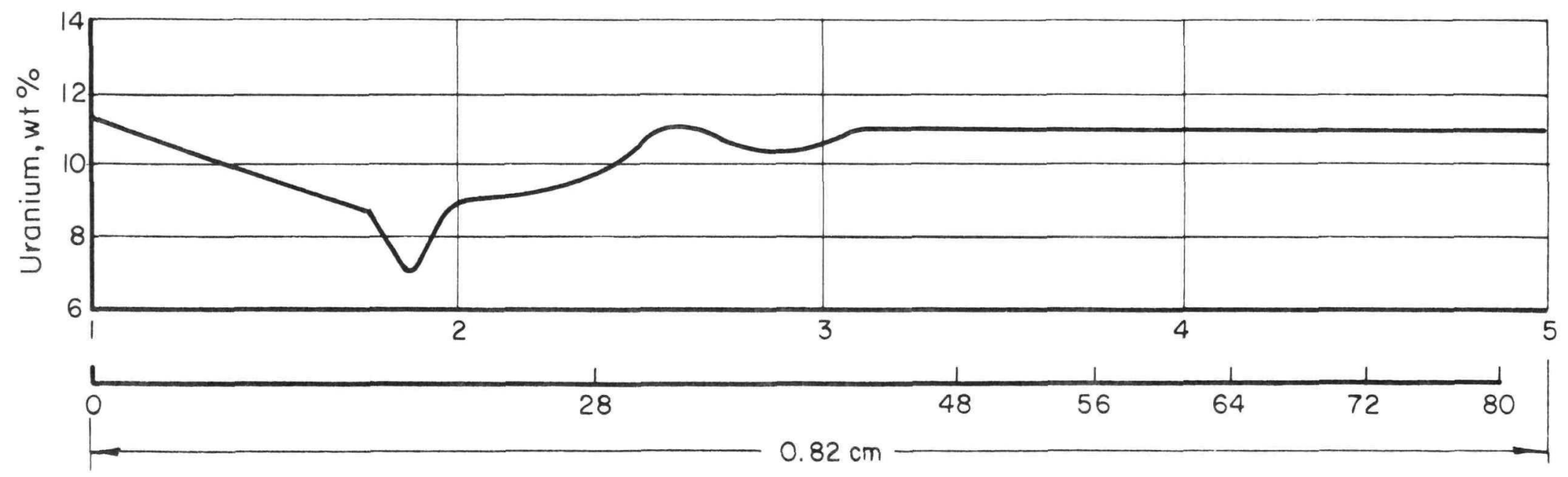

Figure 165. Uranium concentrations across an exposed fuel 
Investigation of Exposed ZrH Specimens

Two 1/2-inch-diameter by 1-1/2-inch-1ong cylinders of hydrided zirconium (from Atomics Internationa1) which were exposed to plasma tests (at Plasmadyne) were obtained by Battelle for examination. Specimens were identified as No. 8 and No. 30, and the following information was given:

TABLE VIII

Plasma Tests

\begin{tabular}{|cccc|}
\hline Test Run & $\begin{array}{c}\text { Pressure } \\
\text { at Nose } \\
\text { atm }\end{array}$ & $\begin{array}{c}\text { Enthalpy } \\
\text { Btu/hr }\end{array}$ & $\begin{array}{c}\text { Stagnating Point } \\
\text { Btu/sq ft-sec }\end{array}$ \\
\cline { 2 - 2 } & 0.054 & 11,000 & 825 \\
B & 0.085 & 8,000 & 770 \\
\hline
\end{tabular}

Although only incomplete information on the history of these particular specimens was available, the materials were examined to gain experience and to aid in the evaluation of alloyed and modified fuel materials.

At Battelle, each cylinder was sectioned longitudinally. One section was then examined by vacuum fusion for hydrogen, nitrogen, and oxygen contents at various distances away from the exposed surface; the second section was mounted, polished, etched, and examined metallographically. The results of these examinations are presented in Figure 166.

\section{Vacuum-Fusion Analysis}

Hydrogen, oxygen, and nitrogen contents were determined in various regions of the two specimens and in drippings that had formed during the testing of Specimen 8. The results of spectrographic analyses are as follows:

TABIE IX

Spectrographic Analyses

\begin{tabular}{|c|c|c|c|c|}
\hline Sample & Location & $\begin{array}{l}\text { Hydrogen, as } \\
\mathrm{x} \text { in } \mathrm{ZrH}_{\mathrm{x}} \\
\end{array}$ & $\begin{array}{c}\text { Oxygen } \\
\text { wt \% } \\
\end{array}$ & $\begin{array}{l}\text { Nitrogen } \\
\text { wt } \%\end{array}$ \\
\hline 30 & $\begin{array}{l}\text { Top (1/16 inch, porous) } \\
\text { Top (1/8 inch, solid, clean) } \\
\text { Middle } \\
\text { Bottom }\end{array}$ & $\begin{array}{l}0.07 \\
0.90 \\
1.30 \\
1.93\end{array}$ & $\begin{array}{c}6.87 \\
-- \\
-- \\
0.16\end{array}$ & $\begin{array}{c}1.2 \\
-- \\
-- \\
--\end{array}$ \\
\hline 8 & $\begin{array}{l}\text { Drippings } \\
\text { Top (1/16 inch, porous) } \\
\text { Top (1/8 inch, solid, clean) } \\
\text { Middle } \\
\text { Bottom }\end{array}$ & $\begin{array}{l}0.01 \\
0.38 \\
0.22 \\
1.95 \\
1.93\end{array}$ & $\begin{array}{l}0.47 \\
0.45 \\
-- \\
-- \\
0.12\end{array}$ & $\begin{array}{r}0.8 \\
0.1 \\
-- \\
-- \\
--\end{array}$ \\
\hline
\end{tabular}

It can be seen that the base hydrogen content of both specimens is represented by the formula $\mathrm{ZrH}_{1.93}$. The hydrogen content of the middle section (an unaffected region) of Specimen 8 was unchanged, while that of the corresponding section (a heat-affected region) of Specimen 30 was reduced to $\mathrm{ZrH}_{1 . \text { зо }}$. The high nitrogen values for Specimen 30 and for the Specimen 8 drippings are interesting to note. 

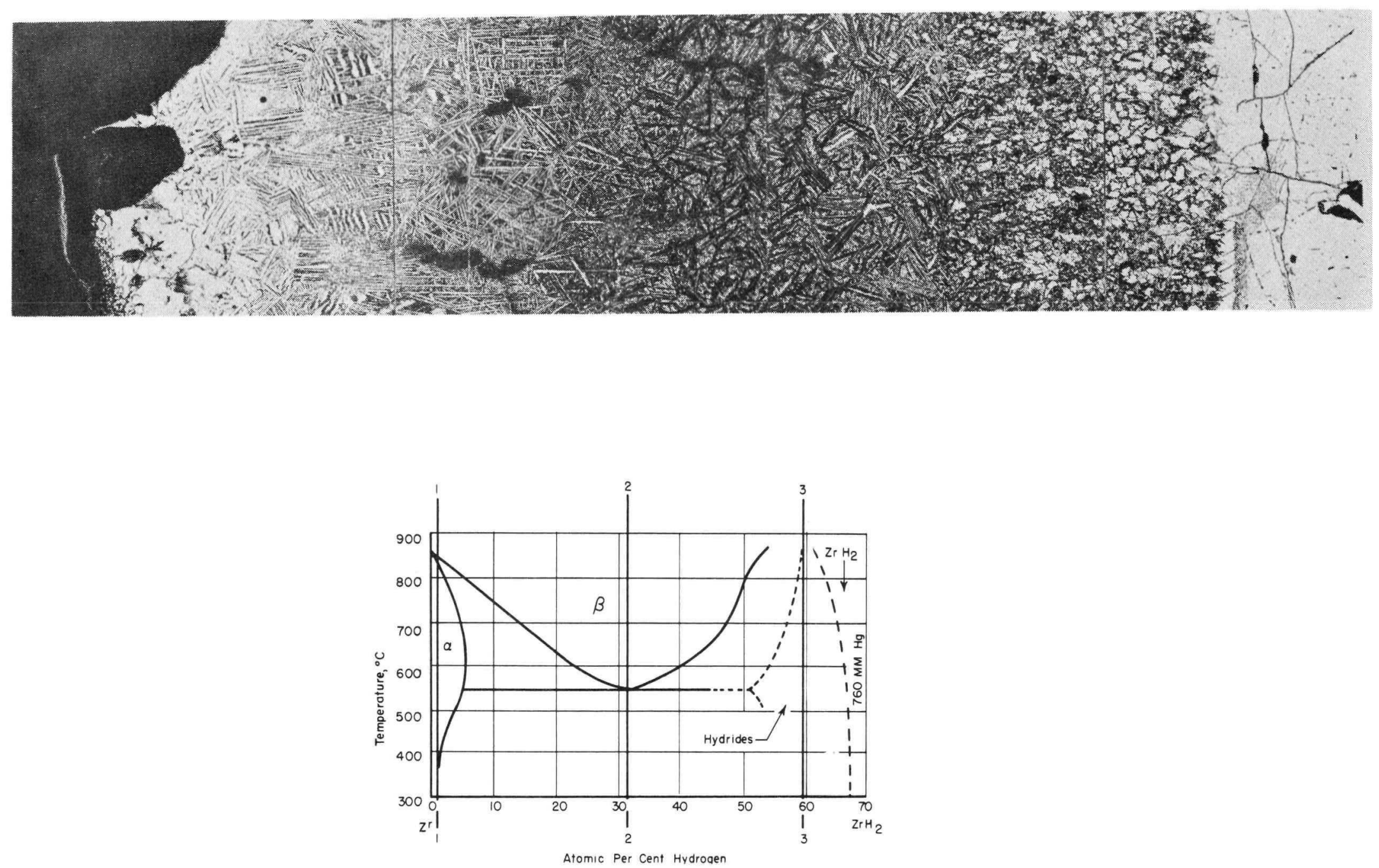

Figure 166. Correlation of microstructure in specimen 30 with the zirconium-hydrogen phase diagram 
The important results and conclusions of both the experimental and analytical studies described in this paper are summarized below.

1. Thirty-eight different modified fuel compositions were prepared. Selections of the type and quantity of alloying additions to be made were based on the effect of the addition on the thermal-neutron cross section of the alloy, on the alloy's melting point and on the mixed oxide's melting points, on the difficulties in making the additions, and on the cost and availability of the additions.

2. Some of the alloying additions caused significant changes in the properties and fabrication characteristics of the fuel (hardness, grain size, melting, casting, rolling, hydriding, and machining). Certain elemental additions improved properties while others caused a deterioration in properties. The majority of the alloys, however, were readily fabricable.

3. A "castability" test was developed to measure the effect of alloying additions on the surface tension and viscosity of the unhydrided fuel alloy. Large differences in fluidity were noted for the different alloys in the "castability" tests. Times for first melting and dripping of molten material from the various alloys in a plasma were noted for a given set of conditions. These times correlated we11 with the extent of metal penetration into the molds in the castability tests.

4. A significant modification in the fabrication technique was used in the preparation of fue1-rod samples containing additions of oxygen, nitrogen, and carbon. These samples were produced by isostatically pressing powders of zirconium hydride and compounds of uranium at high temperatures.

-5. After various modifications were made and instrumentation added to the rocket test facility, no problems were encountered in performing tests. Excellent control and duplication of test conditions were achieved. In tests, no one modified fuel alloy showed any significant increase in ablation that could definitely be attributable to a change in melting point or fluidity over that of the base a11oy.

6. Specimens of 12 different modifications of the reference fuel exhibited ablation losses about the same as the reference fuel. These modifications contained additions of vanadium, tungsten, tantalum, aluminum, bismuth, antimony, strontium, silicon, tin and niobium, oxygen, nitrogen, and carbon.

7. Of the group of materials that ablated with weight losses of about the same magnitude as that of the unmodified fuel, five definitely lost appreciable quantities by fracturing caused by thermal shock. Three of these materials, containing oxygen, nitrogen, and carbon (a11 fabricated by isostatic compaction), were fractured early in the test and little ablation occurred. The modified alloys containing 5 weight-percent antimony and 2 weight-percent tin/2 weight-percent niobium also lost significant weight through fracture. However, in the evaluation of these materials, significant ablation was noted. Moreover, close examination of the remaining portion of the antimony-containing material suggested that a significantly different manner of ablation might have occurred with this specimen.

8. Under the test conditions which were imposed, the products of ablation were definitely molten. This was confirmed in detailed examination of the test products.

9. The typical products of the rocket-exhaust ablation tests were particles that ranged in size from less than 1 to 5000 microns. The volume distribution of particles was bimodule, suggesting that two primary ablation processes were occurring. The smaller particles were probably produced at the specimen surface by physicochemical processes. The larger products probably resulted from mechanical processes and would not be typical of a final ablation product since these particles would subsequently be subjected to additional ablation. 
10. A phenomenology of the ablation of the reference hydride fuel was described in some detail.

11. It can be concluded that it is possible to change the ablation characteristics of the hydride fuel. The most significant changes brought about by alloying additions made directly to the melt, however, appear to be a reduction in ablation tendency. It is believed that a most attractive avenue for further development of a fuel with improved burnup properties lies in exploring and confirming the results that the thermal-shock susceptibility of the fuel can be significantly increased.

\section{Bibliography}

AVCO Corporation, Investigation of Re-Entry Destruction of Nuclear Auxiliary Powerplant, AFSWC-TR-61-69, October, 1961.

Atomics International, SNAP-8 Reactor Preliminary Design Summary, NAA-SR-6207, 27, June $15,1961$.

R. W. Detra, N. H. Kemp, and F. R. Ridde11, "Addendum to 'Heat Transfer to Satellite Vehicles Re-Entering the Atmosphere'," Jet Propulsion, 27, 1256-1257, December, 1957.

J. A. Fay and F. R. Ridde11, "Theory of Stagnation Point Heat Transfer in Dissociated Air," Journal of the Aeronautica1 Sciences, 25, 73-85, February, 1958.

H. Schlichting, Boundary Layer Theory, McGraw-Hill Book Company, Inc., New York, 1960 .

Ting-Yi Li and R. E. Geiger, "Stagnation Point of a Blunt Body in Hypersonic Flow," Journa1 of the Aeronautical Sciences, 24, 25-32 (1957).

S. M. Scala and C. W. Baulknight, "Transport and Thermodynamic Properties in a Hypersonic Laminar Boundary Layer," ARS Journa1, 29, 39-45, January, 1957.

D. R. Bartz, "A Simple Equation for Rapid Estimation of Rocket Nozzle Convective Heat Transfer Coefficients," Jet Propulsion, 27, 49-51, January, 1957).

Genera1 Dynamics/Astronautics, "Re-Entry and Disposal Phenomena for Nuclear Auxiliary Power Systems (RADPNAPS)," Monthly Progress Letter, period ending May 31, 1962.

M. Hansen, Constitution of Binary Alloys, McGraw-Hill Book Company, Inc., New York $(1 \overline{958})$.

E. L. Foster, Jr., "Study 2. Burnup Enhancement for Re-Entering NAP Systems," Battelle Memorial Institute, First Quarterly Progress Report (April 12, 1962), Second Quarterly Progress Report (July 13, 1962), and Third Quarterly Progress Report (October 12, 1962). 


\section{BLANK}




\title{
RE-ENTRY OF FUELED GRAPHITE PARTICLES*
}

\author{
J. M. Bridges \\ H. G. Hargrove \\ Westinghouse Astronuclear Laboratory
}

Introduction

When a nuclear reactor becomes operational in space, the problem of safe disposal of resultant fission products arises and is of particular importance when the reactor undergoes random re-entry into the earth's atmosphere. One method by which this problem may be solved involves reducing the nuclear core, which consists of uranium dispersed in a graphite matrix, into a multitude of smal1 fragments by explosion, nuclear or chemical, before re-entry. In addition, fission product boiloff resulting from aerodynamics heating will contribute to reducing the hazards associated with the core.

Obviously, the effectiveness of any postoperational destruct system will depend upon the extent of burnup of core materials during re-entry. This paper will describe an analytical and experimental study undertaken to evaluate the burnup of fueled graphite fragments during re-entry.

'Theory

\section{Genera1 Considerations}

The same properties which make graphite an attractive core material for nuclear rockets are definite liabilities when it is desired to burn graphite up by aerodynamic heating and oxidation. Graphite may be classified as a nonablative material, i.e., it melts only at high temperatures and pressures, and its rate of sublimation is insignificant up to temperatures of $3000^{\circ} \mathrm{K}$. Since temperatures of this order of magnitude are not achieved during re-entry from near-earth orbits, mass losses of re-entering graphite particles may be attributed to chemical reaction with the ambient gases, oxygen and nitrogen. However, the cyanogen reaction is negligible below approximately $2800^{\circ} \mathrm{K} .{ }^{1}$ Hence, from the foregoing considerations the problem reduces to a consideration of mass depletion by oxygen alone.

The problem of determining mass loss during re-entry depends on both aerodynamics and physical chemistry. Thus, in order to evaluate mass loss rates the following aerodynamic considerations must be taken into account:

1. Is the gas flow viscid, inviscid, or molecular?

2. Is a shock wave present?

3. What is the mechanism and rate of mass transport to the body surface?

\footnotetext{
*Presented by Dr. Bridges. (The authors wish to thank Mr. Donald Hoecker of the Westinghouse Electric Corporation for his considerable effort and for his excellent advice in developing the WEREC Code.)
} 
In the realm of chemistry one must ascertain both the energy state of gases behind the shock, and the rate of reaction between these gases and the solid surface.

In order to develop an analytical model to predict re-entry heating and mass loss rates for graphite, four separate but independent analytical expressions are required:

1. energy balances to determine the aerodynamic heating,

2. mass loss rate (oxidation) equations,

3. trajectory equations, and

4. an aerodynamic flow-field "discrimination" factor, known as the Knudsen number.

The last expression is required since a re-entering graphite particle wil1 pass through a number of different flow regimes, each of which is described by a unique set of aerodynamic heating and mass-loss-rate equations. Thus, the discrimination factor is the key that determines the appropriate set of equations to be used in describing the re-entry particle.

\section{Flow-Regime Discrimination Factor}

There are three general classifications of flow regimes in hypersonic reentry aerodynamics which because of their inherent characteristics determine the heating and mass-transfer characteristics that can be used to determine these phenomena. These flow regimes are termed free-molecule, transition, and continuum, and the existence of any one regime is dependent upon the dynamics of the gas stream flowing past the body. In particular, the criterion for the existence of a given flow regime is generally recognized as being dependent upon the Knudsen number, which is the ratio of a "modified" mean free path of gas just in front of the body to the characteristic body dimension. The modified mean free path takes into account the perturbations of the ambient gas flow field due to the gas molecules reflected from the body surface along the lines of Probstein's analysis. ${ }^{2}$ The characteristic dimension is some fundamental dimension of the general body shape, e.g., the radius of a sphere. Hence, in mathematical notation the Knudsen number, Kn, is:

$$
\mathrm{Kn}=\frac{\lambda_{\mathrm{m}}}{L}
$$

where

$$
\begin{aligned}
\lambda_{\mathrm{m}} & =\text { the modified mean free path } \\
L & =\text { the characteristic dimension }
\end{aligned}
$$

The modified mean free path can be shown to be:

$$
\lambda_{\mathrm{m}}=\frac{4}{\sqrt{\pi \gamma}}\left(\frac{\mathrm{T}_{\mathrm{B}}}{\mathrm{T}_{\infty}}\right)^{\frac{1}{2}} \frac{\lambda_{\infty}}{\mathrm{m}_{\infty}}
$$

where

$$
\begin{aligned}
\gamma & =\text { the ratio of specific heats } \\
\mathrm{T}_{\mathrm{B}} & =\text { the temperature of the body } \\
\mathrm{T}_{\infty} & =\text { the temperature of the ambient gas } \\
\lambda_{\infty} & =\text { the mean free path of the ambient gas } \\
\mathrm{m}_{\infty} & =\text { free-stream mach number. }
\end{aligned}
$$


Finally, the following equation was derived to determine the knudsen number as a function of the ambient gas characteristics and the flight parameters of the reentering body:

$$
\mathrm{Kn}=\frac{95\left(\mathrm{~T}_{\mathrm{B}}\right)^{\frac{1}{2}}}{\mathrm{u}_{\infty}} \frac{\lambda_{\infty}}{\mathrm{R}_{\mathrm{B}}}
$$

where

$$
\begin{aligned}
& \mathrm{u}_{\infty}=\text { free stream body velocity } \\
& \mathrm{R}_{\mathrm{B}}=\text { the radius of the re-entering body. }
\end{aligned}
$$

Equation 3 is the aerodynamic discrimination factor.

It is generally considered that free-molecule flow occurs whenever the Knudsen number is greater than 10, transition flow for the knudsen number is between 10 and $1 / 3$, and the continuum flow for values less than $1 / 3$. There is some latitude in these rather arbitrary limits for the flow regimes, and it is not uncommon to find that some authors will consider free-molecule flow occurring for all Knudsen numbers greater than 1, transition flow between 1 and 0.01 , and continuum flow at values less than 0.01. This inconsistency does not actually affect the energy and mass transfer calculations to any great extent overa11. Physically, in the case of hypersonic flow, the free-molecule flow regime exists whenever the gas-stream mean free path is large compared to the body size to the extent that each gas-molecule interaction with the body surface is completely independent of the presence of other gas molecules. In transition flow, the flow field in front of the body becomes dense enough that only a fraction of the incident molecules that could be intercepted by the body behave in the manner of free-molecule flow, the rest being impeded before contact with the body by either molecules returning from the body surface or other incident molecules. Continuum flow occurs whenever the flow field becomes so dense that a definable shock wave appears in the gas stream just ahead of the body. Here, the free-stream gas undergoes an adiabatic compression as it passes into the shock wave and consequently is both heated and partly dissociated, with the degree of heating and dissociation depending on the intensity of the shock.

\section{Trajectory Analysis}

Probably the most straightforward portion of the entire re-entry problem is the trajectory analysis. Just as the Knudsen number is the determining factor for the validity of an energy-balance or mass-1oss-rate equation, the trajectory analysis enables one to determine the position, attitude, and velocity of a re-entering body. Moreover, a trajectory analysis is required to determine the knudsen number continuously throughout the re-entry process. To complete the interplay between the two, the discrimination factor determines the flow-field characteristics and thus is instrumental in determining the drag and lift coefficients.

The trajectory analysis is based upon the Lagrangian equations of motion in polar co-ordination:

$$
\frac{d^{2} \bar{r}}{d t^{2}}=\hat{r}\left[\frac{d^{2} r}{d t}-r\left(\frac{d \theta}{d t}\right)^{2}\right]+\hat{\tau}\left[2\left(\frac{d r d \theta}{d t d t}\right)+r\left(\frac{d^{2} \theta}{d t^{2}}\right)\right]
$$


where

$$
\begin{aligned}
\frac{\mathrm{d}^{2} \bar{r}}{\mathrm{dt}^{2}} & =\text { acceleration of position vector } \\
\hat{\mathbf{r}} & =\text { unit vector (radial direction) } \\
\hat{\boldsymbol{\tau}} & =\text { unit vector (transverse direction) } \\
\boldsymbol{\theta} & =\text { position angle } \\
\mathbf{t} & =\text { time } \\
\mathbf{r} & =\text { scalar component of position vector. }
\end{aligned}
$$

Equation 4 is combined with the gravitational acceleration and lift and drag forces acting in the body to produce the following expressions:

$$
\begin{aligned}
& \frac{d^{2} r}{d t^{2}}-r\left(\frac{d \theta}{d t}\right)^{2}=-g+\frac{L}{M_{B}} \cos \phi+\frac{D}{M_{B}} \sin \phi \\
& 2\left(\frac{d r}{d t} \frac{d \theta}{d t}\right)+r\left(\frac{d^{2} \theta}{d t^{2}}\right)=-\frac{D}{M_{B}} \cos \phi+\frac{L \sin \phi}{M_{B}}
\end{aligned}
$$

where

$$
\begin{aligned}
\phi & =\text { re-entry angle } \\
D & =\text { drag force } \\
L & =1 \text { ift force } \\
M_{B} & =\text { mass of re-entering particle } \\
\sin \phi & =\frac{d r}{d t}\left[\left(\frac{d t}{d t}\right)^{2}+\left(r \frac{d \theta}{d t}\right)^{2}\right]^{-\frac{1}{2}} \\
\cos \phi & =\frac{r d \theta}{d t}\left[\left(\frac{d r}{d t}\right)^{2}+\left(\frac{r d \theta}{d t}\right)^{2}\right]^{-\frac{1}{2}}
\end{aligned}
$$

The velocity of the re-entering particle is

$$
\mathrm{V}^{2}=\left(\frac{\mathrm{dr}}{\mathrm{dt}}\right)^{2}+\left(\frac{\mathrm{rd} \theta}{\mathrm{dt}}\right)^{2}
$$

and the drag force term, $D$, can be determined from the standard formula:

$$
\mathrm{D}=\frac{1}{2} \mathrm{C}_{\mathrm{D}} \rho_{\infty} \mathrm{V}^{2} \mathrm{~A}_{\mathrm{N}}
$$


where

$$
\begin{aligned}
& C_{D}=\text { drag coefficient } \\
& \rho_{\infty}=\text { atmospheric density } \\
& A_{N}=\text { area normal to flow. }
\end{aligned}
$$

In our studies, we selected the spherical particle shape since the entire reentry program becomes somewhat more amenable to mathematical analysis. For spheres, the drag coefficient $\left(\mathrm{C}_{\mathrm{D}}\right)$, in free-molecule flow can be shown to be equal to 2 . In hypersonic continum flow the drag coefficient is approximately 1 .

\section{Aerodynamic Heating}

Aerodynamic heating of a graphite body in the free-molecule regime can be determined by a modified method based on the number of body-surface/gas-molecule collisions occurring in a volume of "stationary" gas swept out by the moving body. The modifications take into account the Maxwellian energy distribution of the gas molecules and the chemical energy input by oxidation of surface carbon atoms. The mathematical treatment for hypersonic free-molecule flow was first detailed in the classical analysis by J. R. Stalder and D. Jukoff, ${ }^{3}$ in which expressions were developed for determining the heat input to a unit body surface as a function of the body velocity, the most probable molecular velocity, the density of ambient gas, and the angle of attack. The Stalder-Jukoff analysis shows that for Mach numbers in excess of about 2 the number of molecules or atoms colliding with a surface perpendicular to the flow field is equal to the number of molecules existing in the volume swept out by the moving surface, according to the following equation:

$$
N=\frac{3.5 n u \sin \theta}{2 \sqrt{\pi}}
$$

where

$$
\begin{aligned}
& \mathrm{N}=\begin{array}{l}
\text { number of incident molecules per unit surface area and time, } \\
\text { molecules } / \mathrm{sq} \text { ft-sec }
\end{array} \\
& \mathrm{n}=\text { atmospheric molecular density, molecules/ft }{ }^{3} \\
& \theta=\text { angle of attack, radians } \\
& \mathrm{u}=\text { body velocity. }
\end{aligned}
$$

One very important factor in determining the efficiency of free-molecule heat transfer is the thermal accommodation coefficient, a measure of the degree to which the momentum of the incident gas stream is converted into heat upon contact with the body surface. The best theoretical energy conversion occurs when the incident stream of gas molecules comes into complete thermal equilibrium with the surface of the body to such an extent that each gas molecule leaving the surface does so at a velocity defined by the body surface temperature. Because of the porous nature of graphite, each incident molecule should undergo numerous momentum exchanges with the graphite surface and, hence, should be expected to complete thermal equilibrium before it escapes from the surface. The accommodation coefficient of 1 was selected in the present study. It should be pointed out that free-molecule heat and mass transfer equations are the most efficient ones possible and, therefore, represent the upper limit for both cases.

In contrast to the free-molecule case, the energy and mass transfer phenomena for graphite in the continuum-flow regime present a complicated picture, primarily 
because of the existence of the shock wave in front of the body and the physical nature of the partially ionized gas layer between the body surface and the shock front. Several theories have been proposed to describe analytically the continuumflow heat and mass transfer process for a graphite body, but from the standpoint of basic high-temperature gas physics and reaction kinetics, the best of these is that developed by S. M. Scala." Scala's theory is applicable only for well-defined continuum flow, i.e., Knudsen numbers on the order of 0.01 or less. The basic assumptions upon which Scala develops his theory are as follows:

1. The gas phase behind the shock consists of six gaseous species: oxygen atoms, nitrogen atoms, oxygen molecules, nitrogen molecules, carbon monoxide, and carbon dioxide.

2. No homogeneous gas-phase reactions occur, and no heterogeneous reaction occurs between nitrogen molecules and graphite.

3. At surface temperatures below $2800^{\circ} \mathrm{K}$, nitrogen atoms recombine to form nitrogen molecules at the graphite surface. Therefore, the formation of cyanogen in this temperature region need not be considered.

4. The composition of gas at the graphite surface may be evaluated by using equilibrium considerations.

5. The Lewis and Prandt1 numbers of the gas are equal to those for dissociated air.

Using these assumptions, the following equation was developed by Scala to predict the rate of aerodynamic heating in hypersonic continuum flow:

$$
\dot{Q}=r_{B}^{-\frac{1}{2}}(C)(10)^{a}(V)^{b}, B t u / s q \text { ft-sec }
$$

where

$$
\begin{aligned}
\dot{\mathrm{Q}} & =\text { stagnation-point heat flux } \\
\mathrm{r}_{\mathrm{B}} & =\text { body radius, } \mathrm{ft} \\
\mathrm{C} & =1.828-4.156 \times 10^{-4} \mathrm{~T}_{\mathrm{w}}+4.097 \times 10^{-8} \mathrm{~T}_{\mathrm{w}}{ }^{2} \\
\mathrm{~T}_{\mathrm{w}} & =\text { body temperature } \\
\mathrm{a} & =-\left(7.32+8.7763 \times 10^{-6} \mathrm{y}\right) \\
\mathrm{y} & =\text { altitude in feet } \\
\mathrm{b} & =2.5645
\end{aligned}
$$

In the development of Eq. (5), several important boundary conditions or assumptions, in addition to the ones noted above, were made:

1. Radiation from the body is not included in the expression, which accounts only for convective heat input.

2. Radiation into the body from the gas cap is assumed negligible.

3. Account is taken of the exothermic and endothermic chemical reactions occurring in the boundary layers which effectively supply heat.

4. The heat-blocking effect of combustion products injected into the boundary layer is taken into account. The total heat input rate is therefore reduced. 
Unfortunately, the gas dynamics for the transition-flow regime are not as amenable to mathematical analysis as are the continuum and free-molecule flow regimes. The difficulty lies in the fact that transition flow is not a mixture of free molecule and continuun flow but rather a series of separate entities of changing gas-flow fields, each having its own unique characteristics. Instabilities and discontinuities occur in the flow fields, and theoretical treatments are at best approximations or highly restrictive boundary solutions. Fortunately, a large portion of the transition-flow regime is embodied in the subregion known as the nearfree-molecule flow regime which covers the range of the knudsen numbers less than 10 but greater than $1 / 3$. Most of the flow-field discontinuities occur in the region between Knudsen numbers of $1 / 3$ and 0.01 . This region exists for a very short time, however, when compared to the total re-entry time. Therefore, for graphite re-entry, we have assumed that near-free-molecule flow theory adequately describes, within acceptable error limits, mass and heat transfer phenomena in the transition flow regime.

Several analytical models have been proposed to describe aerodynamic heating in the near-free-molecule regime. We have selected the method shown by Probstein, which is based on an earlier work by Willis. ${ }^{5}$ Willis' near-free-molecule theory uses a "first-order-collision" model which considers that an incident molecule suffers only one collision with either an incident or reflected molecule in the near vicinity of the body before contact with the body surface. After a rather involved analysis, the following heating-rate equations are derived:

$$
\mathrm{q}^{*}=\mathrm{q}\left[1-\frac{\mathrm{R}_{\mathrm{B}}}{\lambda_{\mathrm{m}}}\left(0.53+6.4-\frac{\mathrm{C}_{\overline{\mathrm{B}}}}{\mathrm{u}}\right)\right]
$$

where

$$
\begin{aligned}
\mathrm{q}^{*} & =\text { near-free-molecule heating rate, } \mathrm{Btu} / \mathrm{sec}-\mathrm{ft}^{2} \\
\mathrm{q} & =\text { free-molecule heating rate, } \mathrm{Btu} / \mathrm{sec}-\mathrm{ft}^{2} \\
\mathrm{R}_{\mathrm{B}}= & \text { body radius } \\
\mathrm{C}_{\overline{\mathrm{B}}}= & \text { velocity of re-emitted gas molecules corresponding to body } \\
\mathrm{u}= & \text { body velocity } \\
\lambda_{\mathrm{m}}= & \text { modified mean free path }
\end{aligned}
$$

\section{Oxidation}

The reaction of oxygen molecules (or atoms) with graphite is a gas-solid reaction occurring at the interface between the two phases. It is generally considered that five steps are operative in the case of a reaction at a solid interface:

1. diffusion of the reactant molecule to the surface,

2. adsorption of the gas molecules on the reactant surface,

3. chemical reaction in which the adsorbed reactant molecule is converted to the adsorbed product molecule,

4. desorption of the product molecule from the surface, and

5. diffusion of the product molecule away from the surface. 
Usually, it is not possible to differentiate kinetically between steps 2, 3, and 4, and the rate expression for a heterogeneous reaction is a function of ali three steps. These five steps then may be considered to involve two mathematically distinguishable ones: diffusion as summarized in steps 1 and 5 and chemical reaction as summarized in steps 2, 3, and 4. In general, the rate of reaction between graphite and oxygen may best be considered as given by the following equation:

$$
\mathrm{R}=\mathrm{Z} \psi
$$

where

$$
\begin{aligned}
& \mathrm{R}=\text { the rate of reaction between oxygen and graphite } \\
& \mathrm{Z}=\text { the number of collisions between the graphite surface and } \\
& \text { oxygen molecules } \\
& \psi=\begin{array}{l}
\text { the probability that a single collision will result in chemical } \\
\text { reaction. }
\end{array}
\end{aligned}
$$

The term $\psi$ may be represented by the following expression:

$$
\psi=\mathrm{Pe}^{-\mathrm{E} / \mathscr{R} \mathrm{T}}
$$

The terms $\mathrm{P}$ and $\mathrm{E}$ are experimentally determined parameters called the steric factor and the activation energy, respectively, and $\mathscr{R}$ is the universal gas constant per mole and $\mathrm{T}$, the temperature in ${ }^{\circ} \mathrm{K}$.

Since it is not always possible to evaluate the exact number of oxygengraphite collisions occurring, it is often convenient to consider either chemical reaction or diffusion as the rate-determining step. When the rate of diffusion is much slower than the rate of chemical reaction, the reaction is considered to be diffusion-rate controlled. On the other hand, when chemical reaction is the slow step, then reaction is considered to be chemical-reaction-rate controlled. Obvious$1 y$, it is necessary to consider both mass transfer and chemical reaction in attempting to evaluate rates of graphite oxidation during re-entry.

Although numerous investigations have been made of the oxidation of graphite, the only definitive investigation of high-temperature (above $1000^{\circ} \mathrm{C}$ ) kinetics reported in the literature is that of Blyholder and Eyring. ${ }^{6}$ These investigators found that below $1000^{\circ} \mathrm{C}$ the reaction rate increased rapidly with temperature. The activation energy was found to be $42 \mathrm{kilocalories}$ per mole. However, above $1000^{\circ} \mathrm{C}$ the reaction rate became essentially temperature insensitive with the activation energy decreasing to $1 \mathrm{Kcal} / \mathrm{mole}$. Blyholder and Eyring interpreted this change in activation energy to be indicative of a change in the mechanism of the chemical reaction. If this were indeed the case, one would except only slight mass losses during re-entry even at the high temperatures which a re-entering particle would achieve. In fact, Eyring's data was used in a theoretical study by Moore and Z1otnick ${ }^{7}$ and was found to predict excessively low oxidation rates. However, it is possible that at the high temperatures studied by Eyring the reaction became diffusion-rate controlled since activation energies of a few kilocalories per mole are genera1ly associated with diffusion-controlled pressures.

Recently, Gulbransen ${ }^{8}$ resolved this problem. He found that the reaction rate continued increasing rapidly with temperature above $1000^{\circ} \mathrm{C}$ if the diffusional effects were eliminated by using very small graphite samples. An activation energy of $38 \mathrm{Kcal} / \mathrm{mole}$ was found to apply in the temperature region between 500 and $1500^{\circ} \mathrm{C}$. The results of this study are shown in Figure 167 . 


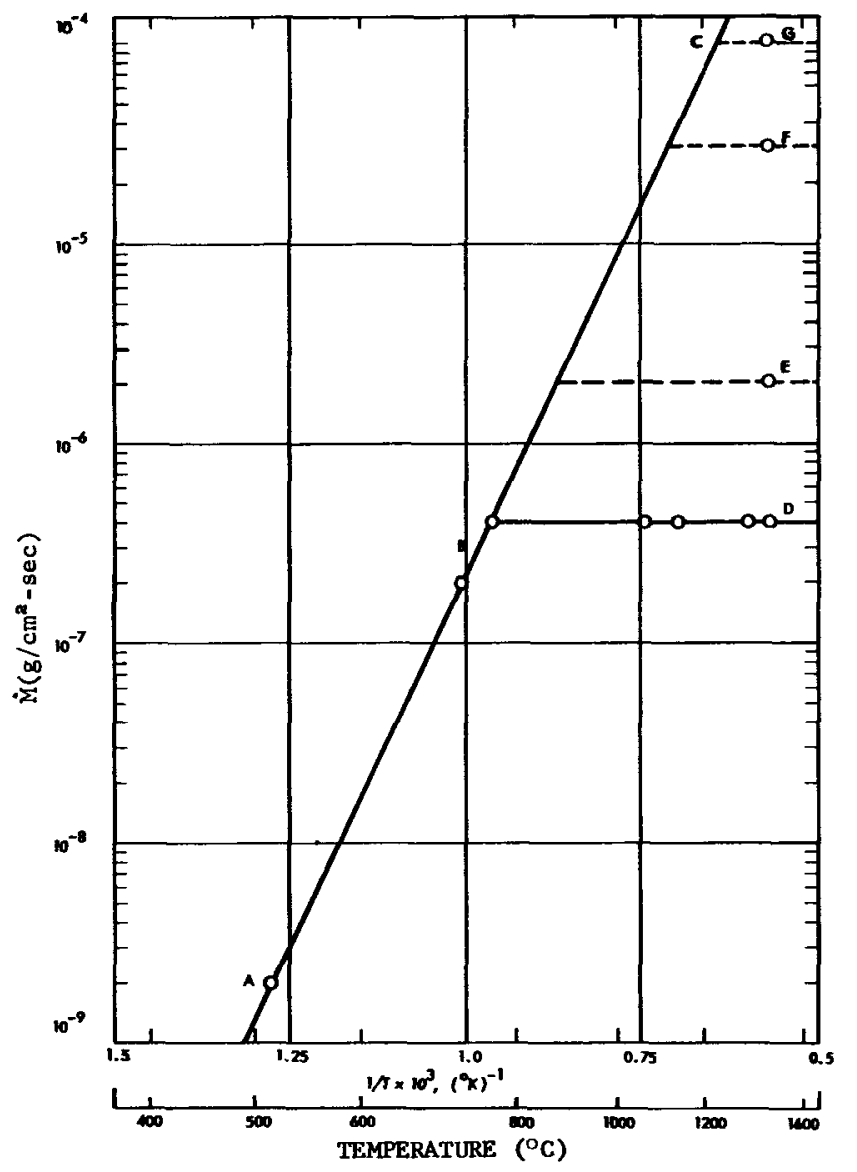

Figure 167.

Activation energy plot for graphite oxidation using Gulbransen's rate data (pressure - 2 torr; line ABC chemical control; sample areas D $-6.2 \mathrm{~cm}^{2}, \mathrm{E}-1.19 \mathrm{~cm}^{2}, \mathrm{~F}-$ $0.136 \mathrm{~cm}^{2}, G$ - estimated $0.0316 \mathrm{~cm}^{2}$ )

Although Gulbransen's data appears to describe the rate of chemical reaction in the absence of diffusional effects, it is not certain that it would be applicable in the case of the oxidation of a re-entering graphite particle. In both Gulbransen's and Eyring's experiments, the oxygen and graphite temperatures were identical. During re-entry, the graphite particle will encounter gases several thousands of degrees hotter than the graphite itself. It is questionable if the reaction rate parameters ( $E$ and $P$ ) applicable to the isothermal case also apply here. Recently, a series of experiments conducted by G. T. Rymer at Westinghouse Astronuclear Laboratory have helped simplify this problem. In these studies, designed to approximate conditions of free molecular flow, high linear flow rates, low pressures $(<1 \mathrm{~mm})$, and small sample sizes were used. The results of this investigation indicate that values of $\psi$ (as defined by Eq. 12), greater than 0.5 are obtainable at $1200^{\circ} \mathrm{C}$. Since $\psi$ must increase as the gas temperature increases and since its maximum value is 1 , it appears safe to assign a value of 1 to $\psi$ for all cases during re-entry in which the surface temperature of the re-entering particle exceeds $1200^{\circ} \mathrm{C}$. At temperatures below $1200^{\circ} \mathrm{C}$, there exists at present neither a theoretical nor an experimental basis for calculating $\psi$.

As in the case of aerodynamic heating, one must consider three flow regimes, free-molecule, transition, and continutu in order to describe graphite oxidation during re-entry. In the case of the hypersonic free-molecule flow regime, the number of gas-molecule/surface collisions occurring has been shown to be equal to the number of molecules existing in the volume of "stationary" gas swept out by the moving body. ${ }^{3}$ In addition, the free-molecule flow regime is generally encountered at altitudes greater than 300,000 feet. $*$ In this altitude region, oxygen is found

\footnotetext{
This statement is not true when the particles re-entering are very sma11. When the diameter of the re-entering particle is less than $1 / 16$ inch, free-molecule flow may persist down to altitudes of 250,000 feet.
} 
primarily in the atomic state. It has been shown ${ }^{10}$ that the value of $\psi$ in the case of a graphite-oxygen atom interaction is equal to 1 . Therefore, the mass loss rate in the case of a sphere may be given by the following equation:

$$
-\frac{\mathrm{dm}}{\mathrm{dt}}=0.75 \rho \mathrm{V} \mathrm{A}
$$

where

$$
\begin{aligned}
& \mathrm{m}=\text { the mass of the re-entering particle } \\
& \mathrm{t}=\text { time } \\
& \boldsymbol{\rho}=\text { atmospheric density } \\
& \mathrm{V}=\text { velocity of the re-entering particle } \\
& \mathrm{A}_{\mathrm{c}}=\text { cross-sectional area of the re-entering particle. }
\end{aligned}
$$

The problem of defining both mass transfer and oxidation rates in the transition flow regime is much more difficult. As noted earlier, we selected the willis first-order-collision model to represent aerodynamic heating in the transition-flow regime. The Willis equations can be used to determine energy input, but they do not include an analysis for mass transfer. Using this first-order-collision theory, we have assumed that one-half the oxygen molecules theoretically intercepted, using the free-molecule flow analysis, would eventually contact the body. A value of $\psi$ equal to 1 was tentatively used for all surface temperatures until such a time as either experimental results or theory could supply a more exact value.

In general, continuum flow is encountered when the re-entering particle reaches an altitude of 240,000 feet. Oxidation in the hypersonic continum-flow regime has been subjected to an extensive theoretical treatment by S. M. Scala. ${ }^{4}$ The basic assumption operative in this theory is that the reaction between graphite and oxygen is completely diffusion-rate controlled if the surface temperature is sufficiently high (above $1000^{\circ} \mathrm{C}$ ). Scala concludes for spherical particles in this regime that the mass loss rate of graphite is given by the following equation:

$$
\frac{-d(M / A)}{d t}=5.92 \times 10^{-4} \frac{P_{e^{\frac{1}{2}}} T_{e^{\frac{1}{4}}}}{M_{e^{\frac{T}{4}}}^{\frac{1}{2}} R_{B}^{\frac{T}{2}}},\left(g / \mathrm{cm}^{2}-\mathrm{sec}\right)
$$

where

$$
\begin{aligned}
\mathrm{M} & =\text { mass of particle } \\
\mathrm{A} & =\text { surface area in square centimeters } \\
\mathrm{t} & =\text { time in seconds } \\
\mathrm{P}_{\mathrm{e}} & =\text { stagnation pressure in atoms } \\
\mathrm{T}_{\mathrm{e}} & =\text { stagnation temperature in }{ }^{\circ} \mathrm{K} \\
\mathrm{M}_{\mathrm{e}} & =\text { molecular weight of air at the stagnation point } \\
\mathrm{R}_{\mathrm{B}} & =\text { radius of the body in centimeters }
\end{aligned}
$$

However, when the re-entering particle is decelerated to velocities less than 10,000 feet per second, the surface temperature begins dropping. As a result, the 
assumption that the reaction rate is completely diffusion controlled is no longer valid. It is necessary to take into account the inherent chemical reactivity of oxygen and graphite. Scala ${ }^{1}$ has suggested that the reaction rate in this case can be represented by a sum of resistances in series:

$$
\mathrm{R}_{\exp }=\frac{1}{\frac{1}{\mathrm{R}_{\mathrm{diff}}}+\frac{1}{\mathrm{R}_{\text {react }}}}
$$

where

$$
\begin{aligned}
\mathrm{R}_{\text {exp }}= & \text { the experimental oxidation rate } \\
\mathrm{R}_{\mathrm{diff}}= & \begin{array}{l}
\text { the calculated reaction rate due to a diffusion-rate- } \\
\text { controlled mechanism }
\end{array} \\
\mathrm{R}_{\text {react }}= & \begin{array}{l}
\text { the calculated reaction rate because of chemical-rate- } \\
\text { controlled mechanism. }
\end{array}
\end{aligned}
$$

As in the case of reaction in the transition-flow regime, this equation suffers from lack of knowledge on the chemical reaction rate during re-entry. In order to evaluate these chemical reaction rates and to verify both Scala's theory and the transition-flow theory in which mass transfer is considered to be the rate-determining step in oxidation, an experimental study of graphite oxidation under simulated re-entry conditions was undertaken.

\section{Experimenta1}

The simulated re-entry studies performed in this investigation were conducted in a plasmajet facility. While it was not possible to duplicate all of the environmental conditions encountered during re-entry, it was possible to reproduce those properties which exist at the surface of the re-entering object, namely, stagnation pressure and enthalpy. Since the mass loss rate of a material depends not on freestream properties but rather on gas and solid properties at the interface and since the designation of both stagnation enthalpy and pressure will define both altitude and velocity of a re-entering particle, it is possible to study experimentally the mass loss rate of re-entering objects with a high degree of certainty.

\section{$\underline{\text { Procedure }}$}

The experimental tests were run in a plasmajet facility using a Mach $=3.0$ contoured nozzle. The materials tested were graphitite $G$, a dense grade of structural graphite having a density of $1.92 \mathrm{~g} / \mathrm{cc}$, and uranium-fueled graphite; both materials were machined into hemispherical mode1s $1 / 8,1 / 4$, and $1 / 2$ inch in diameter. These models were held in place by a graphite sting support, which in turn was attached to a water-cooled model holder. The support method is shown in Figure 168. The model stagnation pressures associated with the runs were obtained using a water-cooled total head probe. Heat fluxes were measured with a watercooled calorimeter. Model surface temperatures were read with a Leeds and Northrup radiation-type pyrometer and were recorded automatically on a 14-channel Midwestern oscillograph during the entire exposure period. Exposure times were measured from the oscillograph records to an accuracy of \pm 0.01 second. Exposures were selected for each model size and test condition which would provide resultant shapes comparable to the initial hemispherical shapes; that is, attempts were made to eliminate errors resulting from changes in model configurations. Unless otherwise noted, a11 materials tested in these investigations were graphitite $G$. 


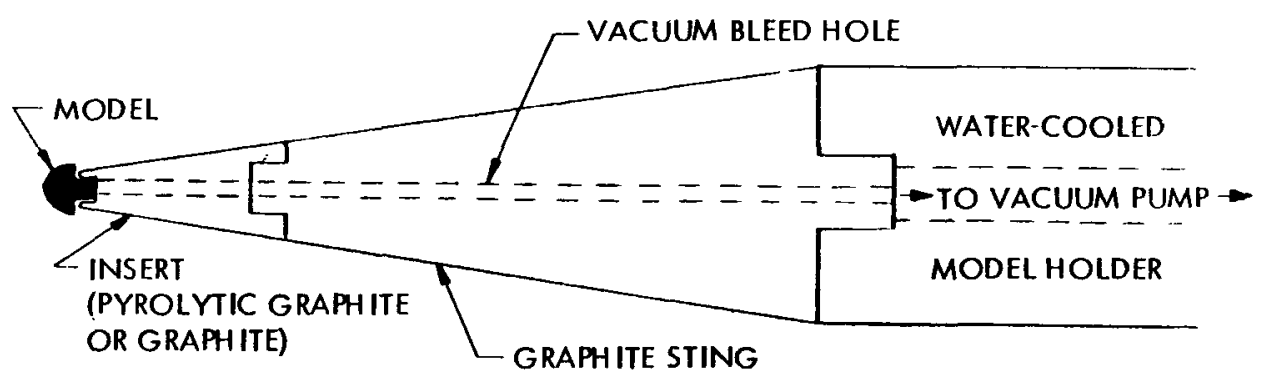

Figure 168. Support for graphite and fueled specimens in a plasmajet facility

At each test point, four or five exposure times were run. The differential mass loss rates, $\mathrm{d}(\mathrm{M} / \mathrm{A}) / \mathrm{dt}$, were evaluated by plotting the mass-to-surface ratio, $\mathrm{M} / \mathrm{A}$, versus time. In all cases the slope of the resulting straight line was taken to be equal to the differential mass loss rate. Typical differential rate plots are shown in Figure 169 .

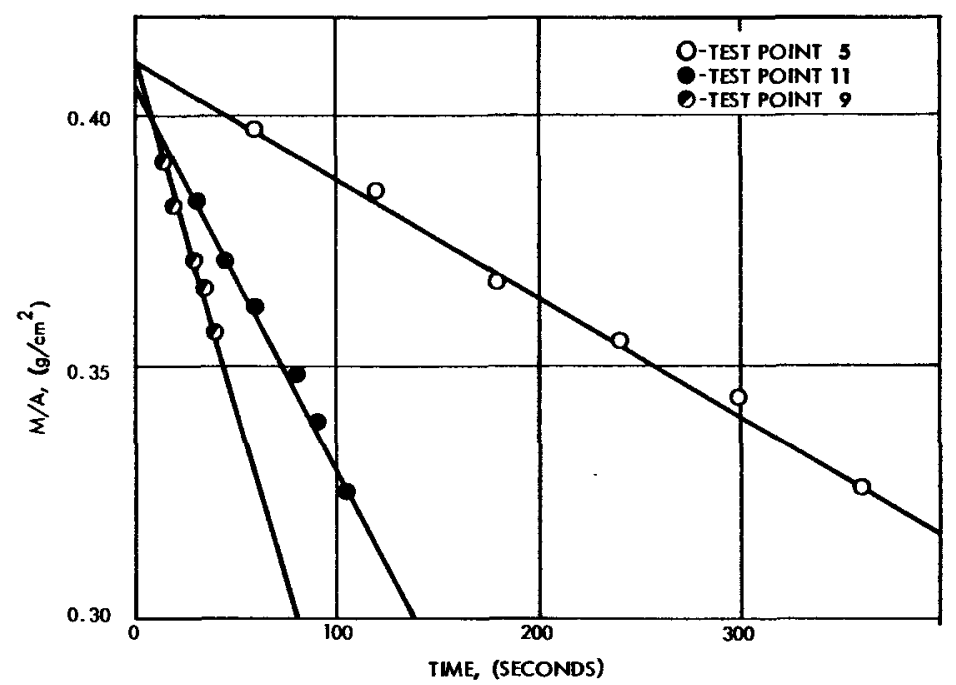

Figure 169. Plots of typical mass loss rates for half-inch graphite specimens

\section{Results}

Hypersonic Continuum-Flow Regime -- The applicability of Scala's equation to the hypersonic continuum-flow regime was the first area investigated. It was in this regime that the highest surface temperatures were achieved and graphite oxidation was maximal. The test points investigated are listed in Table I. A comparison of the experimental and the theoretica1 rates as predicted by Eq. 3 is shown in Figure 170. Here, mass loss rate is plotted as a function of those variables which determine rate. The solid line represents the theoretically predicted rates. The dotted lines represent reaction rates twice and one-half the theoretical values. According to this figure, Scala's theory predicts reaction rates within a factor of two. The results illustrated in Figure 170 are illustrated somewhat more graphically in terms of altitude and velocity in Figure 171. 
TABLE I

Experimental Points in the Hypersonic Continuum Flow Regime Investigated in a Plasmajet Facility

\begin{tabular}{|c|c|c|c|}
\hline $\begin{array}{l}\text { Simulated } \\
\text { Altitude } \\
\text { (ft) } \\
\end{array}$ & $\begin{array}{l}\text { Simulated } \\
\text { Velocity } \\
\text { (ft/sec) } \\
\end{array}$ & $\begin{array}{c}\begin{array}{c}\text { Stagnation } \\
\text { Pressure } \\
\text { (atm) }\end{array} \\
\end{array}$ & $\begin{array}{c}\text { Stagnation } \\
\text { Enthalpy } \\
\text { (Btu/1b) } \\
\end{array}$ \\
\hline 215,000 & 17,250 & 0.042 & 6,000 \\
\hline 240,000 & 22,500 & 0.024 & 10,500 \\
\hline 220,000 & 11,400 & 0.013 & 2,580 \\
\hline 200,000 & 11,250 & 0.029 & 2,500 \\
\hline 168,000 & 11,450 & 0.088 & 2,610 \\
\hline 147,000 & 11,450 & 0.209 & 2,600 \\
\hline 123,000 & 11,200 & 0.650 & 2,490 \\
\hline 215,000 & 15,800 & 0.029 & 4,950 \\
\hline 230,000 & 21,180 & 0.030 & 9,000 \\
\hline
\end{tabular}

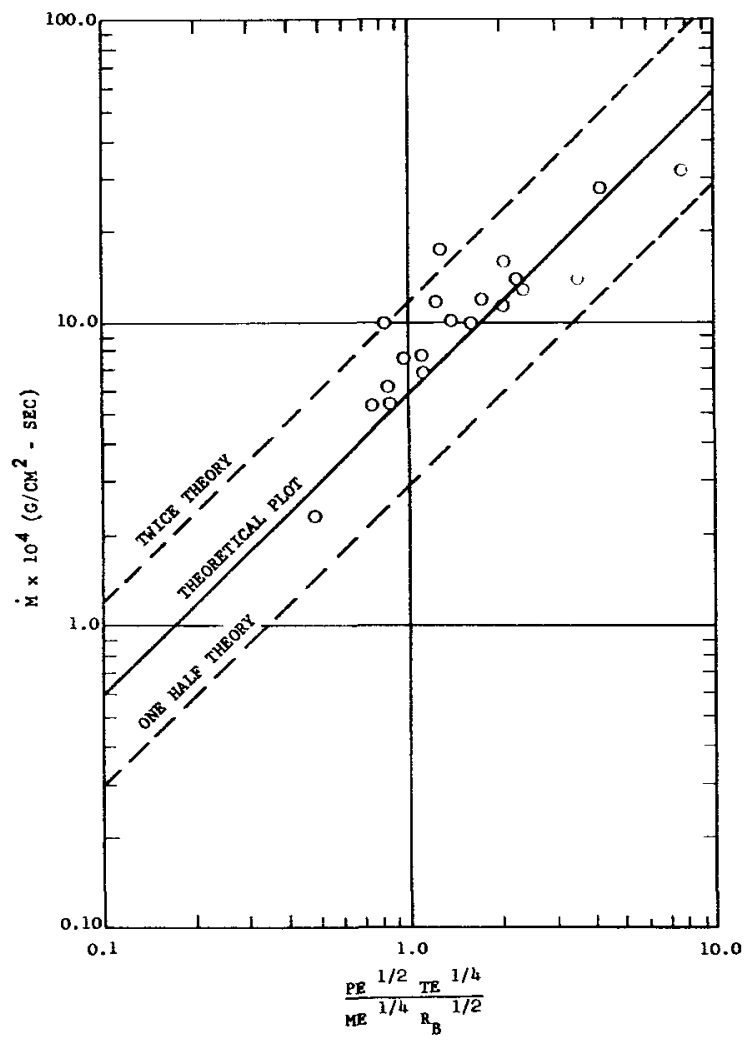

Figure 170. Comparison of experimental and theoretical rate data for graphite oxidation

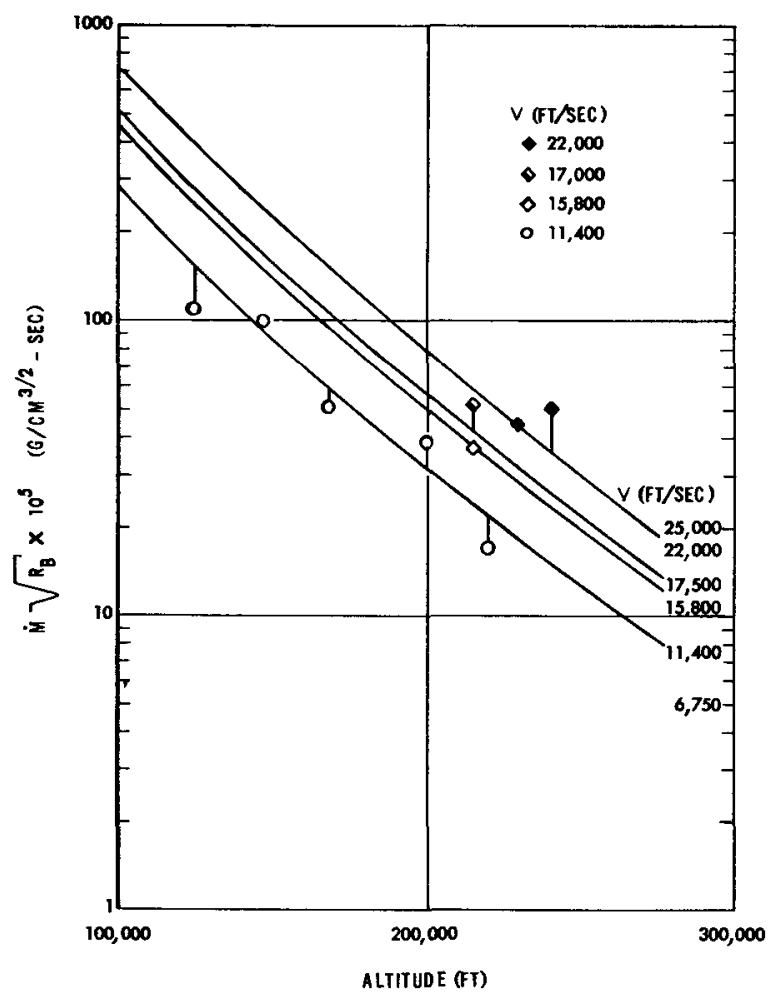

Figure 171. Comparison of experimental and theoretical rate data as a function of altitude and velocity 
Transition Flow Regime -- The series of test points examined to check the applicability of the reaction model chosen to represent the transition flow regime is given in Table II. In this case, temperature data is also given since it was our initial consideration that the reaction model we selected would apply only at temperatures greater than $1200^{\circ} \mathrm{C}$. The results of this investigation are shown in Figure 172 for simulated velocities of 25,000 ft/sec and in Figure 173 for simulated velocities of $18,000 \mathrm{ft} / \mathrm{sec}$. In these graphs, the differential reaction rate, in this case (1/A) dm/dt, is plotted as a function of altitude. Both the model of the transition-flow-regime reaction rate and Scala's theory are illustrated in these graphs. It is apparent that the former model represents these data reasonably we11 except at high altitudes where the experimental rates are too low. An examination of Table II, however, shows that at these points the surface temperature drops below $1200^{\circ} \mathrm{C}$. Such a result would be expected if the chemical reaction rate were becoming a rate-determining step. A more thorough discussion of the role of surface temperature in graphite oxidation is given in the next section.

The Reaction-Rate-Controlled Continuum-Flow Regime -- Since a re-entering particle will spend considerable time at velocities less than $10,000 \mathrm{ft} / \mathrm{sec}$, a portion of the experimental re-entry program was devoted to studying reaction rates in this velocity region. The points tested as we11 as the surface temperatures measured are listed in Table III. The comparison of Scala's theory with the experimentally determined rates is shown in Figure 174. It is apparent that extremely large deviations from theory do occur for most of the points tested. An examination of the temperature data in Table III indicates that these deviations occur when the surface temperature of the sample lies below $1200^{\circ} \mathrm{C}$. In Figure 175 , the effect of surface temperature on reaction rate in both the transition- and continuum-flow regimes is illustrated. Here, the ratio of the experimental to theoretical reaction rates is plotted as a function of temperature. It is apparent that deviations from theory occur at temperatures below approximately $1200^{\circ} \mathrm{C}$. At present, we are interpreting this data in an attempt to define an analytical model appropriate for the reaction-rate-controlled regime.

TABLE II

Experimenta1 Points in the Transition-Flow Regime Investigated in a Plasmajet Facility

\begin{tabular}{|c|c|c|c|c|}
\hline $\begin{array}{l}\text { Simulated } \\
\text { Altitude } \\
\text { (ft) } \\
\end{array}$ & $\begin{array}{l}\text { Simulated } \\
\text { Velocity } \\
\text { (ft/sec) } \\
\end{array}$ & $\begin{array}{c}\text { Stagnation } \\
\text { Pressure } \\
\text { (atm) } \\
\end{array}$ & $\begin{array}{c}\text { Stagnation } \\
\text { Entha1py } \\
\text { (Btu/1b) } \\
\end{array}$ & $\begin{array}{c}\text { Surface } \\
\text { Temperature } \\
\left({ }^{\circ} \mathrm{C}\right)\end{array}$ \\
\hline 240,000 & 18,000 & 0.015 & 6,500 & 1440 \\
\hline 240,000 & 25,000 & 0.030 & 12,400 & 1930 \\
\hline 250,000 & 18,000 & 0.011 & 6,500 & 1235 \\
\hline 250,000 & 25,000 & 0.021 & 12,400 & 1840 \\
\hline 260,000 & 18,000 & 0.0067 & 6,500 & 985 \\
\hline 260,000 & 25,000 & 0.013 & 12,400 & 1507 \\
\hline 270,000 & 25,000 & 0.0075 & 12,400 & 1035 \\
\hline 280,000 & 25,000 & 0.0043 & 12,400 & 882 \\
\hline
\end{tabular}




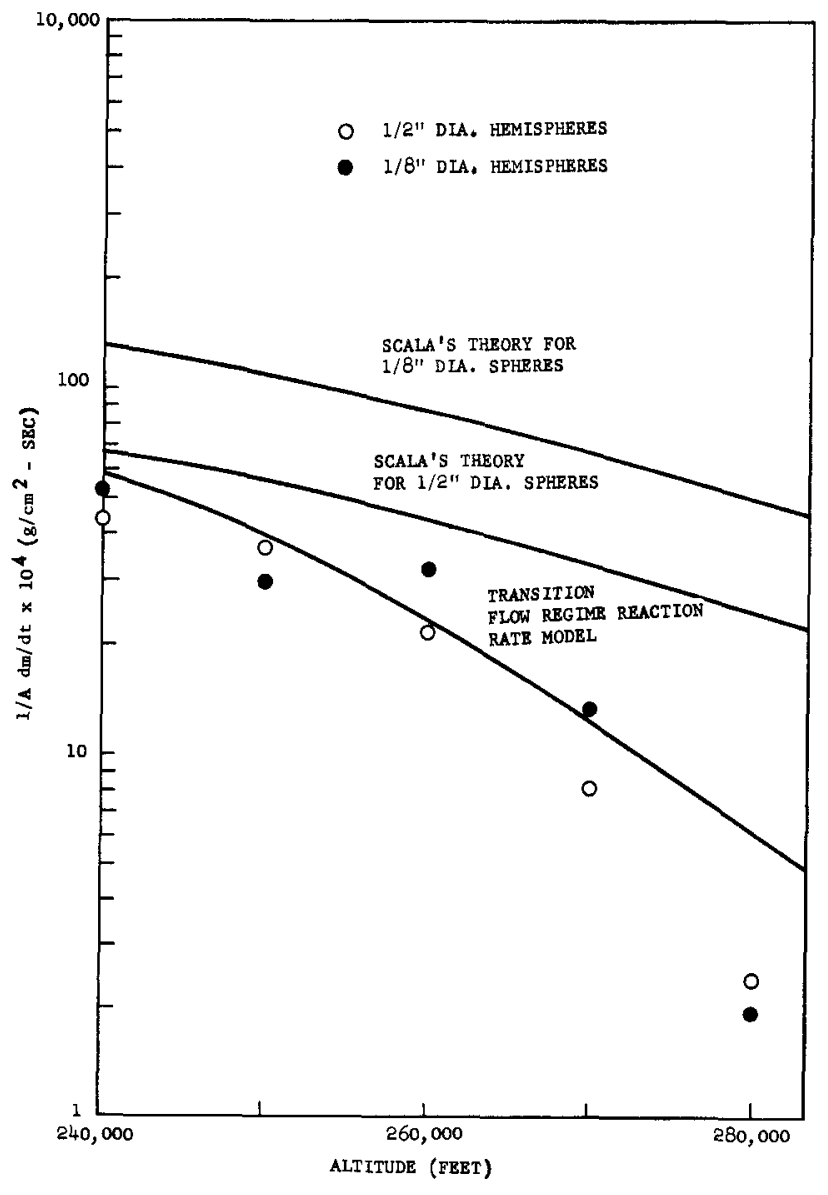

Figure 172. Comparison of theoretical and experimental rate data as a function of altitude $(V=25,000 \mathrm{ft} / \mathrm{sec})$

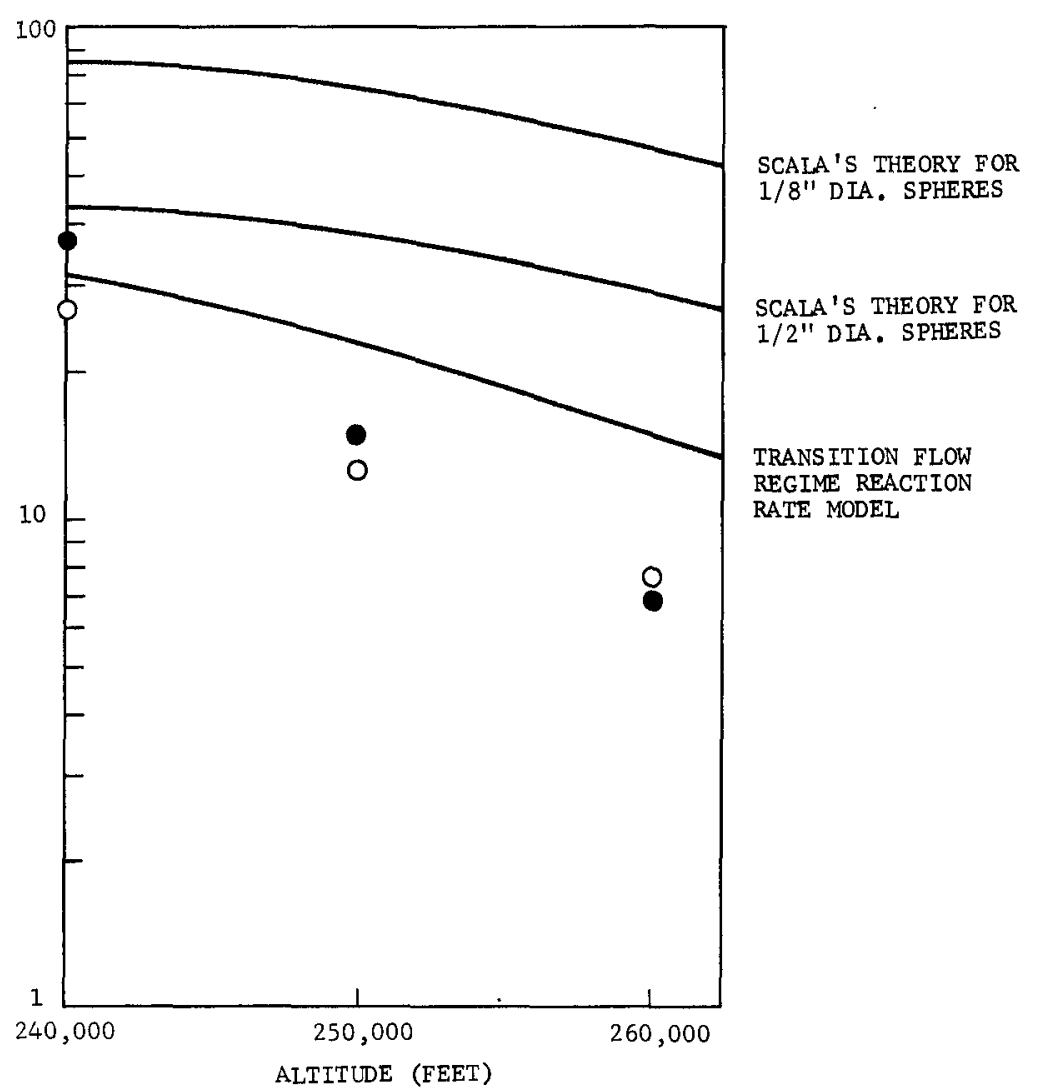

Figure 173. Comparison of theoretical and experimental rate data as a function of altitude $(\mathrm{V}=18,000 \mathrm{ft} / \mathrm{sec})$ 
TABLE III

Experimental Points in the Reaction-Rate-Controlled Regime Investigated in a Plasmajet Facility

\begin{tabular}{|c|c|c|c|c|}
\hline $\begin{array}{l}\text { Simulated } \\
\text { Altitude } \\
\text { (ft) } \\
\end{array}$ & $\begin{array}{l}\text { Simulated } \\
\text { Velocity } \\
\text { (ft/sec) } \\
\end{array}$ & $\begin{array}{c}\text { Stagnation } \\
\text { Pressure } \\
\text { (atm) } \\
\end{array}$ & $\begin{array}{c}\text { Stagnation } \\
\text { Enthalpy } \\
(\mathrm{Btu} / \mathrm{lb}) \\
\end{array}$ & $\begin{array}{c}\text { Surface } \\
\text { Temperature } \\
\left({ }^{\circ} \mathrm{C}\right)\end{array}$ \\
\hline 150,000 & 6,000 & 0.056 & 750 & 889 \\
\hline 150,000 & 8,000 & 0.10 & 1250 & 1205 \\
\hline 150,000 & 10,000 & 0.15 & 2000 & 1605 \\
\hline 200,000 & 6,000 & 0.010 & 750 & $500 *$ \\
\hline 200,000 & 8,000 & 0.0125 & 1250 & 832 \\
\hline 200,000 & 10,000 & 0.0195 & 2000 & 931 \\
\hline 225,000 & 8,000 & 0.0056 & 1250 & -- \\
\hline 225,000 & 10,000 & 0.0080 & 2000 & 857 \\
\hline $\begin{array}{l}{ }^{*} \text { The tem } \\
\text { Measuren }\end{array}$ & $\begin{array}{l}\text { re was } t \\
\text { as made }\end{array}$ & $\begin{array}{r}\text { for mea } \\
\text { a thermoc }\end{array}$ & ent with a & eter. \\
\hline
\end{tabular}

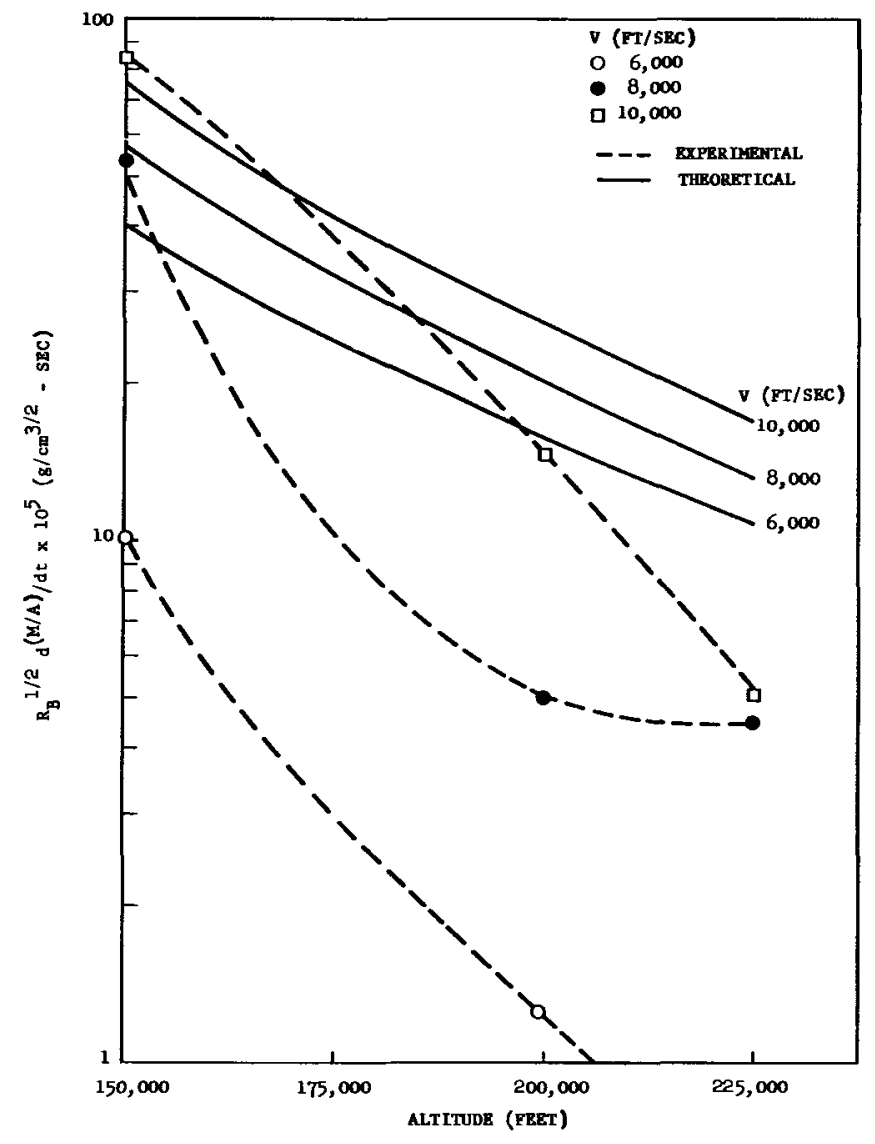

Figure 174. Comparison of experimental and theoretical rate data as a function of altitude and velocity 


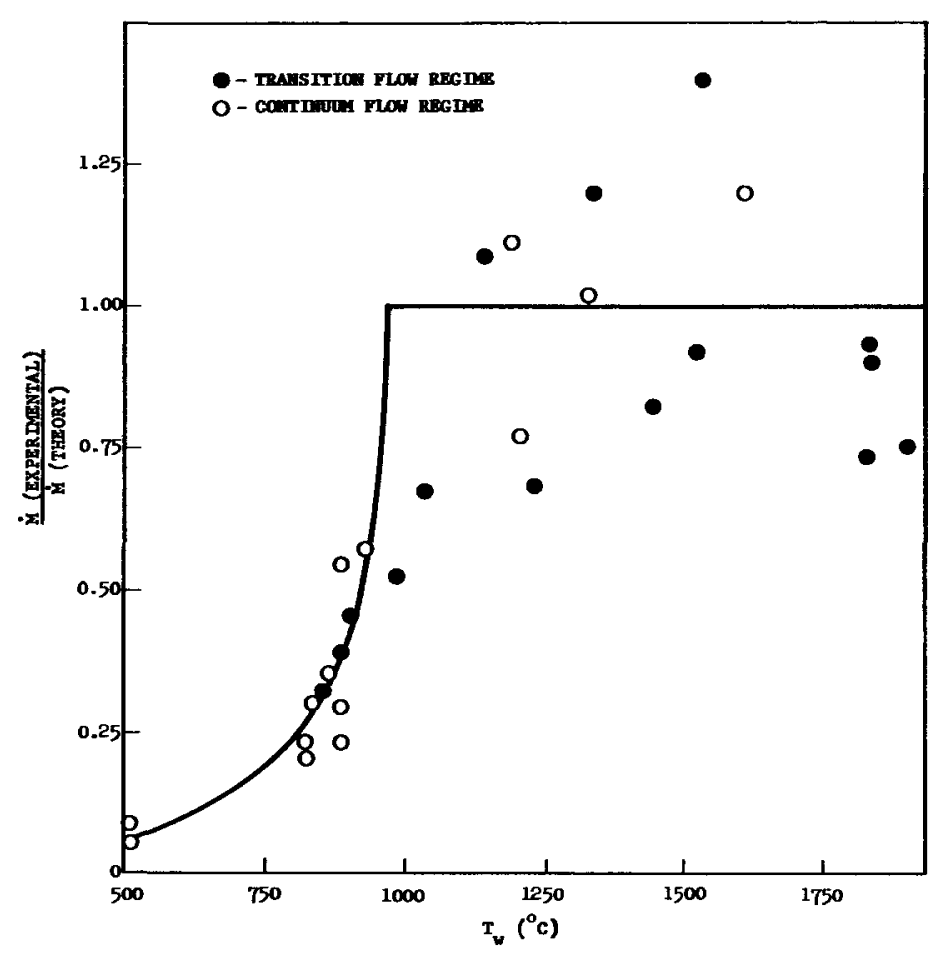

Figure 175. Effect of surface temperature on the applicability of theory to experimental rate data

Comparison of Fueled and Nonfueled Graphite -- Although both Scala's theory and the transition-flow model predict mass loss rates for graphite oxidation at surface temperatures above $1200^{\circ} \mathrm{C}$, the material of actual interest during re-entry is uranium-fueled graphite. Therefore, it is of considerable importance to compare mass loss rates for both fueled and unfueled materials.

In comparing mass loss rates of fueled and unfueled graphite, these rates must be compared on a molar basis because of the difference in molecular weight of the two samples. To accomplish this a new type of rate was defined, an oxidation rate which is equal to the mass loss rate multiplied by the average molecular weight of the samples. A comparison of oxidation rates for fueled and unfueled samples is shown in Table IV. It is apparent that no significant difference exists between the rates of graphite oxidation for both materials. The conclusion may then be made that the oxidation of both fueled and unfueled graphite should follow the same mechanism and that the same rate laws should apply for the oxidation of both materials so long as the surface temperature is greater than $1200^{\circ} \mathrm{C}$, as was the case in all samples examined in Table IV. Of course, this conclusion need not be true in the case of samples with lower surface temperatures. Therefore, we are currently conducting a series of re-entry tests on irradiated fueled samples for simulated re-entry points corresponding to the reaction-rate-controlled regime. completion of these tests, an analytical model will be developed to account for rates in this regime. 
TABLE IV

Comparison of Oxidation Rates for Fueled and Unfueled Graphite Samples

\begin{tabular}{|c|c|c|c|c|}
\hline $\begin{array}{l}\text { Test } \\
\text { Point }\end{array}$ & $\begin{array}{l}\text { Sample } \\
\text { Diameter } \\
\text { (in.) }\end{array}$ & $\frac{\text { (mols }}{\text { Fueled }}$ & $\begin{array}{l}10^{5} \\
n^{2}-\text { sec) } \\
\text { Unfueled }\end{array}$ & $\begin{array}{c}\text { Percent* } \\
\text { Difference }\end{array}$ \\
\hline 1 & $1 / 2$ & 5.86 & 6.47 & -10 \\
\hline 1 & $1 / 4$ & 9.25 & 14.5 & -57 \\
\hline 1 & $1 / 8$ & 10.7 & 11.4 & -7 \\
\hline 2 & $1 / 2$ & 6.3 & 5.1 & +19 \\
\hline 2 & $1 / 4$ & 12.0 & 10.0 & +20 \\
\hline 2 & $1 / 8$ & 11.6 & 10.0 & +16 \\
\hline 3 & $1 / 2$ & 5.1 & 5.3 & -4 \\
\hline 3 & $1 / 4$ & 6.2 & 6.5 & -5 \\
\hline 3 & $1 / 8$ & 10.4 & 7.2 & +32 \\
\hline \multicolumn{5}{|c|}{$\begin{array}{c}\text { *The percent difference is defined as being equal to } \\
\frac{R \text { (fueled) }-\mathrm{R}(\text { unfueled) }}{R(\text { fueled })} \times 100 \% .\end{array}$} \\
\hline
\end{tabular}

Analytical

On the basis of the infomation presented in the foregoing section, the following equations were incorporated into a re-entry code, WEREC, which was programmed for use in an IBM-7094 digital computer.

\section{Free-Molecule Flow}

Body temperature (energy balance)

$$
\begin{aligned}
& \frac{\mathrm{dT}_{\mathrm{B}}}{\mathrm{dt}}=\frac{3}{4 \mathrm{R}_{\mathrm{B}} \rho_{\mathrm{B}} \mathrm{C}_{\mathrm{p}_{\mathrm{B}}}(778)}\left[1.049 \times 10^{-3}\left(\frac{\rho_{\infty}}{\rho_{\mathrm{O}}}\right) \mathrm{u}^{3}-8.763\right. \\
& \left(\frac{\rho_{\infty}}{\rho_{\mathrm{o}}}\right) \mathrm{u} \mathrm{T}_{\mathrm{B}}-11.97 \times 10^{-20} \mathrm{~T}_{\mathrm{B}}^{4}+74.74-5.963 \times 10^{5}\left(\frac{\rho_{\infty}}{\rho_{\mathrm{o}}}\right) \nu \mathrm{u} \\
& \left.+1.857 \times 10^{5}\left(\frac{\rho_{\infty}}{\rho_{\mathrm{o}}}\right) \delta \mathrm{u}\right]{ }_{\mathrm{o}} \mathrm{R} / \mathrm{sec} \text {. }
\end{aligned}
$$

Mass loss rate

$$
\frac{\mathrm{dM}_{\mathrm{B}}}{\mathrm{d} t}=1.9 \times 10^{-1} \mathrm{R}_{\mathrm{B}}^{2} \frac{\rho_{\infty}}{\rho_{\mathrm{o}}}(\nu+\delta),(1 \mathrm{bs} / \mathrm{sec}) .
$$


Knudsen number discriminator

$$
\mathrm{Kn}=\frac{95\left(\mathrm{~T}_{\mathrm{B}}\right)^{\frac{1}{2}}}{\mathrm{u}} \frac{\lambda_{\infty}}{\mathrm{R}_{\mathrm{B}}}
$$

\section{Transition Flow}

Body temperature

$$
\begin{aligned}
& \frac{\mathrm{dT}_{\mathrm{B}}}{\mathrm{dt}}=\left(\frac{3}{4 \mathrm{R}_{\mathrm{B}} \rho_{\mathrm{B}} \mathrm{C}_{\mathrm{P}_{\mathrm{B}}}(778)}\right)\left\{1.049 \times 10^{-3}\left(\frac{\rho_{\infty}}{\rho_{\mathrm{O}}}\right) \mathrm{u}^{3}\right. \\
& -\frac{\mathrm{R}_{\mathrm{B}}}{\lambda_{\infty}}\left[\frac{0.6 \times 10^{-5}}{\mathrm{~T}_{\mathrm{B}}^{\frac{1}{2}}}\left(\frac{\rho_{\infty}}{\rho_{\mathrm{o}}}\right) \mathrm{u}^{4}+4.95 \times 10^{-3}\left(\frac{\rho_{\infty}}{\rho_{\mathrm{o}}}\right) \mathrm{u}^{3}\right] \\
& \left.-8.763\left(\frac{\rho_{\infty}}{\rho_{\mathrm{o}}}\right) \mathrm{u} \mathrm{T}_{\mathrm{B}}-11.97 \times 10^{-10} \mathrm{~T}_{\mathrm{B}}^{4}+1.857 \times 10^{5}\left(\frac{\rho_{\infty}}{\rho_{\mathrm{o}}}\right) \nu \mathrm{u}\right\},{ }^{\circ} \mathrm{R} / \mathrm{sec} .
\end{aligned}
$$

Mass loss rate

$$
\frac{\mathrm{dM}_{\mathrm{B}}}{\mathrm{dt}}=9.5 \times 10^{-2} \mathrm{R}_{\mathrm{B}}^{2}\left(\frac{\rho_{\infty}}{\rho_{\mathrm{o}}}\right) \mathrm{u}(\nu+\delta), 1 \mathrm{~b} / \mathrm{sec}
$$

\section{Continuum F1ow}

Body temperature

$$
\begin{aligned}
& \frac{\mathrm{dT}_{\mathrm{B}}}{\mathrm{dt}}=\left(\frac{3}{4 \pi \mathrm{R}_{\mathrm{B}}^{3} \rho_{\mathrm{B}} \mathrm{C}_{\mathrm{P}} 778}\right)\left[\left(\mathrm{R}_{\mathrm{B}}\right)^{-\frac{1}{2}}(\mathrm{C})(10)^{\mathrm{a}}(\mathrm{u})^{2.5645}\right. \\
& \left.-3.77 \times 10^{-9} \mathrm{R}_{\mathrm{B}}^{2} \mathrm{~T}_{\mathrm{B}}^{4}\right]
\end{aligned}
$$

Mass 1oss rate

$$
\frac{\mathrm{dM}_{\mathrm{B}}}{\mathrm{dt}}=2 \pi \mathrm{R}_{\mathrm{B}}^{3 / 2}(0.130)(\mathrm{C})(10)^{\mathrm{d}}(\mathrm{u})^{0.875}, 1 \mathrm{~b} / \mathrm{sec}
$$


Trajectory

$$
\begin{aligned}
2\left(\frac{d n}{d t}\right)\left(\frac{d \theta}{d t}\right)+ & r \frac{d^{2} \theta}{d t^{2}}=-\frac{D}{M_{B}} \frac{r(d \theta / d t)}{\left[\left(\frac{d r}{d t}\right)^{2}+r^{2}\left(\frac{d \theta}{d t}\right)^{2}\right]^{\frac{1}{2}}} \\
\frac{d^{2} r}{d t^{2}}-r\left(\frac{d \theta}{d t}\right)^{2} & =-g+\frac{D}{M_{B}} \frac{d r / d t}{\left[\left(\frac{d r}{d t}\right)^{2}+r^{2}\left(\frac{d \theta}{d t}\right)^{2}\right]^{\frac{1}{2}}} \\
\mu & =\sqrt{\left(\frac{d r}{d t}\right)^{2}+r^{2}\left(\frac{d \theta}{d t}\right)^{2}} \\
\frac{D}{M_{B}} & =\frac{3}{8} C_{D}\left(\frac{\rho_{\infty}}{\rho_{0}}\right) \frac{u^{2}}{R_{B}} \\
\sin \phi & =\frac{d r / d t}{\left[\left(\frac{d r}{d t}\right)^{2}+\left(\frac{r d \theta}{d t}\right)^{2}\right]^{\frac{1}{2}}} \\
\cos \phi & =\frac{r(d \theta / d t)}{\left[\left(\frac{d r}{d t}\right)^{2}+\left(\frac{r d \theta}{d t}\right)^{2}\right]^{\frac{1}{2}}}
\end{aligned}
$$

where

$$
\begin{aligned}
T_{B} & =\text { body temperature } \\
t & =\text { time } \\
\rho_{B} & =\text { density of body } \\
\rho_{\infty} & =\text { density of gas } \\
\mathbf{r}_{B} & =\text { body radius } \\
\rho_{O} & =\text { sea-level atmospheric density } \\
\mathbf{u} & =\text { body velocity } \\
\lambda_{\infty} & =\text { atmospheric mean free path } \\
\nu & =\text { atom fraction oxygen atoms in atmosphere } \\
\delta & =\text { atom fraction oxygen molecules in atmosphere } \\
\mathrm{C}_{\mathrm{p}} & =\text { specific heat of body }
\end{aligned}
$$




$$
\begin{aligned}
\mathrm{M}_{\mathrm{B}}= & \text { body mass } \\
\mathrm{C}= & 0.508-1.4725 \times 10^{-4} \mathrm{~T}_{\mathrm{B}} \text { for } 1000^{\circ} \mathrm{R}<\mathrm{T}_{\mathrm{B}}<3000^{\circ} \mathrm{R} \\
\mathrm{C}= & 1.17-1.045 \times 10^{-6} \mathrm{y}-\left(7.41 \times 10^{-5}-2.85 \times 10^{-10} \mathrm{y}\right) \mathrm{T}_{\mathrm{B}}, \\
& \text { for } \mathrm{T}_{\mathrm{B}}>3000^{\circ} \mathrm{R} \\
\mathrm{y}= & \text { altitude } \\
\mathrm{d}= & -\left(4.6759-9.16 \times 10^{-6} \mathrm{y}\right) \\
\mathrm{a}= & -\left(7.32+8.7763 \times 10^{-6} \mathrm{y}\right)
\end{aligned}
$$

In order to evaluate the extent of burnup during re-entry, a parametric study was undertaken to investigate the re-entry behavior of spherical particles ranging in diameter from 1 inch to $1 / 256$ inch. An initial altitude of 400,000 feet was selected, since little oxidation occurs above this altitude. Re-entry angles ranging from 0 to 90 degrees were examined. The results of this parametric study are shown in Table V. It should be noted that the mass loss values reported in this table are maximal ones, since no attempt was made to incorporate a rate equation for reaction-rate-controlled oxidation. Rather, it was assumed that either Scala's equation or the transition-flow model applied so long as the re-entering particle was at a velocity greater than Mach 1. It is expected that when the appropriate

\begin{tabular}{|c|c|c|c|c|c|c|c|c|c|}
\hline \multirow{2}{*}{$\begin{array}{c}\text { Angle } \\
\text { (degrees) }\end{array}$} & \multicolumn{9}{|c|}{$\begin{array}{r}\text { Initial Particle Size } \\
\text { (in percent) }\end{array}$} \\
\hline & \multicolumn{9}{|c|}{ Inches } \\
\hline & 1 & $1 / 2$ & $1 / 4$ & $\underline{1 / 8}$ & $1 / 16$ & $1 / 32$ & $1 / 64$ & $1 / 128$ & $1 / 256$ \\
\hline 0 & 7.0 & 12 & 20.0 & 33 & 40 & 52 & 43 & 42 & 41 \\
\hline-1 & 6.9 & 12 & 20.0 & 33 & 40 & 53 & 43 & 42 & 41 \\
\hline-3 & 6.0 & 10 & 19.0 & 33 & 40 & 52 & 43 & 42 & 41 \\
\hline-5 & 5.2 & 10 & 17.0 & 33 & 40 & 52 & 43 & 42 & 41 \\
\hline-10 & 4.3 & 8 & 14.5 & 25 & 38 & 49 & 43 & 42 & 41 \\
\hline-30 & 3.0 & 7 & 10.0 & 18 & 34 & 43 & 43 & 42 & 41 \\
\hline-60 & 2.3 & 7 & 8.0 & 15 & 25 & 41 & 43 & 42 & 41 \\
\hline-90 & 2.2 & 7 & 7.4 & 14 & 25 & 40 & 43 & 42 & 41 \\
\hline \multicolumn{10}{|c|}{ Initial conditions: } \\
\hline
\end{tabular}
rate equations for reaction-rate-controlled oxidation of irradiated fue 1 are incorporated into the code the percentage mass loss will be reduced considerably.

TABLE V

Percent Burnup Versus Initial Particle Size and Re-Entry Angle 
1. S. M. Scala, "The Ablation of Graphite in Dissociated Air, Part 1 Theory," IAS Nationa1 Summer Meeting, Los Angeles, Calif., June 19 - 22, 1962 (IAS Paper No. 62 - 64).

2. R. F. Probstein, "Shock Wave and Flow Field Development in Hypersonic Re-Entry," ARS Semiannual Meeting, May 1960 (ARS Report No. 110-60).

3. J. R. Stalder and D. Jukoff, "Heat Transfer to Bodies Traveling at High Speed in the Upper Atmosphere," Journal of the Aeronautical Sciences, Vo1. 15 No. 7 (July 1958).

4. S. M. Scala, A Study of Hypersonic Ablation, General Electric Missile and Space Vehicle Department, TIS Document No. R5950348 (Sept. 1959).

5. D. R. Willis, "A Study of Near Free Molecule Flow," Symposium on the Aerodynamics of the Upper Atmosphere, Rand Corp. Report No. R-339, Rand Corp., Santa Monica, Calif. (June 1959).

6. G. Blyholder and H. Eyring, J. Phys. Chem., 63, 10004 (1958).

7. J. A. Morre and M. Zlotnick, "Combustion of Carbon in an Air Stream," ARS Journa1, October 1961.

8. E. A. Gulbransen, K. F. Andrews, and F. A. Brassart, The Oxidation of Graphite at Temperatures of $600^{\circ} \mathrm{C}$ to $1500^{\circ} \mathrm{C}$ and at Pressures of 2 to 76 Torr of Oxygen, Westinghouse Research Laboratory, Scientific Paper 62 , 123-121-P2, Sept. 1962.

9. G. T. Rymer, private communication. 


\title{
SOURCE TERM PROGRAM--AN INTEGRATED TREATMENT OF RE-ENTRY PROBLEMS*
}

\author{
H. I. Kraig \\ J. M. Bridges
}

Westinghouse Astronuclear Laboratory

\begin{abstract}
The use of a nuclear engine for space propulsion requires consideration of two principal safety problems. The first is the possibility of an inadvertent nuclear excursion should the reactor be immersed in a noderating material, imploded or compacted by an explosion or collision, or be subjected to an increase in reactivity by control-element withdrawal or by structural failure. The maintenance of a subcritical core, or the provision of devices to ensure subcriticality, is generally a straightforward design problem involving the addition of one or more systems at the possible expense of vehicle reliability. The second is the possibility of deposition, on the ground or in sensitive sea areas, of significant amounts of fission products representing the inventory developed during reactor operation. Of concern also are engine parts which have become activated in the reactor radiation field and which, upon re-entry, may represent a radiological as well as a mechanical hazard. The nature of the reactor fuel returning to the earth's surface may vary from very small particles in the micron range, to entire fuel elements, or even to the entire reactor. The ground hazard will depend on the size and shape of these particles, the place on the earth's surface where they land, the amounts of various nuclides contained, the rate of decay of these nuclides, and the characteristic energy of the nuclide radiation. In order to provide an integrated calculational approach to determination of the ground hazard, a program is in preparation which will accept flight information and yield the required information on fragment activity as a function of time. Because the data will be used by environmental effects groups in assessing possible radiation damage, the program has been called a source term program, after the familiar shielding terminology.
\end{abstract}

In functional concept, the program is illustrated in Figure 176. The desired analytical formulations are shown at the left with supporting experimental programs at the right. In Phase $\mathrm{I}$, the reactor is considered during its power operation, generating power in response to a thrust demand. The resulting buildup of fission products is calculated in a fission-product inventory code which is capable of delivering the concentration of any of 500 nuclides as a function of reactor operating history, time after shutdown, and environmental conditions. The code will also incorporate a materials activation function to develop the inventory of activation products in the engine and associated systems. The diffusion of fission products out of the core by thermal and other environmental effects during operation will be incorporated into the code when data is available from the Kiwi and NRX tests. Following reactor operation, Phase II, a number of situations may occur. The vehicle, if in orbit, may be allowed to remain in orbit for as long a time as possible to permit decay of the fission-product inventory. The reactor may be conditioned thermally by adjusting its cooldown rate or by subjecting it to a nuclear transient. The core may also be conditioned chemically by allowing it to react with materials which leach fission products from the matrix. In any event, the objective of any postoperational treatment is to reduce the fission-product inventory while the reactor is still at altitude. An extensive program is underway at the Westinghouse Astronuclear Laboratory to study the mechanism of fission-product release from fuels under a variety of environmental conditions, to develop mathematical models describing these release phenomena, and to recommend conditioning procedures. In this program, fuel samples, which may be preconditioned, are irradiated in a high-flux field and then subjected to a variety of post-irradiation environments.

Fresented by Mr. Kraig 


\section{BLANK}




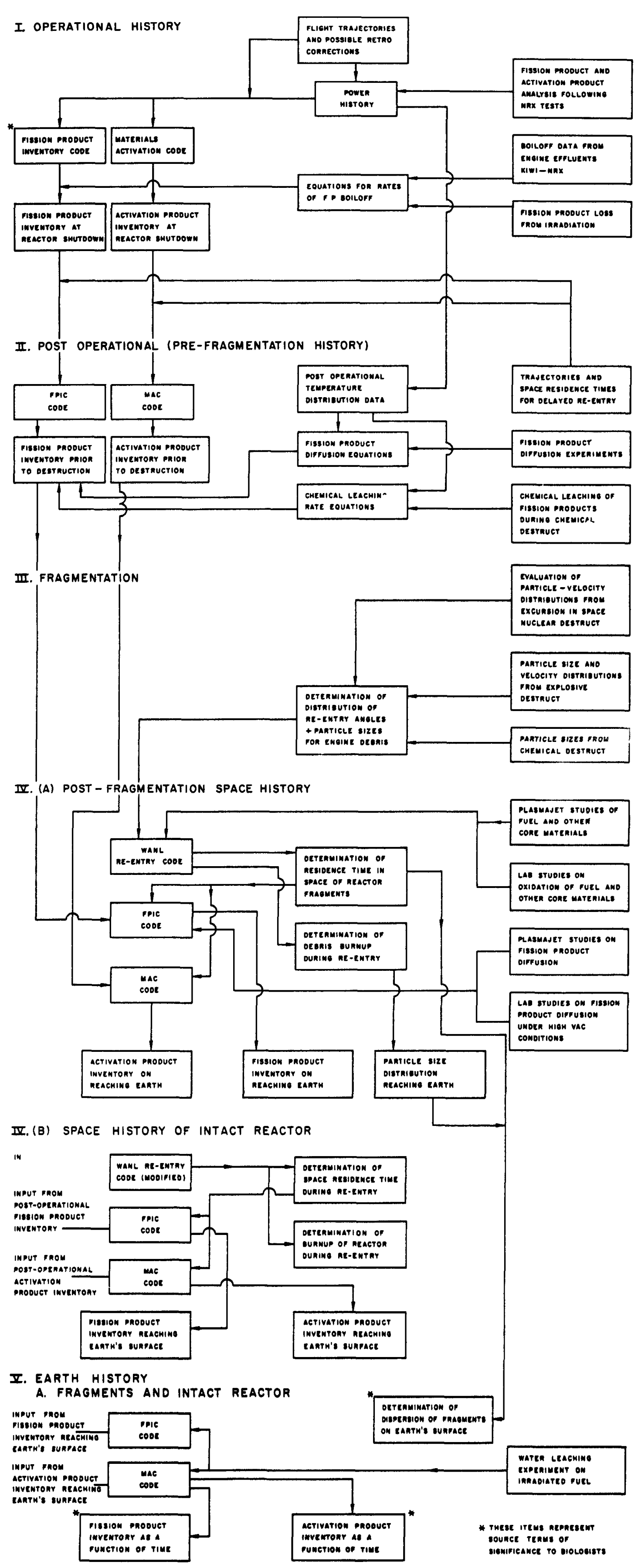




\section{BLANK}


At some time following the termination of reactor operation, a destruct of the reactor may be caused (Phase III). Destruct has as its purpose the extreme fragmentation of the core so that re-entering pieces will be small enough on impact that they do not constitute a significant surface hazard. Three principal types of destruct are being considered. In the explosive destruct technique, conventional explosives are either introduced into the core and exploded or positioned outside the core and the core imploded. The technique is essentially instantaneous but may require considerable amounts of explosive for the fragmentation required. In addition, the velocities imparted to the fragments may be directed opposite to the vehicle's velocity vector, causing retardation and premature re-entry. Since the system must withstand the effects of radiation during and after operation, damage to the explosives will be a major engineering consideration in development of a working system.

An adaptation of the explosive technique, known as nuclear destruct, may use conventional materials to propel moderating and/or fuel materials into the core, causing a nuclear transient with substantial core breakup. This method has the same advantages and disadvantages of the explosive destruct but must have additional protection because of its potentially greater hazard at the launch pad. A third scheme would employ chemicals to attack the core, degrading it into particles, or so weakening the structure that re-entry forces would cause its breakup. This approach has the advantage of creating uniform particles in the range from 80 to 100 microns, with no additional velocity component and containing them within the intact reactor pressure vesse1. A further advantage is the system's inherent ability to withstand radiation without operational compromise. However, the system would require 10 to 30 minutes for reaction, and the mass of reagent might be prohibitive.

Depending on the type of destruct employed, a vector velocity spectrum of particle size groups is followed through re-entry to the earth's surface (Phase IVA). This phenomenon and the experimental and analytical work being done on it are described in the preceding paper by Bridges and Hargrove.

A very vital aspect of re-entry studies is the return to earth of an initially intact reactor (Phase IVB). This event may be operationally desirable because of its passive nature, or it may result from the failure of destruct to occur. The study which is underway at Westinghouse involves an extensive failure-mode analysis, taking into account the response of the engine to after-heat (with and without cooling), re-entry heat, and aerodynamic loads.

Phase $V$ of the program describes the behavior of the fragments after they land on the surface, including their continued time decay, leaching in water, and ecological takeup.

In order to evaluate the effects of varying several operational parameters on the surface dose from core fragments, the engine was considered as operating at 1000 megawatts, starting suborbita11y and orbita1ly, to achieve 100 and 200 nauticalmile orbits. The effect of different types of destruct was examined by varying the retro velocity imparted to particles of different size. Residence time in orbit was varied up to the time when the orbit decayed to 400,000 feet. The dose model employed had the particle falling to the ground and being approached immediately on landing by someone who stayed within 1 meter for 1 day. Individual nuclides were not considered, but the particle inventory was decayed according to the Way-Wigner relation. It is recognized that localized beta skin radiation and ingested or inhaled particles may likewise present health problems. It is obviously possible also for a person to remain in the vicinity of the source for longer than 1 day. These dose considerations are under study at a number of facilities whose refined models will be incorporated into the source term program as soon as they are available. The conclusions to be drawn from this report are general and essentially independent of the dose mode1.

In order to give an appreciation for the settling times of particles, Figure 177 is presented to show the time in seconds for particles of various size to reach the ground from 400,000 feet, with no meteorological effects included. Note that a particle must be less than 0.01 inch in diameter to take a day or more in re-entry. 


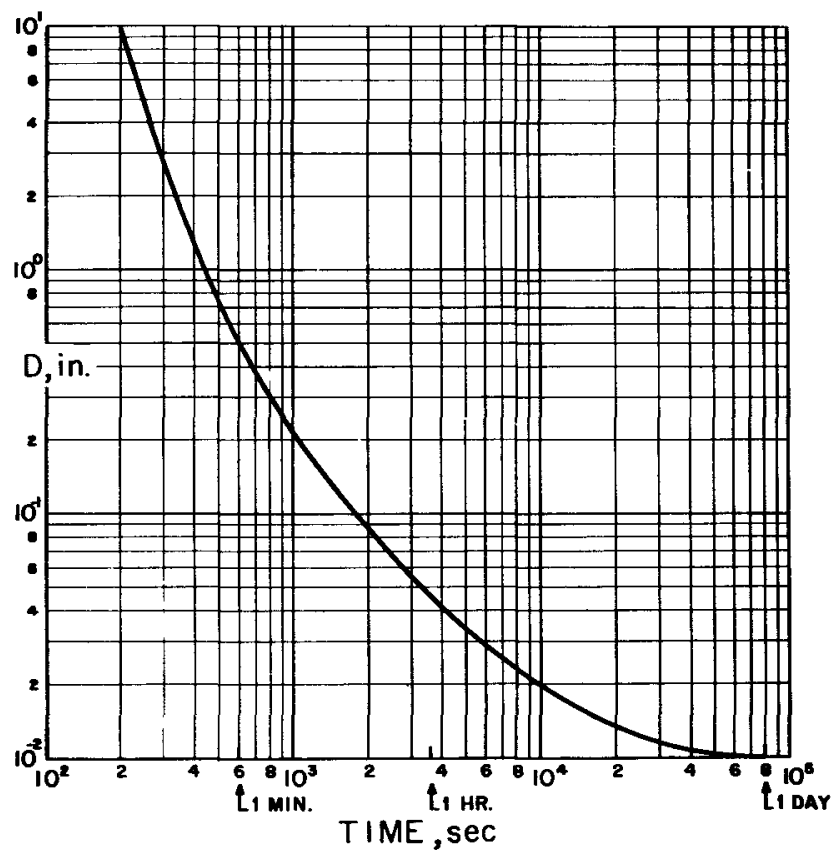

Figure 177.

Settling time of sma11 particles during re-entry

Figure 178 illustrates the effect of destruct and re-entry on a core which has operated at full power suborbitally for 9 minutes. In this application, the destruct must be instantaneous, ruling out a chemical approach. It can also be seen that the retro kick, $\Delta V$, does not affect the dose, indicating that explosive or nuclear destruct may be used without disadvantage.

Figure 178.

First day $y$-dose as a function of destruct retro velocity for various sized particles--9 minutes suborbital operation

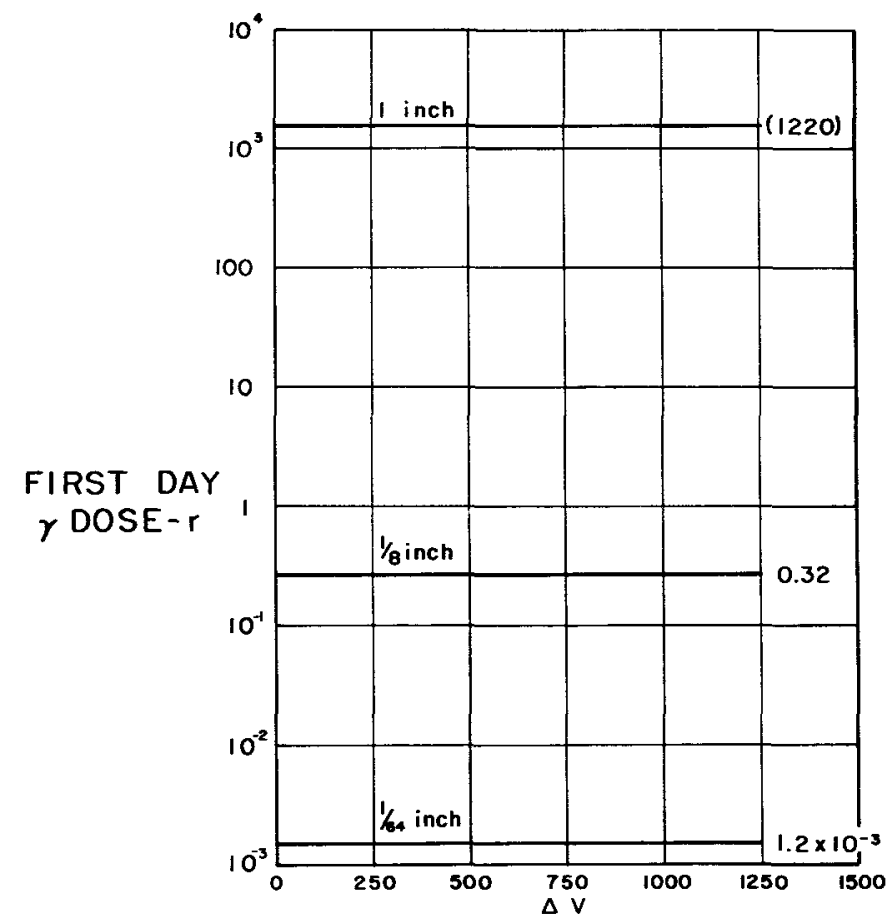


To reach a 100-mile orbit with a suborbital start might require 10 minutes of reactor operation. Similarly, achievement of a 200-mile orbit would require 12 minutes of operation. Both cases are illustrated in Figure 179. Several interesting observations can be drawn by inspection of these curves. First, the advantage of delaying destruct can be observed by comparing the 1-day doses for varying delay times and particle sizes. For the 1-inch particle created by destruct immediately after reactor shutdown (the zero-delay particle), a 1500-r dose would be received by a person on the ground. However, 1-day residence in orbit before destruct can reduce this dose by a factor of 10 and a 16 day delay, which is the maximum for this orbit, can reduce the dose by 200. The effect is even more dramatic for a 1/8-inch particle, with which the zero-delay destruct yields a 4-r 1 day dose, a 1 -day delay gives a factor of reduction of 20, and 16-days delay a factor of 400 . The use of a "contained" destruct, breaking up the core but keeping the fragments within the pressure vessel may allow for maximum fragment residence time in orbit without requiring that the destruct system survive for the entire delay time.

The second observation which can be made is the marked effect of any retro velocity on dose. A 1 -inch zero-delay particle with no retro kick gives a 1-day dose of $150 \mathrm{r}$, but that same particle with only $200 \mathrm{fps}$ retro velocity can cause a 1500-r dose. The 1-inch particle held in orbit for 16 days will give 7.4-r 1-day dose regardless of the retro kick imparted to it. Thus, a "soft" destruct, creating zero-velocity particles, is particularly advantageous in those situations where long residence time in orbit cannot be realized.

The effect of going to higher orbits may be observed by comparing the curves for 100 and 200 nautical-mile orbits. In spite of the fact that the higher orbit requires a greater reactor operating time (12 minutes versus 10), with a correspondingly increased fission-product inventory, the ground dose for a particle from $200 \mathrm{~nm}$ is slightly less than or equal to that of the 100-nm particle. This is attributed to the increased residence time in space of the particle released from a higher altitude. The most marked effect, however, is that of allowing the reactor to remain in orbit before destruct is accomplished, since a particle can stay in a 200-nm orbit for 112 days, compared to only 16 days in a 100-nm orbit.

Figure 180 illustrates for 1-inch particles the advantages to be gained by starting the reactor in a $100-\mathrm{nm}$ orbit and accelerating the reactor to a $200-\mathrm{nm}$ orbit (a 2-minute operation) as compared to starting it suborbitally with a failure after 2 minutes of operation.

The results which have been presented do not include any degradation of the fission-product inventory because of operational, postoperational, or re-entry heating, or by any leaching process. For the whole-body dose, the decrease in inventory will result in a decreased dose on a proportional basis. For cases of ingestion and inhalation, however, the dose may change radically if certain nuclides are preferentially diffused and lost.

Table I summarizes the data collected and data for 1/64-inch particles which were not previously given. 

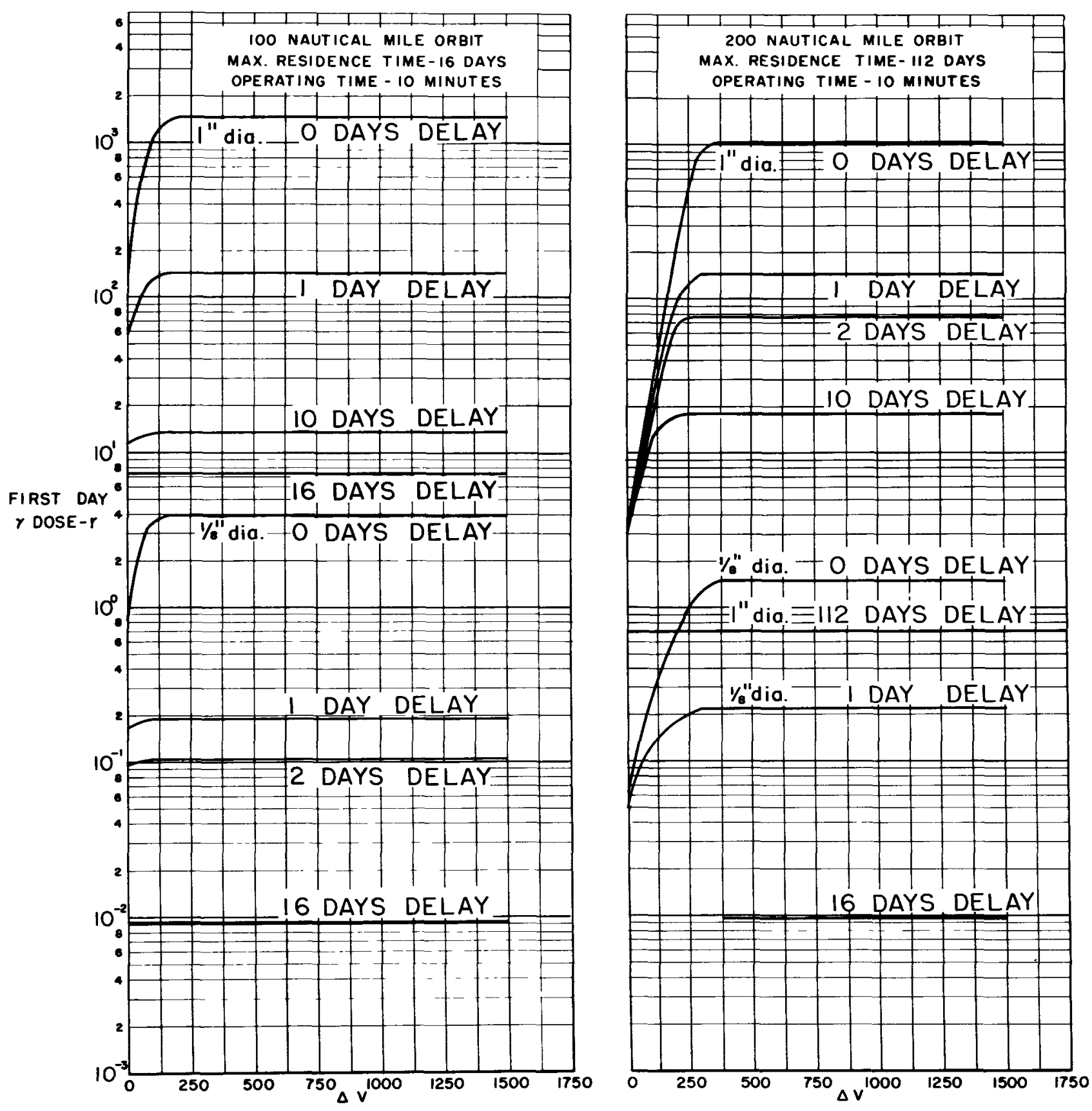

Figure 179. First day $\gamma$ dose as a function of destruct velocity and particle size for $100 \mathrm{~nm}$ and $200 \mathrm{~nm}$ orbits and varying orbital destruct delay times 

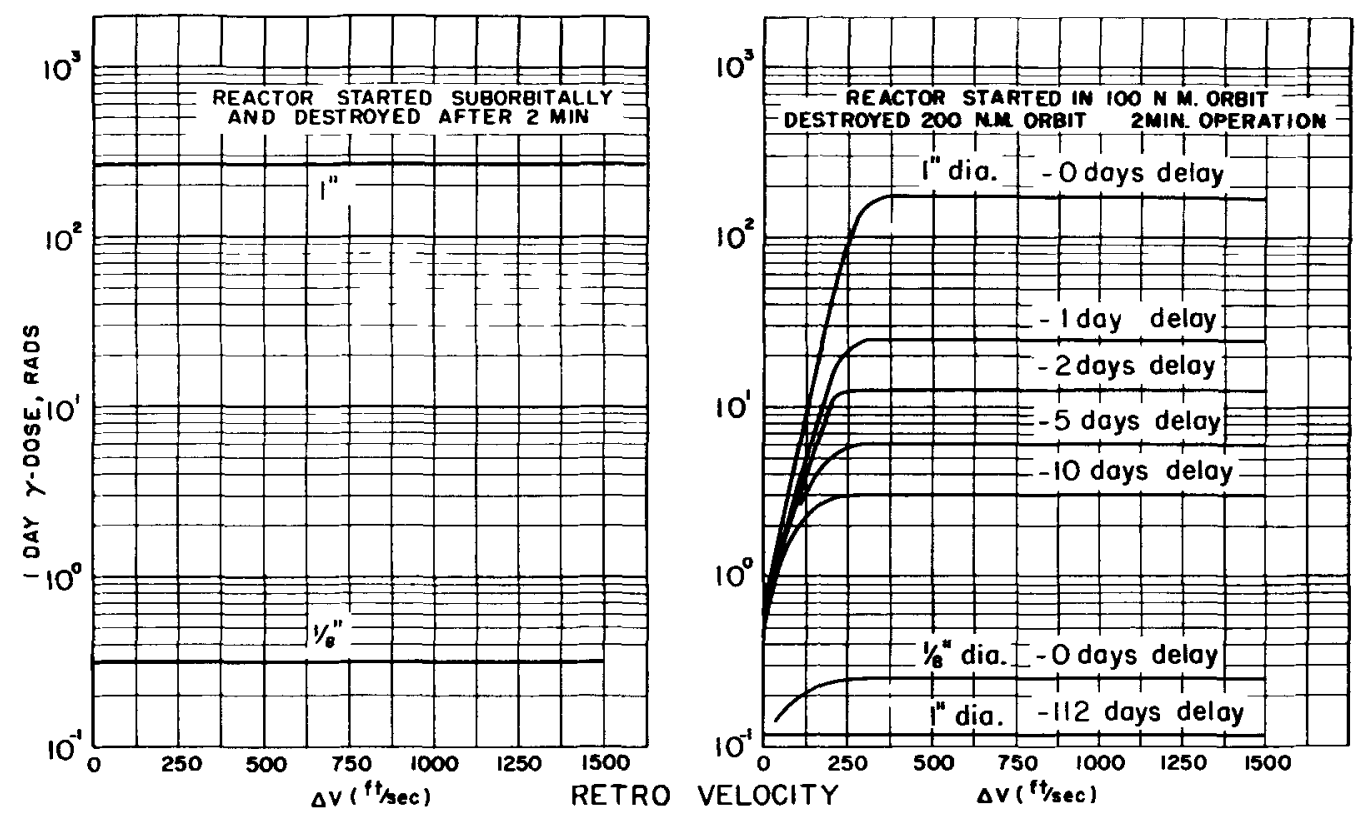

Figure 180. First day $\gamma$-dose delivered on impact as a function of destruct velocity for different modes of operation

TABLE I

Summary of One Day Single Particle Gamma Dose Data For Varying Operational Parameters

\begin{tabular}{|c|c|c|c|c|c|c|c|}
\hline Phase & $\begin{array}{l}\text { Reactor } \\
\text { Start } \\
\text { Location }\end{array}$ & $\begin{array}{l}\text { Destruct } \\
\text { Location }\end{array}$ & $\begin{array}{l}\text { Oper. } \\
\text { Time } \\
\text { (min) }\end{array}$ & $\begin{array}{l}\text { Type of } \\
\text { Destruct }\end{array}$ & $\begin{array}{l}\text { Delay } \\
\text { Time } \\
\text { (days) }\end{array}$ & $\begin{array}{l}\text { Part } \\
\text { Size } \\
\text { (in.) }\end{array}$ & $\begin{array}{l}\text { One Day } \\
\text { Dose (r) }\end{array}$ \\
\hline I & Suborbital & Suborbital & 9 & Hard & 0 & $\begin{array}{l}1 \\
1 / 8 \\
1 / 64\end{array}$ & $\begin{array}{l}1220 \\
0.32 \\
1.2 \times 10^{-3}\end{array}$ \\
\hline \multirow[t]{2}{*}{ II } & Suborbital & $100 \mathrm{~nm}$ & 10 & Hard & 0 & $\begin{array}{l}1 \\
1 / 8 \\
1 / 64\end{array}$ & $\begin{array}{l}1500 \\
1.4 \\
1.6 \times 10^{-3}\end{array}$ \\
\hline & & & & & 16 & $\begin{array}{l}1 \\
1 / 8 \\
1 / 64\end{array}$ & $\begin{array}{l}7.25 \\
9.4 \times 10^{-3} \\
1.75 \times 10^{-5}\end{array}$ \\
\hline III & Suborbital & $100 \mathrm{~nm}$ & 10 & $\begin{array}{c}\text { Soft } \\
\text { (contained) }\end{array}$ & 0 & $80 \mu$ & $2.3 \times 10^{-7}$ \\
\hline \multirow[t]{2}{*}{ IV } & Suborbital & $200 \mathrm{~nm}$ & 12 & Hard & 0 & $\begin{array}{l}1 \\
1 / 8 \\
1 / 64\end{array}$ & $\begin{array}{l}1050 \\
1.5 \\
1.8 \times 10^{-3}\end{array}$ \\
\hline & & $200 \mathrm{~nm}$ & 12 & Hard & 112 & $\begin{array}{l}1 \\
1 / 8 \\
1 / 64\end{array}$ & $\begin{array}{l}0.7 \\
10^{-3} \\
10^{-6}\end{array}$ \\
\hline \multirow[t]{2}{*}{ V } & $100 \mathrm{~nm}$ & $200 \mathrm{~nm}$ & 2 & Hard & 0 & $\begin{array}{l}1 \\
1 / 8 \\
1 / 64\end{array}$ & $\begin{array}{l}175 \\
0.25 \\
3 \times 10^{-4}\end{array}$ \\
\hline & $100 \mathrm{~nm}$ & $200 \mathrm{~nm}$ & 2 & Hard & 112 & 1 & .115 \\
\hline VI & Suborbital & Suborbita1 & 2 & Hard & 0 & $\begin{array}{l}1 \\
1 / 8\end{array}$ & $\begin{array}{r}270 \\
.31\end{array}$ \\
\hline
\end{tabular}


Even on the basis of such preliminary data as have been presented, certain definitive conclusions can be drawn:

1. For a given reactor operating time, the suborbital start mode results in a higher dose than that of a reactor started in orbit.

2. The highest orbit in which the reactor can be placed is the most desirable from the dose standpoint, even if the reactor is started suborbitally.

3. It is desirable to allow the reactor to remain in orbit for as long as possible before destruct is employed.

4. For suborbital operations, the nuclear or explosive destruct schemes offer operational advantages without increase in dose.

5. For orbital operations, a contained destruct, such as chemical attack, offers considerable advantage in ground-dose reduction. Since it is not necessary to destroy the reactor pressure vessel in the destruct process, the maximum orbital decay time is afforded the particles before re-entry.

6. As a general rule, the smallest particle, with the least velocity imparted to it, is the most desirable. It must be recognized, however, that for very high specific activities, a small particle which can be inhaled or ingested may present a greater long-range hazard than a large particle which cannot. In this event, the requirement on the destruct system must be changed so that the particle size becomes even smaller, and remains within the safe regime. 
Special Topic

THE AIR FORCE NUCLEAR WEAPON SAFE'Y PROGRAM

Co1. C. B. Stewart, Director

Directorate of Nuclear Safety, USAF

Although the United States has been a "nuclear power" since 1945, across-theboard integration of nuclear weapons into the Air Force operational inventory is a much more recent development--in terms both of numbers of weapons and readiness posture. Although I cannot, of course, quote stockpile figures, I can point out that most of the growth of our stockpile to its present figure has occurred in the last 5 to 8 years.

Our readiness posture has changed dramatically during the same period. I recall that when I was first assigned to the Air Force Special Weapons Center at Kirtland Air Force Base over 10 years ago, we had a standing operating procedure (SOP) with SAC wherein, after the whistle blew, we would take some bombs out of remote storage areas, transport them some 3 miles to the airstrip, and load them aboard SAC bombers. SOP time was 3 hours. Now, admittedly, these bombers were not first wave. Today, however, all of SAC's bombers have their bombs immediately available. Its first wave, its ground alert aircraft are ready to go in 15 minutes, or even in as little as 5 minutes. Some of its aircraft fly airborne alert. In 1954, no tactical aircraft, fighter bombers, were standing alert. Today, all over the world, we have fighter bombers standing quick reaction alerts. Ten years ago, the MB-1 air-to-air, air defense rocket, was just an idea. Today, it is deployed all over the continental United States ready to scramble on a moment's notice.

The Air Force has entered into the missile age. The ATLAS, TITAN, MINUTEMAN and the BOMARC are today standing alert around the clock.

A11 of the foregoing means that we are today handiing nuclear weapon systems in numbers many times greater than just a few years ago, and we are exposing them to much more advanced operational postures. And it follows, therefore, that our exposure to the possibility, however remote, of a nuclear mishap of devastating consequences has increased.

From a military point of view, it is not only the devastation in terms of lives and property that we have to fear from a catastrophic nuclear accident. A nuclear accident, if it did not lead to the war we are trying to prevent, could have international and national repercussions that would seriously degrade--if not wreck--our overal1 military posture.

This morning I would like to describe for you the major parts of the Air Force Nuclear Safety Program, that is, the program of nuclear weapon accident prevention. First, a word about my organization and its position in the organizational structure of the Air Force. The Directorate of Nuclear Safety, or DNS, a1though located at Kirtland Air Force Base in Alburquerque, is a part of the Air Staff, Headquarters United States Air Force. Al1 safety functions within the Air Force have been consolidated under the Deputy The Inspector Genera1, Major Genera1 Bertram C. Harrison, who is located at Norton Air Force Base, San Bernardino, California. At Norton also is our sister organization, the Directorate of Aerospace Safety with its Flight, Ground, and Missile Safety Divisions.

The broad mission assigned the Directorate of Nuclear Safety is to formulate and develop nuclear safety policies, programs, standards, and procedures and to ensure their prompt and effective implementation. 
Our program natura1ly breaks itself down into two parts. First is the thorough and continuing technical and operational safety analysis of nuclear weapon systems from the cradle to the grave, so to speak. I will describe below the variour steps that are taken in this continuing analysis of each nuclear weapon system. Second is the establishment of an effective and aggressive nuclear safety program at a11 levels of command to assure ourselves that the operating units in the Air Force understand these analyses and apply the resulting safety rules and procedures effectively and continually.

The first part of our program is summarized in Table I.

TABLE I

Safety Milestones in Life of Nuclear Weapon System

1. Initial safety study.

2. Preoperational safety study.

3. JCS approved safety rules.

4. Preoperationa1 safety survey.

5. Operational review--field survey, accidents/

incidents, UR, operational history analysis.

6. Special studies and investigations.

First, an initial safety study is performed on the system very early in its life--just as soon as there is sufficient knowledge about the proposed system to make a study meaningful. The purpose of this study is to provide guidance to the developers during the ensuing development. Secondly, a preoperational study is performed approximately 120 days before the system becomes operationa1. At this point in the life of the system, the hardware is actually in existence, the operational plan for the weapon system has been approved by Headquarters United States Air Force, the techmical orders supporting the system are available (at least in draft form), and we know just how we want to operate the system. The study considers the entire stockpile-to-target sequence.

Both of these studies are performed by the Air Force Nuclear Weapon System Safety Group (NWSSG), the composition and operation of which is described in Table II below. Concurrent with the conduct of the preoperational safety study, the so-called Joint Chiefs of Staff safety rules are developed. These are the broad safety rules which govern and define the operations, procedures, and hardware configurations available in peacetime.

After the preoperational safety study and the JCS safety rules have been approved, the operational commands are almost ready to employ this system in the field. At this time, a preoperational safety survey is conducted by DNS of the first unit to employ this system. The purpose of this survey is to ensure that the approved hardware configurations, the technical procedures, and the safety rules have indeed been translated into understandable, clear, workable, and adequate procedures in the field and at the same time to perform an independent evaluation of the adequacy of safety under actual field conditions.

The fifth safety milestone is an operational review, again performed by DNS, sometime near the end of the first year of field operation of the system. This review includes a field survey of a selected unit, a study of the accident/incident history of the system concerned, an analysis of the unsatisfactory reports that have been submitted on this system and an overall operational history and analysis.

Finally, we have special studies and investigations that are performed as necessary. 
Table II lists the composition of the Air Force Nuclear Weapon Systems Safety Group and the inputs of its various members.

TABIE II

Nuclear Weapon Systems Safety Group

Chairman-Director/Nuclear Safety

\begin{tabular}{|c|c|c|}
\hline $\begin{array}{l}\text { Operating } \\
\text { Commands }\end{array}$ & $\begin{array}{l}\text { Support } \\
\text { Commands }\end{array}$ & $\begin{array}{c}\text { Other } \\
\text { Agencies }\end{array}$ \\
\hline SAC & AFSC & $\mathrm{FC} / \mathrm{DASA}$ \\
\hline TAC & AFLC & AEC-ALOO \\
\hline $\mathrm{ADC}$ & ATC & Supported by \\
\hline USAFE & MATS & SC, LASL \\
\hline PACAF & & LRL \\
\hline
\end{tabular}

AAC

The NWSSG operates as an independent board of officers. Its function is to review, modify, and approve the safety studies and safety rules described in Table I. In a sense, each member wears two hats. He brings the deliberations the official viewpoints of his own command. At the same time, he is expected to evaluate the overa11 Air Force interest and vote on a particular interest as necessary to ensure that safety procedures are maximized to the greatest degree possible without jeopardizing operational posture.

DNS provides the chairman of this group, supervises its activities and provides the channel of communication between it and the rest of the Air Staff.

For its members, the NWSSG has, first, the Air Force Systems Command, specifically the Air Force Weapons Laboratory at Kirtland. Since safety is a function of command and since the AFSC is responsible for the development of the system, the AFWL is responsible for submitting to the group a technical safety evaluation and analysis. This technical evaluation is based on tentatively approved operational concepts and on the technical information on the system provided to them by other elements of the systems command such as the Ballistic Systems Division and its contractors. Logistics Command provides a member to furnish logistics information and data on its support of the system. The Albuquerque Operations office of the AEC provides a member who is always accompanied by technical advisors from Sandia Corporation and sometimes from Los Alamos or Livermore. They are responsible primarily for providing warhead information. The Field Command of the Defense Atomic Support Agency provides a member who can furnish the DOD, or three-service, point of view. The support commands of the Air Force, the Air Training Command and MATS, provide information on training and transport aspects of the weapon system. The operating commands, SAC, TAC, and ADC, have permanent membership on the group. Finally, the overseas commands also provide members when the group considers a system they are scheduled to employ.

Figure 181 shows the channels for processing the JCS safety rules. They are prepared by DNS concurrent with the preoperationa1 safety study. They are reviewed and approved by the NWSSG, coordinated within the Air Staff, and approved by DASA and the JCS. The DOD submits them to the AEC for review and coordination. If the rules permit peacetime airborne operations, they are submitted to the President for his approval. You will note that many agencies are involved in this process. DASA and the AEC review the studies and rules twice--once at the working level in Albuquerque and again at the policy level in Washington. 


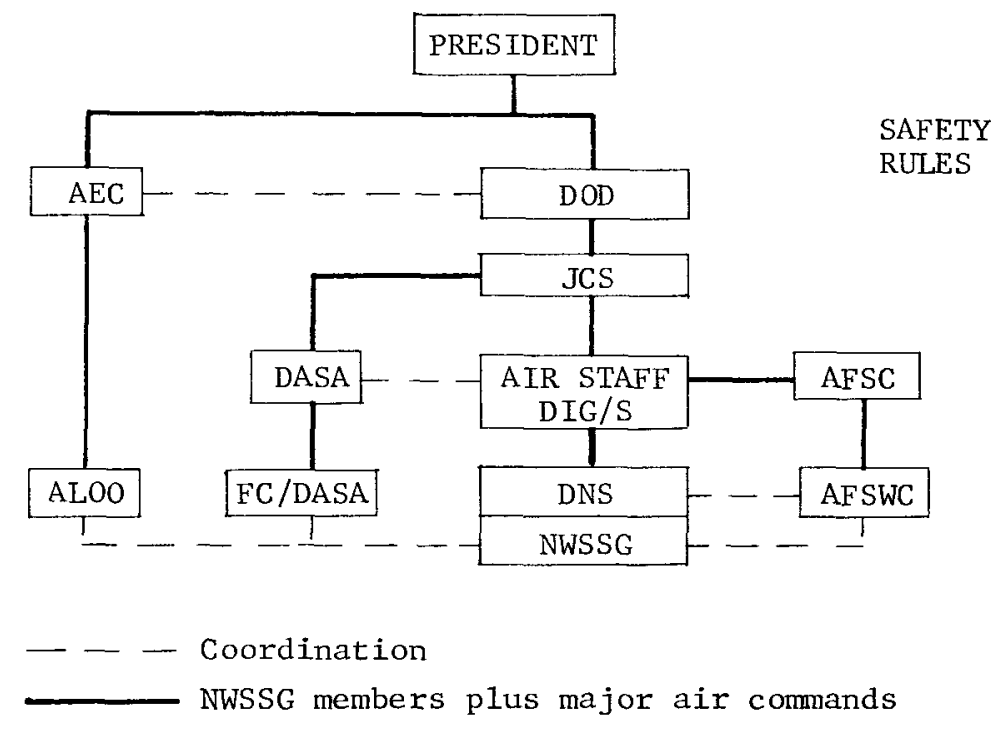

Figure 181. Channels for processing the JCS safety rules

Now that we have taken a look at the administrative processes involved in our continuing analysis of a nuclear weapon system, let's take a look at some of the things that we consider during the se studies and surveys. First of all, what is our problem? What is nuclear safety guarding against? We believe we can define the problem in terms of two dangers: first, a nuclear contribution from a bomb or warhead in an aircraft crash, fire, or ground accident which detonates the high explosive, and, second, accidental or unauthorized acts leading to a nuclear detonation by means of the intended firing system.

For obvious classification reasons, I am not able to discuss the measures taken with respect to the first danger. The measures are, of course, basically the design responsibility of the AEC.

With respect to this danger, the fact that the warheads are indeed safe is supported by the few unfortunate experiences we have had: the collision of a $\mathrm{KC}-135$ and a B-52 in Kentucky in 1959; the burning of a BOMARC missile at McGuire AFB in June 1960; and two separate crashes of $B-52^{\prime} \mathrm{s}$, one in North Carolina and one in California in early 1961 . We have not had such an accident for $2-1 / 2$ years--which is, of course, a tribute to our flying safety program.

The measures taken with respect to the second danger are primarily the responsibility of the Air Force. In addition to safeguarding against this danger, we also wish to prevent mishaps that create public apprehension; an example is the accidental drop from an aircraft of a completely unamed weapon near Florence, South Carolina, 5 or 6 years ago.

I would like to discuss now a few of the design and procedural features that we consider. Very valuable are handling safety devices, (which are also known as environmenta1 sensing devices). These devices positively block an essential channel in the electrical circuitry and operate only when they sense an environment unique to the trajectory of the weapon system on which they are used. They wil1 not operate, for example, because of transportation accidents or a drop from a hoist.

Human error has been, and probably always will be, the largest source of error in the handling or operation of a system. The ideal bomb is one that, just as though it were a wooden block, could sit on the shelf indefinitely without testing and still be put to immediate use when needed. The thought behind this, the 
"wooden bomb" concept, is that if it and the other parts of the weapon can be so designed as to minimize the amount of handling, testing, etc. by a human being, we wil1 ipso facto, have achieved a greater degree of safety.

Our warheads and the rest of our weapon systems have all sorts of safety devices in the electrical circuitry. These are so popular that one of the considerations of the safety group is to guard against redundance and loss of reliability. We have arm/safe switches. We have thermal batteries which are inert until they have received a separate electrical signal to arm them; these batteries are also protected by thermal fuses. We separate arming signals and make sure that two discrete electrical signals are received before key actions in the steps of prearming, arming, and final detonation of the weapon are performed. (Signal separation is not only a guard against electrical malfunctions and short circuits, but it also provides opportunity for the establishment of administrative procedures requiring more than one person to activate the arming and firing circuits.)

For bombs on aircraft, we now have positive locks, and the Florence, South Carolina, incident can no longer happen. All SAC aircraft, as well as fighter bombers, now have positive mechanical locks that require separate releasing and cannot be inadvertently activated. None of the release methods such as the bombnavigation system release, the manual release, or the emergency jettison release system can override this positive lock.

I would now like to discuss procedural features. If we designed all the safety we could into the weapon system, we would probably end up with something we could not use in anger when we had to. The bomb is designed to go off; therefore it will go off, under certain conditions. Our procedural features are designed to assist in ensuring that they will not go off unless we want them to.

We rigidly control access to the weapon system, the bomb or the warhead, and the key parts of the missile system at al1 times. The security measures taken with respect to any part of a nuclear weapon system are spelled out in detail and are strict1y enforced.

We divide operationa1 controls. In the B-52, for instance, separate, positive actions are required of three men to release a prearmed bomb which will detonate by means of the intended firing system. The division of operational controls is particularly important in missile launch sites.

At launch-control centers, the separate, independent actions of at least two men are required to effect a launch. In addition, the emergency war order which authorizes the launch of the missile--or the take-off of the alert aircraft--is so handled administratively that at all times at least two people are necessary in any link in the line of communications from SAC headquarters down to the launch site.

Thorough training of people is, of course, one of the fundamentals of a safety program. A Nuclear Safety Officers Course has been established at the Lowry Training Center at Denver. The Strategic Air Command has its own Nuclear Safety officers Course at McConnel1 Air Force Base. Our Air Force-wide educational program includes a monthly nuclear safety magazine, a number of films on various aspects of the nuclear safety program, and posters. Each of the major commands supplements these with its own nuclear safety education and training program. One of the prime purposes of all training programs is to create continual awareness on the part of every individual in the nuclear weapons field.

In the development of procedures, check lists are made up by the Systems Command and the Logistics Command for all operations such as testing, assembly, loading, and downloading. One of the keystones of our program is the requirement for rigid check-list discipline. We have established the principle that the operation must be built around the use of the check 1ist, since we observed early in our surveys that those organizations that built their operations around the use of check lists invariably did not only a safer but a faster job.

The Air Force, several years ago, established a screening program known as the human reliability program under AFR 35-9 which applies to a11 people handling 
nuclear weapons. This regulation supplements the initial screening process that takes place at the Air Force Induction Center at Lackland Air Force Base. The objective of this regulation is to assist in ensuring that unreliable or psychotic individuals do not remain in the weapons program. It is not a witch hunt. It is an administrative procedure that ensures that the commander and supervisor knows his people and knows how to seek advice from the appropriate medical people whenever an individual gives some indication of suffering from abnormal stresses or domestic situations.

The buddy system, or two-man concept as it is now called, applies to a11 phases of nuclear weapon system handling. No lone individual is ever allowed access to a warhead, to the critical components of the nuclear weapon system with the warhead installed, or to key parts of the missile's launch circuitry. A requirement of the two-man concept is that, whenever access is authorized, each of the two persons must have the ability to be able to detect unauthorized or improper procedures in the task being performed.

I would now like to discuss very briefly the second part of our overall program, that is, the establishment of effective safety programs at al1 levels of command throughout the Air Force. If we assume that we have done our job effectively in the first part of the program, that is, if we have developed workable, understandable, and effective safety rules and procedures, then the final thing to be done is to assure ourselves that these rules and procedures are in force at all times--not only today and tomorrow, but next year and the years after. This we accomplish through programs effectively applied at the squadron, wing, and air command levels. Table III indicates some of the elements of such a program. We in DNS have published a manual entitled "The Air Force Nuclear Weapons Safety Program" which outlines and details for the commander in the field all of the aspects of this program.

TABLE III

Elements of an Effective Safety Program

1. Nuclear safety officer

2. Formalized safety program

3. Safety surveys

4. Supplementary directives

5. Safety councils

6. Standardization boards

7. Unsatisfactory reports

8. Hazard reports

9. Check 1ists

10. Information files

11. Education and training

12. Security

13. Human reliability program

One of the key elements of this program is the appointment of a nuclear safety officer who reports directly to the commander in the field. He assists the commander by becoming expert in all phases of the program and making sure by means of surveys, nuclear safety councils, and monitoring of the local screening program under AFR 35-9 that every effort is being made to maintain the unit's professionalism at all times.

In concluding, we in the Air Force are convinced that our nuclear weapon systems have adequately safe designs and that our supporting rules and procedures are adequately safe. However, as our chief of Staff once said, "We shall leave no stone unturned in the area of nuclear safety." In the safety business, in our effort to foster an awareness, we like to use slogans. One that we borrowed from our friends in Ground Safety is, we think, particularly appropriate to the nuclear safety program--"Nuclear Safety is No Accident." Only through continual awareness and continual emphasis we can maintain our goal of no nuclear accidents and, as an important corollary, reduce the number of incidents involving nuclear weapons to as close to zero as possible. 
Published by

Sandia Corporation, a prime contractor to the

United States Atomic Energy Commission

\section{LEGAL NOTICE}

This report was prepared as an account of Government sponsored work, Neither the United States, nor the Commission, nor any person acting on behalf of the Commission:

A. Makes any warranty or representation, expressed or implied, with respect to the accuracy, completeness, or usefulness of the information contained in this report, or that the use of any information, apparatus, method, or process disclosed in this report may not infringe privately owned rights; or

B. Assumes any liabilities with respect to the use of, or for damages resulting from the use of any information, apparatus, method, or process disclosed in this report.

As used in the above, "person acting on behalf of the Commission" includes any employee or contractor of the Commission, or employee of such contractor, to the extent that such employee or contractor of the Commission, or employee of such contractor prepares, disseminates, or provides access to, anj information pursuant to his employment or contract with the Commission, or his employment with such contractor. 